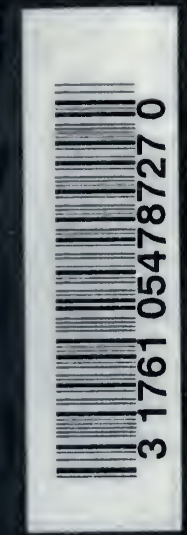




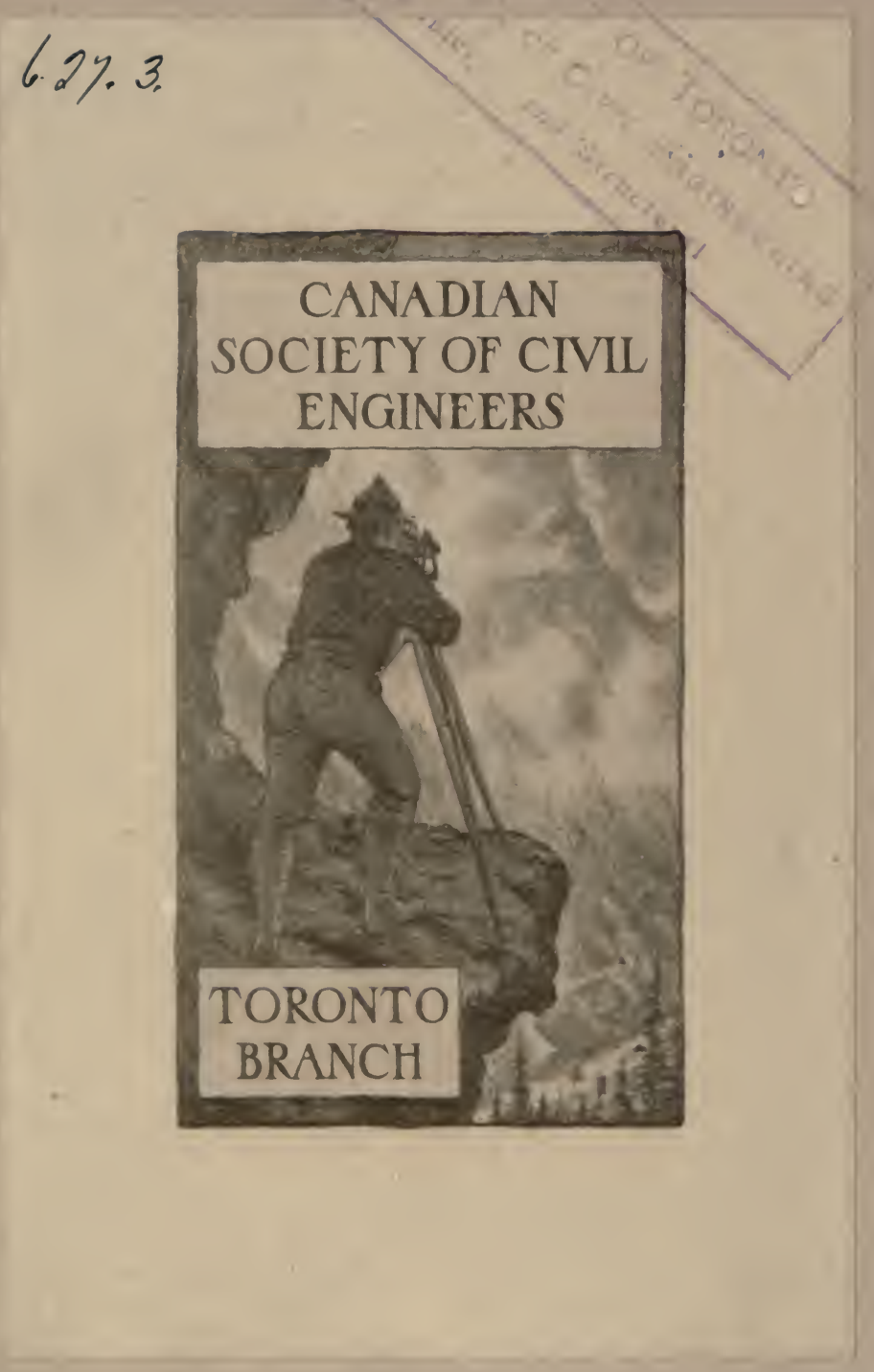

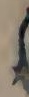


2POPERTY as TORONTO BRAB HW ENGINEERING INSTIUTE.
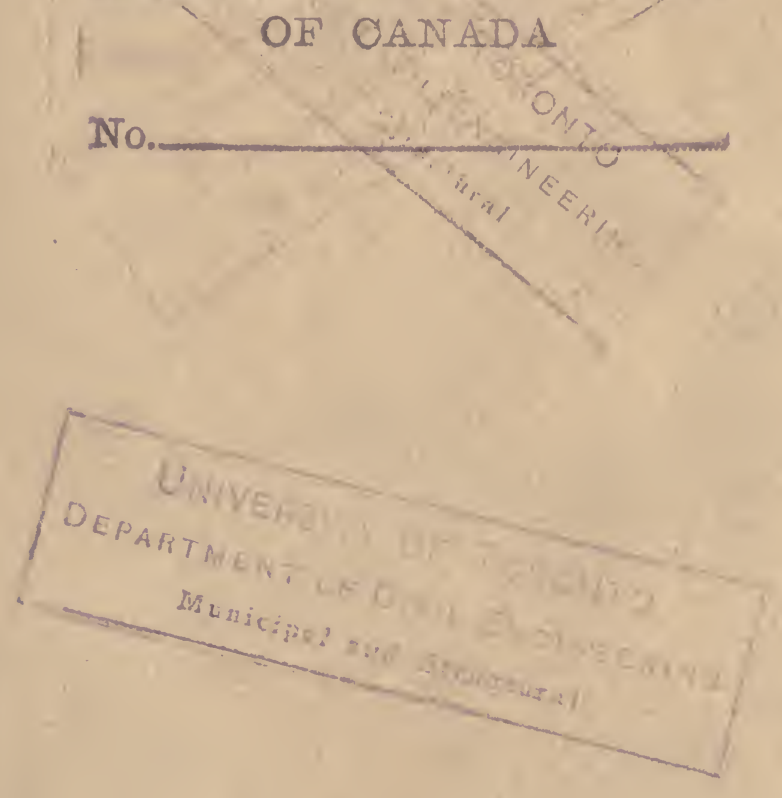


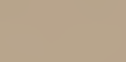

$$
\begin{aligned}
& =
\end{aligned}
$$

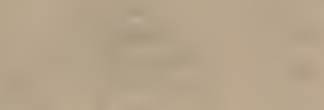


Digitized by the Internet Archive in 2007 with funding from Microsoft Corporation 
LONGMANS' CIVIL ENGINEERING SERIES

NOTES ON DOCKS AND DOCK CONSTRUCTION 


\section{CIVIL ENGINEERING SERIES}

NOTES ON DOCKS AND DOCK CONSTRUCIION.

By C. Colson, C.13., M.Inst.C.E., Deputy Civil Engineer-in-Chief, Loan Works, Admiralty. With 365 Illustrations. Medium 8vo, 21 s. net.

CALCULATIONS IN HYDRAULIC ENGINEERING: a Practical Text-Book for the Use of Students, Draughtsmen, and Engineers.

By T. Claxton Fidler, M.I.C.E., Professor of Enginecring, University College, Dundee.

Part I. Fluid Pressure, and the Calculation of its Effects in Engineering Structures. With numerous Illustrations and Examples. Mfedium Svo, 6s. 6d. nct.

Part II. Calculations in Hydro-Kinetics. With numerous Illustrations and Examples. Medium 8vo, 7s. 6d. net.

RAILWAY CONSTRUCTION.

By W. H. MiLls, M.I.C.E., Engineer-in-Chief, Great Northern Railway of Ireland. With 516 Illustrations. Medium $8 \mathrm{vo}$, 18 s, net.

\section{PRINCIPLES AND PRACTICE OF HARBOUR CON-} STRUCTION.

By William Shield, F.R.S.E., M.Inst.C.E., and Executive Enginecr, National Harbour of Refuge, Petcrhead, N.B. With 97 Illustrations. Medium 8vo, 15s. net.

\section{CIVIL ENGINEERING AS APPLIED IN CON-} STRUCTION.

By Leveson Francis Vernox-IIARCourt, M.A., M.Inst.C.E. With 368 Illustrations. Second Edition, revised by HENRY FIDLER, M.Inst.C.E., F.G.S. Medium 8vo, 16s. net.

SANITARY ENGINEERING WITH RESPECT TO WATER-SUPPLY AND SEWAGE DISPOSAL.

By Leveson Francis Vernon-Harcourt, M.A., M.Inst.C.E. With 287 Illustrations. Medium 8vo, 14s. net.

TIDAL RIVERS : their (1) Hydraulics, (2) Improvement, (3) Navigation.

By W. H. Wheeler, M.Inst.C.E. With 75 Illustrations. Medium 8vo, 16s. net.

NOTES ON CONSTRUCTION IN MILD STEEL: Arranged for the Use of Junior Draughtsmen in the Architectural and Engineering Professions.

By HeNRy Fideer, M.I.C.E., Author of the Article on "Dockyards" in the Encyclopadia Britannica, and Editor of "Notes on Building Construction." With Illustrations from Working Drawings, Diagrams, and Tables. Medium 8vo, 16s. net.

L O NGM A S, GREEN, AND CO. LONDON, NEW YORK, BOMBAY, AND CALCUTTA 


\title{
NOTES ON DOCKS AND DOCK CONSTRUCTION
}

\author{
BY \\ C. COlson, C.B., M.Inst.C.E.
}

FORMERLY ASSISTANT DIRECTOR OF WORKS, ADMIRALTY;

LATE DEPUTY CIVIL ENGINEER-IN-CHIEF, ADMIRALTY LOAN WORKS

(NAVAL DOCKS AND HARBOURS)

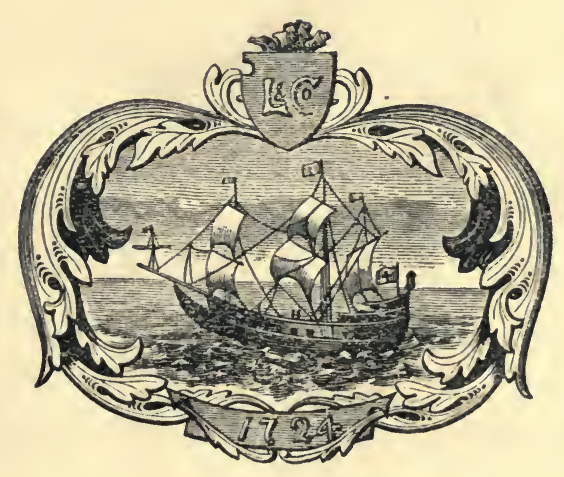

WITH ILLUSTRATIONS

NEW IMPRESSION

LONGM A N , GRE N, A N D CO.

39 PATERNOSTER ROW, LONDON

NEW YORK, BOMBAY, AND CALCUTTA

I9ro 


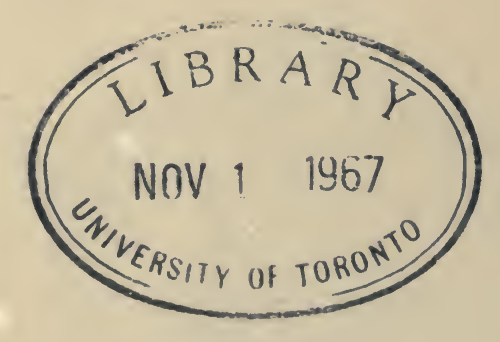




\section{P R E F A C E}

This work does not pretend to be an exhaustive treatise on Docks; it is, in fact, as its title indicates, a collection of notes bearing upon a subject of very great interest, and embracing a very wide field of practice.

Some of these notes are based upon the Author's own observation and experience, extending over a considerable number of years, while others have been compiled from information very kindly communicated, and from the recorded experience of many of the most prominent men in the profession, who have made this -branch of engineering their especial study.

The notes were commenced with a very different object in view. At the suggestion, however, of the Author of "Notes on Building Construction," they have been amplified with the hope of affording useful information to those interested in the subject, and to indicate through the references where further and fuller particulars may be found.

The subject has not been dealt with from all points of view. Such a subject as Docks and their construction 
and equipment, under all the varying conditions to be met with as to use, locality, physical conditions, etc., has too wide a range to be exhaustively treated in such a brief compass as this one volume. The difficulty has been to know what to include and what to omit in order to keep within the prescribed limits. It is claimed, however, that what has been included is the result of actual practice, compiled from authentic records.

The Author takes this opportunity of acknowledging the courtesy with which many friends have replied to inquiries for information. 


\title{
CONTENTS
}

\author{
CHAPTER I.
}

Early notes-Classes of docks-Advantages of docks-Sites near sea-Sites for imperial docks-Prevailing wiuds-General plan-Width of basins -Wharfage-Jetties-Tidal docks-Position of entrance-Relation of sectional area of entrance to dock area-Examples of dock plans .

\section{CHAPTER II.}

Commencement of works, or opening up-Importance of well-considered temporary works-Alexaudra Dock, Hull-Portsmouth Dockyard Extension-Southampton Tidal Dock . . . . . . . . .

\section{CHAPTER III.}

Dams-Importance of efficient dams in marine works-EmbankmentsTimber dams-Leakage-Sluice-valves in dams-Half-timber sheetingGrooved-and-tongued piling-Excessive thickness of clay puddle-Dams subject to rise and fall of tide-Leaks due to through-bolts-Vibration due to pumping-Leaks through clay puddle-Jaminated walingsDams of single rows of piles-Timber shield-dam-Iron dams-Timber dams on Thames-Coffer-dams at middle level, Dublin, Birkenhead, Hull, Pola Dock, Esquimalt, Amsterdam Canal, Portsmouth, Limerick, Chatham, Calais .

\section{CHAPTER IV.}

Water in foundations-Castings for covering boils-Necessity of ample pumping power-Lock foundations, Albert Docks, Hull-A vonmouth Lock foundations-Stopping leaks-Somerset Dock, Malta-Stock rammirgStopping joints in block-work

\section{CHAPTER V.}

Dock and Quay walls-Angle of repose of different materials-Actual lateral pressure of earthwork-Experiments made at Chatham-Experiments made by Sir B. Baker-Use of counterforts-Backing to walls-Curved 
batter to walls-Depth of rater alongside-Voneering-Quay walls, Groenoro-Buckey dock walls-Basin walls at Alexandra Dock, HullCalais basin walls-Southampton tidal basin walls-Wharf wall on river front, New York-Cylinders used at Glasgow-Walls on the DanubeAt Borleaux, Bombay, Rouen, Gourock, Brest, Fiume, Dublin, Greenock, Spezzia, at the mouth of the Rhone-Pola basin walls-Timber wharfing

\section{CHAP'TER VI.}

Dry or graving docks-Locks-Early practice-Docks in a tideless senMethod of construetion-Slope of doek flow-Dimensions of docks-Plan of docks-Depth over sill-Local and shipping conditions to be studiedFloor of dock-Mud docks of India-A vonmouth dock-Genoa dry docks -Panama canal locks-Wivenhoo dock-Green's dock, BlackwallToulon docks-Timber docks-Mount Stewart dock-Calais doeksSomerset dock, Malta-Extension of dock at Ieghorn-Glasgow No. 2 dock-Esquimalt dock

\section{CHAP'TER VII.}

Closing entrances-Principal points to be kept in view-Gate-platformQuoins-Gates-Heel-post-Timber gates-Metal gates-Form of gates -Rise of gates-Nipping-Staunchness-Opening and elosing gatesHydraulic rams and chains-Direct-acting rams-Gate rollers-Support to gates in rough weather-Stay-gates-Dunkirk Dock gates-Amsterdam Ship Canal gates-Avoumouth Dock gates-Whitehaven Dock gatesBarry Dock gates-Sanfernando Dock gates-Alexandra Dock gates, Hull-West India Doek gates-Caissons-Sliding caissons-Floating caissons-Floating box caissons-Caisson at Limckiln Dock-Barry Dock caisson-Kowloon Dock caisson-Esquimalt Dock caisson-Curro Dock caisson-Garvel Dock caisson

\section{CHAP'TER VIII.}

Deposits-Scouring power of water-Primary object in sluicing-Bottom velocity-Duration of scouring-Fresh water for scouring purposesAronmouth entrance-Tilbury Dock entrance-Barry Dock entrancoThames Embankment landing-places-Calais entrance ehannel-Dunkirk entrance channel-St. George's Stage, Liverpool-Removal of shoals by propeller sluicing-Honfleur sluieing basin-Canada Basin, LiverpoolLow-water Basin, Birkenhead . . . : . .

\section{CHAPTER IX.}

Floating docks - Classification - Durability - Strains-A pplicability - Conditions affecting design-Stability-Cartagena dock-Off-shore floating dock-Depositing dock-Hydraulio lifting dock 


\section{CHAPTER $\mathrm{X}$.}

Slipways-Adrantages and disadvantages-Inclination of ways-Methods of constructing foundations-Slipways of ordinary construction-Mode of working-Slipways to accommodate more than one vessel-Hydraulic hauling gear-Wire-rope haulage-Stress in hauling-Resistance on sliding slipways-Broadside slipways . . . . . . .

\section{CHAPTER XI.}

Pumping water from docks-Vertical centrifugal-pumps-Horizontal pumps at Liverpool Docks-Reciprocating plunger-pumps at Portsmouth-Pumps at the Barry Docks-Pumps at Bute Docks, Cardiff-Pumps at the Hamilton Docks, Malta-Temporary pumping . . . . . .

\section{CHAPTER XII.}

Dredging - Class of appliances-Grabs-Pump-dredgers-Bucket-dredgersStationary dredgers versus seagoing hopper-dredgers - Variation of quantities of dredged material as compared with sections-Time actually employed in dredging . . . . . . . . .

\section{CHAPTER XIII.}

Destruction of timber-Marine worms: Teredo navalis-Chelura terebransLimnoria terebrans-The Lepesma of the West Indies-The XycophagoRate at which the worm will destroy timber-Effect of the worm on hard woods-Rot in timber-Preserving timber: Mechanical means-Chemical means-Corrosive sublimate-Sulphate of copper-Chloride of zincCreosote-London oils - Country oils - Scotch oils - Carbolic acid Apparatus used in creosoting-Process of crcosoting-Aitkins' processHayford's process-Charred timber-Practice of Eastern Rivilway of France-Practice on New Zealand Railways . . . . . .

\section{CHAPTER XIV.}

Cost of works-Cost per acre of water area-Cost of locks and docks-Cost of quay walls-Cost of floating docks-Dock gates-Cost of caissons-Cost of dredging .

\section{CHAPTER XV.}

Iron in sea-water-Experiments made by Mr. Rennie-Experiments made by Mr. Mallet-Experiments made by Mr. Thwaite-Composition of sea-salts-Analysis of sea-water-Fixing. bolts in masonry-Anchorbolts-Experiments made by Mr. Moore-Experiments made by Mr. E. F. Miner-Holding power of drift-bolts in timber-Experiments made by the United States Gorernment-Experiments made in counection 
with the Brooklyn Bridge-Experiments made by Mr. Tscharner-HoldPAGB ing power of spikes-Wire-ropo fastenings-Clay suitable for puddlePuddling bottoms of basins-Boring - Surface friction on cylinder foundations-Experiments made by Messrs. Griber and Balzano-Surface friction on piles-Resistance of different inaterials to horizontal stress-Sheetpiling-Increaso in resistance of piles due to quiescence-Displacement of ground by piling-Composite piling-Screw-piles-Serew-piling in unstable ground-Lond on piles-Defective pile-heads-Water-jet in piledriving-Water-jet in cylinder sinking-'l'esting stability of groundPressure on ground unler dock-floors-Equipment-Bollards and wharfmoorings

Miscellaneous Notes

IXDEX 


\section{CHA P T E I.}

Early notes-Classes of docks-Advantages of docks-Sites near sea-Sites for imperial docks-Prevailing winds-General plan-Width of basins-Wharfage -Jetties-Tidal docks-Position of entrance-Relation of sectional area of entrance to dock area-Examples of dock plans.

THE term, "dock," was formerly applied exclusively to the slips or enclosures made for the purpose of building or repairing ships. Such a structure was distinguished as a dry dock, when furnished with gates to prevent the influx of the tide, and as a wet dock when, having no gates, the vessel could only be approached during the period when the tide left her dry.

For all purposes of loading or unloading goods and merchandise there were the open tidal rivers, some private river side wharves, or the public landing-places known as the legal quays and wharves which were constructed by, and were under the control of, the Commissioners of Customs. These legal quays and wharves were established by Act of Parliament during the early part of the reign of Queen Elizabeth for the purpose of facilitating the collection of the customs dues, checking the extensive smuggling transactions that were carried on, and the many other illegal practices which prevailed, and in consequence of which the revenue of the country suffered greatly.

The growth of commerce during the last and beginning of the present century demonstrated the inconvenience and loss incurred in having to load and unload vessels in a tidal river, or in a harbour not entirely land-locked; for either the ships could not be brought close to the wharves, or, when placed there at the flood of the tide, they were left dry at the ebb, and suffered continual damage by straining, by delay from neap tides and other accidents and inconveniences; further, as the number and size of ships increased, the means and appliances for cleaning and repair proved inadequate. These considera-

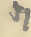


tions led to numerous extensive improvements in the existing docks and slips, and to the introduction of floating basins for the accommodation of vessels loading and discharging. Liverpool appears to have taken the lead in England, the first floating or wet dock having been constructed there in 1709, but nearly a century appears to have elapsed before the example was followed by other ports. At Hull, the old dock, now known as the Queen's Dock, was completed and opened in 1778. At Grimsby, dock and harbour works were in hand in 1797. On the Thames, a small dock existed at the beginning of the century called the Greenland Dock, but it was of very limited capacity, and only used by whaling-vessels. The first of the floating docks constructed on the Thames was the West India, the excavations for which were began in July, 1800, and vessels entered the import dock in the month of September, 1802. The London Docks were opened in 1805, and the East India Docks in 1806. Bristol and Hull appear to have come next with wet or floating docks which were opened in 1808 and 1809. At Wick, a tide basin for the accommodation of the fishing-boats was commenced in 1808 .

The necessity of providing ample dock accommodation has come to be fully recognized, and is looked upon as a question of the first importance, not only by all those seaport towns which aspire to become the outlets of commercial enterprise and energy, but by some of the largest inland centres of industry, as instanced by the case of the Manchester Ship Canal.

The conditions governing the designing and construction of docks are eminently different to what they were during the early part of the century, or even twenty-five or thirty years ago. Then, sailing-ships of a short and bluff type had chiefly to be provided for. Now, provision has to be made for vessels of altogether a different character, of great length and narrow in comparison, and of a much greater draught of water, calling for entirely different treatment in arranging the proportions and details of dock construction.

Classes of Docks.-Docks may be classed as wet docks, or basins; dry, or graving docks; lifting docks ; and slips.

Wet docks are large enclosures, usually several acres in extent. The entrance may be open, but is more frequently closed by gates or caissons, in order that the water may bo retained at a constant level. 
Graving or dry docks comprise all structures formed mainly below the water level, and into which vessels may be floated. They may vary in design and methods of construction according to circumstances and local conditions.

Floating docks are structures of iron or wood which are sunk sufficiently deep in the water to enable a vessel to be placed over them.

The slip consists of an arrangement of ways constructed on an incline which runs into deep water, and carries a cradle or carriage which can be placed under the vessel.

The function of the three latter classes is to lay the vessel dry for examination and repair. This is accomplished in the first case by pumping the water out of the dock, or by running it out wholly or in part as the tide recedes, the vessel being securely shored as the water is lowered. In the second case, by lifting the vessel bodily out of the water; and in the third, by placing her on a carriage, and hauling her up the inclined slipway until she is above the water level.

Advantages of Docks. - The particular advantages attaching to docks or basins are, in tidal basins, i.e. with open entrances affording free ingress and egress to the tides-that ships can be accommodated in the smallest possible space, and can be kept constantly afloat, and be at all times easily moved from place to place as may be required. Whereas, in an open harbour or river, when at low water ships take the ground, they run great risk of being strained or otherwise seriously injured; further, in open anchorages, when the tide is falling, vessels are liable to fall against each other or chafe against the quays; and in harbours at all exposed, when there is a run of sea during stormy weather, or in a river during land floods, there is the risk of the breaking of warps and the consequent fouling of the vessels.

When the dock entrance is closed by gates, the ship's level is never much altered, so that the cargo when being discharged has not to be lifted to the same height as would be the case in a tidal dock. Moreover, the operations of loading and unloading can be carried on regularly and at all times.

It is, however, obvious that these conditions can hardly be maintained if, when the range of tide is considerable, only one set of gates is employed. In such a case, the period during which vessels could be passed in and out of the dock without 
lowering the water too much would be reduced to a very short time before and after high water; the range of time would depend, of course, upon the variation of water level in the dock, which might be considered desirable, and which would be governed in a great measure by the draught of the vessels occupying the dock or basin.

In order to meet this objection, an entrance lock is necessary, and in some cases an outer or half-tide basin, by which adjuncts the time during which vessels can be passed in or out can be materially extended, and under certain conditions as to the water supply, i.e. where the water-level in the dock is kept up by pumping, entry and exit may be performed at any state of the tide outside.

Location and Class of Docks.-With regard to the location and class of docks, the following may be considered as some of the principal conditions which govern the selection of the best localities and most suitable class of docks.

(a) Where the rise of tide is considerable, as, for instance, on the west coast of England, where the rise of spring tides is about 40 feet; or the east coast of America, where the rise is 46 feet, closed docks or basins are more required than in rivers or localities where the tidal rise is moderate, as on some parts of the east coast of England, the south and east and north coasts of Ireland, where ranges of 4, 6, and 7 feet are met with. Where there is no tidal range, or practically none, as in the Mediterranean, closed docks or basins may be considered unnecessary, unless under exceptional local conditions.

(b) Where the nature of the trade requires ships of great length, which are therefore very liable to injury from taking the ground, a dock is more needed than at places where the ships are of small size, and are therefore less likely to be strained when not water-borne.

(c) Where the bottom is soft and muddy there is less need for a dock than where the bottom is hard and uneven, unless where strong currents are likely to burrow out the soft soil so as to make the bottom irregular by forming deep ruts.

(d) Where the harbour or anchorage is open to the entrance of surface waves of considerable height, or of a ground swell, there is more need for a dock than where there is better protection.

(e) Where there is sufficient fresh water, free from mud or 
silt, available for supplying the basins, a dock rnay be more suitably placed than where the supply is from the sea or tidal water, if it is much loaded with matter in mechanical suspension.

No hard-and-fast rule can be laid down as to the selection of a location and the preparation of a dock scheme, as so much must of necessity depend upon local conditions such as prevailing winds, rise and fall of tide, strength and set of currents, configuration of the land, and many other points.

Sites near the Sea.-Owing to the increased size of ships, and consequently the greater accommodation required, the tendency is to select sites nearer the sea than was formerly the case. In considering, however, the advantages and disadvantages of available sites, it is necessary to bear in mind that the principal benefits derivable from them are the conveniences and facilities they offer for commercial purposes, facts which should have the greatest weight in governing the selection of a site, and which would perhaps warrant the works being placed at a distance from the sea.

Should the position selected be in a land-locked bay or a narrow river, no particular precautions as regards the dock entrance is called for. On the other hand, as regards the more exposed positions near the sea, the position and form of the entrance will require careful consideration. With a considerable fetch, waves might be generated during gales of such a height as to endanger the entrance gates or interfere with their being worked during stormy weather.

In reference to entrances and entrance channels, Sir John Rennie very clearly expressed his opinion as to the broad principles on which he held such works should be designed, and although his views referred more particularly to harbour entrances, and the days of sailing-ships than to dock entrances, yet, the $y$ are applicable to a very great extent to the latter when constructed, as is at times unavoidably the case, in exposed positions, and probably requiring an outer basin or entrance channel. It may, therefore, not be altogether out of place to quote them. These principles are: ${ }^{1}$ "That every harbour should have its entrance so placed as to face as much as possible the direction from which vessels can most conveniently enter in stormy weather; but that the heads should be made of such a form as to admit of the. least sea entering, or so as to occasion 1 "Lives of the Engineers," vol. ii. 
as little swell inside as possible. This cannot by any practical construction be entirely avoided, but means should be taken within the harbour to reduce the recoil of the waves to a minimum.

Site for Imperial Docks. - As regards the selection of a site for an imperial establishment, the following conditions will require special attention. A depth of water sufficient to ailow of the sills of docks and basins being placed so low as to admit, at low-water spring tides, the largest class of naval ships at what may be considered damage-draught. Spacious and well-sheltered anchorage of an area sufficient to accommodate a large number of vessels. Natural protection from an enemy's fire. Ceutral position on the coast line, with ready and convenient means of communication with manufacturing districts particularly, and with all parts of the country generally. Close proximity to a well-protected roadstead, or harbour.

Prevailing Winds.-It will be necessary to give some considerable attention to the direction and force of the prevailing wind, as regards the position of an entrance particularly, and the site of enclosed basins and docks generally. In the first case, currents may be generated which it would be desirable, if possible, to avoid. Secondly, a site may possess every advantage in all other respects, yet it may be, if fully exposed to high prevailing winds, unsatisfactory, inasmuch as the wind acting on the high masts and rigging of vessels alongside the wharves may cause them to work and chafe, and thus give rise to considerable damage.

General Plan of Basins.-The general plan and width of dock to afford the maximum accommodation, combined with the greatest facilities for manœuvring ships, will depend in a great measure upon the class of ships and the nature of the trade to be accommodated, modified in the majority of cases by local conditions and peculiarities of the available site.

Width of Basins. - The most suitable width of basins is a point on which, as on many others appertaining to dock construction, some difference of opinion exists; some experts contending that, in view of the increasing length of ocean-going steamers, docks for their accommodation should not be less than 600 feet wide in some particular part where a long ship could be turned, whilst others contend that there should be no difficulty in working a narrower dock, inasmuch as, with proper appliances, 
a ship could be turned pretty nearly on its centre, and that a dock could be safely worked of over 450 feet wide, whilst for ships exceeding this length there could be no objection to their being taken out stern first. The possibility of this course being pursued would depend upon the conditions obtaining outside the dock entrance or in the entrance channel, where the latter is tortuous or contracted. With a high wind or strong current, a vessel backing out would be liable to get into difficulties, and probably considerable danger; on the other hand, where there is a free outlet, there would appear to be no objection to this mode of undocking ships. As a good general rule, it may be laid down that there should be some part of sufficient width, clear of any ships that may be lying at the wharves, to admit of a ship being turned so as to be able to leave the dock stem first.

Assuming that a large class of ship of say 450 feet in length has to be accommodated, the width occupied alongside the wharf would be about 50 or 100 feet, if there are wharves on both sides, and allowing 25 feet clearance on each side, a total width of 600 feet at least would be required in some part to afford sufficient turning space for a vessel of this length.

In determining the width, regard must be had to the necessity of reserving as much area as possible for wharfage purposes, railways, and warehouses, even to the extent of reducing the width of the basins to a minimum or having to undock some of the longest ships stern first. The actual proportion of land to be reserved will obviously depend greatly upon the nature and requirements of the class of trade to be accommodated, but unless care is taken that it is ample for the purpose, the traffic will be

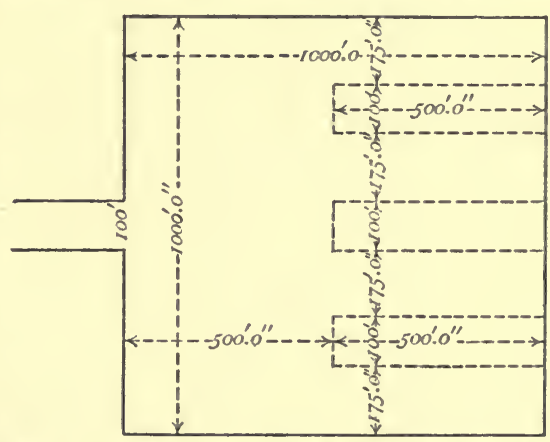

Fig. 1.-Water area, 111,111 square yards; available wharfage, allowing 100 feet for entrance, and 50 feet for beam of ships, 3700 feet. With jetties-Water area, $94,44 \bar{z}$ square yards; wharfage 5800 feet. cramped and the full development of the dock impossible.

Wharfage.-The available wharfage compared with the water 
area will depend upon the form and width of the dock. A square form, whilst it would givo greater facilities for manœuvring vessels and lessen the distance of removal, would give a less length of available wharfage than a basin of an oblong form of

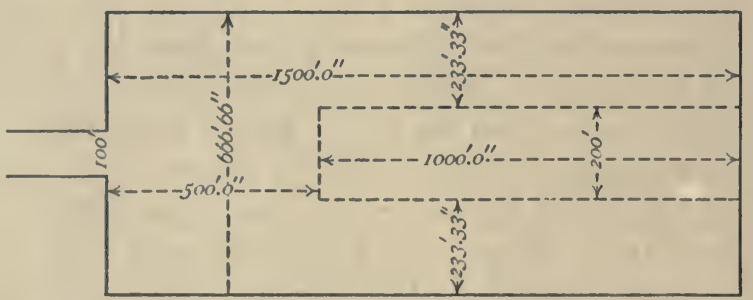

Fic. 2.-Water area, 111,111 square yards; wharfage, 4033.33 feet. With jettics-Water area, 88,889 square yards; wharfage, 5466.66 feet.

the same water area. For instance, a dock 1000 fect by 1000 feet, equal to an area of 111,111 square yards (Fig. 1), would have (allowing 100 feet for the entrance, and ships of 50 feet

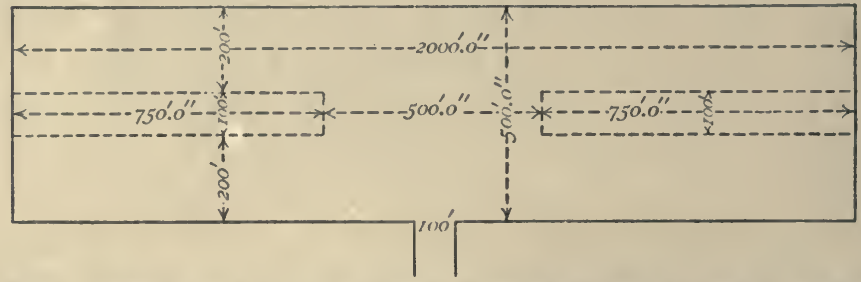

Fig. 3.-Water area, 111,111 square yards; wharfage, 4700 feet. With jetties-Water area, 94,444.34 square yards; wharfage, 6900 feet.

beam) an available wharfage of 3700 feet. Whilst a dock of the same water area, but 1500 by 666.66 , would have an available wharfage of 4033.33 feet (Fig. 2). If the length is 2000 by

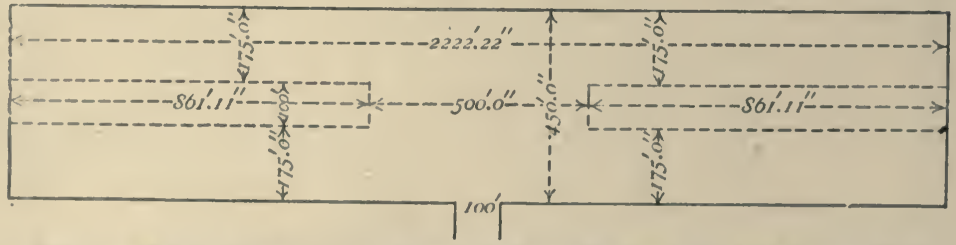

Fig. 4.-Water area, 111,111 square yards; wharfage, $5014 \cdot 44$ feet. With jetties-Water area, 91975.30 square yards; wharfage, 7888.83 feet.

500 (Fig. 3), the available wharfage becomes 4700 feet; in this case, the available length of wharf at the ends of the dock would be 400 fect. If the dimensions are made $2222 \cdot 22$ by 450 (Fig. 4), the wharfage is 504.44 feet, with 350 feet available 
wharfage at the ends of the dock; by a still greater reduction of width, the available wharfage would be still further augmented.

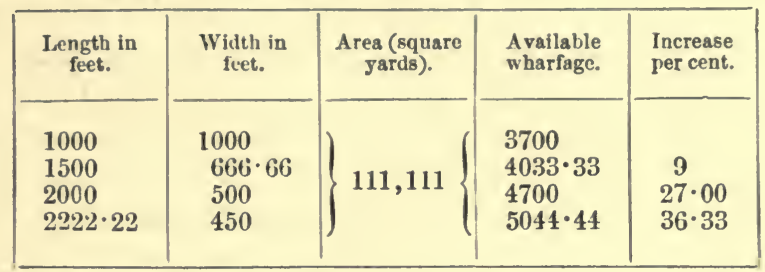

Some: of the objections to a width of dock greater than is actually required for the proper mancuvring of ships may be noticed as follows:-Loss of land area, which would be of the greatest value in developing the full capabilities of the dock property, cost of excavating and forming the unnecessary water area. The excessive length of warps and hawsers required in moving and turning vessels, the distance to which signals or orders as to the working of the capstans, or the manipulation of the hawsers and warps have to be transmitted.

Jetties.-The introduction of jetties projecting into the basin affords a convenient and economical means of increasing the

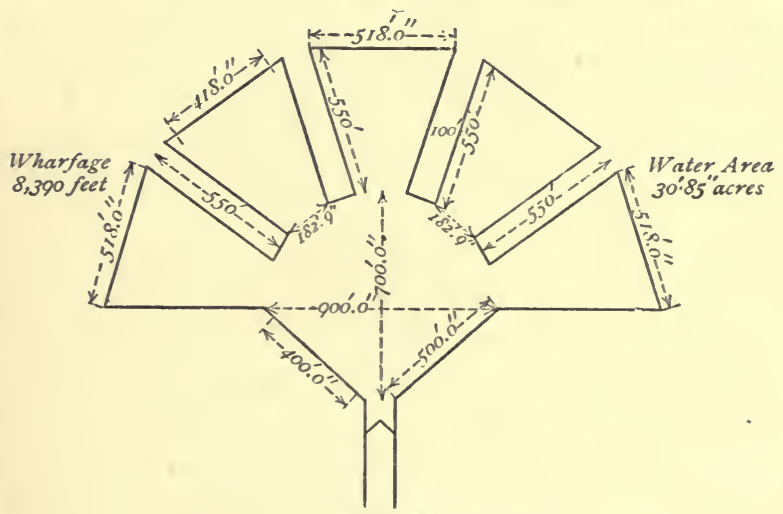

Fig. 5.

wharfage accommodation; it is, however, of the utmost importance to guard against the basin being unduly crowded thereby, and thus hinder the free movements of ships. Referring to Fig. 1, the introduction of jetties, as shown by dotted lines, would add 2100 feet to the available wharfage, whilst still leaving ample room for a ship to turn. In Figs. 2, 3, 4, jetties placed as indicated by dotted lines would add 1433, 2200, and 2744.44 
feet respectively, whilst there would still bo ample room near the entrance for turning long ships.

The plan shown by Fig. 5, which was, it is believed, an arrangement of jetties, first suggested by the late Mr. 'T. Stevenson, M.I.C.E., would perhaps afford, in the least possible area, the greatest amount of accommodation, with room to turn a ship in the most convenient positio:ı, viz. near the entrance. Practically, it would be almost impossible to adopt such an arrangement in its entirety, unless under very exceptional circumstances as to site. Even in cases where such a plan would be possible, it does not follow that it would be the most suitable to meet all the conditions of the trade to be accommodated. The principle may, however, be applied in part with advantage in many instances.

Tidal Docks.-In considering the question of Tidal Basins versus Closed Basins, local conditions as to tides, and the probabilities of silting up, have to be taken into consideration. Where the rise and fall of tide is moderate, and the protection good, open or tidal basins may be adopted with advantage. An exposed entrance, admitting a swell that would cause the ships alongside to work, would preclude such an arrangement. Moreover, vessels rising and falling with the tide when lying alongside a wharf, are always subject to more or less damage through grinding. Added to this, there is the inconvenience caused by the constant attention required in adjusting the hawsers, gangways, etc.

When the water carries with it a large quantity of suspended matter-as for instance on the Humber-it would be injudicious to adopt tidal basins on account of the deposit of mud that would take place, and the expense attending its removal. Where the facilities for scouring are exceptionally good, the objections from this point of view would of course be modified.

The Comparative Cost of, and the facilities afforded by, the two plans have also to be taken into consideration. For instance, with a rise and fall of tide of $\mathbf{1 0}$ feet, a closed basin to accommodate vessels of 27 feet draught, to enter and leave the dock from two hours before to two hours after high tide, would require a total depth of water of 32 feet, allowing a minimum depth of 3 feet under the keel; whilst in a tidal basin, the total depth required would be 40 feet, to ensure the same class of vessel being always afloat at low tide, or an additional depth 
of $S$ feet; involving extra cost of excavations over the whole area of the basin, and also extra depth of walls and foundations, to be compared with the cost of gates and gate machinery (Fig. 6).

In the first case, the times of entering and leaving the dock would be restricted to about eight hours in the twenty-four; whilst in the second case, ships could leave and enter at any time and state of the tide. This would form one of the strongest points in favour of a tidal dock, provided the depth over the sill be maintained throughout the channel to deep water.

Position of Entrances.-There appears to be some difference of opinion as to the most advantageous position for a dock entrance with regard to the stream. With a down-stream

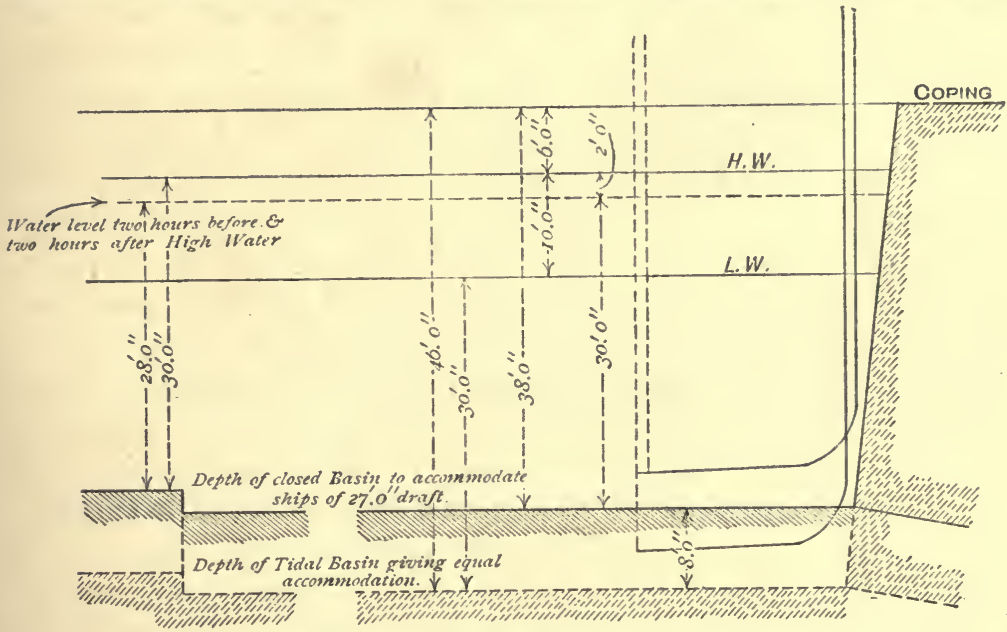

FIG 6.

position, the effect of the current upon a vessel making the entrance on a flood tide would be that, as soon as the head of the vessel came within the shelter of the lower pier, the current would cease to act upon the fore part of the ship, whilst the stern, unless checked, would be slewed round and against the upper pier. The reverse of this would be the case with a vessel leaving on the flood tide; the head of the vessel, as soon as the influence of the current is felt being, unless checked, slewed up-stream. A vessel leaving a down-stream entrance on a down-stream course with an ebb tide, would do so under favourable conditions, but would find more difficulty if an up-stream course has to be taken.

With the entrance heading up-stream, the effect of the 
current on a vessel entering the dock on a flood tide would be to cast her stern up-stream, but this would place her in a favourable position for entering; on the other hand, a vessel leaving the dock on a flood tide, and wishing to take a downstream course, would find it more difficult to do so in consequence of the tendency of the current to set the head of the ship up-stream. As regards the ebb tide, a vessel leaving the docks would be assisted in turning to her down-stream course, but there would be, at the same time, a tendency to set her against the down-stream pier.

Perhaps the most convenient position for an entrance affording equal facilities for entrance or exit on either flood or ebb tide, and one which has been largely adopted in recent dock constructions, is at right angles to the stream, with a deep and wide trumpet-shaped lead, within which slack water is established. A vessel making such an entrance would be affected by the current as long as she remained outside, but once within the piers the influence of the current would cease.

In determining upon the best position for a dock entrance, local conditions must exercise considerable influence, and must be carefully weighed; it must also be borne in mind that the success of any entrance, however placed, will greatly depend upon the skill and judgment with which the ships are handled.

A current has always a tendency to scour the concave bend of a channel, and to silt up the convex side, therefore, it is a wise precaution in determining on the position of an entrance, to place it within the influence of the concave bend of the current.

Relation of Dock Area to Sectional Area of Entrance.-In designing an entrance, particularly for tidal basins or for basins closed by a single set of gates, it is necessary to take into consideration the relation between the area of the basin and the proposed width of the entrance. If this is neglected, a current may be generated through the entrance to tidal basins which might prove inconveniently swift, and, in the case of entrances closed by a single set of gates, incompatible with their safe working; a very small current is sufficient to act injuriously in this way. It is therefore desirable to ascertain the velocity of the outgoing current at different periods of time after the ebb has began, and for this purpose observations of the fall of the tide must be made and compared with the proposed transverse sectional area of the entrance. If the 
velocities thus obtained be considered too great without unduly increasing the width of the entrance, the alternative will be to provide an additional entrance. When the docks are worked entirely by locks, and with an outer basin small in comparison with the width of entrance necessary to admit the largest class of ships expected to frequent the dock, the above considerations will have less weight. At the port of Havre, the gates are kept open until a fall of eight inches in the tide has taken place, but beyond this the currents in the locks and entrances are found to be dangerous to navigation.

Typical Examples of Dock Prans.-The Avonmouth Dock ${ }^{1}$ (Fig. 7), constructed from the designs of Mr. J. Brunlees, M.I.C.E., is situated on the Gloucestershire side of the Avon,

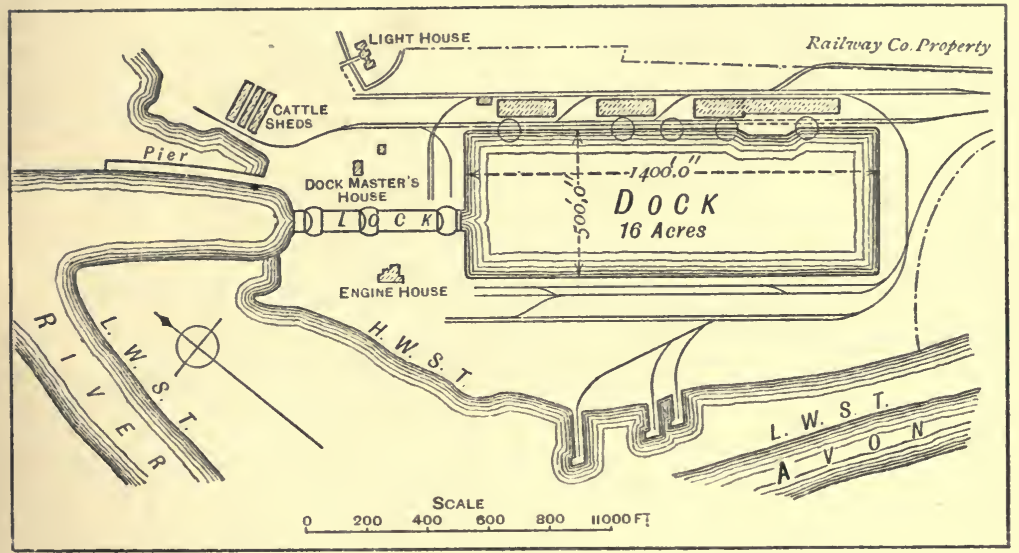

Fig. 7.

and is so near its mouth that from the anchorage of King's Road in the Bristol Channel to the entrance lock the distance is only about 1000 yards. The dock is oblong in shape, 1400 feet long by 500 feet wide, equal to an area of about 16 acres. The available wharfage, after allowing 100 feet across the entrance and for ships' berthage alongside of 50 feet, is 3500 feet. The lock is at the west end of the dock, and has a direct lead to the King's Road anchorage, through an entrance channel of about 350 yards in length by an average width of 70 yards, with a depth of 44 feet at high water of equinoctial spring tides, and 40 feet at ordinary spring tides. The high tides in the Severn and Avon confer special advantages as 
regards provision for vessels of great draught. The depth of water over the sill of the lock at equinoctial springs is $\mathbf{4 2}$ feet, at ordinary springs 38 feet, and at ordinary neaps 26 feet, whilst the depth of water constantly maintained in the dock is 26 feet.

The Alexandra Dock at Hull ${ }^{1}$ (Fig. 8), constructed from the designs of Mr. J. Abernethy, is 2200 feet long, by a total width of 1000 feet, with a water area of $46 \frac{1}{2}$ acres.

On the south side the entrance lock projects 400 feet into the basin through a jetty of 250 feet width, leaving 600 feet

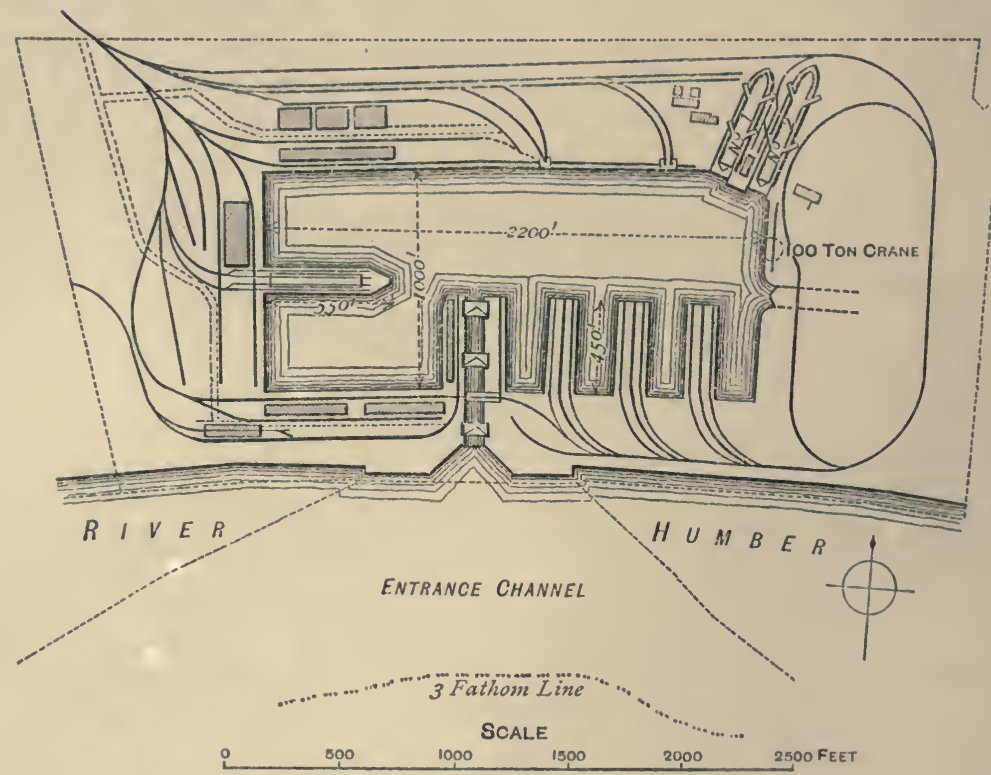

FIG. 8.

as turning room, or, with a ship alongside the north wall, 550 feet clear.

On the south side, between the lock and the east wall, there are three masonry jetties 400 feet long by 100 feet wide. On the west side there is also a masonry jetty 550 feet long by 100 feet wide. In this example, the jetty system has been taken advantage of to the utmost, giving an available wharfage accommodation of about 8500 feet, or sufficient for 21 ships averaging 400 feet in length. The depth of water in the basin

\footnotetext{
1 M.P.I.C.E., rol. xcii. p. 144.
} 
at H.W.O.S.T. is 34 feet 6 inches, whilst the coping level is 6 feet above the water.

The entrance to the lock is placed at right angles to the stream within a deep trumpet-mouthed embayment free from tidal currents. The timber wharfage on either side is continued 300 feet up and down the river. This arrangement of the entrance has answered admirably, vessels being able to pass into the lock from either up or down stream without the least difficulty.

The entrance is exposed to a fetch of about 14 miles. Consequently, with a south-westerly gale, there is a somewhat heavy sea in front of the dock. Owing to the free access of the very muddy water of the Humber into the original Hull Docks for two or three hours each tide, the deposit introduced was found to amount to as much as $1,250,000$ tons of mud in the year, necessitating the employment of a large dredging plant for its removal. To obviate as far as possible the necessity of this dredging in the Alexandra Docks, arrangements have been made by which fresh water from the Holderness drain is pumped into the basin to maintain the water level. This drain is a fresh-water stream draining a large portion of the Holderness division of Yorkshire, and which has its outlet adjacent to the Alexandra Dock. The pumps are capable of delivering $14,500,000$ cubic feet of water into the basin in twenty-four hours, thus benefiting the drainage of the district as well as reducing the cost of maintenance of the dock.

At Bordeaux, in consequence of the large quantity of mud carried in the waters of the Garonne, a number of openings were left in the upper part of the gates of the floating basin. These openings stretch across the full width of the gates, and are provided for the purpose of admitting the surface water of the river at high spring tides. For supplying the basin at low water, three artesian wells were specially sunk for the purpose, from which a supply of fresh water varying from 24,000 to 31,000 cubic feet per hour is obtained, the water being stored in a reservoir having an area of 40 acres, and from which it is passed into the basin as required.

Tilbury Docks (Fig. 9), on the Thames, constructed from the designs of Messrs. Manning and Baynes, M.M.I.C.E., consist of a tidal basin with a wide entrance to the river. A main dock connected with the tidal basin by a lock and three subsidiary 
docks off the main dock. The tidal basin, which is irregular on plan, has an area of 21 acres, with wharfage accommodation for large ships amounting to 1500 feet, in addition to a jetty about 150 feet long, for discharging coal. The depth of water in this basin at low-water spring tides is 26 feet, and at high water of ordinary spring tides 45 feet.

The main dock has an average length of 1800 feet by a width of 600 feet square, to an area of 25 acres. The three branch

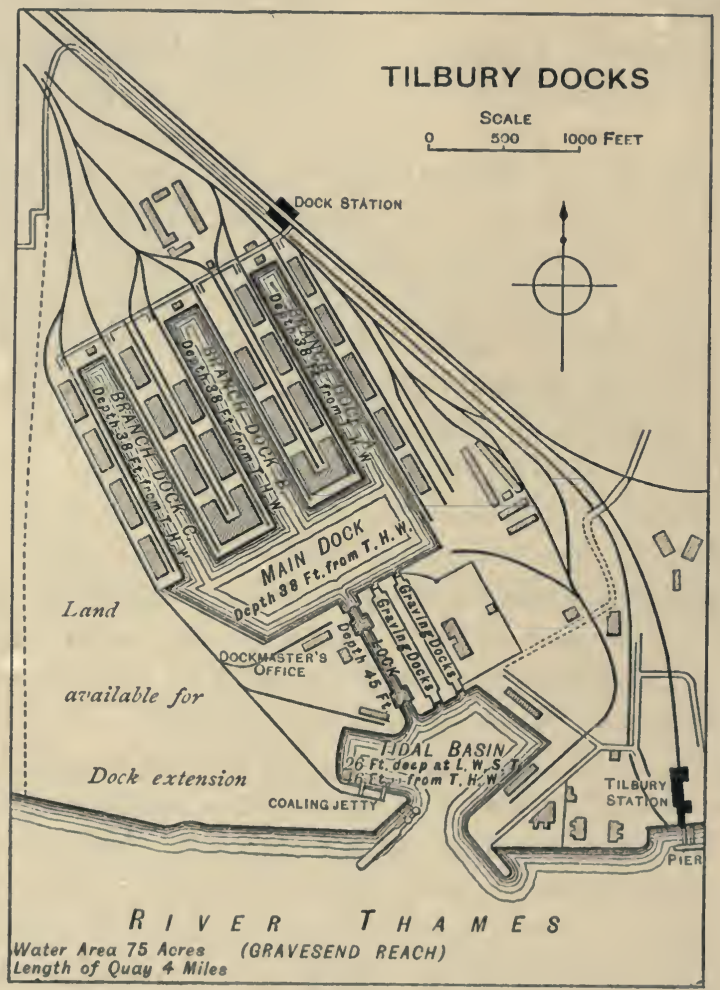

FIG. 9.

docks are parallel to each other and at right angles to the main dock into which they open on the side opposite to the lock. The length of each is 1600 feet. The centre dock has a width of 300 feet, whilst the two side docks have an average width of 250 feet, and having a collective area of about $29 \frac{1}{2}$ acres. The jetties between the three branch docks are 350 feet wide, affording room for a double row of storehouses, railways, etc. The depth of water in the main and branch docks is 38 feet below Trinity 
high-water mark. The length of wall available for wharfage, omitting the entrances to docks and lock, is about 13,800 feet.

The lock connecting the tidal basin with the main dock is 700 feet long by 80 feet wide, and is closed by wrought-iron gates. It is divided by intermediate gates into two chambers, one being 555 feet and the other 145 feet in length; the object of this arrangement being the saving of water in docking and undocking.

Parallel with the lock, there are two dry docks 875 feet long; one has a top width of 70 feet by a total depth of 35 feet, with 32 feet of water over the sill at ordinary spring tides; whilst the other has a width of 60 feet by a total depth of 30 feet, with 27 feet of water over the sill at ordinary spring tides. These docks have entrances, closed by floating caissons, to both the tidal basin and the main dock, therefore either can be used as an entrance lock in case of necessity. Each dock is divided by an intermediate caisson into two unequal lengths, so that there are practically four docks available for repairing purposes.

The entrance to the tidal basin is about at right angles to the river. It is trumpet-shaped, and is formed by running out timber jetties, heading up and down stream.

Bute Docks, Cardiff. ${ }^{1}$-The Roath Dock (Fig. 10), constructed from the designs of the late Mr. J. McConnochie, M.I.C.E., is situated on the south shore. The length of the dock is 2400 feet by a width of 600 feet, equal to an area of approximately 35 acres. The available wharfage, allowing for entrance and the width occupied by ships at the side walls, is about 5700 feet, with a depth of water of 38 feet 8 inches. The dock is entered through the Roath Basin, to which it is connected by a lock 600 feet long by 80 feet wide, with a total depth of 43 feet 6 inches. The depth of water over the sill at high water of ordinary spring tides being 35 feet 8 inches, and at neap tides 25 feet 8 inches. The lock is divided by intermediate gates into two chambers.

The Roath Basin (Fig. 10), which forms the outer entrance to the Roath Dock, is 1000 feet long by 550 feet wide, equal to an area of 12 acres; the available wharfage is 2700 feet.

The entrance lock communicating with the harbour is 350 feet long by 80 feet wide, with a depth of water over the sill 
at high water of ordinary spring tides of 35 feet $8 \frac{1}{2}$ inches, and 25 feet $8 \frac{1}{2}$ inches at neap tides.

At the north and south corners of this basin there are two

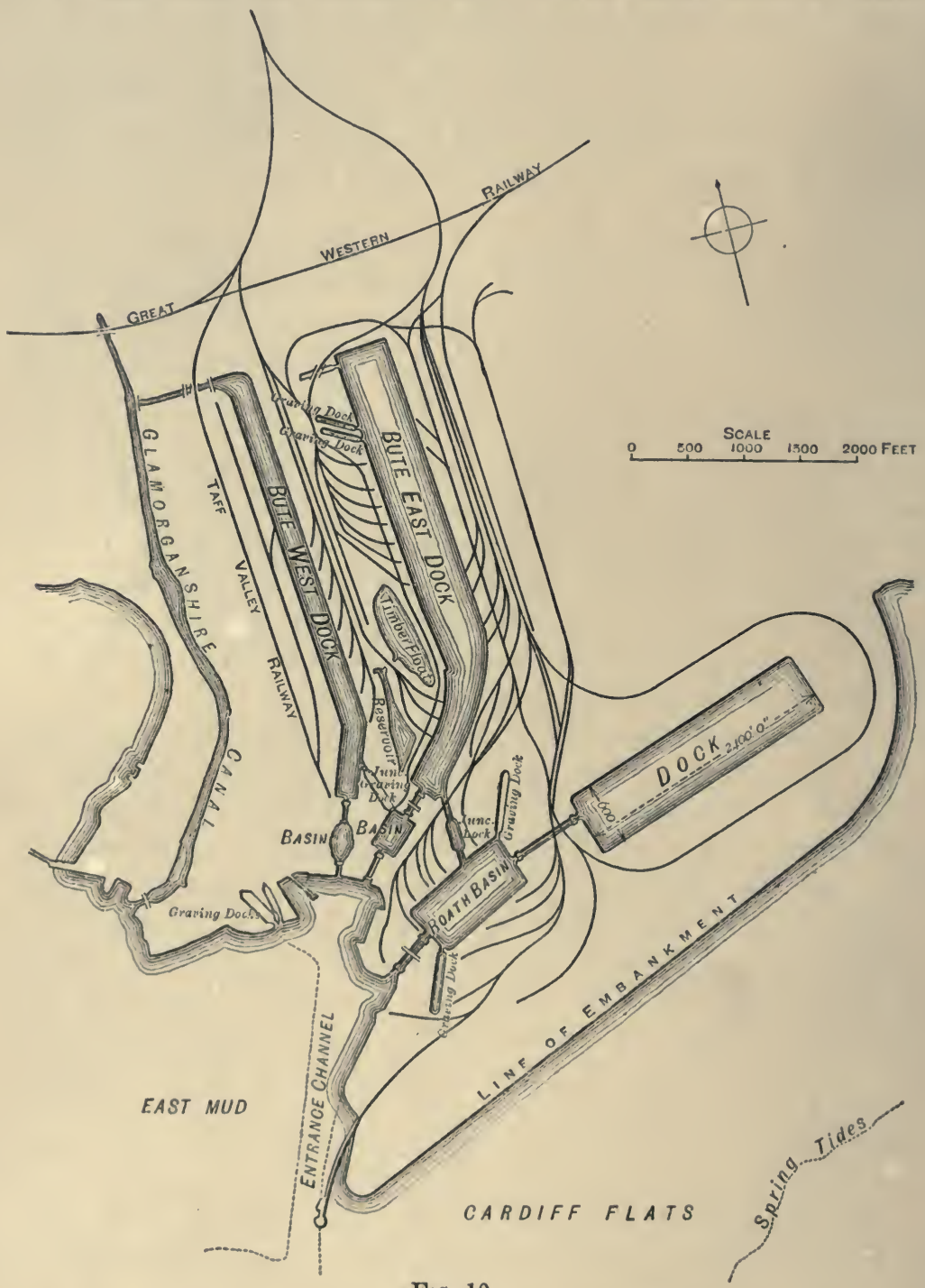

Fig. 10.

dry docks, that at the north being 600 feet long, with 60 feet width of entrance. The depth of water over the sill at highwater spring tides being 23 feet, and at neap tides 13 feet. 
The East and West Docks (Fig. 10) may be referred to as affording a fair comparison between older and recent dock construction, particularly with regard to the width of both basins and entrances. The East Dock is 4300 feet long, 1000 feet of which is 300 feet wide, and 3300 feet 500 feet wide, with a total area of 44 acres. The available wharfage, after allowing for entrances, is equal to approximately 9000 feet with a depth of water of 25 feet.

On the west side, near the north end, there are two dry docks 400 feet and 408 feet respectively, 48 feet width of entrance, and with 17 feet depth of water over the blocks.

The approach to the East Dock is through two locks and an intermediate basin. The outer, or sea loak, is 220 feet long by 55 feet wide, with a depth of water at spring tides of 31 feet $8 \frac{1}{2}$ inches, and at neap tides 21 feet $8 \frac{1}{2}$ inches. The intermediate basin is 380 feet long by 250 feet wide, equal to an area of $2 \frac{1}{4}$ acres, and the inner lock is 200 feet long by 49 feet wide.

The West Dock is 4000 feet long by 200 feet wide for 1550 feet in length; the depth of water is 19 feet, and for the remaining 2450 feet the depth is $\mathbf{1 3}$ feet only. This dock is approached through an outer entrance, basin, and lock. The outer entrance is 45 feet wide; the basin is 300 feet long by 200 feet wide, and the lock 152 feet long by 36 feet wide. The depth of water on the outer sill is 28 feet $8 \frac{1}{2}$ inches at high water. There is means of communication between the West Dock and the East Dock intermediate basin by a junction dry dock; the entrances at both ends, which are closed by caissons, are 50 feet wide with a depth of water of 18 feet. Between the East Dock and the Roath Basin there is also means of communication by a junction lock.

Penarth Docks ${ }^{1}$ (Fig. 11), constructed from the design of Sir J. Hawkshaw, are situated on the south-west side of the river Ely, near its junction with the Severn. The dock is 2900 feet in length, with a greatest width of about 400 feet, and having an area of about 23 acres. The available wharfage is about 6000 feet, with a depth of water of 35 feet at ordinary springtide level, and 25 feet at neap tides.

The dock is approached through an outer or sea entrance and an inner lock, with a small basin intervening. The lock is 270 feet long by 60 feet wide, and the intermediate basin 400 feet long by 330 feet wide, equal to an area of 3 acres. The sea

' Engineering, vol. xxxriii. p. 147. 
entrance to this basin is also 60 feet wide, and opens into the Severn slightly to the south of the mouth of the river Ely, through protecting jetties forming a deep, trumpet-shaped embayment.

On the sills of both the outer entrance and the lock the depth of water at ordinary spring tides is 35 feet, and at neap tides 25 feet.

The outer entrance is somewhat exposed, and subject during stormy weather to seas of a considerable height; outer or sea gates are therefore provided.

Penarth Tidal-harbour. ${ }^{1}$-As a typical example of an open tidal harbour, the lower reach of the river Ely may be referred to. This part of the river forms the Penarth tidal harbour

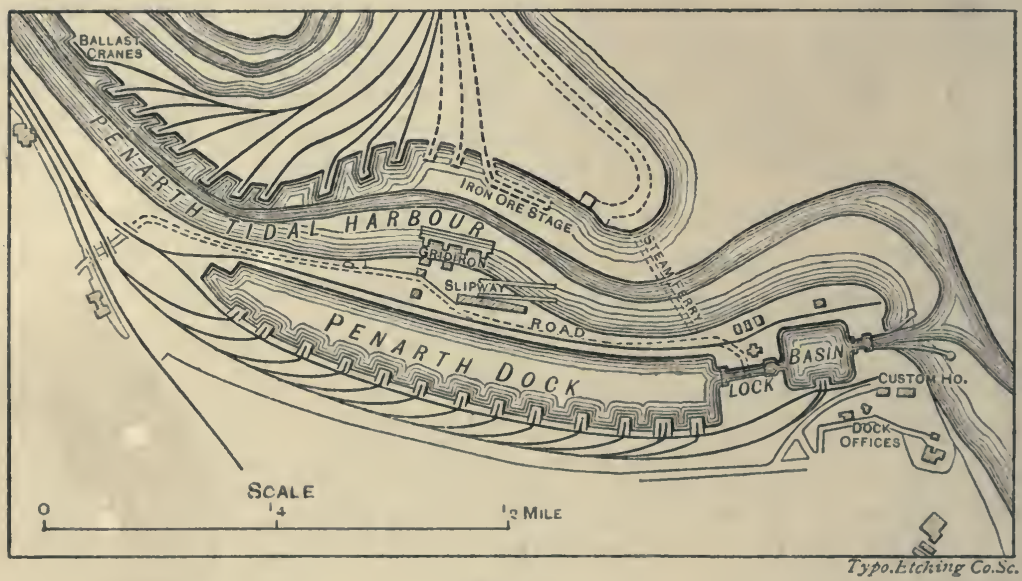

Fig. 11.

(Fig. 11). The depth of water at the loading-berths at high water of ordinary spring tides is 30 feet, and at neap tides 20 feet. Vessels up to 800 tons can be accommodated. The maximum run of the tide in this harbour is about $2 \frac{1}{2}$ knots per hour.

Barry Docks. ${ }^{2}$-Fig. 12, showing the Barry Docks, is a good example of the adaptation of the plan to the peculiar configuration of the site available, which consisted of a channel about a quarter of a mile in width between the mainland and Barry Island.

Alexandra Dock, Newport, Mon. ${ }^{3}$ - This dock (Fig. 13), completed in 1875, from the designs of Mr. J. Abernethy and Mr.

3 Engineering, vol. xxxviii. p. 148.

2 M.P.I C.E., vol. ci. pp. 129-152.

Engineering, vol. $\mathrm{x} \times \mathrm{x}$ viii. p. 149. 
J. Bassell, M.M.I.C.E., has a length of 2500 feet by a width of 500 feet, equal to an area of $28 \frac{3}{4}$ acres, with an ordinary depth of 30 feet over the inner sill of the lock.

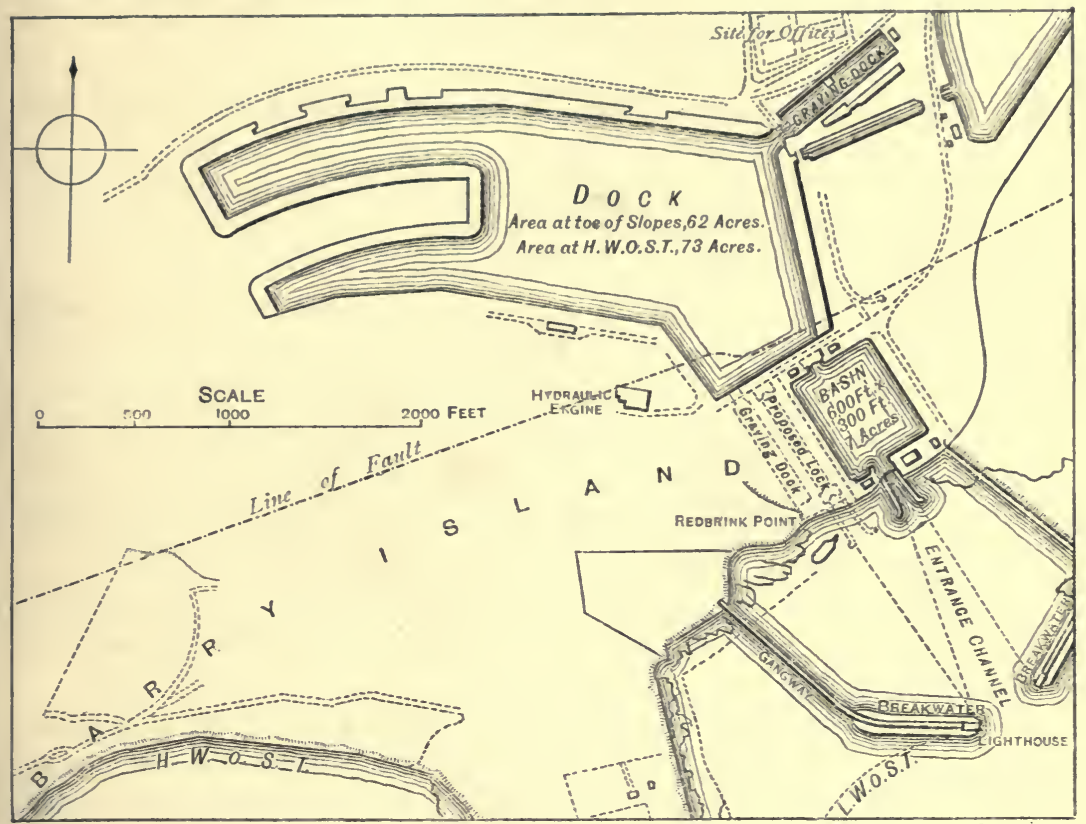

Fia. 12.

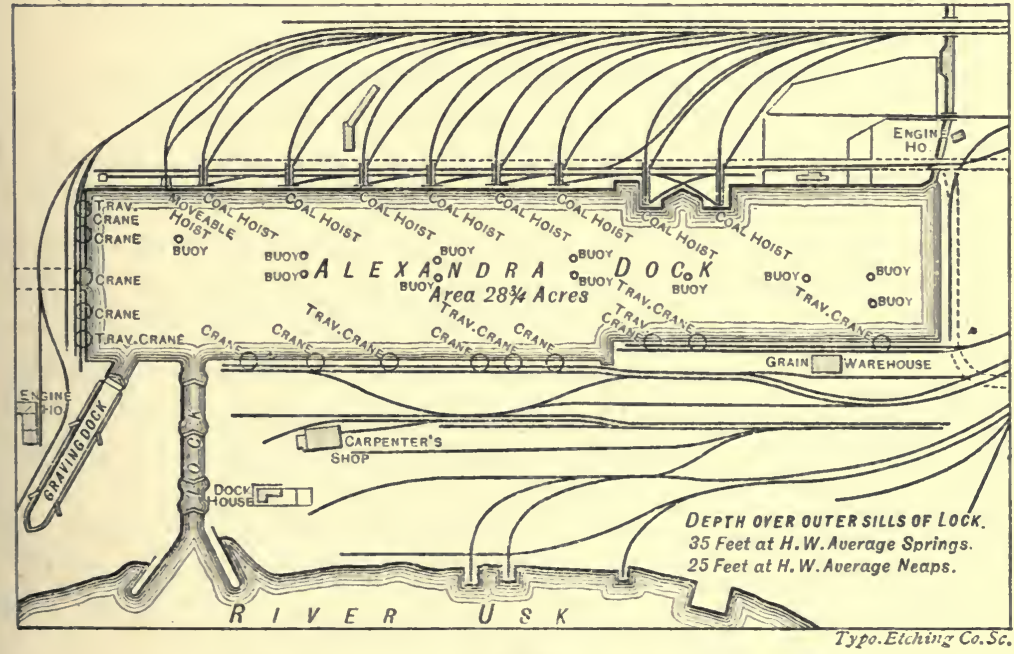

FIG. 13. 
The entrance lock is on the east side, near the south end. The length is 350 feet by a breadth of 36 feet, with a depth of 36 feet of water over the outer sill at average springs, and 25 feet at average neap tides. The inner sill is 8 feet above the outer sill.

The lock is fitted with three pairs of timber gates, and one pair of iron sea-gates.

The position of the lock is practically at right angles to the stream, straight jetties being carried out so as to form a trumpetshaped entrance 300 feet wide and some 210 feet deep.

A dry dock is placed on the east side, between the lock and the south end; the length is 532 feet from the gates to the head of the dock; -and 515 feet on the blocks, with a width of 74 feet between the copings. The entrance is 50 feet wide, with a depth of 20 feet over the sill. Advantage is taken of the great rise and fall of tide to empty the dock by a culvert which discharges into the river.

For the storage of timber, there is a float of 10 acres, and 8 feet deep, on the west side of the dock, with which it is connected by a canal.

The extension of the Alexandra Dock consists of a basin of 27 acres area, with the same depth of water as in the Alexandra Dock, and an entrance lock 503 feet 6 inches between the inner and outer gates, this length being divided by intermediate gates into chambers of 370 feet and 133 feet 6 inches long, with 36 feet of water over the outer sill at average springs.

Queen's Dock, Glasgow.-This dock (Fig. 14) is constructed on the north side of the river Clyde, from the designs of Mr. J. Deas, C.E. The dock is divided by a central tongue or jetty into three basins, viz. the outer basin, 1000 feet long by 695 feet at its widest part, and affording ample room for the largest class of ships to turn; the north basin, 1866 feet long by 270 feet wide; and the south basin, 1647 feet long by 230 feet wide. The width of the quay between the north and south basins is 195 feet. The area of the water space equals $33 \frac{1}{2}$ acres, with a depth of 20 feet at low-water spring tides. The quayage equals $27 \frac{1}{2}$ acres, and the wharfage accommodation 3342 lineal yards.

The entrance, which is a passage 100 feet wide, points down the stream, and is so arranged that vessels entering are soon out of the direct influence of the tide, and have a fair lead without check to any of the three basins. 
The dock is tidal, and although the range of spring tides is 11 feet 2 inches, this rise and fall has caused no inconvenience to the general working.

The special consideration in favour of tidal basins being adopted in Glasgow harbour in preference to closed docks may be stated as follows:-

(a) Vessels are at liberty to come and go at all times of the tide, as suits their draught.

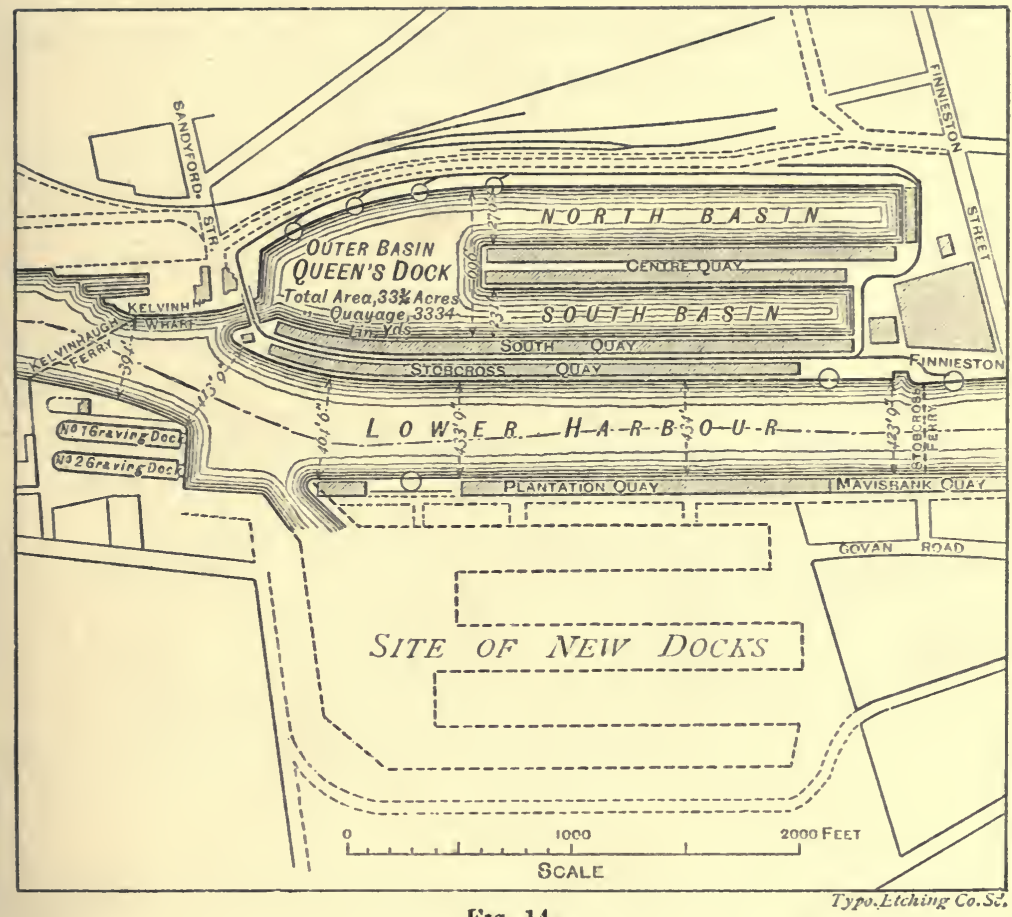

(b) No accumulation or crowding of vessels outside in the river or inside the dock is occasioned in order that they may be ready to take advantage, as in the case of a wet or closed dock, of the very short period of time available about the time of high water for exit and entrance.

(c) The creation of a nuisance to the surrounding neighbourhood, and to the shipping making use of the dock by the impounding of a huge body of water so foul as that in Glasgow harbour is avoided. 
(d) A tidal basin acts as a reservoir from which issues a great volume of water every ebbing tide, which assists in scouring the entrance.

(e) The first cost of a single pair of gates, or of a caisson with relative masonry, or of a double pair of gates, or two caissons with a lock, together with the annual cost of working, is saved.

Tidal Dock at Southampton. ${ }^{1}$-This dock, constructed from the designs of Mr. A. Giles, M.I.C.E., is on the foreshore to the west of the old Southampton Docks, and encloses a deep-water area of 18 acres, with a total length of quay wall of 3854 feet run.

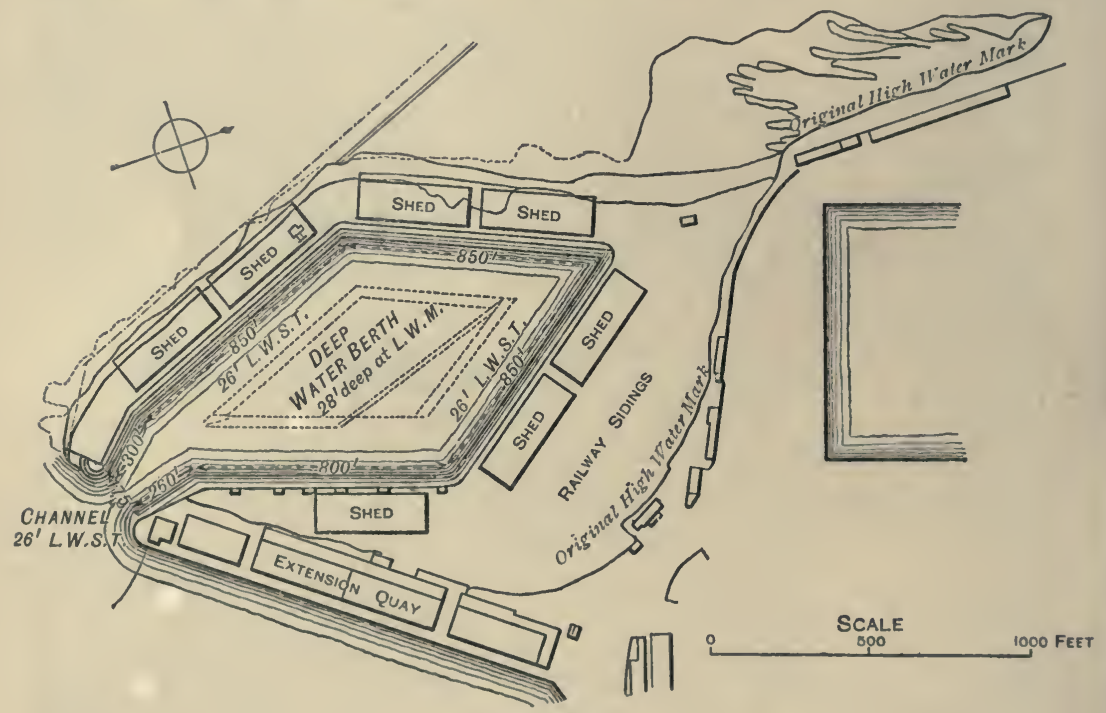

FIG. 15.

The plan of this dock (Fig. 15), of a diamond shape, is somewhat novel, but it is perhaps the best that could have been adopted to meet the peculiarities of the site, and in view of the best position for the entrance, which is placed at the south angle, and has a direct lead by a deep-water channel to Southampton Water.

The bottom of the dock is 45 fect below coping. The level of the water at high springs is 6 feet below coping, and at low springs 19 feet below coping, or a rise and fall of 13 feet; the depth of water in the dock and its approaches is therefore never less

1 Engineering, vol. 1. p. 308. 
than 26 feet. In the middle of the dock a deep-water berth with 28 feet of water has been provided to accommodate ships of a greater draught than 26 feet, which may enter at high tide.

Calais Harbour and Dock. ${ }^{1}$-These works (Fig. 16), constructed from the plans of M. Vetillart, the engineer to the port of Calais, offer a good example of the adaptation of the design to the site. The works consist mainly of an entrance channel confined between jetties, with a sluicing reservoir of 35 acres area at ordinary high water, an outer basin, entrance locks, large floating basin, inner and boat basins, and a large dry dock.

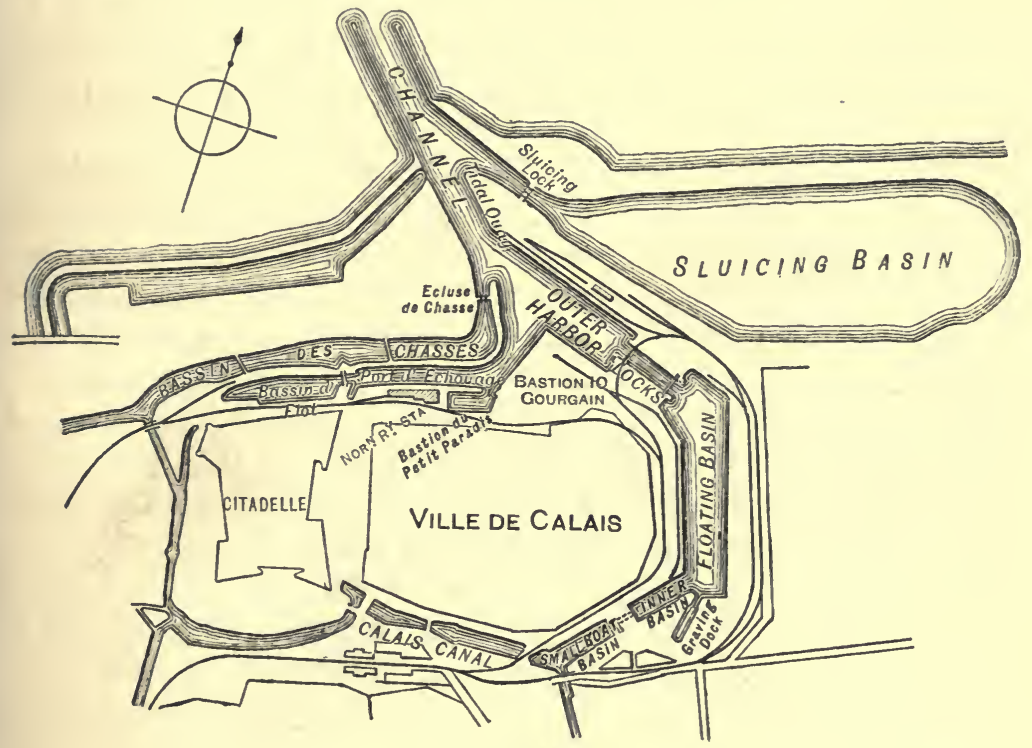

FIG. 16.

The sluicing basin (not yet completed), outer basin, entrance locks, and the northern part of the floating basin, are upon the foreshore; all the excavations were in fine sand, and very special precautions had to be taken to protect the work from the sea.

The outer basin has an area of about $\mathbf{1 5}$ acres, it is enclosed by the north-eastern and south-western quays, which are connected by return walls with the entrance locks to the floating basin. The average width of the outer basin is 524 feet, and the depth 11 feet above datum, which is low water of spring tides, except at the foot of the south-west quay (which is about 800

I Engineering, vol. xlvii. 


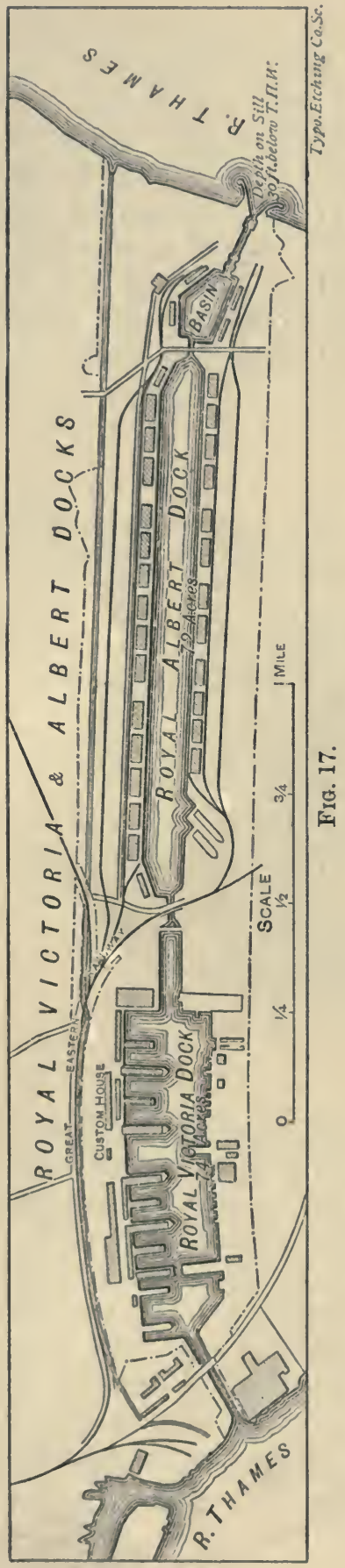

feet in length), where a channel 23 feet deep has been cut to allow of deep-draught vessels laying alongside at low water.

The north-castern quay is 1870 feet in length, with a depth of 13 feet at low water, and is provided with four groups of landing-stages.

The entrance locks are parallel, 68 feet 10 inches and 45 feet 11 inches wide respectively, with a depth of water over the sills at spring tides varying from 22 feet 6 inches to 28 feet 6 inches.

The area of the floating basin is nearly 30 acres, including the small inner basin, with which it is connected; its width 557 feet near the entrance or north end, and 393 feet at the southern end. Close to the locks, however, the width is increased for the purpose of facilitating the movements of long vessels in entering and leaving the basin. The floor of the basin is 1 foot 8 inches below the lock sills, giving a depth of 30 feet 2 inches at high spring-tide level. The total length of quays round this basin is 4820 feet.

The inner basin is 229 feet wide, with 1150 feet of quayage, and is excavated to ordinary low-water level.

The dry dock is placed at the south end of the floating basin.

The small-boat basin, which is connected with the inner basin by two locks 125 feet long by 19 feet 8 inches wide, has an area of 10 acres, and a total length of wharf wall of 5250 feet. This basin extends as far 
as the citadel canal, from which it communicates through the citadel lock with the old port.

The Royal Albert Dock ${ }^{1}$ (Fig. 17), on the Thames, constructed from the designs of Mr. Rendel, M.I.C.E., is in fact a prolongation eastward of the Royal Victoria Dock, with which it is connected by a short passage 80 feet wide.

The entrance to the lock at Gallions Reach is as nearly as possible at right angles to the river, and is formed by curved jetties projecting into the stream, and enclosing a deep trumpetmouthed embayment.

The lock is 800 feet long over all, and 80 feet wide. It is divided into two chambers of unequal lengths by an intermediate pair of gates. The distance between the extreme gates is 550 feet, with a depth of 30 feet over the sills at Trinity high water.

The lock opens into an entrance basin irregular in shape, and of about 9 acres area, with a depth of water from 30 feet to 35 feet 6 inches.

The connection with the main dock is by a passage 300 feet long by 80 feet wide, in which there is placed a pair of gates similar to those in the lock, so that the basin can be utilized as a 9 -acre lock. The depth of water over the sill of these gates is 27 feet.

The main dock is about a mile and a quarter long by a uniform width of 490 feet between the copings, and has an area of about 75 acres.

On the south side of the main dock, near the western end, there are two dry docks. The smaller of these is 420 feet long by 68 feet wide between the copings, and the larger 510 feet long by 85 feet wide between the copings. The sills of both docks are 22 feet below Trinity high water.

1 The Engineer, vol. 1. pp. 6-10. 


\section{CHAPTER II.}

Commencement of works, or opening up-Importance of well-considered temporary works-Alexandra Dock, Hull-Portsmouth Dockyard Extension-Southampton Tidal Dock.

THE course to be pursued in opening up the works of a large dock scheme, particularly if the site is on an exposed foreshore, requires special care and attention, in order, not only that some portion of the permanent work may be commenced with the least possible delay, but that all subsequent portions taken in hand may follow in regular order in accordance with a prearranged plan without calling for extensive, and therefore costly, alterations in the disposition of the temporary works and plant. In fact, in commencing a work, no part requires more anxious care in the conception of, or skill in the carrying out, than the temporary works-which have frequently to be of a very substantial character-and the disposition of plant. Upon a just appreciation of these all-important points will depend in a very great measure the success of the work, both from an engineering and a contractor's point of view.

The following particulars are abridged from accounts of the preliminary course pursued on some of the most important modern dock works.

Alexandra Dock, Hull. ${ }^{1}$ - The site of this dock comprised 192 acres on the foreshore of the Humber, where the range of tide equals 22 feet 6 inches. Of this area 152 acres were below high-water mark, and extended considerably below low-water mark. To reclaim this total area, an embankment 40 feet high and 6000 feet long was required to surround it.

As the permanent works could not be delayed until the completion of the permanent reclamation embankment, temporary embankments were formed to exclude the water from the site of the works in sections. The banks first taken in 
hand were A B and B C (Fig. 18). These were soon completed by casting up at low water the soil from each side, and thus enabled the excavations for the permanent works to be commenced. The next portion of temporary embankments, B D and D E (Fig. 18), had to be carried across a foreshore of mud, and being at a considerably lower level towards the east end, a good deal of the material cast up was washed away by the tides; the work had, therefore, to be carried on at several points simultaneously by large gangs of men taking advantage of low water, especially of spring tides, as these banks were exposed to south-easterly storms, and had to protect the inner works for more than two years; the seaward faces were pitched with

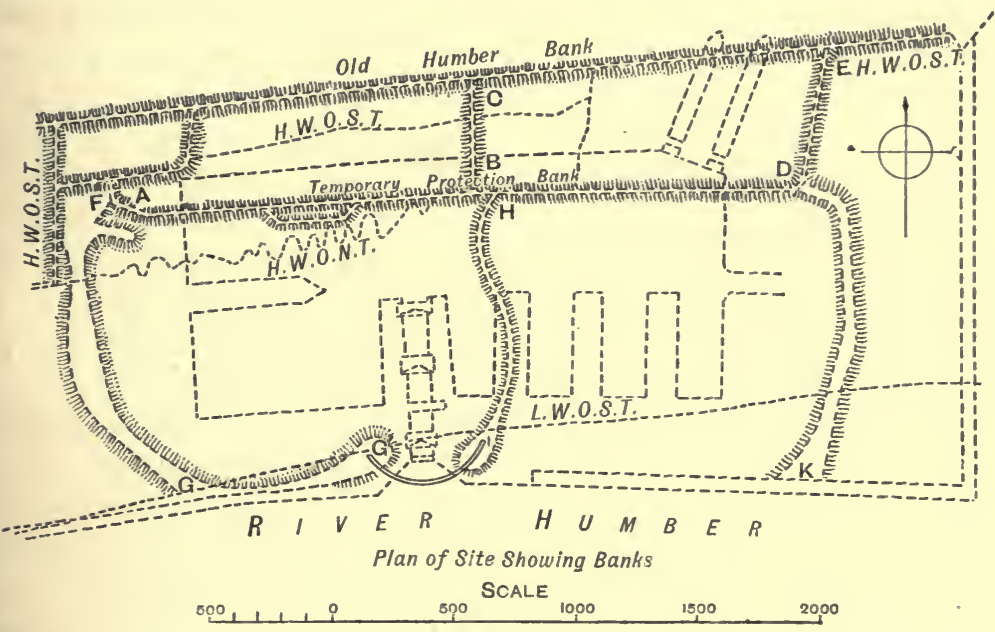

FIG. 18.

chalk. On the completion of these banks, the excavation for the permanent works within the section was carried on, and the material tipped to form the protecting banks, F G and H I (Fig. 18). These banks settled down into the soft muddy foreshore, and spread out a good deal laterally; they were also exposed to the wash of every tide, so that they absorbed a large amount of material. The river embankment, G C I (Fig. 18), was in the mean time being proceeded with by excavating a trench 20 feet wide and about 5 feet deep with a Priestman's grab along the line of the toe of the bank. This trench, which was carried down to the hard gravel or clay, was filled with large chalk, deposited from small vessels holding about 100 tons each. 
The chalk bank was given a width of 30 feet at the level of the river bed; above low-water level, it was roughly formed to a slope of 2 to 1 on the face, and it was intended to back it with solid clay or other hard material. The western bank, F G (Fig. 18), could not, however, be carried across the muddy foreshore to join the outer embankment; the advance made by day was lost by night, and the mud of the foreshore rose gradually until it overtopped the chalk bank. More chalk had then to be added to prevent the mud from flowing into the river, which increased the height of the bank without a corresponding increase in strength. Endeavours were then made to prevent the spreading of the bank, F G (Fig. 18), by sinking several old barges filled with chalk in the line of the tip, but the barges floated along in the mud, and, when the tip head was 100 feet from the outer bank, a portion of the latter, which had been 15 feet above low water, slipped forward. A solid chalk bank was then put in 80 feet wide at the river bed,
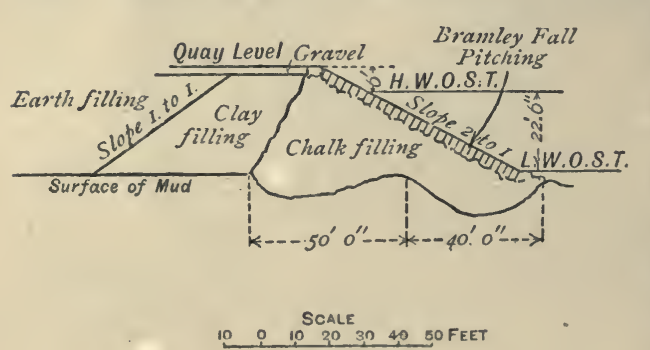

Fig. 19. with a deep-dredged trench 40 feet wide to receive the toe, and backed with stiff clay for 30 feet in average width. The seaward face was pitched with Bramley Fall stones, to protect the chalk from disintegration (Fig. 19). The portion that slipped was secured by two rows of close sheetpiling, the piles being 36 feet long, and the rows spaced 20 feet apart with strong walings; the two rows of piles were firmly strutted and lashed together with chains. The connection between the outer bank and the western tip head was also made with rubble chalk.

The middle bank, H I (Fig. 1S), was continued in the same manner to join the eastern side of the coffer-dam. The main embankment and coffer-dam having been completed, the water was excluded from the second reclamation. The inner embankment, A B (Fig. 18), was then broken through, and the material from the excavations within the reclaimed area were utilized for forming the bank, D K (Fig. 18). The eastern portion of the river embankment, I K (Fig. 18), was at the same time proceeded 
with, and constructed to the same section as G G I (Fig. 18). This formed the final reclamation, and enabled the whole of the permanent works being proceeded with.

Portsmouth Dockyard Extension. ${ }^{1}$ - The site of these works included 95 acres subject to tidal action, and covered at every high water to a depth of from 7 to 10 feet. The whole area was covered with very soft mud varying from 3 to 38 feet deep, the greater part, however, being from 10 to 25 feet deep. This soft deposit overlaid strata of the lower tertiary formation, consisting of beds

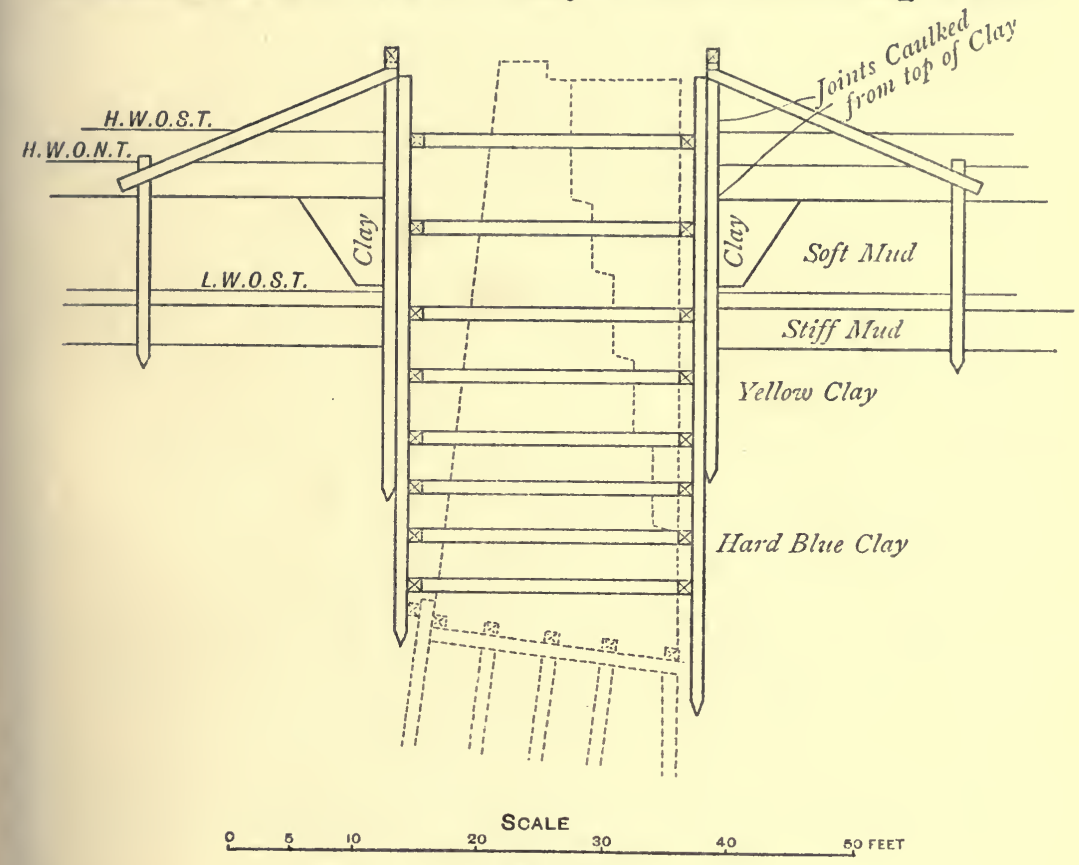

FIG. 20.

belonging to the London clay and those immediately below it. All the undisturbed beds were of a solid description, varying from pure hard clay to sandy strata very compact and retentive.

The depth of the excavations varied from 40 to 65 feet.

The method to be adopted in opening up these works, covering as they did such an extended area of mainland, was a matter of grave consideration.

The original proposition was to enclose the sites of the outer walls, entrances, or, in some cases, only parts of entrances, with 
32 NOTES ON DOCKS AND DOCK CONSTRUCTION.
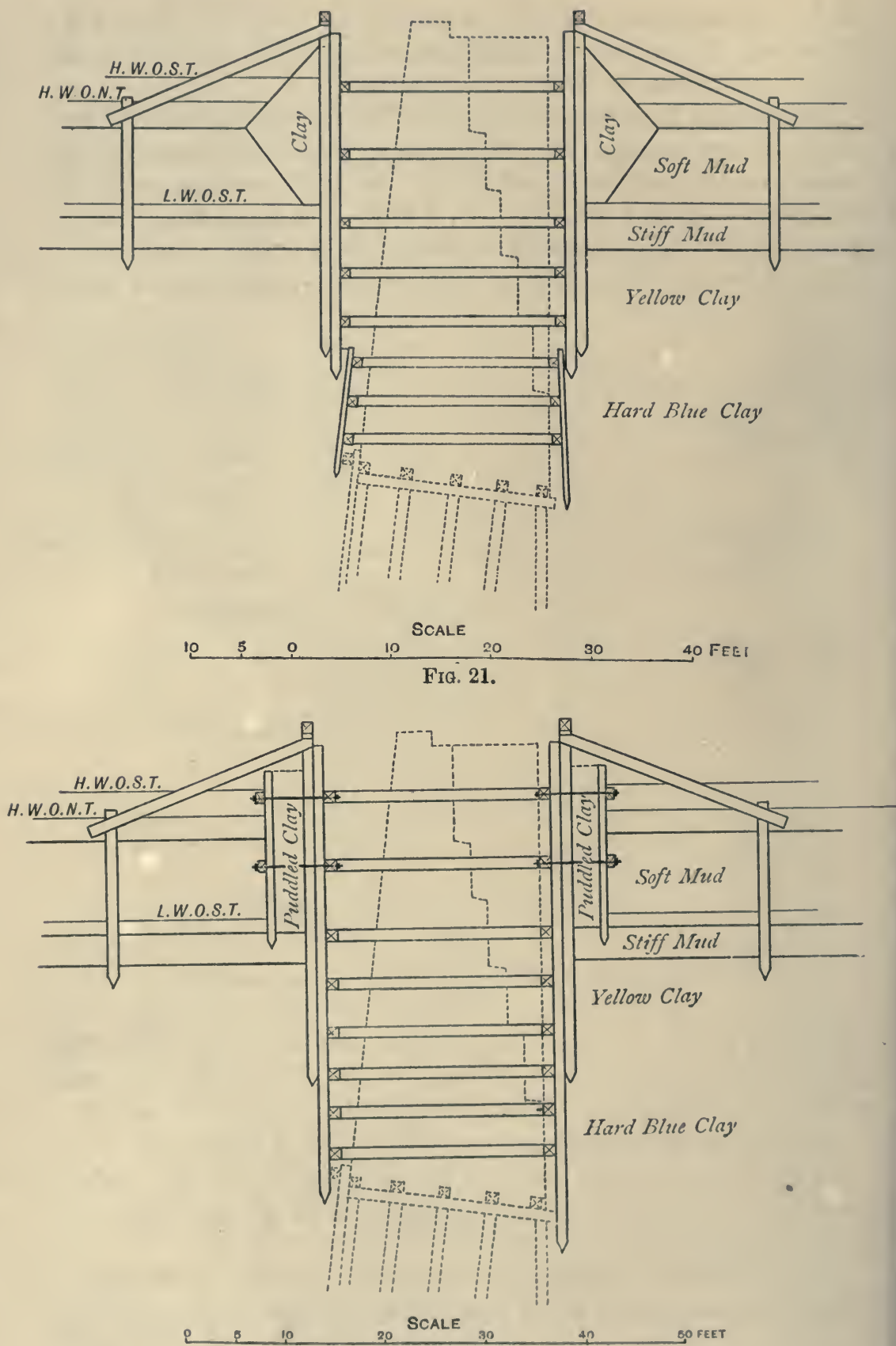

Fig. 22. 
box coffer-dams (Figs. 20,21, 22) sufficiently wide to admit of the construction of the permanent works, and, after completing such works, to utilize them as the means of excluding the water from the site generally.

On consideration, the disadvantages involved in the above method of procedure were clearly seen to be as follows :-

The entire exclusion of the water from the site would have been so long delayed as to have rendered the general progress very slow, besides involving the necessity of providing an immense quantity of very long timber to enable many isolated parts of the work to be commenced simultaneously.

Great risk would have been incurred in having the protecting works in such close proximity to the disturbing influences unavoidable in the operations of excavating and pile-driving in the foundations for the basin walls. Extensive and costly means of access would have been required to convey away the excavated, and to supply building, material.

Under these circumstances, it was proposed by the contractors for the works to reclaim at once the whole of the site subject to tidal influences.

This object was accomplished by constructing first an inner dam or shallow, $a$ on plan (Fig. 23), enclosing all the locks, docks, and a large portion of the inner quay walls, and an outer or main dam in deeper water, $b$ on plan, enclosing the harbour and outer quay walls.

The inner dam, which was of a very simple construction, was placed on the highest part of the mud, and was in no part less than 100 feet from the site of any work, the excavation for which was expected to cause its disturbance.

The outer or main dam, $b$ on plan (Fig. 23), enclosing the second section being in deeper water, and in close proximity to the sites occupied by permanent works, was of a more substantial character although somewhat similar in construction.

During the construction of these dams, the ebb and flow of the tide was provided for by sluices constructed across the different channels, which, on the completion of the dams, were closed at low water, and the tide excluded from the works.

The completion of the inner dam, by which some 75 acres of mud land was reclaimed, enabled the works generally to be speedily opened up, for simultaneously with the construction 


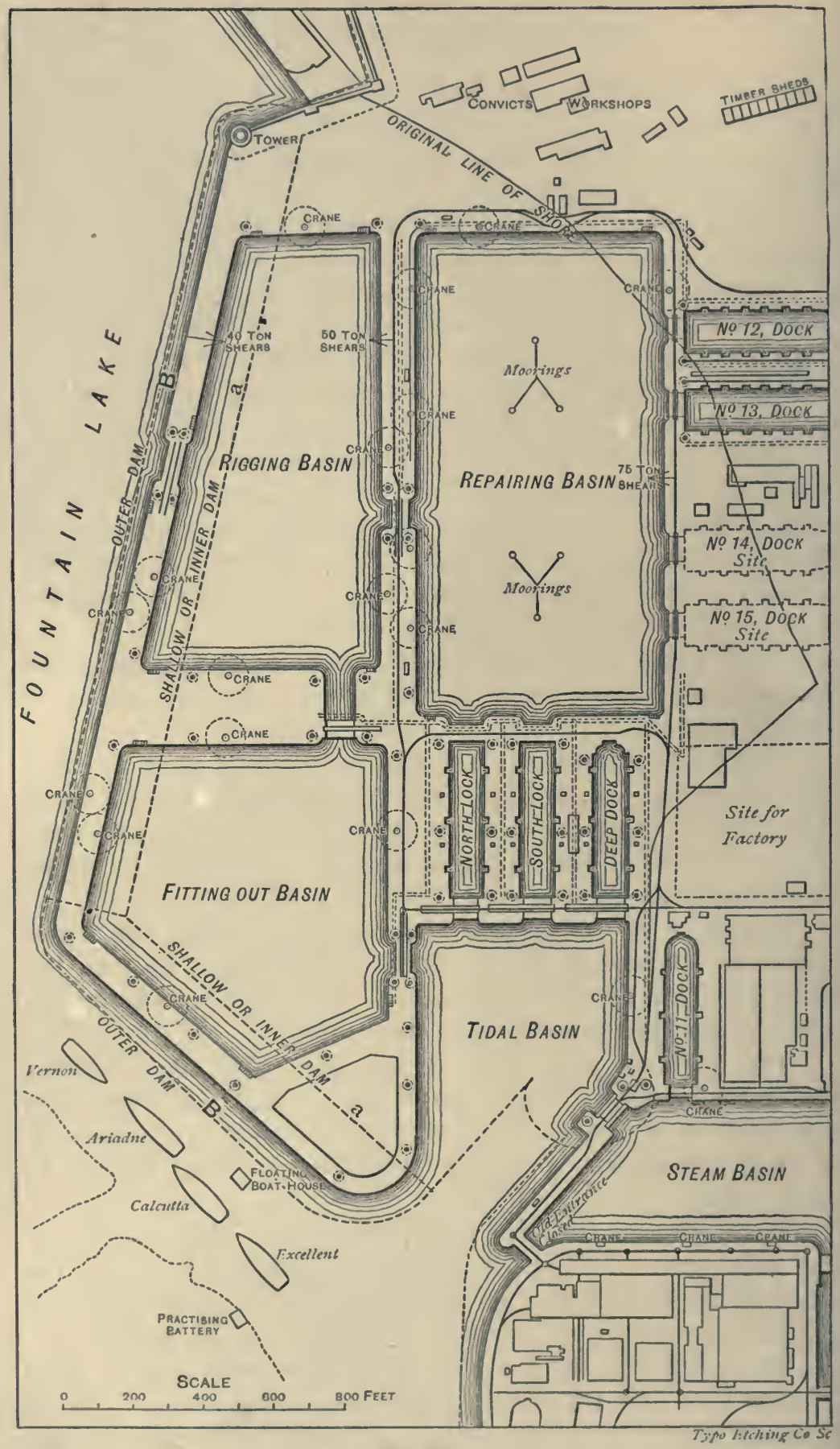

Fia. 23. 
of the dam, other temporary works, such as timber viaducts, etc., were constructed.

By means of these timber viaducts, which carried the railways over and through the mud until firm ground was reached, access to large areas otherwise inaccessible was obtained, and the general excavations proceeded with.

The foundations within the shallow were excavated partly in open cutting and partly in timbered trenches, and all between the outer and inner dams within timbered trenches.

Southampton Tidal Dock. ${ }^{1}$-The site of this dock (Fig. 15), being on the foreshore, was entirely covered at every tide, the average level of the mud being 11 feet below high water of springs.

To reclaim it, an embankment, 3000 feet in length and not less than 20 feet wide at the top, was therefore formed to enclose the whole area amounting to 42 acres of mud land.

The material used for this purpose consisted chiefly of chalk and a little gravel tipped into a trench previously excavated in the mud by grabs working from a barge. The trench varied from 5 to 20 feet in depth below the mud surface, and from 20 to 25 feet wide.

The work was puddled with mud excavated from the sites of the work run out upon the embankment in trucks, where it was cast out and assumed its natural slopes, which was occasionally as much as 1 in 40. This formed an efficient puddle, and made the bank thoroughly water-tight. After completion, the bank withstood unusually powerful gales and high seas without sustaining damage.

1 Engineering, vol. 1. p. 308. 


\section{CHAPTER III.}

Dams-Importance of efficient dams in mariue works-Embankments-Timber dams-Leakage-Sluice-valves in dams-Half-timber sheeting-Grooved-andtongued piling-Excessive thickness of clay puddle-Dams subject to rise and fall of tide-Leaks due to through-bolts-Vibration due to pumpingLeaks through clay puddle-Laminated walings-Dams of single rows of piles - Timber shield-dam-Iron dams-Timber dams on Thames-Coffer-dams at middle level, Dublin, Birkenhead, Hull, Pola Dock, Esquimalt, Amsterdam Canal, Portsmouth, Limerick, Chatham, Calais.

DAMS form very important adjuncts in marine construction, either as a means of shutting the water from a site generally, or for enclosing parts where it is necessary to dry the bottom for the purpose of getting in foundations. Being only a temporary work, the tendency is to push the question of economy of construction to the extreme. An important dam is always a cause of anxiety, any failure or serious accident may entail the loss, not only of much valuable property, but of many lives. A weakly constructed dam augments these anxieties and dangers, and frequently in the end it is more costly on account of the increased expenditure incurred for maintenance and pumping.

In moderate depths of water and unlimited room, a dam may consist simply of an embankment of clay or other suitable material free from foreign matters, such as large stones, roots, etc., that would be likely to give rise to interstices. In forming an embankment on a muddy foreshore, it is best to deposit the material. in horizontal layers, by either tipping it from a stage erected over the site, or dropping it from hopper-barges. If deposited from end-tipping waggons, the material is very liable to slide away with the mud which is pushed both forward and laterally by the tip heads. By adopting the method of horizontal deposit, the mass sinks vertically through the soft mud with far less waste of material.

A heavy material, such as chalk or stone rubble, would sink 
through soft mud with greater facility, but under any circumstances it is desirable and wisest to dredge a trench down to the more solid bed before the material to form the bank is deposited. When chalk or rubble stone is used to form the embankment, the outer or water face must be sealed with an impervious material, such as clay or stiff mud.

Where the head of water is considerable and the working space limited, as is generally the case in dock construction, the use of timber piles, either in single or double rows with clay puddle between, or iron caissons, are resorted to. Dams so constructed are less liable to failure than earthwork dains.

The leakage, and danger of breaches, either in the dam itself or through faulty places in the bottom, increases greatly as the head of water increases.

In all dams of whatever construction ample means should be provided by suitable valves, or, where the area is large, by sluices, to ensure the free escape of the enclosed water at as nearly as possible the same rate as the falling tide. Such valves and sluices are best placed at extreme low water, but in no case should the sill of the valves or sluice be placed more than two feet above the lowest water level.

The practice of driving whole-timber gauge-piles and filling in with half-timber sheeting is not always judicious. Especially in deep dams, by using half timbers, inefficient work is frequently the result; there is greater difficulty in keeping the dam tight, and consequently more water has to be contended with; by the use of whole timbers, as a rule less timber is destroyed and the dam more easily made.

After dam piles have passed the lower walings and entered the ground, they are more or less beyond control; any slight obstruction may give them an inward or outward cant or tendency, so that at the foot they may be very irregular on plan, and, if driven very deep into the ground, may separate entirely. In the case, therefore, of all long piles, they should be tongued and grooved either by working the solid timber, or by spiking 3-inch fillets to the sides of the piles. Another method sometimes adopted is a continuous flat iron tongue, about 3 inches by $\frac{3}{4}$, let into grooves cut in the centre of the piles; the wooden tongue and groove is, however, to be preferred as being stiffer and less liable to displacement in driving. This 
arrangement of tongues and grooves will form in some measure a guide to the piles in their descent, and although they may still be irregular on plan at the foot, the timbers will be more uniformly in contact.

An excessive thickness of clay puddle is a mistake; it throws an undue strain on the tie-bolts and fastenings. It has been proved by experience that a comparatively thin lining of clay well compressed, is all that is required to keep out the water.

Dams subject to a considerable rise and fall of the tide are seldom in a state of rest owing to the varying pressures. A settlement of the puddle is frequently the result, producing leaks of a more or less serious character at the through-bolts. The clay, as it settles, leaves a vacuity under the bolt, through which the water finds its way.

Various devices are resorted to with a view of meeting this difficulty. In some instances, through-bolts have been dispensed with altogether, retaining only the top tier, and buttress piles driven outside, to take the pressure of the puddle within the double row of piles. ${ }^{1}$ This course cannot, however, always be followed; as in cases where the ground is very bad and insufficient to support the vertical and lateral thrust of the clay, it will then be necessary to resort to through-bolts at the bottom, at or near the ground line, to tie the piles together.

An efficient method of overcoming the difficulty of throughbolt leakages consists in the use of a thin plate of wrought or cast iron, from twelve to fifteen inches square, with a hole near the upper edge to fit the bolt. When the bolt is put in place, one or more of these plates are slipped on, and distributed over the length of the bolt, so that they hang down, cutting off any cavity that may form beneath on the settlement of the clay, which, however, still adheres to the sides of the plates, and thus stop the flow of water. ${ }^{2}$

In connecting two rows of piles, great care is necessary to ensure, by efficient walings and equal tightness of the throughbolts, a uniform distribution of the strains due to the weight of the clay puddle. If any bolt is looser than others, the accumulated strain is thrown upon the adjacent bolts, which may in consequence give way, with disastrous results.

To pass an additional bolt through a dam after the puddle

I M.P.I.C.E., vol. li. p. 152 ; vol. xxxi.p.27. ' Ibid., vol. xxxi. p. 27. 
is deposited is always a difficult operation, on account of the tendency of the clay to close round the auger. This difficulty may be met by boring the hole through the inside pile a little larger than the intended bolt, and then driving a sharp-edged tube through the clay until it reaches the outer pile, into which the sharp end of the tube is driven to get a hold; the tube is then cleared of clay, and the hole bored through the outer pile to the proper size. The tube can be withdrawn after the bolt is placed in position.

The vibration caused by pumps, particularly those running at a high speed, working on a dam, or on a stage connected with a dam, has frequently an injurious effect. It is therefore advisable, whenever possible, to work the pumps from a stage or position independent of the dam, or, if this is impossible, to adopt a type of pump working at a low rate of speed, so as to reduce the vibration to a minimum.

When leakage appears, in consequence of a settlement of the puddle causing a vacuity beneath the bolt, the defect may be remedied by boring a hole through the inner pile, just below the bolt where the leakage appears. Through this hole small cylinders or pellets of tempered clay are forced, by means of a hard-wood plug (made very slightly slack to the hole) and maul, until the vacuity under the through-bolt is filled up.

A leak may be reached from the top of a clay dam by boring vertically, but in such a case, it will be necessary to drive a tube down through the clay to the leak, so as to keep the hole open. Plugs of prepared clay are then dropped in and rammed down until the leak is stopped.

Single rows of piles have been successfully adopted in the construction of dams, and are particularly applicable where the working space is limited, and in deep water where there is little or no fall of the tide, conditions which render it difficult to clear out the mud and silt from between two rows of piles, and still more difficult to get in through-bolts. In constructing a dam in this way, very careful work is necessary to ensure the piles being close jointed. The advantages are that much less space is required; any leaks that do occur are at once seen, and can be stopped without great difficulty or loss of time; less timber and iron is required; and the work can be carried on much more expeditiously than is the case with double rows of piles and clay puddle. 
In cases of segmental dams of very sharp radius, a difticulty may be experienced in obtaining suitable timber with which to form solid walings. To meet this difficulty, laminated walings have sometimes been adopted, by building up to the required dimensions with planks, care being taken to effectually break joint. ${ }^{1}$

To guard against the risk of floating, which is augmented by any light movement induced by blows from heavy vessels, or by excessively high water, it is a wise precaution to drive the gaugepiles deeper into the ground than is absolutely necessary for the general piling, in order to get a good hold on the bottom.

With reference to the use of timber as compared with iron, Mr. Abernethy has expressed an opinion that timber is to be preferred, both on account of cost, and the more important element of time. ${ }^{2}$

Dams constructed of a Single Row of Timbers.-A good example ${ }^{8}$ of a dam constructed of a single row of piles was that designed by Mr. B. B. Stoney, for enclosing the foundation of a large bridge over the Liffey. This dam consisted of a single row of whole-timber piles, which were driven until they reached the rock into which the points of the piles were embedded, and were shored against the outside pressure in the usual manner. The piles were sawn parallel on the meeting sides, and driven in close contact, and the joints caulked. Before driving; the piles were fastened together in sets of three, by means of elm dowels sunk 3 inches into each pile at intervals of about 8 feet, and with $1 \frac{1}{4}$-inch wrought-iron dogs. This left only every third joint to be caulked after the piles were driven. The total depth of this dam was 25 feet below high water, or 17 feet below low water, to the rock, which was taken out to 20 feet below low water. This dam proved thoroughly efficient in every way.

A dam used in constructing a quay wall at Rio de Janeiro ${ }^{4}$ is shown by Figs. 24, 25. This dam, which was constructed in a depth of 25 feet at low water, and 30 feet at high water, consisted, on three sides, of a single row of grooved and tongued piles, 11.inches square, driven into the silty clay bottom to a total depth of 42 feet 6 inches below high water, or 22 feet 6 inches into the ground. The tongues were made of flat bar-

1 M.P.I.C.E., vol. li. p. 152.

2 Ibid., vol. liv. p. 27.

Ibid., vol. li. p. 155-160; vol. lxii. p. 60. Ibid., vol. xxxi. p. 28. 
iron, 3 inches by $\frac{3}{4}$, welded up in one length, and housed into grooves cut in the centres of the abutting faces. The dam was

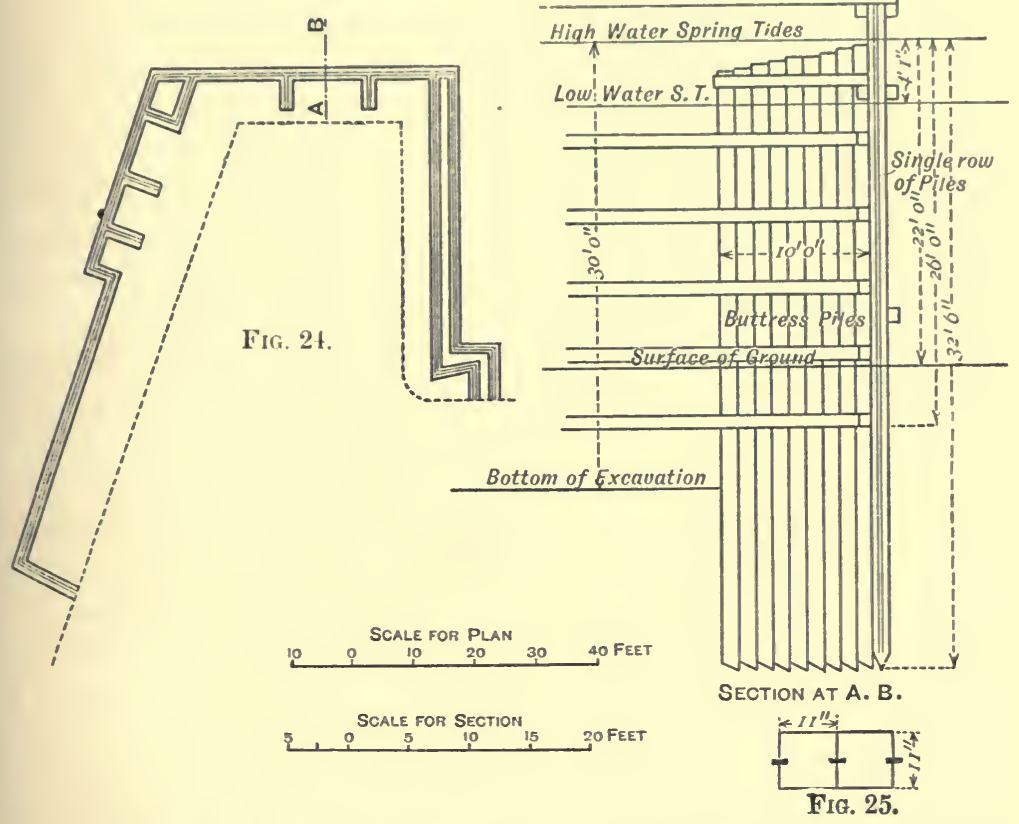

strengthened on the inner side by single-pile buttresses, projecting about 10 feet from the inner face.

Shield.-The following is a description of a very ingenious dam or shield (Fig. 26) designed by Mr. H. Law, and used by him in constructing the entrance of a graving dock at Rio de Janeiro. ${ }^{1}$ The shore being bare granite rock, an ordinary coffer-dam of piles would have been impossible. The site of the proposed entrance was enclosed with a shield of timber, the bottom

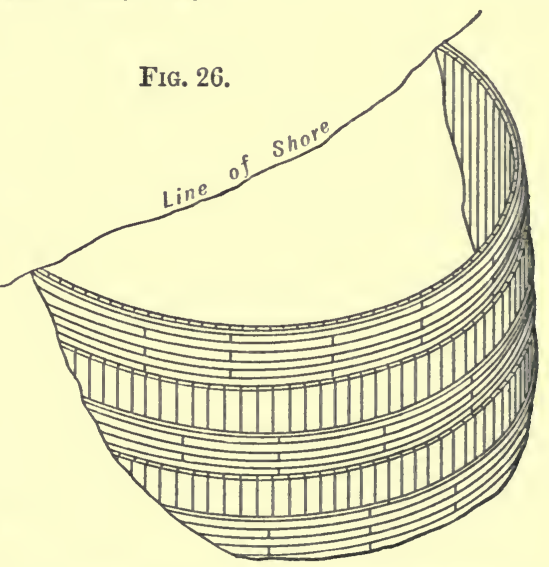
of the shield being cut to the shape of the rock against which

1 M.P.I.C.E., vol. li. r 157. 
it was to be placed. This shape was measured by constructing a temporary stage of the same form as the intended shield; the vertical depth was then taken with a rod at distances of 6 inches apart, and thus a series of ordinates were obtained, to correspond with which the bottom of the shield was cut. The shield was built upon the same temporary stage in a horizontal position; the first, or inside layer of planks, being placed close together upon templates formed to the requisite curve, just in the same manner as the lagging of an ordinary centering. In the next layer the planks were bent round the circumference at right angles to the former, being secured at each intersection by a 5-inch spike; then succeeded another layer of planks parallel to the first, and similarly secured, then another parallel to the second, and so on, until a total thickness of 18 inches was attained, consisting of six planks of the ordinary dimensions of 3 inches thick by 9 inches wide, and 14 feet in length. This number of thicknesses of plank was increased according to the depth of water, the upper 5 feet consisting of only two thicknesses, and an additional plank being added at each additional 5 feet of depth. When completed, it was lowered without difficulty into place, being loaded with sufficient ballast to counteract buoyancy. When in place, it simply bore against the rock at either side, there being no struts or bracing of any sort; a few pine wedges were inserted on the inner side wherever the shield was not in actual contact with the rock.

Iron Dams. - In constructing the Victoria Embankment on the Thames, ${ }^{1}$ wrought-iron caissons were substituted for ordinary timber dams. This method of excluding the water was preferred on account of the difficult nature of the foundation, that the vibration due to pile driving would have been dangerous to adjacent buildings, and with the view of the lower sections forming a portion of the permanent work. ${ }^{2}$

The caissons (Figs. 27, 28, 29) consisted of sections, in two parts, half-oval on plan, formed of wrought-iron plates $\frac{1}{2}$ inch and $\frac{3}{4}$ inch thick with upright flanges at each end, so that when the two halves were bolted together they formed an entire section 12 feet 6 inches long, 7 feet wide in the centre, and 4 feet 6 inches deep. Angle-irons were bolted round the top and bottom of the rings, enabling them to be firmly secured to each other in a vertical position. In every case the lowest ring of

II.P.I.C E., vol. liv. p. 12.

?Iliil., vol. liv. p. 31. 
each separate caisson was of cast iron, weighing about 32 cwt., with a cutting edge at its lowest extremity so as the more readily to penetrate the soil.

In order to form a water-tight joint between the caissons at their junctions, a cast-iron groove $5 \frac{1}{4}$ inches deep and $6 \frac{1}{4}$ inches

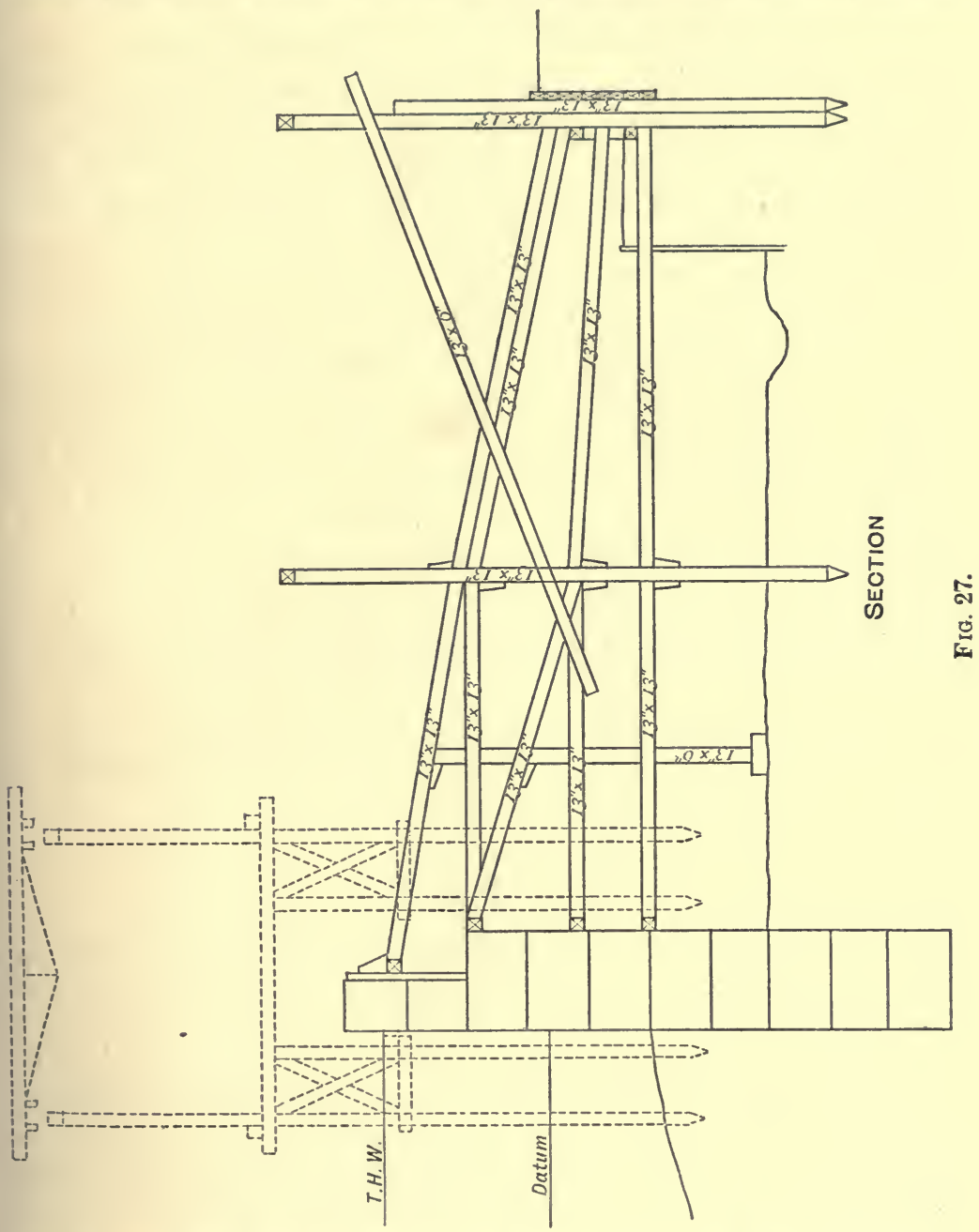

wide, was bolted to the flanges at the end of each caisson, so that when the several portions or sections were placed in position each groove came opposite to that of the contiguous one, and thus formed an aperture $10 \frac{1}{2}$ inches long by $6 \frac{1}{4}$ inches wide from 
the top to the bottom of the caisson. A half-timber pile of dimensions corresponding to this aperture was previously driven and acted as a guide, which, with the assistance of a few surrounding piles, maintained the caissons in their proper position; if the joint leaked, the wood swelled and prevented any serious flow of water.

The cast-iron grooves proving, however, too costly, were abandoned, and the caissons were then held together longitudinally by bolts passed through the angle-irons which were fitted at the junctions. Four guide-piles were in this case ordinarily driven so as to prevent the caisson swerving from

Fra. 28.
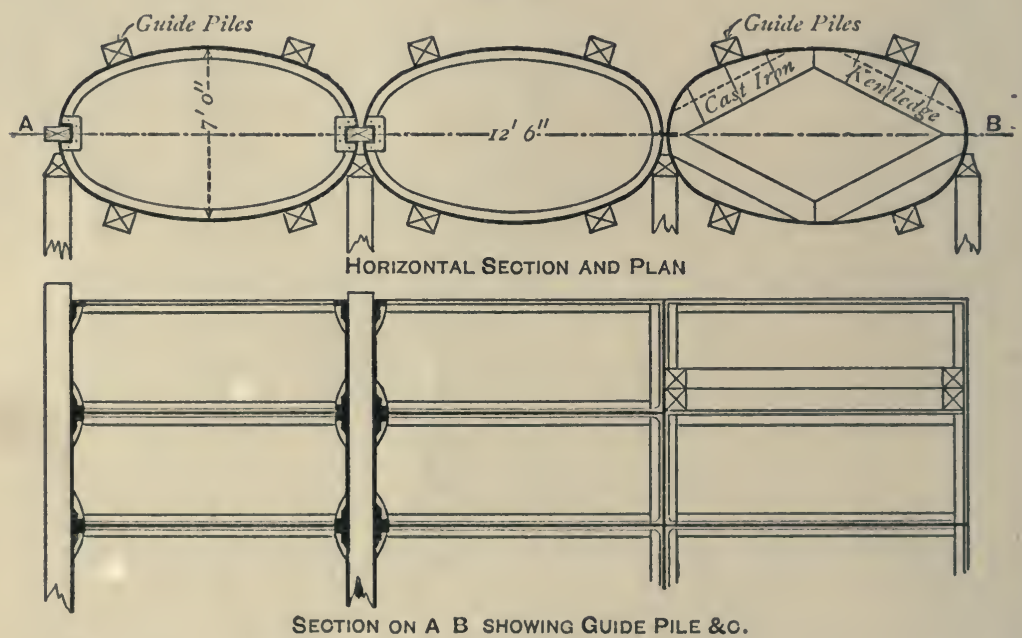

SECTION ON A B SHOWING GUide PILE \&C.

Fig. 29.

the vertical line during descent, and thus facilitated the operation of sinking. Besides these guide-piles, upright pieces of timber cut to the shape of the caisson junction, and lined between with felt, were placed on the inner side of the joints, and timber struts, used inside for strengthening the caisson, were abutted against them. Thus in proportion as the pressure of water outside the dam increased the strain upon the struts, the joint between the caissons became tightened.

Half-section rings only were used in the upper part of the dam; the convex sides facing the water, felted timber and struts supported the end flanges on the inner side of the dam. A frame of timber also stiffened their centre. 
Each section, 12 feet 6 inches long, 7 feet wide and 4 feet 6 inches deep, weighed about $30 \mathrm{cwt}$.

The caissons were sunk by excavating the ground within them, and weighting with iron blocks of about $9 \mathrm{cwt}$. each, cast

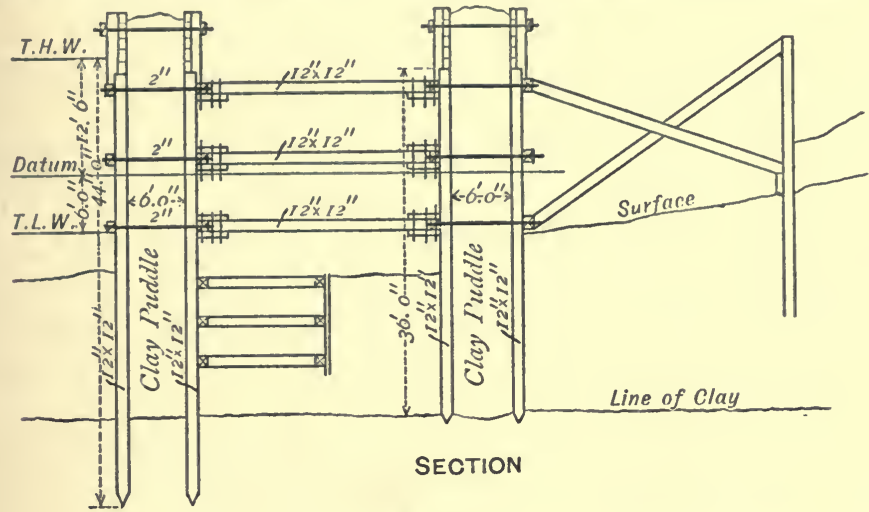

Fig. 30.

to the shape of the rings, and piled upon timbers which rested upon the flanges and formed the strengthening struts.

Timber Dams used on the Thames. ${ }^{1}$-In putting in the dam shown by Figs. 30, 31, with the view of saving time, the ground

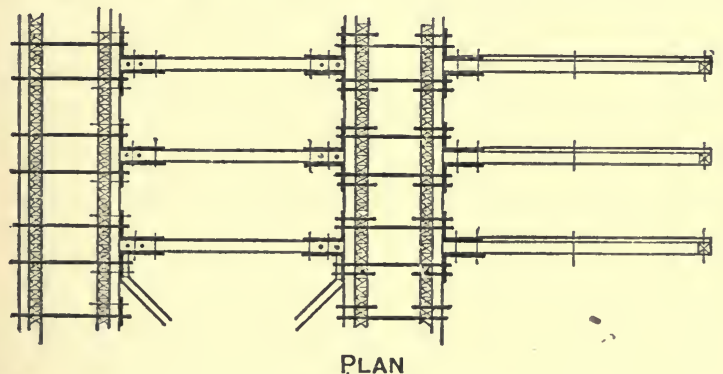

FIG. 31.

was not dredged before the piles were driven; the driving was in consequence a slow and difficult operation. In many cases it was found impossible to force the piles down, and many had to be drawn and replaced. Generally, when drawn, the piles were found to have cast their shoes, and their points were bruised into a mass of tangled shreds. The failure usually occurred whilst the point of the pile was passing through a bed

\footnotetext{
1 M.P.I.C.E., vol. $\mathrm{xxxi.p.} 3$.
} 
of close, compact sand containing fragments of shells which rested on coarse open gravel. Beneath the gravel and resting on the clay, was a layer of septaria, which presented a serious obstruction to the passage of the piles; once through this stratum, and into the clay, the driving became comparatively easy.

The width of the dam was 25 feet in the clear, with a space of 6 feet between the piles for puddle. The piles were of whole timbers in lengths of from 40 to 48 feet, and from 12 to 14 inches square. They were shod with shoes weighing $70 \mathrm{lbs}$. each, and were driven 4 feet into the clay. Shoes having castiron bases and wrought-iron straps were used in preference to shoes made wholly of wrought-iron, as giving at an equal cost a much larger base for the timber, a matter of considerable importance where the driving is difficult.

The piles were secured by three rows of walings of whole timbers 13 to 14 inches square, through which, and passing through the puddled space, were tie-bolts $2 \frac{1}{2}$ inches in diameter in the lower walings, and 2 inches diameter in the middle and upper walings. These bolts were placed at an average distance of 6 feet 6 inches apart in each waling. Their heads and nuts pressed against cast-iron washers 8 inches square and $2 \frac{1}{8}$ inches thick with splayed edges. The washers were afterwards made circular, 9 inches in diameter and $2 \frac{3}{4}$ inches thick, and it was frequently found that the pressure of the puddle had forced them into the walings to the full extent of their thickness.

To avoid the difficulty of procuring long timbers, the heads of the piles were driven below the level of the top of the dam, which was finished to 4 feet above high-water mark. Lengthening pieces were half-lapped to the heads of the piles at short intervals, and were bolted to each other across the puddled space by bolts $1 \frac{1}{4}$ inch in diameter; between these lengthening pieces deals were fitted in, longitudinally, up to the level of the top of the puddle.

Temporary walings, of half timbers, to guide the piles in driving, were fixed to the inner faces of the gauge-piles by bolts $1 \frac{1}{4}$ inch in diameter, and were removed before the puddle was deposited.

The 6 -feet space between the piles was dredged to the level of the clay by means of a bag and spoon, and the puddle filled in. Before the puddle was raised above the level of low-water 
mark, a sluice, formed of elm planks, and having. an internal section of 8 inches square, was fixed through the river side of the dam, and rested on the lower waling. This sluice was closed at the outer end by a hanging flap, to which a ring and chain were attached, to lift it when required.

The transverse struts or shores, of which there was a tier at each waling, were whole timbers, and were 8 feet apart in the length of the dam. Those in the upper tier were secured by angle-plates and bolts reaching through the piles and walings. The shores abutting against the middle and lower walings were kept in place by wooden cleats bolted to the walings. To preserve the vertical position of the dam, backstays were fixed which had angle-plates attached to them, bolted through the

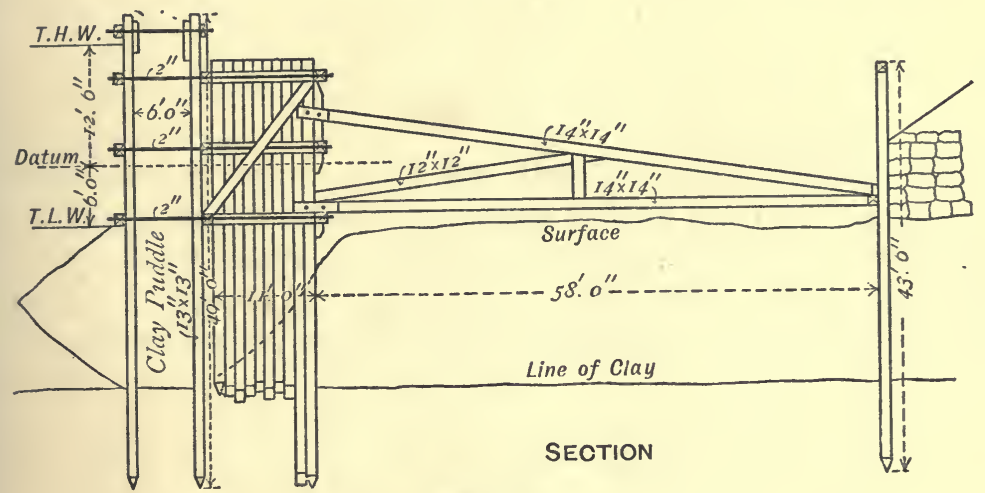

FIG. 32.

thickness of the dam to the corresponding plates of the upper row of shores.

In the dams shown by Figs. 32 to 35 , the material above the clay was dredged away before the piles were driven. As soon as the puddle within the dam was raised to low-water level, the spaces at the front and rear were filled in with a mixture of gravel and clay, to prevent the pressure of the puddle from breaking the piles between the lower walings and the solid ground. These sections also show the different methods adopted for shoring across wide spaces. In Figs. 32, 33, the width of the work was about 69 feet, and in order to avoid the necessity of having so many shores of this length, the dam was supported by means of buttresses, which were placed at intervals of 20 feet. These buttresses were 11 feet in width, constructed 
of whole-timber piles driven close together and tied together by walings corresponding in number and position with those fixed to the dam, and secured by long bolts which passed through to the outer face of the dam. Before the water was excluded, horizontal and raking struts were fixed, abutting against piles

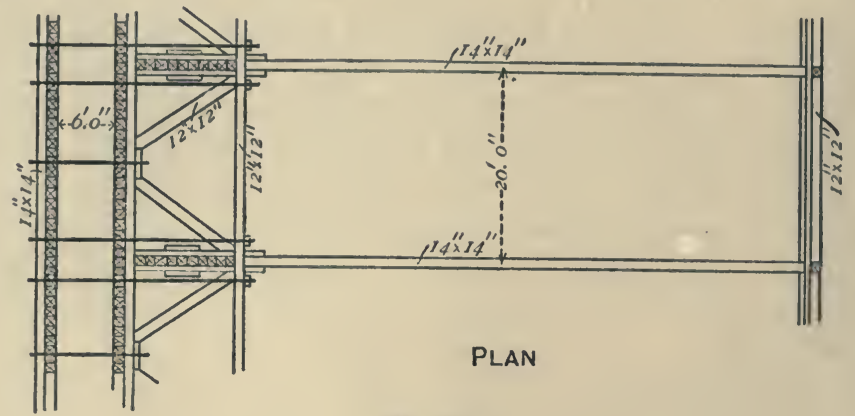

Fig. 33.

driven into the solid ground and backed with rubble stones. In Figs. 34, 35, the shores across the width of the work were horizontal, and abutted against walings of whole timber bolted to pairs of piles driven into the solid ground beyond the line of the foundations. These coupled piles were placed at intervals

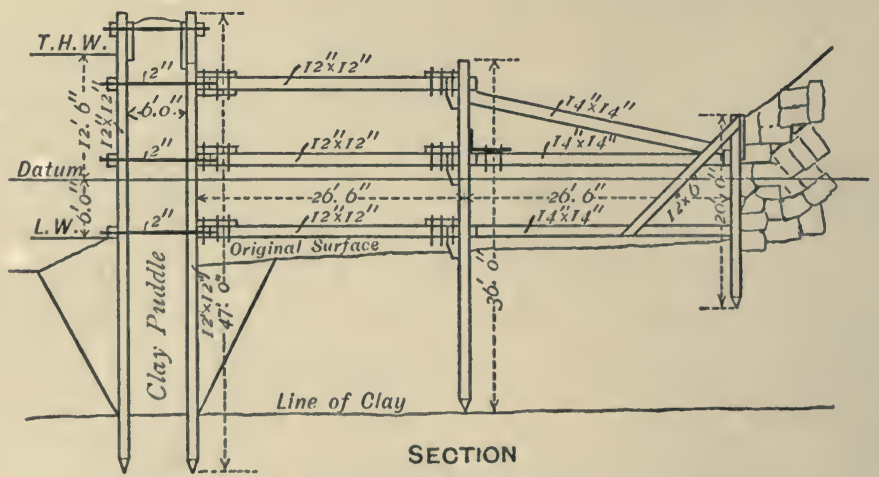

FIG. 34.

of 18 feet from centre to centre, and were strengthened by three back-struts to each pair. These back-struts rested against a row of piles driven into the slope of the embankment filling. To the piles deals were fixed so as to admit of their being backed up with earth and clay to the level of the upper struts. 
Immediately behind each pile, a mass of rubble stones was roughly built, to give further stability, and to divide the pressure over a large surface of earth filling.

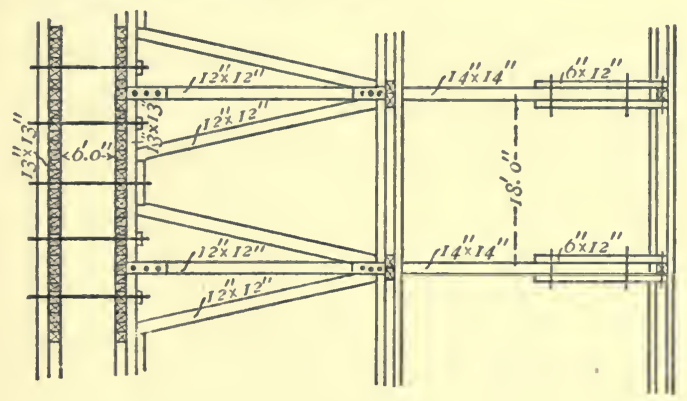

PLAN

Fig. 35.

Coffer-dam at the Middle Level, ${ }^{1}$ - For closing this dam, when the outward rush of water, as the tide fell, was very great, Sir J. Hawkshaw adopted a system of sliding panels. The method of constructing the dam (Figs. 36 to 39) being as follows:-

Temporary piles were first screwed into the ground, on which a platform was erected to carry the pile-driving engines. Two rows of close sheet-piling 25 feet apart were then driven transversely down the slope of the drain on each side and extending

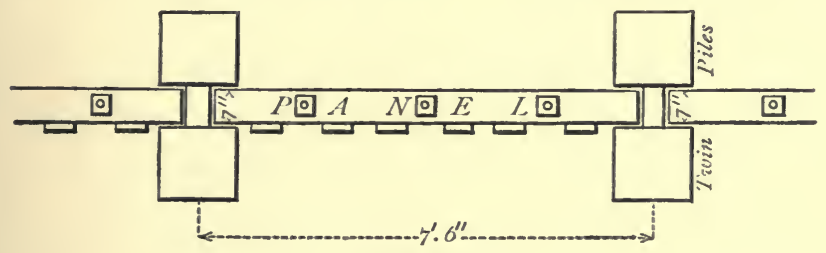

Fig. 36.

from the centre of the banks to within about 20 feet of the bottom, leaving a central space of 88 feet in length to be completed in the following manner:-

Piles of whole timbers were driven on each side so that these would be in pairs 7 feet 6 inches apart from centre to centre. The piles in each pair were placed back to back, a space of 7 inches being left between them, preserved by a central piece 7 inches by 3 inches.

The piles were driven separately; one with the distanceII.P.I.C.E, vol. xxii. p. 499. 
piece attached being first driven, and afterwards the other. The grooves thus left were for the reception of sliding panels, to be

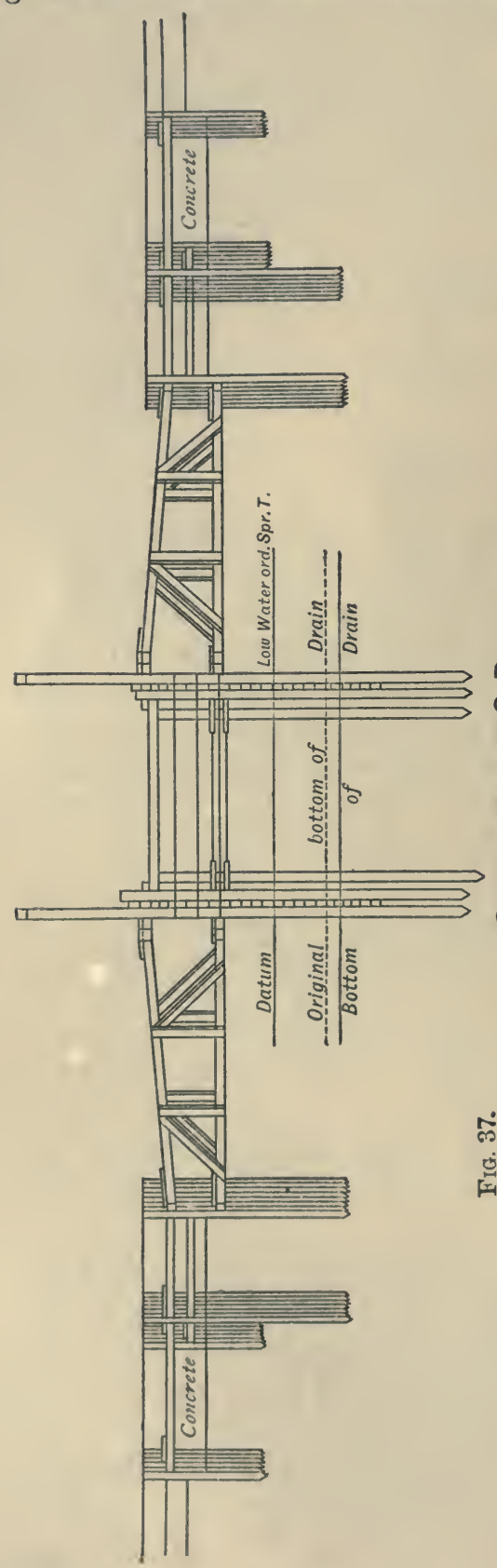
used in order to fill up the spaces between the several twin piles, as shown in Fig. 36. Waling-pieces of whole timber were fixed to the inside and outside, both at the top and as near to the low-water level as possible. As the piles were driven, proper struts and ties were inserted to stiffen and strengthen the dam, and strongly framed raking struts were fixed against abutments composed of piles backed with concrete.

The panels were composed of a series of timbers 7 inches thick, and of a length necessary to enable them to slide in the grooves, fastened together by $1 \frac{1}{4}$-inch round-iron bolts, and further strengthened and weighted by flat wrought-iron plates 6 inches wide by 1 inch thick fixed on one side. In order to put these panels into place, - a frame was erected (Figs. $37,39)$, from which they were suspended, and from which they could be lowered, and raised again if necessary, by pulleys.

The panels in the lowest tier were pointed at the lower end so that they could be driven some depth into the mud. When all the first 
ENCLOSING DAMS.

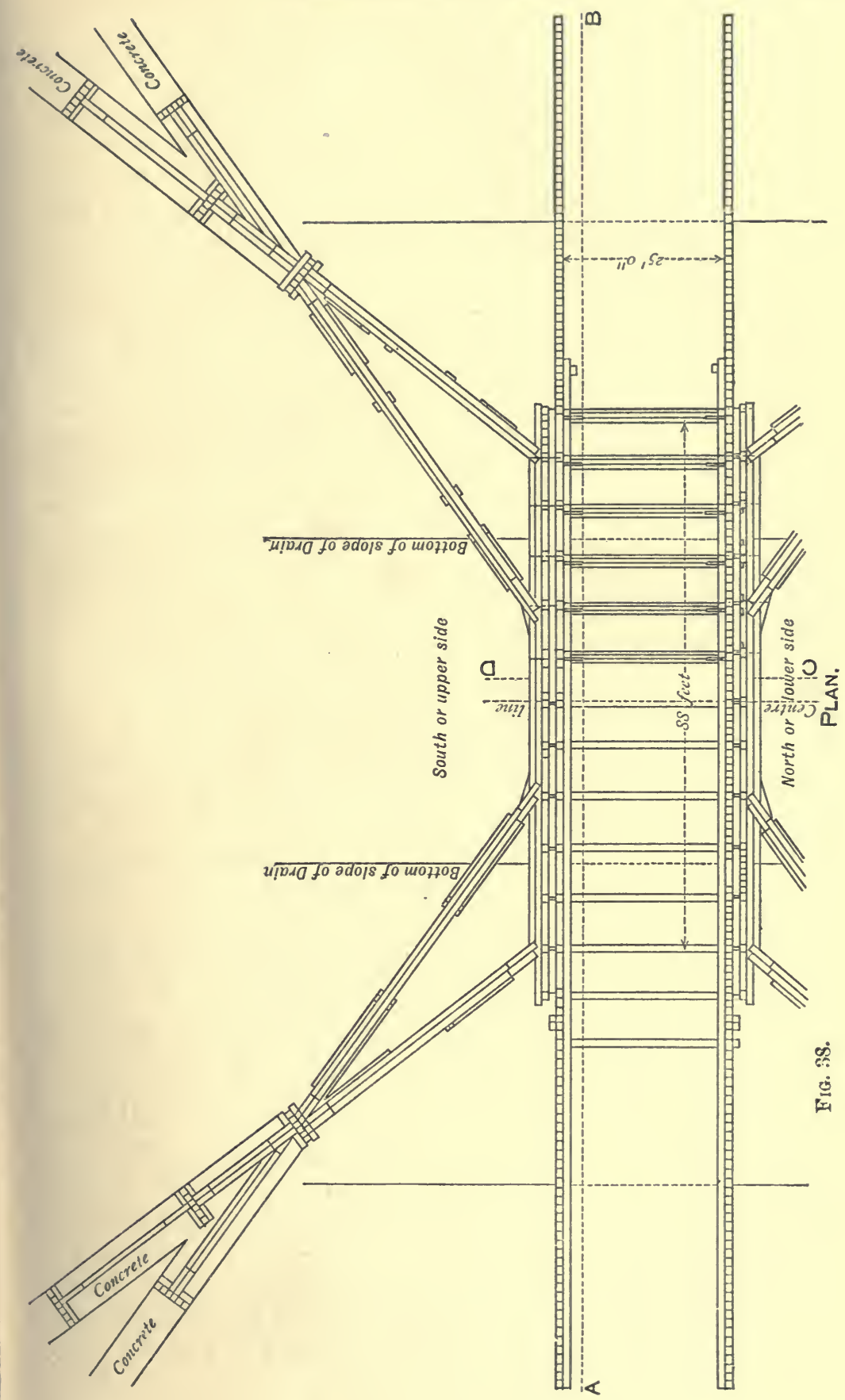


52 NOTES ON DOCKS AND DOCK CONSTRUCTION.

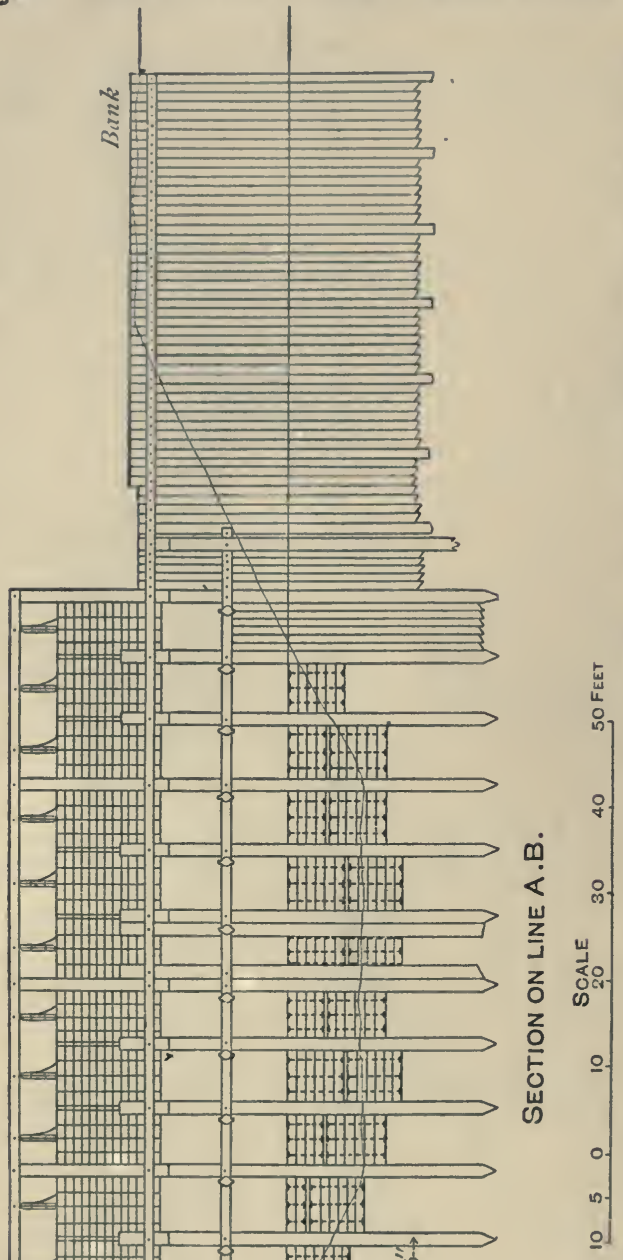

set were driven, the second tier or set was put in, so that the top edge was uniformly level with the low-water line of spring tides. While the lower panels were being driven, and after they were down, sacks of clay and gravel and other material were deposited both inside and outside the dam.

The remaining upper pancls were closed at one operation, and in in order to accomplish this, the whole were sus-

\% pended by tackles from the overhead scaffolding on each side of the dam (Figs. 37, 39), so as to be ready to be dropped into place at slack water.

The first attempt to close the dam was a failure, owing to the fracture of three of the twin piles in driving. The damage was made good by driving additional piles in the spaces between and adjoining $\therefore$ the broken piles. A second attempt to close the dam was successful. The panels were lowered at slack water of the ebb tide. Immediately the panels were 
lowered, the inside of the dam was filled with clay and bags of gravel.

After the panels were placed in position and the dam filled with clay, etc., the spaces between the twin piles were filled in by driving close sheet-piling, then by converting the lower side of the dam into a continuous row of sheet-piling; extra piles were also driven at the sides of some of the twin piles where it appeared that the panels had not sufficient hold.

Dam at Entrance of Avonmouth Dock. ${ }^{1}$-For closing the entrance of the lock while the outer clay dam was being removed,Mr. Brunlees constructed a timber dam somewhat on the principle of a dock gate (Figs. $40,411)$. The foundation or base consisted of whole-timber close sheet-piling driven 18 feet into the sand below the foundation

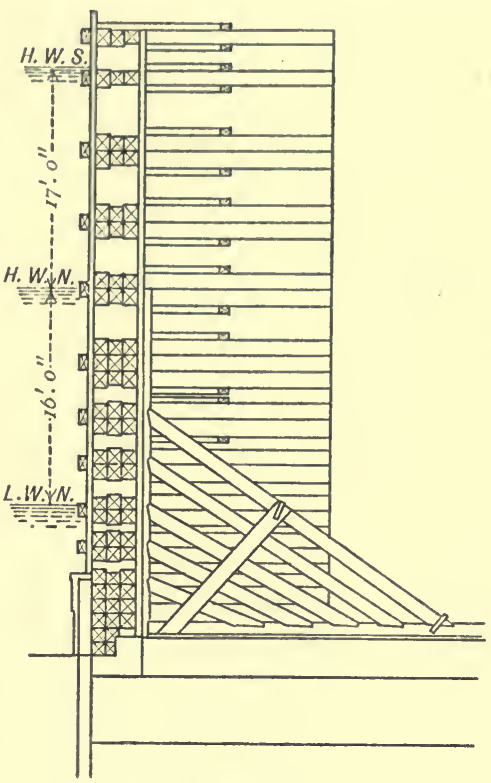

FIG. 40. of the lock. Above the level of the sill, the timbers were arranged much in the same manner as the horizontal timbers
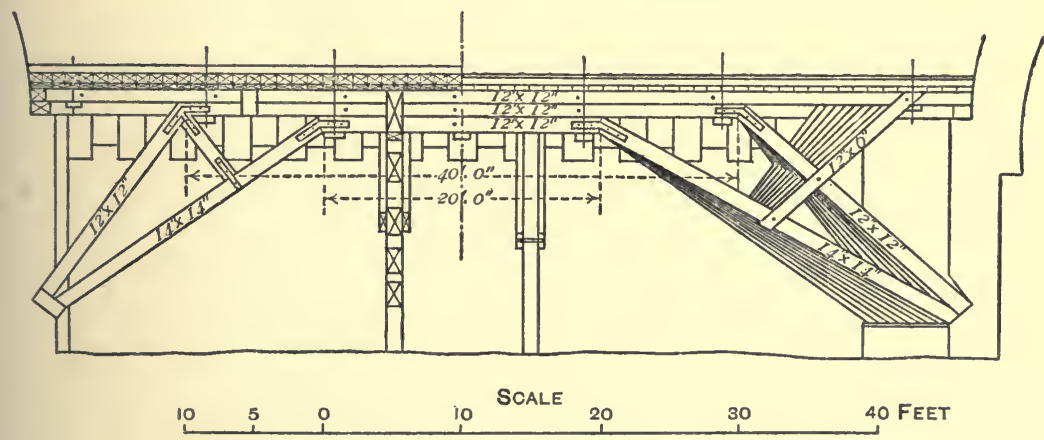

FIG. 41.

of a gate, strutted to the side walls of the entrance, and forming trusses of a simple and inexpensive character. On the outside, 1 M.P.I.C.E., vol. lv. p. 8; vol. li. p. 153. 
the dam was close planked and thoroughly caulked. The head of pressure at high water of ordinary spring tides was 44 feet. This dam proved satisfactory in every way, and so little ironwork was used in framing the trusses that the whole of the timber was fit for permanent purposes after the dam was removed.

Dublin Coffer-dam. ${ }^{1}$ - This dam (Fig. 42) was considered to be of very light construction, bearing in mind the purpose for which it was used, viz. the removal of an old quay wall, and the construction of a new wall at a much greater depth.

"The strata consisted of 2 feet of soft mud, 4 feet of fine sand, 3 feet of vegetable deposit overlaying a thick bed of alluvial clay, ranging in thickness from 4 to 11 feet, and a bed of strong gravel, interspersed with fine sand and boulders, and in some places brown clay."

The design consisted of two rows of piles with clay-puddle filling. In the outer row, the main piles of Memel timber, 32 feet long by 12 inches square, were driven as gauge-piles at distances of 12 feet from centre to centre. In the inner row, the piles were 40 to 42 feet long, spaced to correspond with the piles in the outer row; the space for the puddle between the two rows of piles being 4 feet 6 inches. The spaces between the main piles in both the inner and outer rows were filled in with sheet-piles 12 inches wide by 6 inches thick. Those in the outer row were driven 12 feet into the ground, and reached up to the level of high water; the total length being 28 feet. The sheet-piles in the inner row were of similar length, but were driven down to the level of the foundation of the new wall, 24 feet below low water, their heads reaching to 4 feet above low-water level.

The sheet-piling was driven in line with the inner faces of the gauge-piles, so as to offer no obstruction to the settlement of the puddle, and the lower edge of the 3-inch horizontal planking with which the dam was sheeted on the inner row was levelled off with the same object.

Two $1 \frac{1}{2}$-inch tie-rods of wrought iron were passed through two half-timber wales on the outside and inside of the main piles, provided with cast-iron washers 8 inches square and $2 \frac{1}{2}$ inches thick at each end, and screwed up with hexagonal nuts. The tie-rods were placed one at 1 foot below high-water mark, and the other at 2 feet above low water.

I M.P.I.C.E. vol. li. p. 137. 


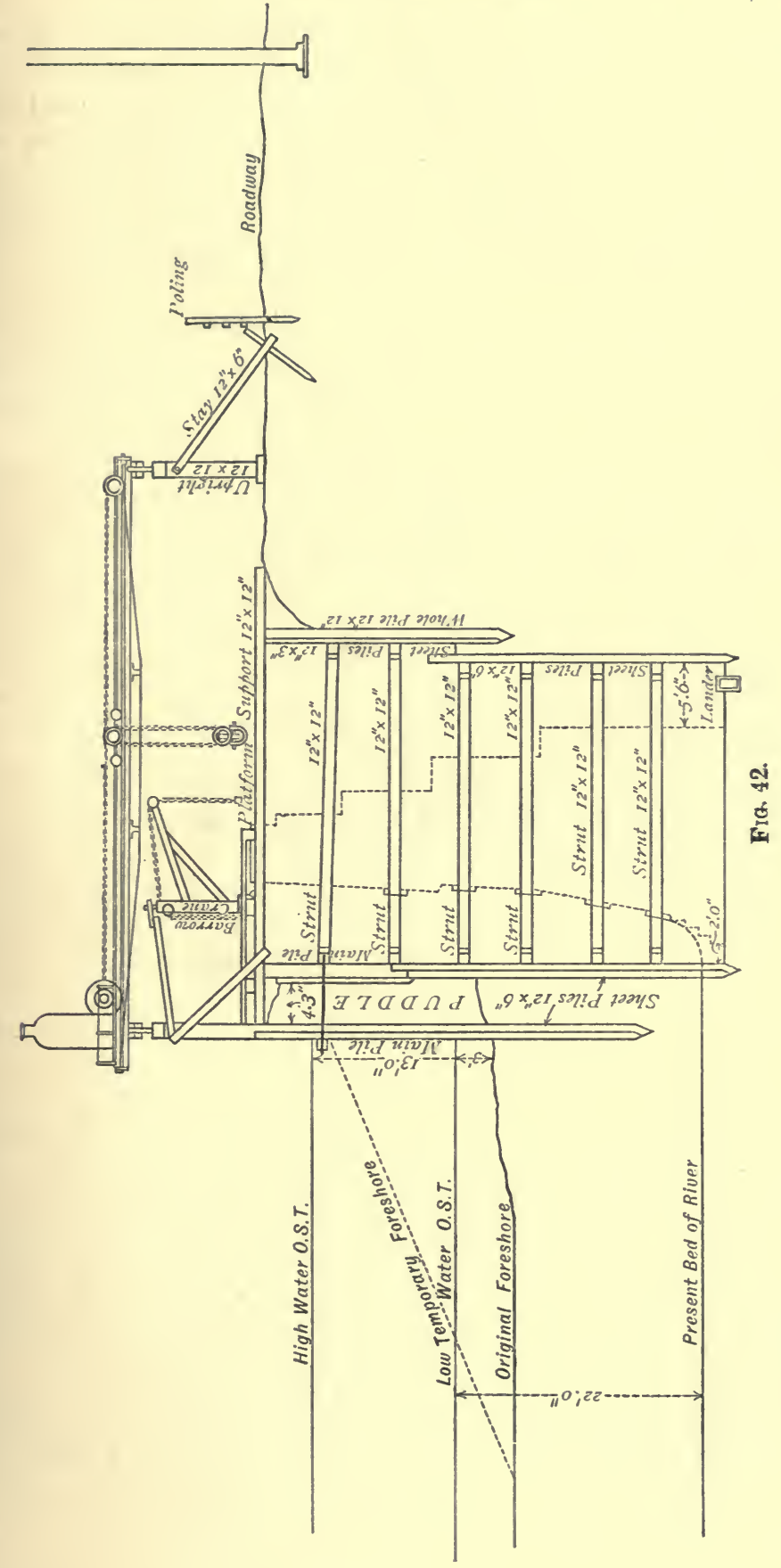


After the exclusion of the water, and when the dam had been sufficiently strutted against the old wall, a row of piles 25 feet long by 12 inches square was driven on the land side about 32 feet from the inner row of piling of the dam, and spaced to correspond with the main piles; between these gaugepiles a row of sheet-piling was driven, extending from the surface of the roadway to below the level of the foundation of the old wall.

As the masonry of the old wall and the struts against it were removed, whole-timber shores 30 feet long were inserted, resting against the land row of whole piles and the dam. A

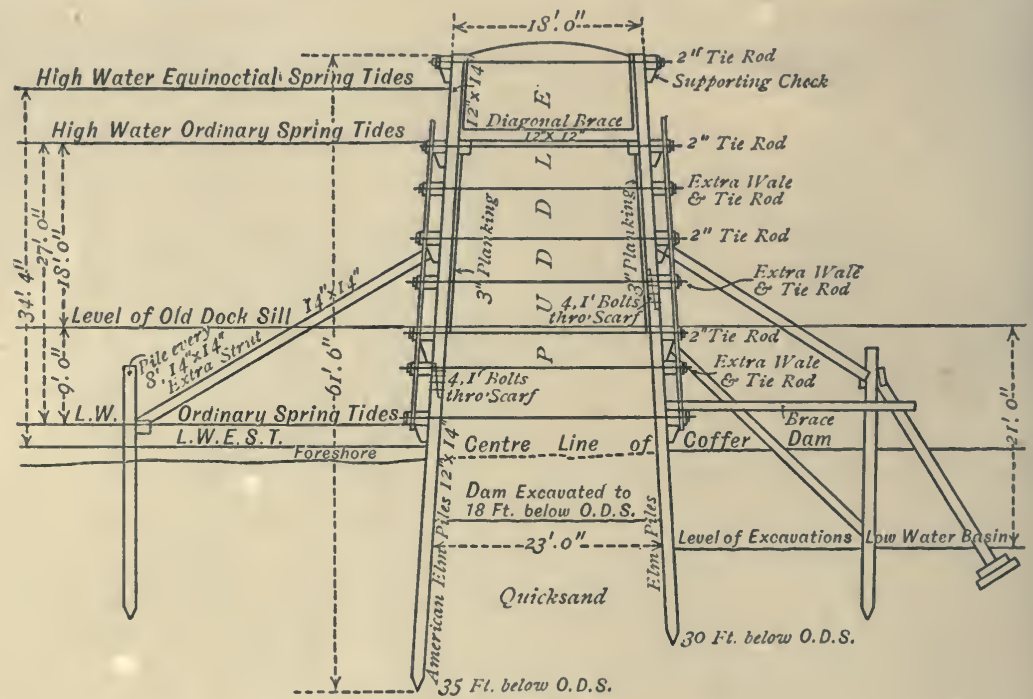

FIG. 43.

lower row of continuous sheet-piling, 24 to 26 feet long, 12 inches by 6 inches, was then driven along the land side. The excavation and shoring was then continued to the bottom.

The weak point in this dam appears to have been that the walings and shores were placed too far apart, and that the fastenings generally were too weak; and although it stood and answered its purpose, it must have been strained very nearly to its ultimate powers of endurance.

Dam across the Entrance to the Low-water Basin at Birkenhead. ${ }^{1}$ -This dam (Fig. 43) was on plan a segment of a circle with 1 M.P.I.C.E., vol. li. p. 146. 
a chord of 467 feet and a versed line of 76 feet. The width at the top was 18 feet, and at the ground line 23 feet. The extreme height from the toe of the outer row of piles to the top of the dam was 61 feet 6 inches. The dam was formed with two rows of whole piles battering both ways, the outer row in lengths of 35 to 40 feet, 12 inches wide by 14 inches thick, and driven close together, as sheet-piling, with the toes reaching to 35 feet below the level of the old dock sill. The piles in the inner row were from 30 to 35 feet long, of the same width and thickness, driven also as sheet-piles, with the toes reaching to 30 feet below the same datum.

On every fourth pile of both the outer and inner rows was placed an upright, 12 inches wide by 14 inches thick, by means of a scarf 4 feet long, secured by four 1 -inch bolts, and reaching to the level of $\mathbf{3}$ feet above high-water equinoctial spring tides, the whole being secured by five tiers of wales, placed on the outside of the piles and uprights, at vertical distances of about 8 feet. Through these wales were passed, at longitudinal distances of 12 feet, a series of 2 -inch wrought-iron tie-rods, screwed up at each end with hexagonal nuts on cast-iron washer plates 9 inches square by 2 inches thick.

At the level of high-water spring tides an inner wale $\mathbf{1 2}$ inches square was fixed on both the inner and outer rows of uprights, to which diagonal horizontal struts or braces, 12 inches square, were bolted for the purpose of keeping the uprights asunder to the proper width at the top.

The whole interior of the dam on both the inner and outer rows of uprights from the level of the old dock sill to the top was sheeted with horizontal planking 3 inches in thickness to hold the puddle.

The excavation within the dam was taken down to 18 feet below the old dock sill before the puddle was put in. The ground upon which the dam rested was chiefly fine sand; this, when saturated with water, became a quicksand.

The timber specified to be used was crown Memel, but it was ascertained as the work proceeded that over a considerable portion of the site Memel could not be used owing to the compactness of the sand; American elm piles were therefore substituted.

Excavation within the dam was a difficult operation, requiring to be done by tide work in short lengths.

After the dam had been filled with puddle to the height 
of 12 feet above the old dock sill level, the cast-iron washers began to sink into the wales and break. To remedy this, pieces of American elm 3 fect long by 12 inches wide by 6 inches thick were placed under the washers. Then the wales exhibited signs of giving way where the tie-rods passed through; as a precaution, additional wales were put on between each of those originally in place with an extra tie-rod driven through each additional wale at the intermediate distances, with a vertical piece of elm overlapping two wales, so as to distribute the bearing surface. The tie-rods were screwed up over these vertical chocks. This treatment proved effectual in keeping the puddle in place.

When the puddling of the dam was near completion, the structure showed symptoms of going out towards the river, particularly near the crown of the segment. To prevent this, an extra row of piles was driven for a distance of 200 feet run at 30 feet outside the dam, 8 feet apart from centre to centre, upon which a waling 14 inches square was bolted as low down as the lowest tide would permit. From this waling, raking struts 14 inches square were placed, reaching to the under side of the waling on the dam at the level of 8 feet above the old dock sill. It was considered expedient, during the time the dam was in place, not to remove a quantity of contiguous soil intended to be excavated, so as to prevent a "blow."

All the other portions of the work within the low-water basin being completed, the excavation was proceeded with, the object being to lessen as much as possible the subsequent dredging.

When the excavation was nearly completed, the water commenced bubbling up in half a dozen places at about 30 feet behind the dam. Additional struts were therefore placed on the basin side as the structure commenced to warp a little, and the puddle to settle down slightly. The bubbling up of the water however continued, and after a day or two the nuts of the tie-rods began to fly off, and it became evident that the dam would not much longer resist the undermining and the pressure from without; ultimately the dam suddenly gave way.

The head of water of 33 fect, rushing in to fill the empty space of 14 acres, scoured a channel 30 feet in depth and 50 feet in width within the basin. A large portion of the piles were 
broken off short, rendering the pulling of the stumps exceedingly difficult.

It may be noted with regard to this dam that the piles being battered both ways, the puddle was narrower at the top than at the bottom, therefore, in settling, it would have a tendency to leave the sides of the dam, which would very greatly increase the difficulty of keeping it tight. ${ }^{1}$ The excessive thickness of clay puddle was a great source of danger, inasmuch as it brought an enormous strain upon the lower part of the inside sheetpiles where there was nothing to resist the pressure, after the removal of the excavation, but a few feet of quicksand; this excessive pressure of the clay, aided by the percolation of the water through the bottom, rendering the sand still more unstable, no doubt led in a very great measure to the ultimate failure of the dam.

Coffer-Dam at the Victoria Dock, Hull. ${ }^{2}$ - This dam (Fig. 44) was con-

1 M.P.I.C.E., vol. li. p. 154.

2 Ibid., p. 149.

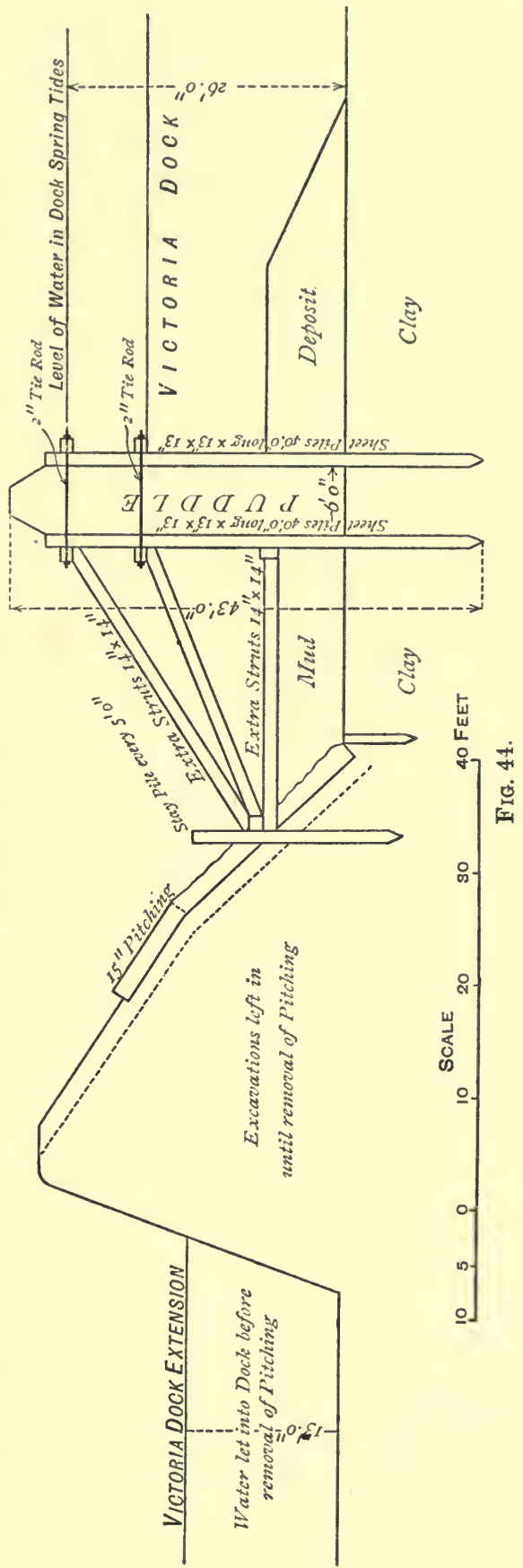


structed across the Victoria Dock so that the business of the dock might be carried on during the time an extension to the basin was in progress; it was therefore subject to a constant instead of a tidal head of water.

The dam was the segment of a circle, the radius being 1500 feet, and 470 feet long, the versed line 20 feet, and consisted of two rows of whole-timber piles, each 40 feet long by 13 inches square, driven as close-sheeting about 10 feet into the ground and 6 feet apart between the inner surfaces. It was tied together with two sets of walings 13 inches square, one set at the level of high water in the dock, and the other at 6 feet below high-water level; through each of these a 2 -inch tie-rod passed, and was screwed up on timber chocks and washers on the outside of the walings. The deposit of mud 7 feet in depth between the two rows of piles was cleared out with a bagand-spoon dredger before the puddle was filled in.

The water remained at nearly the same level on both sides of the dam during the excavation of the soil in the extension of the dock. When the works had been so far completed that nothing remained but an embankment 40 feet wide parallel with the dam, the water on the extension side was lowered. After the water had been thus lowered 6 feet, the dam showed signs of yielding; shoring struts 14 inches square were therefore placed against the walings and pitching of the slopes, and the water further run off. The pressure then showed itself greatest near the level of the accumulated mud, and it was found necessary to drive stay piles in the slopes 8 feet apart, from which struts were placed resting against an extra waling 13 inches square, fastened to the dam at the level of the mud; it was also considered prudent to fill the extension works with water to a depth of 13 feet. The pressure from the dam was so great that many of the stay piles were pressed 1 foot into the solid bank. As soon as the great bulk of the pitching on the bank had been removed, the water was permitted to rise in the extension to the same height as in the dock, thereby averting all further risk to the shipping lying therein.

This dam caused a great deal of anxiety during the time the dock work was in progress, and if it had failed the result would have been disastrous; fortunately it stood, and the reason assigned for its doing so was that it had been constructed of a circular form, according to Sir John Hawkshaw's design, and 
that it acted as an arch. ${ }^{1}$ It may, however, be noted that this would only hold good providing the workmanship was perfect; that is, that all the piles were in close contact, and that the dam retained its perfect segmental form; it appears, however, that the dam became very irregular in form, and bearing in mind the large radius and small versed line, but little support could have been derived from its circular design.

Alexandra Dock, Hull. ${ }^{2}$ - This coffer-dam (Fig. 45), enclosing the lock entrance to the Alexandra Dock, Hull, was 461 feet total length. It was constructed of two rows of whole-timber piles 13 inches square, spaced 6 feet apart, with clay puddle between, and shored at the rear in the manner shown by Fig. 45.

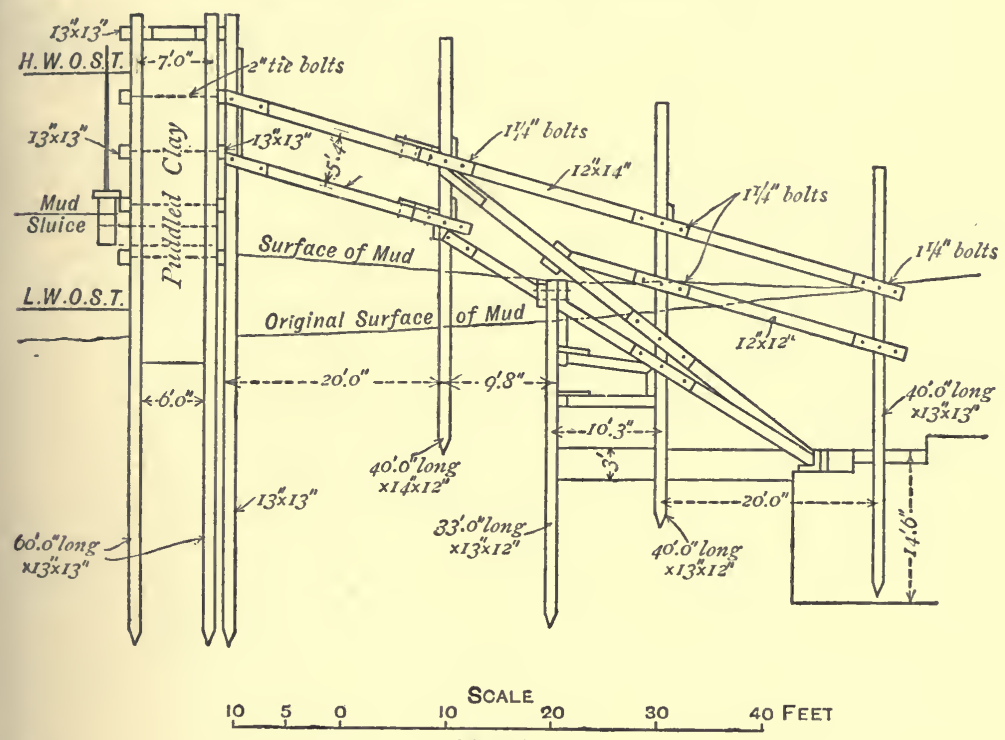

FIG. 45.

The piles were from 50 to 60 feet long, and were driven about 33 feet into the ground, the main piles reaching down to 54 feet below high water.

Inside and outside walings 13 inches square were spaced about 5 feet apart, centre to centre, and tied together with 2 -inch through-bolts.

Five sluice-valves or openings 2 feet square were made to allow the tide to flow in and out till the completion of the dam.

The connections between the ends of the dam and the em. II.P.I.C.E., vol, li. p. 152. 
bankment were to be made good by a seal of clay keyed into the clay backing of the embankment, but on the western side some runaway trucks deposited their loads of chalk in the trench which was being formed round the dam; and, as this chalk was not fully removed, owing to its low level, the water leaked through in several places near the junction.

The leakage was stopped by sinking a trench outside the dam, removing all the chalk, and filling the trench with fresh puddle. This difficult operation was also carried out at the western junction for the purpose of overcoming a similar leakage.

Pola Dock. ${ }^{1}$-In driving the sheet-piling to form the casing for the concrete walls of the Pola Dock it was desirable that the inner surface should be accurate and even, so as to render the face of the beton wall uniformly smooth.

This, in deep water and with timber of light specific gravity, was somewhat difficult of accomplishment. To obviate the difficulty, an apparatus termed a "Spider" was devised by the engineer, Mr. H. E. Towle (Fig. 46). Two timbers were formed by sawing a log 35 feet long and 12 inches square so that the larger ends were 8 inches by 12 inches, and the smaller ends 4 inches by 12 inches. These were placed side by side horizontally, with the larger ends in the same direction, and spaced 12 inches apart, and parallel to each other, to form the side pieces. At about 8 feet from the thicker ends was fitted a solid oak block 30 inches thick and about 6 feet in length, a width of 9 inches on either side of the lower end of the block was cut away, leaving a thickness of 12 inches in the centre, which was fitted between the parallel side pieces at an angle with the vertical of $33^{\circ}$, and the whole securely bolted together. Two inclined side pieces or cleats of timber 8 inches by 12 inches, and 17 feet long, were secured to the oak block and to the side timbers at their thicker ends, the whole forming a throat or clip in which to receive the piles, the side pieces and sloping oak block forming a guide for the point of the pile to the 12-inch space between the horizontal timbers below. Two vertical timbers, termed hangers, 8 inches by 12 inches, and about 20 feet in length, were inserted between the side pieces in the rear of the oak block and spaced about 20 feet apart, and hinged at the lower ends by stout iron bolts passing through the side 
pieces. The horizontal side timbers were clamped firmly together at the rear end with a distance-piece 12 inches thick between them. Two ordinary tackles were made fast to the smaller or rear ends of the horizontal side pieces to serve as lateral guys, and a 9-inch hawser to the forward end, near the oak block. The apparatus was next weighted with iron ballast laid across the side pieces until it sank promptly; it was then ready for use.

The method of applying this apparatus is as follows:-

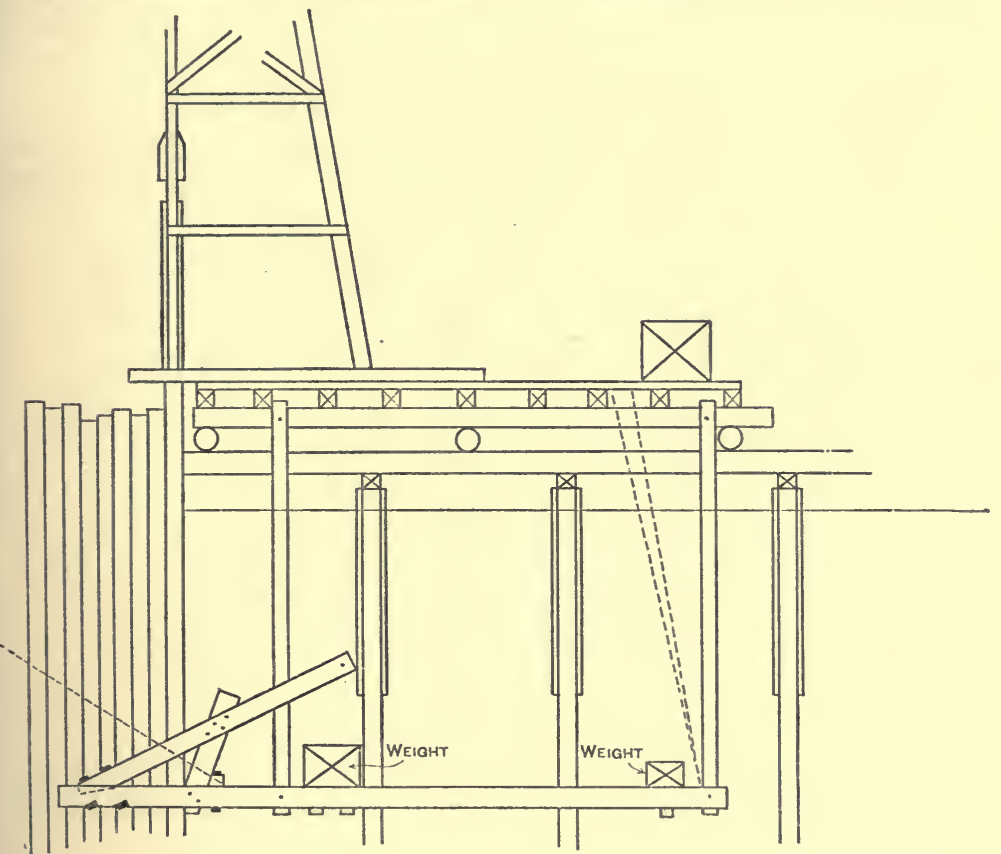

Fic. 46.

assuming a pile to have been driven and the pile-driving machine to be in a proper position for driving another pile in the line, the "spider" is advanced so that the two side pieces or horns of the machine are made to pass one on either side of, and clasp the sheet-piles already driven. The hawser is then drawn taut until the oak throat block presses hard against the pile last driven, and the lateral side guys properly secured are drawn up by the men on the platform until the machine below is in proper line, which is readily known if the hangers are vertical. All being adjusted, a sheet-pile is raised 
by the pile-driving machine, and is readily driven in line with those already down. The throat of the "spider" guides the point and body of the pile to its place, and the elasticity of the hawser permits a pile or two to pass through before slacking. In the result, the control of the work was so perfect that, only at intervals of from 20 to 30 feet a special wedgeshaped pile was required to be driven butt down to keep the work vertical at the driving point.

With a "spider," at least double the number of sheet-piles could be driven in deep water, where the mud was shallow, than was possible, at the same expense, without such a contrivance, and the work was much better done.

On the surfaces of contiguous sheet-piles a single thread of ordinary spun yarn or marline was tacked; this made

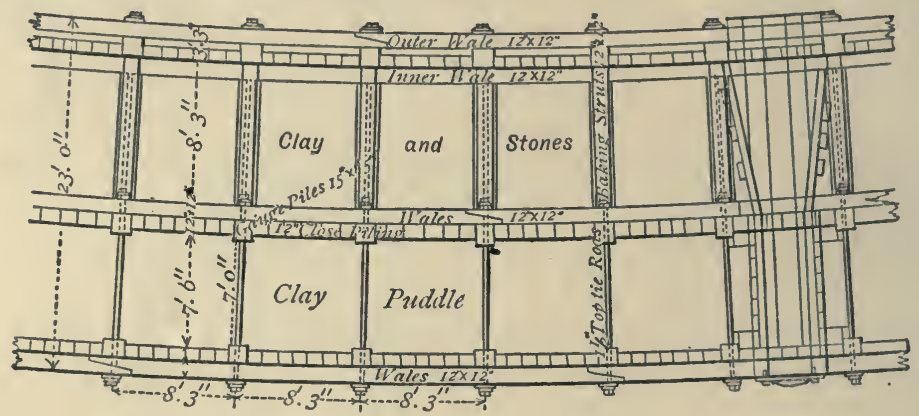

FIg. 47.

the joint almost water-tight, as was proved by the fact that the water was often found 2 feet higher inside than outside the enclosed space.

The sides of the enclosure with the cross dam and quay having been completed for one block or section, the whole was secured by ties and bolted together above the level of the concrete.

Esquimalt Dock. ${ }^{1}$-The dam (Figs. 47, 48) adopted by Messrs. Kiniple and Morris, M.M.I.C.E., to enclose the site of the Esquimalt Dock, consisted of three rows of close sheet-piling driven circular on plan to a radius of 400 feet for the outer row, and 379 feet for the inner row.

The bottom for the greater part of the length consisted of ' Engineering, vol. xlvi. p. 87. 
about two feet of sand and shells overlying hard blue clay. The abutments and a portion of the piling at each end were upon the rock.

The gauge-piles were driven into the clay about 12 feet, and the filling piles about 8 feet. The tops of the two outer rows were kept at 7 feet above high-water level. They were spaced 7 feet 6 inches apart, and were secured together by four tiers of $1 \frac{1}{2}$-inch through-bolts screwed up on whole-tirnber inside

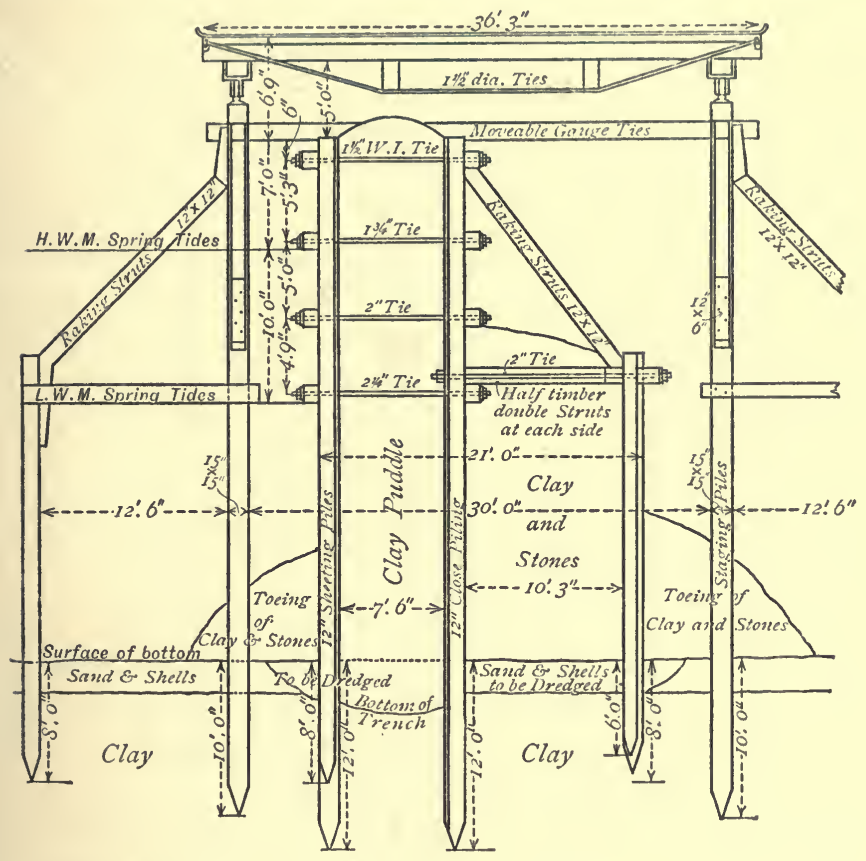

Fra. 48.

and outside walings. The space between the piles was cleared of all sand and loose material, and filled in with well-rammed puddled clay.

The inner row of piles was driven 10 feet 3 inches to the rear, the heads being about 3 feet above the low-water level; the heads were secured with inside and outside whole-timber walings, and connected with the second row of piles by halftimber double horizontal struts and 2-inch through tie-bolts. Whole-timber raking shores were fixed from the top of the inner 
waling to the under side of the top waling on the second row of piles.

The space between the second and the third rows of piles was filled in with well-rammed clay and stones, a bank of the same material being also placed both inside and outside the dam to increase the stability.

At either end, where the dam rested upon the rock, 6-inch sheeting-piles were used, secured at the foot to inner and outer sills laid in trenches cut in the rock.

For controlling the water during construction, and for letting in the water on completion of the work, three trunks, closed with screw sluices, were fixed through the dam with the sills at low-water level.

When the water was pumped out, the dam proved perfectly tight in every respect, and did not show any straining when the full head of water was brought against it. No pumping was required during the time the dam was in use-a period of seven years-beyond that which was due to percolation through the strata or rainfall.

On the completion of the works, preparations were made for removing the dam by digging away the earth and bank from the inside. This having proceeded for some time, water commenced to leak through the dam.

The possibility of the dam giving way was at once realized, and endeavours were made to avert the danger by opening the sluices to admit the water; while, however, there was still a head of 10 feet outside, the dam gave way suddenly, an opening being made about 40 feet wide.

Amsterdam Canal. ${ }^{1}$ - The circular coffer-dam within which the Zuider Zee Locks of the Amsterdam Ship Canal were constructed was 525 feet inside diameter, and consisted of two consecutive rows of sheet-piles of Dantzig white pine, with a clear space of 6 feet 6 inches between them.

The outer row of piles was of whole timbers sawn to 12 inches wide on the surfaces of contact. For the inner row, the piles were sawn to 8 inches wide on surfaces of contact, except the gauge-piles, which were of whole timbers.

'The puddled clay between the piles was carried up to the level of the ordinary high water, and a mound of sand was deposited on the inside as a counterweight to the pressure of the water.

II.P.I.C.E., vol. 1xii. p. 11. 
The outer row of piles projected 8 feet above ordinary high water, as at times the height of this ordinary tide level was much exceeded. The inner gauge-piles came up to the same level, but the row of sheet-piling was only carried up to the level of ordinary high water.

The walings were arranged as shown by Fig. 49. The lower waling or the inside consisted of laminated timbers breaking joint.

This dam would have been more efficient had the inner piles

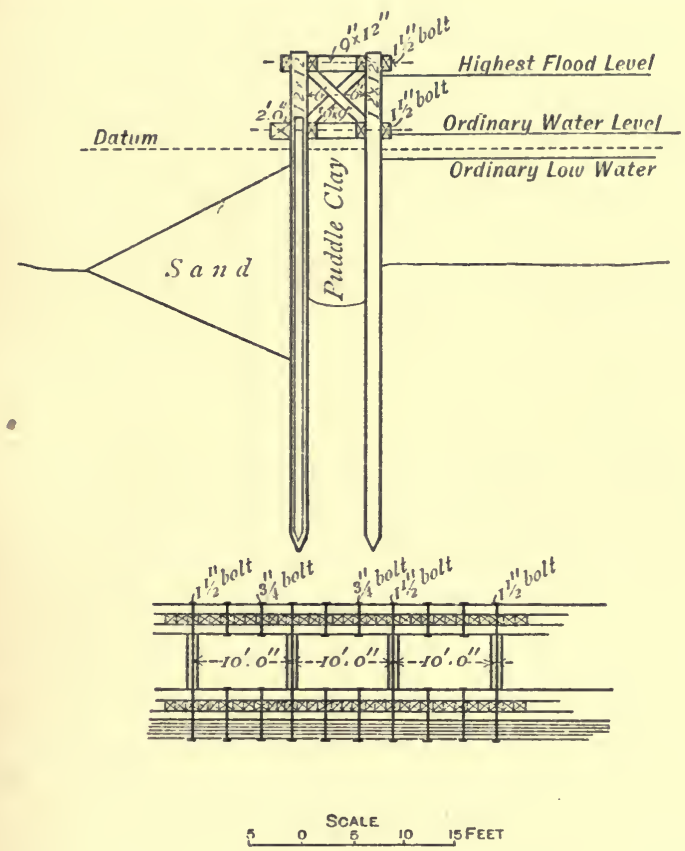

Fig. 49.

been of whole timbers carried up to the same height as the outer row, and if the upper inside waling had been made of the same strength as the lower laminated walings. The timber for the piles, however, were required of exceptional length, and so many were needed that it became a difficult matter to procure a sufficient number of the right size; hence it was an object with the contractors to adopt a design which would allow of shorter timbers being used.

In order to construct the dam, a dolphin was first erected 
in the centre of the area to be enclosed. At the commencement, some difficulty was experienced in getting the piles of the exterior ring set out to a true circle, which was important. At first a hempen rope previously strained was fastened to the central dolphin, but the rope stretching irregularly the piles were not true to a circle. Floating rods were then tried, but the wind and the tide deflected them sideways. At last a light iron wire rope about $\frac{1}{4}$ inch in diameter, kept strained by a weight, was used; for a few days it gave irregular results, but soon acquired its maximum stretch, and became sufficiently accurate. It was found that if the guide-piles were set out in this manner as close as $\mathbf{1 0}$ feet apart the resulting curve was not very regular, they were, therefore, spaced 40 feet apart. Three pile-engines were then set to the curve on a radial lighter 40 feet broad at one end and 20 feet at the other. These engines drove three piles equidistant in the 40 -foot space. The three pile-engines were driven by an 8 horse-power engine with triple-purchase gear on to a long shaft. On this shaft were three drums, each of which could be thrown out of gear at any moment.

In order to drive the sheet-piles, two other lighters were provided, with one pile-engine on each, driven by an Appleby steam crab. In every bay, the last pile but one was wider at the base, the last pile being as usual a wedge or key to close the other piles up. For preparing the piles, one circularsaw table, driven by a 14 horse-power engine, just kept the work going.

The ground was of a very variable character; many of the piles could be driven in about 10 minutes, whilst others could not be got down without being split, and some could only be kept down by letting the monkey rest upon them after the blow had been struck, as they rose 18 or 20 inches if the monkey was lifted immediately after the blow. It was subsequently found that this occurred where the layer of peat was the thickest and the substratum of sandy clay the softest. The weight of the monkey used was one ton.

To prevent the ground being scoured on the south sicle, where there was at one time an extraordinary current, due to the narrowing of the lake by the Zuider Zee dam, long mattresses of fascine work were sunk against the coffer-dam.

As soon as the coffer-dam had been pumped out, the embank- 
ments, which had been brought close up on both the north and south sides, began to push it inwards, distorting the circle by unequal pressure, which had taken no effect as long as the water was inside the coffer-dam. Some of the clay from the Zuider Zee embankment was removed to the inside of the dam, but as it still continued to move, the water was let in again; not, however, before it had bulged in on both sides. More sand was then deposited inside the dam, where it had bulged, and the water again pumped out.

For letting the water into the dam, a syphon was adopted. This was 16 inches in diameter, fitted with a foot valve outside, and screw sluice-valve inside.

At one time the dam was subjected to a different kind of strain from any which it was calculated to resist. The water outside, owing to a violent south-west wind, fell to about 8 feet 7 inches below datum, leaving a depth of nearly 7 feet inside the dam. An attempt was made to reverse the syphon, but this being unsuccessful the water bent the dam outwards, opening the laminated waling, as well as the other walings at the joints, to the extent generally of 2 or 3 inches, but no actual rupture occurred sufficient to cause leakage. 'The openings in the walings were afterwards filled up with blocks of wood, and when the water was again pumped out, the outside pressure effectually tightened the work. A second laminated waling of four half timbers of Riga red pine was also added just above the original laminated waling, and was secured with $1 \frac{1}{2}$-inch bolts to the inside ring of piles only, in order to avoid increasing the number of through-bolts. More sand was also deposited inside, until the quantity reached some 33 cubic yards per lineal yard of coffer-dam.

Subsequently the water found its way into the dam, and overpowered the pumps. It first made its appearance as a small stream at the bottom of the pump well. By filling the hole with straw, clay, and stones, and depositing sand against the dam on the outside, the leak was stopped; but it soon burst out again in the pump well, a little on one side of the spot where it first appeared. To prevent disaster, two sluices were opened, and the water let in. These sluices were about 4 feet long by 15 inches deep, their tops being at the level of high water. The sheetingpiles of the pump well were at once drawn, and a row of sheeting-piles of whole timbers were driven across the bad place 
at a distance of about 16 feet 6 inches inside the second ring of the dam, and tied back with whole-timber baulks. The space between this additional sheeting and the dam was then filled in with sand.

The effect of the vibration caused by the pumps working on a stage connected with the dam was considered to be injurious; therefore a new stage was erected in a position clesr of the dam.

The water was again pumped out, and the excavation for the lock was proceeding, when a larige mass of earth broke off inside the dam at a distance of 38 feet from the inner ring of piles, in the line of a small grip which had been made for drainage. The sluice-valves were immediately opened, the water from them being allowed to fall on a bed of fascines laid for the purpose at the spot. The ground, however, between the place where the mass of earth had slipped and the dam soon fell in, leaving the piles bare for a depth of 30 feet, and causing a breach in the dam. An interval of two minutes elapsed from the time the dam first began to bend until the breach opened, and in about three minutes more the space inside the dam was filled with water.

It became evident from these failures that the dam needed further strengthening; this was done chicfly by depositing more sand both inside and on the outside, and driving a fiesh row of close sheet-piles on the outside, at a distance of 29 feet 6 inches from the inner row of piles, to keep the sand in place. Sand-bag buttresses, with layers of fascines, were also constructed inside the dam, when there was sufficient space between the dam and the brickwork.

Outside it always proved difficult to keep the sand from being disturbed by the wash of the waves. Three groynes of pile-work driven on the most exposed side had a useful effect, but the waves still continued to disturb the mound of sand, and it was some time before it could be raised to the water level and covered with fascines.

Much trouble was experienced in winter from floating ice, raking piles were driven outside the dam 10 feet apart, but they frequently broke when huge masses of ice came against them, triangular chocks were spiked at intervals under the outer lower waling, so that the ice might the more readily slide up the waling, and not lift it. When the lake was frozen, the ice was always kept broken round the dam; the result of these precautionary measures was that no damage occurred to the dam. 
At every high tide there was trouble with leakage at the through-bolts, owing to the settlement of the puddle. This leakage tended to disturb the mud and peat under the inside artificial bank of sand. To remedy this as much as possible, every conceivable expedient was resorted to; could throughbolts have been dispensed with, and the puddle reduced in thickness, fewer difficulties would probably have been encountered.

Portsmouth Dockyard Extension-Temporary Dams. ${ }^{1}$ The general arrangement of the dams used on these works is shown by Fig. 23.

The Shallow, or inner dam (Fig. 50), consisted of a single

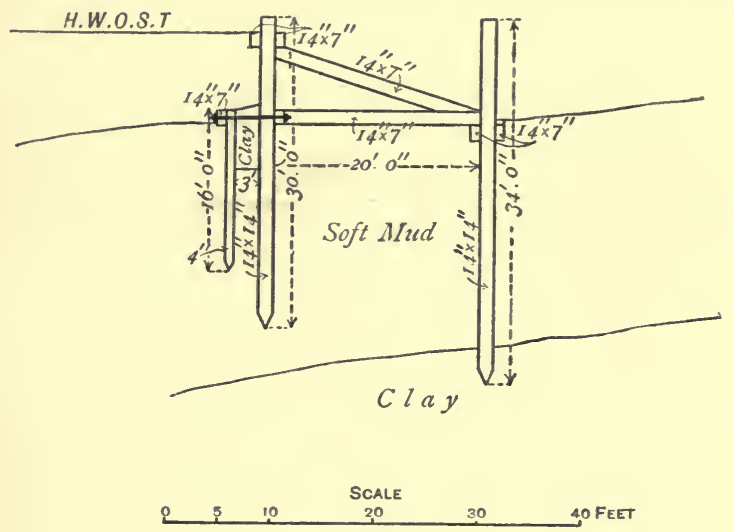

FIG. 50.

row of whole-timber piles averaging about 30 feet long. No shoes were used, as they had only to penetrate soft mud. The heads of the piles were on an average 10 feet above the surface of the mud, or about 2 feet above high-water level. On the inside, close down to the mud, a half-timber waling was fixed. Similar half-timber walings were fixed on both sides about 2 feet below the heads of the piles. Shoring-piles of whole timber, sufficiently long to penetrate the mud and be firmly driven into the hard soil below, were driven at a distance of 20 feet from the dam piles, spaced 9 feet from centre to centre. The shoring consisted of one horizontal and one inclined half-timber, secured to the back shoring-pile and to the upper and lower walings. The horizontal shore was secured with $1 \frac{1}{2}$-inch strap bolts, whilst 
the whole of the other fastenings consisted of $\frac{7}{8}$-inch round iron bolts.

On the outside, at a distance of $\mathbf{3}$ feet from the face of the whole-timber piles, a continuous row of sheet-piling was driven, consisting of 4-inch fir planks 16 feet long driven until the tops were about 1 foot above the mud level on the outside; a halftimber waling was fixed and connected with the dam by $1 \frac{1}{2}$-inch bolts at 9 feet distances, with 6 -jnch cast-iron washers under heads and nuts. The mud was removed from the enclosed space to a depth of 4 feet. The main piles were carefully caulked from the heads to the bottom of the trench, which was then filled in with puddled clay to a height of 1 foot above the original mud level at the sheeting-piles, and slightly higher next the main piles.

This dam was not intended to resist under ordinary circumstances more than 7 feet depth of water; this was, however, exceeded on many occasions by about 1 foot, and in one instance by 3 feet. In consequence of the softness of the mud, the dam did not maintain its original straightness, a very slight difference in the head of water being sufficient to produce a very perceptible effect.

The Outer Dam ${ }^{1}$ (Fig. 51) was very similar to the shallow dam in design, but more substantial. It consisted of two rows of whole-timber piles; in the outer row, the piles were from 20 to 30 feet long, and were driven down to about 2 feet above the ordinary level of the mud; in the inner row, the piles were from 46 to 55 feet long, and stood from 12 to 15 feet above the mud level. Whole-timber walings were fixed on both sides of the piles immediately above the mud level, and connected together by $1 \frac{1}{2}$-inch bolts spaced 9 feet apart. The mud was removed from between the piles to a depth of from 4 to 5 feet. The inner or main piles were then carefully caulked from the heads down to the bottom of the trench, which was then filled in with puddled clay to the top of the outer row of piles, thus covering the tie-bolts from 1 foot to 1 foot 6 inches. Along the top of the main row of piles whole-timber walings were fixed at about 4 feet below the pile heads. Shoring-piles were driven at a distance of 20 feet in the rear of the main piles and spaced 9 feet apart centre to centre. Whole-timber shores, one horizontal and one inclined, were fixed to each back pile. The 
upper end of the inclined shore abutted against the piles and under the upper waling, whilst the lower end rested upon the horizontal shore and against the shoring-piles.

The dam piles were secured to the back shoring-piles, and the horizontal shoring-piles kept in place by long tie-bolts placed immediately over the horizontal shores, and screwed up on castiron washers, 13 inches by 9 inches, webbed at the back.

This darn was also very pliant, and yielded considerably to the varying pressure of the tides, as had been anticipated, but no ill consequences resulted.

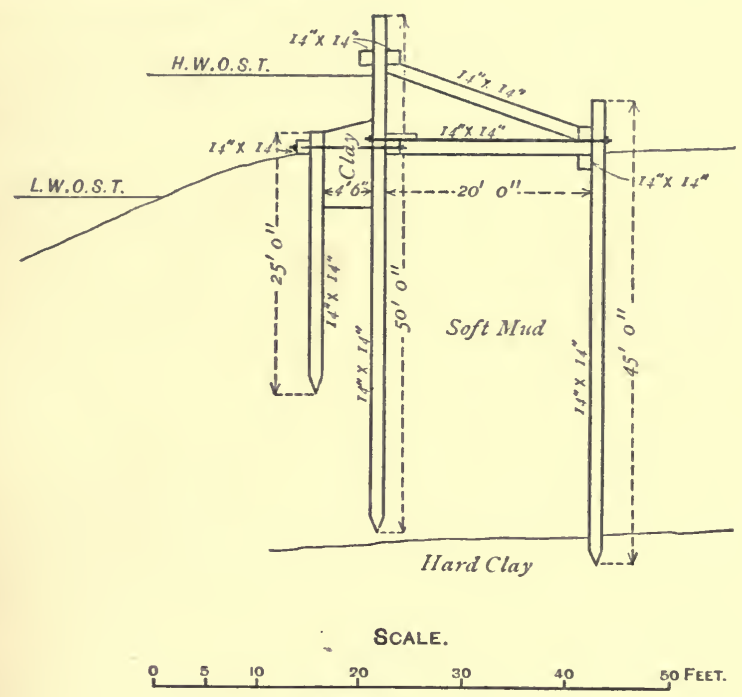

FIG. 51.

A Circular Dam ${ }^{1}$ (Figs. 52, 53), constructed in the steam basin of the dockyard, was designed to maintain the water, in that basin, so as not to interrupt its use while one of its walls was cut away, and a new entrance built to connect the tidal basin with the steam basin.

The dam was constructed to the segment of a circle of 162 feet radius to its outer fan; it consisted of two rows of wholetimber piles driven as firmly into a strong clay as the timber. would endure, or until they met with septaria which the clay contained. They were 5 feet apart in the clear, and were vcry strongly supported by laminated walings of whole timbers cut to the proper curve, the ends breaking joint, a space being 
left between each for oak wedges to be inserted, thus to distribute, as soon as they were finally bolted up, an equal pressure throughout the whole.

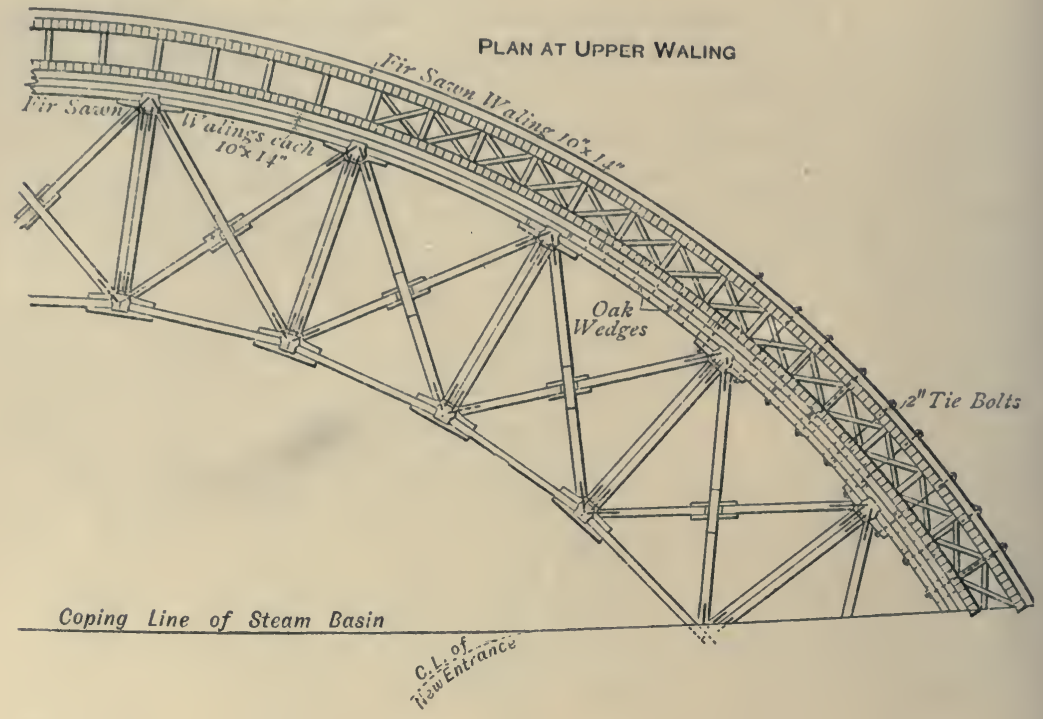

FIG. 52.

The ends of this dam abutted against the wall of the steam basin, chases being cut into the masonry part of the way down

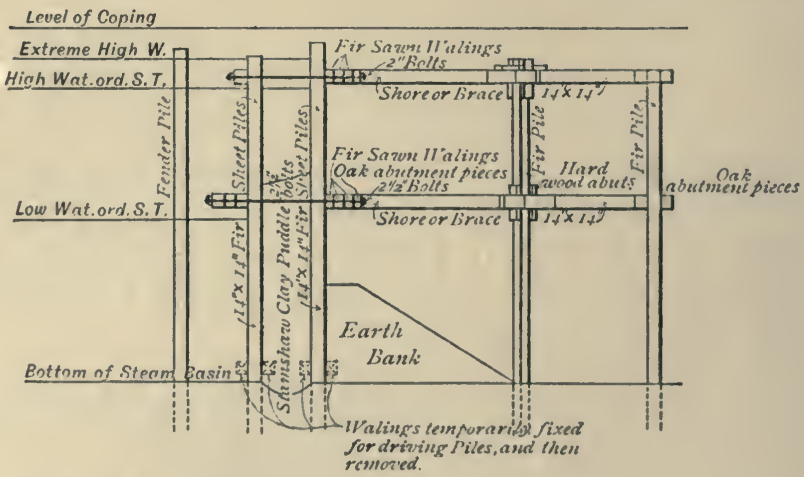

FIG. 53.

for the piles, and recesses were also cut for the ends of the walings. A regular system of diagonal bracing was provided at the level of each waling, of which there were two tiers, respec- 
tively at about 18 feet and 30 feet from the bottom of the basin; the intention of this bracing was to prevent the dam losing its symmetrical form, all the parts being so attached as to resist strains, whether of tension or compression. Beyond this there was no shoring, for the only piles provided within the dam had simply to support the bracing, though of course forming part of the whole.

The ends of all the shores or braces abutted against massive oak seatings, so as not to admit of much compression in any part. After the piling and other timber-work was so far completed, a slight amount of dredging between the piles was done to remove chips or similar rubbish. Stamshaw clay puddle was then filled in to a height of about 2 feet above the lower waling, the inner row of piles having been carefully caulked to about 1 foot below that waling; the clay being rather higher against the inner row, the water from this level was resisted only by the inner row. The outer row of piles had, however, been carried up so as to come above the upper waling with a view to protect the inner piles from injury, and to make the dam more rigid against possible blows from vessels using the steam basin; distance-pieces were also inserted between the upper walings, with diagonals again carefully fitted between them, the farther to carry out this idea. Through the lower walings $2 \frac{1}{2}$-inch tie-bolts, spaced about 6 feet apart, passed, under the heads and nuts of which heavy cast-iron plates, 16 inches long by 12 inches wide, were fixed. These plates were webbed at the back to resist pressure, and had the faces next the timber curved in their length, to avoid their cutting the fibre of the timber when the pressure came on; 2-inch tie-bolts, with plates 9 inches by 13 inches under the heads and nuts, were fixed at similar intervals through the upper walings. The ordinary depth of water against this dam was 29 feet, which was occasionally increased to 32 feet, in order to meet the requirements of some of the heaviest ships in the navy.

Before the water was removed from inside the dam, and consequently before any pressure came upon it, a straight line was cut upon the timbers forming the upper tier of bracing, and so tightly had everything been previously wedged up that not more than about 4 inches deflection was shown when the water was removed and the full pressure of 29-feet head had come upon it. This was near the crown of the arch, and 
became rapidly less toward the ends; and very little farther compression was noticed during the use of this dam. Probably more took place where the pressure was directly greater, but it was not shown by any undue straining, and there were no direct means of testing the amount, the greatest visible strain being the sinking of the washer-plates into the lower waling, and even this was not severe.

When the water had been partially removed, a bank of earth was deposited against the inside of the dam, to about 10 feet above the bottom of the basin, thus coming up to within 8 feet of the lower waling; this had a top of about 3 to 4 feet in width against the dam, with a slope of about $1 \frac{1}{2}$ to 1 ; it was added as a support to the inner row of piles, not that they in any way seemed to require it.

To cnsure perfect accuracy of form, and that no lateral displacement might be possible in any of the piles-which, if it had occurred, would have been fatal to the very intention of its curved form-a temporary third tier of walings was used. This tier was composed of whole timbers, sawn like the rest, to the proper curve. After the gauge-piles had been driven, and the upper walings fixed, these timbers were attached to the gaugepiles, close to the bottom of the basin, by divers, and through them the piles were driven; by this course they could not escape being correctly driven and the true form of the dam preserved.

On the completion of each bay, the temporary walings were removed and refixed in advance of the pile driving.

Limerick Dock. ${ }^{1}$-Fig. 54 shows the dam adopted by $\mathrm{Mr}$. J. Hall, B.E., A.M.I.C.E., in reconstructing the Limerick Dock walls. It consisted of two rows of piles 40 feet long and 12 inches by 10 inches scantling, placed 5 feet apart and driven 10 feet into the ground, and the space between being filled in with puddled clay well rammed. The foot of the dam inside was strengthened by a counter-dam filled with the excavated rubbish, and the whole stayed immediately from the shore.

Dockyard, Chatham.-Fig. 55 shows an embankment formed across the entrance of St. Mary's Creek, Chatham, for the purpose of enclosing the site of the new docks. It was constructed of soil, gravel, and loam, taken from the general excavations and deposited on the soft upper mud, through which it sunk to the denser mud below. 
Calais. ${ }^{1}$ - In carrying out the improvements to the harbour very special precautions were necessary to protect the worksa large portion of which was on the foreshore-from the action of the sea. For this reason the dykes or dams had to be of

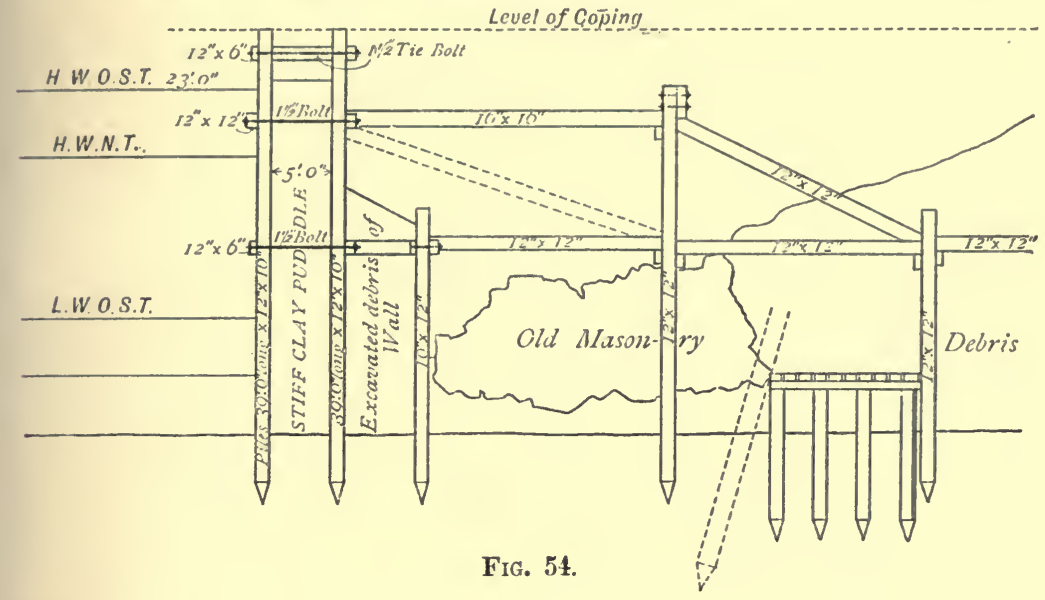

unusual dimensions. The most exposed portion of the work was the protecting embankment of the sluicing basin, the level of the beach at this spot being 11 feet below high water of high spring tides.

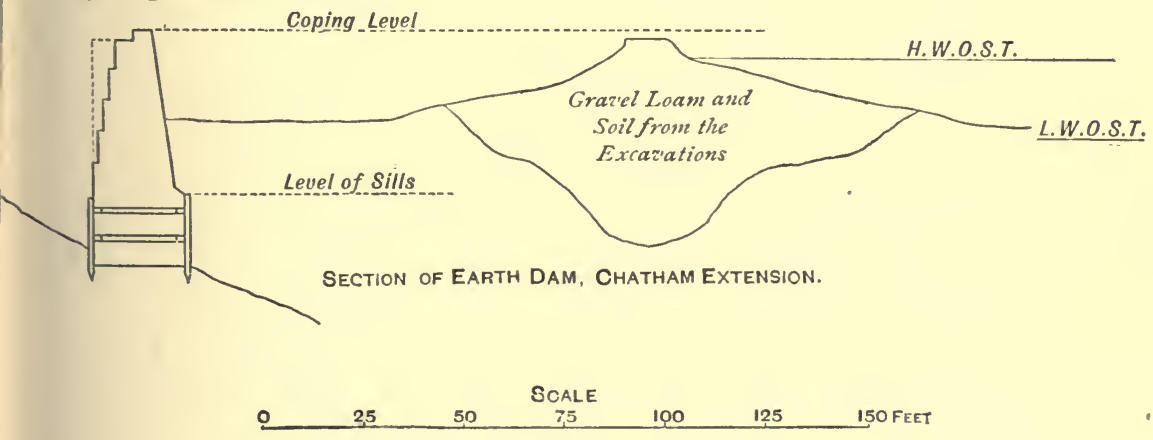

FIG. 55.

The dam (Fig. 56) was formed of a heavy bank of sand with a front slope of 2 to 1, heavily riveted with stone pitching and supported at the foot of the slope by sheet-piling, which was itself protected by a continuous toe of Portland cement

' Engineering, vol. xlvii. pp. 577, 609. 
concrete carried down about 5 feet into the sand. The stone pitching in the face of the slope was 20 inches thick, set in
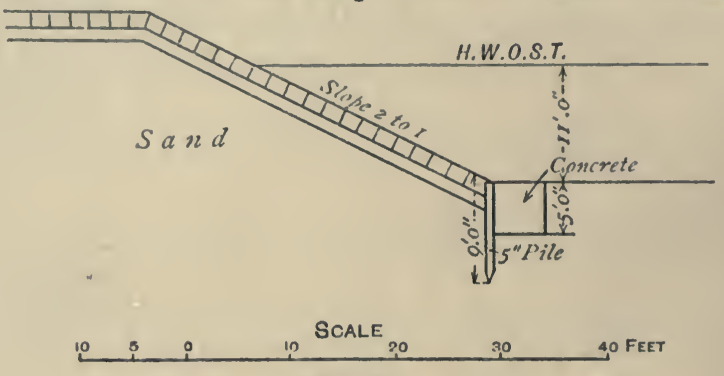

FIG. 56.

Portland cement, bedded on, and well rammed into a layer of puddled clay 1 foot thick, overlying the sand forming the dam. 


\section{CHAPTER IV.}

Water in foundations-Castings for corering boils-Necessity of ample pumping power-Lock foundations, Albert Docks, Hull - Avonmouth Lock foundations -Stopping leaks-Somerset Dock, Malta-Stock ramming-Stopping joints in block-work.

THE best method of dealing with water in connection with foundations is, perhaps, one of the most difficult problems in practical engineering. There are no golden rules, or royal road that can be followed; every case must be dealt with according to its own conditions.

Whenever it is possible to dry a foundation at a not prohibitory cost, it is desirable to do so. In such a case the points mainly to be kept in view are to put all the sumps well down, so that the water may be kept always below the work, and at the outset to provide ample pumping power, in duplicate if possible. Pumps and boilers cannot be expected to work continuously. Stoppages must take place periodically for cleaning, petty repairs, and adjustments; and if the pumping appliances are pressed constantly at their full power the risk of serious breakdown is augmented.

It is wiser and more economical generally to incur a liberal expenditure in this direction in the first instance, than by stinting the pumping appliances to run the risk of an important work being stopped, pcrhaps at a critical tirne, while additional pumps are being fixed.

Stopping leaks is also an important matter, whether in connection with temporary or permanent work. The best preparation for dealing with such difficulties is a knowledge of what has been done in this connection, and the methods which have been successfully adopted under different conditions.

Lock Foundations, Albert Docks, Hull. ${ }^{1}$-The following particulars abridged from a paper by Mr. J. C. Hawkshaw, M.I.C.E., 
with regard to the foundations for the entrance lock at the Albert Docks, Hull, carried out under the direction of Sir J. Hawkshaw, P.P.M.I.C.E., are of special interest, illustrating as they do the difficulties encountered, and the expedients adopted in dealing with clay and sand under exceptional conditions.

The whole length of the entrance is 656 feet, and of the lock 320 feet, between the sills, by a width of 80 feet. The depth of water over the sills is 27 feet 3 inches at high water of ordinary spring tides, and at low water 22 feet 9 inches.

The strata consisted of first a deposit of silt or warp resting on a bed of peat, beneath the peat came two beds of boulder clay divided by a deposit of sand. The clay in both beds was compact and generally without pot-holes of sand and gravel. The upper bed was full of rounded and angular fragments of various rocks, whilst the lower bed was free from stones. The lower clay was separated from the chalk by a bed of sand some 16 feet thick (Fig. 57).

Guided by the strata excavated for the return wall near the railway creek and by borings, it seemed probable that a bed

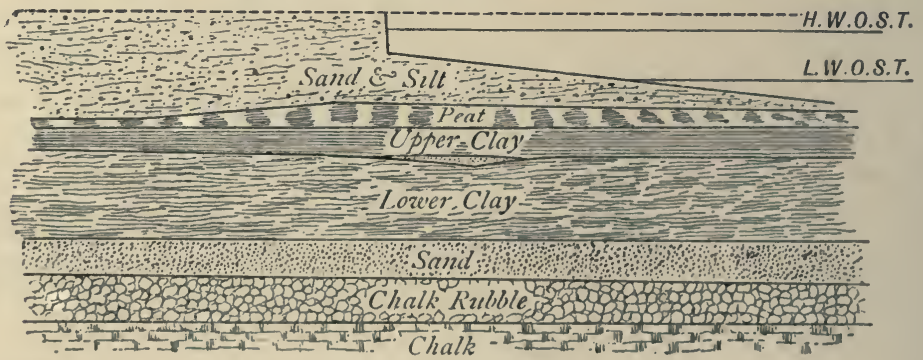

SECTION ON LINE K L, FIGE8.

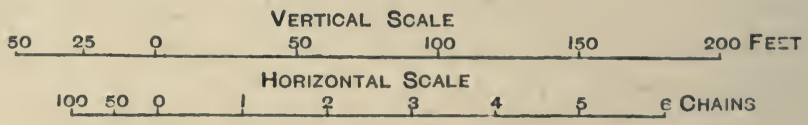

FIG. 57.

of sand about 8 feet thick would be found between the upper and lower beds of clay at a depth varying from 50 to 54 feet below coping. It was therefore decided that the same plan should be adopted for the foundations of the lock as had previously been successfully carried out for the dock walls, i.e. to remove the upper bed of clay and the sand below it, and 
to place the masonry on concrete resting on the bottom clay. This would have given an average thickness of 14 feet of concrete below the masonry.

In accordance with this plan, after the silt had been removed from the greater part of the site of the dock, a cutting was made throughout its entire length on the level of the upper surface of the bottom clay, which was found to dip gradually from west to east.

The bed of sand proved much thinner than had been anticipated, varying from 2 to 3 feet, but passing in many places into pot-holes in the clay. At the east end of the lock, where it was expected that the sand bed would be of greater thickness, the pot-holes were more numerous; but in no case was the sand bed continuously of the thickness indicated by the borings.

When the excavations had so far advanced that a part of the surface of the bottom clay had been laid bare at the east end of the lock, further progress was prevented by the appearance of two springs or "boils" near the line of the sheetpiling which had been driven from the return wall about halfway across the lock entrance. The water from these boils, which was brackish and charged with yellow sand, soon mastered the hand-pumps which were fixed to clear the foundation of water, and necessitated the abandonment of the east end of the lock. A stank was made across the gullet on the site of the east sill to confine the water to that end of the lock. This stank was barely finished before an accident to the river bank at another part of the works, gave the waters of the Humber free access to the lock pit, and delayed the works for three months.

Soon after the boils started, and prior to the breach in the river bank, a crack appeared in the shore piece of the north basin wall, against which the coffer-dam abutted on the north side of the lock entrance. Fear was entertained lest the water from the basin should have found a passage beneath this wall, the foundation of which nearest the basin was built on bearingpiles, and the remainder, near the lock, on concrete resting on the lower bed of clay. That this might be the case appeared likely from the fact that the crack divided the wall vertically near the point where the change in the plan of the foundation occurred. It was thought possible at one time that the crack 
might be caused by the pressure from the coffer-dam at ligh water. That this was not the case was shown by the change in the width of the crack. At high water the crack was scarcely visible, whilst during low water, when the pressure from the dam was least, it increased to the extent of 1 inch in width. As any further set!lement in this wall might have endangered the safety of the dam, the two portions into which the wall was divided by the fissure were connected by four wroughtiron tie-rods 2 inches in diameter, which were secured to the finished portion of the wall adjoining the Railway Creek by lewis bolts and passed through baulks placed across the unfinished end of the wall. No further change occurred in this wall during the progress of the work.

For the further protection of this side of the lock a dain (X, Y, Fig. 5S) was driven from the north basin wall eastwards

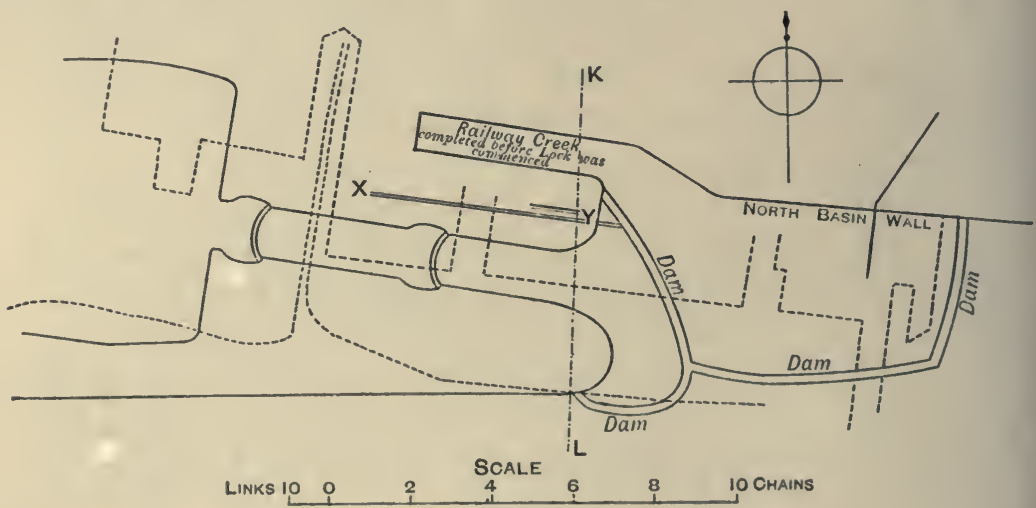

Fig 58.

parallel to the Railway Creek. The dam consisted for the first 80 feet west of the return wall of 2 rows of sawn piles 13 inches square and 5 feet apart, and for the remaining distance of about 300 feet of a single row of sawn piles averaging 47 feet long, and extending to a depth of 55 feet below coping level. It was constructed throughout its whole length with the wharfing of the Railway Creek by iron tie-bars from $1 \frac{1}{2}$ to 2 inches diameter, carried through the bank at a depth of 2 or 3 feet below the surface and at distances of about 30 feet apart. A single row of piles was also driven across the angle formed by the large semicircular dam and the return wall. 
As soon as the water was sufficiently lowered to admit of a pile-engine being got to work, the row of sheet-piling across the dock was continued to the back of the south wall of the lock; a row of sheet-piles was also driven along the back of this wall for a distance of $\mathbf{1 1 0}$ feet. It was considered the more necessary at this time to enclose the east end of the lock with sheet-piling, as no fixed conclusion had been arrived at as to the inmediate source of the boils. This proved eventually to be far more deepseated than it was assumed to be at first, and in no way connected with the superficial strata, through which the piling hitherto driven had penetrated.

After the water had been pumped out of the lock pit, the part excavated for the foundations was found to be filled with mud to the height of the sill level, or to 23 feet above the rails of the lower waggon road. Much of this mud was raised to the level of the top of the river bank by a large chain-pump. To assist in removing this mud, a 6 -inch syphon was laid over the coffer-dam, and by the water from this source combining with it, a continuous stream of liquid mud was kept flowing to the chain-pumps. The drier material was removed by swing and horse roads, and by waggon roads in the ordinary way. At the east end of the lock there was laid bare a large bed of sand deposited by the water flowing from the boils, which as yet gave no signs of activity.

The dam parallel to the railway creek having shown signs of yielding, and as there was no means of strutting from the lock side, inasmuch as all the lower part of the excavation was still filled with mud to a depth of from 10 to 15 feet, preparations were made to drive a row of sheet-piles along the back of the north wall of the lock, at a distance of 20 feet from the foot of the dam, and also two rows across the lock at distances of 74 feet and 144 feet respectively, from the row already driven at the entrance.

Before much progress had been made with this piling, a boil appeared not far from the centre line of the lock and near the site of the east sill. A circular rim of sand about 5 feet in diameter first rose above the surface of the mud and water; in the centre of which a hole extended to a depth of 26 feet. A pile 25 feet long, driven into the centre of this hole, disappeared below the surface of the water after a few blows.

Signs of failing in the dam became more evident; several of 
the tie-bars broke in succession, and on being replaced by new ones, the timber gave way along a line about 20 feet below the pile heads. Owing to this settlement, numerous cracks appeared in the bank between the dam and the creek. This bank was reduced, and the slope behind the dam tightened to as great an extent as was deemed consistent with its efficiency. By this means, and with the assistance of struts from the piles already driven in the lock, the movement in the dam was so far arrested as to allay the fear for the safety of the bank.

An event occurred about this time which threw some light on the origin of the eruptions. It has been already remarked that the water from the boils was charged with yellow sand. The only sand which had been found by boring or otherwise in the lock pit was that composing the thin bed dividing the two clays, and this was grey, loamy, and passing into small gravel in places. A boring in the neighbourhood of the lock extending to the surface of the chalk, which was reached at 109 feet below the quay level, passed through a bed of sand overlaying that formation. The great depth of this bed below the surface, and the thickness of the overlaying clay, seemed to preclude the possibility of the boils being in any way connected with it. To ascertain the nature of the strata underlying the lock pit, a series of borings were taken in three parallel lines along the centre line of the lock and along the centre line of the walls; the borings were 25 feet apart, and extended to 65 feet below the coping. Solid homogeneous brown clay was met with in every case for the lower 10 feet. The borings were made with a common auger, one inch in diameter, and without pipes, excepting in places where the mud had not yet been removed from the surface. At the fourth bore-hole from the piling at the lock entrance the water boiled up charged with yellow sand, similar to that brought up by the former boils. This occurrence seemed to indicate that the boils had their source below the lower bed of clay. To set the matter at rest, a 3 -inch boring was made through this bed; the boring was began at a depth of 43 feet below the coping, and a thickness of 42 feet of solid brown clay was penetrated. This clay was free from water, and the borehole remained dry until the bottom of the bed was reached, when water charged with yellow sand flowed up the hole with considerable force. The water was allowed to rise in a vertical pipe connected with the bore-hole, and ceased to flow at a height 
of $\mathbf{1 1}$ feet above the sill level, or $\mathbf{2 4}$ feet below coping. That the boils had their source in the sand bed, resting on the chalk seemed proved beyond doubt, as the chalk wolds extended over a large area, attaining an elevation of 500 feet, at no great distance from Hull, and giving rise to copious springs at their base. These boils were possibly as much due to land water accumulated in the chalk as to any connection with the sand beds of the Humber. That some such connection, however, did exist is probable, as the water was brackish. A third boil soon appeared, followed within a few days by the fourth, and in consequence of the quantity of sand brought up, the ground began to settle on the north and south sides and east end of the lock. A crack appeared on the top of the river bank about 30 feet from, and parallel to, the line of the river wharfing, and extended eventually 400 feet in length. That part of the bank between the crack and the lock subsided vertically to the extent of 10 feet, and in some places $\mathbf{1 2}$ feet. The settlement was gradual, and the maximum was not reached until the foundation of the lock had been made comparatively secure several months after the first appearance of the crack.

To strengthen the bank on the river side, clay was tipped outside the river wharfing. Mounds of clay about 10 feet high were also formed round the third and fourth boils, and by this means the quantity of sand flowing from them was much abated. The first boil was stopped, and was replaced by a fifth which appeared on the westernmost cross row of piling, and nearer than any other to the chain-pump, into which it poured such a quantity of sand that a bank 6 feet high was soon formed in the river near the place where the water was discharged from the pump. This boil, which was one of the worst, suddenly stopped, and reappeared 10 feet to the east of the piling. In this position the boil continued to flow for four months after its first appearance.

In addition to the two rows of piles already driven across the lock, two more were driven parallel to the centre line of the lock, dividing the east end into six compartments. It was determined to leave those in which the boils were until the last. In the compartments free from them, the sand peat or mud was removed over an area of about 4 yards square, divided from the remaining area by sawn planks 5 or 6 inches wide, and driven by hand. When a bottom of hard clay was found, 
the clay being either the upper or the lower bed, the space was filled with concrete. It may appear that the order of taking the compartments should have been reversed, and that those in which the boils were situated should have been dealt with first; but boils had appeared in all the compartments, and, without doubt, if the boil were stopped in one compartment before that adjoining it had been made good, it would have reappeared in the latter place. Sections of old bore-holes were exposed in the foundations choked up with fine gravel or sand; but time was not allowed for the water to clear out these vents, though within a distance of a few yards it was rising from the same strata with which the bore-hole communicated, to a height of 15 feet above the bottom of the foundation. The compartments on the north side of the losk were filled with concrete without accident; and all went well with those on the south side until the last length to the westward was being excavated, when a boil burst up by the side of the second row of piling; a sinall stank or dam was formed round this boil by driving 4-inch sawn planks on three sides, the piling forming the fourth side. The concreting was then completed in this compartment, with the exception of the part surrounded by the stank, round which clay was heaped to check the flow of water. In order to facilitate the excavation of the eastermmost of the centre compartments, two rows of sheet-piling were driven across it at right angles to the centre line of the lock, dividing it into three spaces 15 feet, 40 feet, and 18 feet wide respectively, the latter being to the westward and partly underlying the sill. The space to the eastward was first excavated to a depth of 13 feet 6 inches below the sill level and filled with concrete. In the centre, beneath the apron, no attempt was made to reach the clay, as the whole of the upper bed had been removed, and it would have required the excavation to be carried to a depth of 20 feet below the sill level to reach the surface of the lower bed of clay. Accordingly the concrete was carried to a depth of 10 feet only below sill level. In the third compartment, which would form the foundation of the back part of the sill, the bottom bed of clay was reached over one third of the area, and the old rails of one of the waggon roads were found at a depth of 19 feet below sill level. In the remaining part of the space, the excavation was carried to the same depth, but the clay hottom was not found, nor was there any trace of 
the waggon road which had passed over this spot. The bottom consisted of a quicksand which could be penetrated with a bar to the depth of 8 feet. This excavation was filled with concrete to a height of 11 feet above the bottom. A boil started shortly after the concreting was began, and filled the foundation with water, which continued to rise through a thickness of 11 feet of concrete. The hand-pumps had been quite inadequate to remove the water which flowed into this foundation, and much of the concrete was impaired, the water having washed the lime out of it. The removal of the concrete was not attempted until two small chain-pumps had been fixed, each capable of lifting 800 gallons of water per minute. After one of these pumps had been started in the foundation, the imperfect concrete was removed for a depth of 5 feet, and the flow of water which had become very strong was confined to two places by concrete made of Medina cement. This was lowered into the foundation in a box containing one cubic yard; an old millstone, with a hole in the centre, was set over one of these vents in a good bed of Medina cement, and though some difficulty was experienced in forcing the water up the hole, this was eventually done. A hole was made in a second stone, which was in like manner set over the second vent. The holes were afterwards plugged up, but not before great trouble had been experienced with this length of foundation, as the water found its way up in many places through the ordinary lime concrete. After the wooden plugs were driven into the holes in the stones, so great was the pressure of the water below that it oozed up through many spots in the neighbourhood. Much trouble was experienced on the east side of this foundation, when two large and several smaller boils had to be confined to holes in stones surrounded by brickwork set in Portland cement.

Of the six compartments into which the east end of the lock had been divided, one only now remained, of which the greater part lay beneath the east sill. No attempt was made to reach the lower bed of clay 20 feet below the sill level. It was decided that a bed of 6 feet below the bottom of the masonry sill would be sufficient. As the masonry would be 9 feet thick, this gave a depth of 15 feet below the sill level for the bottom foundation. The compartment had already been divided into two nearly equal spaces by a row of piles 16 feet 
long driven at right angles to the line of the lock, and the easternmost of these spaces was again divided by a row of sawn 4-inch planks driven in the same direction.

It was decided to substitute brickwork for concrete in this compartment for the following reasons:-When the bottom of the foundation was of sand, boils had on more than one occasion broken out soon after the concreting had been commenced; and it was believed that the fall of the concrete from the barrows on the sandy bottom, which thereby assumed the nature of a quicksand, accelerated their appearance. Moreover, by adopting brickwork, as soon as the requisite depth had been reached over a small part of the area to be excavated, this portion could at once be made secure; whilst, on the other hand, the bottom could not be made secure with concrete until an area of considerable extent had been excavated to the required depth.

In the two areas divided by the sawn planking the following plan was adopted:-As soon as a space about 3 yards square had been reduced to the required depth, a flagstone about 5 feet square was set in a bed of concrete made with Medina cement, the upper surface of the flag being level with the bottom of the foundation; on the centre of this flag a small chain-pump was fixed, and four courses of brickwork set in Portland cement were laid over the bottom of the foundation as fast as it could be excavated, the brickwork overlapping the flag and forming a well-hole for the pump, from which also a channel about 1 foot wide, with a bottom of flagstones, was left up the centre of the foundation; so that in the event of a boil bursting out, the foundation could be drained to the lowest level required, whilst the pump-hole remained secure and available to the last. The eastern half of the sixth compartment was thus covered with four courses of brickwork; the pump was then removed, and the foundation levelled with a layer of concrete 1 foot thick, made with Portland cement. In the western division of this same compartment, a boil which was still in an active state was first surrounded on three sides with 4 -inch planking, driven by a small hand-engine. With the exception of the space, 33 feet by 7 feet, so enclosed, this division was dealt with in the same manner as the last.

To overcome the larger boils, some castings were made which it was thought would be an improvement on the stones perforated, as described above. These castings were in the form 
of a hemispherical shell 3 feet in diameter at the base, with a circular opening 6 inches in diameter at the top continued in the form of a pipe terminating in a flange, to which 6 -inch pipes could be bolted, room biing left for the nuts between the lower

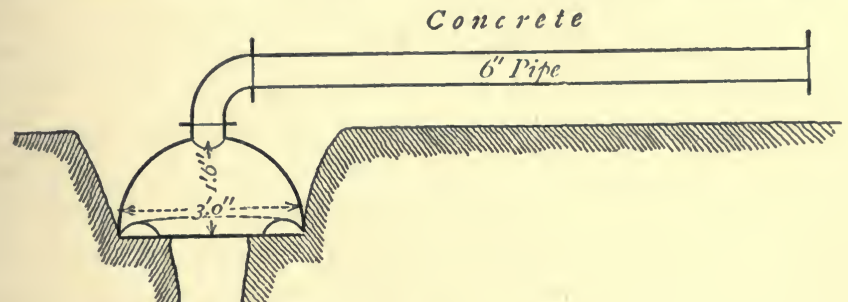

FIG. 59

surface of the flange and the shell (Figs. 59,60). As the excavation was proceeded with in the neighbourhood of the boil within the stank formed by the planking, the flow of water and the quantity of sand increased very much, and it was necessary to keep two chain-pumps at work to remove the water. A 9-foot length of 6-inch pipe, bolted to one of the castings just described, was then lowered into the funnelshaped cavity (Fig. 59), from which the water flowed; the casting sank until the top of the pipe was just level with the water. The space within the planking was half filled with concrete to within 1 foot of the top of the pipe. If the dia-

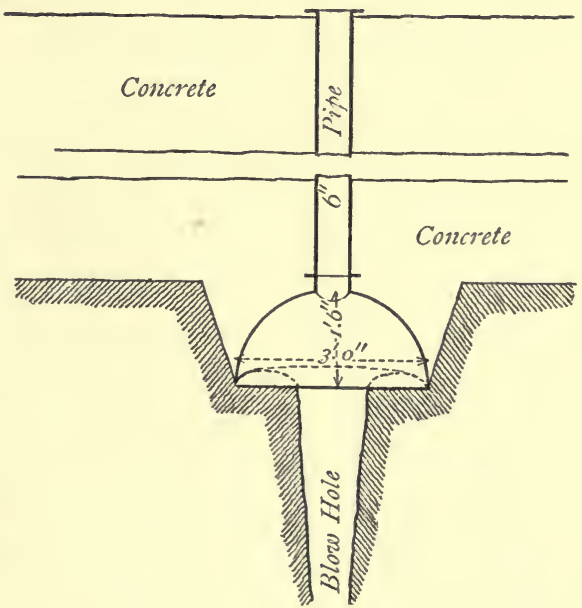

FIG. 60.

meter of the pipe had been larger, the whole of the water would probably have flowed up it, and the concrete would have been sound; as it was, the pipe could not take all the water, which at one time rose in a jet 2 feet high, and much water 
still.flowed through the concrete. The injured concrete in the vicinity of the pipe was covered with brickwork set in Portland cement, space being left between the bricks for the escape of the water flowing from the concrete. This water was gradually collected into one channel, and conducted through a 6 -inch pipe, 9 feet long, laid horizontally and set in bricks and cement; but the combined capacity of the pumps was not sufficient at the time of high water to take all the water, which found outlets through several weak places in the brickwork and concrete.

Two chain-pumps were kept constantly at work during the time of high water. On one of these breaking down, it was quickly sanded up; about 20 cubic yards of clean sand were deposited in the foundation in the course of twelve hours. Short lengths were added to the vertical pipe until the total length above the casting amounted to 22 feet. The top of the upper length terminated at sill-level; at this height the water still flowed, but gradually diminished in quantity, latterly bringing up fine mud instead of sand. When the water ceased to flow-which it did sooner, probably, from boils having broken out in the cutting to the westward-the pipe was filled with Portland cement, and the horizontal pipe was with difficulty plugged up at the low level.

During the time occupied in forming the foundations to the extent just described at the east end of the lock, the cutting throughout the remaining portion had been gradually re-excavated and filled with concrete. A row of sheet-piling had been driven along the south side to sustain the river bank, but as the upper clay had not been removed on the north side, the coffer-dam piling was then considered sufficient. The concrete had been placed on the bottom clay when the upper bed had been removed, excepting for about 50 feet west of the row of piles bounding the compartments. The piles forming this row, of which the tops had been cut off at a uniform level of 4 feet 6 inches below the sill level, had settled, especially towards the south side and the centre of the lock, to the extent in the latter place of 5 feet. As the bottom clay had also sank, the sand and silt overlaying it were only removed to a depth of from 47 to 49 feet below quay level, and the concreting proceeded with. The foundations at this part gave much trouble, and several boils were dealt with. Two of the castings above described were used, to which lengths of horizontal pipes 9 feet long were 
bolted (Fig. 60). This addition was a great improvement, as the site of the boil could, on the casting being placed over it, at once be covered with concrete, and by means of an elbow subsequently bolted to the horizontal pipe, the outlet could be gradually raised vertically by short lengths of pipe as the concreting was proceeded with. When a vertical pipe had been used directly over the casting, it had been found that the water almost invariably came up through the fresh, concrete surrounding the casting; for, as the surface of the concrete had to be kept at least 1 foot below the top of the pipe, in order to leave room to bolt on the additional lengths of vertical piping, the water had less height to rise than would have been the case if it had flowed up the pipe. Another obvious advantage in using the horizontal pipe was the removal of the flow of water to a distance from the concrete. A canvas hose had been tried for this purpose, but the first objection to the vertical pipe applied equally to it.

Four vertical pipes 6 inches in diameter were brought up in the concrete west of the compartments; when the concrete round the pipes had set, additional lengths were bolted to them, until the top of the pipe exceeded the level to which the water would rise. As much cement grout as they would hold was then poured into them.

It had hitherto been found quite useless to attempt to stop even small boils with concrete alone; accordingly, when a boil now occurred in the concrete a shaft of brickwork set in cement was built over it, an opening for the escape of the water being left on the side nearest the pumps. From this opening a narrow channel was formed by two brick walls extending in the direction of the pump to a distance from the shaft depending on the size of the boil and more or less perfect state of the concrete. On the top of the shaft was placed a stone with a hole in the centre. The top of the stone was set even with the finished level of the concrete, which was then put round the brickwork. When this concrete was consolidated, the narrow channel between the brick walls was also filled, and the water forced up through the hole in the stone.

The water flowing through the concrete in the silt was thus confined to five places. Owing to settlement which was still going on, an unforeseen difficulty occurred at the pump-hole. The lime concrete parted from the more rigid layer of cement 
concrete above it, and with it the lower part of the pump-hole. Through the crack thus formed in the walls of the pumphole the water found a vent. To remedy this, a wall of brickwork set in cement was built round the well-hole of the pump to a height beyond which the water would not rise. The space so enclosed was then filled with concrete. The holes in the stones were stopped with wooden plugs; but the plan which of necessity had been adopted for the pump-hole, and also for the cast-iron pipes, was found to be much preferable. When plugs were used, the water was left with a free communication to a point too near the surface, and consequently, when the concrete had been formed to the different levels, and the lower settled away from the upper layer, the brick shafts were divided below the plugs, and the water escaped from between the layers.

The boils in the gate floor were treated in the same way as those in the sills. A dam was placed across the masonry of the invert, and the water was allowed to accumulate at the east end of the lock until it attained a level of 2 feet above the sill. On the water being pumped out, a strong boil was found to have burst up through the cement concrete in the sill, where further settlement had taken place. A wall of brickwork set in cement was built round this boil, enclosing a space of about 4 feet square. It was subsequently determined to remove the east sill 190 feet to the westward, and to cover the abandoned site of the sill, gate floor, and apron, with brickwork set in Portland cement to within 2 feet of sill level. This being done, the brickwork was continued beneath the lock walls at the same level; a portion of the back of the lock walls, to a height of 12 feet, was also built of brickwork set in lias-lime mortar. This brickwork effectually stopped the flow of water. The space behind the lock walls was at once bricked up, and the difficulties with these foundations seemed to be finally overcome.

Fleetwood Docks. ${ }^{1}$-In dealing with the foundations for the dock walls at Fleetwood, where difficulties were met with from springs, the following course was adopted by the engineers. The walls were constructed in timbered trenches throughout. It was originally intended to found them at a depth of 17 feet below the dock bottom, so as to reach hard clay; but the level 
of the clay proving irregular, and, as the overlying fine red silt was for the most part hard and compact when undisturbed, the walls were founded upon it at a general depth of 9 or 10 feet below the dock bottom. In places, however, where the foundations were bad, the walls were founded at a lower level.

These foundations, although they were firm and compact when left quiet, quickly became very unstable if disturbed or chafed in any way; they therefore required careful treatment. Springs were of frequent occurrence and were dealt with according to circumstances; but in a general way they were allowed perfect freedom until the surrounding area of foundation had been made secure, after which they were choked by concrete deposited in mass. In dealing with a spring, concrete was prepared in sufficient quantity upon a platform immediately above it, and, on word being given, it was deposited as quickly as possible, the operation being performed in the course of a minute or two. When the springs carried sand with themwhich was often the case-stable litter was freely used, and weighted down so as to filter the water and hold back the sand.

In the foundations of the passage leading from the Fleetwood Dock to the timber pond, numerous springs caused a good deal of trouble; they threw up large quantities of sand, which it was difficult to check. No attempt was made to stop these springs, but the passage of sand was checked by using straw and stable litter so as to filter the water and keep back the sand.

The foundation was divided into sections or compartments of from 6 to 8 feet square, formed by close boarding driven 12 inches into the bottom, the object being to prevent the sand washing out from beneath the concrete when deposited, and to secure the latter against the wash of the water. Sufficient concrete was prepared to fill each compartment to a height of 3 or 4 feet; when all was ready, this was quickly deposited almost as one mass, whereupon the spring, taking the line of least resistance, immediately appeared in an adjoiring compartment only to receive similar treatment. The springs were in this manner driven to the corner or point first decided upon, and, when the floor had been further strengthened by the addition of concrete, they were smothered without difficulty 
by a sufficiently large quantity of concrete in bulk. As the compartments were filled with concrete, the boards were withdrawn so as to allow the concrete to unite and thus avoid vertical joints.

Alexandra Dock, Hull. ${ }^{1}$ - In the foundations for the lock at the Alexandra Dock, boils which occurred in the bottom of the trenches were dealt with by the engineers in the following manner. In the western trench, the clay was found at 51 feet below high-water springs, or 2 feet 6 inches lower than was anticipated. At one point in this trench a boil occurred which was dealt with by placing an iron pipe in the hole and surrounding it with chalk rubble to the surface level of the clay. This was then covered with Portland cement in bags, and upon this the foundation concrete was laid. The water at first brought up a great deal of sand and fine silt; but eventually, when the concrete had set, it flowed away quite clean and clear through the pipe, and, as the masonry was built up, it was led away by a horizontal pipe to a sump.

The first length of the foundation at the north end of the west trench was excavated in remarkably dry material; the clay being reached at a somewhat low level, and running irregularly across the trench. The bottom suddenly began to heave, and soon the water burst up in two or three places and rapidly filled up the trench, mastering the pumps. Though additional pumping power was provided, the impossibility of pumping out the water to the required level was apparent, not only on account of the great volume of water to be dealt with, but because of the large amount of extremely fine silt brought up with it from below the bed of clay, which was thus gradually undermined, so that the sides of the timbered trench settled very much, and large holes appeared in the adjacent ground, forming fresh exits for the water from below, whilst the material was brought up into the trench through the main blow-hole. These holes were stanched by tipping in clay puddle mixed with stable litter, straw, and bags loosely filled with Portland-cement concrete.

Soundings showed that the bottom of the trench was covered with a layer of silt 5 feet 9 inches thick; while a rod could be put more than 40 fect down the blow-hole.

' M.I.I.C.E., vol xcii. p. 150. 
The total collapse of the trench was threatened. Strong lacings were inserted, while the centre piles and struttings were partially suspended by long beams thrown across the trench.

The pumping was then reduced to the amount necessary to get in a piled foundation for the side walls at the highest possible level. The holes were filled in with chalk, and the whole area of the trench was also covered with it, in order to intercept as nuch as possible the silt brought up by the water. Bearing-piles were then driven between the network of temporary timbering, connected at the top by whole-timber eaps, on which a double thickness of elm planking was laid, forming the foundation of the inner gate recess wall and the heel-post stone. The timber platform was placed as high as the level of the under side of the heel-post stone to reduce the pumping to a minimum, and thereby obviate further ill effects of the boil.

Borings made east and west of the lock showed that the bed of clay was over 15 feet thick, whilst at the blow it was only 2 feet thick.

The excavations for the fuundation of the outer and middle gate platforms was taken in bands about 20 feet wide, the alternate trenches being timbered, and after the masonry had been built to a sufficient height, the intermediate bands were excavated without timbering.

The principal difficulty being anticipated at the inner gate platform, it was proposed to excavate the foundations in small areas enclosed by half-timber, grooved-and-tongued sheeting, but after driving a short length of sheet-piling, about $25 \frac{1}{2}$ feet long, transversely, and two or three gauge-piles in a longitudinal direction, some blows occurred at the surface, which was a little above dock bottom, and considerable quantities of water came up. In a short time several large holes were formed, and some of the sheeting sank down and disappeared. Cast-iron pipes were driven as deep as possible into the two principal springs, and in one of these the water subsequently rose 14 feet above dock bottom, and remained at this level, indicating the upward pressure at this point. Clay puddle was tipped into the large holes and well trodden in, one hole alone absorbing several hundred cubic yards of puddle. The extensive area of the disturbance was manifested by the cracking and settling of the 
east and west dock walls at certain points, and the whole of the work at the northern end of the lock seemed in jeopardy.

The continued flow of water highly charged with silt was likely to lead to further injury, whilst 14 feet of excavation remained to be accomplished for the foundations under the sill as designed. To reach the origin of the disturbance, it was clearly necessary to carry the sheeting lower down; and accordingly, pitch-pine piles were driven so as to enclose the principal blow-holes and disturbed places, and effectually cut off the flow of water into the foundation. The excavations were then made, and the foundations completed without the slightest appearance of water.

Avonmouth Lock Foundations. ${ }^{1}$ - The foundations of this lock rest upon a bed of fine grey sand underlying the clay at an almost uniform level throughout its length, and at a depth of about 6 feet under low water of equinoctial spring tides, or about the level of the bed of the Avon near the dock. The depth of the bed of sand was not ascertained, the trial borings not reaching deeper than 16 feet below low water of equinoctial spring tides; piles were, however, driven to 9 feet below the level of the borings, and as far as pile-driving can be relied upon as indicating the nature of the sub-strata, there appeared to be no change down to that depth. The frequent occurrence of springs in this sand was a source of some trouble and difficulty; most of them were weak, though two or three discharged a considerable quantity of water; but whether weak or strong, they never appeared until the last layer of clay was removed, and the sand laid bare. A layer of clay 6 inches thick was sufficient to keep the water down, but when this was once removed or disturbed the springs burst out; and though the smaller ones were stopped after some weight of masonry had been placed on them, it was impossible to overcome the strong ones, and they had to be provided with permanent outlets. One of the strongest occurred in laying the foundations of the outer round head, on the west side, which for a long time persisted in coming up at the same spot, in spite of every effort to shift it to a less dangerous place. After the wall had been built, it continued to wash up a little sand at the toe of the footings, producing large cracks in the masonry, and causing the whole of the round head to settle downwards about 3 inches. The cracks were filled up

1 M.P.I.C.E., vol. Iv. p. 10. 
with cement grout, and ultimately the spring was forced into another outlet, and further movement of the wall stopped.

In putting in the apron in front of the outer entrance, more springs were met with; some of the most important were dealt with by placing over them vertical wooden shoots about 12 inches square and funnel-shaped at the bottom; whilst horizontal shoots of the same kind were laid through the concrete to take the water to the pumps. On completion of the work, the shoots were filled up by pouring cement grout into them. To ensure this being thoroughly done, a wrought-iron pipe 2 inches in diameter, and about fifty feet long, reaching from the top of the lock walls to the apron, was inserted in the upright shoots and the grout poured through it. By this means all the springs were forced into one outlet, which was made of a cast-iron pipe fitted with a valve at the top, so that the spring water might have relief when the pressure of the tide was not counteracting it.

Stopping Leaks.-The following description of some experiments made by Mr. Kinipple, M.I.C.E., with a view to stopping some bad leaks in a dock entrance are of some interest as showing what can be done in this direction. The work in question was an old graving dock in the west harbour of Greenock, constructed, it is believed, from the designs of James Watt about the year 1785. For some years it was a question, owing to the leaky condition of the entrance, whether reconstruction or abandonment should be adopted, but before deciding, it was determined to try if the case could be dealt with by other means. With this object in view, 3-inch bore-holes, from 1 to 2 feet apart, were put down through the masonry behind the heelposts into the sand for several feet below the foundations. Bore holes were also put down through the inner and outer aprons, close to, and at a few feet from the sill, all of which were sunk well down into the foundations. Stand-pipes were fixed in the various holes, and thick grout of Portland cement was then poured down; the idea being that it would penetrate through the various fissures and open joints, and vertically join the boreholes together, and thereby form in fact a water-tight sheeting of Portland cement. The cement was run in only when the dock gates were open, or when the water was at the same level inside and out, in order that there should be no disturbance of the grout by runs of water, until the cement had set. The result of the 
experiments was satisfactory in every way; inasmuch as before, an 18-inch pump was required to be constantly at work to keep the water down, whilst afterwards only one hour's pumping was necessary in about 40 hours. ${ }^{1}$

The following course was pursued by Mr. J. Kingston, C.E., in constructing a large sea-sluice at the River Glen Outfall, in 1879. In this case the foundations were in quicksand; the aprons and floors were constructed of $3 \frac{3}{4}$-inch Memel planks laid on whole timbers, and secured to them with treenails and spikes, whilst, under the planking and surrounding the timbers, there was 3 feet of concrete. Before laying the planks, every care was taken to render the surface of the concrete with Portlandcement mortar. It was discovered that the act of driving the spikes and treenails had a tendency to shake the mortar away from the under side of the planks, causing thereby leaks to appear. As an experiment, a hole was bored in the floor, and a stand-pipe about 8 feet long inserted, and to the top of which a small hopper was fixed; Portland-cement grout was then poured in, which diffused itself under the floor. A small force-pump connected with a tub for containing the grout was then prepared, and the grout was pumped under the floor with a heavy pressure, until every fissure or space was filled, and the whole of the floor made absolutely water-tight.

In executing some extensive repairs to a large sea-sluice, much the same course was followed by the same engineer. In this case, the foundations were in quick silt, the sill being 6 feet below low water in the river with a tidal rise of 20 feet. The oak planking of the entrance was taken up, and about 3 feet of concrete was got in and brought to within about $\frac{1}{4}$ of an inch of the top of the horizontal timbers. The concrete set very satisfactorily, but, owing to the head at high water, it was impossible to prevent the upward filtration of water from the silty subsoil, and, consequently, the percolation of water between the concrete and the floor timbers. No attempt was therefore made to render the surface of the concrete before laying the planking; the constant streaming of the water would have rendered such a course useless. The $3 \frac{3}{4}$-inch Memel planking was therefore laid on the whole timbers, and secured in the usual way with treenails and spikes with a full $\frac{1}{4}$ of an inch 
clearance between the surface of the concrete and the planking. After the floors were completed in this manner, cement grout was pumped in, soon the leakage from one point and then another ceased, and eventually the whole floor became perfectly tight. ${ }^{1}$

In a case where the water overpowered the pumps, Mr. W. Dyce Cay, M.I.C.E., adopted the following expedient. Instead of trying to overcome the water, it was allowed to rise to the natural level; the excavation was then completed by dredging, and the pile heads cut off to their proper level by divers. The area was then covered with jute cloth, sunk and fastened to the piling, and Portland-cement concrete deposited on it under water by skips opening at the bottom, and brought up to such a height as would keep down the water pressure, and as the work allowed. After giving the concrete time to set, the water was pumped out, and the work finished without further trouble. ${ }^{\text {a }}$

Borings put down to a water-bearing strata, or blow-holes, may frequently be stopped by driving a pipe to the bottom of the hole, or into a superimposed impervious bed, sufficiently deep to ensure a water-tight joint, and allowing the water to rise to the tide level, and then pumping in liquid Portland cement; or, if the pipe is sufficiently large, running down cement mortar, or fine concrete, the pipe being withdrawn as the hole is filled. This latter course has been adopted in cases where the holes were from 300 to 400 feet deep, and 10 to 24 inches in diameter. Provided there is no flow of water, blowholes, borings, or leaks may be effectually stopped by these means. When the holes are small, an expanding screw plug may be worked into the hole sufficiently low down as to be well below the level of the foundations. ${ }^{3}$

For stopping a powerful spring at the bottom of a shaft, Mr. Bateman, M.I.C.E., adopted the expedient of nearly filling bags with shot, and sinking them to the bottom of the shaft. The bags, not being quite full, took their shape one against the other, and effectually overcame the difficulty.

This would be a valuable expedient in cases where a great weight is required within a limited thickness or depth to withstand hydrostatic pressure.

Somerset Dock, Malta. ${ }^{5}$-During the construction of the

${ }^{1}$ Engineering.

${ }^{2}$ M.P.I.C.E., vol. xcii. p. 177.

3 Ibid., vol. xli. p. 120.

4 Ibid. $\quad$ Ibid., vol. xxxiii. p. 358. 
Somerset Dock, at Malta, an expedient, resorted to with the view of stopping the flow of water from a fissure which gave a great deal of trouble, is described by Mr. C. Andrews, M.I.C.E., in his paper on that work, and of which description the following is an abridgment:- "The removal of the rock round the main fissure, which had been left at 34 feet below the sea level, until the invert (of the entrance) had been set, being proceeded with, the discharge under so great a head increased daily, wedges were driven in, but new openings were formed which increased the evil. The pumping power available was collectively 143 horse-power, and the discharge from the fissures amounted to 7500 gallons per minute, but the labour of keeping so large a number of engines and pumps in repair, under incessant work, became so great that the water could not be kept down for any practical purpose lower than 32 feet below the level of the sea. To have obtained additional engine and pumping power from England would have required some months, during which a great outlay would have been incurred, or the works must have been wholly suspended at a critical point. These considerations led to an effort being made to check the flow in the following manner. The water was allowed to rise to 28 feet below sea level in order to relieve the pressure. A stage was then erected, from which a guide-box was lowered over the

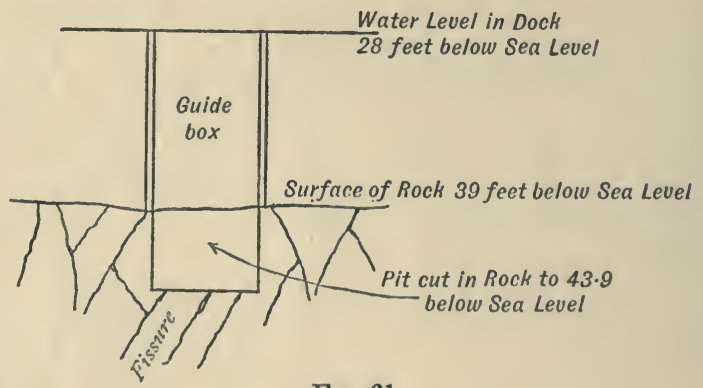

Fia. 61.

fissure; within this guide-box a chisel 21 feet long was worked by a ringing engine, by which means a pit was cut in the rock to the level of 43 fect 9 inches below the sea (Figs. 61, 62). The bottom of the hole was then roughly levelled and squared by a diver. A block of limestone 6 feet 6 inches by 3 feet 6 inches by 1 foot 5 inches having been prepared, a thick cushion or bed of Pozzuolana mortar, protected by canvas, was secured to 
the under bed, and the whole lowered into the pit and over the main fissure (Fig. 63). After being carefully set in place and rammed down, the space all round between the stone and

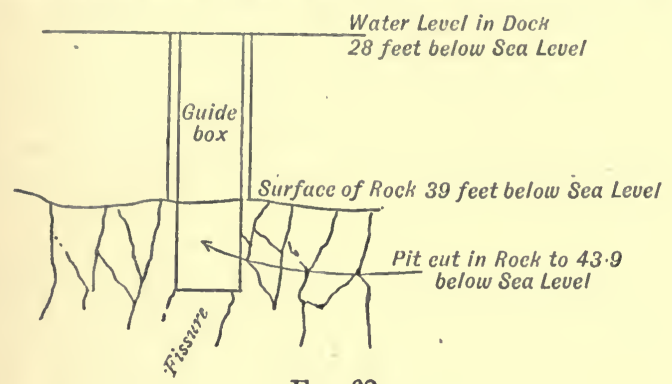

FIG. 62.

the rock was closely packed with wedges well driven down. This checked the flow, and enabled the water to be lowered. Other parts of the same fissure, but which could be got at as soon as the water was lowered, were covered with flat stones in the manner shown in Fig. 6t. The course followed was altogether satisfactory, and ultimately enabled the water to be completely brought under control, and the lock removed to the extent required without

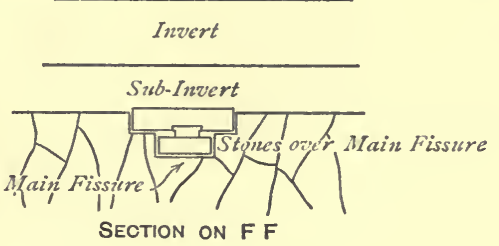

Fig. 63. further difficulty. What leakage remained was collected in a channel cut in the extra masonry, and led away to drainage pipes.

Stock Ramming.-Mr. W. R. Kinipple, M.I.C.E., strongly

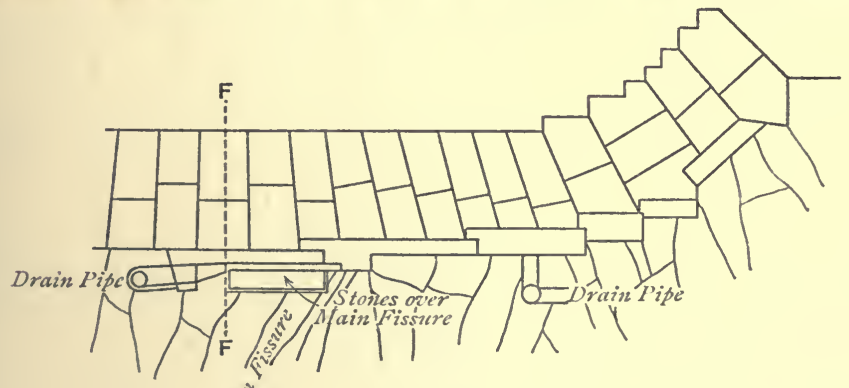

FIg. 6t. 
advocates stock ramming as a means of stopping leaks under permanent structures, or securing or underpinning the foundations of works, which, placed on clay or clayey strata, show signs of settlement.

To carry out this operation, holes 3 inches to 6 inches in diameter are bored at intervals of from 5 to 10 feet, according to circumstances, to the bottom of the work; into these holes pipes are placed extending some inches into the strata beneath (Figs. 65, 66).

Clay worked up with cement or hydraulic lime, sand mixed with iron filings and sal ammoniac, partly set Portland cement,

Quay Wall

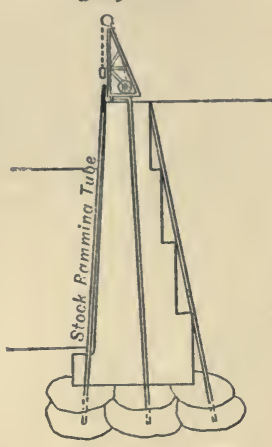

Fig. 65 .

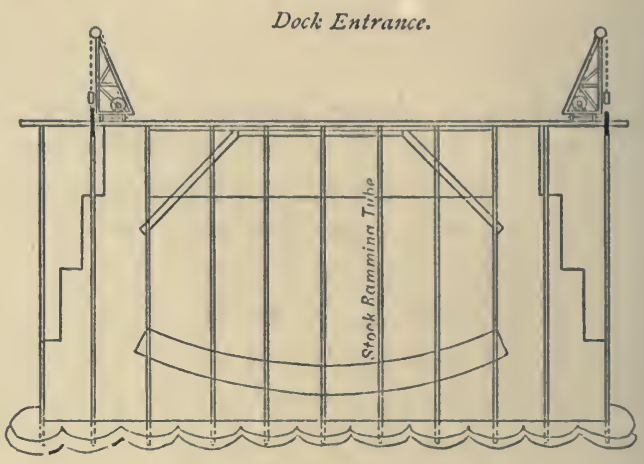

Fig. 66.

or fine Portland and Medina cement concrete is then made up into convenient sizes to handle, and rammed down through the pipes by a heavy ram, worked by a hand or steam ringing-engine, so as to force the material under the foundation and into the soft strata below. ${ }^{1}$

Stopping Joints.-Before grouting under water, Mr. W. R. Kinipple, M.I.C.E., ${ }^{2}$ adopts the following methods of stopping open joints in concrete-block work. For horizontal joints between blocks, comparatively close canvas bagging is forced in a few inches and firmly caulked, similar to caulking ordinary seams of planking.

In vertical joints, the sides are trimmed down or cut away when necessary, and slightly dovetailed in order to give a hold for the stopping. For the narrower openings from 2 to 4 inches wide, thin canvas cases, making rolls of about 6 inches diameter, are used. These cases are partly filled with cement 
paste, and lowered down the prepared joint, and afterwards filled up with cement, which is rammed down solid whilst soft into the dovetailed opening; the ramming causes the bag to project a little on the face of the work, as shown by Fig. 67 .

In the case of wider joints, which are also trimmed and dovetailed, larger bags are inserted. To prevent the bag spread-

Sketch shewing method of Stopping or Caulking Small Foints

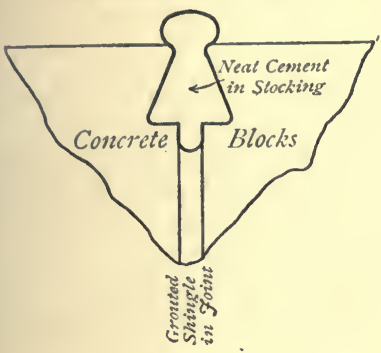

Frg. 67.
Sketch sheriving method of Slopping

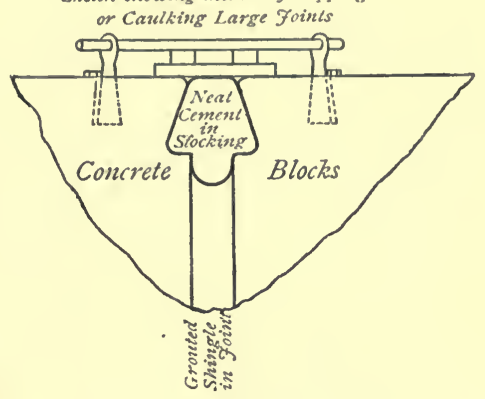

FIG. 68.

ing out in front, a plank is fixed in front of the joint. This plank is held in position by a bar passed through lewised eyebolts, fixed in the face of the work (Fig. 68).

For still larger joints, up to as much as 2 feet wide, the sides are dressed down and dovetailed as before. Small bags of neat cement are then stacked on top of each other and rammed tight, so as to fill up the dovetailed space and joints between the bags: 


\section{CHAPTER V.}

Dock and Quay walls-Angle of repose of different materials-Actual lateral pressure of earthwork-Experiments made at Chatham-Experiments made by Sir B. Baker-Use of counterforts-Backing to walls-Curved batter to wallsDepth of water alongside-Veneering-Quay walls, Greenore-Buckey dock walls-Basin walls at Alexandra Dock, Hull-Calais basin walls--Southampton tidal basin walls-Wharf wall on river front, New York-Cylinders used at Glasgow-Walls on the Danube-At Bordeaux, Bombay, Rouen, Gourock, Brest, Fiume, Dublin, Greenock, Spezzia, at the mouth of the Rhone-Pola basin walls-Timber wharfing.

A KNOWLEDGE of the actual pressure of earthwork is of the greatest importance. It affects not only the stability of retaining-walls generally, but the strength of tunnel linings, the timbering of shafts, tunnel headings, deep trenches for retainingwalls, and many other works of a like character and everyday practice.

In no branch of engineering is there such a lack of exact experimental data as that referring to the actual lateral pressure and strains to which retaining-walls are subjected, or one in which the individual judgment has to be exercised so fully as in the design and construction, a fact which is greatly accentuated in the case of dock and quay walls.

The mass which it is theoretically understood a wall has to support, is shown by Fig. 69, where $a b$ is the vertical height

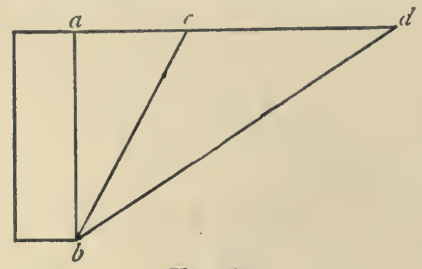

FIG. 69. of a wall, backed up by a material having a natural slope or angle of repose which is indicated by the line $b \quad d$. If, however, the wall were to be removed, the backing would not fall away to the full extent of the natural slope $b d$, but along a line of rupture bisecting the angle of repose, as $b c$; therefore the maximum thrust which the 
wall has to resist, and tending to overturn or push it forward, is due to the weight of the angular mass $a b c$, and varies greatly with the character of the material forming the backing.

The angle of repose, or natural slope, is the inclination which any material will assume on being cast into a heap. The following table ${ }^{1}$ gives the angle which different materials may be expected to take:-

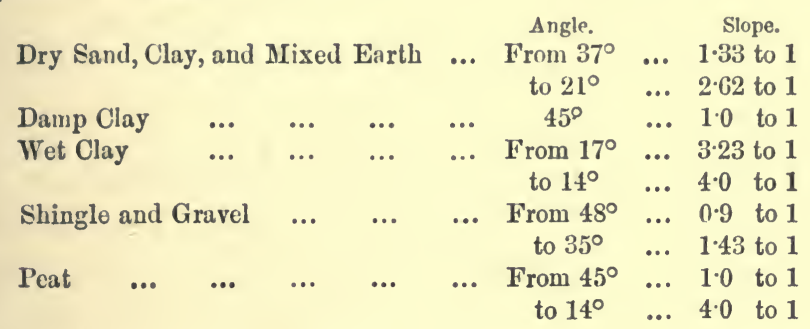

It would, however, be unwise to trust too implicitly to these figures; therefore, the material to be dealt with should be in all cases carefully examined and, if necessary, tested under different conditions before deciding upon the angle of repose to be adopted. A material perfectly suitable for backing up a wall under favourable conditions may become saturated before a sufticient time has elapsed for it to become thoroughly consolidated and, in consequence, reduced to a condition by which the thrust on the wall would be very greatly augmented. Clay is perhaps the most treacherous material to deal with as backing, inasmuch as on exposure it is liable to expand; and under the influence of wet, to slip away to almost any angle.

Sir B. Baker, in a paper read before the Institute of Civil Engineers, on "The Actual Lateral Pressure of Earthwork,"2 questions the accuracy of the generally accepted theory that the mass to which the lateral thrust is due is found by bisecting the angle of repose; and demonstrates by direct experiment and from practical experience and observation on work of both a permanent and temporary character that the actual pressure to which a wall is subjected is only about half that indicated by theory.

Experiments made at Chatham ${ }^{3}$ many years ago by Lieutonant Hope, R.E., with coloured sand in a vessel with glass

1 Rankiue's " Manual of Civil Engineering."

II.P.I.C.E., vol. 1xv. p. 140. Ibid. 
sides, did not uniformly confirm the usual theory that the angle of pressure of maximum thrust is half that contained between the natural slope and the back of the wall. Thus the line of separation was found to be at an angle of $24^{\circ}$ with the vertical, instead of $28^{\circ}$. Again, with a gravel bank 10 feet high, the line of separation ranged from 3 feet 8 inches to 5 feet 8 inches from the back of the wall; whilst, as the natural slope was $1 \frac{1}{3}$ to $\mathbf{1}$, the distance should have been 5 feet in all instances, if Cnulomb's theory applied strictly to even such exceptionally favourable materials as dry sand and shingle.

Experience has shown ${ }^{1}$ that a wall a quarter of the height in thickness, and battering from 1 to 2 inches per foot on the face, possesses sufficient stability when the foundations and backing material are both satisfactory. Sir B. Baker prefers, however, to say that experiment has shown that when the backing and foundations are favourable, the actual thrust of good filling is equivalent to that of a fluid weighing about 10 lbs. per cubic foot; but to allow for variations in the ground, vibration, and contingencies, a factor of safety of 2 should be adopted. Therefore, any wall under ordinary favourable conditions should be able to sustain a $20 \mathrm{lbs}$. fluid pressure, or in other words, a pressure due to a fluid weighing $20 \mathrm{lbs}$. per cubic foot, which will be the case if the thickness is made a quarter of the height.

'The results of experiments carried out by Lieutenant Hope, R.E., ${ }^{2}$ and General Pasley, R.E., at Chatham, justify the conclusion that a properly built wall, in mortar or cement, just balancing the theoretical pressure, would really have a factor of safety in the ratio of 2 to 1 .

Experiments made by Sir B. Baker ${ }^{3}$ prove that a wall which, according to the ordinary theory, would be on the point of being overturned by the thrust of a bank of large boulders would in fact have a factor of safety of 2.5 to 1 .

Sir B. Baker ${ }^{4}$ draws attention to the fact, which must also have been observed by many who have had to deal with construction, that the methods adopted in temporarily stacking and storing materials, coal, quarry rubbish, etc., where rough-andready retaining-walls are run up with the larger portions of the same materials, built up dry, and with the least expenditure

I M.P.I.C.E., vol. $1 \times \mathrm{vv}$, p. 183.

Itid., p. 156.
\& Ilid., p. 149.

- Ibid., p. 141. 
of labour that everyday experience justifies, afford a very close measure of the actual lateral pressure of the materials retained.

A wall may fail by settling bodily owing to unstable foundations, turning outwards at the top due to the same cause, or to the resulting direction of the thrust due to the vertical pressure of the wall and the horizontal effort of the backing cutting the base too near the toe, or to sliding forward bodily, owing to the back pressure overcoming the frictional resistance at the base. A wall efficient in every way as regards dimensions, foundations, and backing, may move in consequence of the full pressure being brought upon it when the work is in a green state, and therefore in its weakest condition. Hence arises the desirability, especially in dock works, of using a quick setting material for the mortar, such as Portland cement, or allowing ample time for the work to consolidate and set before the full pressure of the backing is brought against it.

Wharf and dock walls generally are subjected to conditions altogether different from those affecting ordinary retaining-walls, and have, therefore, to be dealt with exceptionally. Heavy traffic often setting up strong vibration, the erection of buildings and the depositing of heavy merchandise upon the wharf have to be taken into consideration in determining the section of wall to be adopted; in addition, there is the contingency of the dock having at some time or other to be emptied for cleaning or repairs, in which case additional strain would be thrown upon the walls, as they would then probably be called upon to bear an abnormal pressure, bearing in mind that it is practically impossible to prevent in all cases the accumulation of water at the back of a dock wall.

Mr. Giles, M.I.C.E., ${ }^{1}$ is of opinion that for dock walls quality is of secondary importance compared with quantity; the desideratum being weight to resist the lateral pressure, and that a wall should be constructed strong enough to carry a head of water equal to its height. A frequent error is in not making the base wide enough and in not putting a sufficient toe.

It may be necessary in cases when the backing is exceptionally bad, and is likely to assume a semi-fluid condition, to provide for a still greater pressure, to be arrived at by substituting the weight per cubic foot of the saturated material forming the backing for the weight of water. 
Water ${ }^{1}$ naturally gravitates to the foundation of a wall, and softening of the strata commences. Owing to the lateral thrust of the backing, the pressure is not uniform, and instead of settling regularly, the outer edge or toe of the wall settles quickest, and the top of the wall is thrown forward.

Water will act as an admirable lubricant in diminishing the frictional resistance obtaining between the bottom of a wall and the ground on which it rests, and thus facilitate a forward movement. The same softening, due to saturation, may reduce the ground in front of the toe to a condition in which it is easily ploughed up by the advancing wall.

In designing dock walls there is a general tendency to make them wider at the top than is actually necessary for stability, and to reduce the width at the bottom as much as possible, a course by which the centre of gravity is raised higher than it should properly be, and the tendency to move outwards at the top augmented. This widening of the top is due in some measure to the necessity of providing a substantial coping to carry fairleads, mooring-rings, etc., whilst the base is reduced on account of the additional expense that a wide foundation would entail. Generally, it would be better to narrow the wall at the top as much as possible and to spread the base more, so as to distribute the weight over a greater area, and thus increase the resistance to sinking. Sir J. Rennie ${ }^{2}$ adopted the expedient of hollow walls, in order to secure a greater supporting area without increasing the quality of material.

Mr. A. Jacob, ${ }^{3}$ B.A., M.I.C.E., gives the following as a good general rule for the mean, top, and bottom proportions of a wall designed to sustain water, or earth in a semi-fluid condition, the height being represented by unity: top, 0.3 ; middle, 0.5 ; base, $0.7 .{ }^{4}$

The use of counterforts at the back of a dock wall, unless under exceptional circumstances, and when placed very close together, is of very doubtful utility. In practice, it has been found that they frequently separate from the body of the wall owing to defective bond. When, however, Portland-ccinent mortar, or concrete is used, this defect may be looked upon as no longer possible, provided the work in the counterforts is

${ }^{1}$ M.P.I.C.E., vol. $1 \times \mathrm{xv}$. pp. 167.

2 "Lives of the Engineers," vol. ii. chap. vii. p. 207.

" "Practical Designing of Retaining-walls," by A. Jacob, B.A., M.I.C.E.

- Note-these proportions apply more to dams than to rctaining walls. 
carried up simultaneously with the body of the wall. Exceptionally, they may be assumed, if carried well back, to increase the grip on the bottom, and bond the wall with the backing to some extent, or where the ground is very solid they may be of great use in holding or keying the wall back to the backing, and so admitting of a reduction in the thickness of the facework; but practically, under ordinary circumstances, they add to the difficulty and cost of construction without affording equivalent advantages. In the majority of cases, the same mass of material would be far more usefully employed in widening and deepening the base, or in providing a substantial protecting toe, or apron, in front.

In putting in backing, it is of the first importance that there should be no continuous sloping bed between the filling and the natural ground, otherwise the whole wedge will have a tendency to slide. In all cases, therefore, the natural ground should be stepped and the filling deposited in layers inclined backwards from the wall and well rammed; this treatment will tend to increase the angle of repose.

The front profile of a dock wall must be designed with some regard to the convenience of the shipping that will use the dock. An excessive batter is objectionable, inasmuch as the tendency is to throw the side of a vessel further from the wall than is convenient, and entails the use of cranes with longer jibs. Convenient and ordinary batters are 1 in 8 or 1 in 12 .

A curved batter, particularly of short radius, is unsuitable for tidal basins, especially where the rise and fall of tide is considerable. The object of a curved batter is to increase the stability of a wall by bringing the centre of gravity nearer the back and somewhat lower; practically the advantages are problematical, they are more difficult to construct and add to the cost.

Where a curved batter is adopted, the radius is usually two and a half to three times the height of the wall, and the centre of the curve should be level with the top of the coping, by which arrangement a portion of nearly perpendicular face is ensured for ships lying alongside.

Very long straight walls without a break often appear to have a slight deviation outwards from the straight line; this apparent defect may be much minimized by giving to walls of over two or three hundred feet in length a very slight curve inwards at the coping level. 
The following remarks, bearing specially on dock walls, are taken verbatim from Sir Benjamin Baker's paper on "The Lateral Pressure of Earthwork." 1

"A dock wall is subject to far greater contingencies than an ordinary retaining-wall, and the required strength will be included only within correspondingly large limits.

"Hydrostatic pressure alone may more than double or halve the factor of safety in a given wall. Thus, with a wellpuddled dock bottom the subsoil water in the ground at the back of the walls will frequently stand far below the level of the water in the dock, and the hydrostatic pressure may thus wholly neutralize the lateral thrust of the earth, or even reverse it.

"On the other hand, with a porous subsoil at a lock entrance, the back of the walls may be subject, on a receding tide, to the full hydrostatic pressure due to the range of tide plus the lateral pressure of the filling.

"Again, the water may stand at the same level on both sides of the wall, but may or may not get underneath it. If the wall is founded on rock or clay, there is no more reason why the water should get under than that it should creep through any stratum of a well-constructed masonry or puddle dam; and, under these conditions, the pressure of the water will increase the stability by diminishing the lateral thrust of the filling.

"With rubble filling, assuming the weight of the solid stone to be $\mathbf{1 5 5}$ pounds per cubic foot, and the voids to be 35 per cent., the weight of the filling would be 100 pounds per cubic foot in air, and 59 pounds in water, whilst the lateral thrust will be that due to the latter weight.

"If, however, as is perhaps more frequently the case, the wall is founded on a porous stratum, the full hydrostatic pressure will act on the base of the wall, and reduce its stability practically by about one half. Thus, the 30-ton concrete-block walls on rubble mounds at Marseilles and elsewhere have the stability due to a weight of say 130 pounds per cubic foot in the air, and 66 pounds per cubic foot in sea-water; but the rubble filling at the back of the wall, being similarly immersed, is also reduced in weight, and consequently thrust to a corresponding extent, so the factor of safety is unaffected.

"In walls with offsets at the back and water on both sides, 
the stability will be much increased by the hydrostatic pressure on the tops of the offsets should the wall rest on an impermeable foundation. ${ }^{1}$ It is generally assumed in theoretical investigations that the weight of earthwork superimposed vertically over the offsets should be included in the weight of the wall in estimating the moment of stability, but the author (Sir B. Baker) found no justification in practice for this assumption. He had invariably observed that when a retaining-wall moved by settlement or otherwise, it drops away from the filling, and cavities are formed. Settlement of but $\frac{1}{32}$ of an inch, after the backing had become thoroughly consolidated, would suffice to relieve the offsets of all vertical pressure from the superimposed earth, and the latter cannot therefore be properly considered as contributing to the moment of stability.

"A wall with deep offsets at the back is not a desirable form when the foundations are bad, and when consequently the pressure over the foundations should be as uniform as possible, so that a settlement should take the form of a uniform sinking, and not a tilting forward of the coping by reason of the toe sinking quicker than the back of the wall."

It is important, especially when dealing with a foundation of at all a yielding character, to gradually carry up the walls by regular lifts, so as to distribute the weight as uniformly as possible over the whole area of the foundation.

All works naturally subside to some extent as they become consolidated; therefore, if a portion is carried up very far in advance, it comes to its bearings before the adjoining portion is completed, with the result that the latter being worked to the gauge of the older portion, in its turn subsides and shows an unsightly crack at the point of junction. This will apply more to works executed with lime-mortar than when Portland cement is used, but at the same time it applies to a greater or less extent to all works.

Depth of Water alongside.-In determining the depth to be provided alongside a wharf wall at extreme low water, and consequently the total height of the wall, it is necessary to take into consideration, not only the maximum load-draught of the largest class of vessels to be accommodated, but also the exposure of the wall, and to what extent the water level is likely to be affected by high winds, which set up a send or vertical motion

1 Rankine's “Manual of Civil Engineering," p. 402. 
of the water within the basin. Therefore, in dealing with outer wharf walls such as in a tidal basin, or walls in any position where the water level is likely to be influenced by outside swell, it is necessary to provide a greater margin of safety between the greatest draught of ships and the basin bottom than is the case in an enclosed basin where the water is practically quiescent. In basins, or alongside wharf walls, when this precaution has been neglected, a slight send only may expose ships to a considerable amount of risk.

Veneering.-In dealing with some of the sandstone rock met with in carrying out the dock extension at Liverpool, Mr. G. F. Lyster, M.I.C.E., adopted a method by which a very sound system of "veneering" was attained."

The rock was cut away to a nearly vertical face at a distance of 2 to 4 feet behind the face line of the stonework with which it was to be veneered. At distances of about 20 feet apart along the line of the wall excavations were made from coping to foundation levels in the form of counterforts. They were 5 feet in width by 4 feet in depth, and were dovetailed in shape from top to bottom. Into these were inserted large blocks of ashlar, also cut dovetail, so as to fit the excavated chamber, and shaped dovetail outwardly to interlock the masonry panels which intervened between the counterfort stones. The whole, being of sound selected stone, presents to the eye the appearance of a wall of ordinary character, and is so interlocked and held in place by the dovetail jointing that no possible failure of the panels can occur (Figs. 70, 71).

Quay Wall at Greenore. ${ }^{2}$-In constructing a quay wall at Greenore, Mr. J. Barton, M.I.C.E., adopted the following method. It was intended at first to form the whole of the foundation up to low-water level with Portland-cement concrete, deposited in a soft state through the water within close sheet-piling, and a short length of 30 feet was commenced and carried out in this way. In consequence, however, of some defects having been discovered in the face of the work it was considered advisable not to proceed further.

The face below the water level was then formed of concrete blocks, set in place by divers, and backed as far as the piling had been driven by soft concrete deposited through the water as before. The face blocks, 4 feet 8 inches by 4 feet by 3 feet, and 
5 feet 7 inches by 3 feet by 2 feet 3 inches, and the weight about $3 \frac{1}{2}$ tons each.

Beyond the sheet-piling, the rear face was formed of concrete in bags, each containing a cubic yard. The bags were made to fit the skips, which opened at the bottom; when the bag was filled, the canvas was laid across the top and quickly sewn up; the skip was then lowered from a gantry, and the bags placed in position by divers. The hearting between the front and back faces was

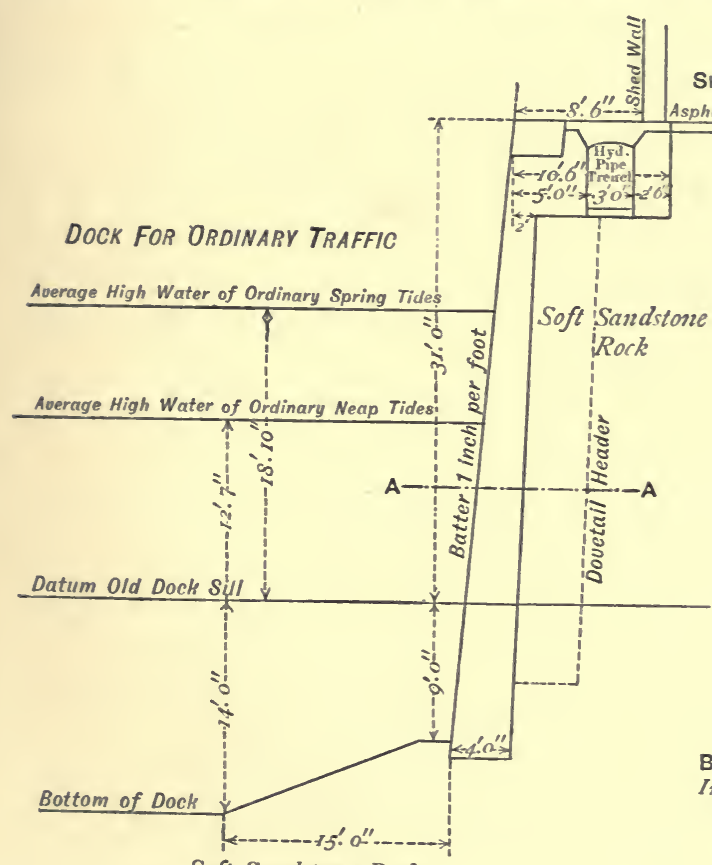

Soft Sandstone Rock

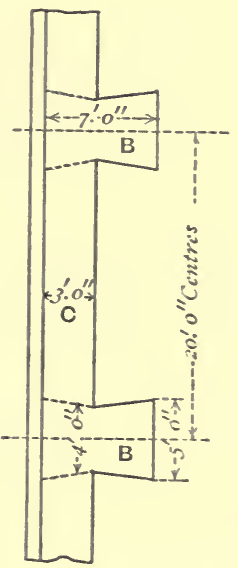

B B. Doretail Headers to retain Intervening Masonry Panel C PLAN AT A A.

Fig. 71.

Fig. 70.

HERCULANEUM DOCK MASONRY FACING TO SANDSTONE ROCK

filled in as the work progressed with soft concrete deposited by the skips (Fig. 72).

The outer or sea end of the foundation up to the water level was formed of concrete blocks weighing 100 tons each. 'These blocks were formed in timber moulds constructed of 3-inch planks, and placed just above low water. Their size was regulated by the fact that they were to be lifted by flotation before high water. Each block was the full thickness of the wall, and constituted a 10 -feet length half the height of the foundation (Fig. 73). 
The blocks were lifted by two barges fitted for the purpose with a suitable stage and winches, suspension bars were passed down through holes left in the concrete, the ends of the bars entered oblong holes in cast-iron girders placed beneath the blocks, and by turning a quarter round held securely. Horizontal shafts were left in the bottom of the blocks for the beams to be put in at low water, and they were withdrawn after the blocks were set (Fig. 74).

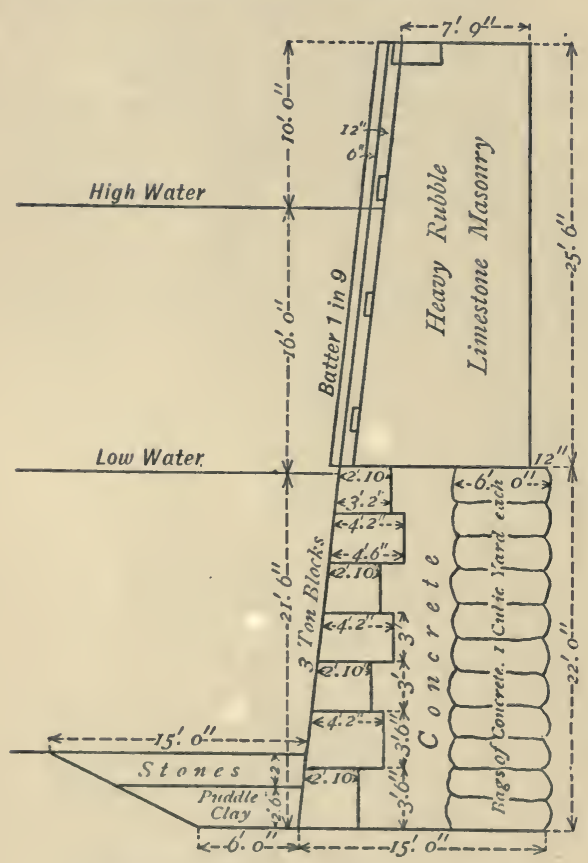

SECTION OF QUAY WALL, SHOWING BAGS

FIG. 72.

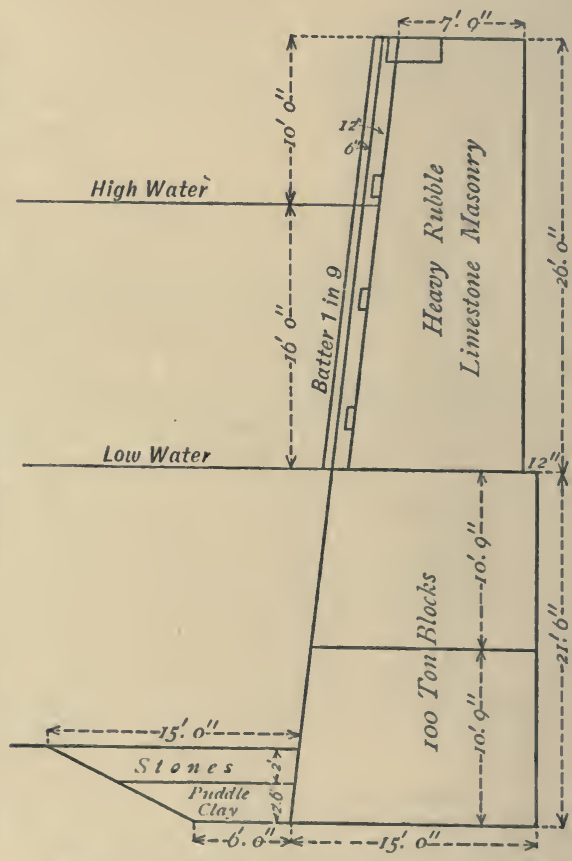

S:ECTION OF QUAY WALL, SHOWING BLOCKS Frg. 73.

The barges were placed over the blocks an hour or two before high water, the lifting bars were then secured to the cross-heads and the chains strained by the winches until the blocks were nearly lifted; the tide then completed the lifting.

Above low-water level the work was constructed of heavy rubble limestone masonry, set in lias-lime mortar, the face being set in Roman cement for 6 inches in, and the whole coped with limestone blocks 16 inches thick. ${ }^{1}$ 


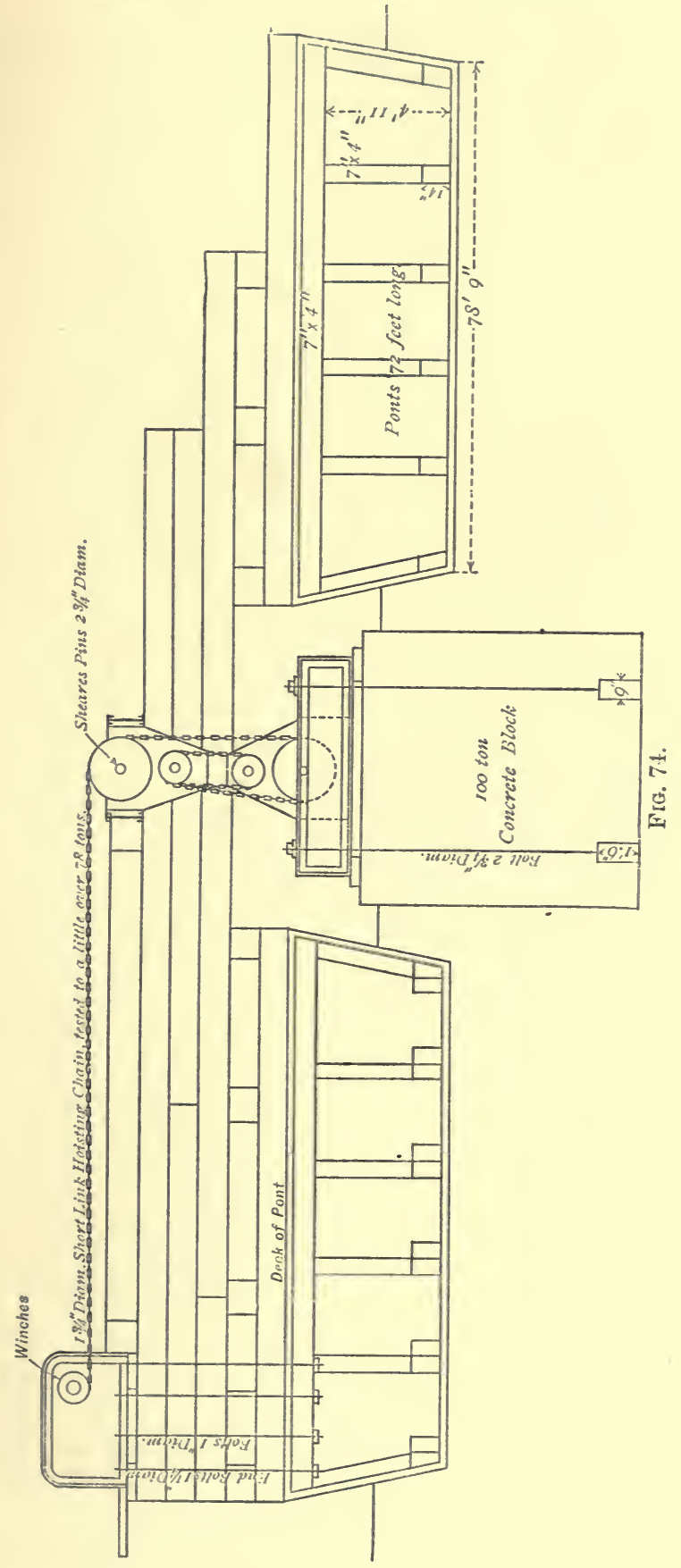


Buckey Dock and Harbour. ${ }^{1}$-Figs. $75,76,77$, represent the method adopted for the concrete walls, pier, and breakwater at Buckey. The east pier has a somewhat novel appearance. The work was tidal, but whilst the outer-wall foundations were dry
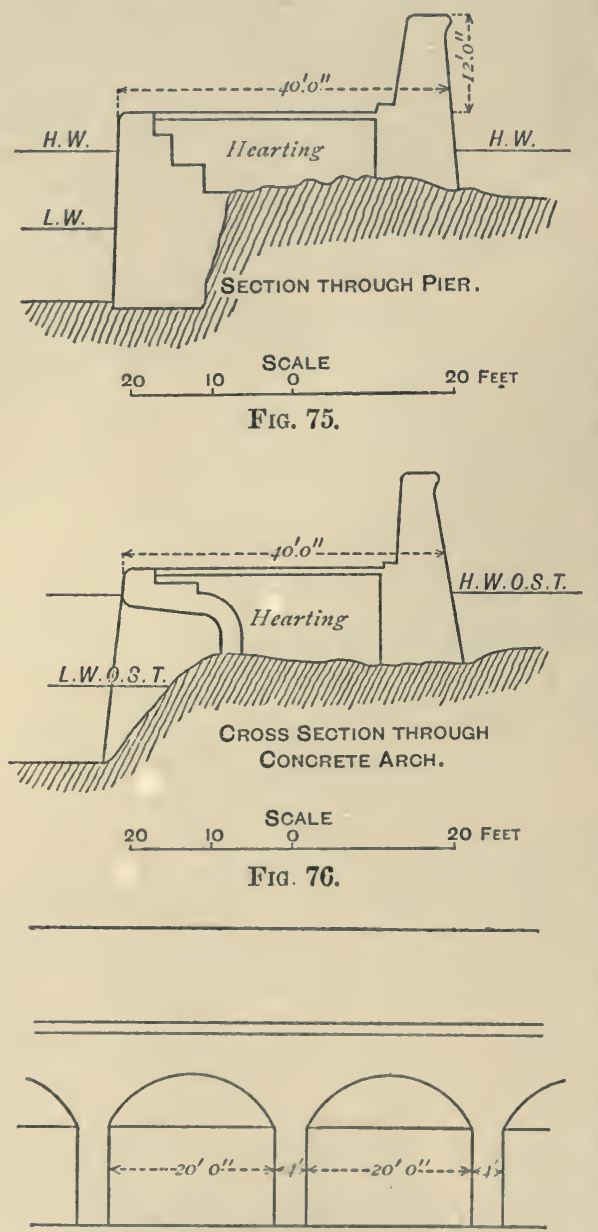

Elevation of Arches. EAst Pier

Fic. 77.

at low water, the inner wall was founded at 7 feet below low-water line, and was carried out within coffer-dams.

To economize labour on such tidal work, and to expedite the progress of construction, the inner wall was built on piers 4 feet thick, placed so that the clear span of the arches was 20 feet. This plan saved a considerable amount of rock excavation, and enabled the work generally to be much expedited, Figs. 75,76 .

The framing for the pier forming the breakwater founded at a depth of 10 feet below low water, and part of the west pier founded at a depth of 7 feet below low water of ordinary spring tides, was erected in the following manner:-Horizontal beams of timber 9 inches square were bolted to posts of the framing of the last length of concrete built. These beams projected in the line of the extension of the wall; posts 9 inches square were then erected 6 fect apart from centre to centre, and bolted to the horizontal beams, and lined on the inner side with planking 
21 inches thick. The timber and planking below the water level was fixed by divers; for keeping the framework in proper position 34 -inch wrought-iron tie-rods were used. Previous to the concrete being deposited over them, the rods were protected with $\Lambda$-shaped covers, formed of two pieces of board nailed together. This arrangement allowed of the rods being drawn after the concrete had set.

Within the timber casing, a bag of ample dimensions made of several thicknesses of jute cloth, weighing $19 \frac{1}{2}$ ounces per square yard, was drawn down into position by pulleys secured to the lower tier of the framing. Above the low-water level the sides of the timber casing was lined with jute cloth, weighing 17 ounces per square yard, and secured to the wood casing with 1-inch clout nails. On depositing the concrete through the water, the jute cloth protected it until it had consolidated. To secure the framing from being washed away by the sea, it was necessary to load it with old iron, until such time as a portion of the concrete had been deposited.

The moulds and frames for the parapet, tunnel, etc., were made in suitable lengths, so as to admit of their being shifted and re-erected as the work progressed.

The proportions adopted for the concrete up to low-water level was 4 of stone and sand to 1 of cement; above lowwater, in the faces for a thickness of 5 feet the proportions were $7 \frac{1}{2}$ parts of stone to 1 of cement; and for the hearting 12 stone and sand to 1 of cement.

Alexandra Dock, Hull. ${ }^{1}$ - The basin walls were designed to be constructed with Ashlar stone faced with rubble chalk, backing up to 14 feet below the coping, and the upper portion of 14 feet with Ashlar facing projecting 6 inches beyond the lower part of the wall, with rubble stone backing and granite coping; the whole set in lias-lime mortar. Iron pipes were built into the walls at two levels, so as to provide warp-holes at intervals of about 75 feet all round the dock, and a rubble drain 2 feet 6 inches square was placed along the back of the wall. In some places water was constantly running through these warp-holes after the backing was in to the full height, and thus the walls were preserved from undue pressure at the back. The chalk used for backing was hard and durable when not exposed to frost, but during construction in the winter months it required 
to be protected by a thin casing of harder material (in this

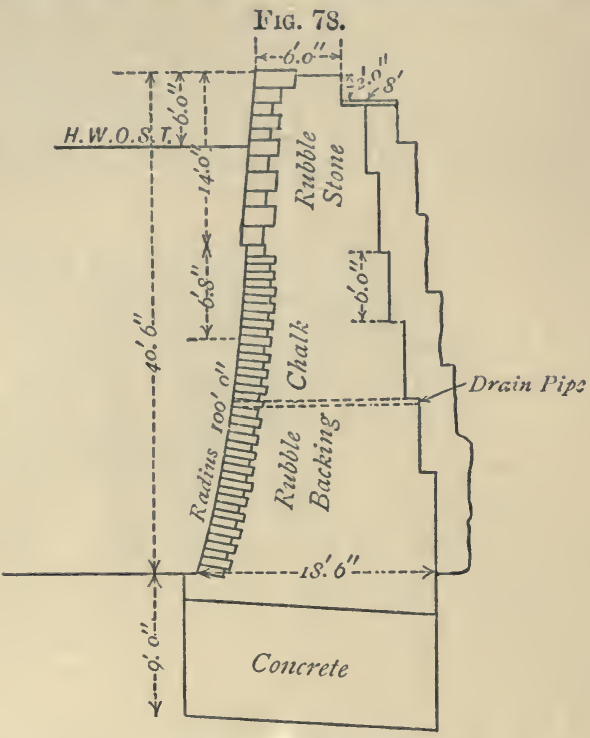

SECTION OF DOCK WALL
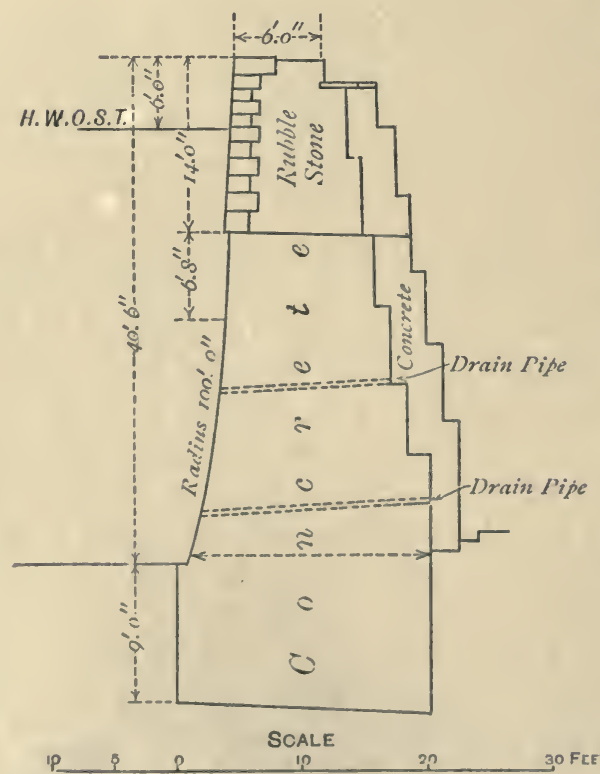

FIG. 79. case Bramley Fall rubble), to preserve it from injury before the backing could be carried up (Fig. 78). A modification consisted in the substitution of Portlandcement concrete for the Ashlar and chalk rubble in the lower part of the walls. The proportion for the face was 5 of stone and sand to 1 of cement, and for the backing 7 of stone to 1 of cement (Fig. 79).

Calais Basin Walls. ${ }^{1}$ -For putting down the foundations of the north-eastern and south-western walls the system adopted by Mr. Vetellart possesses many features of interest. The ground consisted of fine sand, and it was necessary in the case of the north-eastern quay to reach a depth of 16 feet below the normal bottom of the basin. The ordinary method of excavating and removing the sand would have involved great trouble and

\ Engineering, vol. xlvii. p. 577. 
expense, the timber necessary for such a work would have been very heavy, the use of caissons and compressed air was also open to objection. It was therefore decided to adopt a series of masonry curbs, placed side by side, to form the foundation of the wall, and to sink them through the sand by the aid of water jets to the required depth. The blocks were built on the sites they were to occupy in the foundations, and were constructed of masonry set in cement, resting on a base of concrete 1 foot 8 inches thick (Figs. 80, 81).

The dimensions of the smaller blocks in the foundations of the north-east wall of the basin were 23 feet by 21 feet $33_{4}^{3}$ inches,

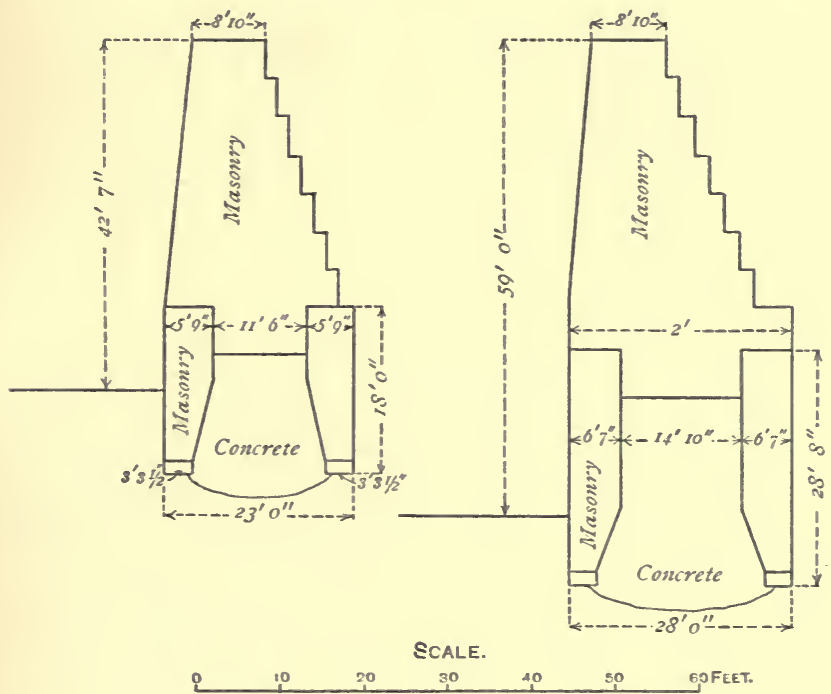

Fig. 80.

Fig. 81 .

with an octagonal central opening or well as shown in Figs. 84 to 89 .

The larger curbs used in the foundations of the south-west wall were made 28 feet square (Fig. 81), the weight of each being 800 tons.

Two vertical grooves were left in the opposite sides of each block to form keys for connecting the consecutive blocks. All the blocks or curbs were allowed to stand ten days or a fortnight before being sunk into place.

The operation of sinking was performed by subjecting the sand beneath the blocks to the action of powerful water jets, and 
pumping the mixture of sand and water thus produced through the opening in the middle of the block. For the latter purpose a centrifugal pump driven by a 10 horse-power portable engine was employed; the suction-pipe was held suspended by a light staging so that the mouth was set a little below the bottom of the block.

Four powerful pumps were used to force the water into the sand; each pipe supplied three nozzles connected to the main

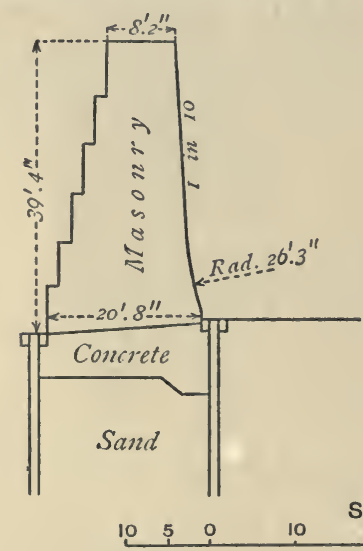

Fig. 82.

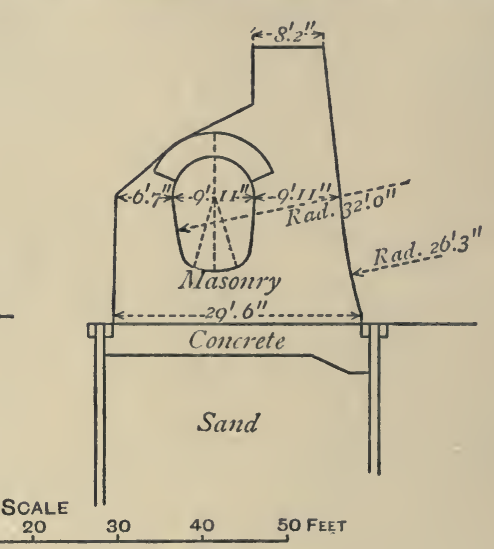

FIG. 83.

delivery by a rubber hose, which passed over a set of pulleys mounted on a light portable scaffold. For convenience of trans-

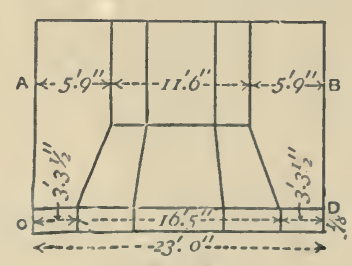

FIG. 84 .

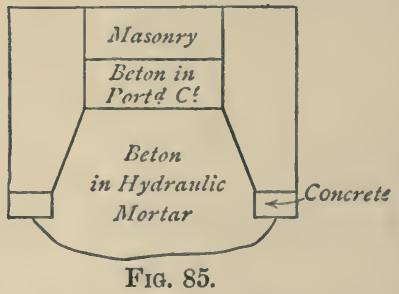

FIG. 85.

port, the whole of this plant was mounted on four platform waggons running on rails laid parallel to the face of the quay. Fig. 89 shows the manner in which the twelve jets were distributed. Eight of them were arranged round the sides of the opening in the curb, the four others were placed in the middle, round the suction-pipe of the centrifugal pump. One of the four nozzles just referred to was connected to the suction-pipe in such a way that the jet of water discharged kept the pump constantly clear. 
Care was taken that the quantity of water pumped out should be equal to that forced in, so that the level of the sand and water within the cube should be always maintained somewhat below the ordinary level at which the water stood in the surrounding sand.

As the blocks were lowered, two spirit-levels were laid upon the upper surface, and from these it was easy to see if the blocks were going down perpendicularly; if not, their descent was

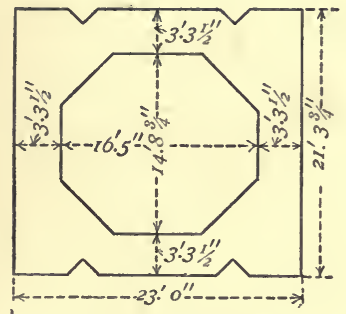

SECTION ON A B FIG. 84.

Fig. 86.

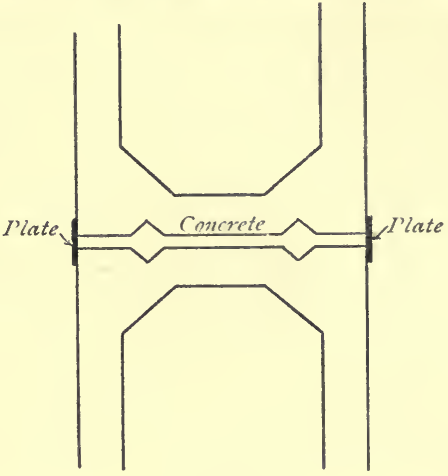

Fig. 87.

regulated by shutting off one or more of the nozzles on the side which was going down too quickly.

When a curb had reached its ultimate level, the sand in it

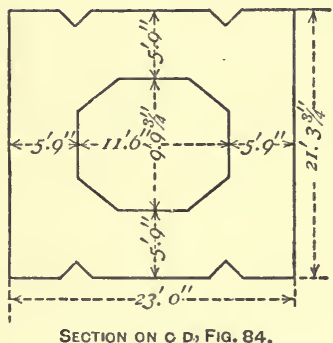

FIG. 88.

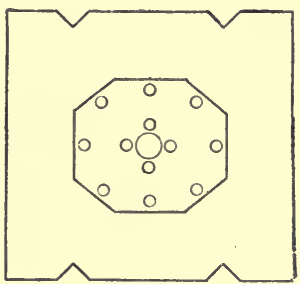

Fig. 89.

was allowed to settle, and the opening was then filled in with hydraulic concrete; the coned form of the aperture serving to keep the whole together and to prevent any leakage between the filling and the curb. In this way the apertures were filled nearly to the top of the curb (Figs. 80, 81), when the masonry of the wall was commenced.

The plan of operations adopted was as follows:-The positions of all the blocks were carefully set out on a plan, and laid 
down on the ground; their dimensions were marked, and they were spaced so far from each other as to leave a distance of 15 inches between the adjacent sides of the curbs. Experiments had shown that if in sinking a row of such foundation blocks every alternate one was lowered, the condition of the intermediate ground remained unaffected; the work was therefore carried on in this manner until all the curbs were in place and spaced at such intervals apart that there was a distance of $15 \frac{3}{4}$ inches between them (Fig. 87). None of the curbs were filled with concrete until the adjoining ones were in place, in order to avoid any trouble that might arise from the displacement of the sand beneath the foundations. When a series had been completed and filled, the consecutive blocks were cemented together. This was effected in the following manner. On the front and back faces of the blocks iron plates (Fig. 87) were sunk by means of a water jet to the bottom of the foundations which thus enclosed the space between two consecutive blocks. The sand was then removed by the sand pumps, and the space filled in with hydraulic concrete.

The larger blocks were sunk with as much accuracy as the smaller ones, but some difficulty was experienced in connecting thern together on account of the sand forcing its way through the joints between the plates and the faces of the blocks.

The time occupied in sinking the smaller blocks to a mean depth of 15 feet varied from 10 hours to 35 hours, or an average of 22 hours for each foundation curb. The volume of sand displaced per hour was 225 cubic feet. The larger blocks occupied a longer time in sinking, the average being 44 hours each, and the amount of sand displaced 380 cubic feet per hour. The sinking of some still smaller blocks was carried on very rapidly, about 440 cubic feet of sand being displaced per hour.

The sections of the north-eastern and south-western quay walls of the outer harbour are shown by Figs. 80, 81. The superstructure is entirely of solid masonry set in cement mortar. Near the base the face is vertical up to the lowest sea level; above this, the face has a batter of 1 in 10 .

The quay wall of the floating basin, east side (Fig. 82), rests upon a foundation of concrete 20 feet 8 inches wide, carried down to a sufficient depth into the sand to secure absolute safety, and enclosed both front and back with closo sheet-piling. The height of the coping above the concrete 
is 33 feet 7 inches, the width at the base 19 feet, and at the top 8 feet 2 inches. This difference of thickness is obtained on the outer face by a batter of 1 in 10 , followed by a curved face to the foot to a radius of 26 feet, and at the back by offsets of $14 \frac{1}{2}$ inches wide.

Fig. 83 shows the wall on the west side of the floating basin, modified to include a culvert at the rear. The total width of the base in this case is 29 feet 6 inches, resting on a concrete foundation 31 feet 6 inches wide enclosed with close sheet-piling, as in the case of Fig. 82.

Southampton Deep-water Tidal Dock. ${ }^{1}$-The trenches for these walls were excavated 100 feet wide at the top, battered down at a slope of $1 \frac{1}{2}$ to 1 in the mud by barrow roads to a depth of 18 feet, and were then continued at a slope of 1 to 1 by horse roads to a depth of 34 feet, when timbering was resorted to for supporting the sides of the excavation; the material being lifted by the aid of steam-cranes and skips.

The borings along the east wall (Fig. 15) indicated the worst soil; 17 feet in depth was found to be mud with 14 feet of peat under it overlying gravel. On the line of the northeast wall (Fig. 15), there was 10 feet of mud in some places, and in others 5 to 6 feet; then followed gravel and considerable depth of clay on which the foundation of the wall was for the most part laid. On the line of the west and south-west walls (Fig. 15) there was 10 to 12 feet of mud with gravel and clay underneath, on which the wall was founded. At the north-east corner of the dock it was deemed necessary, owing to the sandy nature of the strata, to put in piles, which were driven to a depth of 12 feet, 2 to 3 feet being left above the surface to form a key with the foundation as a precaution against the wall slipping forward. It was, however, found extremely difficult to drive these piles, and the attempt was ultimately abandoned and the sand removed instead.

The walls were constructed entirely of concrete to the general sections shown by Figs. 90, 91 ; the proportions being 8 parts of clean gravel and sand to 1 part of Portland cement for the body of the wall, with a facing from 26 feet below coping upwards, and 12 inches thick mixed in the proportions of 5 to 1 .

The concrete was laid in layers from 2 to 3 feet thick, and was allowed two clear days to set before the casing was 
removed and another layer added. Before commencing the following layer, the surface of the previous one was thoroughly cleaned and watered, and all vertical joints roughed with the pick.

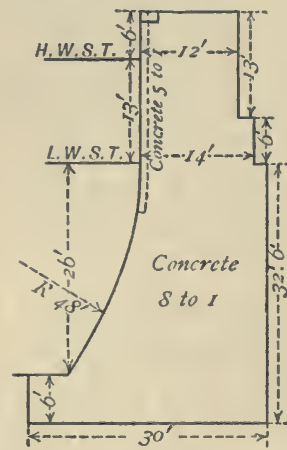

Fig. 90.

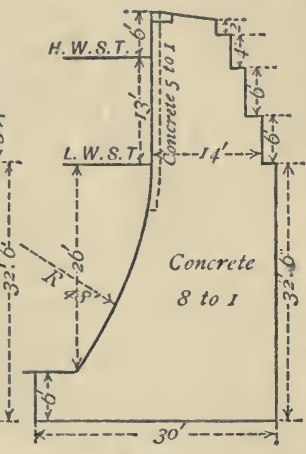

Fig. 91.

In order to allow for expansion and contraction, and to avoid unsightly cracks, straight joints reaching from the lowwater mark to coping level, and extending 7 feet back into the work, were formed in the wall at 100 -feet intervals, by means of iron plates $\frac{3}{16}$ to $\frac{1}{2}$ inch thick, 4 feet deep by 3 feet 6 inches wide, placed edge to edge. These plates were embedded in the concrete, and drawn up as it set.

After a sufficient time had elapsed to allow the concrete to thoroughly set, the vertical joints were pointed up on the face and grouted.

For draining the back of the walls, the following course was adopted. Where water was met with, a column of dry brick rubbish 3 feet square was built up at the rear, and from the base of this column a 10-inch pipe was carried through the wall to the front. Smaller pipes, 3 inches and 6 inches diameter, were also built through the walls at a level of 19 feet below coping at 80 feet distances, and again at 34 feet below coping level at intervals of 50 feet.

All backing behind the walls was thoroughly chopped and punned in 9-inch layers. When any slips occurred, they were removed to solid ground, and any mud left in the excavation behind the walls was removed to 100 feet back from the face line. The slope of the original soil was benched out in steps of 3 to 4 feet, from top to bottom.

Wharf Wall, River Front, New York. ${ }^{1}$-In improving the river front of New York, Mr. G. G. Green, the engineer-in-chief of the Department of Docks, adopted a method of construction combining in a suitable measure the necessary elements of strength, endurance, and stability, not difficult of execution,

\footnotetext{
1 Scientific American, "Commissioners' Report to Dept. of Docks," New Yurk. December, 1881.
} 
and specially calculated to meet the exceptional conditions obtaining, viz. a bed of soft yielding material of abnormal depth.

The general idea was a foundation of timber piles capped

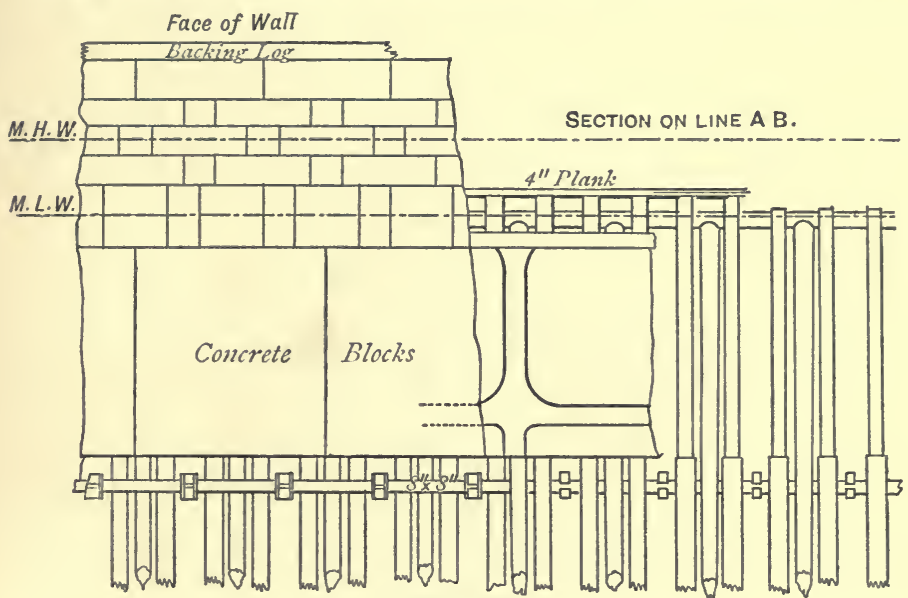

FrG. 92.

by a platform at the rear, with a monolithic concrete block facing to about 15 feet below low water, sustaining above a stone-faced wall. The section and details of construction varied somewhat, as occasion required, to meet local peculiarities of

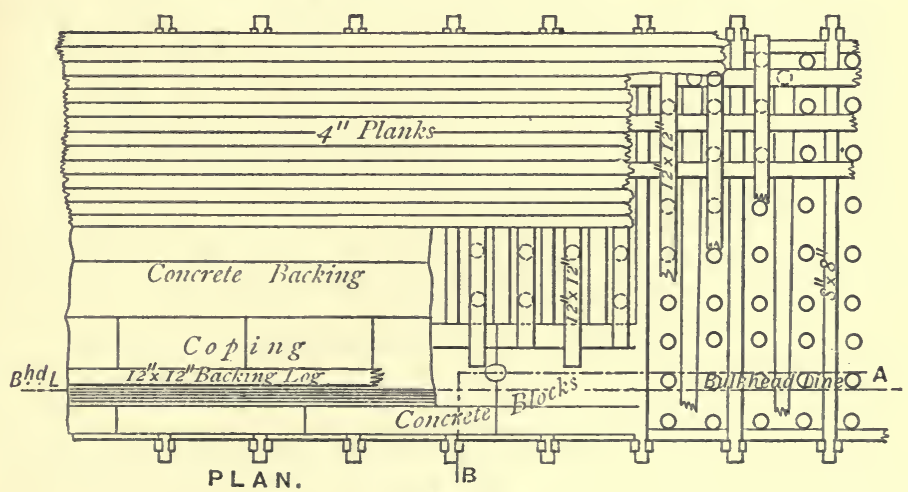

Fi木. 93.

site, but practically the method of construction is shown by Figs. 92 to 98 .

The timber used for piles consisted of white, yellow, or Norway pine, Cyprus or spruce, varying in diameter from 
16 to 28 inches, and reaching a maximum length of 90 feet. Practically, the hard bottom was, as a rule, too deep to be reached by the piles, their sustaining power therefore depended almost entirely on the friction of the mud on their sides or skin resistance. The piles were shod only where loose stones had to be penetrated.

All the vertical piles arranged as shown by Figs. 92 to 95 were driven first. The three front rows (Fig. 94) were then cut

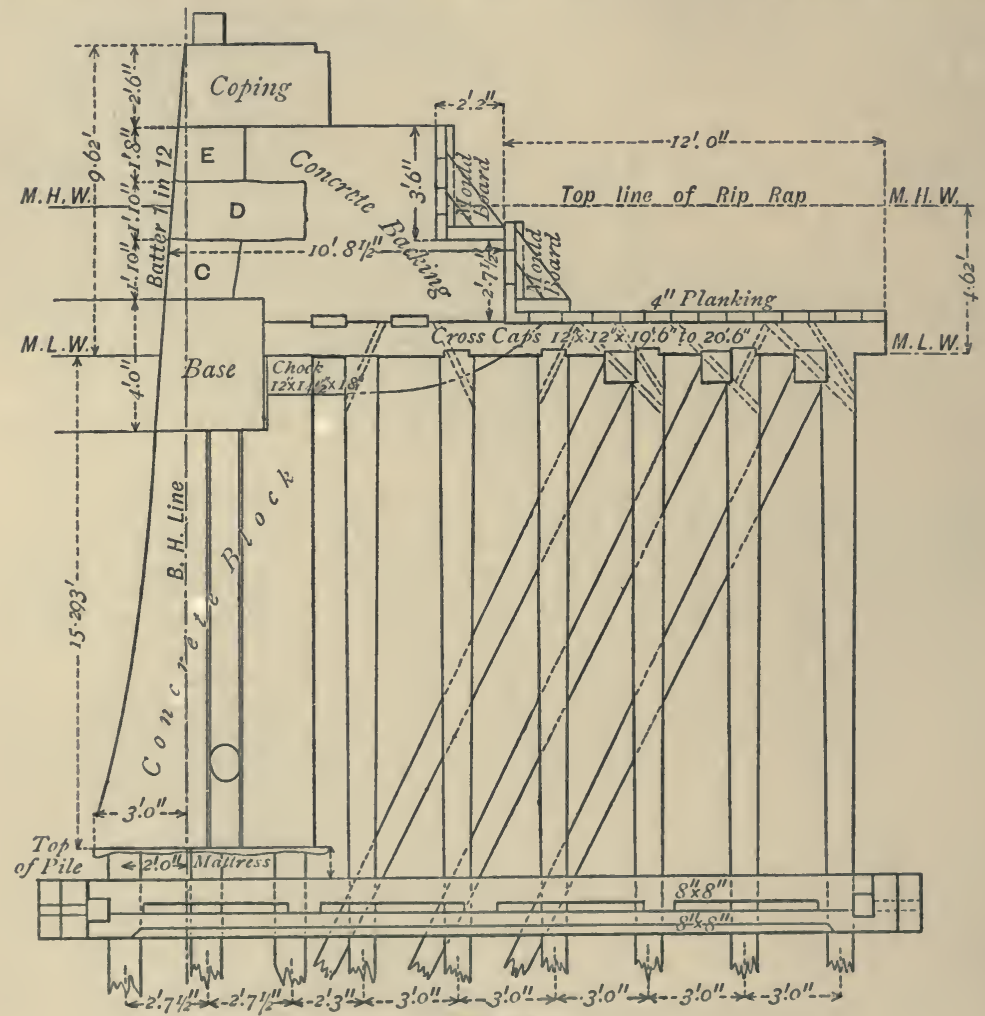

Frg. 34.

off at 15 feet 3 inches below low water by a circular saw, which was attached to a large timber, lowered to the required depth, and worked from a floating pile-driver.

The rear rows of piles terminate 2 inches above mean lowwater, and are notched at the top to receive the transverse caps or sleepers and planking forming a rear platform just above mean low water (Figs. 92, 93, 94). 
The inclined bracing-piles (Figs. 94, 95), driven between the vertical piles, were placed at distances of 3 feet from centre to centre, and at an inclination of two vertical to one horizontal. These bracing-piles were cut off at the same level as the rear vertical piles, and notched to receive longitudinal timbers 12 inches square (Fig. 94).

The vertical piles were braced together at a depth of 16 feet 6 inches below low water by binding-frames formed of two fir timbers 10 inches by 5 inches placed one above the other,

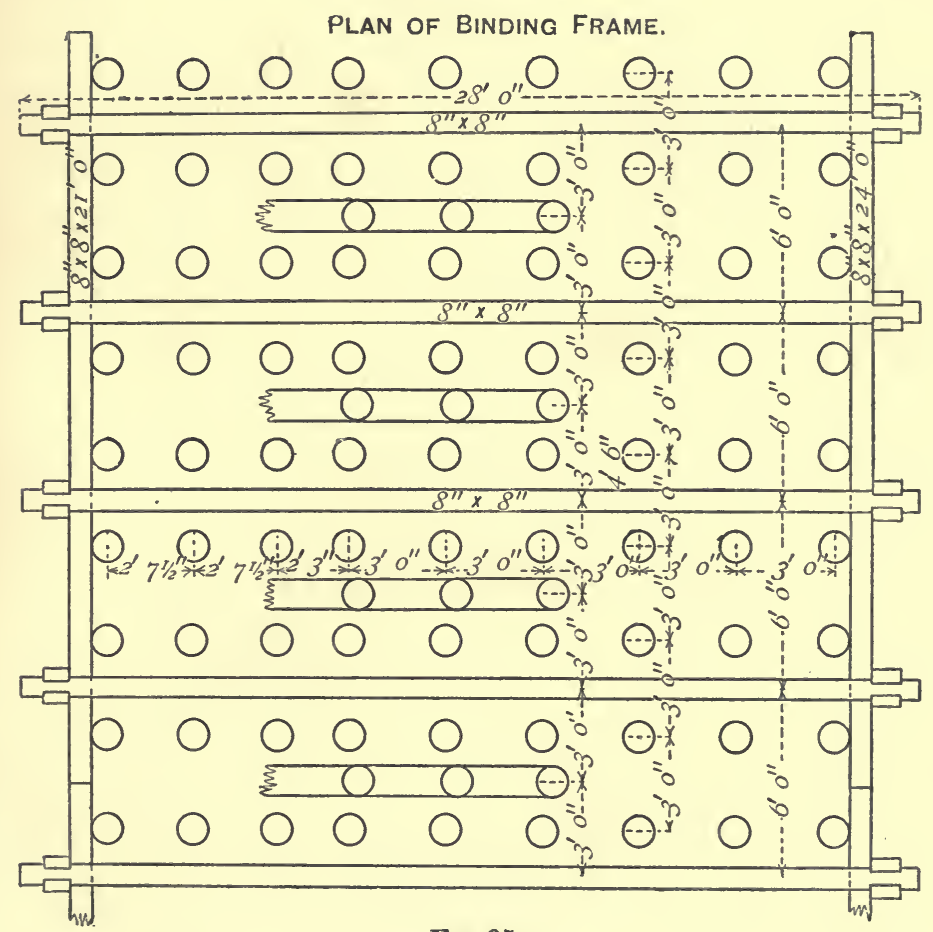

Fig. 95.

and secured to oak beams 8 inches square placed outside the front and rear rows of piles (Fig. 94).

Oak treenails were used for all fastenings, so that the whole represents a structure built without metal of any kind.

After the piles were driven, filling, consisting of cobble stones, gravel, and rip-rap, was deposited round and between the piles in layers. Masses of the same material were also deposited at the front and rear. This heavy material sinking into the mud 
served to increase the thickness of the base, and afforded increased resistance to the thrust of the back piling.

The concrete blocks (Figs. 96, 98), forming the face of the wall below the low-water level, were made 12 feet in length, 7 feet wide at the base, and 5 feet at the top, the height in front 13 feet, and at the back 14 feet, the weight of each being 70 tons.

The blocks were moulded in timber casings; the concrete being composed of one part Portland cement to two parts of sand mixed dry, and afterwards moistened with a sufficiency of water to form stiff mortar. To this mortar stones broken to pass through a 3-inch gauge were added in such proportion that the mortar was just sufficient to fill the interstices of the mass when well rammed. The ratio of interstices to bulk of stone was determined by a water test as well as by the practical mixing of samples. There was some variation in the proportions depending greatly on the nature and size of the stone used. Practically, however, the proportions used were 1 of Portland cement, 2 of sand, and 5 of broken stone.

Vertical grooves were moulded on each side (Figs. 96, 97, 98 ), and an opening formed through the block near the bottom for housing the chains used for lifting. After being lowered into position, a rope was made fast to one end of the chain, which was then drawn out, the use of the rope being to allow the chain to descend only as fast as it could be withdrawn, so as to prevent fouling in the groove.

Before the blocks were lowered into place, a mattress, of the same area as the base, consisting of a bag filled with two inches of mortar composed of a slow-setting cement, was placed on the top of the pile heads. In order to place this mattress in its proper position, it was attached to the under side of a wooden frame by a network of merlin; when sunk, divers cut away the lashings and liberated the frame which floated, leaving the mattress laid out flat in its proper position on the pile heads. The block was then lowered on to the mattress, which, owing to its plastic condition, neutralized any irregularity in the cutting off, and ensured a fair and regular bedding for the block on the pile heads.

In order to demonstrate the utility of the mattress, an experiment, under conditions as closely as possible those obtaining in the actual work, was carried out in such a manner that 
the result could be examined. The usual number of piles were cut off at high water by a submerged saw, but only to the level of low water, instead of at the proper depth. A diver, blindfolded, then laid a mattress on the top of the piles in the ordinary way, after which a concrete block was placed in its proper position on the top of the mattress. The block was subsequently removed at very low tide, which enabled the mattress to be examined. The result was in every way satisfactory, and proved that the weight of the block could, by the use of the mattress, be well distributed on the pile heads.

Fig. 96.

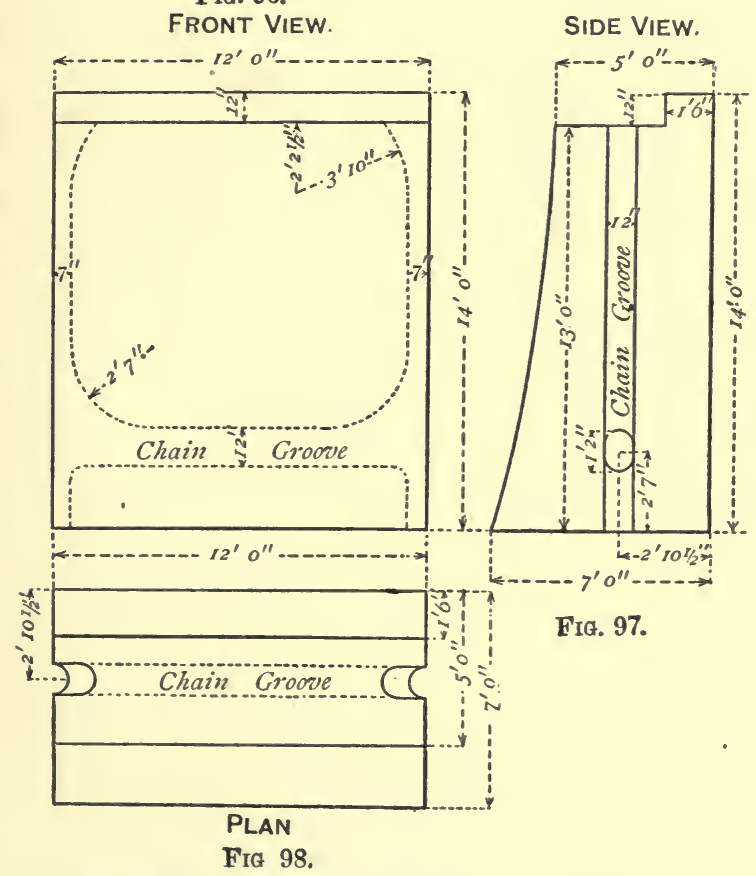

When the blocks were in their proper positions, the vertical grooves came together, and were then filled with concrete in bags well rammed down, so that a key or tongue was formed between the two blocks.

The upper part of the wall was constructed of granite ashlar backed with concrete, the headers being all dovetailed at the rear end so as to ensure a good grip with the concrete backing.

At Glasgow, ${ }^{1}$ a method of construction similar to the well-

'Description of Queen's Dock, Glasgow, by J. Deas, C.E. 
known Indian well foundations, by which coffer-dams are entirely avoided, was introduced by Mr. J. Deas, C.E., in 1869, and has been largely adopted since that date in the extensive works carried out by the Clyde Trustees, notably, the Queen's Dock, the river quay walls, and, more recently, the Cessnoch Dock.

The strata generally, except where the boulder clay was met with, was proved, by extensive boring, to be the worst possible in which to construct such works as dock and quay walls, viz. water-bearing gravel, and sand interspersed with pockets of mud.

Owing to the immense quantity of water, the walls could not, at any reasonable expense, have been constructed by excavating trenches in the gravel and sand to the required depth.

To meet these conditions, a system of cylinders was devised by Mr. Deas, by the use of which the base of the walls was brought up to low-water level.

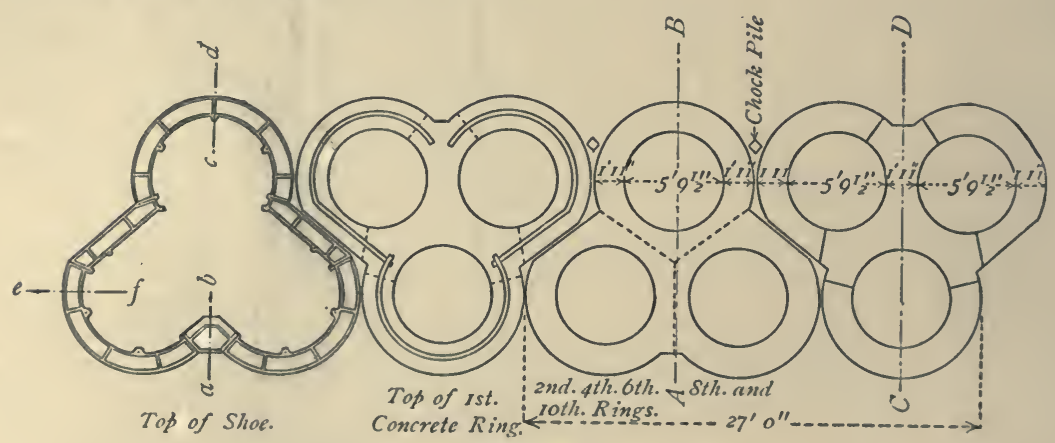

FIG. 99.

These cylinders, constructed of concrete, have become the standard pattern of foundations on the Clyde. They are generally triune in shape (Fig. 99); single cylinders being, however, used when the conditions require them.

The proportions adopted by Mr. Deas for the concrete are 5 parts of gravel, with a sufficiency of sand to fill the interstices, to 1 part of Portland cement.

The cylinders are made up of rings 2 feet 6 inches deep, which are cast in movable wooden moulds placed on a suitable platform.

To facilitate lifting, the rings are divided into three and four pieces alternately, so as to break joint when built into the cylinders (Fig. 99). The division of the rings is effected by $\frac{3}{8}$-inch iron plates placed across the wooden moulds in the 
positions required. The concrete is then put in and well rammed so as to secure homogeneity and a smooth surface; about twelve hours after filling the moulds the division plates are withdrawn, and two days after the wooden moulds are removed. In periods varying from nine days to three weeks, depending upon the

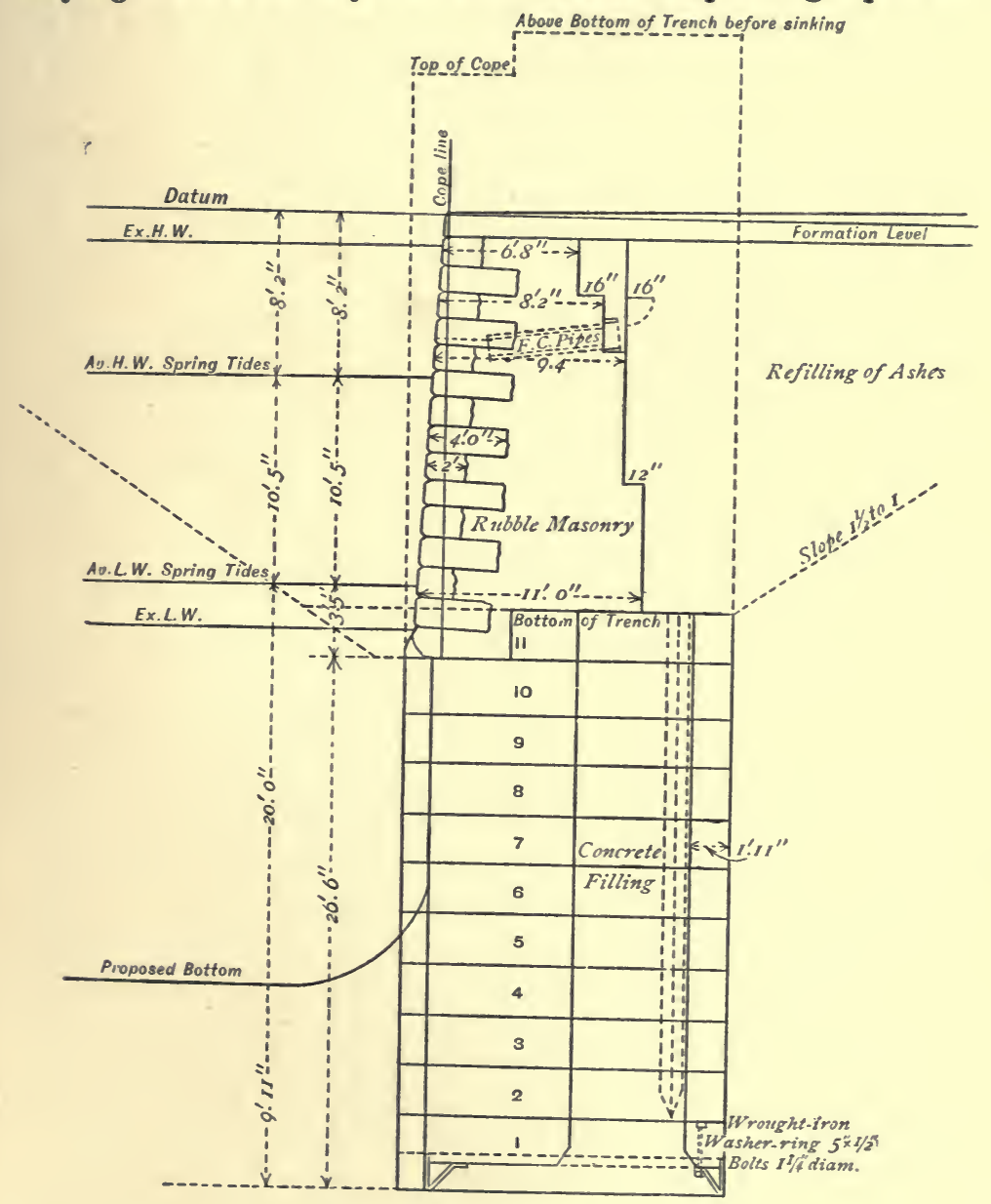

SECTION OF WALL ON LINE A.B.

Fig. 100.

time of year and the weather, the rings are ready for removal and building into the work. The contents of one section or ring complete is 10.5 cubic yards, the heaviest portion weighs about 6 tons, whilst the total is about 18 tons. 
The bottom ring differs from the others, and is called the corbled ring, because it is made less in thickness at the bottom to fit into the shoe, and tapers upwards to the full thickness of 1 foot 11 inches (Figs. 100, 101).

The shoe is made of cast iron 2 feet deep, 1 inch metal, and of the same external size and shape as the rings. The under side of the bottom ring rests on a shelf in the shoe, placed 6

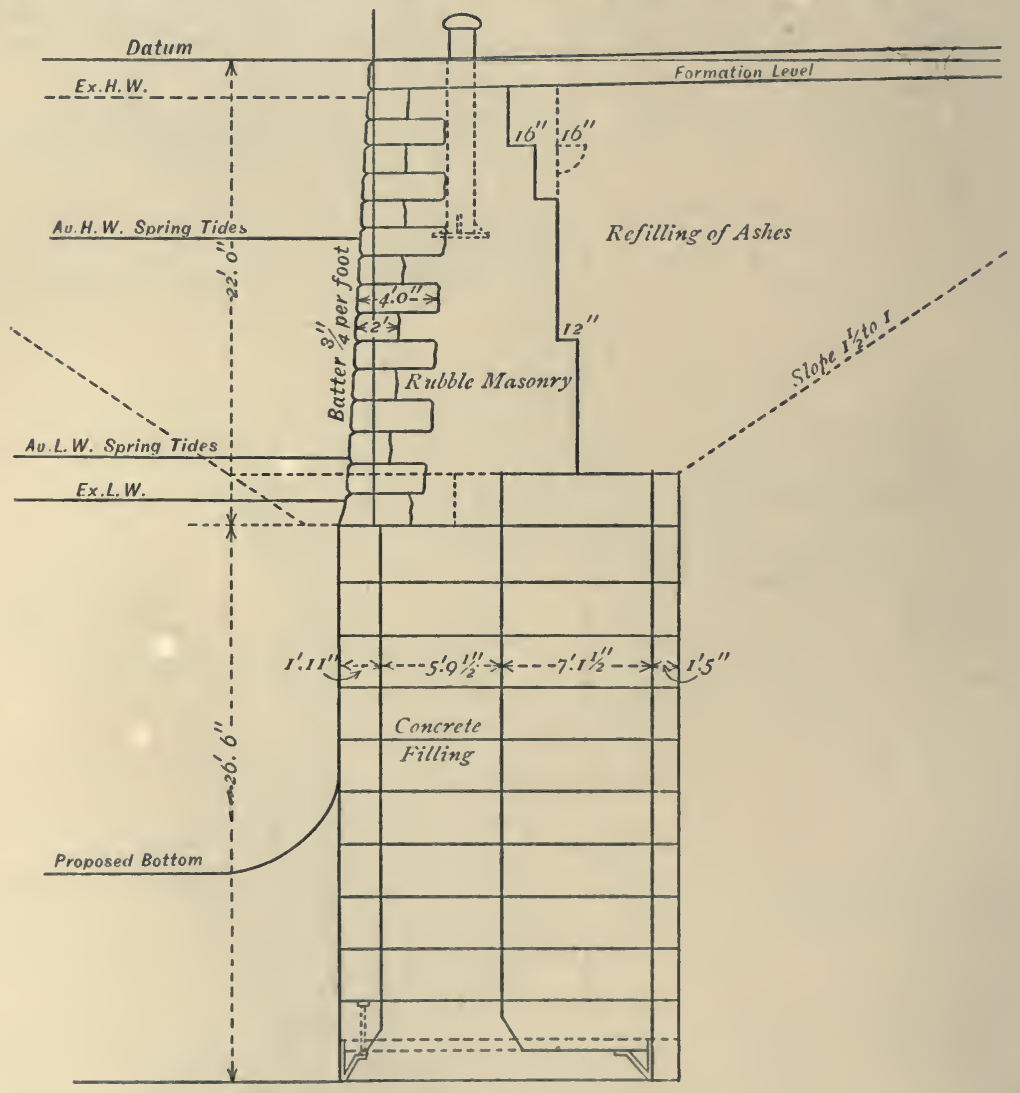

SECTION OF WALL ON LINE C D

FIG. 101.

inches below the top edge, and about 12 inches wide. This shelf is formed by an inner ring of cast iron 1 inch thick, which, being connected with the bottom of the outer plate, forms a bevelled cutting edge to the shoe. The total weight of the shoe is about 4 tons $10 \mathrm{cwt}$., and for convenience of handling is made in six sections. 
Describing the course pursued in constructing the walls of the Queen's Dock at Glasgow, Mr. Deas says, "In proceeding with the substructure, a trench was cut in the line of the quay wall; the bottom of this trench was about 12 inches below lowwater mark, when it was made 21 feet wide with the sides sloping upwards with a batter of $1 \frac{1}{2}$ horizontal to 1 vertical, and over it was erected the necessary staging to carry the travelling-cranes and digging apparatus.

On the bottom of this trench the shoes were placed exactly in the line of the quay wall, and the space between the outer and inner plates filled up with concrete. The corbelled ring is placed on this shelf, to which it is secured by thirteen $1 \frac{1}{4}$-inch bolts; on the top of this ring a wrought-iron washer-band 5 inches by $\frac{1}{2}$ inch was sunk into a groove formed in the concrete to take the heads of the bolts.

The remaining rings forming the complete cylinder are then set one above the other in Portland cement, in three and four pieces alternately, so as to break joint.

The cylinders being triune, or in groups of three, are placed so as to dovetail into each other, one in front and two behind, and two in front and one behind alternately. The groups where they come together are flattened for a length of 5 feet so as to ensure a good bearing.

On the completion of the rings forming one group of cylinders, the sand and gravel was dug out simultaneously from within each of the three cylinders by means of excavators especially designed for the purpose, and the sinking proceeded with. From 300 to 400 tons of cast iron weights of the same shape as the rings were generally required to force each group of cylinders down to the required depth of 48 feet 6 inches below the coping level. The average rate of sinking was 12 inches per hour. In good working sand, however, as much as 3 feet per hour was attained.

When the group was sunk with the top 9 inches below low-water mark, it was cleaned out to the level of the bottom of the shoe, and each well was filled to the top with Portlandcement concrete.

To effectually close the apertures formed by the joining of each two groups of cylinders, a timber choke-pile 9 inches square was driven behind anglewise so that a sharp corner bore hard against each of the cylinders. 
134 NOTES ON DOCKS AND DOCK CONSTRUCTION.

The wall above the cylinders was constructed of heavy concrete rubble, faced with ashlar in courses (Figs. 100, 101).

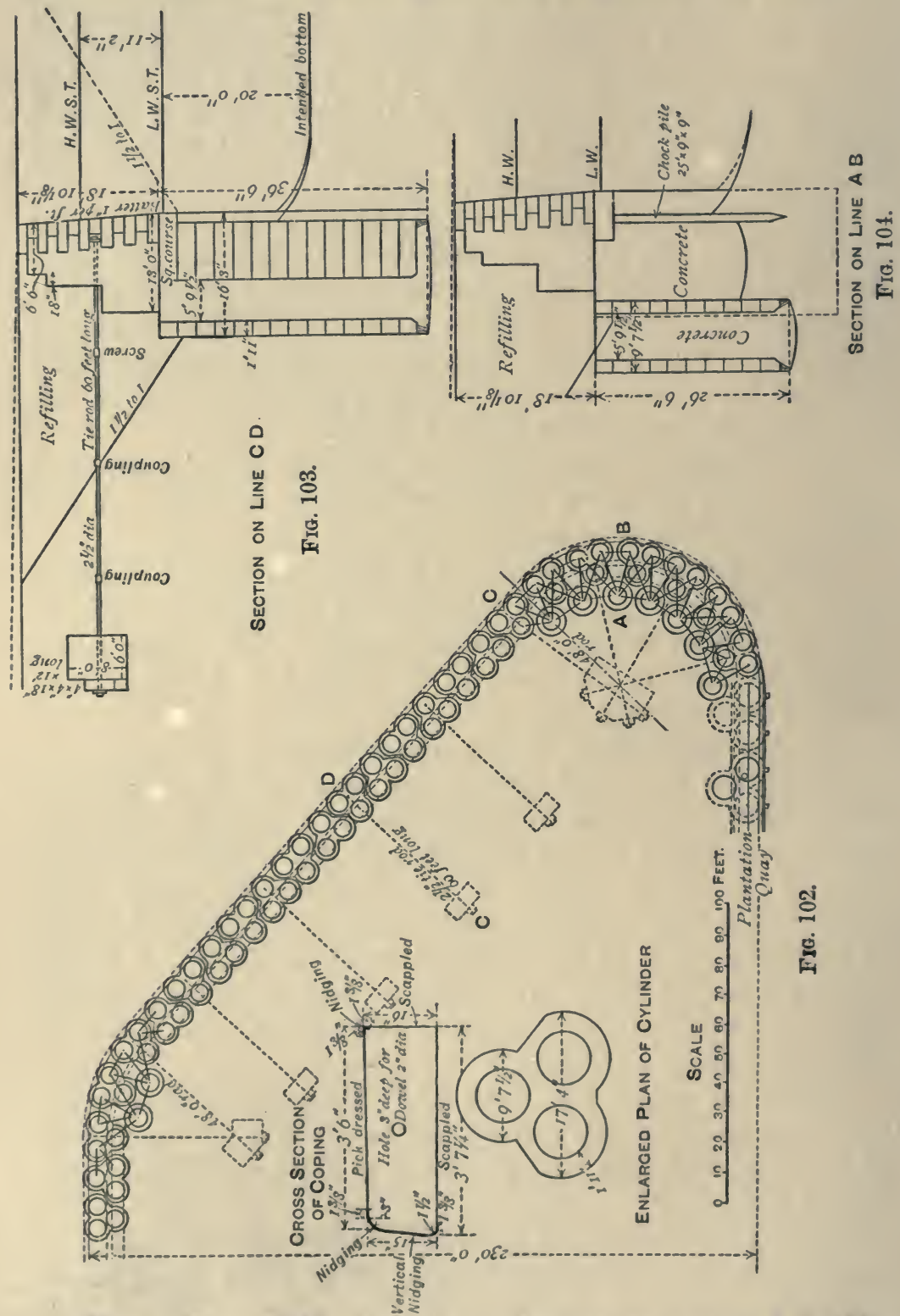

Figs. 102 to $104^{1}$ show the cylinders as arranged by Mr. 1 Engineering, vol. Jviii. p. 167. 
Deas, to form the wharf wall at the entrance to the New Cessnoch Docks. In this case, an additional precaution was taken at the curves to tie the cylinders together with ordinary steel rails in the manner shown by Fig. 102. The total depth in this case to the bottom of the cylinders was 35 feet from the coping level, so as to admit of a depth of 25 feet at low water being obtained.

In this case the walls above the cylinder were constructed of granolithic-faced concrete ashlar, the face being 6 inches thick, chamfered on both upper and under edges. The face blocks were made 4 feet long by 2 feet deep on the bed, whilst the courses ranged from 15 to 18 inches deep. Two stretchers were laid to one header. The backing to the ashlar face was constructed of heavy rubble, ranging from $\frac{1}{2}$ cwt. to 2 tons, set in 5 to 1 concrete, finished with a coping 3 feet 6 inches broad, 15 inches deep, and in lengths of not less than 4 feet.

To keep the walls in position when the material was dredged from the front, $2 \frac{1}{2}$-inch iron tie-rods, secured to heavy blocks of concrete 12 feet by 8 feet by 6 feet were introduced at intervals of 50 feet.

Fig. 105 shows the ordinary construction of quay walls adopted at the Queen's Dock, Glasgow, when the foundation was on the boulder clay.

Danube Improvements. ${ }^{1}$-Fig. 106 shows the section of wall adopted in forming the quay walls in the new channel through the flat alluvial lands near Vienna.

The walls are founded on concrete bases 12 feet 6 inches deep by 13 feet 6 inches wide, confined within continuous sheet-piling front and back, the timbers in the former being 12 inches square in section, and in the latter, half timbers.

The height of the coping above zero or datum is 12 feet 6 inches, and the bottom of the foundation trench 14 feet 6 inches below zero, making a total height of 27 feet.

The face of the wall is of granite ashlar, in courses 1 foot 9 inches in depth, backed with rubble Inasonry; the coping is also of granite, 2 feet thick.

The face has a batter of 1 in 10 , and is set back from the front of the concrete base about 2 feet.

Quay Walls at the Port of Bordeaux. ${ }^{2}$ - The riverside quays are 
136 NOTES ON DOCKS AND DOCK CONSTRUCTION.

built on foundations made by the aid of compressed air at a depth of 52 feet 6 inches below low water.
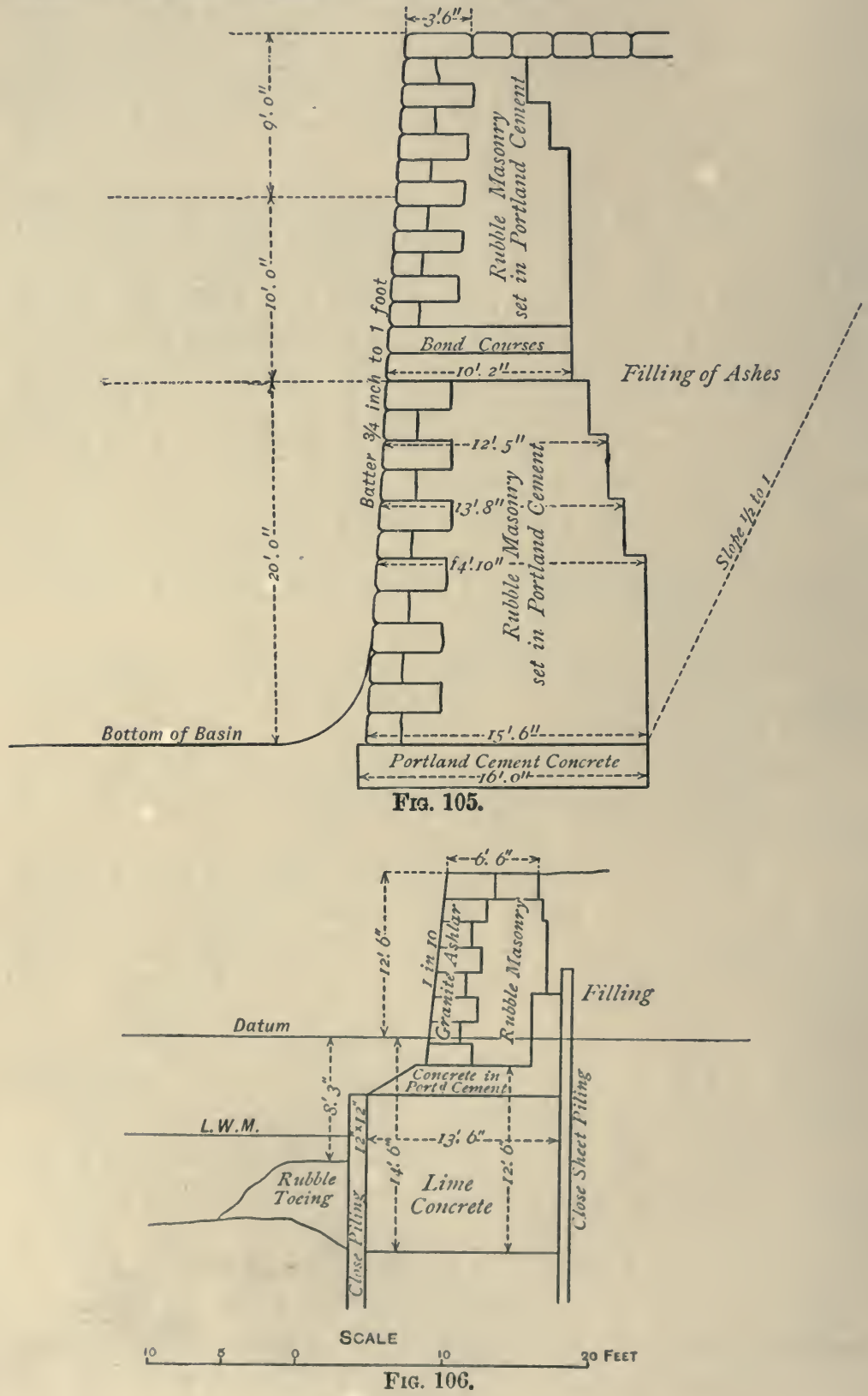
They consist of piers 32 feet 9 inches deep by 13 feet 1 inch wide, which carry arches of 39 feet 4 inches span. Beneath these arches the facing that maintains the surface of the quay is laid et its natural șlope. The tops of the quays are 21 feet above low

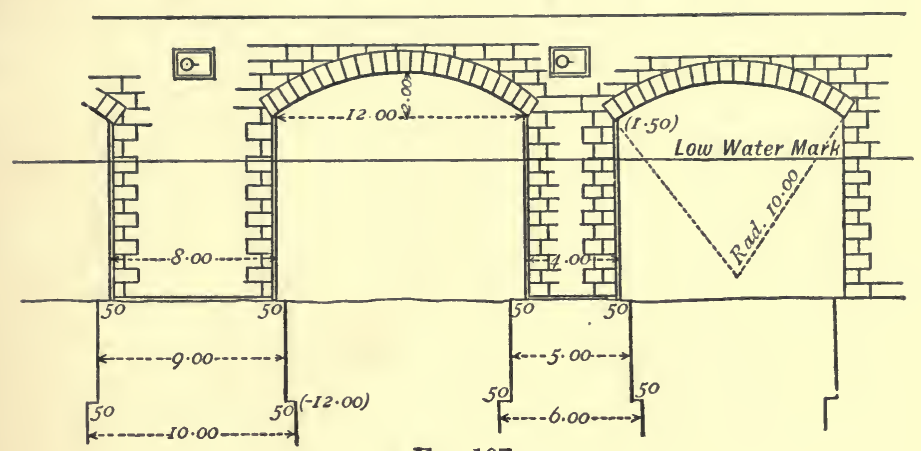

FiG. 107.

water, and the foundations are sunk at least 3 feet 4 inches in the bed of marl that underlies the bed of the river Garonne (Figs. 107, 108).

The walls of the floating basin are on compact clay, met with at a level of 39 feet below low-water mark. A length of 750 feet is founded on piles driven 40 inches apart longitudinally, and 68 inches transversely. At intervals of 165 feet, the wall is

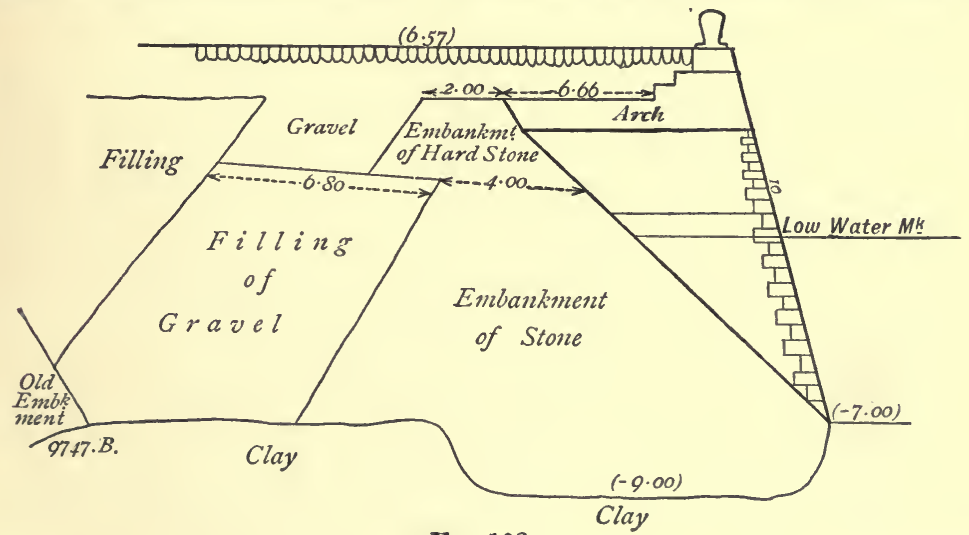

Fig. 108.

strengthened by blocks of masonry 16 feet 4 inches wide, and 19 to 26 feet long. The remainder of the basin walls stand on blocks placed about 42 feet apart, connected by arches of 26 feet 3 inches span. 
Figs. 109 to 112 show the concrete blocks used in the foundations, and Figs. 113 to 116 the various sections adopted for the quay walls.

Princes Dock, Bombay. ${ }^{1}$-The standard height of the walls of this dock was 37 feet, but there were places where it was

FIG. 109.

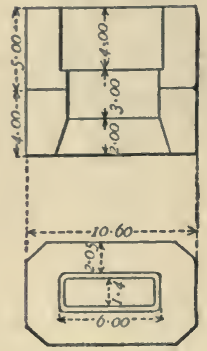

Fig. 110.
Fig. 111.

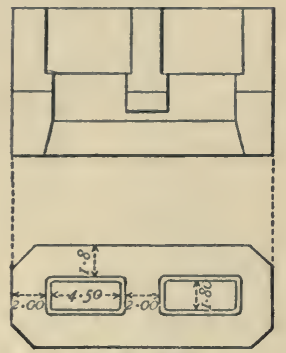

Fig. 112.

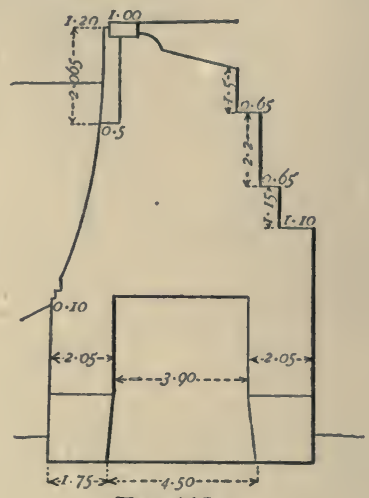

FiG. 113.

necessary to go 5 to 6 feet deeper in order to reach a firm foundation.

The strata consisted of surface silt and black mud overlying, to a depth of 4 to 5 feet, a bed of dense blue clay of varying

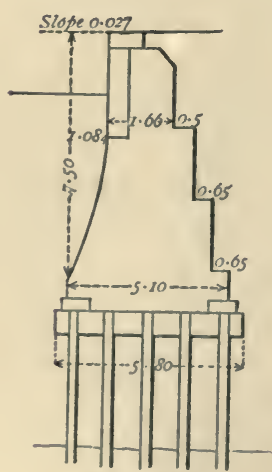

Fig. 114.

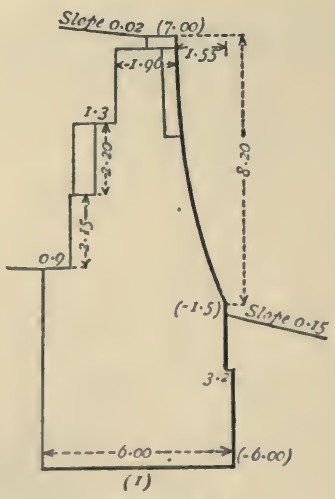

FIG. 115.

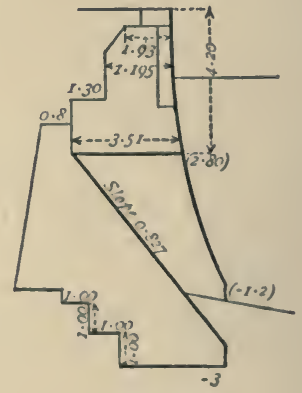

Fig. 116.

thickness, but nearly level on top; under this bed there was found loam and disintegrated trap down to the solid trap rock.

The trenches were from 25 to 30 feet deep by 15 feet wide, 
and were timbered throughout. The poling boards for supporting the sides were 2 inches thick, with walings 4 feet apart vertically, and struts or shores 7 to 8 feet apart horizontally.

The walls (Fig. 117) are 17 feet thick at the bottom, and 5 feet 4 inches at the top; the front face is battered 1 in 12, whilst the back is vertical up to the level of the mud, above which there are two offsets.

The wall is constructed entirely of masonry set in bydraulic mortar, the face joints being afterwards raked out and pointed with Portland cement. The body of the work consists of blue basalt rubble masonry, whilst the face consists of ashlar in courses 9 inches high, laid in header and stretcher courses, 9 inches and 18 inches alternately, with binders 18 inches square

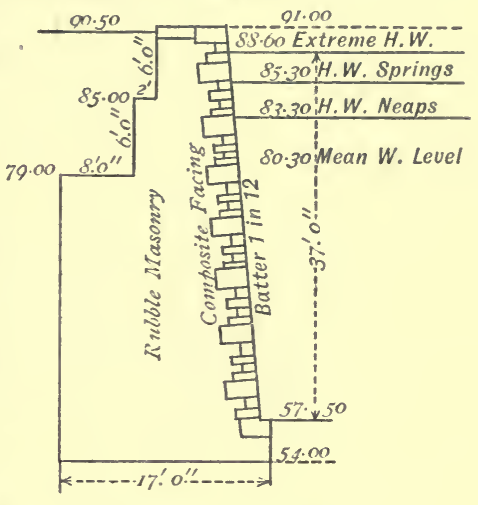
n 5 SCALE

Fig. 117. and 3 feet long placed about 6 feet apart horizontally and 3 feet vertically. The coping consists of two stretchers to one header, the former being 3 feet high, and the latter 1 foot 6 inches.

Quay Walls at Rouen. ${ }^{1}$-At Rouen the quays have been constructed in a peculiar manner, which the experience of the engineers attached to the port has gradually improved, and which have been imitated in many similar cases where quay walls have had to be constructed on the banks of rivers. The wall is built upon piles driven down to the chalk and constructed independently of the dam which forms the real embankment to the river; by this arrangement the wall is, as it were, independent of the embankment, and the tide is free to rise behind it. The structure is, however, connected to the dam by a platform in masonry built also on piles, the lower part being at the level of mean low tide; this masonry is tied back by iron rods passing through the embankment to masonry anchorages; the top of the masonry platform is filled in with chalk, and forms the foundation for the road constructed on the top of the quay.

The section (Fig. 118) shows the form of wall adopted; immediately on the top of the piles is laid a mass of concrete, 
which was set within timber caissons about 67 feet long and 13 feet wide; these caissons were floated at high tide over the piles, and allowed to settle down upon them as the tide receded. The sides of these caissons were removed when the mass of béton within was set, and they are used repeatedly in the construction of this part of the wall. The blocks of béton are surmounted by a wall in masonry, but this was constructed at low tides, before the caisson that served as a coffer-dam was removed; a facing of brick covers the whole front of the

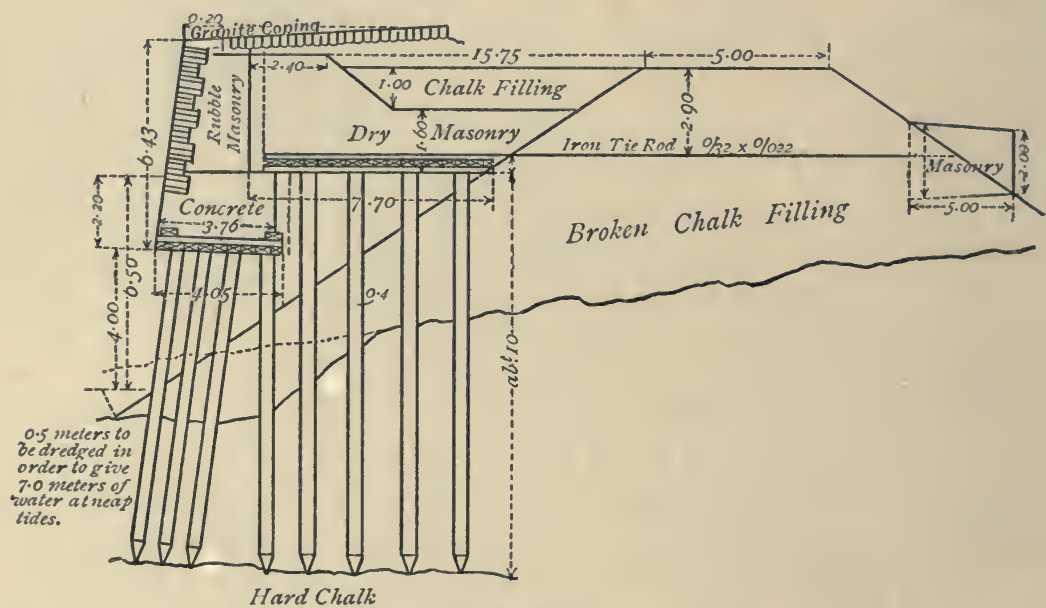

Fig. 118.

masonry that is exposed to the action of water, and a clear space of 12 inches left between the successive blocks of beton is filled in with cement.

This type of quay wall has given very excellent results, and has shown itself capable of resisting the thrust of the water and the mud deposited, and as it is very economical in construction, costing less than $£ 75$ per yard run, French engineers have not hesitated to adopt a similar type in other special works that have had to be constructed in this and other ports.

Training-walls on the Lower Seine.-These embankments or training-walls are composed chiefly of chalk, with a facing of concrete, or a stone-pitched face set dry (Figs. 119, 120). The concrete was deposited in place during periods of low water, and protected from the action of the rising tides by

1 Engineering, vol. slviii. p. 415. 
a coating of quick-setting cement. The foot of the embankment is protected by a toe, about 6 feet in width, placed at low-water level; and where it is exposed to the "bore" it is still further protected by sheet-piling.

The bore sweeps along at certain periods of the tide with a

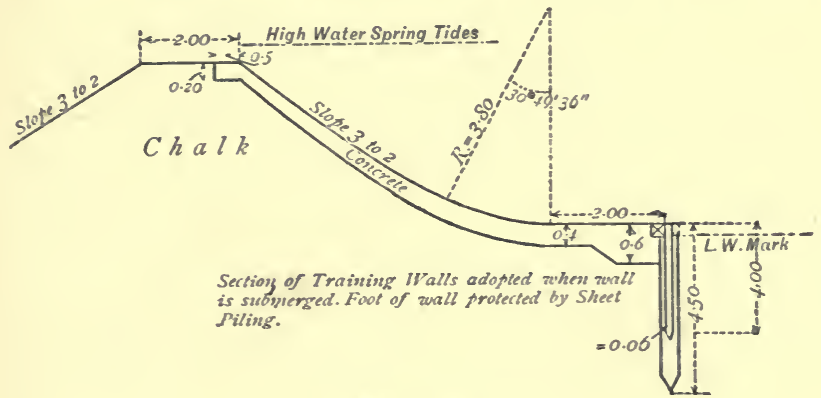

Fig. 119.

speed of 26 feet per second, and during the equinoxes often attains a height of 10 feet.

Gourock Quay Walls. ${ }^{1}$ - In carrying out the concrete quay walls at Gourock, Mr. Graham, C.E., of Glasgow, adopted a method of construction by which the use of costly coffer-dams and pumping was avoided.

A temporary staging was first erected along the lines of

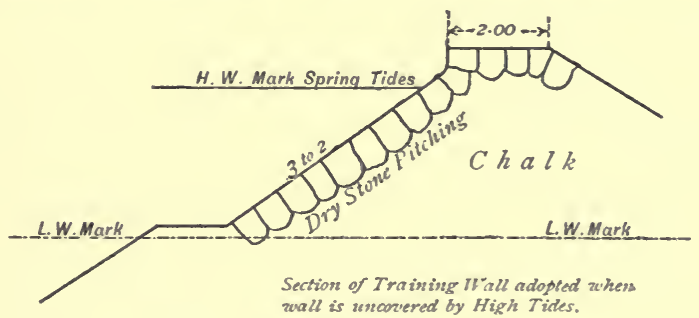

Fig. 120.

the wall to carry the pile-drivers, concrete-mixing machinery, cranes, etc.

The sheet-piling forming the casing for the concrete consisted of timbers from 42 feet to 55 feet long; the front piles were 12 inches thick and those at the back 9 inches.

The piles were bolted together in sets of three, shod and 
ringed, and driven in bays of $\mathbf{1 5}$ feet, with a key or wedge-pile in each bay for the purpose of tightening up the joints.

The pile heads were driven down and trimmed to low-water level and secured to longitudinal walings 12 inches by 6 inches (Figs. 121, 122).

The casing was divided into sections 50 feet in length by a temporary cross-end of timber, which was removed after the concrete was deposited.

On the completion of a section of the casing, the interior was excavated to the required depth by a Priestman's grab-dredger.

Owing to the very soft muddy character of the material over

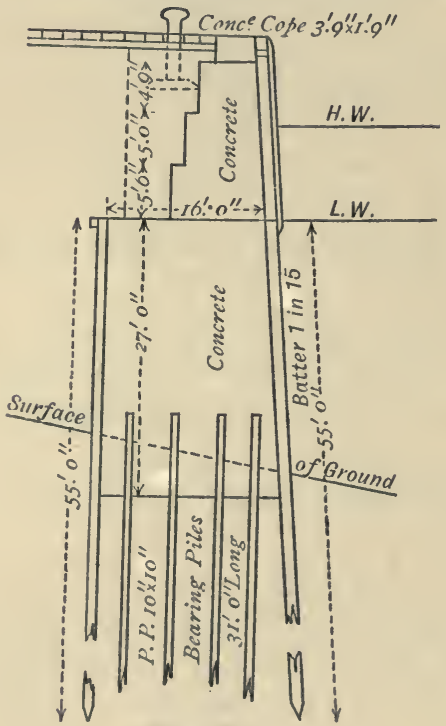

Fra. 121.

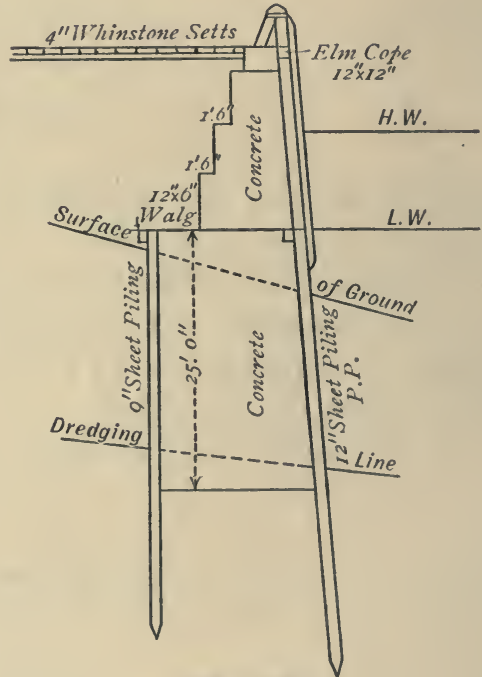

Fir. 122.

a portion of the bottom, extending over about 150 feet in length, the foundation required to be materially strengthened; this was effected by driving, after the excavation had been removed, pitchpine bearing-piles 10 inches square, and spaced 4 feet centre to centre. These piles were 31 feet long, and were driven until the heads were 8 feet above the bottom of the wall (Fig. 121).

The concrete was made in the proportion of 1 part Portland cement, $1 \frac{1}{2}$ part clean sand, and $4 \frac{1}{2}$ parts of clean ballast, or stones broken to pass a 2 -inch gauge. The mixing was done by apparatus erected on a travelling-stage following the pile-drivers; when thoroughly mixed, it was delivered into a hopper-box 
holding about two cubic yards, and was then lowered through the water by a steam-crane, and deposited in the required position. The mass was brought up in this way to the top of the sheet-piling at low-water level. Above this level, the wall was constructed as shown by Figs. 121, 122, by tide-work. The concrete was made in the same proportions as the base, but the face was formed smooth on the surface.

The coping, 3 feet 9 inches by 1 foot 9 inches, was also formed of concrete.

Counterforts to carry the bollards were placed at distances of 65 feet.

To protect the face of the wall above the sheet-piling from injury, fenders of greenheart timber 12 inches square were placed at 20 feet centres. The bottom of the fenders were inserted and secured 3 feet down into the sheet-piling, for which purpose the top of one of the sheet-piles was cut away. At the top, the fenders are secured to the wall by iron holdfasts, and finished with a longitudinal elm fender 12 inches square, checked between the vertical fenders. To protect the fenders, elm rubbing-pieces, 12 inches by 5 inches, are fixed to the front. For use when the tides are very high, longer fenders are placed in pairs along the wall.

Quay Wall at Brest. ${ }^{1}$ - The following method was adopted by the French engineers in the construction of a deep-water quay wall at Brest.

The range of tide at Brest is considerable-spring tides rising about 20 feet and neap tides 14 feet. This range greatly increased the facilities for carrying out the work, and had con-

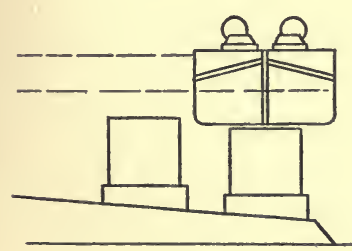

Fig. 123. siderable weight in determining the method of construction.

The foundation of the wall was a mound of loose rubble stone, which was brought up to a level of about 15 feet below low water of ordinary spring tides.

From the top of the rubble mound to just above low-water level the work consisted of artificial blocks of large size, deposited in two tiers or courses (Fig. 123), whilst the upper part was constructed in the ordinary manner by tide-work. 
The blocks were constructed of rubble-stone masonry, set in cement mortar, consisting of 1 part of cement to 4 parts of sand. The size varied, averaging about 16 feet long, 9 feet 10 inches wide, by 8 feet 10 inches high. The average contents would therefore be 53 cubic yards, equal to about 100 tons in weight. The blocks were built in a specially arranged yard above high water, each on a separate timber platform, or carriage, resting on an inclined slipway.

The slipway consisted of three longitudinal timbers, placed about 7 feet 6 inches apart centre to centre, rounded on the upper surface, and laid at an inclination of 1 in 16 feet 6 inches. Bearing-pieces hollowed out to the same curve as the rounding on the longitudinals were fixed to the under side of the platforms, which were thus enabled to slide down the ways without risk of lateral movement. The slip was 380 feet long and could accommodate twenty-eight to thirty blocks.

The blocks, when sufficiently consolidated, were removed to the lower end of the slip to low-water level by means of endless chains, which traversed the whole length of the ways, one on either side of the block.

After submersion, and when the tide had risen to a convenient height, the blocks were lifted by a barge, and transported under water to the work.

For lifting the blocks, T-headed rods were used, suitable rectangular openings being formed vertically in the mass. The heads, when turned, took a bearing upon pieces of hard wood covered with sheet iron on the under side built into the block about 1 foot above the base.

For lifting the blocks, one of the hopper-barges employed in depositing the rubble mound was used, the dimensions being 92 feet long, 16 feet 6 inches wide, with a draught of 1 foot 8 inches light and 4 feet 6 inches loaded. With the view of the barges being used for this purpose, the hopper doors were so arranged that when open, their lower edges did not project below the bottom of the barge.

To prepare the barge for lifting purposes, four baulk timbers were placed on the deck in pairs over two of the hopper openings, each pair of timbers having a clear space of 15 inches between them, so as to admit of the free passage of the suspending bars and chains. Each pair of baulks carried two winches fitted with pitch chains, which connected up with the tops of the suspension bars. 
At flood tide, when the water had risen sufficiently, the barge was placed over the block (Fig. 124), the four T-headed suspending bars were then lowered into the vertical holes in the block, turned at right angles, and the chains tightened. As the tide rose, the barge was immersed until the displacement equalled the weight of the block, which in sea-water would be about 55 tons, the barge then drawing about 3 feet with the block just clear of the bottom.

The barge, with the block attached, was then towed to the position the latter was intended to occupy in the work, and, when the tide had fallen sufficiently, it was

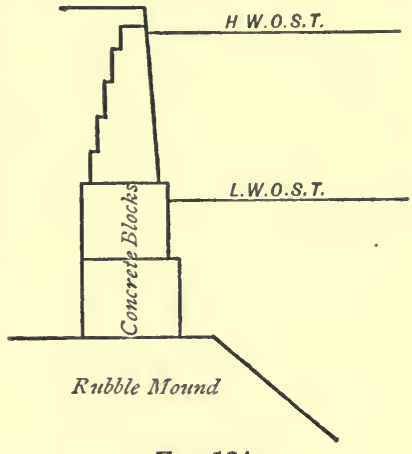

Fig. 124. carefully lowered into its place. It was found, after a little practice, that the blocks could be laid with great precision in two courses, one over the other (Fig. 124).

The system adopted at Brest possesses many advantages to recommend it, where the conditions generally are favourable. The submerging of the block not only reduces the weight to be lifted, but its position during transit increases the normal stability of the barge, enabling it to bear with safety the disturbing influence of the waves.

The block being suspended from the centre of the barge instead of from the end, the necessity of a counterpoise weight is obviated and the displacement reduced by one-half, and the dimensions of the barge decreased in proportion. These may be considerations of great moment when the work is to be carried out in a confined or crowded river or harbour.

An essential condition in all cases where heavy blocks have to be floated into position is fine weather. That method, therefore, will be the most applicable which, under all the conditions obtaining, admits of every advantage being taken of favourable weather, so as to ensure the manipulation of the greatest number of blocks in the shortest time.

Fiume.-A modification of the same method was adopted in the construction of a deep-water quay wall at Fiume, on the north-east shore of the Adriatic, where the rise of tide is but slightly over 3 feet. 
The largest blocks in this instance were 12 feet long, 6 feet 6 inches wide, by 5 feet high, and weighed 25 tons. They were transported from the block-yard on tramways worked by ropes driven by steam power, and were allowed to run down a slip into the sea, until the upper surface was slightly below the surface.

A raft consisting of two boxes or pontoons, placed at such a distance apart as to admit a block between them, and connected at the top by a frame of timber, was then floated over the submerged block.

By admitting water into the pontoons, the raft was lowered over the block, which was then made fast to the timbers by chains. On the water being pumped out, the raft rose with the block suspended ready for removal.

When placed over the proper position in the work, the block was gradually lowered by again letting the water into the pontoons, and guided in its descent by a diver; when accurately placed, the chains were removed and the raft floated away.

Quay Walls at Dublin. ${ }^{1}-\mathbf{A}$ good example of a deep-water quay wall constructed without a dam may be found in the work carried out by Mr. B. B. Stoney, M.A.M.I.C.E., in improving the basin accommodation at Dublin.

The method adopted consisted in the use of artificial blocks of such magnitude as rapidly to bring the wharf wall above low-water mark, and so to avoid the use of coffer-dams, staging, and all the incidental expenses connected with the usual methods of getting in foundations under water.

The special appliances required were a powerful floating shears (Figs. 125, 126) for lifting the blocks off the building wharf and conveying them to their destination, and a divingbell for excavating and levelling the ground (Figs. 127, 128).

The position of the works was extremely well sheltered, and interruptions due to bad weather were consequently reduced to a minimum.

The blocks were built upon a wharf about $\frac{1}{3}$ mile from the site of the work (Figs. 129, 130).

The blocks as constructed on the wharf were 27 feet in height, 21 feet 4 inches wide at the base, 12 feet 9 inches at the top, and 12 feet long in the direction of the wall. Each block contained nearly 5000 cubic feet of material, and weighed

'M.P.I.C.E., vol. xxxvii. p. 332 ; and Lingineering. 



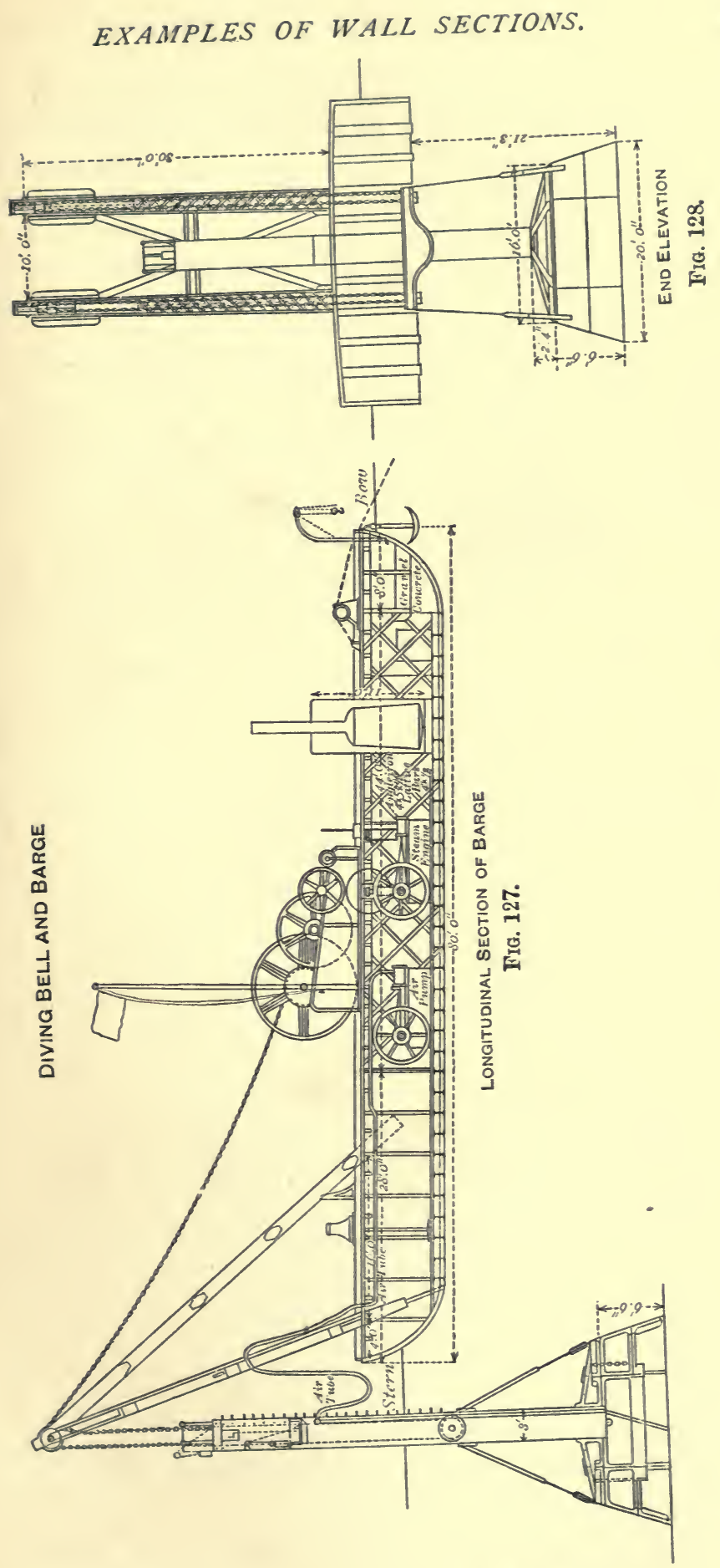
350 tons. When placed in position, it completed at one operation 12 feet of quay wall up to the level of ordinary low water.

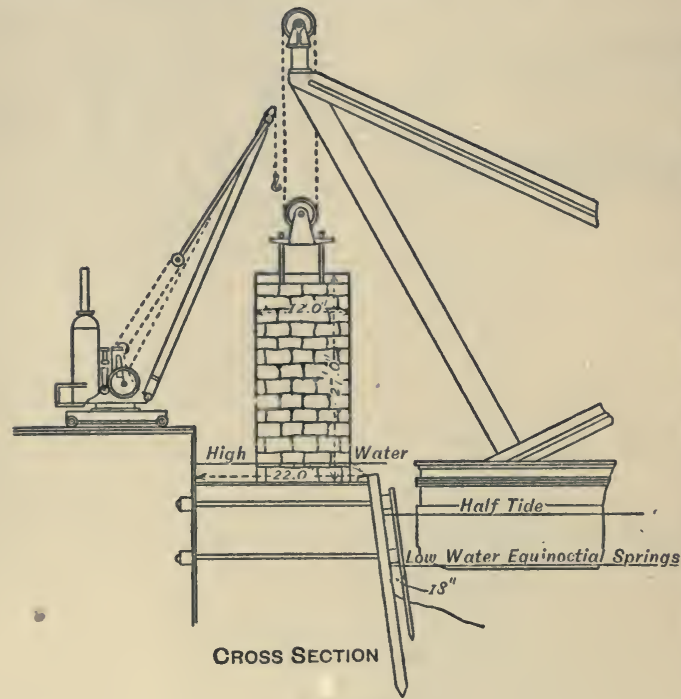

Fig. 129.

The outer face of the block was formed of limestone set in mortar composed of 4. parts of sand to 1 of Portland cement. The hearting of the block consisted of stones weighing from 2 tons downwards, as they came from the quarry, and placed not on their flat beds but on their ends, or on their edges, and bonded in every direction without any regular coursing. Every interval was filled up with concrete, into which smaller stones were rammed to form a coinpact mass.

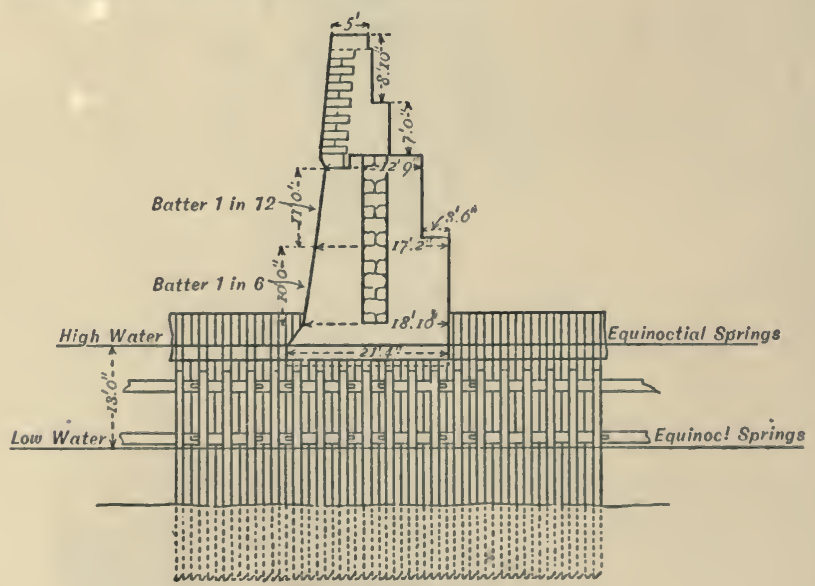

FRONT ELEVATION

Fig. 130.

That nothing could exceed the soundness of this work was proved whenever a mass was broken off, which was done with 
the greatest difficulty, the large stones generally fracturing in preference to the concrete.

The concrete was made of 1 part, by measure, of Portland cement to 7 parts of ballast dredged from the harbour.

The sides and rear of each block were defined and kept in shape by wooden panels which were removed when the block was completed, and re-used for the same purpose.

A block took from three to four weeks to build, and was considered sufficiently consolidated to move after an interval of ten weeks.

The length of 12 feet was preserved for a width of 2 feet in from the face. The block then tapered about 2 inches on each side to the rear, in order to give some latitude for adjustment at the time of setting, so as to ensure the range being accurately maintained without having an open joint on the face.

Vertical grooves (Fig. 130) 3 feet wide and 18 inches deep were formed in the sides of the blocks. When, therefore, two blocks were placed in position, a rectangular aperture 3 feet square was formed, in which concrete was deposited which acted as a dowel or key connecting the two blocks. This detail was introduced as an element of safety rather than as an essential, as no doubt the blocks would have acted satisfactorily had the dowels been omitted.

To provide for lifting, two cast-iron girders, weighing 11 cwt. each, were laid on the platform, and built into the bottom of each block (Fig. 126). The girders acted as washers to spread the local pressure of the suspension bars which supported the block and connected it with the lifting chains.

The suspension bars were of wrought iron 5 inches in diameter, and 31 feet long, with $\mathbf{T}$ ends at both top and bottom. Two rectangular holes were formed in each girder, and over each hole a tube of boards was placed vertically, round which the masonry was built so that there were four rectangular apertures, each 20 inches broad by 11 inches wide, passing vertically through the heart of the block. When the block was ready for lifting, the suspending bars were dropped down through the apertures and turned at right angles, so that their $T$ ends caught in the girders below, and thus took the bearing of the block. After the block had been set in place, the suspending bars were turned round 90 degrees and withdrawn, to be re-used for lifting other blocks. 
Each of the lifting bars was proved to a tensile strain of 150 tons, or nearly 8 tons per square inch. The aggregate proof strain of the four bars was therefore 600 tons, and as their calculated breaking strain was about 1600 tons, the coefficient of safety was 4.5 .

The foundation was prepared first by dredging, and the surface afterwards completed and very carefully levelled by means of a diving-bell. This bell (Figs. 127, 128) was of special construction, and consisted of a chamber 20 feet square at the bottom, 16 feet square at the roof, and 6 feet 6 inches high inside. A vertical tube 3 feet in diameter rose from the centre of the roof to a height of 37 feet 6 inches, and in the upper end was formed the air lock, 6 feet 6 inches high, with suitable fittings for admitting compressed air into the bell.

The bell weighed about $80 \frac{1}{2}$ tons, and was suspended from shear legs projecting over the stern of the barge by two $1 \frac{3}{8}$-inch close-linked chains rove through two sets of pulley blocks. Two other sets of blocks were attached to the ends of a cross-head of plate and angle iron riveted outside the funnel, and connected by strong iron stays to the chamber of the bell. Inside the bell, two large sheet-iron trays were suspended by chains from the roof. Each tray was 11 feet long, 4 feet wide, and 18 inches deep, and were for the purpose of removing the excavated material. They were hung on gimbals, and were so adjusted as to readily tilt and to discharge the load.

The barge for carrying the bell was rectangular (Figs. 127, 128) in form, 80 feet long, 30 feet wide, by 8 feet deep, and was fitted with suitable shears from which the bell was suspended over the end. 'The barge' also carried the engine and boilers, air-pumps and winches, and all other gear necessary for working the bell. A quantity of concrete at one end balanced the weight of the gear at the other, and ensured a safe free-board at the stern when the bell was out of the water.

The operations of preparing a section of foundation were as follows:-The site having been roughly dredged, the bell was placed in position and rested on the bottom. The excavated material was then loaded into the trays; when filled, the proper signal was given, the bell raised from the bottom, and removed to the proper position for discharging. On a signal from the deck, the hanging trays were canted by the men in the bell, and 
the contents discharged. The barge was then hauled back to its original position, and the bell again lowered. An area of 400 square feet was thus levelled with the greatest facility and accuracy.

For lifting, transporting, and placing the blocks in position a specially constructed shear pontoon was used. This vessel was rectangular in section, 130 feet long over all, 48 feet wide, by 14 feet deep, and provided with two pairs of lofty shear legs; one pair forward and the other aft. The cross-head of the former, which lifted the blocks, was 54 feet above the deck, and carried two sets of heavy four-shear pulleys, through which, and corresponding lower blocks, the pitch-chains for lifting the concrete blocks were rove. The lower pulley blocks were provided with forged projections which gripped the upper heads of the suspension rods passing through the concrete block.

The after shear legs supported a counterbalance tank of the same width as the pontoon, 30 feet long by 17 feet deep, and loaded partly with concrete and partly with water.

The centre of the block, when suspended, was 15 feet from the bow of the vessel, the centre of the tank was also 15 feet from the stern; therefore, with a block suspended at one end and balanced at the other, the pontoon, when on an even keel, supported a weight double that of the block.

In lifting a block, the shear pontoon was placed end on to the wharf during flood tide, and the suspension bars, already in position in the block, attached to the cross-heads of the lower set of pulleys. The lifting chains were then hauled in, and the pump started to fill the counterpoise tank; but, as its action was slower than the winches hauling in the chains, the vessel soon dipped at the head a few feet more than at the stern. As soon as this dip was considered sufficient, the hauling in of the chains ceased and the final lift of the block was done by the quiet action of the water filling the counterbalance tank, and bringing the vessel on an even keel.

The block being suspended from a height of 53 feet 6 inches above the deck, any serious deviation from the centre would have established a powerful leverage tending to overturn the vessel. To prevent this, a pair of strong timber booms provided with diagonal stay chains and tightening screws were hinged near the feet of the shear legs by which the block, when 
suspended, was gripped on either side and so kept from swaying.

As soon as the block was lifted, the pontoon was warped off from the wharf and the block lowered into the water about half its height, so as to relieve the lifting gear by the partial displacement.

The vessel was then moored in position, and the block lowered to within a few inches of the bottom, and close to the block previously set.

The exact adjustment of the block in line was effected by temporarily fixing short timber bollards in the grooves left in the sides of each block; two were set in the block already in position, and two in that about to be set. On either side of these bollards a short piece of baulk timber was placed horizontally, which secured by screw bolts to the block already in place, kept all four in line, and adjusted the range of the block being set, which was then drawn up into close contact by a small tackle, one end of which was attached to the top of the suspending bars, and the other to one of the blocks previously set.

The Albert Harbour, Greenock. ${ }^{1}$ - A method of construction, adopted by Messrs. Meller and Bell, in forming the outer sea-piers of the Albert Harbour, Greenock, where the conditions were such as to render the construction of a cofferdam inexpedient, consisted of cast-iron piles with stone slabs enclosing them, and forming the face of the work with concrete backing deposited in a soft state up to the low-water level, above which the walls were continued in the ordinary manner.

The pier was 60 feet wide at the top, with quay walls on both sides which were 33 feet in height from the foundations, 11 feet 6 inches thick at the base, and diminished to 5 feet at the top (Fig. 133).

The ground was very unequal, the hard substratum being in some places 20 feet below the bottom of the wall, the upper strata being mud and soft sand. In such cases, timber piling, driven to the same level as the iron facing-piles, was used to form a platform to sustain the part of the wall above the low-water level, but where the ground was firm this was not required (Figs. 133, 135). 
EXAMPLES OF WALL SECTIONS.

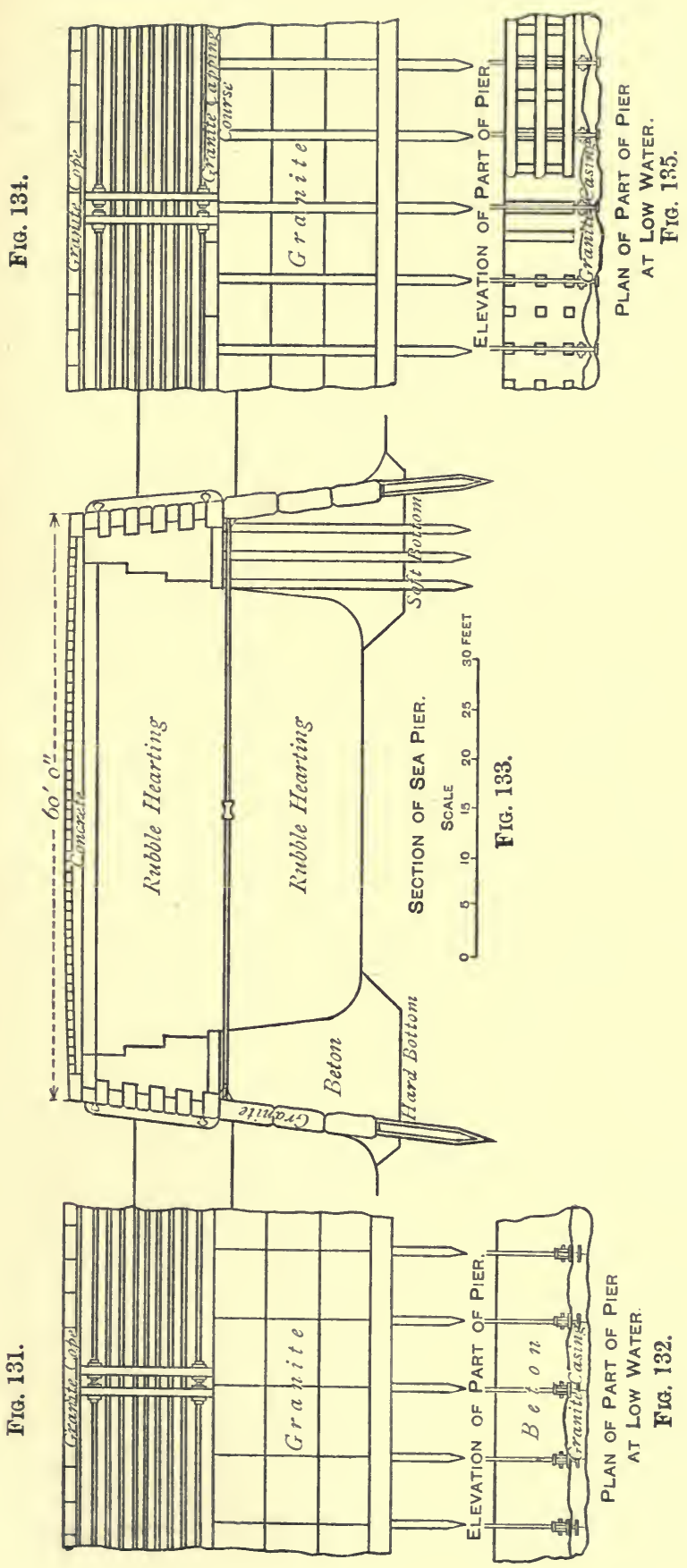


The first operation, where the water was not sufficiently deep, was to dredge two parallel trenches to 17 feet below low water, for the foundations of the walls. The erection of a timber staging followed, extending over the whole width of the work, for carrying the tramways, travelling-cranes, and pileengines.

Cast-iron guide-piles, placed 7 feet apart in the line of the quay walls, were then driven until the heads were near the lowwater mark; they were then connected transversely by wroughtiron tie-rods which extended through the pier.

When the proper depth had been made by dredging, and the piling driven, a bed of concrete 3 feet thick and 20 feet wide was deposited in the trenches to form a base for the wall, and to ensure a large bearing surface.

Granite slabs from 18 inches to 2 feet thick were then placed in position. At the commencement of the work, they were dropped into the grooves formed by the flanges of the cast-iron piles, the bottom slab resting on the concrete base, and on a projecting web cast on the piles (Figs. 134, 135).

This arrangement exposed the outer face of the piles to the action of the sea-water; to remedy this, in the latter part of the work, the reverse plan was adopted, and the groove made in the stones which therefore overlapped the iron piles, and formed a continuous facing (Figs. 131, 132). The grooves were then filled up with cement which enclosed the iron, and effectually preserved it from the action of the salt water. In each compartment between the piles, 16 feet in height and 7 feet in width, there were only three stones. Behind this facing, hydraulic concrete was lowered through the water in large boxes having movable bottoms to form the backing and body of the wall. To confine this mass at the back, loose rubble stones were deposited and carried up simultaneously with it. The hearting between the two walls consisted of the same description of materials, namely, rubble stones carried up to the level of low water.

The entire mass, piles and stone facing, concrete backing, and hearting, was allowed to consolidate for some time, after which the heads of the cast-iron piles and the facing blocks were capped at the level of low water by a granite string course; the upper portion of the wall was then continued with free stone ashlar face and rubble backing. The remainder of 
the hearting was then filled in, and the whole finished with a granite coping and causeway.

Spezzia.-At the Italian Naval Station of Spezzia, ${ }^{1}$ experiments made in 1865 to ascertain the true nature of the ground, which was composed of silt, sand, and clay in varying proportions, demonstrated the necessity of building the dock walls of unusual thickness to prevent them slipping forward by pressure from behind, which, experience had proved, would be exceptionally severe.

Two sections were adopted, viz. Fig. 136, where the bottom was comparatively solid, and Fig. 137, on soft ground.

The walls were $4 \mathrm{l}$ feet high throughout. In the lighter section, with a base of 23 feet (Fig. 136), there were no open
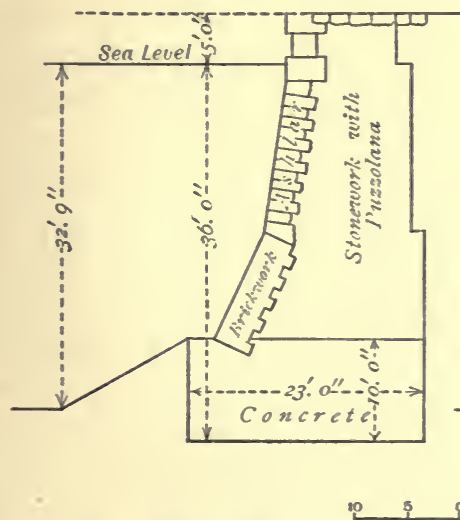

Fig. 136.

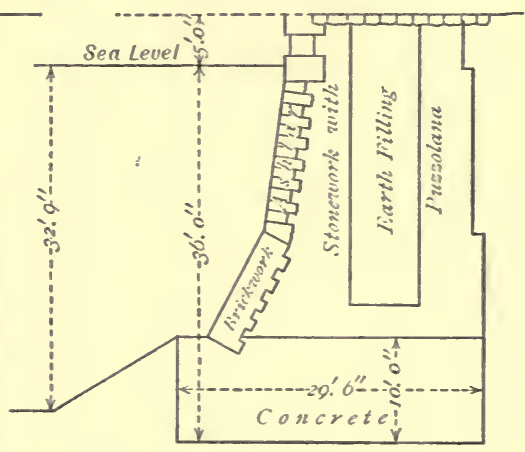
3० FEET

FIG. 137.

spaces in the body of the work; whilst in the heavier section, with a base of 29 feet 6 inches (Fig. 137), pockets or wells were formed 15 feet long with division walls 5 feet thick between them.

In constructing the interior dock walls, the necessary excavations were first made to 13 feet below the sea level, leaving the earth at the natural slope; then having to lay the foundations at 36 feet under water level, and to cut through a muddy stratum, the work was done in lengths or sections, the vertical sides of the trench being sustained by boarding and heavy timbering. The sections varied from 23 feet to 33 feet in 
length, and between them like distances were left, and were filled in afterwards when the first sections had been raised to a certain height; in other words, the sections of wall up to a height of 23 feet were divided from each other in the first instance by sections of undisturbed material, by which means the treacherous nature of the ground was more easily dealt with. The wall was thus built in the dry, the water from infiltration was pumped out by machinery conveniently placed for the purpose.

The foundation consisted of a mass of concrete 10 feet thick, composed of 2 parts of Pozzuolana to 1 of lime and 3 of broken stone. The body of the wall was of rubble set in Pozzuolana, and the facing of bricks and ashlar stone, the former being more convenient to handle than ashlar in the close timbered trenches.

Since these works were completed, only a slight settlement had been observed in a few places, but the walls had nowhere been thrust out of the perpendicular.

This result indicated that if careful precautions were taken in the erection of dock walls on ground peculiarly liable to slip, as at Spezzia, and a sufficient weight given to the wall to sustain unusually great lateral pressure, an almost certain immunity from failure may be secured without resorting to bearingpiles.

The Rhone.-At the mouth of the Rhone, facing the river entrance to the St. Louis Maritimes Canal, ${ }^{1}$ the quay walls are com-

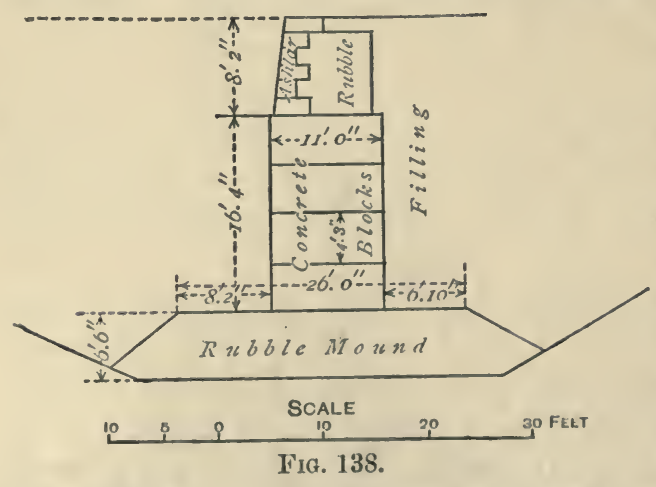

posed of four concrete blocks (Fig. 138), each 11 feet long, 8 feet 7 inches wide, and 4 feet 1 inch high, built up on a base of pierres perdues, 26 feet wide and 6 feet 6 inches high. 'This concrete wall was surmounted by a superstructure of rubble faced with ashlar, 8 feet 3 inches in height, and 9 feet 6 inches wide. The total height from the coping to the bottom of the dredged trench was 
therefore 31 feet, the width of the wall being 11 feet, equal to the length of the concrete blocks.

A precaution against undue ultimate settlement, universally adopted by French engineers, in structures similar to this wall, is to load the concrete wall with blocks before adding the superstructure.

Pola Basin Walls. ${ }^{1}$-The following course was pursued by Mr. H. E. Towle in constructing the enclosing walls of the Pola Dock basin, to provide for anticipated settlements.

The conditions obtaining required that, in order to ensure a water-tight joint with the bottom, the wall should be founded on a bed of tenacious mud, varying from 2 feet to 12 feet in depth, overlying in one unbroken tough sheet rock totally unreliable, and full of irregular cavities and passages of a honeycomb nature.

A plain rectangular section of wall was adopted, as, under the circumstances, offering the greatest advantages and least objections. The width varied from 15 feet to 20 and 26 feet, and slightly exceeded 42 feet 6 inches at the deepest part. The body of the wall. was constructed of béton, deposited in situ, up to within 7 feet 6 inches of the top. The superstructure consisted of inside and outside facings of masonry in 2 feet 6 inch header-and-stretcher courses, backed with common rubble masonry covered with flagging 9 inches thick.

Owing to the fact that the wall was to be founded on a compressible material, which also dipped towards deep water at an angle of from 2 to 10 degrees, it was evident that settlements, causing vertical cracks and fissures, would take place, and it was desirable to ascertain, if possible, when such fissures would be likely to occur.

A careful survey and contouring of the upper and lower surface of the mud bottom, showing the irregularities, mud, and the protuberances and depressions of the rock surface, rendered the location of the cracks almost a certainty, and they were then provided for by vertical joints across the wall at intervals varying from 40 to 90 feet in length.

To check the passage of water through the vertical joints, and to connect the adjoining ends of contiguous blocks of béton, so as to prevent them moving upon each other laterally, a rectangular post 18 inches by 24 inches was inserted vertically 
at each point, reaching from the upper surface of the blocks to the rock.

These posts or keys projected 12 inches into each block of béton, and were made up of two logs of timber 12 inches square, jointed and bolted together. To make up the dimension of 18 inches, one side was smoothed off, and close planking 6 inches thick well secured with bolts and treenails; the joints between the timbers and the planking were then well caulked.

The largest opening that occurred at any vertical joint was $5 \frac{1}{2}$ inches after all appearance ceased. The keys were in all cases found to answer their intended purpose perfectly.

The joints on the inner face were, when the basin was pumped out, carefully cleaned out and walled up with masonry to a depth of 1 foot from the face. On the outer face a pad secured to a piece of timber was firmly braced against the wall, until sufficiently tight to prevent the escape of fine mortar or hydraulic cement which was injected through a tube under a head of about 10 feet above the wall.

Timber Wharfing-Alexandra Dock Entrance, Hull.-The timber wharfing (Fig. 139) forming the sides of the trumpetshaped entrance to the lock is constructed in bays of 10 feet
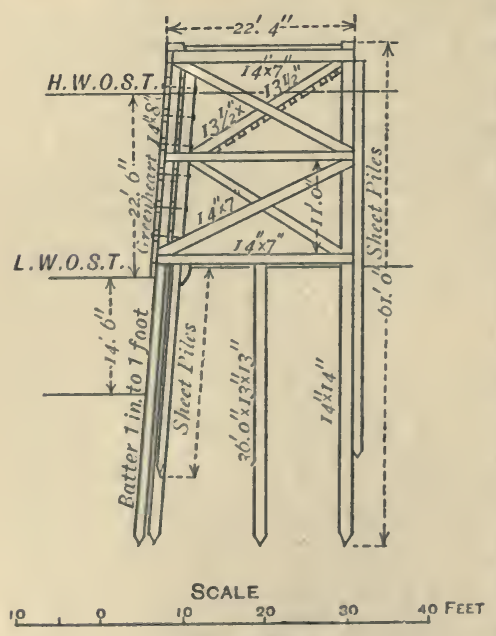

Fig. 139. span generally, and 3 feet only at the corners. The front and back piles are 61 feet long, 14 inches square, braced longitudinally and transversely with timbers $13 \frac{1}{2}$ inches square and 14 inches by 7 inches, and covered with a 5-inch decking. Grooved and tongued half-timber sheet-piles were driven all along the front. This sheeting was driven simultaneously, all the piles in one bay being pitched together and driven about 6 feet at a time, until the whole bay was driven down. This method of driving ensured the tongues being properly engaged in the grooves, and the sheeting being very close and tight. These piles held up the material at the back while the river bed was deepened in front. During construction, the mud accumulated 
so deeply in the recesses at the back that whole-timber sheet-piles had to be driven behind the jetties to retain the mud, in order that the soil between the piles might be excavated to enable the braces to be fixed at as low a level as possible. ${ }^{1}$

A design adopted by Mr. W. Dyce Cay, at Aberdeen, combining a pitched slope with a timber wharfing, is shown by Fig. $1400^{2}$

Queen's Quay, Belfast. - The construction of the Queen's Quay, Belfast, which is 2150 feet long, is shown by Fig. 141. The bearing-piles, of pitch-pine 12 inches square, are 48 feet long in the front row, in the centre row 43

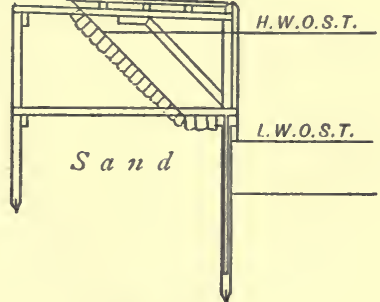

FiG. 140. feet, and in the back row 40 feet, the front and back piles being braced together by diagonal timbers 12 inches by 6 inches. Longitudinally the piles are spaced 6 feet apart centre to centre. The spaces between the piles of the front row are filled in with close sheeting of American elm, 37 feet long by 11 inches in thickness. The platform consists of timber joists 12 inches wide by 6 inches thick, supporting close planking 6 inches thick, covered with a layer of bitumen and paved with stone setts.

The back row of piles was close planked with
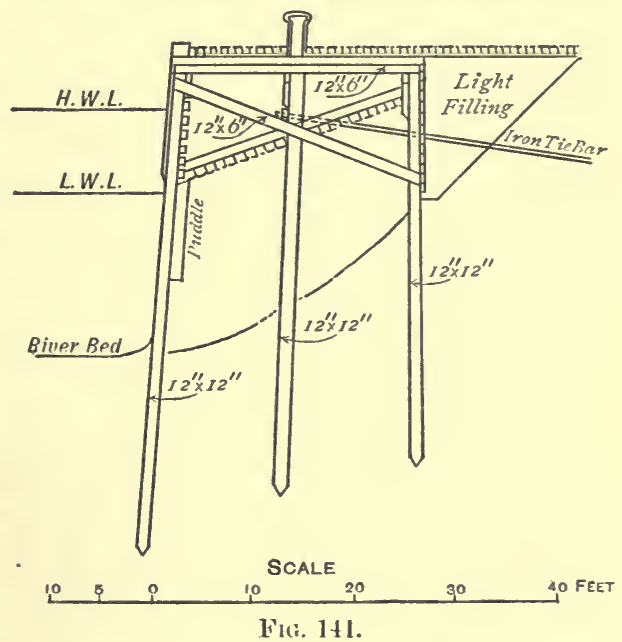
4-inch timber, and the back filled in with light material. The space between the front and back rows of piles is filled and formed to a slight slope, and pitched with square setts. The

$$
\text { ' M.P.I.C.E., vol. xcii. p. } 15 \text { S. } 2 \text { Ibid., vol. xcii. p. } 173 .
$$




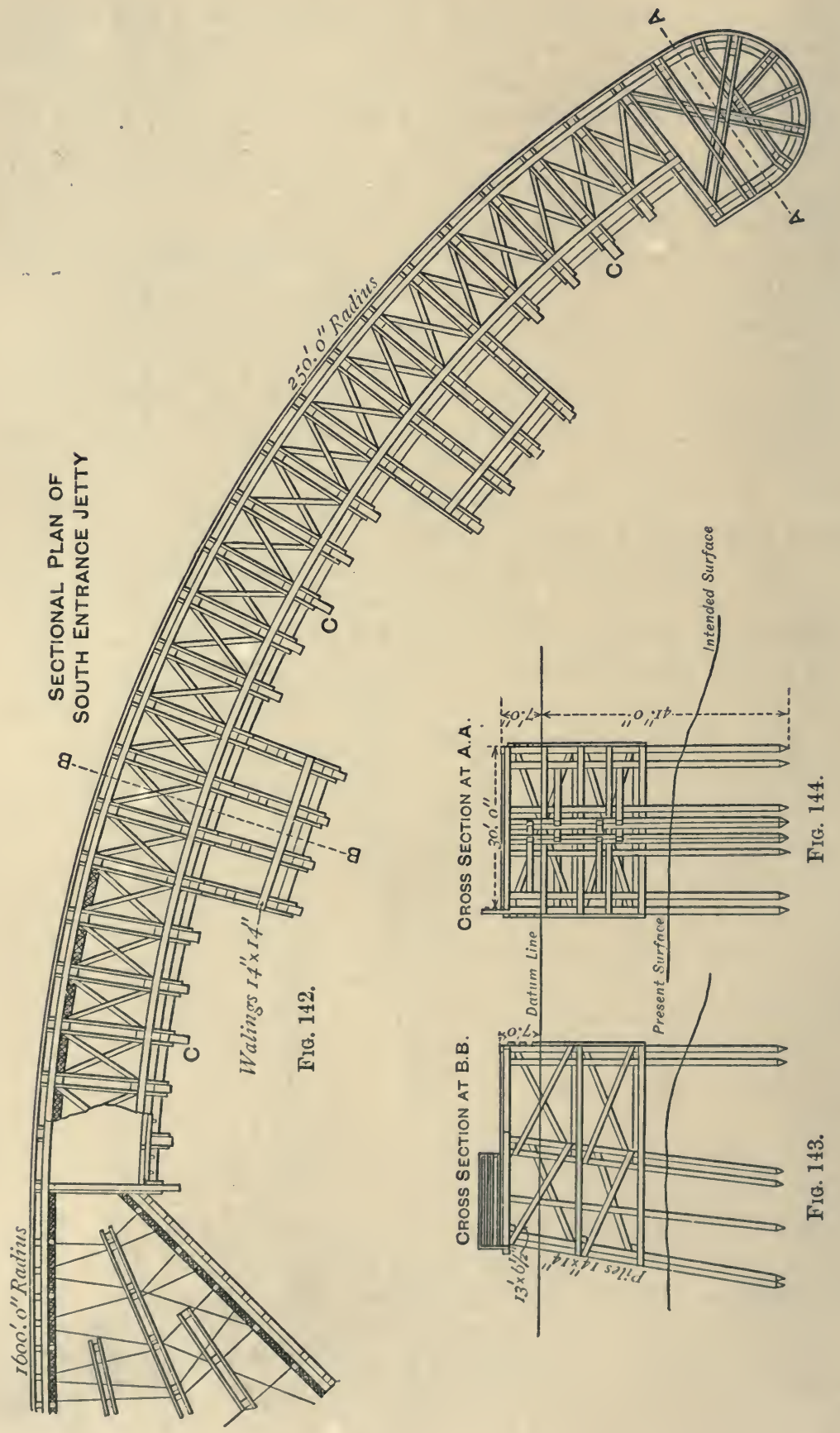


front row of piles is finished with open planking on the inside, to prevent the deposit of bulky matter on the slope.

Royal Albert Dock.-Figs. 142 to 144 show the timber-work .jetties forming the bell-mouth entrance to the Royal Albert Dock. The curved part is open timber-work, but the triangular part to which it is attached is filled in solid. ${ }^{1}$

${ }^{1}$ Engineer, vol. 1. pp. 6, 10. 


\section{CHAPTER VI.}

Dry or graving docks-Locks-Early practice-Docks in a tideless sea-Method of construction-Slope of dock floor-Dimensions of docks-Plan of docksDepth over sill-Local and shipping conditions to be studied-Floor of dockMud docks of India-Avonmouth dock-Genoa dry docks-Panama canal locks -Wivenhoe dock-Green's dock, Blackwall-Toulon docks-Timber docksMount Stewart dock-Calais docks-Somerset dock, Malta-Extcnsion of dock at Leghorn-Glasgow No. 2 dock-Esquimalt dock.

THE earliest example of a graving or repairing dock is illustrated by the practice of the Greeks, who ran their boats upon the sandy beach, and then dragging them out of the reach of the tide, surrounded them with earthworks for their protection. ${ }^{1}$ A natural improvement, where the ground was suitable, was to prepare an inclined plane of timber to facilitate the operation. Where the tides were favourable, the vessels were simply beached at high-water spring tides, and then left high and dry till the following springs. In situations, however, where the formation of the beach allowed of it, a convenient bed or grave was dug for receiving the vessel during high water at springs, such excavations being protected from the ingress of the water at the following springs by an artificial bank thrown up in the interval. This was the first graving dock.

The ordinary dry dock, as formerly used in tidal rivers, was generally a simple excavation, usually lined with timber, with a brick or concrete floor, and, to exclude the tide, fitted with gates or floating pontoons. The vessel entered at high tide, and the entrance closed; as the tide went down, the dock emptied itself through a tidal sluice, and the vessel settled down on the blocks prepared for it, and being at the same time shored horizontally to prevent its heeling over.

The sluice and entrance being closed, the returning tide was

I II.P.I.C.E., vol. хxv. p. 293. 
excluded, and with moderate pumping the ship was kept dry enough for access. In a tideless sea, or where there was comparatively little or no rise and fall, a graving dock was precisely similar, except that the whole of the water had to be pumped out. As ships increased in size, dry docks became important works; solid masonry was adopted for lining, and the sides constructed with steps - technically termed altars-for the double purpose of affording convenient access and also for the support of the necessary timbers for shoring. Pumping machinery on a large scale was added for rapidly clearing the water, or for rendering that operation altogether independent of the tides.

It is worthy of note that the first principles involved in early dock construction still obtain. A first-class dock of the present day, however, differs largely in its dimensions, details of construction, and in the elaborate character of its equipment, and necessitates a large amount of engineering skill of the highest order.

The method of construction to be adopted will depend greatly on the strata, and whether it is likely to be waterlogged on the completion of the works and the cessation of the temporary pumping.

With such material as mud, silt, and sand, or any pervious strata, it may be necessary to surround the site with one or more rows of continuous sheet-piling for the purpose of cutting off the water.

The work in the sides of a dock will partake of the character of retaining-walls of a section and weight sufficient to withstand the thrust of the material in a saturated condition. They will also be called upon to counteract, as abutments or piers, the upward hydrostatic pressure on the floor.

The floor is generally constructed with radial joints so as to preserve the character of an inverted arch, by which the upward hydrostatic pressure is transferred to the sides. In the case of very wide docks, where the floor is formed of horizontal work, special care is required to ensure stability.

The efficiency of all flat work in the floor of a dock that has not in itself a weight per unit of area exceeding the hydrostatic pressure will depend upon the means and care taken to prevent the water penetrating between the foundation strata and the work, and so lifting, and possibly destroying it; hence the importance of using such precautions as close sheet-piling for the 
purpose of cutting off springs, and removing all doubtful material before putting in the permanent work.

When the excavations are in rock, it may be necessary to adopt a lining only. In such a case, it will be of the utmost importance to key the work in such a manner as to get a good grip on the foundation strata, and at the same time to break up all continuous joints between the lining and the natural rock.

It is customary to give the floor of a dock a rise of a foot or more towards the head, so as to drain the water to the entrance. In the earlier docks, with a moderate depth of water over the sill, and when the water was drained into the river or sea at low tide, there was an advantage in this; but in modern docks, with the greater draught of water over the sill, bringing it as a rule some depth below low-water mark, there is no advantage in forming the floor out of level longitudinally; it is more convenient and certainly not more costly to construct the floor level throughout, giving a sufficient fall transversely from the centre either way, and providing for any longitudinal drainage that may be necessary in the side gutters.

The dimensions of a dry dock must be determined by the class of vessel it is intended to accommodate, and the characteristics of the site. As regards the cross section, the desideratum is to have ample room around all parts of the ship, so as to admit of efficient examination and repair, and the admission of light and air to the bottom of the vessel. An abnormal width involves additional cost of timber and labour for shoring, and the additional cost of pumping; excessively long shores are inconvenient to manipulate, especially in removing from the dock after use, and where the width of the wharf on the dock side is contracted, they are a decided disadvantage. To meet some of these objections, Mr. Abernethy, M.I.C.E., in constructing docks at Birkenhead and Falmouth, adopted at certain portions of the dock upright piers in place of the altars. ${ }^{1}$ In a later dock, however, constructed by the same engineer at Falmouth, these upright piers were omitted, presumably on account of the obstruction they offered to the light and air reaching the bottom of the ship.

At the head, the plan should follow as closely as possible, or as circumstances will permit, the bow lines of the largest vessel to be accommodated; by doing so, less expense is incurred in con-

$$
1 \text { M.P.I.C.E., vol. xxv. p. } 321 .
$$


struction, and frequently valuable wharf space may be gained. There will also be greater economy in working, inasmuch as shorter shores and timbers for stages are required, and the quantity of water to be pumped is reduced.

The depth of water over the sill will be governed by the draught of the ships to be accommodated, the position of the entrance-that is, whether it opens upon a basin where the water is always kept practically at the same level, or into a tidewaythe range of tide, and whether it is intended that ships should be able to enter at low water of spring tides.

The length of a dock will, like the other dimensions, be governed by the class of ship to be accommodated. Whilst, however, it may be desirable to provide for the longest ship likely to visit the port, such a dock may be too long for the ordinary requirements ; in such a case, the dock may be divided into two chambers. The advantages of such an arrangement are that the expense of pumping out the whole of the water when a moderate-sized vessel is docked is avoided, and that two ships may be dealt with at the same time without inconvenience. There is also this further advantage, that it may be possible to complete the outer section so that it may be brought into use whilst the inner section is in progress, the intermediate gates or caisson forming the dam between the two.

Entrance locks differ from dry docks in having gates or caissons at both ends, and in detail as regards the width, and that the altars are as a rule omitted either wholly or in part. In some cases, however, the arrangement of the altars, slides and slips, and means of pumping, are such as to admit of a lock being used as a dock when required.

In designing the lock, local and shipping conditions will have considerable weight. For a large dock, it may be advantageous to make the width sufficient to admit of two ships lying side by side, with the object of saving time in passing ships in or out of the basin, reducing the quantity of water required for lockage, and avoiding the necessity of constructing additional locks.

A wide lock is advantageous where there is a large traffic by lighters, or small barges, which have to be passed into the basin for transhipment of cargo. Such traffic can hardly be dealt with by a small lock in a satisfactory manner.

By dividing a long lock into two parts, it can be used for 
moderate-sized vessels for long periods before and after high water, without unduly reducing the water in the basin; this is a matter of great importance where the water level has to be kept up by pumping. This plan ${ }^{1}$ of dividing a long lock is, however, considered by some injudicious, inasmuch as it involves the risk of breaking a long ship's back should it ground on the middle sill. An alternative means of providing for the smaller class of vessels, when it is necessary to pass them out singly, is to have a short lock alongside the longer one.

There being always a tendency to increase the draught of vessels, it is a wise precaution to place the sill of a lock as low as possible, although it may not be contemplated to make the same depth in the approach in the first instance, and in muddy rivers or estuaries there might be some trouble in keeping the entrance clear. In after time, as the necessity arises, the depth outside may be lowered with comparatively little difficulty; but to lower the sill of an entrance would be a very formidable and costly operation.

Whilst a batter on the face of an ordinary basin wall is an advantage as adding to its stability, there is a decided disadvantage, as regards the side walls of a lock, in giving more than a nominal batter to the face; even a nominal batter is unnecessary, regarded as an aid to stability in view of the support afforded to the walls by the lock floor. Although with the lock full there may be ample room for two ordinary vessels, yet, with much batter on the face, as the water level is lowered, the effective width will decrease, and consequently there will always be, when two ships are being passed out at the same time on a falling tide, or at low water, some risk of one being nipped against the side; the most satisfactory way is to have the side walls of the lock vertical, so as to ensure the same width at whatever the water level may be. Through the entrance, a plain straight face is preferable, inasmuch as when the gates are open there are no projections beyond the fair line of the gates, and consequently no risk of the bow or bilge of a vessel striking the quoin of the vertical recess provided for the accommodation of the gates, which would be the case were the side walls of an entrance constructed with a batter. Where ordinary floating-ship caissons are used instead of gates for closing the entrance, the side walls cannot be made perpendicular, 
or with a very slight batter, inasmuch as the design must be such as to admit of the caisson being floated in or out of its position, the batter on the side walls must therefore be sufficient to enable the caisson to rise to a sufficient height to clear the stems from the stop, without endangering the stability of the caisson.

For the purpose of keeping the floor of the gate recess and the roller-paths clear of mud, sluiceways are generally arranged in the side walls at the back of the gate recesses in such a manner as to distribute a current of water over the entire area. The scour caused by the adjustment of the lock water level has been found in practice to be sufficient to keep the rollerpaths clear of mud.

Cracks in Floor of Docks and Locks.-When the strata is at all of a yielding character, cracks will frequently appear in the floor joints, especially near the centre. These cracks are caused by the settlement of the side walls, due to the greater pressure their weight throws upon the foundations, and inducing a spreading or bearing action on the invert of the floor. This tendency to crack can only be met by distributing the weights over as large an area as possible, careful attention to the foundations, and in putting in the backing and the adjustment of the pressures due to the weight of the side walls and backing combined, so that the resultant may fall somewhat nearer the front than is usually considered desirable in ordinary retaining-walls. This will induce a slight inward tendency in the side walls, which will, however, be resisted by the invert of the floor.

Mud Docks.-In India, very primitive methods of docking appear to be still in use at some of the minor ports, as the following account ${ }^{1}$ of the method pursued at the port of Vizagapatam will show. A large ditch of a little more than the ship's length, and deep enough to contain sufficient water to float the ship, is excavated in the mud at right angles to the river, and into it at high water the vessel is floated. A bund, or dam, consisting of two rows of strong stakes driven into the mud, lined with common palmyra, date, or bamboo mats, and the intermediate space filled with sand, mud, or silt, is then formed across the entrance. The basin being surrounded by a high mud bank formed by the material excavated from the dock, the water level is raised by returning some of the exca-

${ }^{1}$ Abridged from Indian Engineering, vol. vi. p. 372. 
vated material, and thus raising the bottom of the basin, and consequently elevating the water, and with it the vessel, which is by this process raised considerably higher than the level of the water in the river. The water being then run out, strong beams of timber are next placed transversely under the ship at two, three, or four different places, varying according to the length of the ship. At the place where the beams are to be placed, a trench is dug under the vessel, three beams are then passed under her, and placed side by side, the same being repeated at as many places as deemed necessary. The mud thrown in is then removed and the banks levelled, so as to expose the sides and bottom of the ship. For undocking, or rather for lowering the ship into the dock after repair, hawsers coiled into the shape of a cone are used. The diameter of each cone at the base is about 5 or 6 feet, and at the top about 2 feet less; as the coiling is going on, it is made solid by filling the interior with mud. Four of these cones are generally used, two

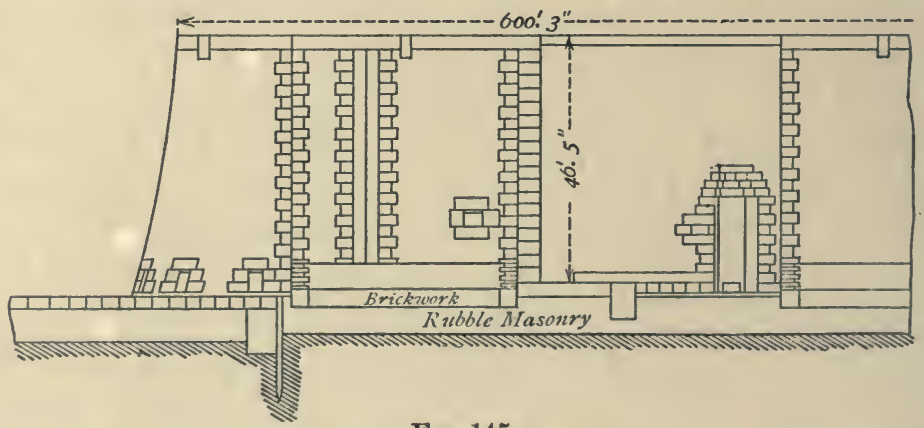

FiG. 145.

on each side of the ship, unless it is of more than 300 tons burthen, then the number is increased. After the coils are placed in position, the beams are removed, and the excavation completed to the required depth. The vessel, which rests entirely on the cones, is then gradually lowered by withdrawing simultaneously from the base of each cone, a coil or flake, causing the vessel to bodily subside at a slow rate to the required depth. The cross-bund or dam closing the entrance is then removed, and the water flowing in floats the vessel at high tide. Vessels of 400 to 500 tons have been built and undocked in this manner, at Vizagapatam.

Avonmouth Lock ${ }^{1}$ (Figs. 145 to 150). - The total over-all length 1 M.P.I.C.E., vol. Iv. p. 19. 
of this lock is 600 feet, and between the outer and inner gates 454 feet; this latter length is divided by a set of intermediate

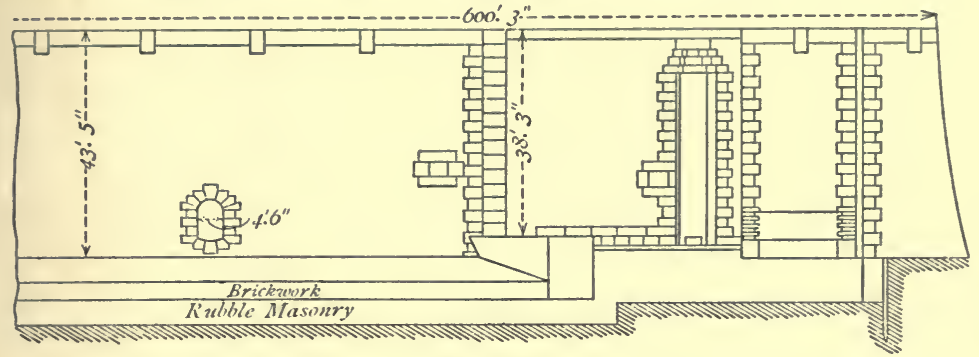

Fig. 146.

gates into two compartments, the inner one being about 50 feet longer than the outer one.

The foundations consist of rubble masonry, varying from

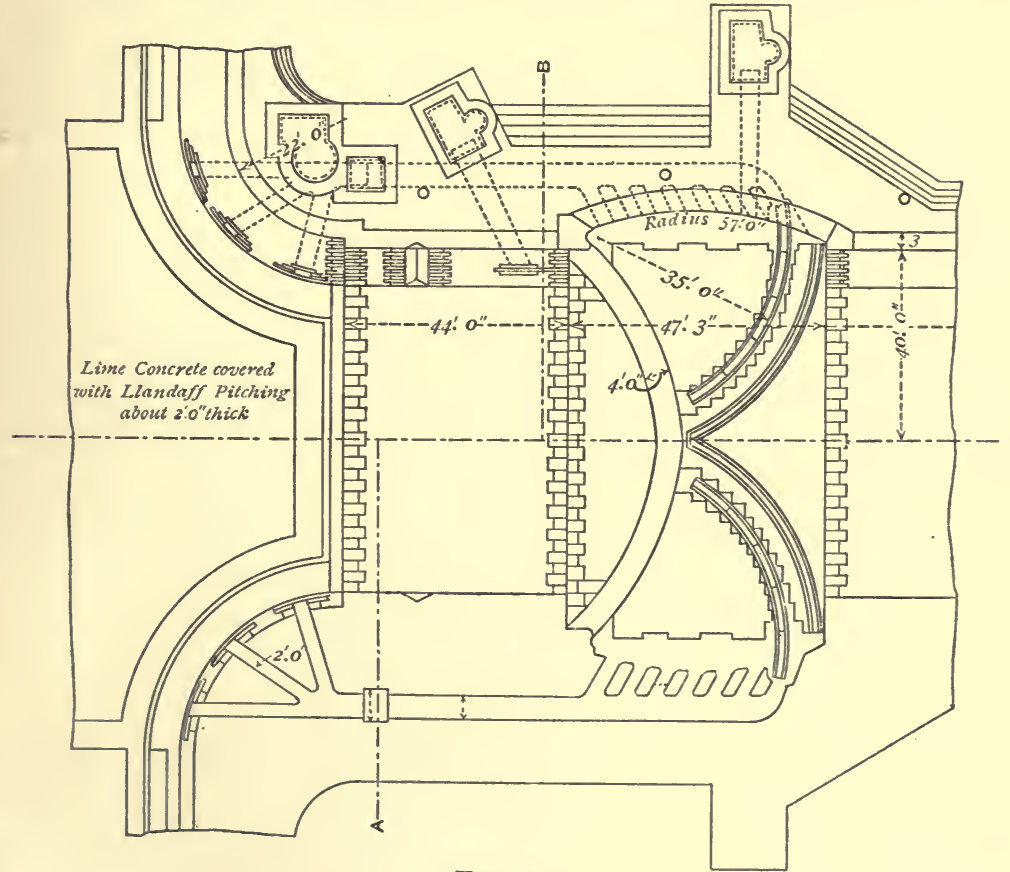

Fig. 147.

100 to 120 feet wide, and from 5 to 6 feet deep; on this bed of masonry the walls and inverts are built. The side walls are constructed of rubble masonry faced with random-coursed 
ashlar. The height from the coping to the skewback of the invert is 47 feet 5 inches, with a batter on the face of 6 feet 3 inches curved to a radius of 157 feet. The inverts are of brick

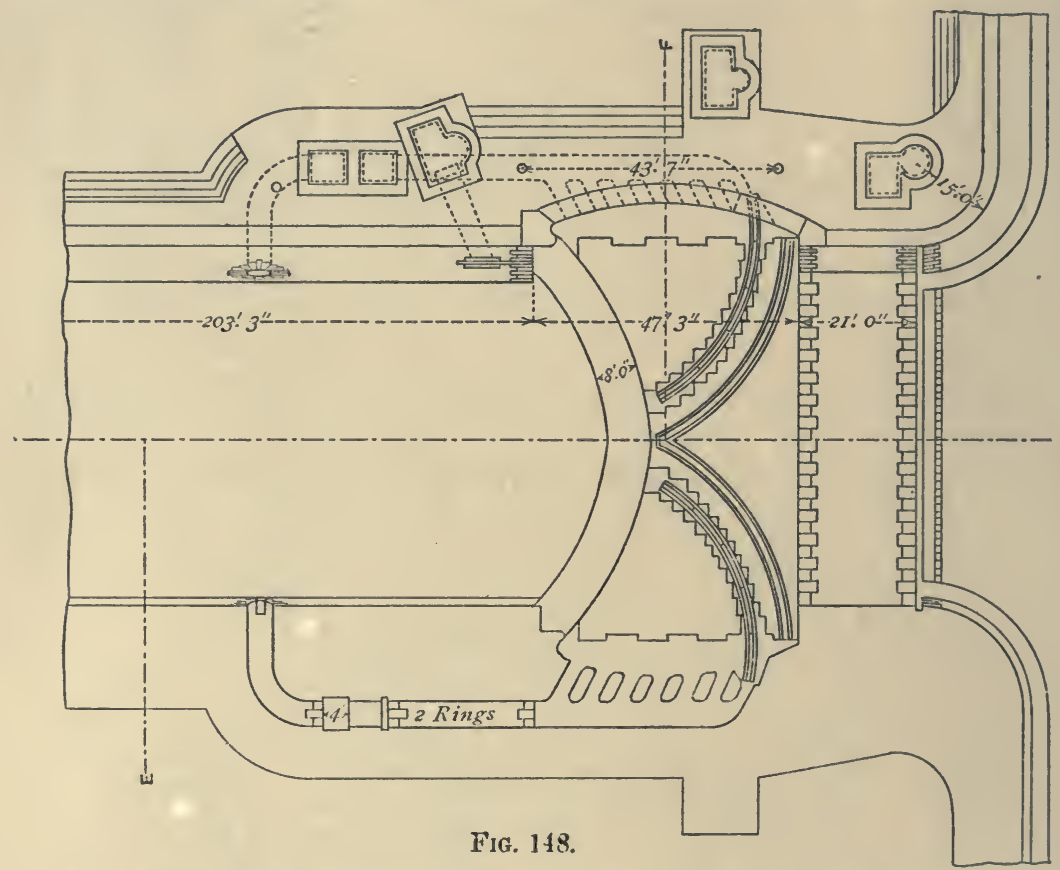

3 feet thick, the radius to which they are formed being 105 feet, and the depth, at the centre, from the chord line 4 feet.

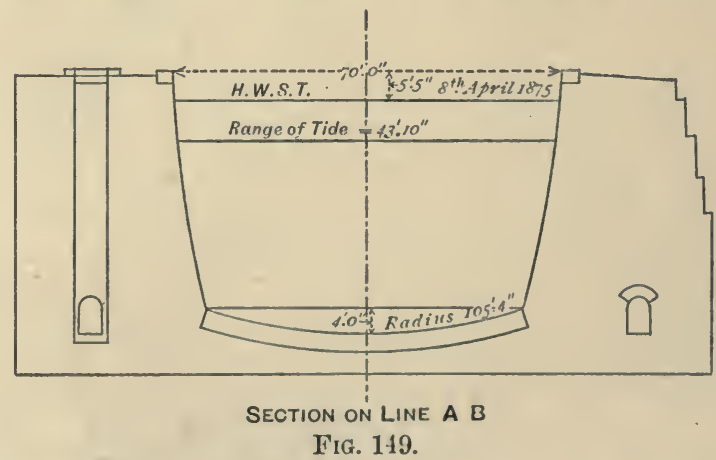

The lower sills are placed 2 feet 7 inches above low water of equinoctial spring tides. The lift of the upper sill is 8 feet 3 inches above the dock floor. 
Sluice-ways for adjusting the level of the water in the lock and scouring the gate floors are formed in the interior of the side walls; they are 7 feet wide by 4 feet 6 inches high, constructed with stone sides and brick-incement arches and inverts; they are placed parallel with the line of the walls with their outlets within the locks. Placed 50 feet from the hollow quoins within the gate recesses there are seven

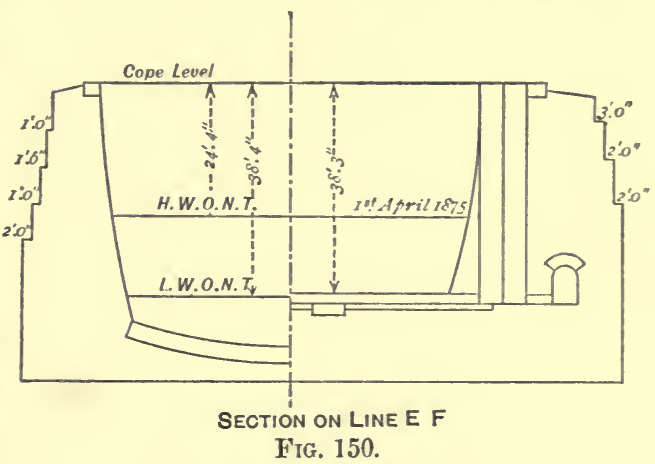
inlets 2 feet 4 inches wide by 1 foot 9 inches high, constructed with granite cutwaters and lintels; each of the sluice-ways is furnished with a strong cast-iron frame and valve, both being fitted with brass faces. The upper sluice-ways are also furnished with a pair of wooden paddles, fitted for the purpose of allowing repairs being carried out to the iron penstock valves.

The apron in front of the lock at the outer end extends 60 feet beyond the invert, and is 120 feet in width. It consists of a mass of lime concrete 6 to 8 feet deep, with blocks of stone from 2 to 3 tons weight embedded in it, and surrounded by walls of Portland-cement concrete 5 feet in thickness, founded at a depth of from $S$ to 10 feet below low-water mark of equinoctial spring tides, or about 2 feet lower than the hearting. The top of the apron was pitched with heavy stonework rough faced but dressed on the joints, and bedded in lias-lime mortar.

Genoa Dry Docks. ${ }^{1}$ - These docks have the following dimensions :-

Maximum length at coping, including entrance $\begin{array}{llllllllll}\text { Effectire length on the blocks } & \ldots & \ldots & \ldots & \ldots & \ldots & 525 & 0 & 656 & 0\end{array}$ $\begin{array}{llllllllllll}\text { Width at coping } & \ldots & \ldots & \ldots & \ldots & \ldots & \ldots & \ldots & 96 & 0 & 81 & s\end{array}$

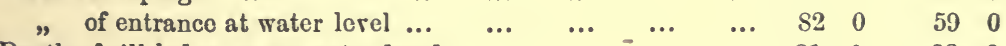
$\begin{array}{lllllllll}\text { Depth of sill below mean water level } & \ldots & \ldots & \ldots & \ldots & 31 & 0 & 23 & 0\end{array}$ $\begin{array}{lllllllllll}\text { Greatest depth in dock } & \ldots & \ldots & \ldots & \ldots & \ldots & \ldots & 32 & 9 & 29 & 6\end{array}$ Maximum length of ressel between perpendiculars the docks can take in 5610

6950

1 M.P.I.C.E., vol. xciii. p. 521; and Giomale del Genio Cevi'e, Quinta Scrie, vol. ii. p. 75. 
172 NOTES ON DOCKS AND DOCK CONSTRUCTION.

The maximum range of spring tides at the port of Genoa does not exceed two feet.

The site of the works (Figs. 151, 152) being in open water, special means of construction were necessary. A system of floating caissons proposed by Messis. Zschokke and Terrier was

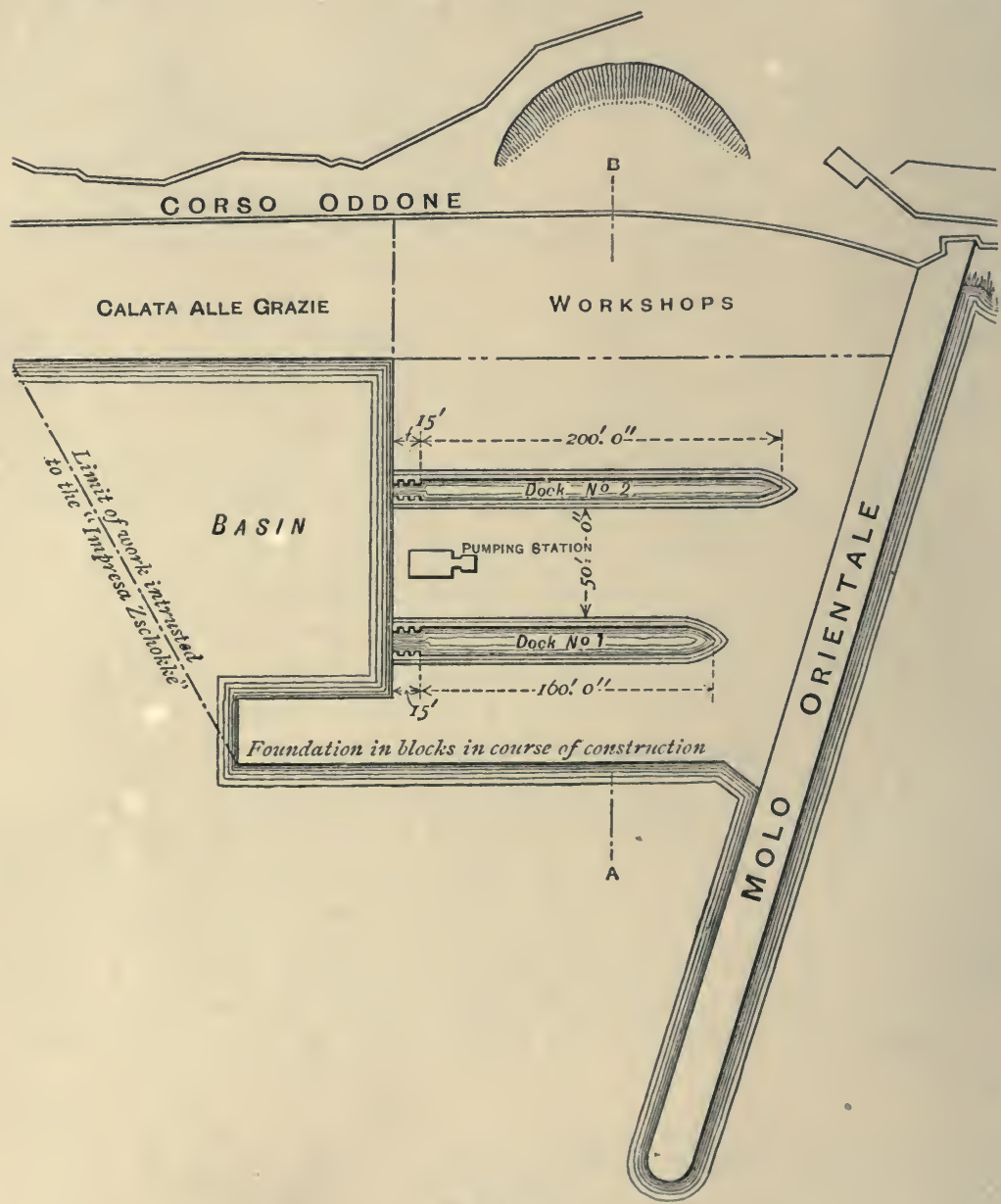

Fig. 151.

therefore adopted, not as the most economical, but as affording the best guarantee of success from a technical point of view (Figs. 153 to 155).

Each caisson is 105 feet by 225 feet, or sufficient to take in the entire width of the dock. The working chamber is 6 feet 
6 inches high ; and above it is the equilibrium chamber, 10 feet 6 inches high; above this chamber there are six regulating wells or tanks 10 feet wide and 40 to 52 feet long by 38 feet high, open at the top and provided with pipes and valves for admitting and discharging water. These tanks also formed the supports for the staging to carry the workmen, engines, air compressors, cranes, and other appliances. The whole was weighted with 3040 tons of iron ballast, and was floated into position, and sunk or raised by admitting water into the chambers or forcing it out by compressed air.

The caisson was used only for working in, and no part was left permanently in the work.

The system of working with this caisson is as follows:-When the wells and the equilibrium chamber are empty, the caisson floats and is brought into position; by introducing water into the equilibrium chamber, it is sunk until it touches the bottom (in this case, at a depth of 33 feet); there will then be about 2 feet 6 inches of water in the chamber. When it is desired to commence work, compressed air is forced into the working chamber, and more water let into the equilibrium chamber till the caisson rests firmly on the bottom. The excavation is then began, and the caisson follows it down by the addition of water in the wells. In this way the maximum depth of 50 feet below water level is reached, when the water will stand in the wells at a height of 21 feet above the top of the working chamber; concrete is then filled in through tubes
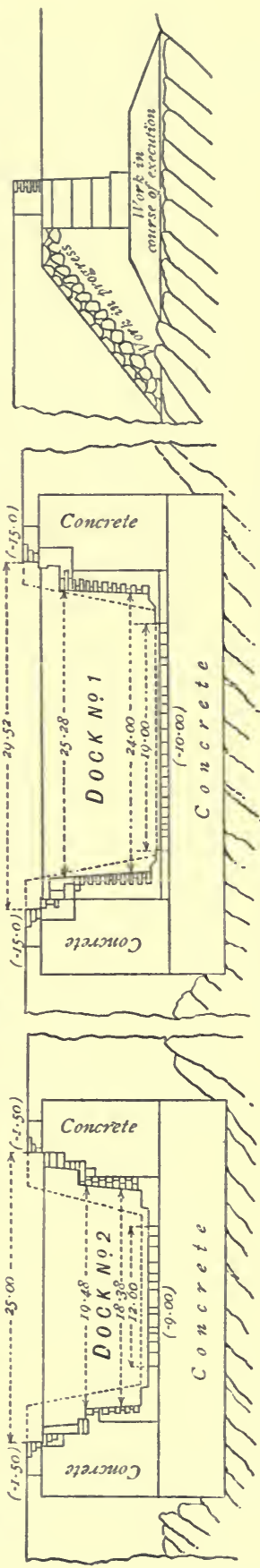
made for the purpose, and, as the work progresses, the caisson is raised by forcing water out of it. In this manner the whole

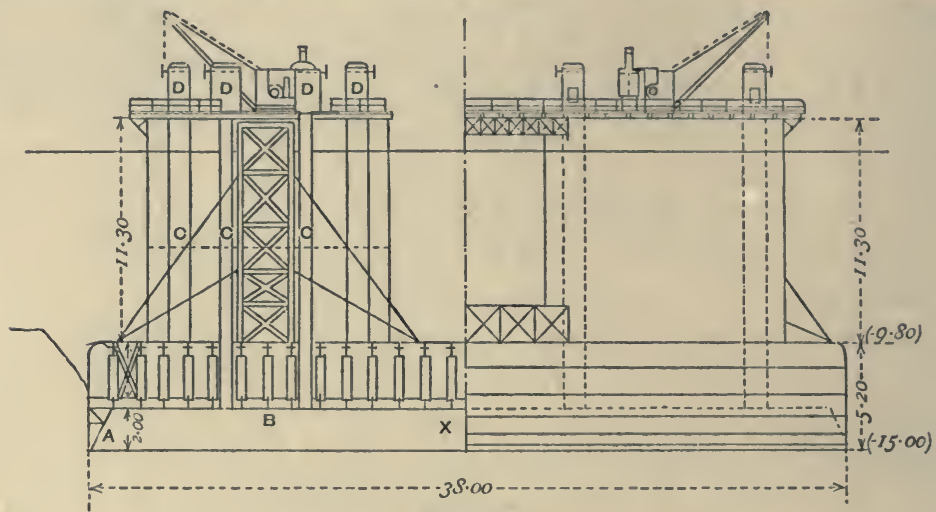

FIG. 153.

of the dock bottom is put in by sections extending the full width. After the bottom is completed, the concrete in the side walls is put in by means of caissons slung from pontoons.

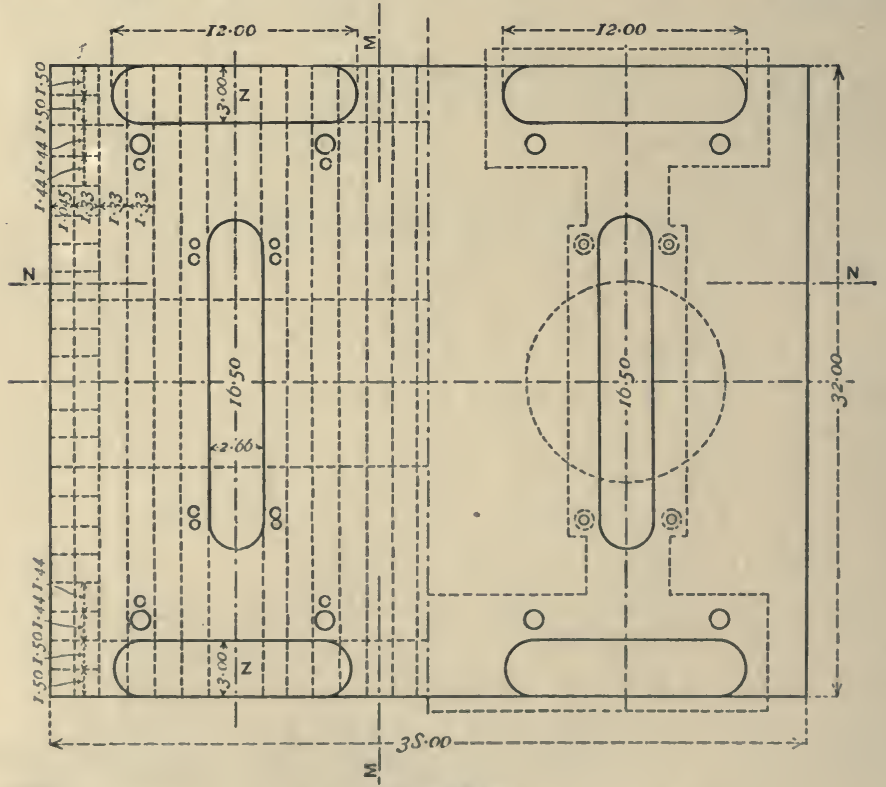

FIG. 154 .

Panama Canal Locks. ${ }^{1}$ - These locks, of which a typical 'Engineering, vol. xlviii. p. 512. 
example is shown by Figs. 156 to 160, designed and partly constructed by M. Eiffel, present many points of originality. The length from centre to centre of the caisson chambers is 652 feet 2 inches, and the clear length on the floor 584 feet. The width at the coping level is 67 feet 7 inches, and at the bottom 44 feet 7 inches, by a depth, from coping level to the floor, of 68 feet 1 inch. The depth of water over the lower sill with the lock fall is 62 feet 4 inches, and over the upper sill 27 feet 1 inch. These dimensions are sufficient to allow of the admission of the largest types of trans-Atlantic steamers.

The sections show the excavations in the solid rock; where,

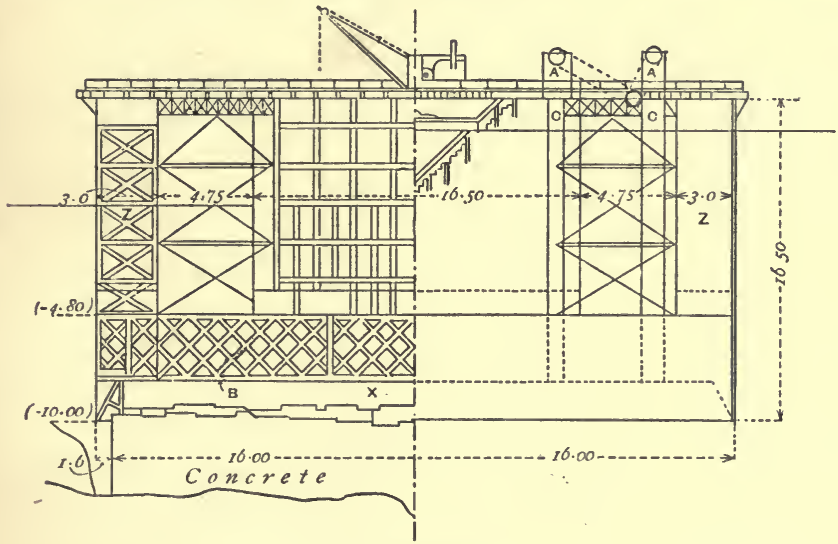

Fig. 155.

however, the ground proved unfavourable, the sides and bottom would be lined with masonry.

The entrances are shown to be constructed with iron caissons recessed into the rock and filled with concrete. The sides are vertical, and the width 61 feet 6 inches.

A very special feature in these locks is the method adopted by M. Eiffel for the admission and discharge of the water. This is effected by two lines of iron pipes about 13 feet in diameter, laid in grooves cut in the bottom of the lock and extending from end to end, and terminating outside the entrances where the openings for the admission or discharge of the water are controlled by valves. These mains are set in concrete with the upper side just beneath the floor of the lock, except under the entrances, where they are buried entirely beneath the concrete. 

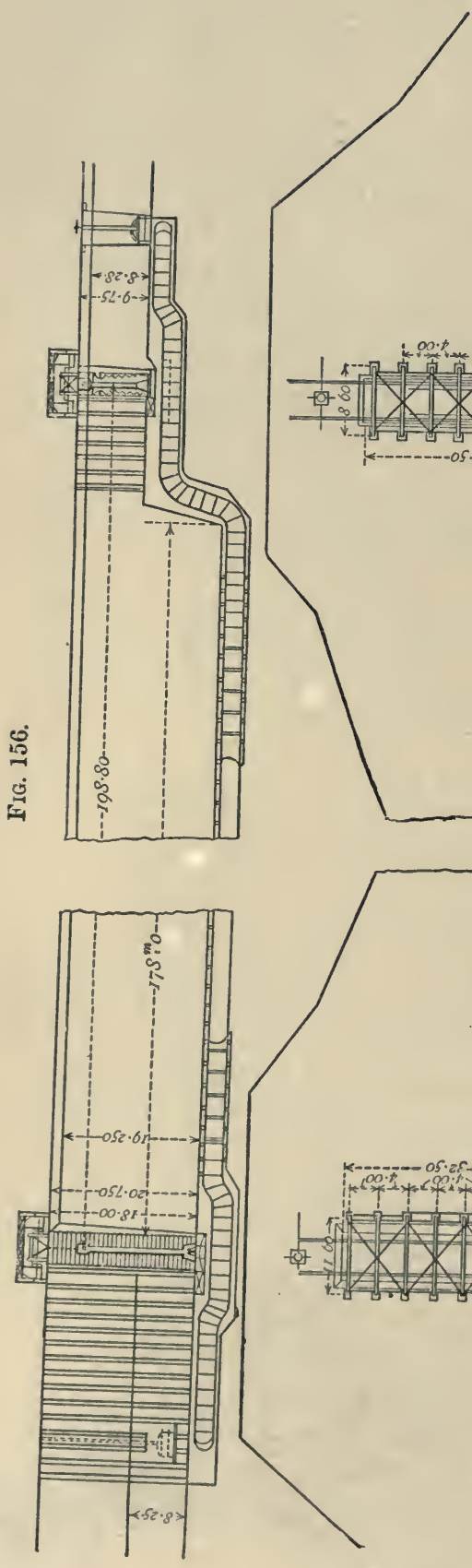
In the upper side of the pipes within the lock there are openings at frequent intervals along the whole length (Figs. 156 and 157), and it is through these openings that the water is

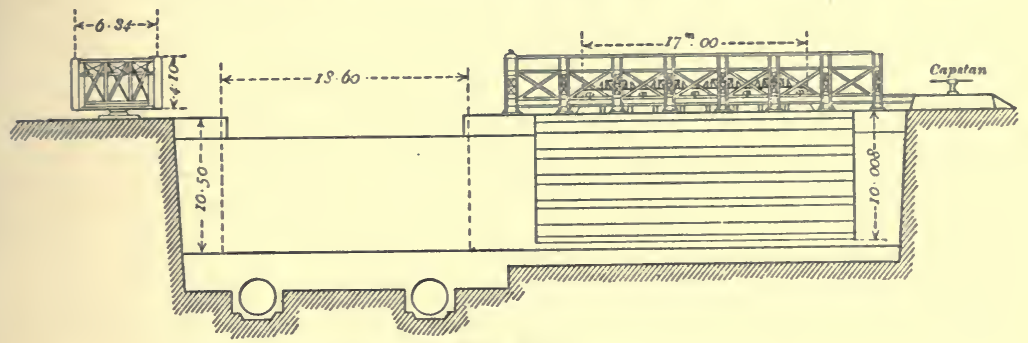

FIG. 158.

discharged or admitted according as the sluices at either end are operated. It is claimed that many advantages attend this method of regulating the water level; one of the most important being that the admission or exit of the 5.00 water is unattended with any agitation of the surface.

The arrangements for closing the ends of the lock was by float-

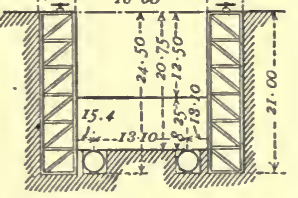

Frg. 159.

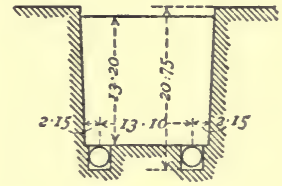

FIG. 160. ing caissons moving into chambers with a swing-bridge spanning the entrance, the whole being moved by hydraulic machinery.

Wivenhoe Dock. ${ }^{1}$ - A good example of a small dry dock suitable for yachting purposes is shown by Figs. 161 to 163.

This dock, constructed from the design of Mr. R. M. Wilkinson, A.M.I.C.E., is 205 feet long, 45 feet wide between the copings, and 35 feet wide in the entrance. The total depth from coping to invert is 18 feet, affording accommodation for vessels drawing 15 feet of water.

In plan the dock conforms, at the head, closely to the shape of the class of vessel it is designed to accommodate, and so economizes surface area, and reduces the quantity of water to be pumped.

Two rudder wells are provided, that nearest the caisson being intended for steam-vessels which have their rudders vertical, and the inner for sailing-ships in which the rudders

1 Engineer, vol. 1xvi. p. 30 ; vol. 1xix. p. 158. 
178 NOTES ON DOCKS AND DOCK CONSTRUCTION.
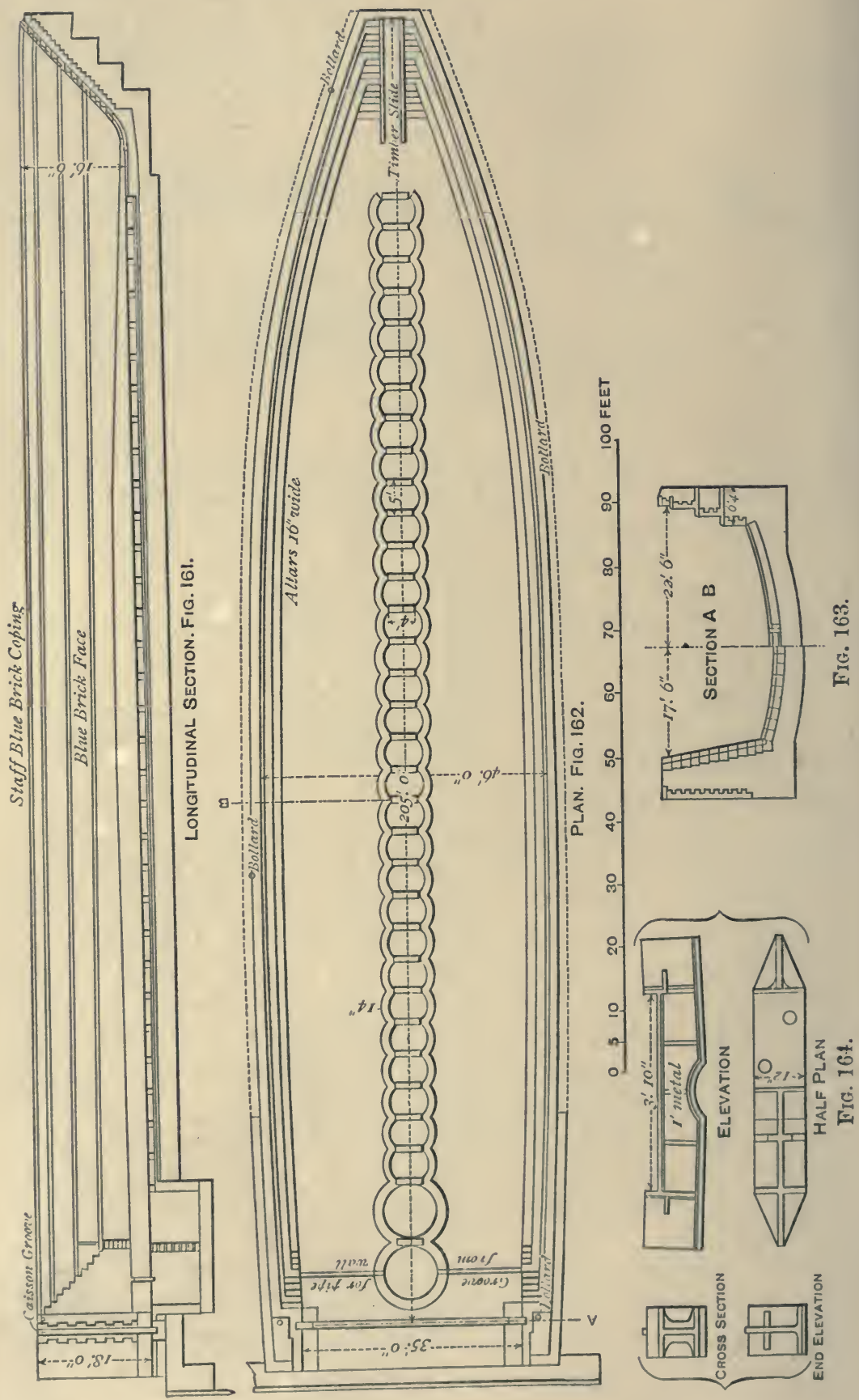
generally slope. A special feature in this dock is that a portion of the invert in the centre has been omitted, and castings (Fig. 164) substituted to take the thrust of the arch, and forming a series of shallow wells down the centre of the dock. The castings take the place of the lower keel-blocks; the upper blocks being removed, and the vessel grounded upon the castings, advantage can be taken of the full depth of water in the dock whilst the wells or spaces between the castings admit of free passage under the vessel's keel.

The work was carried out in brickwork faced with Staffordshire blue bricks, set in 3-to-1 cement mortar, and backed with concrete composed of 1 part Portland cement to 10 parts of ballast and sufficient sand to fill the interstices. Stone was only used in the caisson groove to form the water-tight faces.

A caisson was adopted for closing the entrance in preference to gates, in order that the water might be retained in the dock for sluicing the outside approach.

Messrs. Green's Dock, Blackwall. ${ }^{1}$-This dock (Figs. 165 to 167), constructed from the plans of Messrs. Kinipple and Morris, is arranged to take in two vessels when required, by placing two diagonal lines of keel-blocks.

The dock increases in width from the entrance towards the head, and at a point about 136 feet from the caisson stop or meeting-face of the invert there is an offset or break in the east-side wall for stairs and timber slide. From this point, the side walls are continued to the head in regular curves of 1152 feet radius. The head of the dock is circular to a radius of 25 feet at coping level.

The following are the principal dimensions :-

Clear length on centre line from caisson stop to coping at heal $\quad \ldots \quad \begin{array}{cccc}\text { Ft. } & \text { in. }\end{array}$

$\begin{array}{llllllllll}\text { Width of entrance at coping level } & \ldots & \ldots & \ldots & \ldots & \ldots & \ldots & 65 & 0\end{array}$

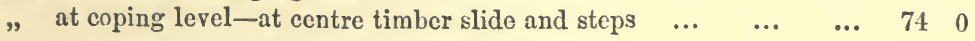

$\begin{array}{lllllllllll} & \| \quad & \quad & \end{array}$

$\begin{array}{lllllll}\text { Depth of water on sill at high water of ordinary spring tides } & \ldots & \ldots & 23 & 0\end{array}$

$\begin{array}{llllllll} & \prime \quad \text { over bottom of dock at ordinary spring tides } & \ldots & \ldots & 25 & 0\end{array}$

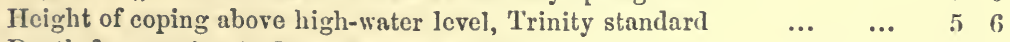

$\begin{array}{llllllllll}\text { Depth from coping to floor of caisson berth } & \ldots & \ldots & \ldots & \ldots & \ldots & 29 & 6\end{array}$

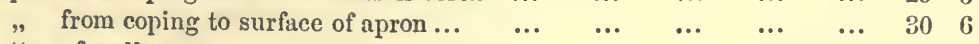

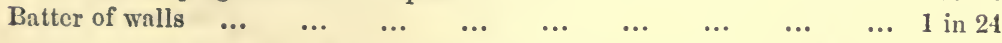

1 Engineering, xxvi. p. 110. 
I8O NOTES ON DOCKS AND DOCK CONSTRUCTION.

The strata consisted of made ground, peat, sand, and gravel, overlying the London clay.

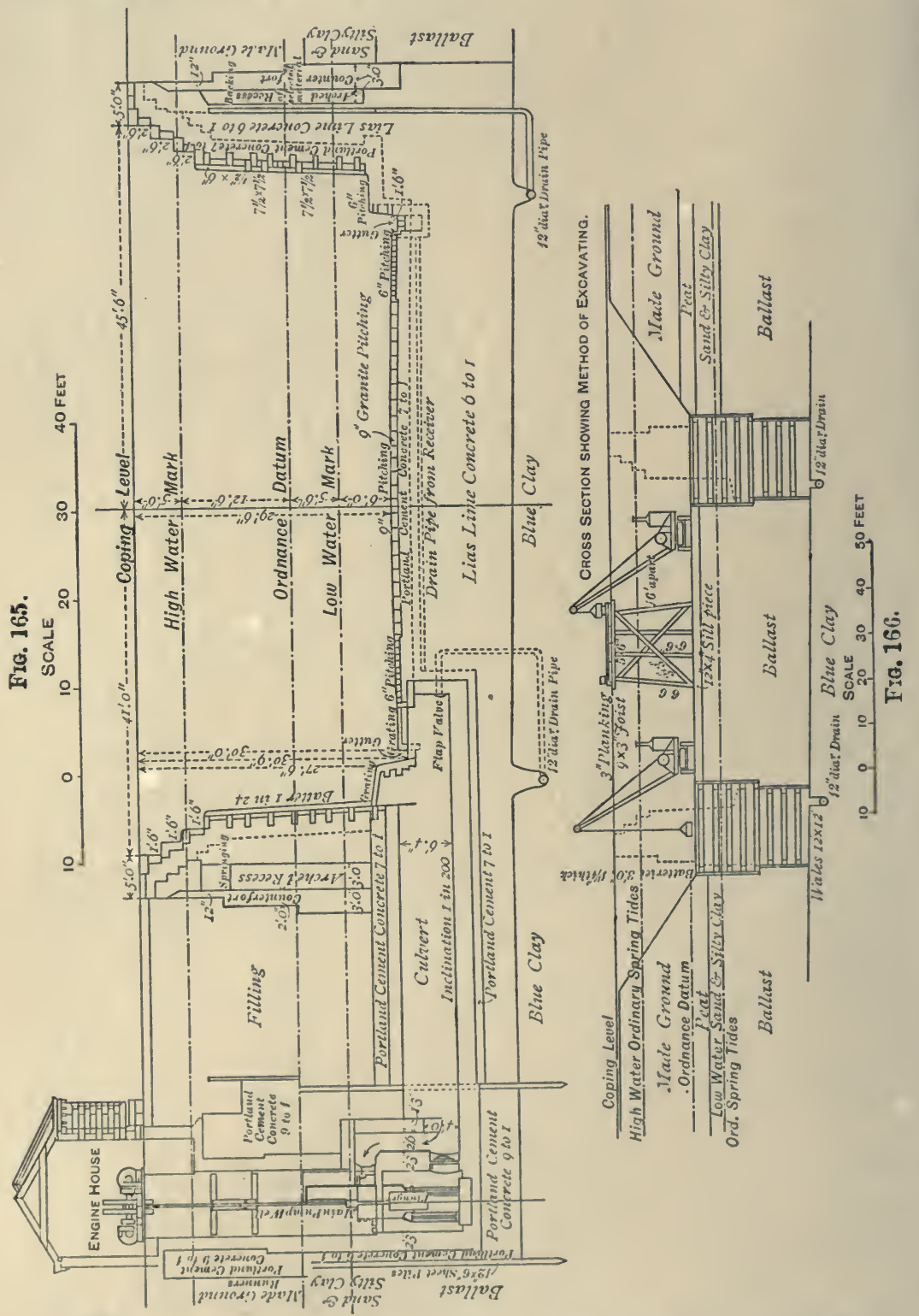

The average of the borings give the following depths from coping level to the blue clay :- 
Ft. in.

Made ground $\quad$... $16 \quad 0$

$\begin{array}{lllll}\text { Peat ... } & \ldots & \ldots & 4 & 0\end{array}$

Sand and silty clay 80

Ballast and running sand $\quad \ldots . \quad \ldots \quad 15 \quad 0$

Iraking the mean level of the clay below coping level $43 \quad 0$

In carrying out the work, the excavations over the whole area were taken down by tide-work from the surface to about 12 feet below high-water level, and the material barged away to places of deposit.

The coffer-dam was then erected, and the water excluded from the site.

After the water was shut out, trenches were sunk, as shown by Fig. 166, along each side of the excavation, in order to get in the foundations for the side walls. The sides of the trenches were timbered with pole boarding for about 15 feet down from the top, and below that level with 9 -inch by 3 -inch runners. The struts or shores were spaced 3 feet vertically and $\mathbf{1 2}$ feet horizontally, both walings and shores being 12 inches square.

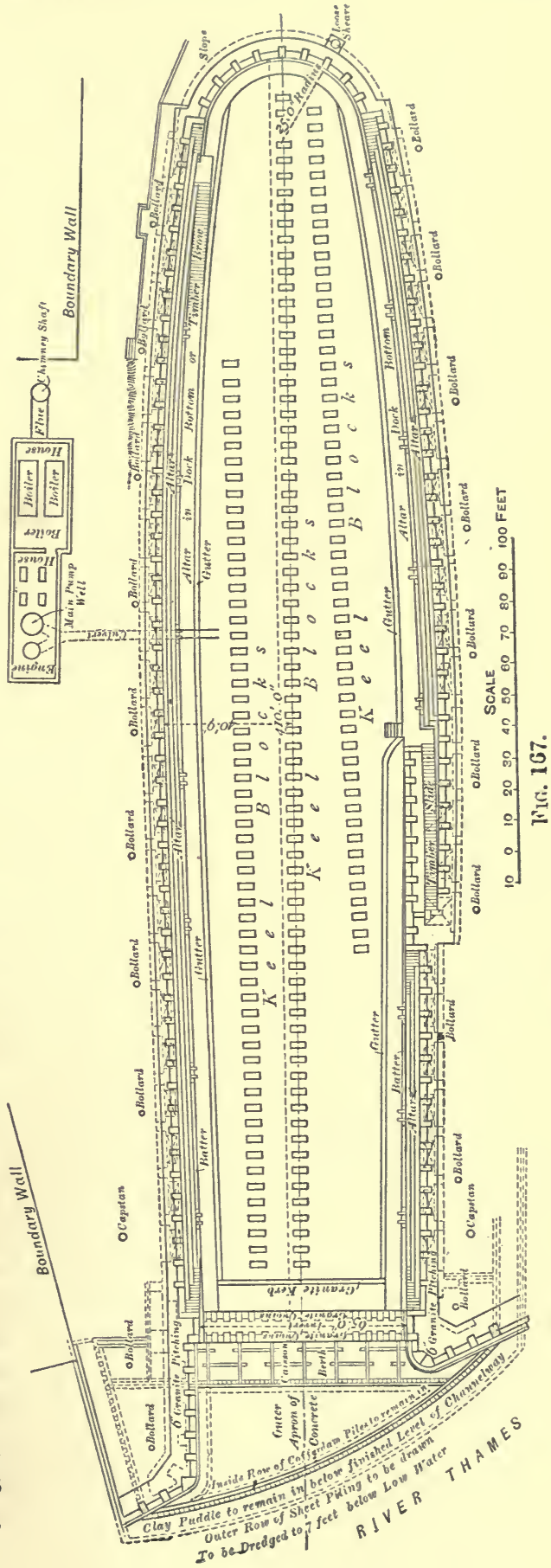


Travelling-cranes placed at the sides of the trenches raised the excavated material to a high-level tramway extending the whole length of the dock. 'The skips used for lifting the excavated material were formed of the upper part of the tipping waggons, and were lowered into the trench by the travellingcranes, the waggon bed remaining on the tramway. When loaded, the waggons were run along the tramway and tipped into barges lying outside the dam.

The gravel in the bottom of the trenches was excavated down to the clay, turned over and mixed with one-sixth part of lias lime, thus making a solid concrete foundation of great depth resting on the clay.

The side walls were then built of lias lime and 7-to-1 Portland-cement concrete, faced with granite ashlar in 8-inch courses.

After the side walls were built, the centre portion was excavated, and the gravel in the bottom turned over and made into 6-to-1 lias concrete. On the top of the lias concrete, a layer of Portland-cement concrete 15 inches thick was added; upon this 6 and 9 -inch granite pitchers or paving setts were bedded in Portland cement, forming the finished bottom of the dock, and having the appearance of a well-dressed street crossing.

On each side of the dock, at the top, there are three shoringaltars, each 18 inches in width by 2 feet 6 inches deep; the remainder of the depth having simply a batter of $I$ in 12 .

Access to the dock bottom is obtained by means of a combined stair and timber slide at the break in the east-side wall, and by a timber stair or brow in the west-side wall, near the head of the dock, and also by ladders formed of the vertical fenders attached to the side walls.

The foundations of the entrance were formed of Portlandcement concrete, carried down to the clay, and across the longitudinal walls of brickwork, on which are built the invert floor of caisson berth, and inner apron and sides of the entrance.

The pockets between the brickwork walls are filled with 9to-1 Portland-cement concrete. The invert is of brickwork in Portland cement, faced with granite.

The caisson stop-quoins are granite, having a raised meetingface of $\frac{3}{4}$ inch projection and 12 inches in width, against which the caisson abuts.

The drainage of the dock is effected at the centre of the 
length on the west side by a culvert leading to the well, placed about 50 feet back from the coping (Fig. 167).

Toulon Graving Dock (Figs. 168 to 170).-The conditions obtaining at the port of Toulon were such as to render the ordinary methods of dock construction inapplicable. To meet the difficulties of the case, two courses were proposed by Mr. Hersent, the engineer. First, to construct the entire dock within a large iron caisson with a flat and rigid bottom. The caisson would be gradually lowered as the masonry was laid within it, and finally rest upon the bed, which would be previously prepared for it with great care. Secondly, to construct the dock within a similar caisson, but with the addition of working chambers beneath, which would be utilized by means of compressed air, for forming the bed. By such means, the bed on which the dock would ultimately rest could be more carefully prepared and levelled, and a uniform bearing over the whole surface ensured.

The second proposition appeared to be the most advantageous, and was therefore adopted.

The caisson was of sufficient size to enclose the whole of the masonry; the total length was 472 feet 6 inches, the width 134 feet 6 inches, and the depth 62 feet 4 inches.

1 Engineering, vol. xxvi. p. 503.
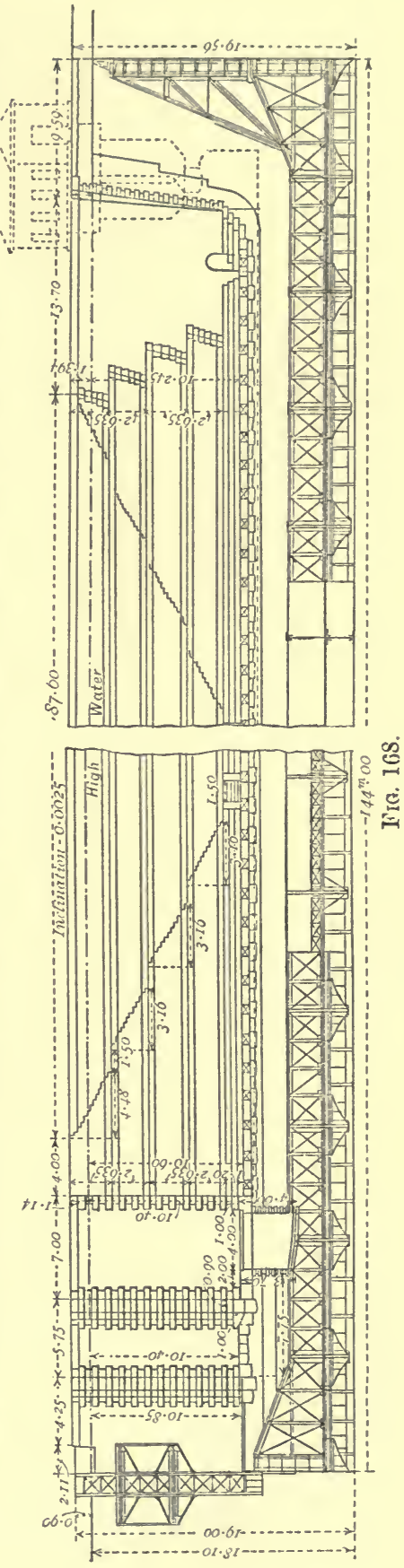
184 NOTES ON DOCKS AND DOCK CONSTRUCTION

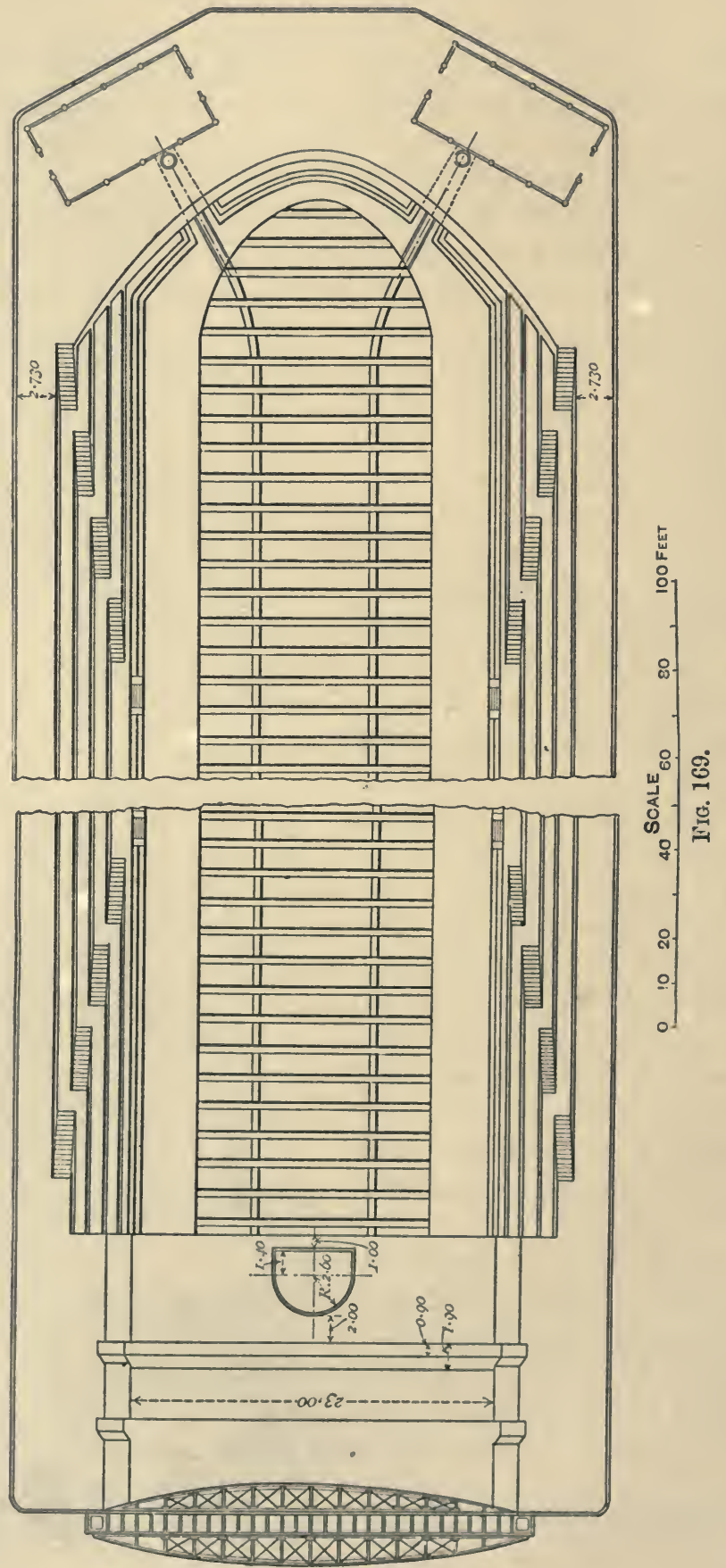


The following are the finished dimensions of the dock :-

Length of coping level from head to face of inner caisson stop ... $401 \quad 3$

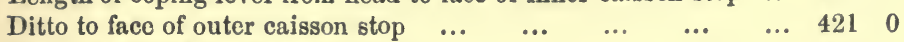

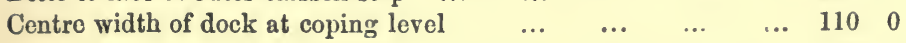

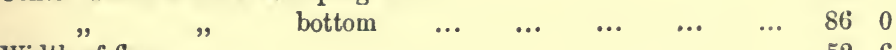

$\begin{array}{lllllllllll}\text { Width of floor } & \ldots & \ldots & \ldots & \ldots & \ldots & \ldots & \ldots & \ldots & 52 & 6\end{array}$

$\begin{array}{lllllllll}\text { Width of entrance at coping level } & \ldots & \ldots & \ldots & \ldots & \ldots & 94 & 8\end{array}$

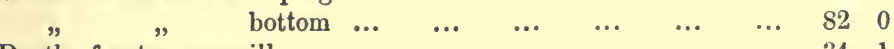

$\begin{array}{llllllllll}\text { Depth of water over sill } & \ldots & \ldots & \ldots & \ldots & \ldots & \ldots & 34 & 1\end{array}$

$\begin{array}{llllllllll}\text { Total depth of entrance } & \ldots & \ldots & \ldots & \ldots & \ldots & \ldots & 37 & 0\end{array}$

$\begin{array}{llllllllll}\text { Depth of water over blocks } & \ldots & \ldots & \ldots & \ldots & \ldots & \ldots & 34 & 9\end{array}$

$\begin{array}{lllllllllll}\text { Total depth in dock } & \ldots & \ldots & \ldots & \ldots & \ldots & \ldots & \ldots & 37 & 8\end{array}$

$\begin{array}{lllllllll}\text { Coping above water level } & \ldots & \ldots & \ldots & \ldots & \ldots & \ldots & 2 & 11\end{array}$

The total height of the caisson, viz. 62 feet 4 inches, was divided into two distinct portions. The lower part, or bottom,

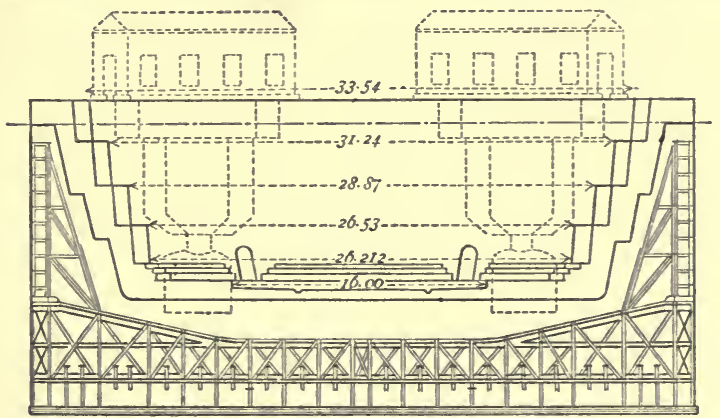

Frs. 170.

to the level of the top of the air-chamber, was divided longitudinally into 18 compartments by transverse water-tight bulkheads. The second portion, extending to the top of the caisson, formed a large, uninterrupted chamber, within which was constructed the invert and side walls of the dock, the weight of which formed the load necessary for its submersion.

In its construction, the caisson was divided into three parts : (a) the caisson proper, forming the base of the structure; (b) the sides resting above the base to about 3 feet above the water level; and (c) the dam for closing the entrance.

The base consists of outer walls, and top of iron plates, with a large double girder extending round the whole structure. The outer web of this girder was made solid, and the inner one open, in order to admit of the masonry being more efficiently built in. The length was divided by 17 transverse girders, extending the full width of the caisson, and the width by two 
intermediate longitudinal girders, which were joined up to the transverse girders. The top plates were carried by rolled-iron joists, the whole being tied to the girders and side walls by brackets and gusset-plates.

The sinking of the caisson after it had been brought into position was effected by the masonry of the dock, which was executed in such a way as to distribute the weight as equally as possible over the whole surface, and also so as to disturb as little as possible the balance between the load and the pressure of the water.

In order to obviate any difficulties arising from expansion and contraction, the sides and bottom were enclosed with masonry as quickly as possible.

In order to detect and provide against any signs of weakness, arrangements were made to observe and record the behaviour of the caisson as the work progressed.

When the masonry was so far completed that an immersion of 60 feet was reached, and the bottom of the caisson near the ground, the lower chambers were filled with compressed air, and from these chambers the bed which had been partially prepared by dredging was completed.

To displace the water, a set of twelve air compressors were provided, each being capable of compressing about 22,000 cubic feet of air per hour to a pressure equivalent to a 60 -feet head of water. The semi-liquid mud and débris was removed by means of syphons and a small amount of compressed air, whilst stones and solid material were passed through the air locks.

After the bed for the caisson had been properly levelled, the lower chambers were filled with concrete, which was passed through two special air locks into each chamber. The concrete was packed from the ends towards the centre for the whole depth, the portion immediately in the centre was filled in direct from the locks, which were then removed, leaving the shafts to be filled up with concrete to the level of the masonry of the invert.

Timber Docks. ${ }^{1}$-In the United States of America, timber has been extensively used in the construction of dry docks, and it appears to be much preferred to masonry, on account of the nature of the North-American climate.

The advantages claimed for this method of construction are

1. Engineering, and Scientific American, vol. 1xi. p. 311. 
as follows :-The original cost is comparatively low, being from 30 to 50 per cent. less than the cost of masonry.

Docks constructed of timber resist the action of frost better than those constructed of masonry. The alternations of excessive heat and cold peculiar to the North-American climate set up extreme expansion and contraction, causing the joints to separate and the water to enter; hence, through the severe frosts of successive winters, the stones are apt to be dislodged.

The cost of repairs and maintenance is stated to be less than in the case of masonry under like conditions. Experience of some of the oldest timber-constructed docks in America shows that extensive repairs are required only after twenty years, and then only to the most exposed parts, such as the floor planking and altars; whilst the piles, keel and floor timbers, sill, and abutments remain in a good state of preservation.

Wood is safer than stone to work upon in severe weather, inasmuch as ice is not so liable to form and remain on wood as on stone.

The low and narrow altars afford a safe and easy means of access to the bottom of the dock, and as they entirely surround the dock, no choice of a place is needed in going to and from work. Moreover, the low angle of the sides admits of more light and air to the ship's bottom, and, consequently, the discomfort of the damp, chilling air inseparable from the use of stone docks in winter is largely obviated.

The method of construction adopted by Messrs. Simpson and Company, of New York, is shown by Figs. 171, 172, which represent the half-transverse section of a dock of this type lately completed at the Brooklyn Navy Yard, United States.

The dimensions of this dock are-

$\begin{array}{ccccccccc}\text { Length over all on coping } & \ldots & \ldots & \ldots & \ldots & \ldots & 530 & 0 \\ \text { inside of caisson } & \ldots & \ldots & \ldots & \ldots & 500 & 0 \\ \text { Width on top 'midships } & \ldots & \ldots & \ldots & \ldots & \ldots & \ldots & 130 & 4 \\ \Rightarrow \quad \text { floor 'midships } & \ldots & \ldots & \ldots & \ldots & \ldots & 50 & 0 \\ \text { floor at entrance } & \ldots & \ldots & \ldots & \ldots & \ldots & 53 & 0 \\ \text { Width of entrance at coping } & \ldots & \ldots & \ldots & \ldots & \ldots & 85 & 0 \\ \text { Depth of sill below coping } & \ldots & \ldots & \ldots & \ldots & \ldots & 30 & 6 \\ \text { Depth to floor of dock below coping } & \ldots & \ldots & \ldots & \ldots & 32 & 8 \\ \text { Depth of water over sill at high tide } & \ldots & \ldots & \ldots & \ldots & 25 & 6\end{array}$

The entire area of the floor is enclosed with continuous 8-inch grooved-and-tongued sheet-piling, the practice being in good ground to drive this sheeting to a depth of 7 feet 6 inches. In 
this instance, however, on account of quicksand having been met with, the sheeting was driven to a depth of 45 feet.

Within the area enclosed by the sheeting, bearing-piles, consisting of round fir timber 12 inches in diameter, were driven. These piles were spaced 3 feet between centres transversely, and 4 feet longitudinally, down the centre, and covering a width of 10 feet. Special rows of piles were driven to carry the keelblocks. Each row of piles carries a longitudinal timber 12 inches square, and on these rest transverse timbers of the same size, spaced 3 feet from centre to centre.

The floor consists of 3-inch planking, spiked or bolted to the transverse timbers; upon every third transverse floor timber, oak beams are placed, upon which the bilge-blocks slide.

Under the floor, and surrounding the pile heads and longitudinal timbers, is a bed of Portland-cement concrete 5 feet deep in the centre, sloping upwards to the sides (between the floor timbers), one foot giving a maximum thickness under the first altar of 6 feet; any water which may find its way to the surface of the concrete flows to the centre, where drains are provided to receive it and lead it away to the culvert.

The sides rise at an angle of about 39 degrees. The altars consist of fir timbers 10 inches wide by 11 inches in height on the front face, chamfered off to 3 inches vertical face at the back. These timbers run horizontally round the dock, forming steps or altars 10 inches tread and 8 inches rise. Where the altars cross the sloping side timbers, they are bolted as shown by Fig. 171; one bolt passes through the centre of the altar vertically, a second being driven through the face of the altar diagonally, so as to enter the side timber perpendicularly.

The side timbers are square baulks not less than 12 inches square, and are supported on rows of piles spaced 3 feet apart longitudinally. The lower ends abut upon and are secured to the transverse floor timbers, and against square longitudinal timbers forming the lowest altar.

The floor concrete is continued up the back of the altars for a height of 6 feet, and above this the altars are backed with puddled clay well rammed in, so as to form a compact and impervious mass.

At a distance of 26 feet from the coping line of the dock there is a second continuous line of 8-'nch tongued-and-grooved sheet-piling driven well below the floor level of the dock so as 
to completely surround it. Between the outer sheet-piling and the coping line of the dock there are four rows of 12-inch round piles spaced 3 feet apart longitudinally, each row carries a transverse sill or cap, upon which the wharfing is laid.

The sides are further supported by diagonal braces fixed to the upper side sills and the sloping side timbers.

The dock entrance consists of heavy abutment and side timbers, supported and backed by concrete and puddled clay. The entrance is closed by an iron floating caisson. For making a tight joint between the entrance stop and the keel and stems of the caisson heavy indiarubber packing is used.

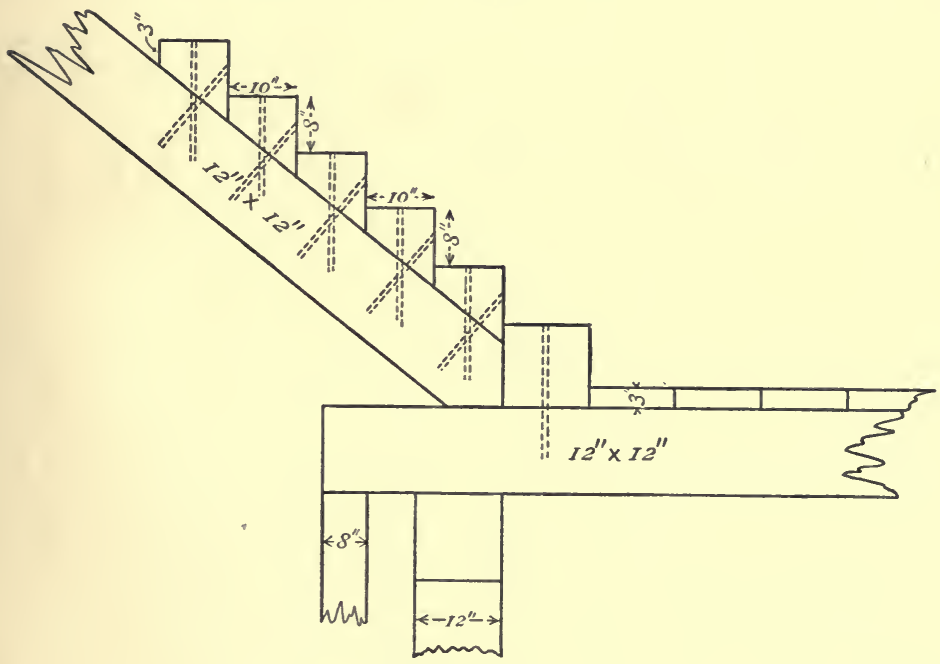

FIG. 171.

For clearing the water, drains are constructed in the concrete under the floor timbers on each side of the keel-blocks, which lead to the drainage culvert and pump well, which in this case is near the dock entrance.

For emptying the dock, there are two centrifugal pumps of 42 inches in diameter driven by two vertical engines with cylinders 28 inches diameter and 24-inch stroke. The pumps have a capacity of 80,000 gallons per minute, and can empty the dock in 90 minutes when no vessel is in it. The filling is done through valves in the caisson.

Another good example of this method of construction is the dock completed in 1884, by Messrs. Simpson, at St. John's, 
Newfoundland, for the Colonial Government (Figs. 171, 172). The dimensions of this dock are as follows :-

Greatest length on floor from head to outer gate sill... Ft. in,

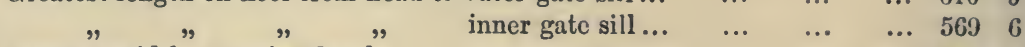

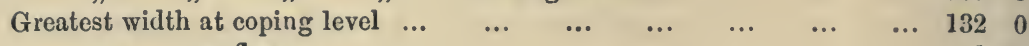

$\begin{array}{lllllllllllll} & \text { on floor } & \ldots & \ldots & \ldots & \ldots & \ldots & \ldots & \ldots & \ldots & 49 & 10\end{array}$

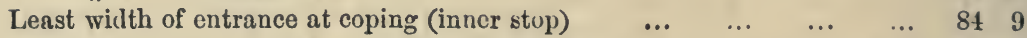

" $\quad " \quad$ on floor (inner stop) ...

Greatest draught of water over inner gate sill at high water of spring tides $\quad 25 \quad 0$

This dock is built upon spruce-fir foundation-piles, except the floor, which rests upon a bed of Portland-cement concrete, varying from $2 \frac{1}{2}$ feet in depth at the head to about 6 feet at

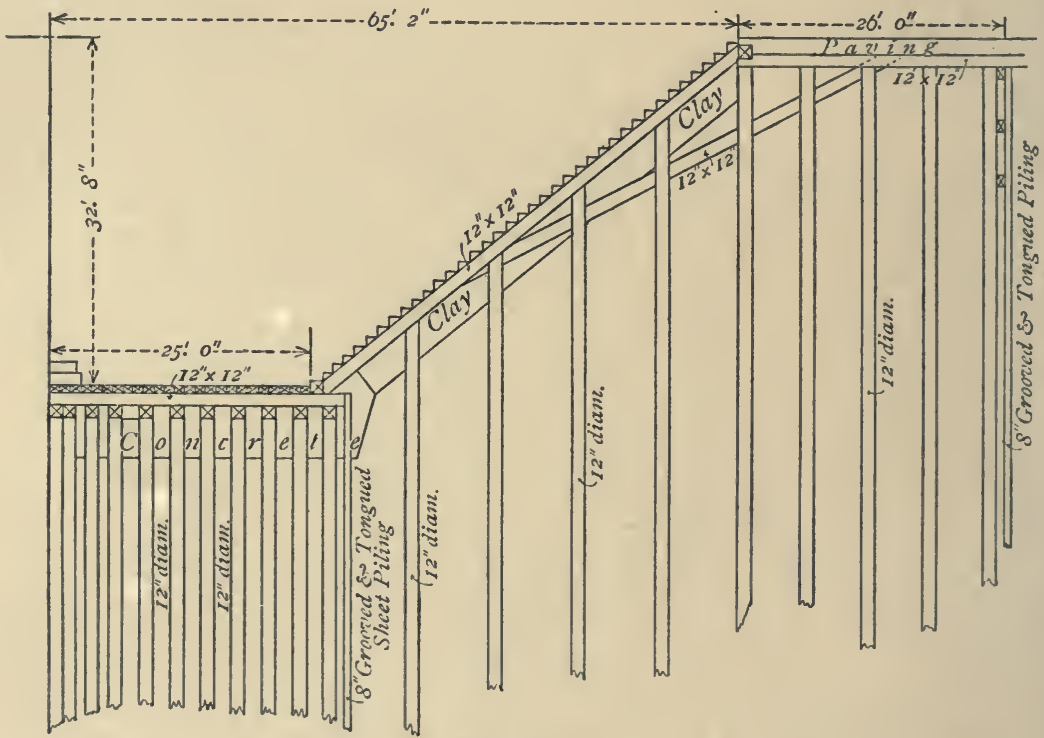

FIG. 172 .

the entrance. The concrete floor itself rests upon a glacial deposit of compact slaty gravel immediately overlying the bed rock.

Mount Stuart Dock.-An example of an abnormally wide dock on the floor, which has, it is stated, proved a great success, is the Mount Stuart Dock at Cardiff (Fig. 173). In this case the wiath at coping level is 105 feet, and 90 feet wide above the first altar, which is about 1 foot 3 inches above the sill level. The keel blocks are arranged to accommodate two vessels up to 350 feet long alongside of each other. In the event of 
accommodation for a vessel over 350 feet long being required, a centre row of keel-blocks are provided. T'he entrance is 52 feet wide, with a depth of water over the sill and keel-blocks of 25 fect 3 inches at high water of ordinary spring tides. In addition to the outer gates, there are a set of inner gates, by closing which a depth of 20 feet of water can be retained over the keel-blocks.

Calais Harbour. ${ }^{1}$-Communication between the outer port and the floating basin is obtained by two parallel docks of the

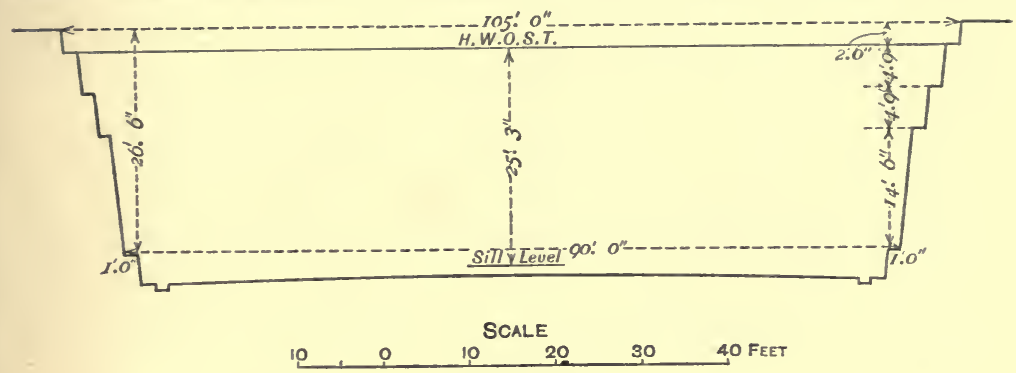

FIG. 173.

same length over all, but of unequal width and unequal effective length between the gates (Fig. 174).

The larger dock has a clear width of 68 feet 11 inches, and the smaller one 45 feet 11 inches.

The form and dimensions of the sections at different points of the length are shown by Figs. 175 to 177.

The level of the sills is so arranged that the depth of water over them at high water springs varies from 22 feet 6 inches to 28 feet 6 inches; the extreme rise and fall of tide is 23 feet.

Each dock is fitted with three sets of entrance gates, one pair at the upper or basin entrance, and two pairs at the lower or harbour entrance. In order to economize water in docking vessels of different dimensions, each dock is also divided into two chambers of unequal lengths by intermediate gates.

In the wider dock, the total length between the sills of the extreme gates is 505 feet 3 inches, and the clear length between the inner or ebb gates 434 feet 3 inches; when divided by clusing the intermediate gates, one chamber is 185 feet long, and the other 249 feet 4 inches between the gates. In the narrow dock, the total length between the sills of the extreme gates is 521 feet 4 inches, and the maximum clear length be-

1 Engineering, vol. xlvii. pp. 577, 611 . 
192 NOTES ON DOCKS AND DOCK CONSTRUCTION.
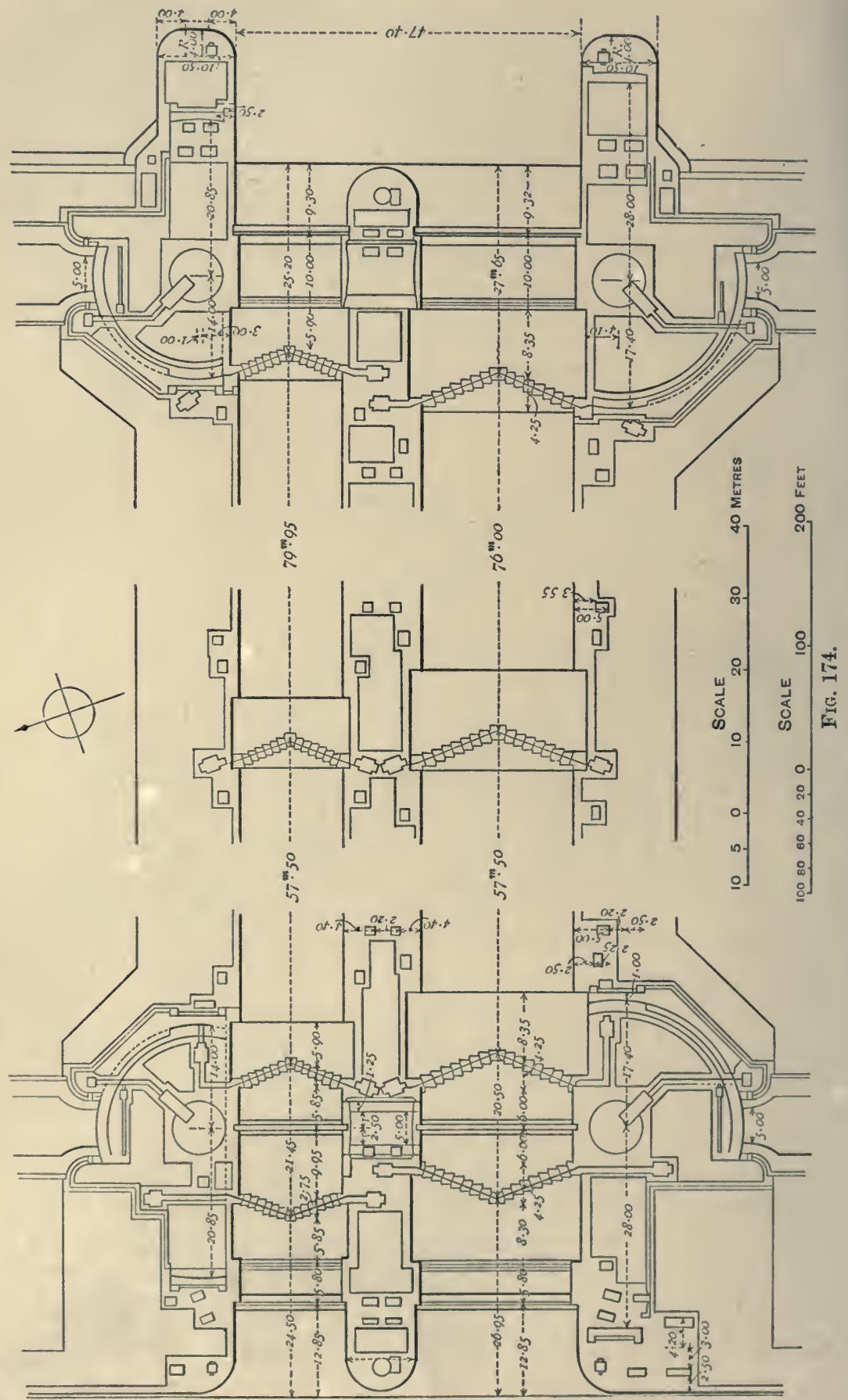
tween the inner ebb gates 447 feet 3 inches; when divided by closing the intermediate gates, one chamber is $\mathbf{1 8 5}$ feet long, and the other 258 feet 6 inches.

On the left side of the larger dock there are two culverts,

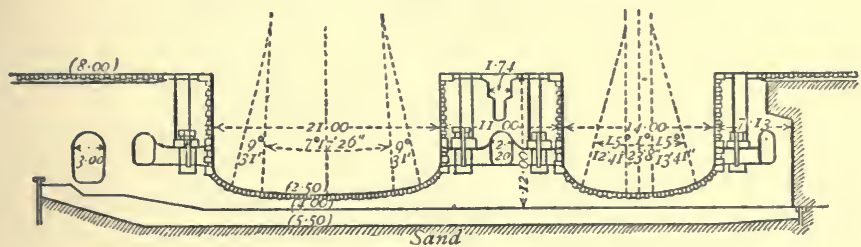

Fis. 175.

one 9 feet 10 inches wide and about 15 feet high, and the other 7 feet 3 inches wide by 9 feet 10 inches high. The larger culvert takes the water from the floating dock, the dry dock, and the flood water from the Calais Canal, etc. The smaller culvert serves for regulating the water level in the lock, and

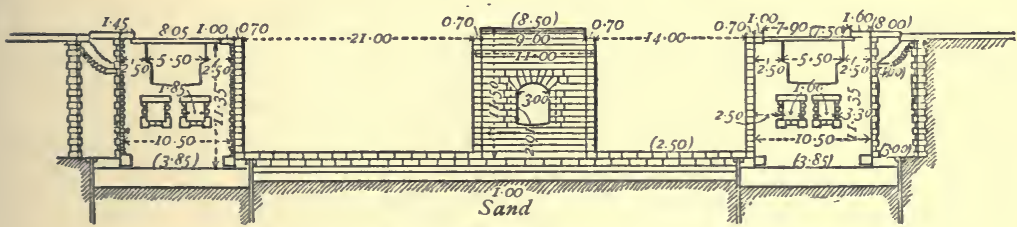

FIG. 176.

also for sluicing the outer port and the lower entrance and sill of the larger lock. Other culverts are formed in the central wall between the two locks, and on the right side of the smaller lock. The former is 7 feet 4 inches wide by 9 feet 10 inches high, and the latter 5 feet 3 inches wide by 9 feet 10 inches

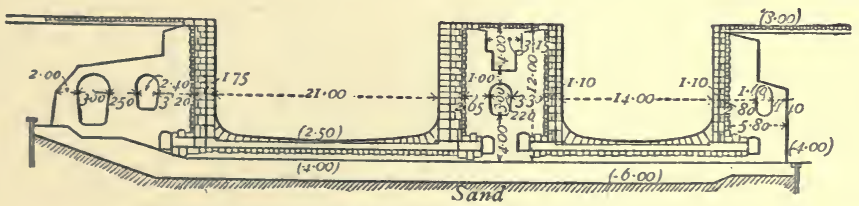

Fig. 177.

high. Communications are made between these culverts and the locks by transverse channels, and a complete system of valves is introduced so as to control the flow of water through the culverts. The strata being fine sand, the sill was surrounded with 
194 NOTES ON DOCKS AND DOCK CONSTRUCTION.

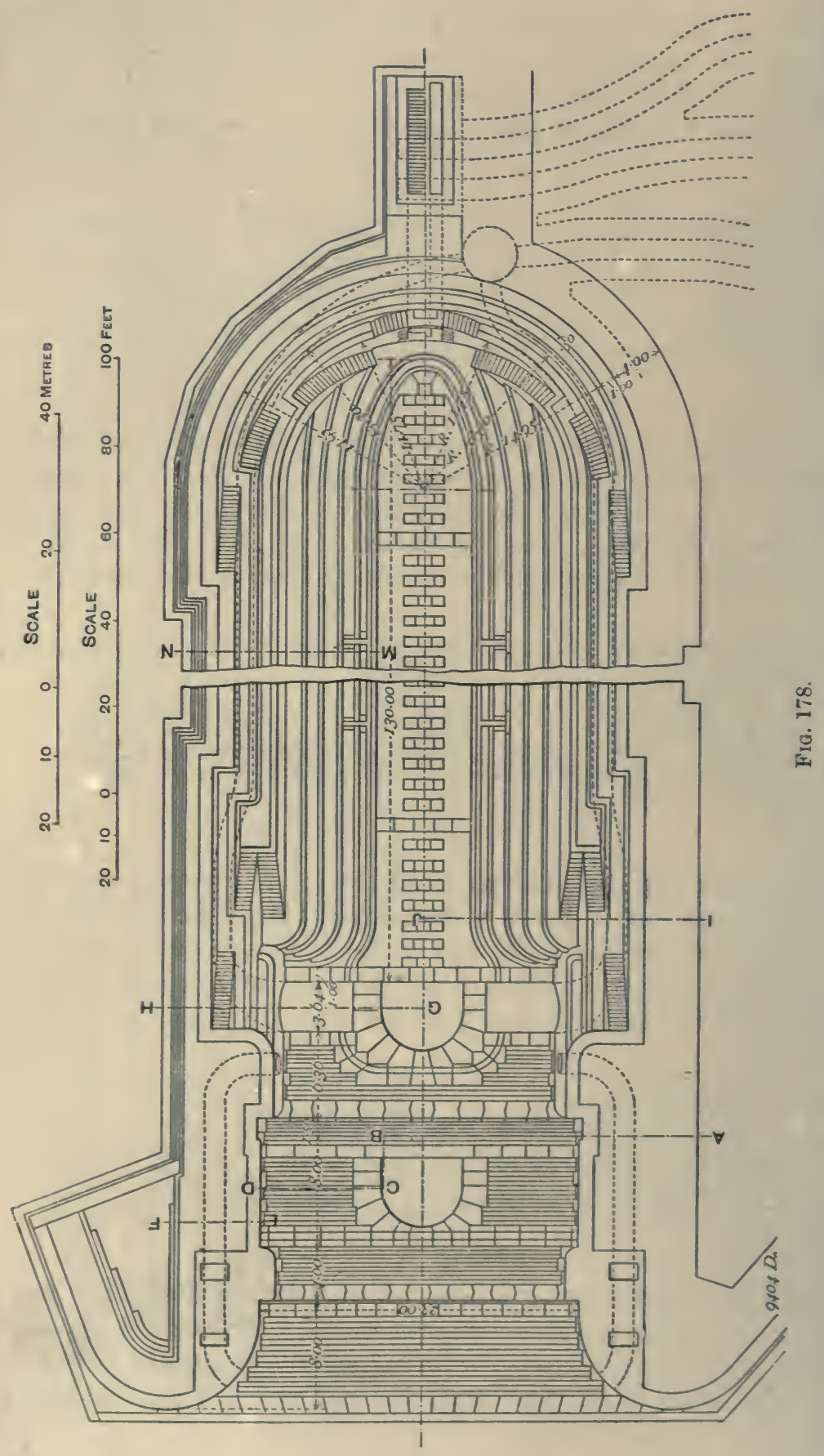


stout sheet-piling; bearing-piles were also driven by the aid of. the water-jet system with a 50 -feet head of water over the whole area enclosed. Above the piles was laid a bed of concrete 4 feet 11 inches thick, on which the masonry, laid entirely in Portland cement, was commenced. Whilst the bed of concrete was being deposited, the whole area was kept submerged under 3 feet of water.

Calais Graving Dock. ${ }^{1}$-This dock (Figs. 178 to 181) was constructed from the design of $\mathrm{Mr}$. Vetillart, the engineer to the Port of Calais. The total length from the line of the entrance piers to the coping at the head is 546 feet 10 inches. On the

FrG. 179.

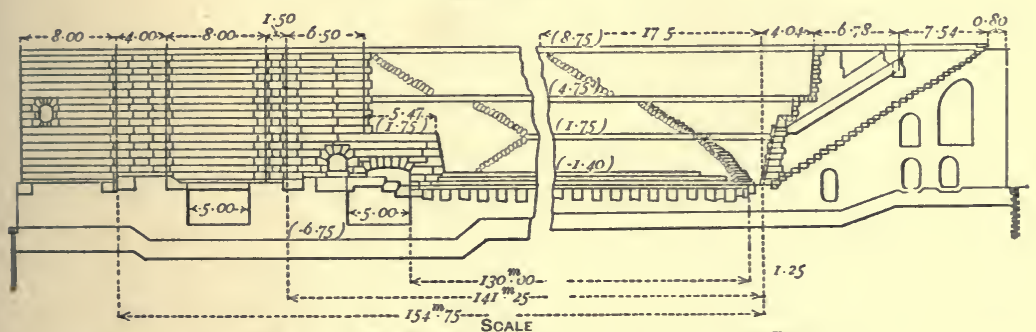

$1050 \quad 102030 \quad 4050 \quad 60$

120 FEET

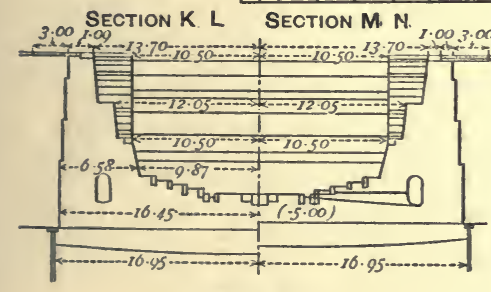

Fig. 180.

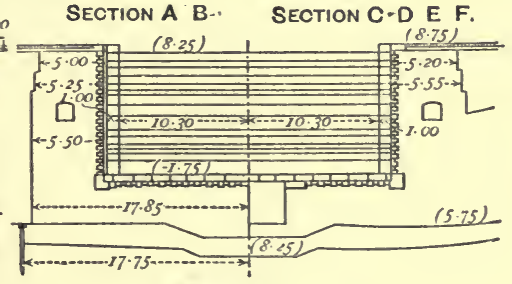

FiG. 181.

floor, from the inner recess of the caisson to the base of the rounded end, the length is 463 feet 3 inches; the additional length obtainable by putting the caisson in the outer stop is 44 feet 3 inches; therefore the maximum length on the floor at the invert level is 507 feet 6 inches. The width of the floor between the bottom altars is 30 feet 6 inches, including the side drainage channels $15 \frac{3}{4}$ inches wide, which are carried round the floor of the dock. The four first altars, starting from the bottom of the dock, are $13 \frac{3}{4}$ inches high, and their width 4 feet 3 inches. The width of the dock at the level of the fourth altar is therefore 64 feet 7 inches. From the top of the fourth altar to the

\section{Engineering, vol. xlvii.}



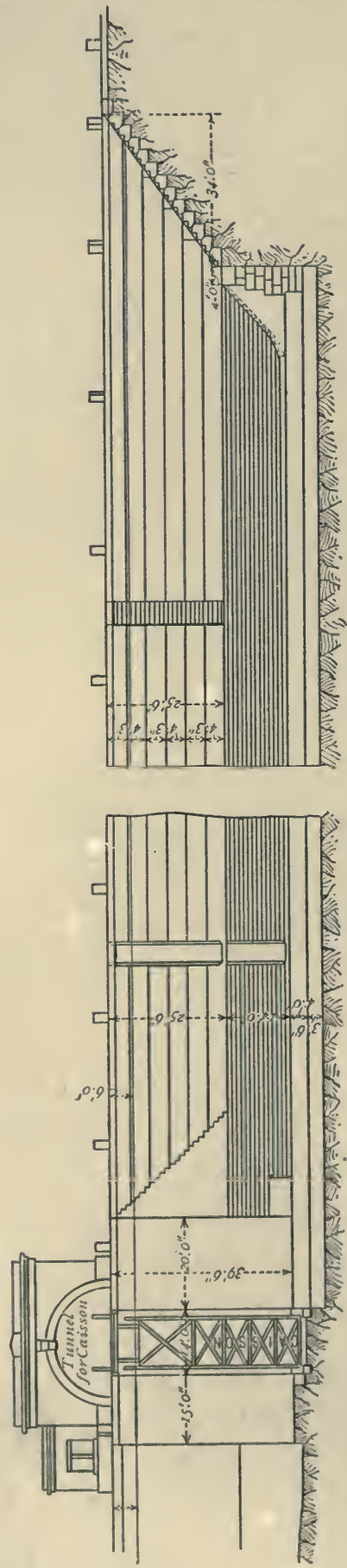

ground level, the sides of the dock have two altars 4 feet 1 inch wide, and, the face being constructed with a batter of 1 in 5 , makes the total width at the ground level 89 feet 10 inches.

Stairways are placed on the sides at either end; and at the centre of the rounded end there is an additional flight of steps with timber slides on each side.

For emptying the dock, culverts 4 feet 1 inch wide by 8 feet 2 inches high are placed on each side of the dock, and are connected with a sump on the centre line just inside the entrance. A small transverse drain connects the side-floor channels with the drainage culverts. The culverts terminate in a sluicechamber, from which a series of secondary culverts, controlled by valves, lead to the main pumping well which is constructed independent of the dock.

The pumping power consists of three large centrifugal pumps, which, when working together, empty the dock from the highest level in less than three hours. Supplementary centrifugal pumps are employed to keep the dock dry when it is in use.

Somerset Dock, Malta. ${ }^{1}$-The general plan and sections of this dock are shown by Figs. 182 to 185. The leading dimensions being as follows :-

1 M.P.I.C.E., vol. $\Sigma \times x i i i$. p. 352. 


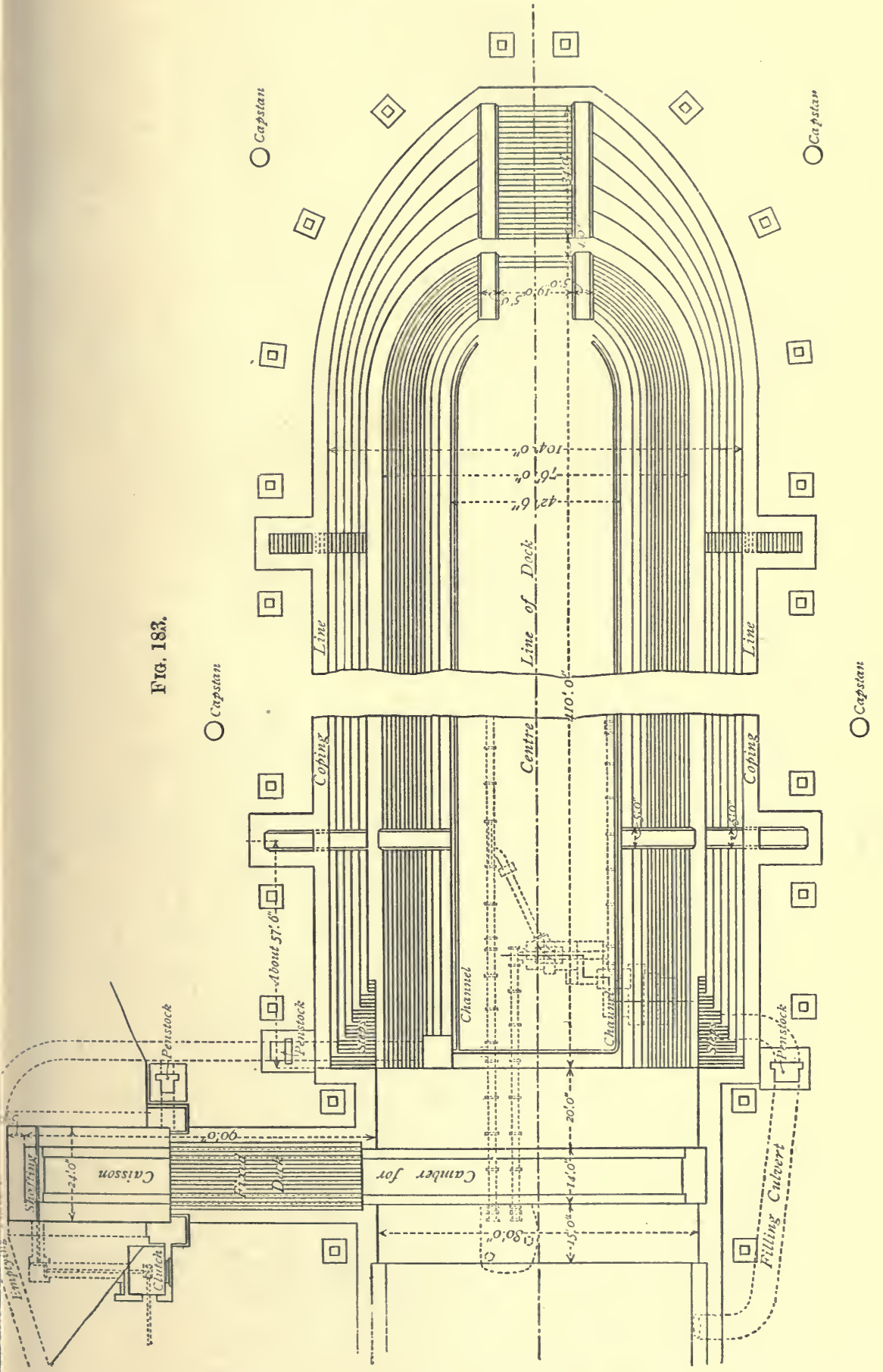




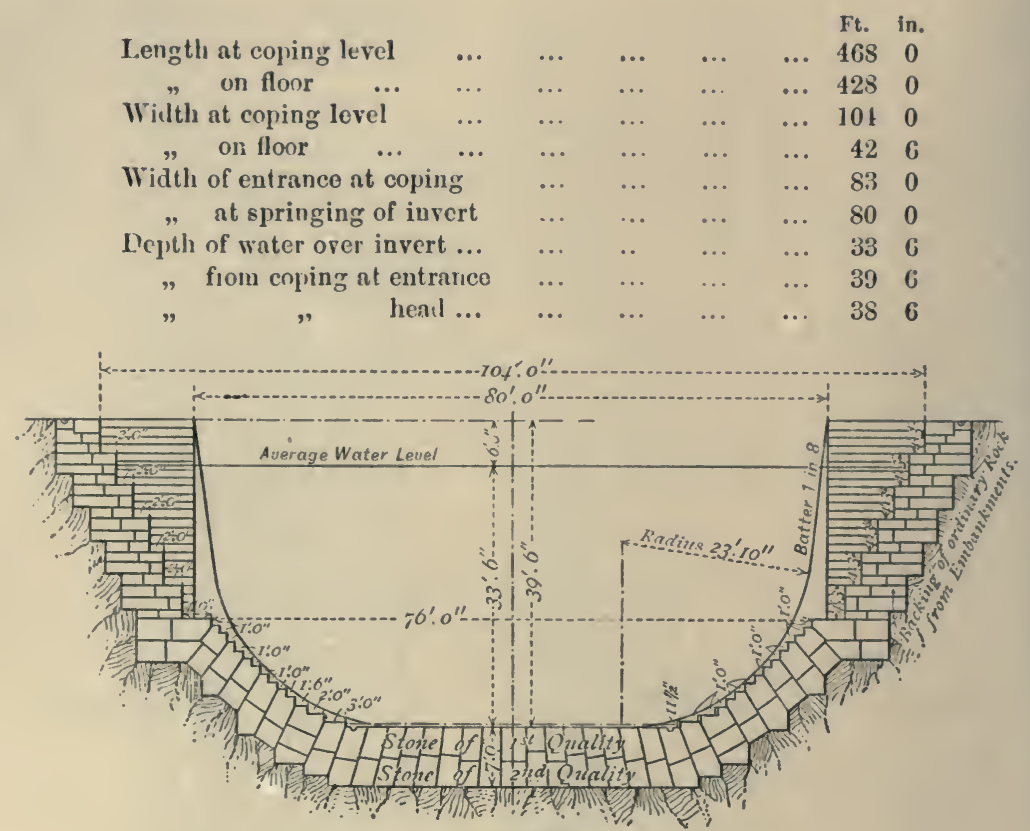

FiG. 184 .

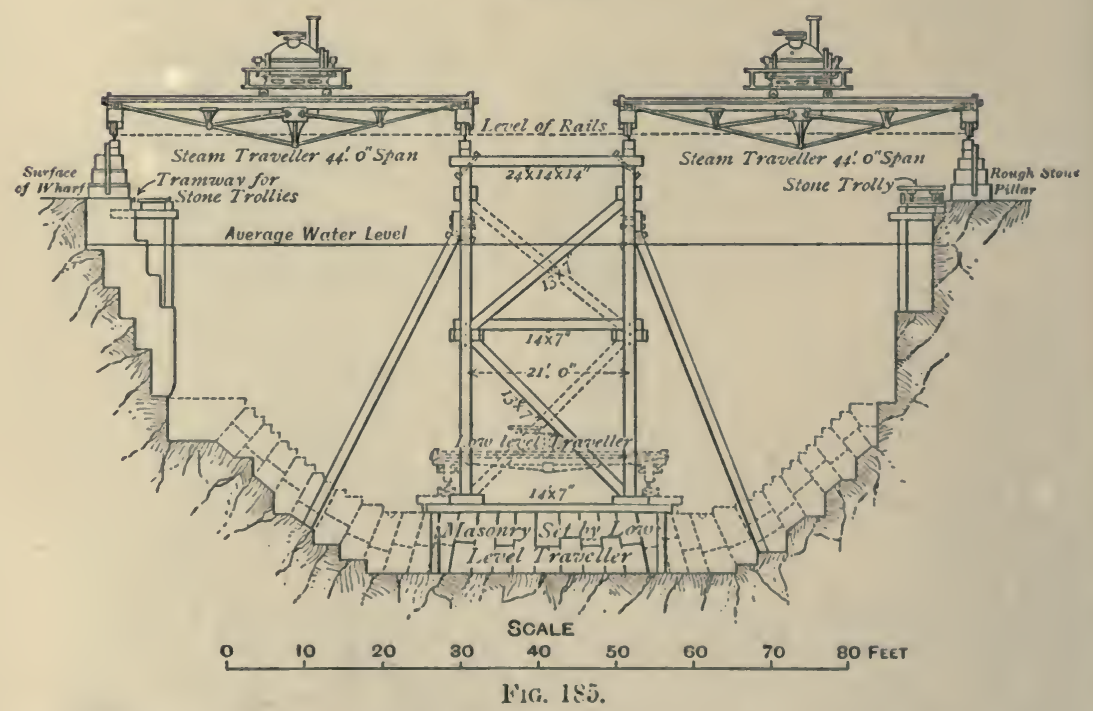

The following method was adopted for getting in the masonry :- The centre courses of both the sub and upper floor were set by a traveller, working at a low level on the centre 
line of the dock (Fig. 185). When these courses were set, they formed the base for carrying a staging 48 feet high, with corresponding road timbers on the dock sides. Steam-travellers placed upon these gantries continued the masonry nearly to the water level, above which ordinary shears were used. The centre staging was 150 feet in length, divided into five bays; the rear bay being taken down and re-erected in front as the work advanced.

The floor and lining of the dock generally was formed of the best quality hard crystalline limestone, found in the islands of Malta and Gozo, in blocks weighing from 3 to 8 tons. The sub-floor and backing was partly of an inferior quality of the same stone and partly of the stone found suitable from the excavation of the dock.

The whole of the masonry was set in mortar composed of 1 part Pozzuolana to 60 parts of lime, ground in a mill with edge-runners for 15 minutes.

Extension of a Dry Dock at Leghorn. ${ }^{1}$ - The dry dock at the port of Leghorn, constructed in 1863, having become too short to accommodate the improved class of ships frequenting the port, an extension to the extent of 68 feet 8 inches was decided upon (Fig. 186).

The dimensions of the original dock were:-

$\begin{array}{ccccccr}\text { Length on blocks } \ldots & \ldots & \ldots & \ldots & \ldots & \ldots & 356 \cdot 32 \\ \text { at mean water level } & & \ldots & \ldots & \ldots & \ldots & 373 \cdot 21 \\ \text { Width at block level ... } & \ldots & \ldots & \ldots & \ldots & \ldots & 37 \cdot 50 \\ \text { wepth of water level } \ldots & \ldots & \ldots & \ldots & \ldots & \ldots & 73 \cdot 16 \\ \text { Dever sill } & \ldots & \ldots & \ldots & \ldots & \ldots & 22.96\end{array}$

The foundation was muddy sand, so slightly permeable as to admit of the work being carried out in the open with ordinary pumping.

Since the completion of the dock, the surrounding conditions have changed. The construction of a wet dock and a canal brought the water close up to the old dock, and rendered the ordinary method of executing the extension by open cutting and pumping inapplicable. An attempt made to carry out the construction of the wells proved a failure, in consequence of the influx of water being so great as to overcome all attempts at drainage, except at a very great risk of affecting the stability of the old work. A method of execution by the

1 Le Genie Civil, vol. xvi. p. 337. 
aid of a large caisson and compressed air was proposed by M.M. Zschokke and Terrier, and approved by the Council of Public Works.

'The work to be executed consisted of three parts. First,

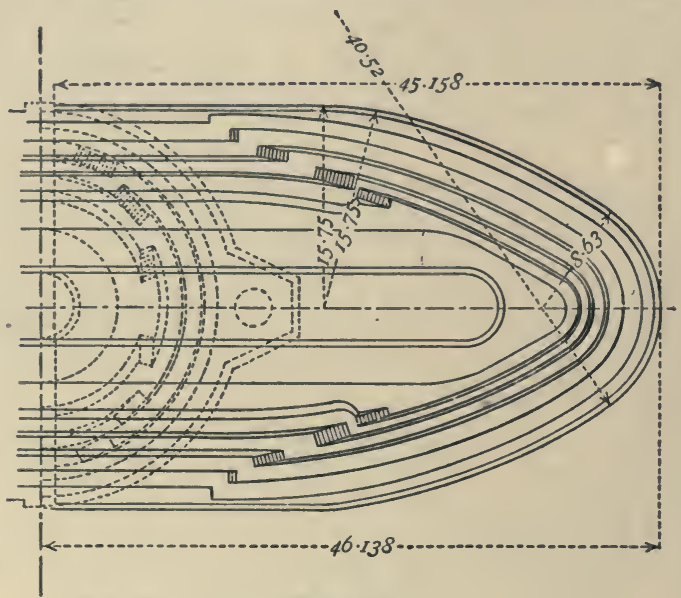

Fig. 186.

the lengthening of the dock; secondly, the removal and reconstruction of the pumping station; and thirdly, the sinking of the pump wells and their connection with the dock.

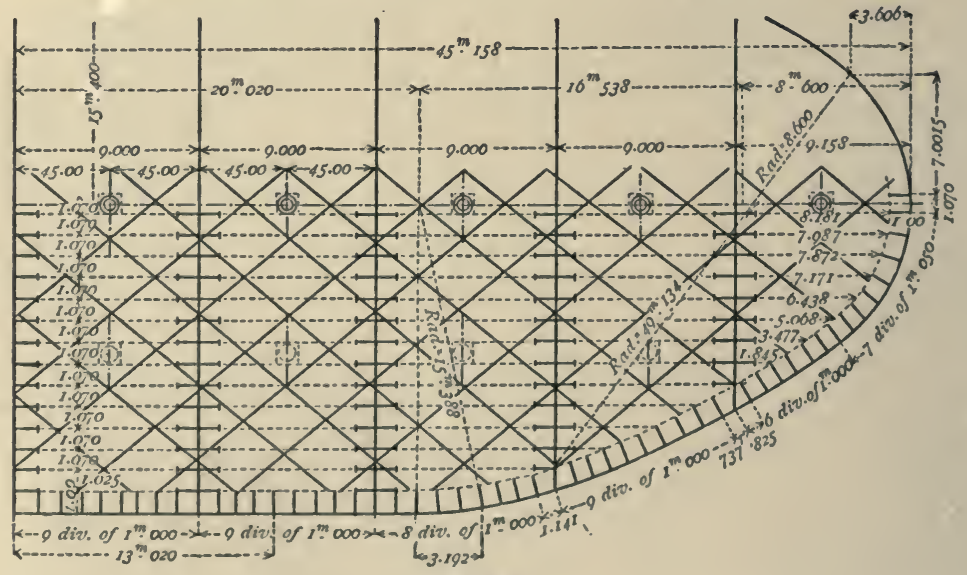

FrG. 187.

Extension of the Dock.-The first operation was to construct a temporary wall across the dock at the springing of the circular head, capable of resisting the full head of water (Fig. 186). 
It was then possible to remove in the dry the ashlar facing of the circular head and floor. The masonry and concrete backing was also removed, as far as it was safe to do so without risk of the soil slipping. The hole was then filled up to within 6 feet 6 inches of the surface, to form the bed or platform on which to construct the caisson.

The form of this caisson was partly rectangular and partly parabolic, corresponding to the outline of the new head of the dock (Fig. 187); the length was 148 feet 2 inches, and the width 101 feet, giving a total area of 1402 square yards. The working chamber was divided into five compartments by means of four principal equidistant transverse girders, armed with a
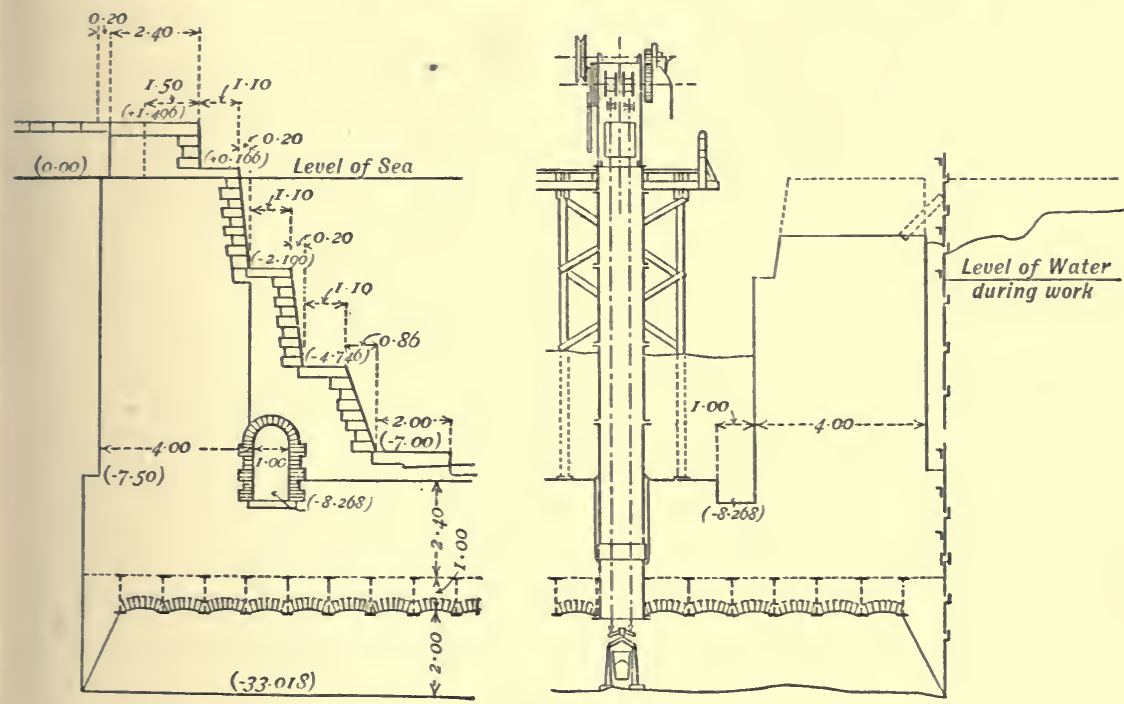

Fig. 188.

cutting edge, and placed in the same plane as the cutting edge of the sides. These open girders were maintained in position and strengthened by means of raking struts, presenting the form of two brackets placed back to back. By this arrangement of cross-girders the weight of the caisson was distributed over the surface much more satisfactorily than if the lines of support consisted only of the cutting edges of the sides of the caisson. The arrangement also admitted of the ceiling of the workingchamber being constructed of longitudinal beams 3 feet $3 \frac{3}{8}$ inches deep and 50 feet 6 inches long only, instead of transverse beams exceeding 98 feet 6 inches in length. 
Means of communication between the compartments was provided by specially arranged openings through the transverse girders.

It was a matter of the first importance to ensure a perfect connection between the upper mass of masonry which formed the floor proper of the duck and the filling of the working chamber.

An ordinary floor, or ceiling, of the working chamber of iron plates would have constituted a permanent separation between the two masses, and would have established water-ways, which, considering the nature of the work, it was imperative should be avoided. Iron, as a roof or ceiling of the working chamber, was

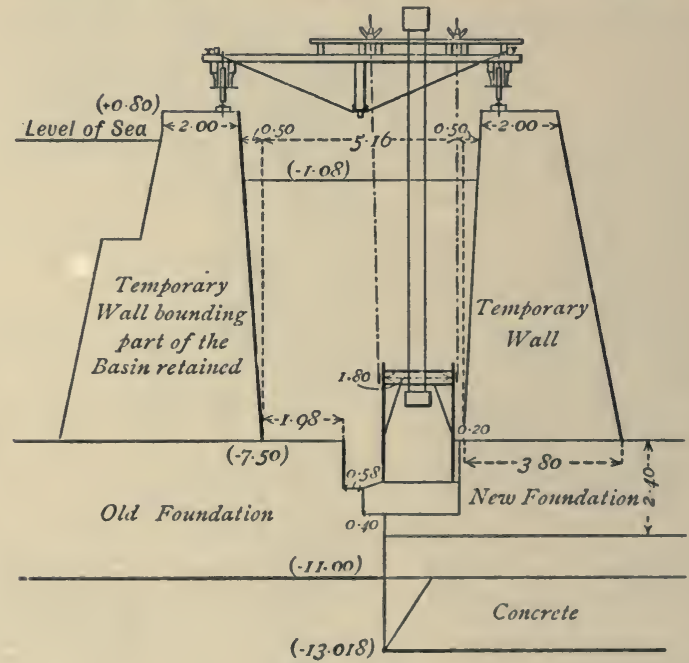

Fig. 183.

therefore replaced by brickwork arches resting upon the lower flanges of the girders. These arches, covered with a rendering of cement, were as impervious to the compressed air as a ceiling of iron plates, and after the working chamber was filled up, their soffits were in direct contact with the concrete filling (Fig. 188).

Nine air locks, of which four were for materials only, were provided for the entry into the working chamber and the removal of délvis. The sinking was rendered difficult by meeting with a part of the old circular head of the dock, which necessitated blasting within the working chamber.

The cutting edge of the caisson reached its proper level of 42 feet 8 inches below datum in 113 days. 
During the time the sinking was in progress, the masonry immediately above the ceiling of the working chamber of the caisson, and forming the floor of the dock, was proceeded with to within about 6 feet 7 inches of the end abutting upon the old work. Upon this floor a second temporary transverse wall was erected, parallel to the previous one constructed across the head of the old dock, and, like it, capable of resisting the full head of water (Fig. 1S9).

At the same time, the rough masonry of the sides of the extension was proceeded with. The débris arising from the sinking was deposited in the interior of the dock to give weight to overcome the friction, and to counteract the upward pressure.

Between the ends of the caisson and the second transverse wall there was a narrow width of invert, upon which a mass of dry masonry was placed, for the purpose of equalizing the weighting of that part of the caisson.

When the caisson had reached its proper depth, the working chamber was filled in, an operation which occupied twentyseven days. The débris was then removed from the floor, the locks were removed, and the wells through the floor filled in, and the face lining of the sides and invert completed.

The only part then remaining to be done to complete the work was to connect the old and the new masonry within the space between the two temporary transverse walls, which enclosed a space about 9 feet 10 inches wide (Fig. 189). For this purpose, rails were laid on the tops of the walls, and upon which was placed a travelling-stage and crab.

A caisson, 24 feet 7 inches long by 5 feet 11 inches wide, was suspended to the travelling-stage by six chains; by the aid of this caisson, or bell, the old masonry and rubbish found between the two walls was removed down to the top of the ceiling beams, that is, to 8 feet below the floor. By successive removals of the caisson, the two floors were connected by filling in the gap with concrete 'aid in thin layers.

In order to complete the enclosure of which the concrete formed the bottom and the temporary walls the two sides, sheetpiling was driven at the ends, that is, in line with the back of the side walls. The enclosure was then pumped out, and the masonry of the sides completed. The two temporary walls were then demolished, and the paving of the floor made good.

Foundation of the Pump-house.-The extension of the dock 
was preceded by the sinking of a new well and the erection of a new building to contain the pumps, engines, etc.

The original building was founded partly upon piles and partly by the aid of compressed air. In order to avoid the inequalities in bearing this method of construction would have engendered, a method was devised of founding the entire building on concrete by the aid of compressed air, and special arrangeinents which enabled the work to be executed at a pace but little above that for pile foundations. These foundations consisted of four piers of the following dimensions, one 10 feet by 10 feet, one 19 feet 8 inches by 10 feet, and the remaining two 32 feet 5 inches by 10 feet. They were constructed of concrete, upon a working chamber also constructed of the same material. The side walls were surrounded by a plate-iron casing, and armed on the lower edge with an iron shoe.

The iron casing was secured to the concrete by bolts attached to the plates, and embedded in the mass. The whole was further strengthened by anchor-bolts, which tied the shoe to the block forming the top of the working chamber. The object of these bolts was to prevent the displacement of the shoe, should the caisson or chamber encounter an obstruction.

As regards air and water tightness, the concrete working chamber gave the best results. The arrangement was also one which admitted of a minimum quantity of iron being used and left in the work.

Sinking the New Pump-wells, and Connecting with the Dock.This work was also carried out by the aid of compressed air, and was executed before the extension of the dock was commenced.

The caisson was 42 feet 6 inches long by 31 feet wide. As in the case of the large caisson, the ordinary iron roof was replaced by a platform of brick arches upon iron girders. The caisson was sunk at about 3 feet 3 inches from the outer face of the old work, with the view of clearing the massive foundations of the dock, which extended 3 feet outside the back lines of the wall.

The sinking terminated at 44 feet 3 inches below datum. It was then necessary to make a water-tiglit connection with the old dock, at a depth of 26 feet 3 inches below water level. This was effected in the following manner. On three sides of the well, the masonry was carried up within the casing, whilst 
on the fourth side it was omitted, leaving the iron plates of the caisson next the dock. By means of piles and close boarding, the two ends of the space between the iron casing of the caisson and the side of the dock were first closed. The small pocket thus formed was then cleared out and filled in with concrete. The top of the well was then closed by an iron platform, bedded onindiarubber, to ensure a water-tight joint. An air-lock was attached to the platform, which was then covered with concrete and ballasting, with a weight sufficient to resist the pressure. The iron casing of the caisson and the concrete out-

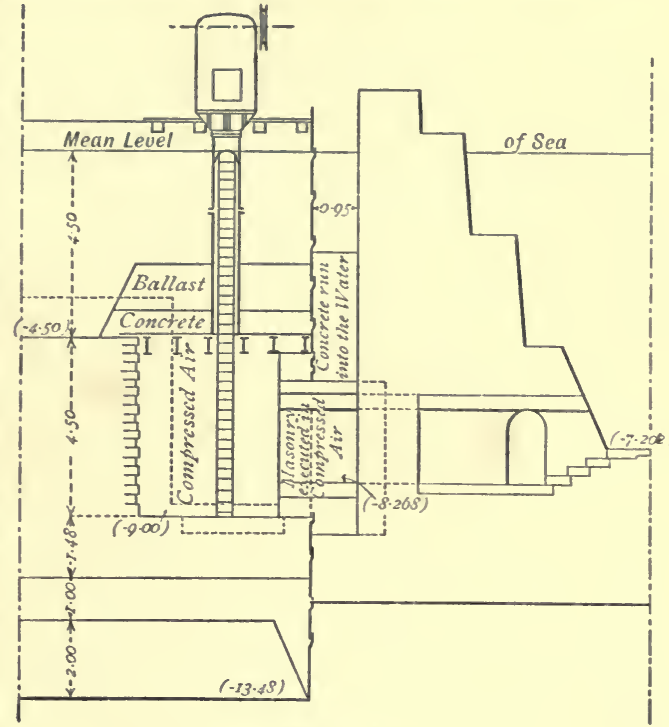

Fig. 190. side was then cut through for the culvert, which was lined with brickwork laid in cement, forming a solid connection with the old foundation and side of the dock. The only work then remaining to be done was to drive a heading through the intervening old masonry, and to line it with brickwork in cement (Fig. 190).

No. 2 Dock, Glasgow. ${ }^{1}$-This dock, completed in 1886, from the designs of, and under the superintendence of Mr. J. Deas, C.E., is of the following dimensions :-

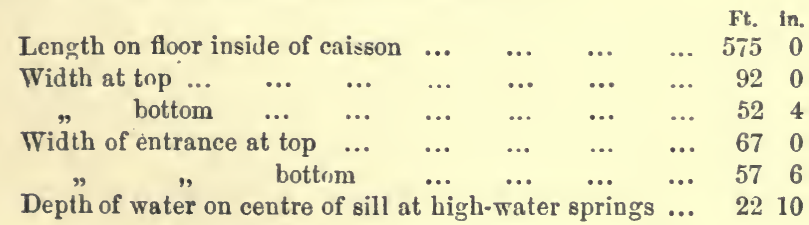

Borings taken over the site of the works proved the strata to consist of sand, clay, and gravel in about equal proportions.

1 Engineering, vol. xlii. p. 566. 
When the ground had been excavated to a depth of 3 feet

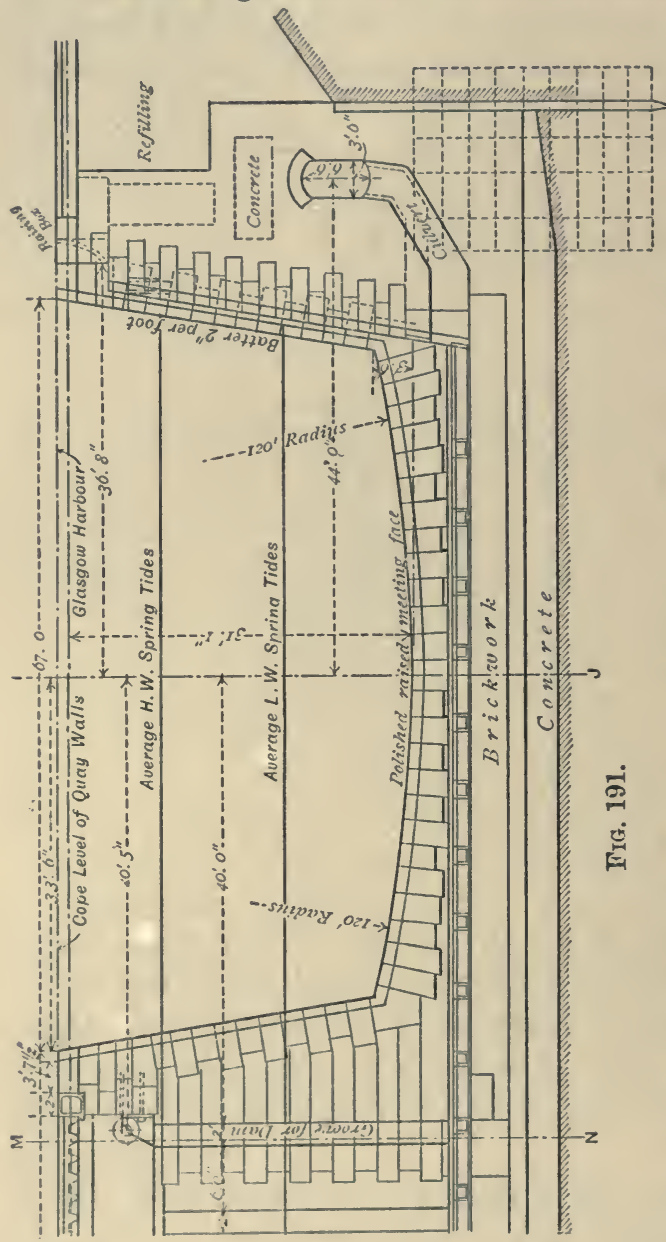
above low-waterlevel, water made its appearance, requiring the constant use of a 12-inch centrifugal pump to keep the excavations dry. Operations were continued until a depth of 27 feet below coping was reached, at which level triune concrete cylinders were sunk to form the foundation of the wing walls and the apron of the entrance (Figs. 192 to 194). These cylinders were 9 feet in external, and 5 feet 9 inches internal diameter. They were sunk 24 feet into the ground, the tops being 3 feet below the sill at the centre (Fig. 194). When down to the required depth, the interior was cleared out, and filled up with concrete.

In order to deal with the heavy leakage met with in the gravel strata into which the excavations had to be carried, the following course was adopted. One of the triune 


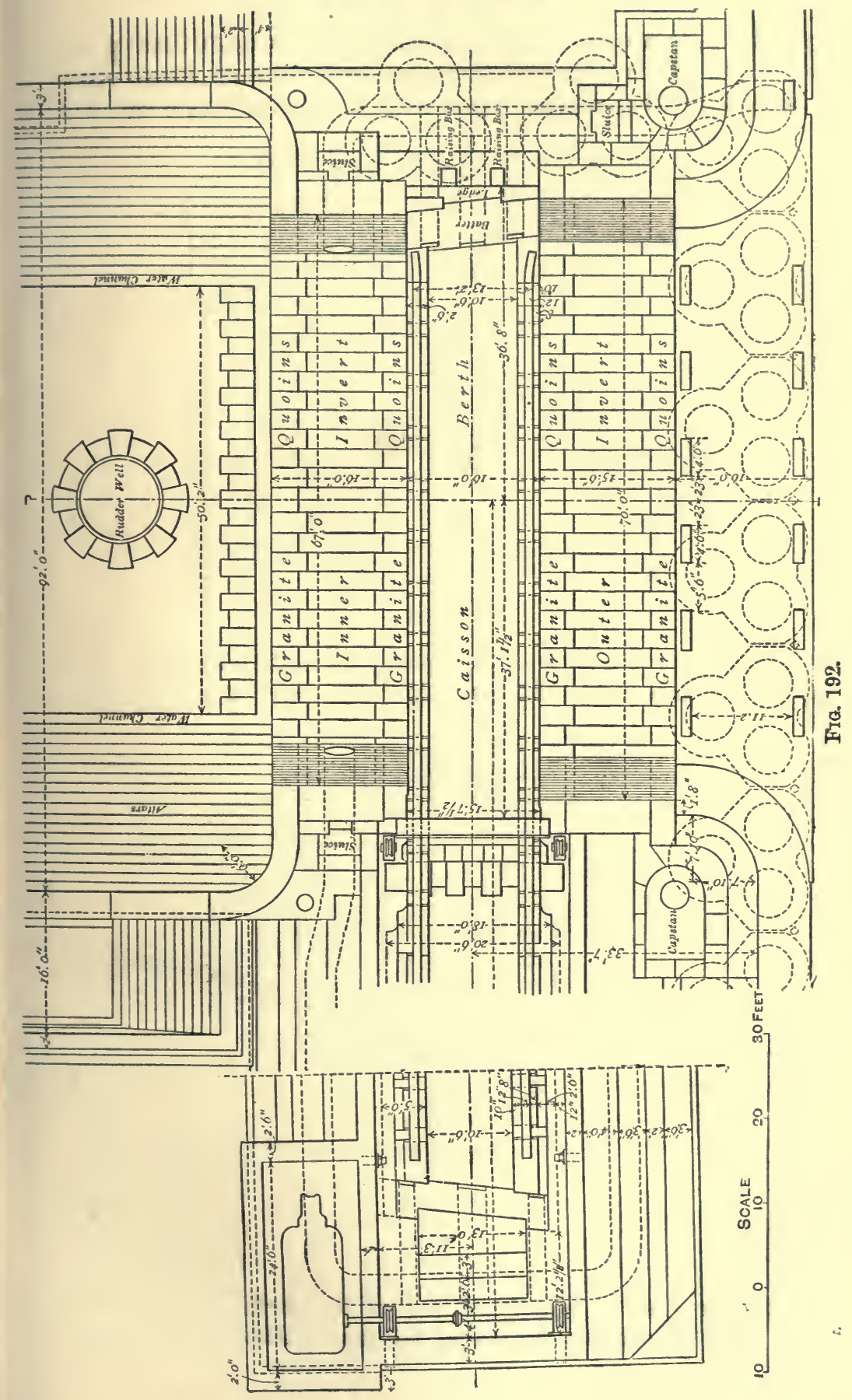


cylinders was used as a well in which a 13-inch centrifugal pump was fixed. From this well were led three lines of 9-inch openjointed spigot-and-faucet pipes, with side branches as required,

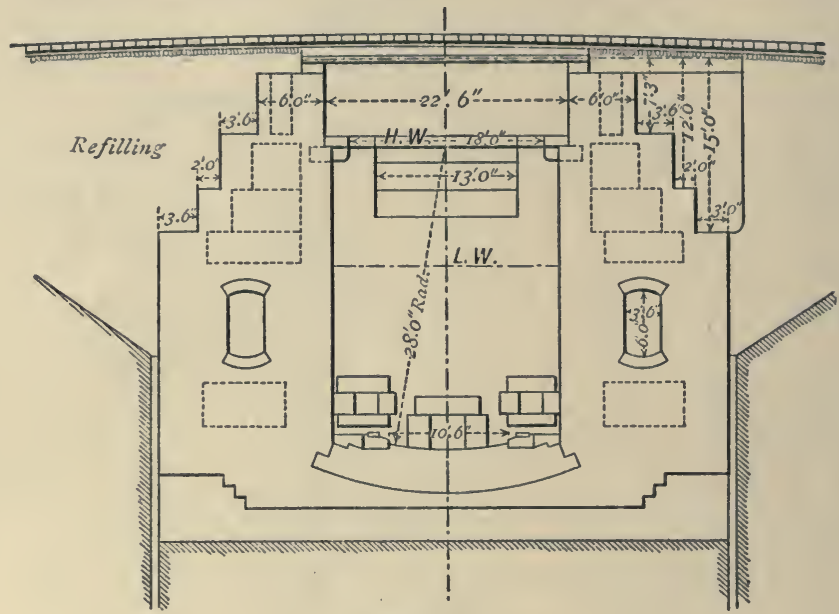

Fig. 193.

to give free passage to every spring of water met with. The pipes laid under the sill were cast iron, and the remainder,

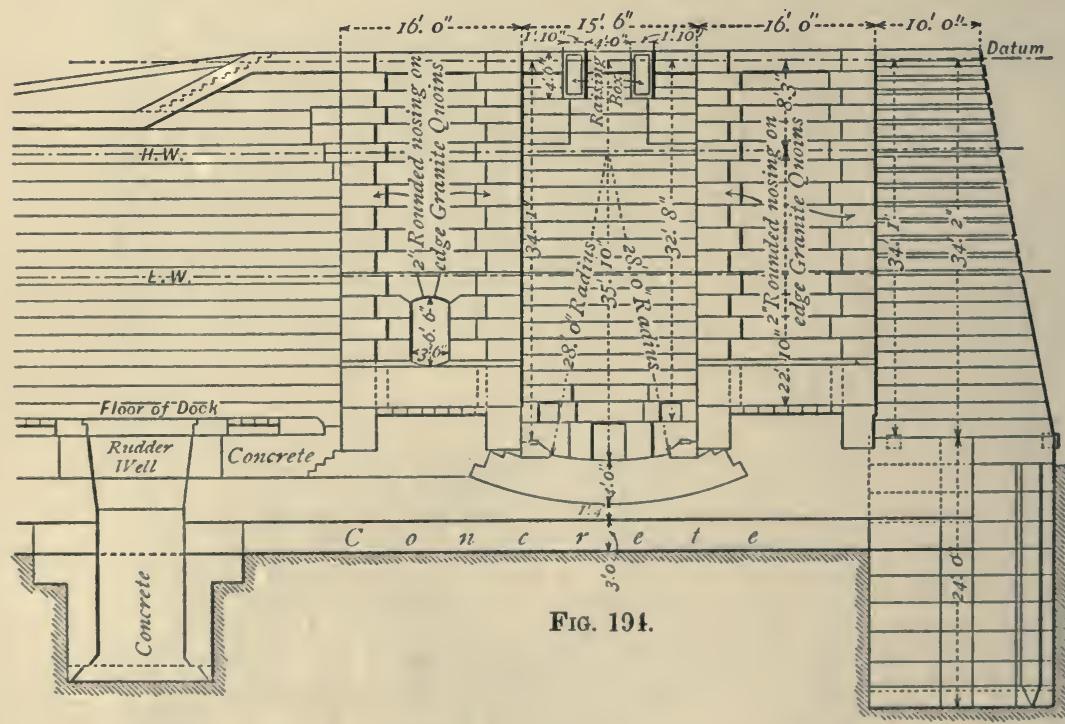

which extended to the upper end of the dock, were fire-clay. They were laid in trenches under the foundations at an inclina- 
tion of about 1 in 300, surrounded and covered to a depth of 18 inches with screened gravel. In order to prevent the pipes choking with sand which worked in through the open joints, a small wire rope with wire brush attached was carried through each from the well to the extreme end, as the excavation proceeded. This arrangement of drainage pipes and method of keeping them clear was successful in securing a well-dried

Fig. 195.
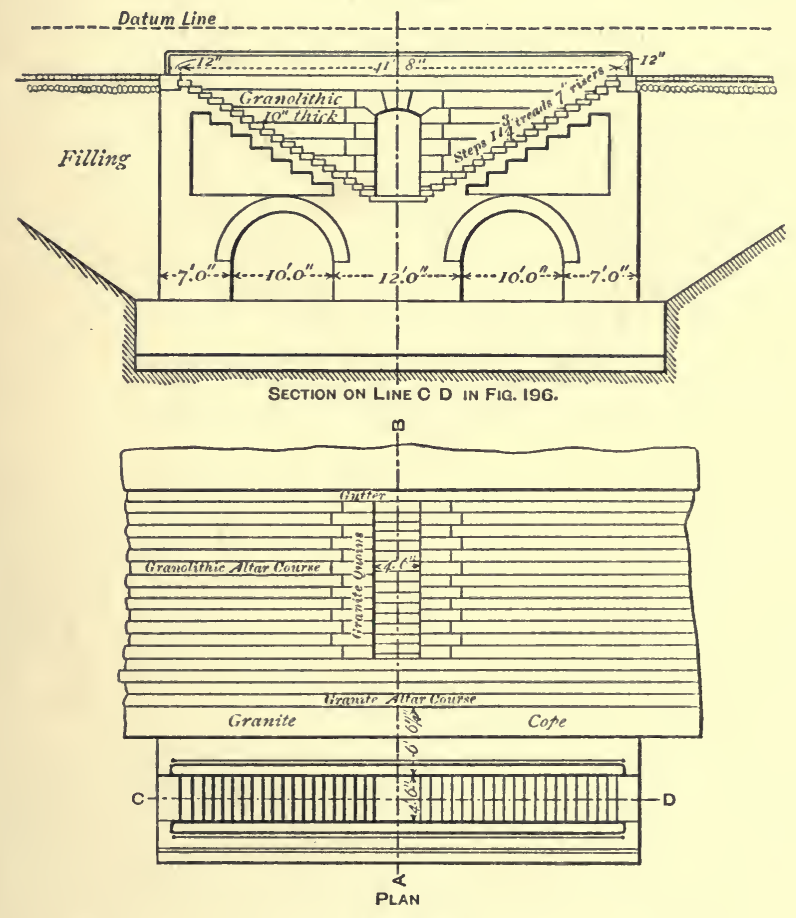

FIG. 196.

surface on which to lay the bottom bed of concrete forming the lowest section of the foundations for the floor and side walls.

The bottom bed of concrete shown in Figs. 197, 199, 200, is 12 inches thick at the centre, and 3 feet 2 inches at the sides, and on this a brick-in-cement invert, 4 feet 2 inches in thickness, was laid to a radius of 120 feet. On this invert was placed an upper bed of concrete 4 feet 5 inches thick in the centre, thinning out to 12 inches at the sides. The upper surface was cambered 6 inches, and on this was laid the flooring 
of the dock, consisting of a causeway formed of nidged granite blocks 6 inches thick, set in and grouted with neat Portland cement.

The floor of the dock is level longitudinally, with a fall transversely either way, for drainage to the side gutters.

The exigencies of the site necessitated the driving along

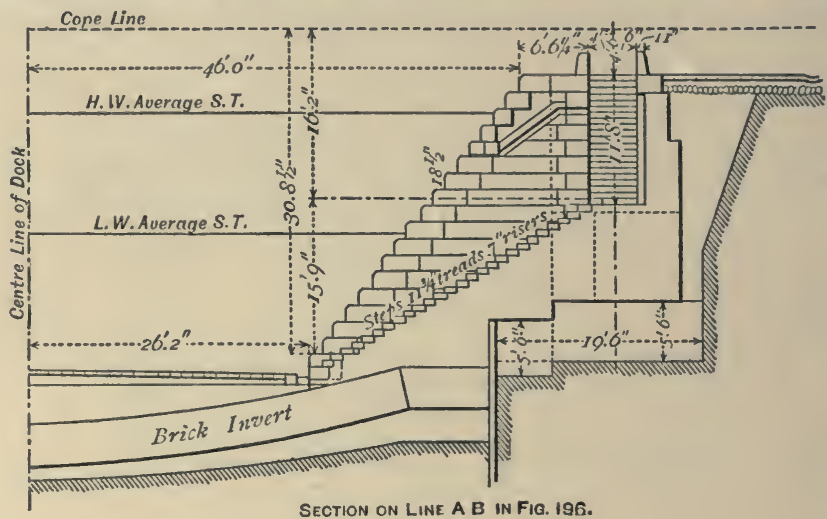

Fig. 197.

both sides and round the head a row of close, tongued-andgrooved sheet-piling (Figs. 199, 200) of pitch-pine timber, 28 feet long by 9 inches thick at the sides, and 12 inches round the head. They were driven 16 feet into the undisturbed bottom in four pile-bays.

At the back of this sheet-piling, the ground was taken out

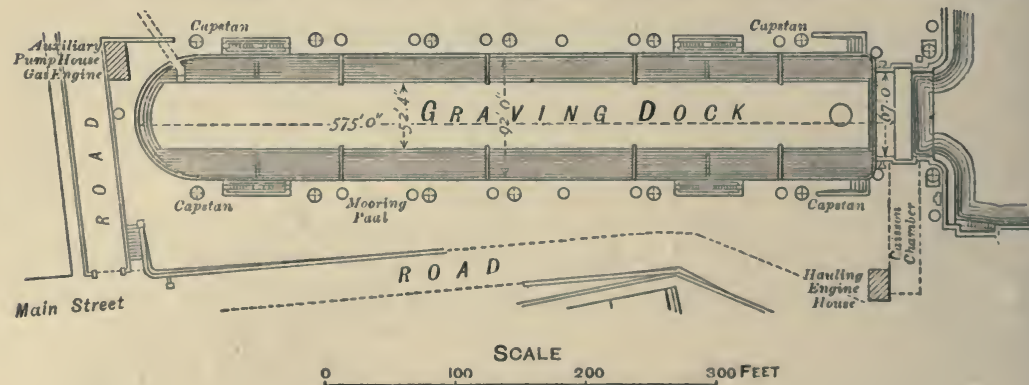

Fig. 198 .

for a width of 7 feet 6 inches, and to a depth of 6 feet, and the space filled up with concrete to the top of the piles (Figs. 199, 200). In front of the piles, the brickwork was brought up from the invert, and carried over the tops of the piles, and over the concrete at the back, forming a bed or platform on which 
the outer side walls were built. These walls (Figs. 199, 200) were constructed of brick in cement, 37 inches thick at the bottom, stepped off on the inside to 18 inches at the top, the outside face being plumb, and carefully pointed to secure water-tightness.

Except the side walls of the entrance, the steps, timber slides, top altar course, and coping-the whole of which are of granite-the body of the dock is constructed of concrete, and was, except the altar courses, deposited in situ within movable frames. The altar courses are formed of granolithic blocks which were moulded on a platform, and when thoroughly set were built into the work like

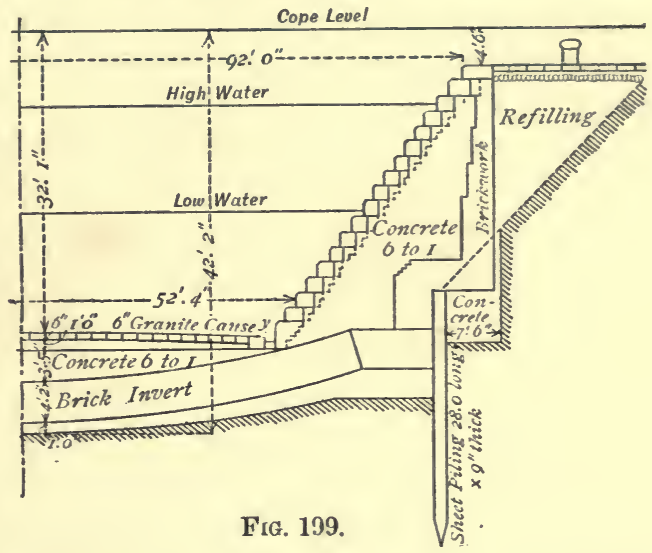
ashlar stones. An exception was the bottom altar course, which was made in situ in 8-feet lengths, and in alternate blocks, to allow for shrinkage in setting. This lower altar was made 14 inches on the tread and 30 inches average rise, the remainder being 14 inches tread and $18 \frac{1}{2}$ inches rise.

The semicircular head of the dock was formed of brick in cement, stepped at the back, and having rectangular voids filled with concrete; the whole faced with granolithic-concrete ashlar, battered to one inch per foot, in courses 18 inches deep, and chamfered on the top and bottom edges. The stretchers were made 4 feet by 1 foot 9 inches on the bed, and the headers 3 feet 6 inches long by 2 feet on the bed.

On each side of the dock there are two sets of steps, and four timber slides. Each set of steps is 4 feet 6 inches wide, with landings about halfway down, approached from the surface by two flights of steps which are placed parallel with the dock (Figs. 196, 197). The steps are 12 inches on tho tread, and $6 \frac{1}{2}$ inches rise.

The chamber for the reception of the caisson for closing the entrance is shown by Figs. 191, 192, 193. The side and 
end walls are formed of brickwork with rectangular voids filled with concrete, and having a freestone string-course on each side for the hauling-chain path. The floor is brick in cement, with granite stones and cast-iron blocks alternately for carrying the rails on which the caisson travels.

The covering of the chamber consists of Lindsay's steeltrough decking, the troughs of which are filled in with concrete, with, in addition, a layer of concrete 4 inches thick over the whole surface, which is causewayed over to form part of the ordinary roadway.

The dock is emptied by the main pumping engines of the

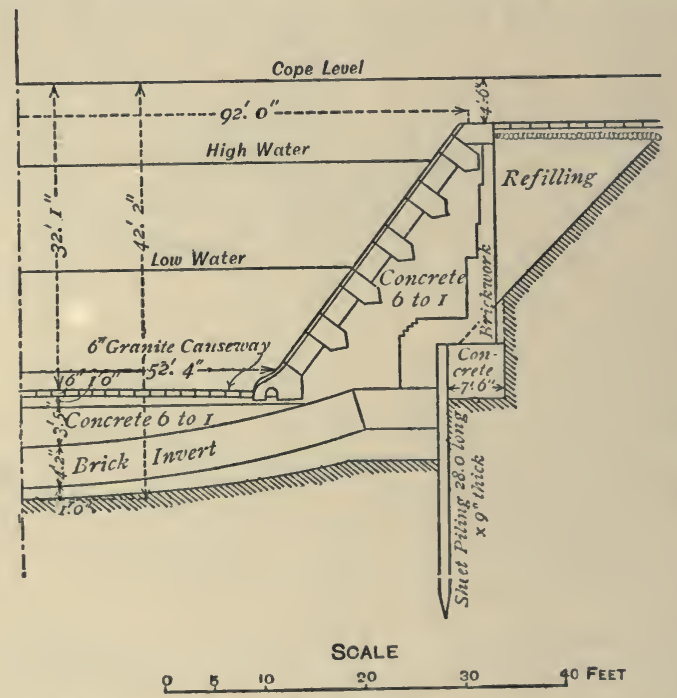

Fig. 200 .

adjacent dock through a culvert at the head 5 feet 6 inches in diameter.

The engines are placed underground in roomy houses, the walls of which were lined with white glazed bricks; the roofs being formed by rolled beams and concrete, with prismatic lenses inserted for admitting light by day.

The proportions used for making the concrete were, for the cylinders, 5 parts of gravel and sand to 1 part of Portland cement. For the floor and sides of the dock, 6 parts of stone and sand to 1 part of Portland cement. For the covering of the caisson chamber, 8 parts of stone and sand to 1 part of Portland cement, and for filling the concrete cylinders, 9 parts of stone 
and sand to 1 part of Portland cement. The granolithic blocks for the altars were composed of 3 parts of crushed granite to 1 of Portland cement, and for the granolithic-faced ashlar used in the circular head of the dock, 5 parts of stone and sand to 1 of Portland cement, with a facing 6 inches thick composed of the same ingredients and proportions as the altar blocks.

The dock is closed by an iron caisson, rectangular in shape, 15 feet wide on the deck, 67 feet long at the top, and 57 feet 6 inches at the bottom, and capable of carrying a load of 20 tons. It is moved into the chamber by hydraulic power on rollers fixed under it which run on broad iron rails laid on each side of the chamber and berth.

Esquimait Dock. ${ }^{1}$-Figs. 201 to 204.-This dock, constructed from the plans of Mr. Kinipple, M.I.C.E., has the following dimensions :-

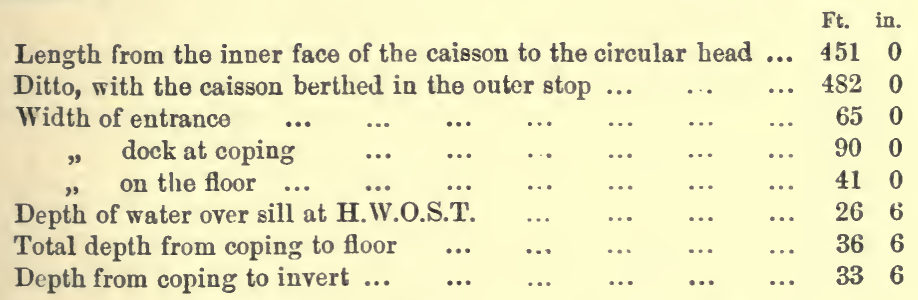

Noticeable features in the design of this dock are, the arrangement of the entrance and the arched recesses at the rear of the side walls. With regard to the entrance by the arrangement adopted, it is possible, whilst having the advantages of straight sides to the entrance, to remove the caisson from its normal berth without difficulty.

This is effected by making the width across the outer invert greater than the inner invert, as at $a$, in Fig. 201. The caisson being run a very short distance into the chamber, and raised only sufficiently to clear the invert, can then be readily removed from the entrance.

The strata in which this work was carried out consisted chiefly of sand and shells for a depth of 6

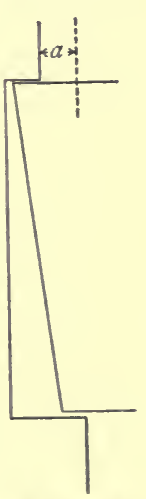

FIG. 201. feet. Below this level, very stiff blue clay was reached, and extended over the whole area with the exception of an outcrop 
214 NOTES ON DOCKS AND DOCK CONSTRUCTION.
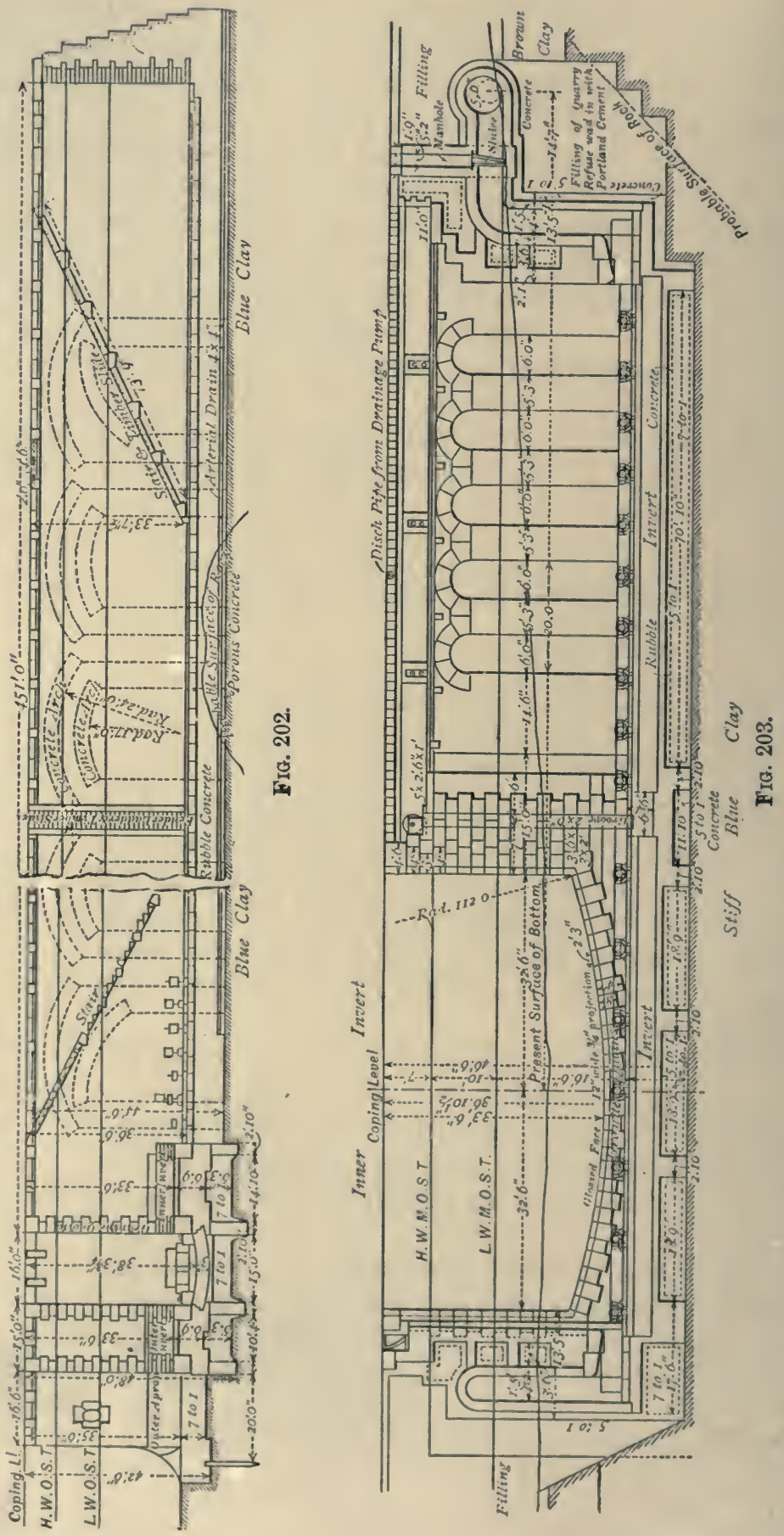
of rock which occurred near the head of the dock, and under the caisson-chamber and engine-house.

A 9-inch layer of 5-to-1 fine concrete was laid over the whole surface of the foundations, and against the backs of all the walls; it was also introduced behind the brickwork and stone facing generally throughout the work.

The whole of the foundations of the entrance are brickwork in 3-to-1 Portland-cement mortar, laid on a bed of 7-to-1 concrete.

The dock side walls and entrance walls are constructed of rubble faced with ashlar stones in 2-feet courses. At the back the side walls are vertical, with arched recesses, the object being principally the economy of material.

The floor of the dock is constructed of 7-to-1 concrete

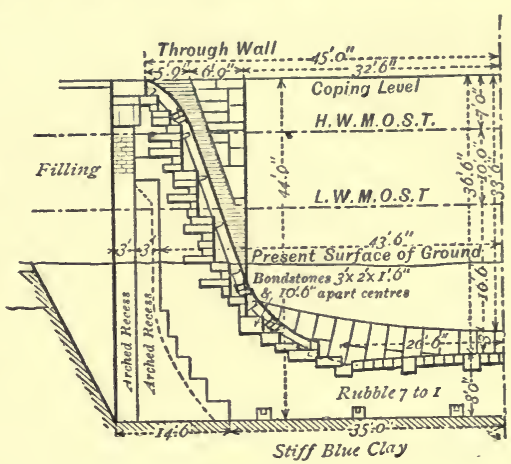

Fig. 204. with rubble stones embedded in it. The paving for 10 feet in the centre consists of two courses of stone, 2 feet in depth and 1 foot 9 inches in width, filled in between with five courses, 18 inches in depth. The remaining portion of the dock floor is paved with two courses, 2 feet in depth and 18 inches wide, and the remainder with stone 15 inches deep; the whole being bedded and jointed with Portland-cement mortar.

The inverts of the entrance are 112 feet radius, the outer being 15 feet wide and the inner 20 feet wide; both are faced with sandstone, with a hearting of brickwork and 7-to-1 concrete.

The caisson-stops, or rubbing faces, are granite, with a polished surface 12 inches wide, projecting $\frac{3}{4}$ of an inch.

The walls of the caisson chamber are constructed with arched recesses on each side 6 feet wide. This arrangement gives more room for effecting repairs when the chamber is used as a dock for the caisson.

For clearing away any mud that may accumulate upon the roller-paths or floor of the chamber, a sluicing culvert is provided at the far end of the chamber (Fig. 203).

To relieve the bottom of upward hydraulic pressure when 
the dock is empty, six arterial box-drains are provided under the floor. These are also connected with rubble drains running behind the walls in the recesses, the whole being carried to the drainage-well.

For access to the bottom of the dock, and for the removal of timber, four sets of masonry slides and slips are provided-two at the head and two at the stern; whilst at the sides there are four sets of steps or ladders 4 feet wide, formed in the doublefender timbers fixed to the altars. 


\section{CHAPTER VII.}

Closing entrances-Principal points to be kept in view-Gate-platform-Quoins Gates-Heel-post-Timber gates-Metal gates-Form of gates-Rise of gates-Nipping-Staunchness-Opening and clusing gates-Hydraulic rams and chains-Direct-acting rams-Gate rollers-Support to gates in rough weather-Stay-gates-Dunkirk Dock gates-Amsterdam Ship Canal gitesAvonmouth Dock gates-Whitehaven Dock gates-Barry Dock gates-Sanfernando Dock gates-Alexandra Dock gates, Hull-West India Dock gatesCaissons-Sliding caissons-Floating caissons-Floating box caissons-Caisson at Limekiln Dock-Barry Dock caisson-Kowloon Dock caisson-Esquimalt Dock caisson-Cerro Dock caisson-Garvel Dock caisson.

Closing Entrances.-The principal points to be kept in view in determining the method to be adopted in closing dock and lock entrances are safety in working, rapidity of manipulation, and facility of inspection and keeping in repair; local conditions as to site will also have considerable weight. The choice rests between gates and caissons.

Where gates are adopted, the passage is constructed with substantial side walls and sill against which the gates close. The bottom may be in the form of an inverted arch, or as a flat floor of masonry, depending somewhat upon the dimensions of the entrance, the materials used, and the conditions obtaining as regards the site.

In each side wall recesses are formed of a depth sufticiently great to admit of the gates, when opened, being completely housed so as to be well clear of the fairway of the entrance.

The gate-platform, or that part over which the gate travels when swinging, is level, and of course below the lowest point of the sill; the step thus formed becomes the sill against which the gates press. The face of the sill is vertical, and must be so truly dressed as to form a perfectly water-tight joint with the gates when closed.

The end of the recess corresponding with the free end of the gate is termed the square quoin, and forms a protection to the gate when laid back in the recess; they require to be of considerable strength, in order to meet the heavy blows and general hard 
usage to which they are subjected; the salient angle should be rounded off to avoid damage to passing ships.

The ends of the recess against which the gates abut are termed the hollow quoins, and require to be made of suitable form and strength to withstand the thrust of the gates. They are generally constructed of massive blocks of hard stone, backed up by heavy counterforts. The axes of the curved faces are strictly vertical, so as to form a uniform hollow groove extending from the top to the level of the gate-platform on either side of the passage; the hollow faces of the bottom blocks coinciding with and forming the terminals of the sill face.

Various forms of hollow quoins have been devised. The most common is that which presents on plan an outline more or less similar to an ogee moulding. A modification of this form,

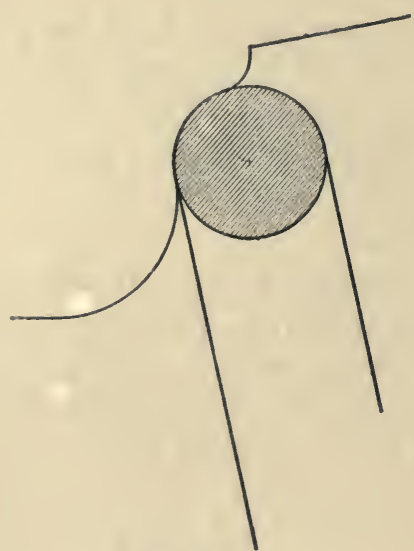

FIG. 205.

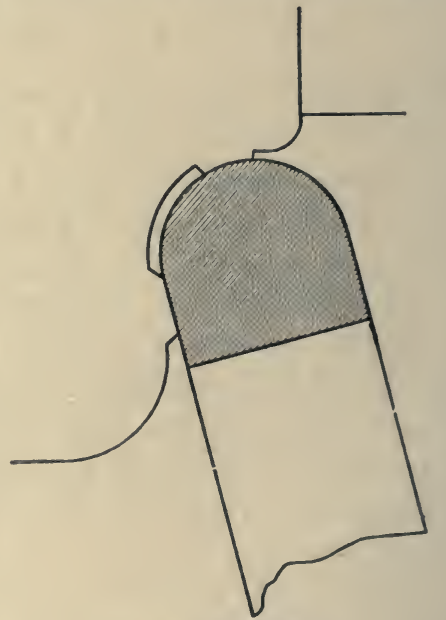

Fic. 206.

in use at the Liverpool Docks, is shown by Fig. 205. The tightness of the joint between the heel-post and the quoin is dependent upon accurate fitting and close contact between the circular surfaces. This is not easy to ensure, and there is always more or less leakage round the hollow quoin.

Fig. $206^{1}$ shows a method much in favour in Holland for making a water-tight joint. The hollow quoin is brought more into the dock than usual, and the joint made against a narrow straight face, usually about 8 inches wide, and polished from top 
to bottom; a clearance is given round the quoins, except at the outer portion where the gate-post is in close contact with the stones to prevent loose material being carried round the hollow quoin.

Gates.-These consist of two exactly similar doors, each somewhat longer than half the width of the entrance, and of a sufficient depth to reach from the highest water level to below the sill against which they shut.

The material to be used in the construction of the gates, i.e. wood or iron, will depend greatly upon expediency, local conditions, and no doubt to some extent personal prejudice. An important element in the consideration of material is the presence or otherwise of the marine worm. There are some

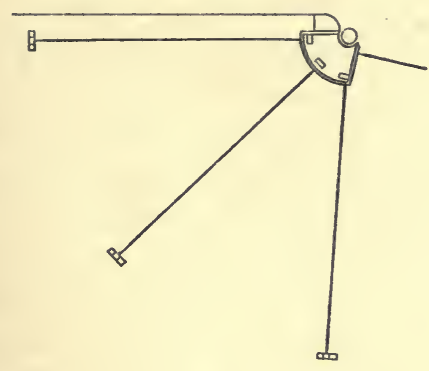

FIG. 207.

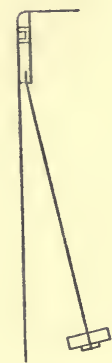

FIG. 208.

parts, however, which are always constructed entirely of, or are faced with wood, i.e. the heel and mitre-posts and the meeting-sill.

The Heel-post is vertical, and formed so as to correspond with and accurately fit the hollow quoin. At the bottom it is kept in place by a pivot and socket connecting the gate with the masonry of the gate-platform, and at the top secured by an iron strap passing round the upper end of the post, and very securely anchored to the masonry of the side walls (Figs. 207, 208).

Mitre-post.-Each leaf of the gate being similar, they meet on the centre line of the entrance; the meeting- or mitre-posts constitute, or are attached to, the end framing of each leaf, and are so worked that the meeting faces extend the entire depth, and should consequently bear fair and true against each other, and form, when closed, a tight joint.

Timber Gates. ${ }^{1}$-In favour of wood it is urged that, when carefully selected, timber will last for a very considerable time 
without deterioration or decay. That, when constructed of this material, gates are quite as cheap, if not cheaper, than those constructed of iron; and that they are equally as durable. Also that wood, owing probably to its more yielding nature than iron, permits the gate to accommodate itself more readily to the sill, and where bearing-rollers are employed, to adjust itself better to any slight irregularity in the roller path; further, that gates properly constructed of timber will, on the whole, stand a greater amount of rough usage without serious results as compared with iron.

The principal disadvantages of timber are that, unless efficiently protected, the attacks of the marine worm will do more harm in a few months than natural deterioration and decay will do in years; and for some forms, as, for instance, circular gates for large spans, the difficulty of obtaining logs of sufficiently large scantling to serve for the continuous horizontal beans. To meet this difficulty, however, it is the practice to construct each leaf in panels or divisions, which are bolted together at the intermediate vertical timbers, and by connecting pieces bolted to the horizontal timbers. With this sectional principle of construction, the timbers used need not be of unusual dimensions. The gates can be built in a workshop, and then readily removed in parts to their place for erection. If properly constructed, they will stand a considerable amount of rough usage. They require, however, to be well housed in the recesses, and guarded against heavy blows from passing vessels; such blows will not as a rule injure gates with continuous beams, whether of wood or iron; but there arises the risk of dislocation from such blows acting on the concave side of timber gates constructed on the sectional principle, which does not admit of great resistance to a strain contrary to the usual direction of the water pressure.

Metal Gates.-There was and still is with some engineers great prejudice against the use of iron or steel as a material of construction; the objections advanced being that gates so constructed are difficult to keep water-tight, that they are much more liable to damage by vessels striking against them than timber gates, and that metal is subject to much more rapid deterioration from rust and the action of sea water than timber. Practically, there appears to be no valid reason for this prejudice. The advantages ${ }^{1}$ of iron and steel are durability, strength, 
simplicity of construction, and freedom from the attacks of the worm. Another and important advantage claimed for metal gates is the buoyancy capable of being given to them by the introduction of air-chambers of sufficient capacity to float the gates. The working weight on the bottom, and consequently the strain upon the hinges, being regulated by ballast, ${ }^{1}$ or the air-chambers may be of such a capacity only that there may be a preponderance of weight to prevent the gate lifting.

At the Bute Docks, Cardiff, a composite gate has been adopted with success. This method of construction consists of a wooden skin, supported on plate girders, strengthened by vertical and diagonal ribs. It is claimed that a leak can be at once detected and easily repaired, either by fresh caulking or by cutting out and replacing a plank, whilst the dimensions and position of the girders can be exactly adjusted to the requirements of both theory and practice. ${ }^{2}$

Form of Gates.-The simplest form of construction is a straight gate, with continuous horizontal beams meeting with a mitred joint on the centre line of the entrance, and, for small spans, is perhaps the best that can be adopted.

For wide openings, however, the conditions are different, and elaborate investigations point to the conclusion that the nearer a gate approaches a true circular are the stronger it will be; or, expressing the same thing in another way, "with a circular form, equal strength can be obtained with less expenditure of material."

Mr. Barlow, ${ }^{3}$ Sir F. Bramwell, ${ }^{4}$ Mr. Kingsbury, ${ }^{5}$ and others refer to several important advantages attaching to curved gates as compared with straight ones; amongst others, that when closed, and forming a true segment of a circle, they are not subject to transverse strains, and therefore not to any liability to distortion which such strains alone can produce, but that the whole of the material in the gates is in compression, and that they require less material than straight ones.

A form approaching that of a Gothic arch is advocated and adopted by some engineers, on the ground that less material is required than for a true cylindrical form, also that the latter form is liable to flexure, by which the character of the strains are altered, a defect which does not obtain in a Gothic or pointed form of gates.

1 M.P.I.C.E., vol. xxxi. p. 357.

Itid., vol. $\mathrm{xxxi.p.} 343$.
2 Ibid., p. 335. s Ibid., vol. i. p. 74.

Ibid., vol. xviii. p. 445. 
Rise of Gates.-An important element as regards the plan of gates is the rise. This is the length of the perpendicular line drawn from the meeting-point on the centre line of the passage to a transverse line passing through the centre of the heel-posts. The amount of rise greatly influences the compressive strains - that is, the strains vary inversely as the rise.

Sir F. Bramwell ${ }^{1}$ has pointed out that the most economical form generally is that which, when the gates are closed, produces a continuous circular arc, subtending an angle of $133.56^{\circ}$ at the centre of the circle of which the arc forms a part. 'The rise of the gates is thus equal to the width from centre to centre of the heel-posts, multiplied by 32958 , or, in round numbers, one-third of the span.

The most economical is not, however, necessarily always the most advisable form to adopt. A large rise increases the length of the gate-leaf, and therefore affects the effective length of the entrance. This, in the case of locks and dry docks, more especially, might prove a serious matter.

A large camber in the gates requires a greater depth of recess, which is inconvenient, is not always admissible, anil is generally to be avoided if possible. ${ }^{2}$

The greater the rise ${ }^{3}$ the more oblique is the thrust on the hollow quoin with respect to the side walls, and therefore more difficult to meet; particularly ${ }^{4}$ when the gates are required to be near the outer side of the entrance; for in such a case it may be undesirable to put a great amount of masonry in front of the gates; and, therefore, necessary to direct the thrust, if possible, across the wall, where an abutment can be obtained by placing heavy counterfoils at the rear.

The longer the gate-leaf ${ }^{5}$ the weaker it is to withstand the strain of opening and shutting, and any blows which it may receive when home in the recess.

For small and medium-sized gates, say up to 60 feet clear span, Mr. Brown, in his paper on "Dock Gates," "suggested as a convenient form that shown in Fig. 209. In this figure, the line of thrust is a continuous arc, $\mathrm{A} \mathrm{B}$, passing through the centre of the heel-posts and of the meeting faces of the mitre-posts, and having its centre on the central line of the entrance, the rise or

1 M.P.I.C.E., vol. Iviii. p. 202.

2 Ibid., vol, xxxi. p. 334 ; and vol. lviii. p. 202.

- Ilid., p.318. s Ilbill, vol. xxxi. p.31t. 
versed line of the arc being one-sixth the span from centre to centre of the heel-posts. The back of the gate is the arc of a circle of such a radius that at the middle of the gate it coincides with the arc A B. The front of the gate is a straight line from heel to mitre-post. With this form, the recess in the side walls would not be inconveniently large. The face of the gates, when open, would-with the ordinary fenders-be in line with the side walls of the entrance, and the gangway at the top would also form a straight line with the side walls. This form would allow of access to the interior for repairs, etc.; whilst the width would give considerable flotation power; moreover, the straight face would

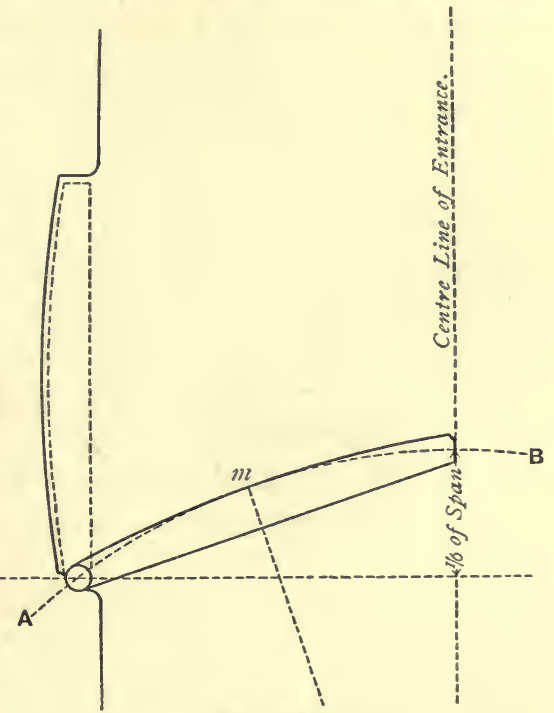

Frg. 209. permit of the gate being braced diagonally from the heel-post to the foot of the mitre-post, and thus enable the greater part of the weight being sustained by the anchor-straps, to the relief of the roller.

In practice, the rise will be found to vary from one-sixth to one-fourth the span of the entrance, the latter predominating.

\section{Name.}

Victoria Dock Extension, London

Dunkirk

Whitehaven

A vonmouth

$\begin{array}{cccc}\cdots & \ldots & 70 & 0\end{array}$

$\begin{array}{llllllll}\text { Barry } \quad \ldots & \ldots & \ldots & \ldots & 80 & 0\end{array}$

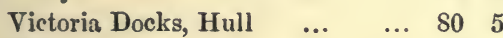

Authority.

M.P.I.C.E., vol. lix. p. 30.

Ibid., p. 29.

Ibid., vol. lv. p. 42, 44.

Ibid., vol. lv., plans.

Ibid., vol. xcvii. p. 336.

Ibid., vol. ci. p. 139.

Ibid., vol. xcii. p. 153, and plang.

1bid., vol. 1xx., plans.

Nipping.-This consists in the line of pressure being thrown to the extreme inner or outer edge of the meeting faces ${ }^{1}$ of the mitre-posts. The condition may be due to faulty workmanship in fitting the gate-leaves; they may be made a little 
too long, in which case they will nip on the outer edge of the meeting faces. By wear, they may become a little too short, causing them to nip on the inner or dock side, or foreign substances may lodge between the heel-post or the sill and the stonework. ${ }^{1}$ In practice, this difficulty is met by slightly rounding the meeting faces, or by chamfering the edges so as to bring the line of pressure more to the centre of the mitreposts.

Staunchness.-In order to ensure the staunchness or watertightness of the gates at the centre, it is sometimes the practice to arrange that they first close at the bottom of the mitre-posts, leaving them a little apart at the top, so that the gates, touching the sill at the bottom, gradually close by a slight twist, as the pressure increases.

Opening and closing Gates.-The usual method of opening and closing large gates is by an arrangement of chains. Each gate-leaf is provided with two chains, one for opening, and the other for closing; one being attached to the front and the other to the back of the gate, as low down as possible, and as near to the rollers and mitre-posts as can be conveniently arranged.

The opening chain passes from the back of the gate through a culvert in the wall of the gate recess, up to the hauling machinery, situated on or below the quay level.

The closing chain is attached to the front of the gate; it crosses the passage and passes through a culvert in the opposite side wall, at a convenient distance outside the hollow quoin, to the hauling machinery.

Formerly the hauling gear consisted of ordinary crab-winches or capstans, worked by manual labour. Now, however, hydraulic power is almost universally adopted; applied to pressure-rams fitted with multiplying speed-gear for hauling on the chains; by small engines working crabs placed underground and attached to the usual arrangement of chains; or by rams acting directly on the gates without the intervention of hauling chains.

The method adopted at the Victoria Dock Extension, London, ${ }^{2}$ is shown by Fig. 210. The arrangement consists of two hydraulic rams of 16 inches diameter to each gate, one of 12-feet stroke, and the other of 8-feet stroke. The chains are attached to the gates in the ordinary way, and are guided to the rams by vertical and horizontal rollers built into the walls.

M.P.I.C.E., vol. lviii. p. 159.

2 Ibid., vol. lix. p. 20. 
A very convenient and efficient method $^{1}$ of manipulating dock gates is shown by Figs. 211, 212. In this arrangement, a single hydraulic engine is attached to a crab having two cupped drums, either of which can be thrown out of, or into,

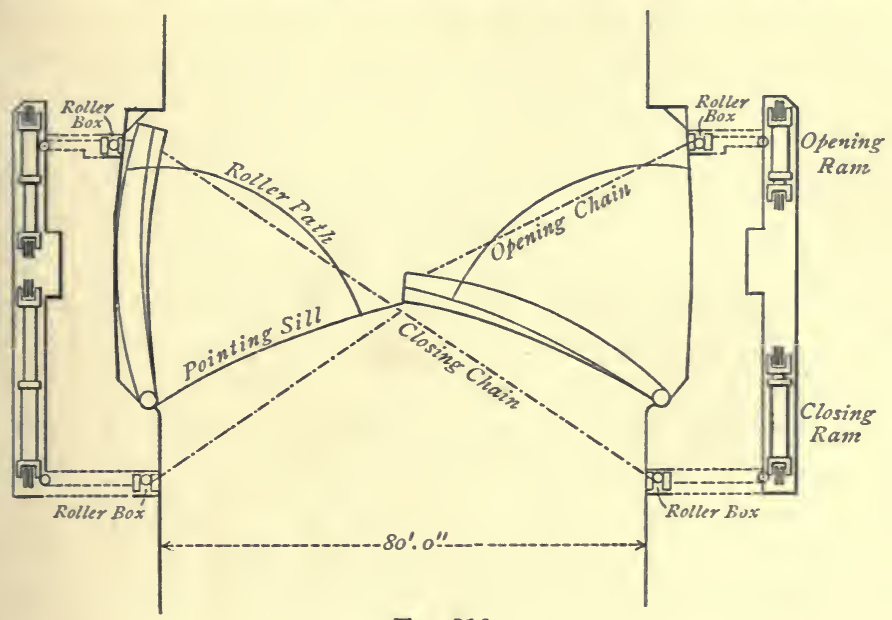

Fig. 210.

gear by a clutch, leaving the other free for overhauling. This one engine, with its double crab, serves for two chains, and these, instead of descending in chainways through the masonry, are led along the top of the gates, as shown in Fig. 212, in which

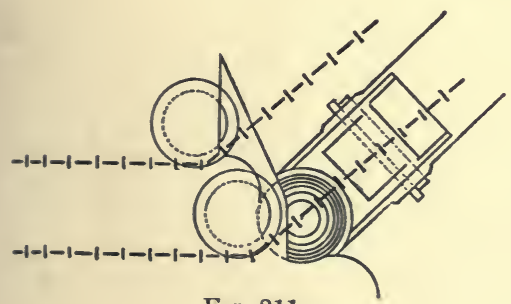

FIG. 211.

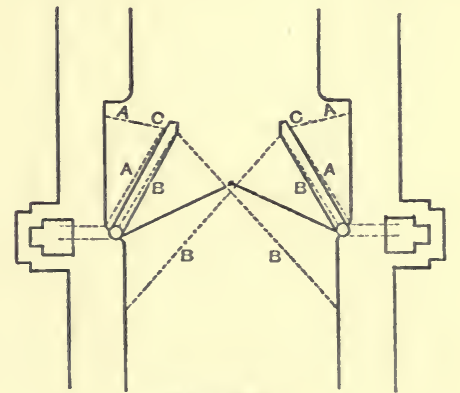

FIG. 212.

A is the chain for opening, and B the chain for closing. The opening chain passes over a pulley at $\mathrm{C}$, and then descends vertically by the side of the gate to a point corresponding to that at which the end of the chain is usually attached; at that 
point it passes over another pulley, and finally is secured to the masonry at the place where, in ordinary practice, the roller-box is fixed. The chain for closing follows a similar course on the other side of the gate, and in like manner is made fast to the masonry on the opposite side of the entrance.

The advantages of this arrangement of gate machinery and chains are, that two engines with double crabs do the work of four with single crabs; the usual chainways in the masonry of the side walls, with the numerous roller-boxes for guiding the chains, are entirely dispensed with; and that each leaf is worked both ways from the same side, so that in the case of sea gates, which require to be held back against the action of waves, the closing can be effected by one man, instead of two, at each side of the opening.

An objection to the chains crossing the entrance, as in the above methods of manipulating the gates, is that the effective

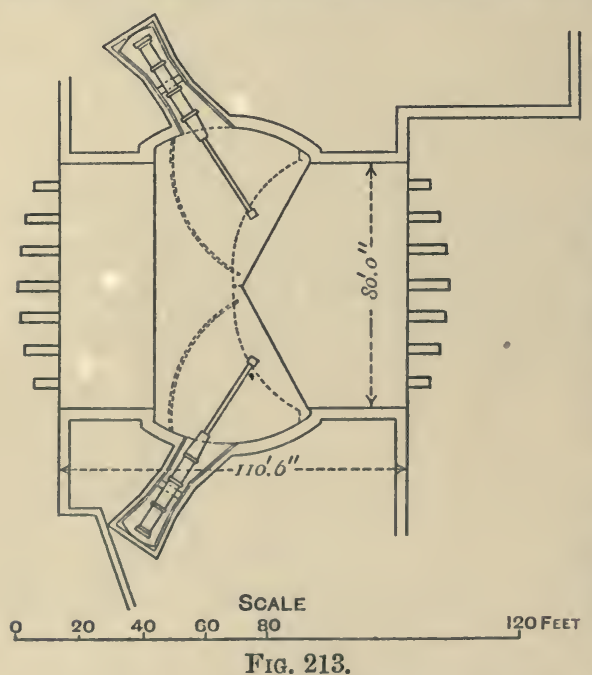
depth of water over the sill is reduced. Further, it is necessary to pay out a large amount of slack in the closing chains, so as not only to allow vessels to pass between the gates, but also to admit of the chains being pushed clear, in the event of a vessel fouling them.

At the Barry Docks, the gates are moved by direct-acting hydraulic rams (Fig. 213), the following description of which is taken from $\mathrm{Mr}$.

J. Robinson's paper on "The Barry Dock Works." 1

"In the case of the entrance-gate machinery, the water is admitted to a direct-acting hydraulic cylinder, having a piston 2 feet $5_{4}^{3}$ inches in diameter, and a 18-inch ram, with a stroke 25 feet 9 inches, attached to the gate.

"The cast-steel cylinder is made in three parts, and tested to withstand a pressure of $3000 \mathrm{lbs}$. on the square inch. The 
ram is of iron, cast vertically in one length, and is firmly guided and fixed to the gate by a forged-steel cross-head and couplingpin. Trunnions are cast on the cylinders, projecting above and below, and pivot in saddle-bearings, which also have trunnions on their sides, and these pivot in bearings fixed to the side walls of the ram-chamber, thus permitting the cylinder to oscillate horizontally and vertically. The hydraulic rams are of sufficient strength to resist shocks of waves and to hold the gates rigidly during movement. In the passage gates, the ram is attached to a radius arm near the top, with a slide against the back of the gate, the other end of the arm working on a pin in the holdingdown bracket over the top of the heel-post. As the power required is less, the diameter of the piston is only 2 feet $1 \frac{1}{2}$ inches, and that of the ram 1 foot 6 inches, with a stroke of 16 feet 7 inches. The cylinder for the passage-gate machine is of iron, cast in one piece, and tested to a pressure of $2400 \mathrm{lbs}$. per square inch.

"A combined regulating and escape valve ${ }^{1}$ is fixed to each machine, in order to reduce the pressure of $700 \mathrm{lbs}$. per square inch to any degree below 500 and $100 \mathrm{lbs}$. The pressure usually employed for the entrance-gate rams is $250 \mathrm{lbs}$., and the ordinary time occupied in opening the gates is one minute and a half, and the same in closing. At the passage, the full accumulator pressure is admitted to the ram cylinders, and the time occupied in opening is less than one minute, and the same in closing."

One great advantage attaching to this method of moving gates is that there are no chains to interfere with the fairway of the entrance.

A drawback in connection with gates is the difficulty and cost of efficient inspection and repair. It is absolutely necessary for their proper preservation that they should be periodically examined and painted. As a general rule, this is done by lifting and docking the gates, or provision may be made for enclosing them temporarily by forming stops in the masonry of the entrance, in which caissons can be placed; by this course, the gates can be dried and thorough examination and repairs effected in position.

Rollers. ${ }^{2}$-To take the weight of the gates and relieve the strain on the side walls, it is usual to place a truck or bracket carrying a roller or slide under the gates. During the operation 
of opening or closing this roller runs on a metal racer or pathway fixed to the entrance platform.

To ensure contact between the roller and the pathway, provision is made for adjusting by mechanical means the vertical position of the roller with regard to the gate.

As the roller-path forms part of a segment of a circle of which the centre is the axis of the heel-post, it follows that the outer edge of the roller has to travel a greater distance than the inner edge in the same time. On this account the roller should be made conical to a corresponding degree, and the axle on which it turns should coincide with a straight line passing through the axis of the heel-post and position of the roller.

In the case of curved gates, ${ }^{1}$ the usual practice is to place the roller under the centre of gravity of the gate, this being the position which gives the greatest steadiness in travelling and the least racking and working of the joints. The true position of the roller is, however, difficult to determine with accuracy, especially when the gates are composed of materials of varying specific gravity.

In the case of straight gates, ${ }^{2}$ the most suitable position for the roller, and the one usually adopted in practice, is to place it so that it takes half the weight of the gate, the other half being borne by the gate pivot.

Strong opinions have been expressed both for and against the use of rollers. In the opinion of the late Sir J. Hawkshaw, ${ }^{3}$ their only use is to relieve to some extent the pressure of the heel-post against the lower part of the hollow quoin.

Mr. Hayter considers ${ }^{4}$ that, unless under exceptional circumstances, it would be better to abandon rollers altogether, on the ground of the greater facility with which the gates can be manipulated. When, however, gates are of great span, one roller may be introduced with advantage. In support of this opinion, Mr. Hayter ${ }^{5}$ refers to the fact that in Holland rollers have been almost universally abandoned; and in the case of obstruction occurring on the roller-path, preventing the proper closing of the gates, the water would escape from the dock, and much damage would result to shipping. ${ }^{6}$

When one of the gates at the Bristol Dock entrance, ${ }^{7}$ which had been in use many years, was removed, it was found that,

' M.P.I.C.E., vol. lv. p. 117.

- Ibid., vol. lv. p. 72 ; vol. lix. p. 5.

- 1lid., p. 5.
2 Ibid., p. 110.

- Ilid., vol. 1. p. 89.

s Ibid., vol. lix. p. 4.

It Ilid., p. 11. 
through some mal-adjustment, the roller had never borne upon the roller-path, but was about $\frac{1}{4}$ inch clear. No difficulty had, however, been experienced in working the gate, and the fact would not have been known had the gate not been removed. The span of the entrance was about 40 feet, and the rise and fall of tide 30 feet. This fact goes to support the view that rollers under gates of moderate spans are unnecessary.

Mr. Stoney is also of opinion ${ }^{1}$ that, although the practice, following precedent, has been to support large gates on rollers, it is by no means desirable or necessary, for iron gates may be supported on the pintles alone, and in support of this opinion, alludes to the fact that when the roller and path of one leaf of the gates of the Dublin Graving Dock got out of order, instead of going to the expense of repairing the defects under water, the expedient was tried of tying back the upper pintle by strong wrought-iron bars with adjusting screws, and lifting the roller so that the weight of the gate did not bear on the roller-path. The result was that this leaf was far easier to move than the other one, and gave no further trouble.

On the other hand, Mr. Abernethy ${ }^{2}$ strongly objects to the abandonment of rollers, on account of the tendency of the unsupported gate to drag forward, a condition which involves a continuous strain on the masonry at the upper part of the side walls.

Sir W. Armstrong is of opinion ${ }^{3}$ that it is not so much a question of sufficient rigidity of gates to support their own weight-as there can be no difficulty in making them, whether of wood or iron, of sufficient strength to carry their own overhanging weight-as the wear and tear on the heel-post. Without the support of a roller a thrusting force is brought against the bottom of the hollow quoin and a pulling force upon the upper holding or anchor-straps. As regards the top bearings there is no great difficulty, as they can be made sufficiently strong and efficiently anchored back, and can always be lubricated and adjusted as wear takes place. As regards the heel-pivot, however, the case is somewhat different; there is a continual grinding due to the weight of the gates, the effect of which cannot be met by adjustment, and access is difficult; therefore, in his opinion, it would be unwise to abandon rollers and rollerpaths in the case of heavy gates.

I M.P.I.C.E., vol. 1v. p. 113.

${ }^{2}$ Ibid., vol, l. p. 90.

Ibid., p. 97. 
Mr. Blendy remarks in his paper on dock gates, ${ }^{1}$ that when gates are of large size, the weight is greater than can be safely allowed to depend on the attachments at the heel-post, unless means be adopted to reduce the working weight by the aid of flotation or otherwise, and even then it is advisable to provide against accidents from defective fastenings.

Although abutments may be constructed of ample strength, the constant vibration caused by heavy gates swinging backwards and forwards will have some detrimental effect on the masonry, or the mass may give slightly one way or the other without any apparent reason. Anchor-straps, however well adjusted and keyed up, will soon wear slack, or the anchor-bolts may deteriorate through rust.

A reasonable conclusion appears to be that, with a moderate width of entrance, say not exceeding 60 feet, ${ }^{2}$ rollers may be dispensed with entirely; but that in the case of entrances exceeding 60 feet, $^{3}$ while it is desirable to hang the gates as much as possible from the anchor-blocks and heel-pivot, rollers are necessary, attached in such a manner as to relieve the wear and tear on the anchor fastenings and heel-pivot. This applies with additional force when the gates are worked at considerable variations of tide.

Support to Dock Gates when exposed to Rough Water. ${ }^{4}-\mathrm{Mr}$. Ramsey, the resident engineer at Ramsgate Harbour, devised the following method of supporting the entrance gates under the very severe strain to which they were subjected when struck by waves when the tide outside was nearly level with the water in the basin.

The end of a stout beam or stay of greenheart timber was connected, by means of a massive iron movable joint, to the fore part of each gate near the mitre-post on the inner or basin side, and at about high water of equinoctial spring tides. The opposite end of this beam passed through an opening in the masonry of the side walls of the entrance. The inner end of the beam was supported by a small bogie truck running upon a pair of rails laid in a channel underground, the object of this being to support the inner end of the beam and admit of its ready motion in a horizontal plane.

On the vertical face of the beam nearest the gates was
'M.I.I.C.E., vol. lviii. p. 155.
2 Ilid., vol. lix. p. 14.
sllid., p. 5. 
fixed a strong toothed rack working in a pinion at the end of a train of gearing, the first motion of which was a screw and worm-wheel. By means of this gearing, the power of the men was communicated to the gate through the beam or stay. The action was so perfect that the gate would remain stationary in any intermediate position of the gearing when let go, even when there was a considerable amount of disturbance in the harbour. The span of the gates was 50 feet, and the shock of the waves was occasionally very great.

By this simple contrivance the gates were opened and closed without difficulty when there was a considerable amount of undulation in the harbour.

Stay Gates.-These consist of small gates which, when the large gates are closed, take a position as shown in the diagram at $a$ (Fig. 214). Fitting tight against the back of the gates, they form shores or struts, and so keep them steady when a swell sets in against them. These stay gates are usually worked by chains in a manner similar to the main gates.

Dunkirk Dock Gates.-M. Guillain, the engineer of the Port of Dunkirk, has expressed an opinion ${ }^{1}$ that a mode of con-

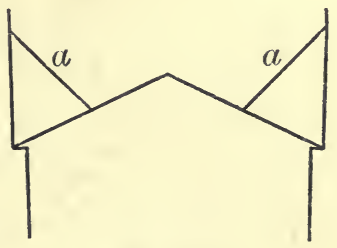

FIG. 214. struction which throws upon the face of the sill the greater part of the total strain due to water pressure, will produce considerable economy of material, when the length of the leaf is greater than the height. It is then necessary to have a few horizontal flanges and vertical members properly proportioned; an extreme case being that in which the gate would comprise only a top flange, vertical girders, and a bottom flange resting against the sill, and sheeting stiffened by ribs. In this case, the top flange would bear one-third of the maximum total pressure, while the sill would bear the remaining two-thirds by means of the bottom flanges.

This system was adopted by M. Guillain in the iron gates for the new Dunkirk Docks (Figs. 215 to 218). The width of the lock entrance is 69 feet, and the rise of the sill one-sixth ; the gates are 27 feet high above the sill; the outer surfaces are flat, so that each leaf has a total length of 38 feet 4 inches, by a height of 27 feet 9 inches, and a thickness in the middle of 3 feet 7 inches. 
The sheeting covers the whole of the outer surface, and reaches about halfway up the inner surface.

The horizontal iron plates between the vertical girders form the water-tight chamber which occupies the lower half of the gates. This system of construction was adopted not so much to economize a few tons of metal as to secure easy maintenanco and manipulation, while allowing the employment of large sluices, of which there are two in each leaf, having a total area of 75 feet super.

The water-tight chamber, reached by means of the heel- and mitre-posts, is of great height; the men work standing, and the

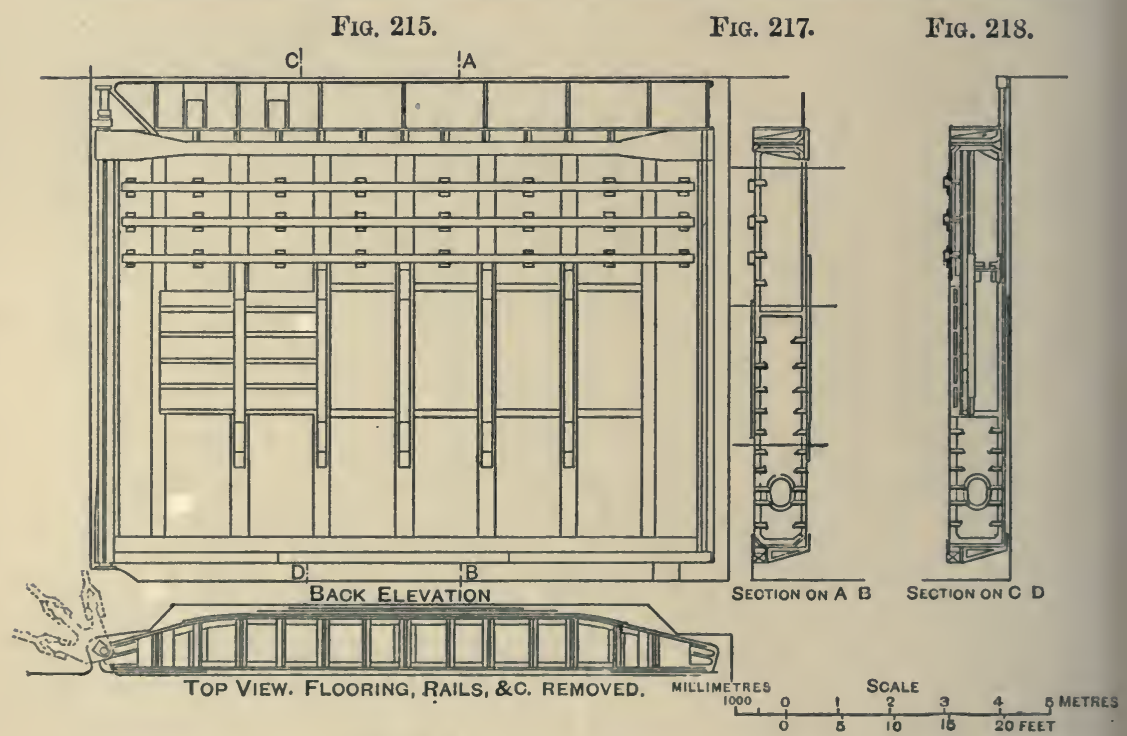

FIG. 216.

paint inside can be renewed as easily as in the inside of a ship.

In turning, the greatest horizontal strain on the upper collar and the lower pivot does not exceed $4 \frac{1}{2}$ tons.

Amsterdam Ship Canal Lock Gates. ${ }^{1}$-The design and construction of the iron sea-gates is shown by Figs. 219, 222. The length from out to out of iron is 33 feet 2 inches by a height of 23 feet 6 inches, the width at the centre of the leaf being 2 feet 7 inches.

For making the joint against the hollow quoin, ${ }^{2}$ a vertical

' M.P.I.C.E., vol. lxii. p. 9.

${ }^{2}$ Ibid., p. 29. 
timber was attached to the iron heel-post; this piece of timber closes against a corresponding vertical projection on the stonework about 8 inches wide, and polished from top to bottom.

The gate thus clears the circle of the hollow quoin, except in the line of thrust, which is communicated to the wall by the interposition and accurate fitting of a piece of timber about

Fig. 219.

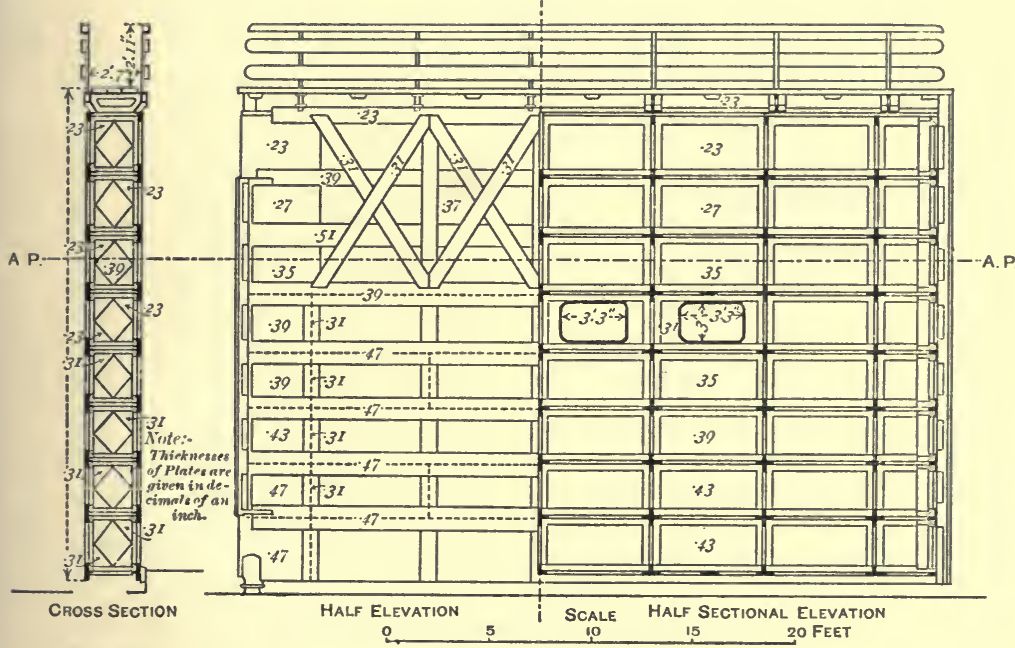

Fig. 220.
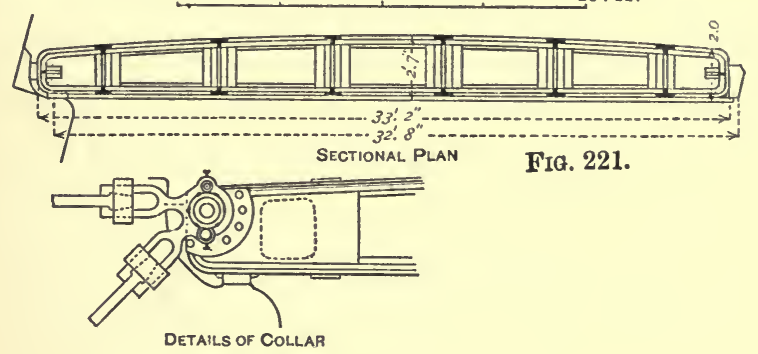

FIG. 222.

8 or 9 inches wide. The arrangement of these timbers is shown in Figs. 221, 222.

To relieve the friction between the gate-post and the quoin, 1 the pivots are placed a little out of the centre, so that immediately the leaf is moved it clears the hollow quoin. A difficulty attaching to this arrangement is that a space is left between

I M.P.I.C.E., vol. 1xii. p. 29. 


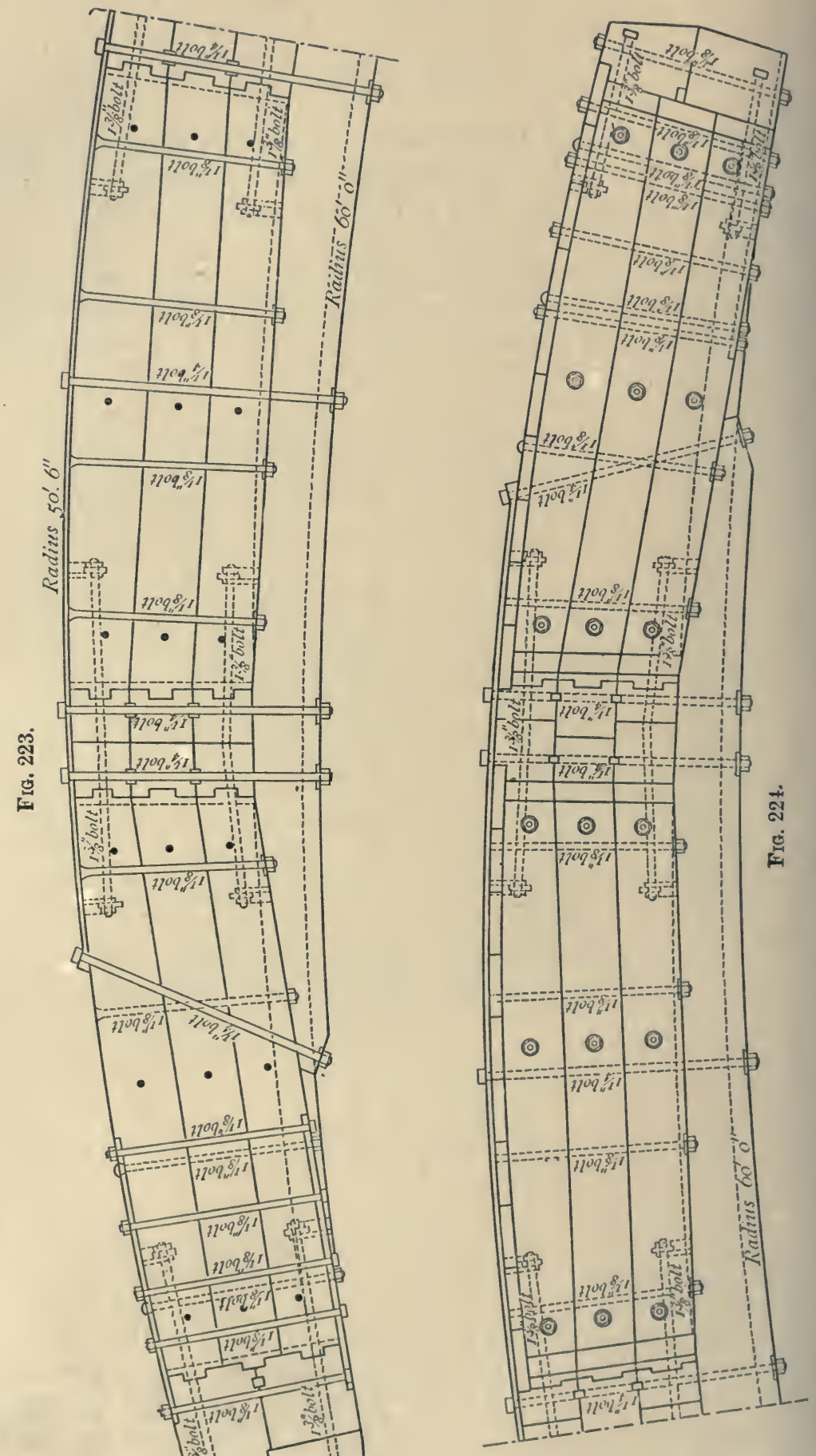


the quoin and the post, in which loose material may lodge and prevent the gates closing with accuracy.

Avonmouth Dock Gates. ${ }^{1}$-These gates consist of oak heeland mitre-posts, except in the case of the outer pair of gates, which are of greenheart, with ribs, intermediate posts, and walings of pitch-pine and Memel. The thickness at the heeland mitre-posts is 2 feet 8 inches, and at the centre of the leaf about 2 feet 11 inches, exclusive of the walings. The back when closed forms, from one hollow quoin to the other, a continuous arc of a circle, the radius of which is 50 feet.

In the upper gates, the three layers of cross-pieces, of which the thickness of the gate is made up, are all cut to the same radius, and are divided into lengths or segments, the ends of which overlap or break joint with each other, and meet in a vertical post 12 inches square.

The objection to this arrangement was that nearly all the segments required an 18-inch baulk of timber to cut them to the proper curvature, involving a waste of about 50 per cent. To reduce this waste, and retain the same curvature and thickness of gate, the arrangement as shown in Figs. 223, 224, 225, was adopted for the middle and outer gates. In this design, the back of the ribs is the only curved face that has to be cut, all the other joints or faces being straight, involving scarcely any waste of timber. The ends of the rib segments do not break joint as in the upper gates, but meet in an intermediate post composed of six vertical pieces strongly built together. The whole of this system of ribs and posts is thoroughly braced and tied together by wrought-iron straps and bolts and timber walings.

The timber work of the gates was prepared and fitted under a gantry on the works. It was then taken to pieces, conveyed to the lock, and built in place with travelling-cranes and hydraulic jacks.

As the work approached completion, it was found, when a gate was moved on its roller, that it did not stand plumb, but hung forward to the extent of 14 inches. It would have been impossible to have obtained a good mitre joint with so much deviation from the perpendicular as 14 inches. To remedy this defect, it was decided to fix a small roller under the mitrepost, and to lay down an additional roller-path on the platform.

' M.P.I.C.E., vol. 1v. p. 11. 


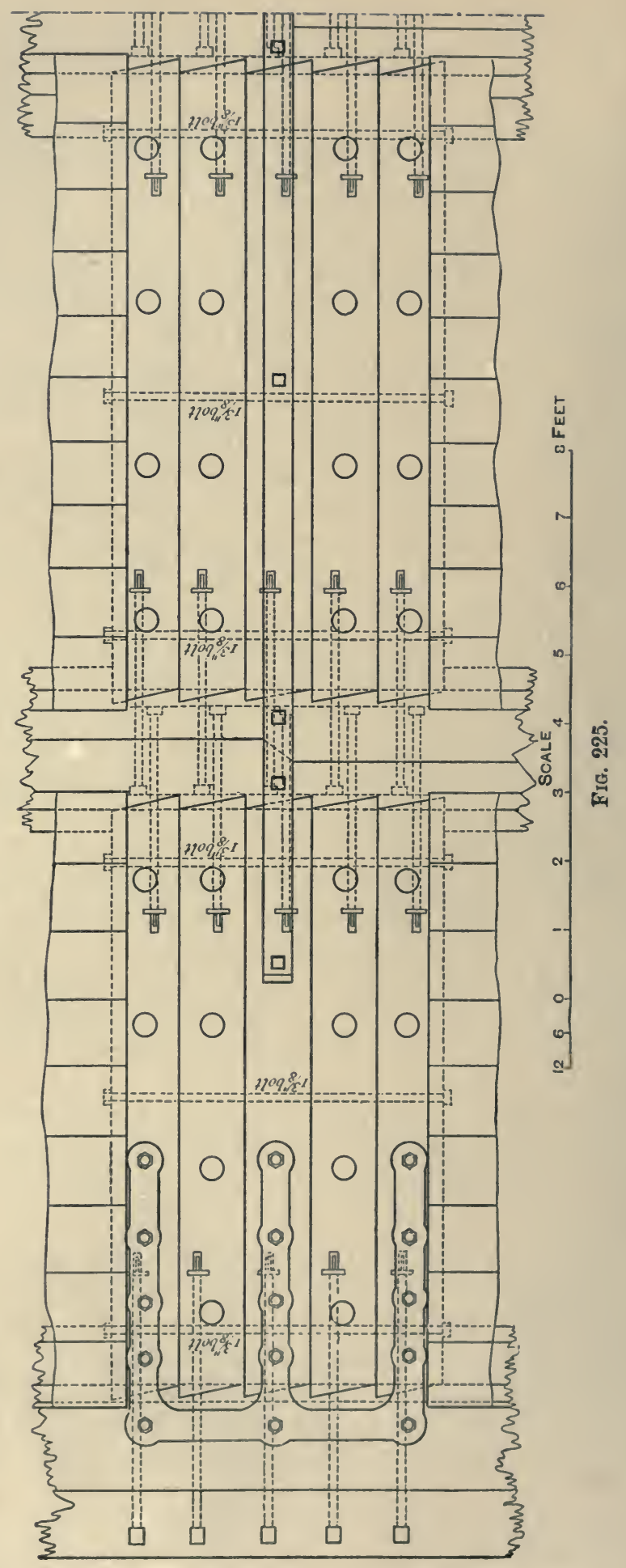


This small roller was not made adjustable, the chief object being to keep the gates perpendicular while they were being mitred. The plan was successful, and enabled a perfect mitre joint to be made.

Whitehaven Dock Gates. ${ }^{1}$ - These gates are constructed of pitch-pine, with the exception of the heel- and mitre-posts, which are of greenheart.

The height from the roller-path to the gangway is 35 feet, and when closed the ratio of rise to span is 1 to 5 .

The ribs, which are straight next the sill and curved on the pressure side, are formed of two baulks placed side by side, bolted and dowelled together, and tenoned into the heel- and mitre-posts. Their depth is 12 inches, and constant throughout; the thickness at the centre being 2 feet 2 inches, diminished to 1 foot $4 \frac{1}{2}$ inches at the ends.

The planking consists of pitch-pine 3 inches thick, feathered, caulked, and secured to the ribs by treenails $1 \frac{1}{4}$ inch in diameter and 15 inches long.

A cast-iron cup, fitted with a gun-metal disc, is let into the bottom of each heel-post. The disc bears upon a cast-iron pivot 9 inches in diameter let into and bolted down to the granite heel-post stone. The radius of the bearing surface of the pivot is 9 inches, and that of the disc 12 inches.

The top hollow quoin consists of a cast-iron block formed to clip the heel-post in a similar manner to the granite quoins: and tied into the side wall by wrought-iron anchor-straps.

The heel-post is hooped, and held in position by a wroughtiron strap screwed at each end, the nuts clamping the inside of the anchor casting.

Each gate is fitted with a cast-iron roller, bearing upon a cast-iron roller-path of 26 feet radius. The weight upon the roller is adjusted by a screw working in a fixed nut attached to the gate in a casting fixed above high-water mark.

The gates are surmounted with a gangway 4 feet wide, supported on saddle castings bolted to the top rib, and fitted on each side with movable standards and guard-chains.

Two sluices are fitted to each gate for adjusting the level of the water in the dock, for scouring the apron, and for keeping the channel clear in the vicinity of the entrance.

Fig. 226 shows a section through the centre of the leaf. 
Barry Docks. ${ }^{1}$-The entrance gates (Figs. 227 to 229), are constructed of iron. The rise is a quarter the span of the entrance, or 20 feet. The height at the mitre-posts is 48 feet 10 inches, and at the heel-posts 42 feet 1 inch. The length of

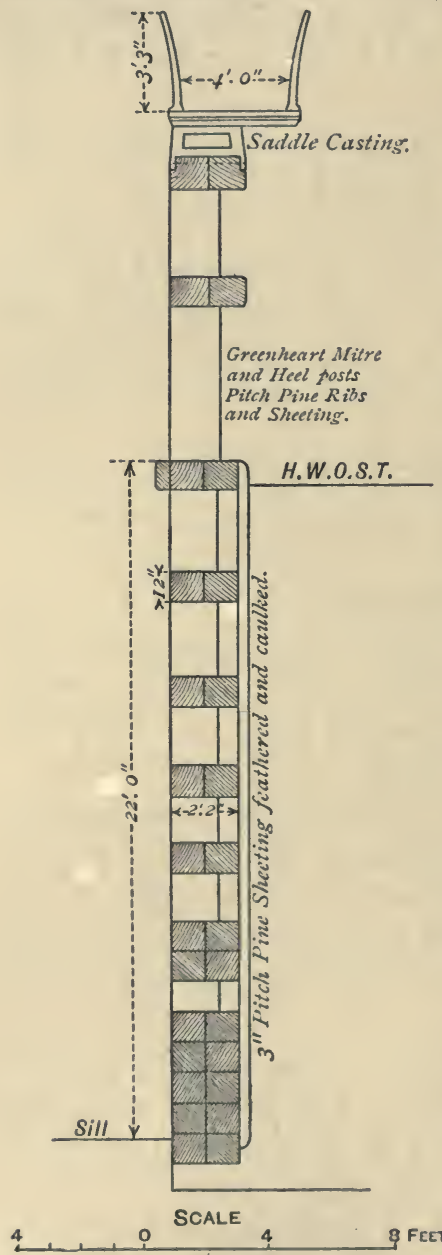

FIG. 226 . each leaf is 50 feet, and the maximum width 8 feet at the centre.

When closed, the backs of the gates form a continuous are of a circle of 48 feet radius, but the front of the leaf is straight, and closes against a straight sill.

Each leaf is divided into fifteen water-tight compartments by decks and bulkheads.

Below deck No. 5 are the airchambers, which are almost sufficient to float the gates, leaving only a small weight to be carried by the roller and bottom pivot; above No. 5 deck the interior of the gate is open at the back, access to the air-chambers being provided by a trunk leading from the top deck through this open portion of the gate.

The air-chambers are drained to the bottom of the gates, from whence the water is pumped out.

In each leaf there are six sluices, having a combined area of 100 square feet, worked by directacting hydraulic gear.

The meeting-sills, mitre- and heel-posts are of greenheart, the latter having a radius of 15 inches.

The heel-posts rest upon cast-steel hemispherical pivots, with a sliding surface on the top, covered with a cupped saddle, sufficient play being allowed to admit of the gate on opening being thrown out slightly from the hollow quoin, and so prevent the wearing of the heel-post and hollow quoins when the gates 
The gates are fitted with forged-steel rollers carried in a frame, having a bearing under the lower timbers, and supported behind by a spear terminating with a screw adjustment. Each roller carries a scraper fitting close down to the path.

The roller paths are laid to a radius of 43 feet, and are constructed of wrought-iron plates on edge with a steel face on the top.

To prevent the gates from floating, a cast-steel holding-down bracket is fitted and fastened to the top of each heel-post.

The San Fernando Dock, Buenos Ayres. ${ }^{1}$ - These gates, designed by Mr. D. Macalister, A.M.I.C.E., have some novel and interesting features of detail, i.e. in the material used in the sill, and the method adopted in securing a water-tight joint at the mitreposts.

The width of the entrance is 64 feet, and the depth from coping to sill 18 feet 2 inches; the normal depth of water on the sill is 13 feet, but the rise and fall is very variable, being more dependent on the winds than the tides.

The conditions to be met were-the gates to be capable of excluding the water to coping level, and of working under these conditions, and also with only 5 feet of water on the sill, the ordinary low-water level. Owing to the absence of suitable stone and the expense of skilled labour, and also to the rapid decay of timber, it was decided to make the meeting-face of the dock sill of cast iron (Figs. 231, 232).

'I'he gates (Figs. 230 to 232) were constructed of wrought iron with timber meeting-faces and mitre-posts. The lower portions consist of tanks of such capacity that when the water is at its normal level the gates are almost in a state of flotation, and they can then be opened and shut with ease. But as the gates have to be opened with only 5 feet of water on the sill the displacement is then considerably less, and consequently roilers had to be provided to take the excess weight. Each gato consists of four horizontal girders connected by the vertical boxgirders or manhole trunks (or perhaps the water-tight tanks may be regarded as one girder), and the horizontal strains are transmitted from the four adjustable thrust-blocks to the thrustblocks built in the masonry.

Any one who has had to do with gates knows the difficulty of getting a water-tight joint at the hollow quoins, not to

1 Engineering, rol. xliv. p. 540. 
to avoid the necessity of making a water-tight joint at the hollow quoins, the method described by Mr. Hayter ${ }^{1}$ was adopted, viz., by making the gate a little longer and forming the joint on a plane surface.

The strains were calculated and the thickness so adjusted that the tension of wrought iron should not exceed 5 tons nor the compression 4 tons per square inch. The pressure on the brasses of the thrust-blocks, when the water is level with the top of the gates, is under 1 ton per square inch, and then the pressure exerted on the brickwork by the cast-iron thrust-blocks does not exceed 5 tons per square foot. The pressure when the water is at its normal level is about 50 per cent. less.

The details of construction can, perhaps, be described best by giving the following particulars, taken from the specification :-

The actual length of each gate, exclusive of woodwork, is 35 feet 3 inches, and the width at centre 2 feet 9 inches, and at ends 1 foot 9 inches. The inner face is straight, but the outer is to a curve of about 154 feet radius, and all work is bent or cut to this curve.

The horizontal bottom and top plates of the tank are $\frac{1}{2}$ inch in thickness, each in three pieces, or plates, with $\frac{5}{8}$-inch butt straps 12 inches in breadth, and treble riveted; the intermediate plates are $\frac{3}{8}$ inch thick, with $\frac{1}{2}$-inch butt straps. Manholes 18 inches by 14 inches are cut at the ends. The top plate or deck is $\frac{1}{2}$ inch in thickness, with manholes, welded rings, and covers made water-tight. The vertical end plates are $\frac{1}{2}$ inch in thickness, each in one length of 20 feet 8 inches and 1 foot 9 inches in breadth. The vertical plates forming the inside of the manhole trunks are in three lengths of about 3 feet $55_{16}^{5}$ inches, 3 feet $5 \frac{5}{16}$ inches, and 11 feet 7 inches respectively, and $\frac{1}{2}$ inch in thickness. The plates of intermediate bulkheads or bracing are $\frac{3}{8}$ inch in thickness of similar lengths, and have holes cut to lighten them. The skin plating of the inside face consists of three strakes $\frac{1}{2}$ inch in thickness, the four strakes above it being $\frac{7}{16}$ inch, $\frac{3}{8}$ inch, $\frac{5}{16}$ inch, and $\frac{5}{16}$ inch in thickness respectively. The skin plating of the outside face consists of three strakes forming a tank of $\frac{1}{2}$ inch in thickness, and with stiffening plates at the sluices. The strake forming the flange of the deck or tnp girder is 12 inches in width and $\frac{1}{2}$ inch in thickness, in two lengths, with 12-inch cover straps. 
The horizontals or longitudinal angle-irons are each in one length of 35 feet 3 inches, and of $3 \frac{1}{2}$ inches by $3 \frac{1}{2}$ inches by $\frac{1}{2}$ inch. Those at the bulkheads or vertical bracing are of $3 \frac{1}{2}$ inches by $3 \frac{1}{2}$ inches by $\frac{1}{2}$ inch, welded and bent so as to form a continuous ring, and juggled where necessary. The frames are 3 inches by 3 inches by $\frac{3}{8}$ inch, spaced about 1 foot 10 inches apart, and in lengths of about 3 feet 5 inches, 3 feet 5 inches, 5 feet 8 inches, and 5 feet 8 inches respectively. The angle-irons securing the greenheart meeting-faces, etc., are of $3 \frac{1}{2}$ inches by $3 \frac{1}{2}$ inches by $\frac{1}{2}$ inch, bent at corners, and having countersunk holes for bolts.

Alexander Dock, Hull.-Figs. 233 to 235 show the construction of the entrance gates; the material is greenheart throughout; in form they are segmental with a rise of about 14 feet." Each leaf is constructed in three panels and is supported on a roller which travels on a cast-steel roller-path of 39 feet 6 inches radius Fig. 233. Fig. 234. Fig. 235.

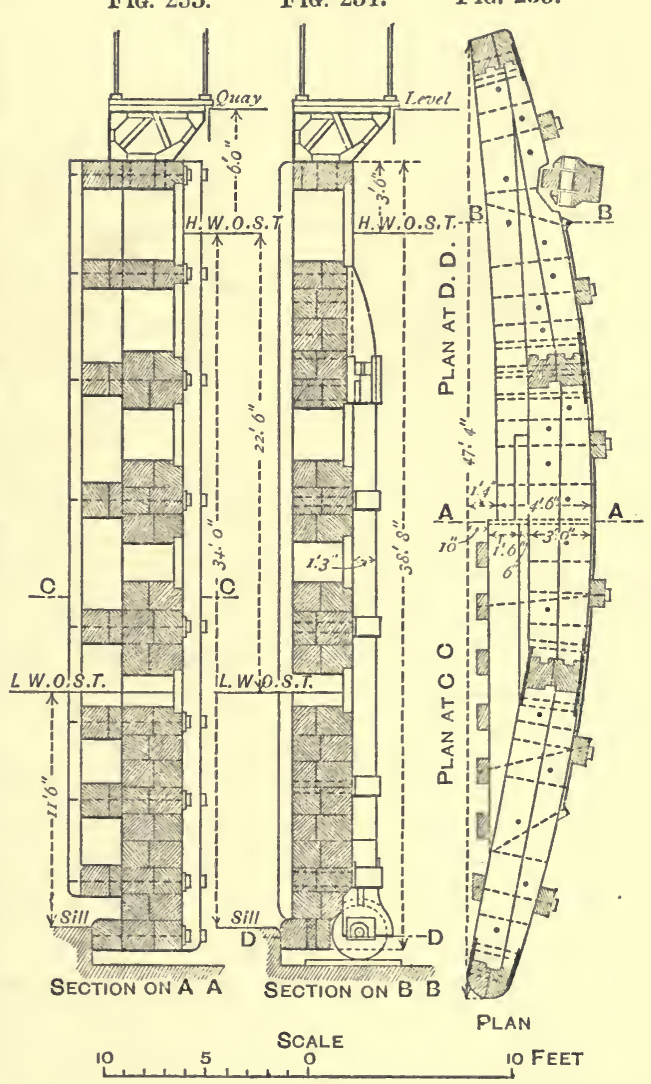
accurately bedded on granite blocks. The weight of one leaf is 176 tons.

Havre Dock Gates.-A form of gate-caisson ${ }^{1}$ designed by $\mathrm{Mr}_{\mathrm{r}}$. D. Cunningham, M.I.C.E., is fastened at one end to the masonry of the dock entrance, and on being opened is swung round into a recess in the side wall in a similar manner to one leaf of an 
ordinary dock gate. In construction it is similar to a gate with the addition of a special pneumatic chamber or reservoir. To open the dock, air is pumped into the pneumatic reservoir, which causes the vessel to float off its bearings. To close the entrance,

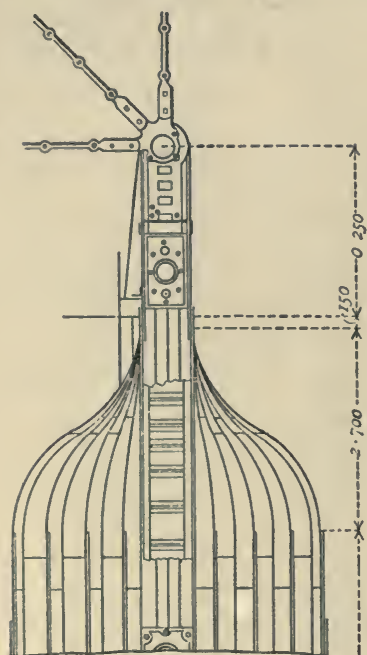
the air is allowed to escape from the reservoir, and the vessel then sinks to its place.

The Bellot Lock gates or caissons ${ }^{1}$ at the Port of Havre, designed by M. Guillain, are on this principle, Figs. 236, 237,238 . Each of the leaves is 54 feet 2 inches wide and 35 feet 11 inches high. They are made with vertical frames placed about 40 inches apart, and two horizontal intermediate frames, which with the top and bottom members divide the leaf into three equal parts. The space comprised between the upper and first of the intermediate frames is open, the remaining part of the leaf is formed partly as an airchamber and partly as a ballastchamber into which water is admitted; by this arrangement the weight on the turning-post is reduced from 155 tons to 25 tons. Access to these chambers is obtained from the upper part of the gate; and the water can be driven out of the lower compartments by forcing in compressed air, the pump employed for this purpose being placed on a

FIG. 236.

travelling-carriage on the top of the gate. The operations of opening and closing are effected by chains actuated by hydraulic pistons.

West-India Dock Gates. ${ }^{2}$-These gates (Figs. 239 to 241) are of iron with the exception of the heel-posts, meeting-posts, and sill-pieces, which are of greenheurt timber. The gates are cellular, with two skins formed of iron plates separated by and riveted to horizontal and vertical ribs. The gates are curved outwards, but the sill-piece is straight to fit the sill. The

1 Engineering, vol. xlviii. p. 620.

2 M.P.I.C.E., vol. xषxiv. p. 159. 
curves of the sides are ares of circles whose radii are 60 feet and 120 feet.

The heel-post works on a steel pivot let into the heel-post stone, and there is a roller fixed to each gate at a distance of 26 feet 8 inches from the heel-post, running on a cast-iron roller-path, to assist in bearing the weight of the gate.

The gates are secured at the top by strong iron anchors let into the masonry.

Caissons.-Caissons may be considered as of two types, viz. floating and sliding. Under the first may be included all those which, whatever their shape, are raised from the bottom, and floated out of their position when the entrance is opened. Under

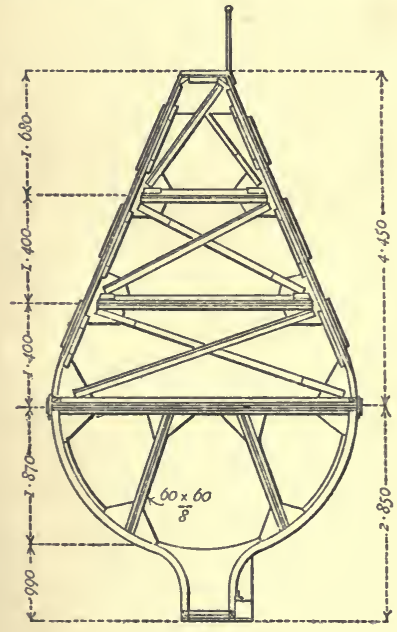

Fig. 237.

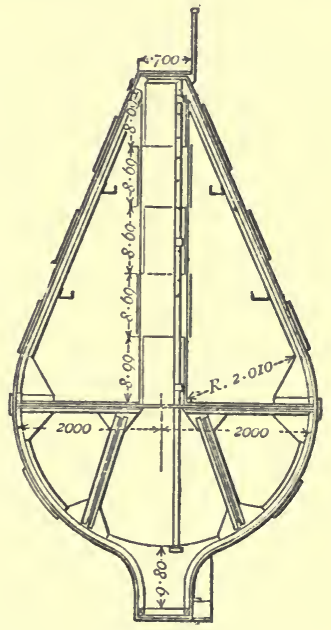

Fig. 238.

the second may be classed all those which, while still resting on the bottom, are removed from the entrance by being hauled endways into a chamber specially constructed for its reception, over ways which have plane sliding surfaces only, or on rollers fixed to the masoniry or to the bottom of the caisson.

An objection to rollers is, that being always submerged they are difficult to get at in case of repairs being needed. If the rollers are fixed to the bottom of the caisson, there is the additional risk of the whole being brought up by any obstruction falling on the pathway and getting under the rollers. On the whole, it appears that less trouble is likely to be experienced with a caisson which is fitted simply to slide over the ways than 
with one fitted with rollers. Instances, however, are not wanting where they have been in use for years without getting out of order.

The materials of construction may be timber, iron, or steel; practically, however, the latter are now universally adopted for all large structures.

The treatment of the masonry of the entrance will be somewhat different in detail, depending upon the class of caisson

FIG. 240.

FIG. 239.
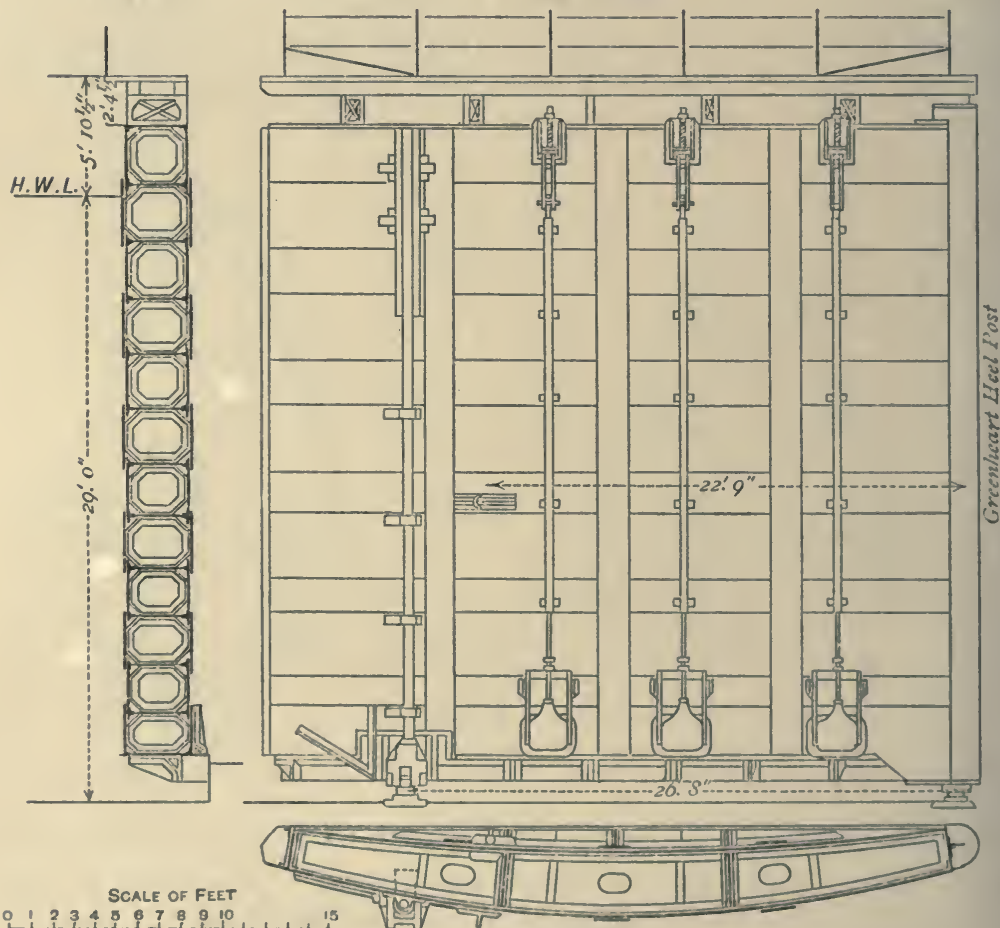

FIG. 211.

adopted. The faces or stops against which the caisson presses are carried square across the entrance and up the sides to the required height. These faces must be worked to a true plane throughout, and carefully smoothed and polished so as to ensure a water-tight joint between the stone and the timber keels or meeting-faces of the caisson.

A simple and efficient method of getting a true plane is to stretch a fine but strong wire across the entrance, at a distance 
of two or three inches from the stop. Vertical wires with heavy weights attached are then dropped at the sides, reaching to the bottom of the entrance, or as low down as possible, with the weights immersed in buckets of oil to steady them. A second horizontal wire is then fixed at the bottom, with one or more intermediate wires according to the shape of the entrance. Wires are then fixed at the top and bottom to suit the batter of the side walls, and, if necessary, others to suit the curve of the haunches. From these wires the work can be spotted in to gauge at very short distances, and the face finished off with straight-edges, which should be as long as possible. In working round the curves of the haunches where only short straightedges can be used, the tendency is, unless great care be taken, to work a little hollow, with the result that leakage takes place between the stone face and the timber keel-pieces; to avoid this, the stone faces round the short curves should be worked a shade full.

The advantages attaching to caissons are, the saving of room in shortening the length of the entrance, particularly where double gates would be required; the facility with which they can be maintained and repaired as compared with gates; the power they give of examining the sill and masonry of the entrance by their removal temporarily to an outer stop provided for the purpose; and the extra length which such removal gives on the floor for docking purposes whenever it may be necessary to deal with an extra long ship. Hollow quoins which are costly and difficult to work, and are seldom water-tight, are dispensed with. They afford a ready means of carrying an ordinary road or railway across a dock entrance, thus avoiding the heavy additional cost and inconvenience of swing-bridges, while the dock-side is kept clear of all obstructions, a most important point to be kept in view. When the traffic is heavy, one of the conditions is that the deck of the caisson must be level with the coping on either side of the entrance.

In the case of the floating type, this is effected by adjusting the total height of the caisson, when sunk to its bearings on the invert, to coincide with the coping level.

In the sliding or rolling type, the object may be effected by making the roadway deck capable of being lowered sufficiently to admit of the caisson passing under the deck of the chamber, by lowering the caisson bodily, by sinking it to a sufficient 
depth to clear the caisson-chamber deck, or by arranging the sliding ways in a series of slopes, by which the caisson is lowered as it is hauled into the chamber.
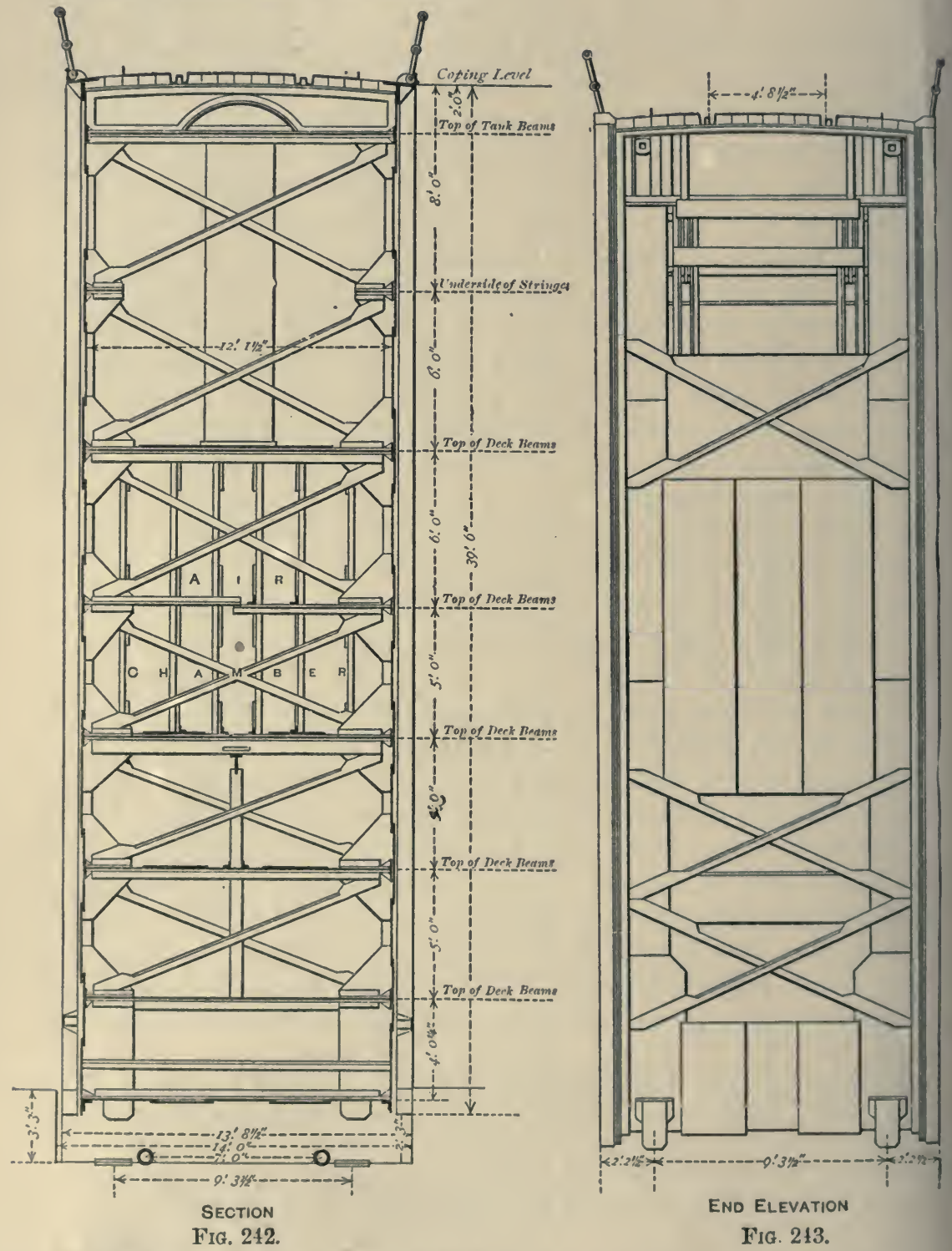

Sliding Caissons.-Figs. 242, 243 show the section of a sliding caisson with a fixed deck, as adopted for closing one of the 
basin entrances, Portsmouth Dockyard. When closing the passage, the caisson is raised off the bottom by the removal of the water ballast to an extent sufficient to give it a lifting power in excess of any load it may have to bear, the caisson being kept down to the wharf level by strong cross-girders fixed to the masonry on each side of the entrance. When it is required to open the entrance, water is let into the ballast-tanks, and the caisson sinks to the bottom of the berth; it is then drawn over the sliding ways under the fixed deck of the chamber. The pipes shown on the section are connected with the compressed-air system, and are used for stirring up and blowing out any mud that may collect in the caisson berth and chamber.

When the conditions are such that it is not imperative that the whole of the deck of the caisson should be continuous with

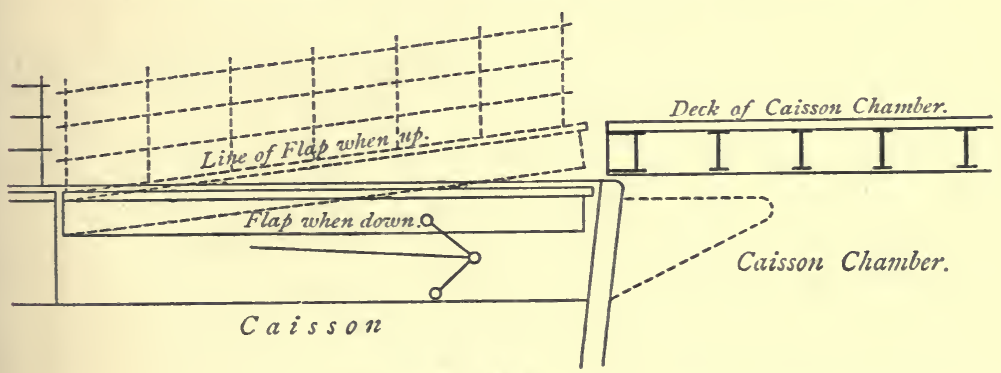

FIG. 244.

the coping level, as in the case when only light traffic has to be accommodated, the main portion of the deck may be fixed at such a level as to clear the underside of the chamber cover, while a portion at each end is hinged and capable of being lifted to the coping level, thus forming a convenient ramp for the passage of light traffic. This arrangement is shown by Fig. 244.

Sliding caissons have the advantage over floating caissons in so far that the latter require space in which to stow them when removed from the entrance. This becomes an important matter where the water area is at all restricted; this difficulty may, however, be met by the construction of a recess in the wharf adjoining the entrance sufficiently deep that the caisson, when housed, may not project beyond the face of the wall.

Floating caissons take a longer time to handle. As a rule, 
they can only be removed from the entrance at a given height of tide, to give them a sufficient height above the bottom to clear the batter of the sides. They require a greater number of men to work them, and with a high wind are difficult to manage on account of the surface exposed.

Box floating caissons have been designed by Mr. Kinipplo that can be removed from the entrance when raised sufficiently only to clear the sill. To accomplish this, the sides of the entrance are made vertical, and the ends of the caisson, instead of being square, are splayed.

To guard against the risk of the caisson rising through the water-tank being inadvertently emptied, or the ballast being

Fig. 246.

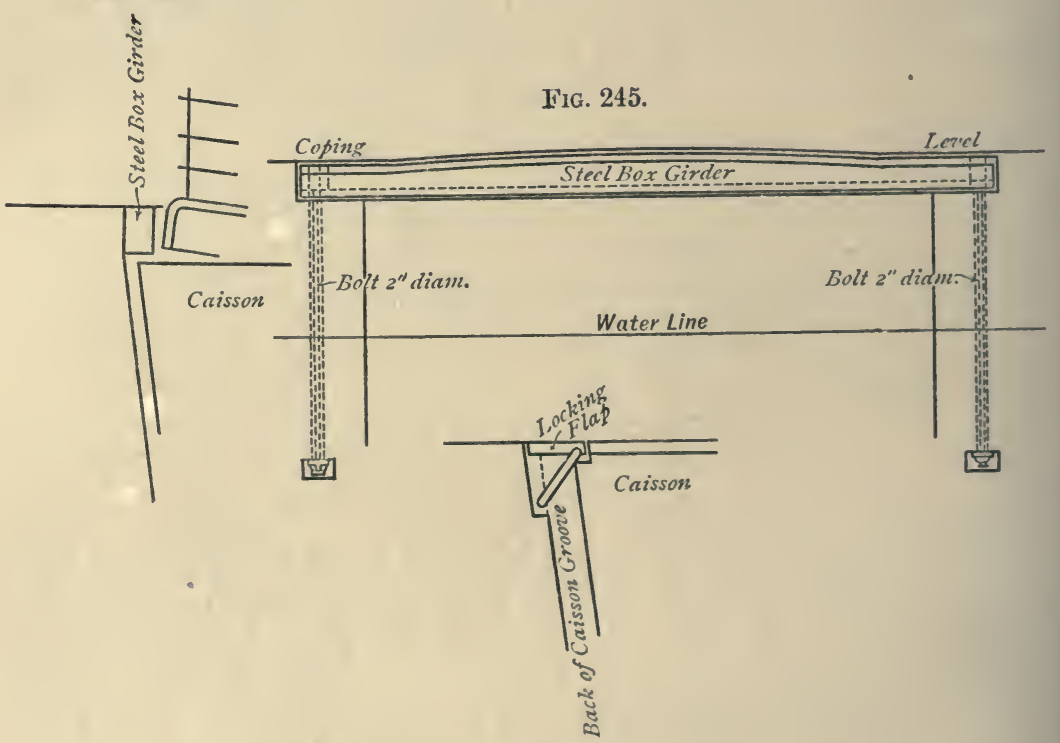

FiG. 247.

displaced, strong iron girders are generally fixed to the masonry at either side of the entrance (Figs. 245, 246), or, in the case of floating caissons, by holding-down straps, as shown by Fig. 247.

The question as to when caissons should be adopted for closing entrances in preference to gates will depend upon local conditions, and, to some extent, upon personal predilection. It may, however, be taken as a general rule that caissons are more especially adapted for closing dry docks and locks and 
basin entrances in sheltered positions, and gates for closing entrances in exposed positions.

Floating Ship Caisson.-The ordinary form of a floating ship caisson is shown by Fig. 248, which represents one in use at Portsmouth Dockyard. ${ }^{1}$ It consists of a wrought-iron body constructed of angle- and T-irons, and plated sides, covered with a deck or roadway of Dantzic oak 4 inches thick in 6-inch widths. On this deck, railway bars are fixed to a gauge of 4 feet $8 \frac{1}{2}$ inches, sunk into the planking and fixed to the deckbeams. The sides are protected by a handrailing 3 feet 6 inches high, constructed of 1inch and $1 \frac{1}{2}$-inch tubing, hinged so as to turn down on to the deck when the caisson is removed from the entrance. Immediately under the roadway deck is a second deck of diagonal bracing, sup-

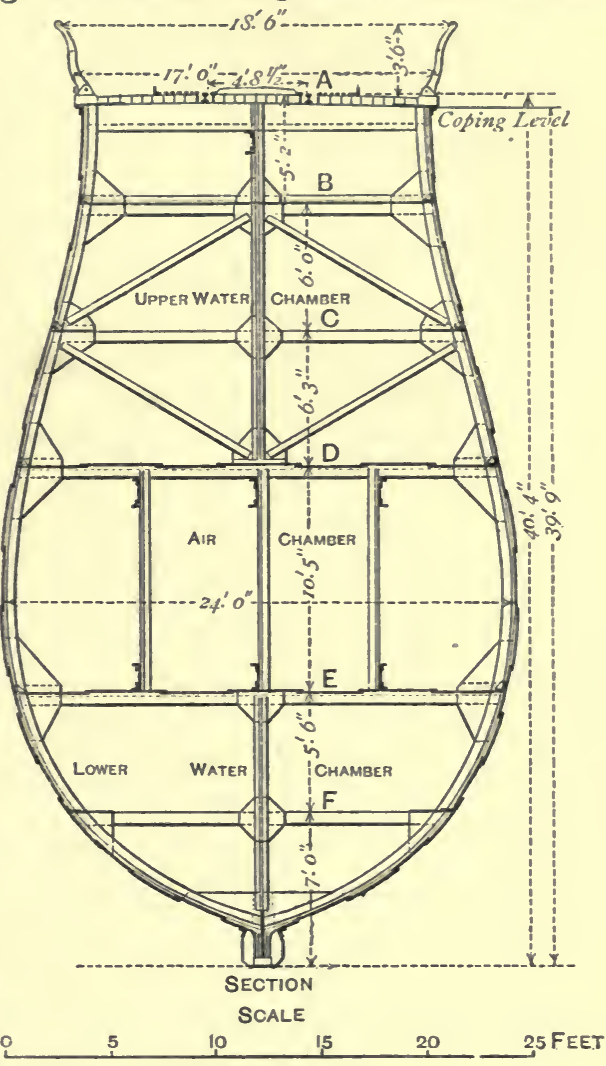

FIG. 248. porting a water-tank in the centre; below this is the upper water-chamber, strengthened by a third deck constructed of diagonal bracing, the floor of the water-chamber being formed by a water-tight deck.

Through this chamber, and terminating in the roadway deck, are two water-tight trunks communicating with the air-chamber below, one used as a means of access, the other containing the pump for removing the water from the well.

Below the water-chamber is the air-chamber, which is of 1 I.P.I.C.E., vol. Ixiv. p. 146. 
sufficient capacity to float the caisson with all ballast and machinery and with four tons of water in the tank, when the water. line is level with the top of the chamber. In the centre of the lower deck of the air-chamber is placed the well for the drainage pump, and at each end is a water-tight trunk connecting the upper and lower water-chambers.

In the lower water-chamber is another deck, formed of diagonal bracing and supporting the pump-well in the bottom of the air-chamber before referred to. The timber keel and stems consist of the best seasoned English oak, bedded on the iron with canvas coated with red lead so as to form a watertight joint. The outer surfaces are planed perfectly true to meet the masonry faces of the groove.

The method of working a ship caisson will differ somewhat according to the details of construction, but generally it is as follows:-Supposing it to be afloat, it is towed or hauled into the entrance. One of the stems is then placed in the groove or stop constructed in the masonry, the caisson is then swung round until the other stem is opposite the groove on the other side of the entrance; then, having adjusted the caisson so that it has an equal bearing on either side against the masonry, water is let into the tank until the caisson sinks into place. To raise the caisson, the valve in the water-tank is opened to allow as much water as necessary to escape, when the caisson will rise; then bringing one of the stems well into the groove, the caisson may be swung round and out of the entrance.

Iron Floating Box Caisson. ${ }^{1}$-Figs. 249, 250 show the elevation, plan, and cross-section of the caisson at Messrs. Green's new graving dock, Blackwall, designed by Messrs. Kinipple and Morris, M.I.C.E. It is a box-caisson 67 feet 3 inches in length, 10 feet in width, and 28 feet 9 inches in depth, having the outer corners rounded.

The caisson has one meeting-face of teak wood, which is protected from injury while the caisson is being shifted in and out of the berth by horizontal and vertical fenders projecting beyond the face. The outer plating is of wrought-iron plates $\frac{7}{16}$ inch in thickness up to the water-tight deck, and above that level $\frac{3}{8}$ inch and $1 \frac{5}{6}$ inch in thickness. The plating runs horizontally in alternate inside and outside strakes, lap-jointed and single riveted. The vertical butt-joints have cover-plates doublo

1 M.P.I.C.E., vol. lxv. p. 339. 
riveted. The plating of the bottom of the caisson is $\frac{1}{2}$ inch in thickness, and is stiffened by the vertical floor-plates, $\frac{1}{2}$ inch in thickness, riveted to the side and bottom angle-irons. The spaces between the floor-plates are filled with cast-iron kentledge and Portland-cement concrete as ballast, to give stability to the caisson when floating. The angle-irons forming the side framing are 3 inches by 3 inches by $\frac{3}{8}$ inch, and placed 18 inches apart; the cross-beams of angle-iron up to the level of high water, are 4 inches by 4 inches by $\frac{1}{2}$ inch, and above that level are 3 inches by 3 inches by $\frac{3}{8}$ inch, fastened with gussets to the side angle-irons. The uprights in the centre of the caisson are 4 inches by 4 inches by $\frac{3}{8}$ inch, and 18 inches apart; the angle-irons under the water-tight deck are 5 inches by 3 inches by $\frac{3}{8}$ inch, widened at the ends and secured to the side frames; the deck-beams are 3 inches by 3 inches by $\frac{3}{8}$ inch, secured by gussets. Horizontal plate-stringers 15 inches in width and $\frac{1}{2}$ inch in thickness, below the second tier from the top, and above that $\frac{3}{8}$ inch and $\frac{1}{4}$ inch in thickness, are riveted to the cross-beams and secured by angle-irons to the outside plating and frames. The upper portion of the caisson is divided by water-tight bulkheads into three compartments, each provided with regulating valves for admitting the water in order to sink the caisson into its berth in the dock entrance. At each end of the upper portion a water-tight bulkhead forms a ventilator and manhole access to the air-chamber below the water-tight deck. The bulkheads are of plating $\frac{3}{8}$ inch thick, stiffened with angle-irons riveted to the frames and beams, and secured to the water-tight deck by angle-irons, thus forming efficient cross-bracing to the caisson. The meeting-face of the caisson is of teak 14 inches in width by 7 inches in thickness, scarfed at the junctions, bedded in red lead, and bolted to 6 -inch by 6 -inch by $\frac{1}{2}$-inch angle-irons, riveted to the caisson, and following the curve of the masonry invert and the batter of the stop-quoins.

The seams between the angle-irons and teak face are caulked with oakum and pitch. The fenders are of rock elm, 10 inches by 10 inches, secured by wrought-iron clips or brackets to the caisson.

The planking to the roadway deck is English oak, 3 inches thick, secured to the deck-beams and made water-tight by caulking. Manholes are provided for access to the three upper compartments and the ventilators. 

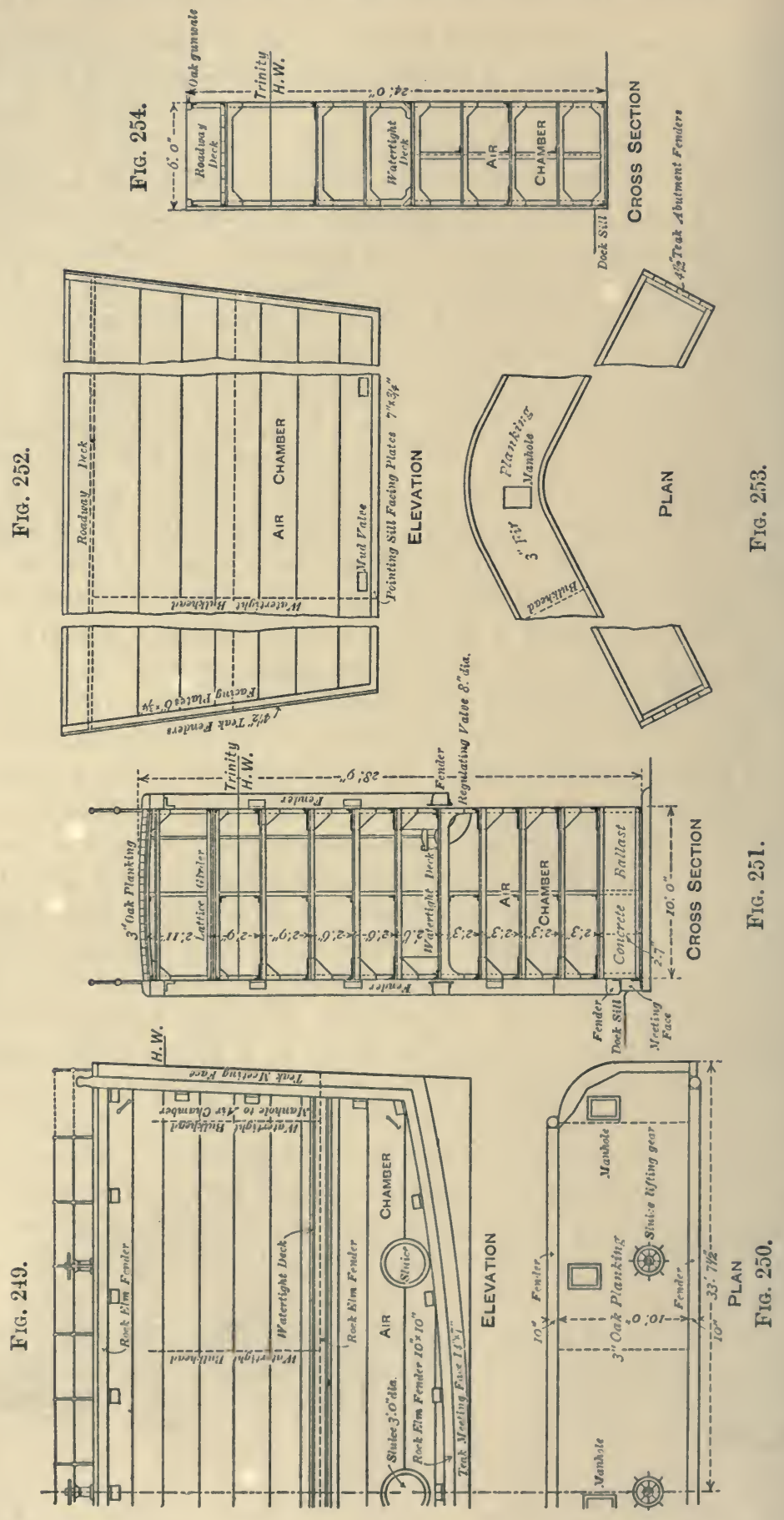
Loop-bolts are fixed to the corners of the caisson for attaching tackle for hauling it into and out of its berth.

A 2-inch brass cock is fixed near the bottom of the inside face of the caisson to run off the bilge water into the graving dock, and a hand-pump is provided to pump out any water in the event of the caisson springing a leak while out of its berth. The sinking valves are conical spindle-valves of gun-metal, with spindles carried up to the roadway deck; the cast-iron inlet pipes pass by bends through the water-tight deck and are secured to the outside skin, the mouths being protected by brass rose-heads. There are three sluices through the air-chamber for filling the dock with water; the valves are three feet in diameter, of cast-iron, faced on both sides with gun-metal, and enclosed in cast-iron cases with gun-metal faces, and connected with the sides of the caisson by cast-iron pipes 3 feet in diameter, supported by the floor-plates. The spindles are of gun-metal, passing up through the water-tight deck in gun-metal stuffing-boxes, and continued up to the roadway deck by wrought-iron rods worked by wheels and screws provided with indicators.

Iron Floating Caisson at the Lime-kiln Dock. ${ }^{1}$ - This caisson, shown by Figs. 252, 253, 254, designed by Mr. W. R. Kinipple, is of a box form of unusual plan, being like the two leaves of an ordinary dock gate, and is divided into an upper and lower compartment by a water-tight deck, these compartments being subdivided by two water-tight bulkheads.

The outer plating is of wrought iron, the three lowest strakes being $\frac{1}{2}$ inch in thickness; the three above are $1^{7} 6$ inch, and the two top strakes $\frac{3}{8}$ inch in thickness in alternate inside and outside strakes, with single-riveted lap-joints and vertical buttjoints with cover-straps. The upper edge of the top strake is finished off with an angle-iron, to which is bolted a timber handrail.

The plating of the bottom is 1 inch in thickness and stiffened by angle-irons forming the floor beams. The p!ating of the water-tight deck is $\frac{7}{16}$ inch in thickness, having butt-joints and cover-straps, and connected to the skin plating and framing by angle-irons 3 inches by 3 inches by $\frac{3}{8}$ inch. The side frames are formed of single angle-irons spaced 2 feet apart, and divided into two pieces by the water-tight deck. The angle-iron cross-beams are also of the same size, screwed to the side frames with lugs.

\footnotetext{
1 M.P.I.C.E., vol. $1 \times \mathbf{v}$. p. 341.
} 
The upright angle-irons in the centre of the caisson are 4 inches by 4 inches by $\frac{1}{2}$ inch riveted at the intersections to the longitudinal angle-irons and the cross-beams. The horizontal stringers in the lower compartment are 15 inches in width and $\frac{1}{2}$ inch in thickness, and are screwed in the same manner. The two water-tight bulkheads are formed of plating of the same thickness as the corresponding strakes of the skin plating and stiffened by angle-irons, thus forming very efficient cross-bracing. The roadway deck is of fir planking 3 inches in thickness, caulked and made water-tight, and is 2 feet below the top of the caisson, the sides of which form the handrails. The meeting-face of the caisson is of 6 -inch by $\frac{3}{4}$-inch plate iron, and abuts against the timber meeting-face of the dock. Ringbolts are fixed to the caisson for securing the tackle used in hauling the caisson into and out of the berth. The ends of the caisson are protected by fenders of teak which abut against the skewbacks or abutments of the dock entrance.

The caisson is provided with sinking valves, drainage cocks, and sluices similar to those previously described; and in addition there are two sluices or mud ports at the level of the dock sill for the escape of muddy water. Each sluice is 18 inches by 9 inches clear dimensions, formed of plate iron with a cast-iron flap valve on the outer end worked by chains from the deck.

Barry Dock Caisson. ${ }^{1}$ - This caisson (Figs. 255, 256) is a floating vessel of a somewhat unusual section, and is designed to be used in several positions.

The length is 85 feet, and the beam 'midships 24 feet. The height at the ends is 42 feet, and at the centre 48 feet 9 inches.

The keel is formed to a radius of 137 feet, to correspond with the inverts, the meeting-faces being lined with greenheart 15 inches by 7 inches. The caisson is ship-shaped on one side, and flat on the other, so as to enable it to fit against any of the faces, and to be placed, when out of use, in a recess provided for it in the wall, when it will not project beyond the line of the wall. It is divided vertically by two water-tight bulkheads, and horizontally by eight decks, two of which are water-tight, forming air, and water-chambers. The lower parts of the skin are of wrought-iron, and the upper 19 feet of steel.

1 M.P.I.C.E., vol. ci. p. 140. 
Immediately below the bottom deck, which is water-tight, there are two sluices, each 4 feet by 2 feet, for lowering or raising the water level on the two sides. Cast-iron kentledge is packed as ballast in the bottom of the caisson. The caisson contains

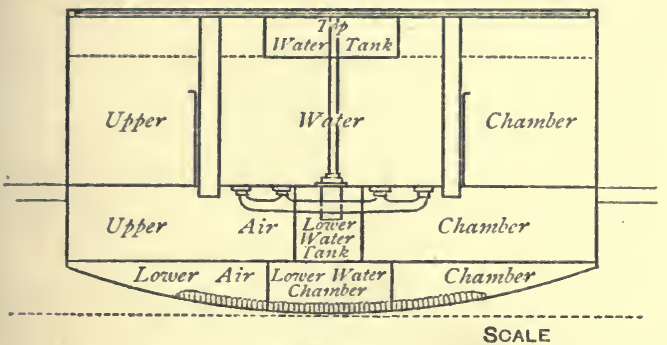

$20, \ldots$ in

FIG. 255.

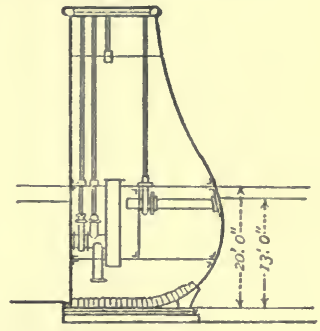

40 FEET

FIG. 256.

about 328 tons of wrought-iron and steel, 22 tons of cast-iron, 354 tons of iron ballast, and 335 cubic feet of timber.

Kowloon Dock Caisson. ${ }^{1-T h i s ~ c a i s s o n ~(F i g s . ~ 257, ~ 258, ~ 259) ~ i s ~}$ of the ship form, built entirely of iron. It is divided vertically

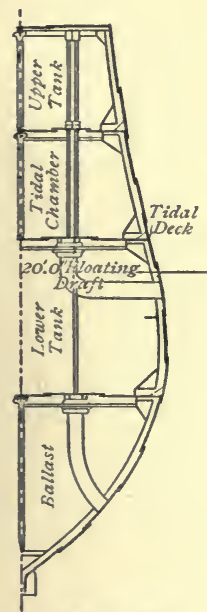

Fir. 257.

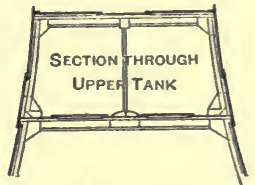

FIG. 25S,

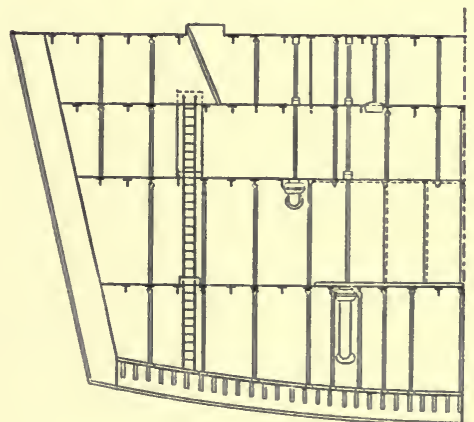

FiG. 259.

into four compartments by four water-tight decks. Under the first or lower deck the permanent ballast is placed, and between the first and second decks a water-tight tank is formed in the centre of the caisson, having an air-chamber at each end. This 
tank has also a longitudinal bulkhead in the centre, but it is not water-tight, as it only saves as a break to the water in case of the vessel taking a list. Between the second and third decks is what is termed the tidal chamber, the water being allowed free access to the whole with the exception of two water-tight trunks for the ladders; between the third and fourth decks another tank is formed in the centre of the caisson of a capacity of 60 tons. No pumps are fitted, the caisson being lowered and raised by the use of the tanks, the upper tank being filled from a hydrant on the dock side through a hose.

The floating draught of the caisson is 20 feet from the top of the sill; this leaves the second or tidal dock 2 feet above the water line.

To sink the caisson, the lower tank valves are opened and the tank filled. As this tank contains 150 tons, the tidal deck will then be 3 feet below the water level, therefore the valves of the tidal chamber being opened the water will flow in and the caisson gradually sink until it touches the bottom, when the water in the tidal chamber will be level with the water inside and outside of the dock. The valves of the lower tank on each side of the caisson are then closed, also those of the tidal chamber on the side next the dock, and the pumping out of the dock proceeded with, at the same time the upper tank of 60-tons' capacity is filled.

To raise the caisson, previous to filling the dock, the lower tank is emptied and the valves closed; the water is then let into the dock. As the valves of the tidal chamber on the side next the sea have always been open, the water in this compartment will be at the general level 'also. All the tidal valves on the dock side are then opened; also the valves of the upper tank, allowing the water to flow from it into the tidal chamber; the caisson then gradually rises until it reaches its flotation draught, viz. 20 feet.

From the floating draught-line of the caisson to the tidal deck the displacement is 60 tons. This weight being in the upper tank, no matter what the state of the tide may be on the tidal deck, the caisson will be in a state of equilibrium when the water in the dock is level with the water outside. This is proved by the fact that in the tidal chamber weight and displacement are practically neutralized; therefore, when the tank is empty, 
the caisson has a lifting power of 60 tons, which is only exhausted when it reaches the floating draught of 20 feet.

FIG. 260.
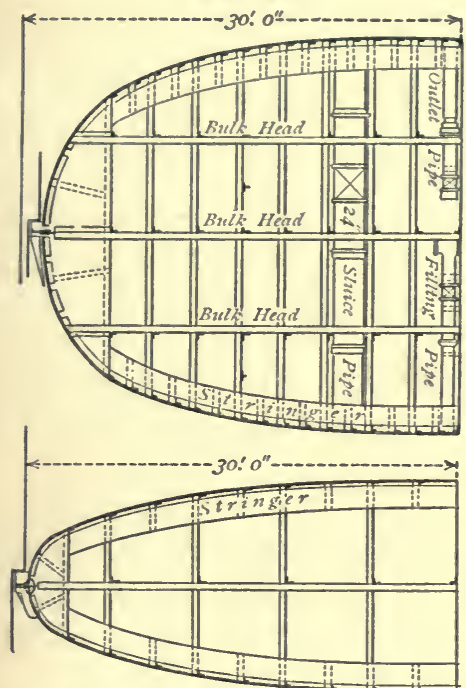

FIG. 261.

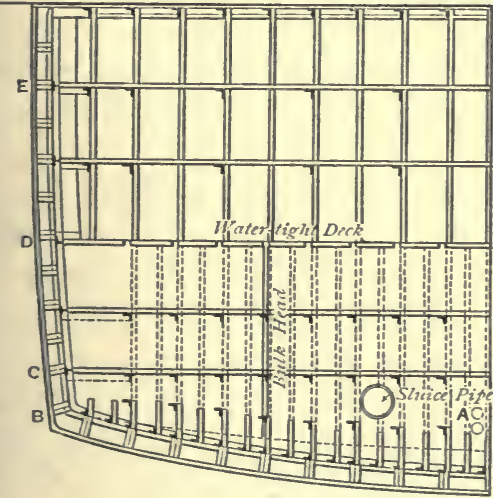

운

SCALE

Fig. 262

A weak point in this design appears to be that, in the absence of pumps for clearing the lower tank, the caisson cannot be prepared for lifting without first pumping out the dock.

Bute Docks. ${ }^{1}$-Figs. 260 to 263 show the caisson closing the entrance of the public graving dock. It is a floatingship caisson of somewhat unusual section, constructed of wrought iron, 60 feet long, 26 feet wide at its greatest beam, and 13 feet in least width at the centre, and 30 feet 6 inches in depth. It is constructed of angle-iron frames, columns,

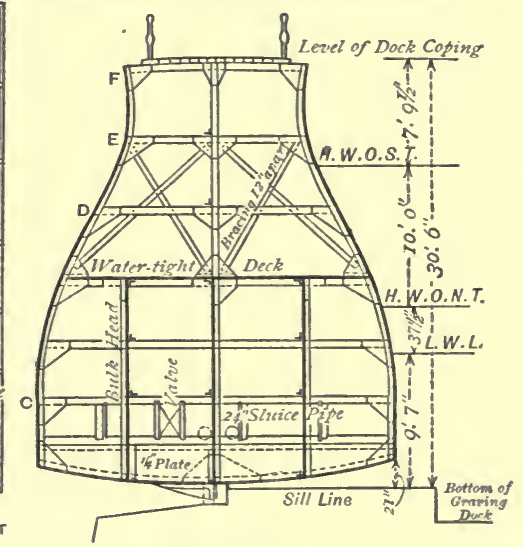

FIG. 263.

beams, and skin-plates, with oak stems and keel, and fir deckplanking.

It is divided by a water-tight deck and bulkheads into sixteen compartments, communicating with one another by

1 Engineering, vol. xxxviii. p. 165. 
means of small slide-valves for the purpose of adjusting the water ballast.

To give the necessary displacement for any required flotation level, the water ballast is admitted to the four central compartments-from which it flows to the others-by two 9-inch cast-iron inlet-pipes A A (Fig. 262), or is discharged through the outlet pipe B (Fig. 262), each of which is fitted with a brassfaced valve worked from the deck.

A small steam-pump is fired on the water-tight deck, for the purpose of discharging the water ballast, in case of the depth of water on the sill being reduced while the vessel is afloat.

For filling the dock, 24-inch cast-iron pipes, fitted with sluicevalves worked from the deck, are fixed in the lower part of the caisson.

In addition to the water ballast, there are about 120 tons of iron ballast, which, with the weight of the caisson itself, including the cast-iron pipes, pumps, etc., amounting to 152 tons, is equal to the displacement at the lowest water level at which the caisson requires to be floated.

Esquimalt Dock Caisson (Figs. 264 to 267). ${ }^{1}$-This caisson, constructed from the designs of Messrs. Kinipple and Morris, is of somewhat more than ordinary interest, on account of the arrangements for facilitating removal from the stops with but slight lifting.

The sides of the caisson are vertical, but are bevelled horizontally, the inner face being of less width than the outer; this was done in order that, by moving the caisson a short distance back into the chamber, and allowing it to rise by the removal of ballast sufficiently only to clear the stop, the caisson may be more readily floated out when necessary. Further, by constructing the caisson in this way, the usual battering sides are dispensed with, and a saving of about 10 feet in the width of the entrance is effected.

The height from the under side of the keel plates to the coping level is $3+$ feet 10 inches. The length on the inner or dock side is 67 feet 2 inches, and on the outer or harbour side 71 feet 2 inches.

The caisson is divided into two parts; the lower being the air-chamber, of sufficient capacity to reduce the weight on the

1 Engineering, vol. xlvi. p. 87. 
ways to a minimum. The upper part is a flotation chamber, from which the water is excluded when the caisson is floated out of the entrance.

To facilitate the removal of the caisson into the chamber, two lines of rollers running in bearings carried by cast-iron

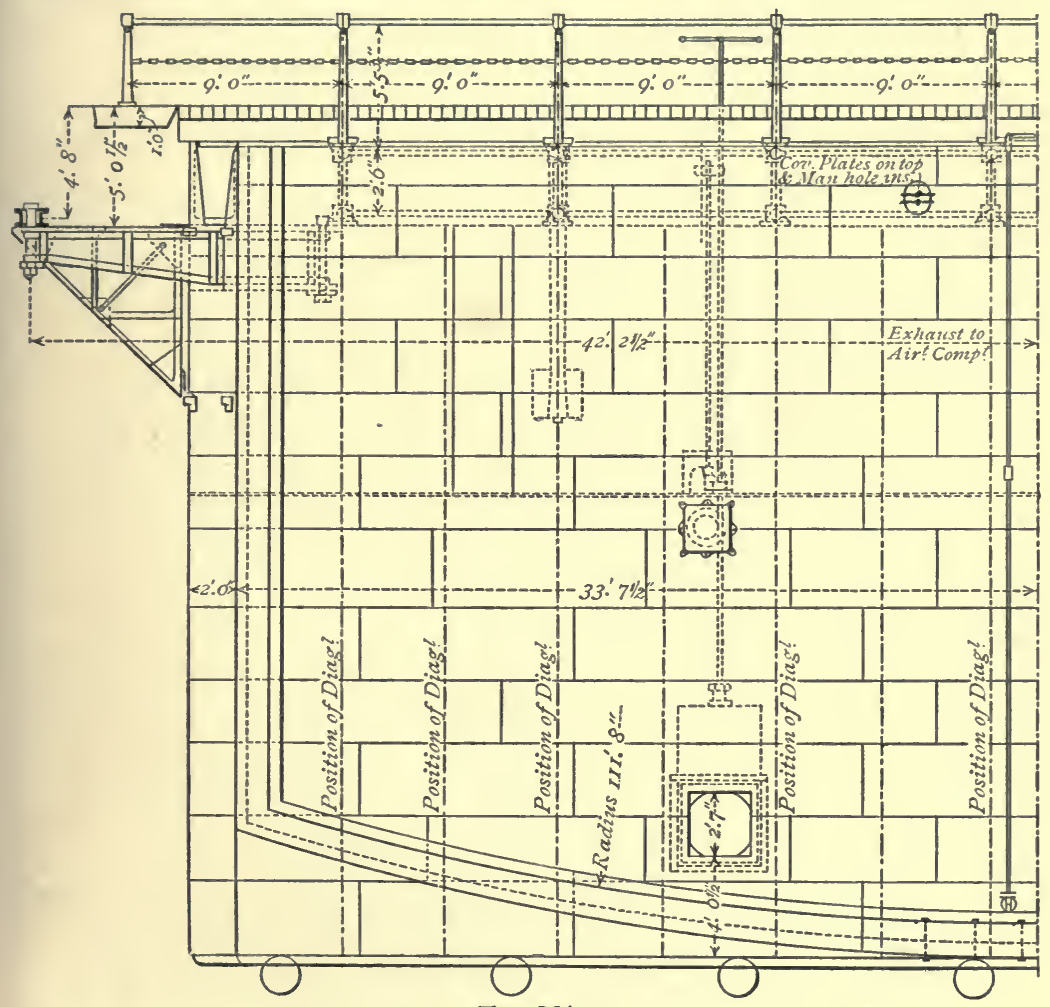

Fig. 264.

boxes were fixed to the masonry in the bottom of the caisson camber and recess across the entrance.

The meeting or rubbing faces were made of teak timber, 1 foot 3 inches wide, secured to the inner face, and were formed to follow the outline of the masonry. Abrasion of the meetingfaces with the faces of the stone stops was prevented by metal swells projecting about $\frac{3}{4}$ inch from the wood, which insures a clearance between all the meeting-faces when the caisson is hauled into or out of the chamber.

The folding or rising and falling platform on the top of 
the caisson is supported and balanced by levers and adjustable tail weights which together form a parallel motion. The rising and falling of the platform is effected by rollers fixed to the

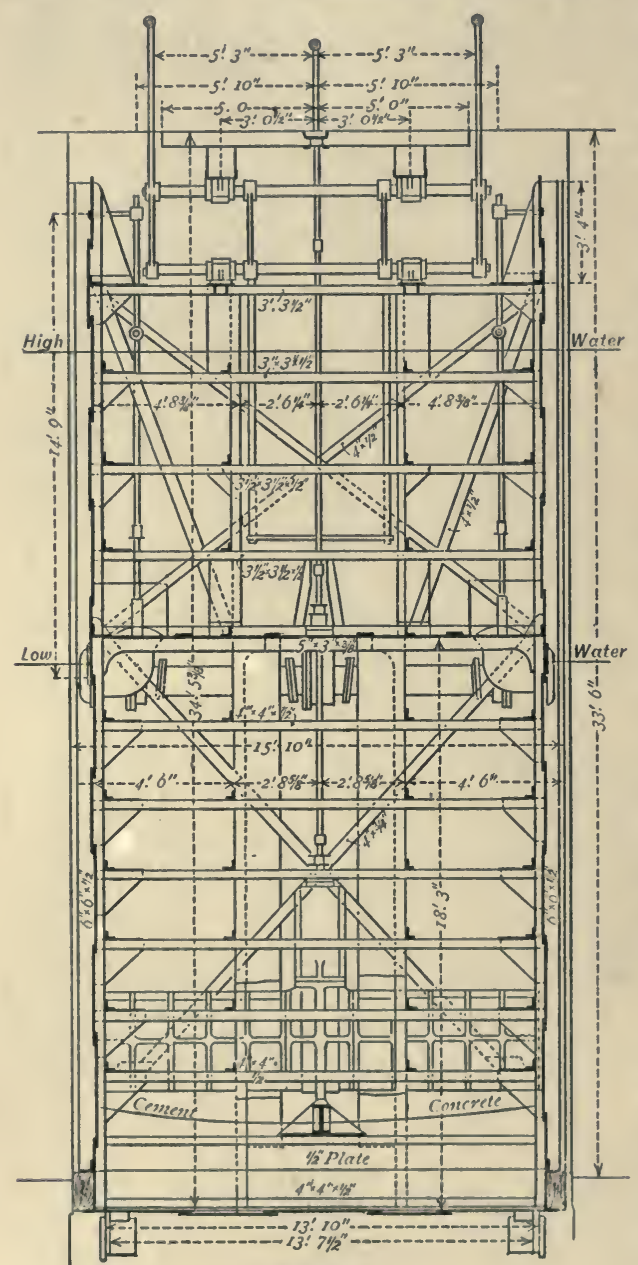

Fig. 265. end of the platform working against curved plates placed in the abụtment.

The displacement of this caisson is 530 tons, and its entire weight 294 tons. The weight of concrete ballast required to adjust the caisson was 160 tons.

Cerro Graving Dock Caisson, Monte Video. ${ }^{1}$ -This caisson (Figs. 268 to 271 ) is of a box form, with keels attached to the bottom, which run on rollers placed on the floor of the caisson berth and the chamber in the side walls of the dock entrance.

The air-chamber is of such capacity, and the caisson is so ballasted, as to bear on the keels with a pressure of about 5 tons when the tide is at the level of the water-tight deck; and to keep this pressure uniform, adjusting valves are provided to allow the water to flow into the upper compartment as the tide rises above this deck; these valves are 8 inches in diameter, two on each side of the caisson.

The keel-rollers set in the floor of the chamber are of cast ${ }^{1}$ II.P.I.C.E., vol, 18v. p. 343. 
УกО у ४४н
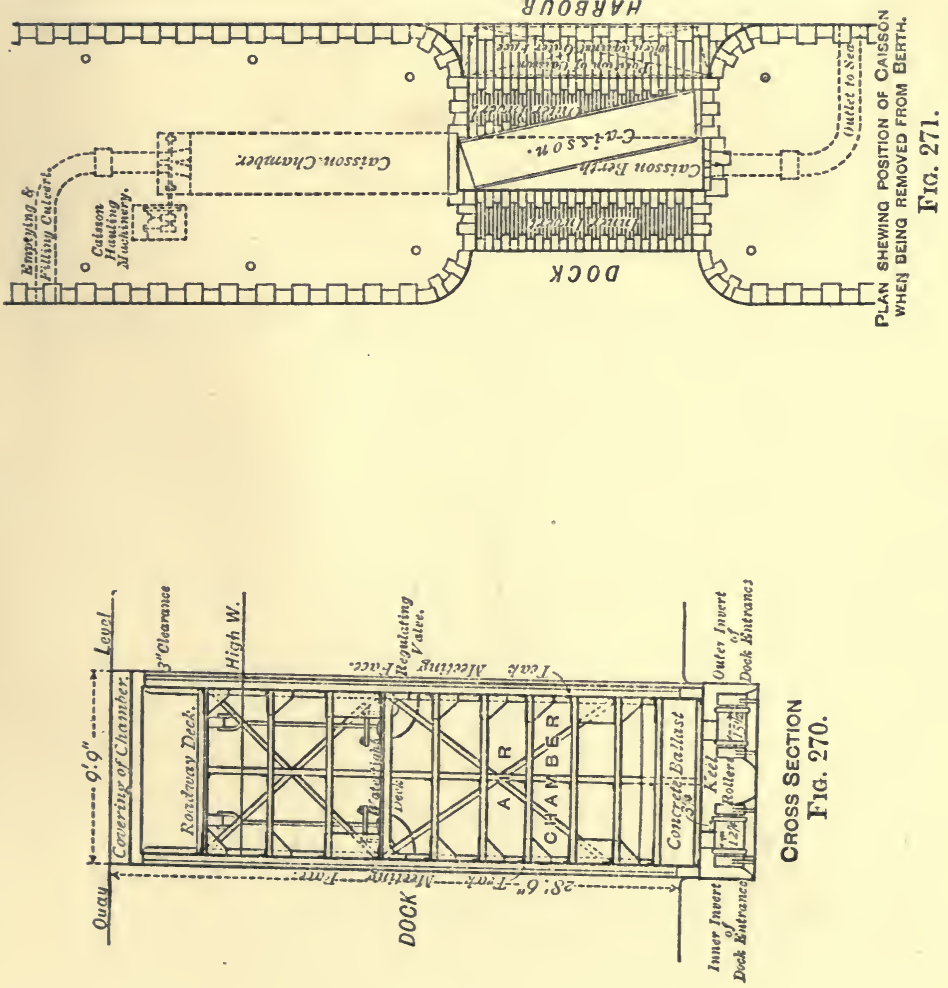

iron, with wrought-iron spindles lined with gun metal, and working in gun-metal bearings in cast-iron frames. The rollers have flanges, against which the spear ends of the keels press

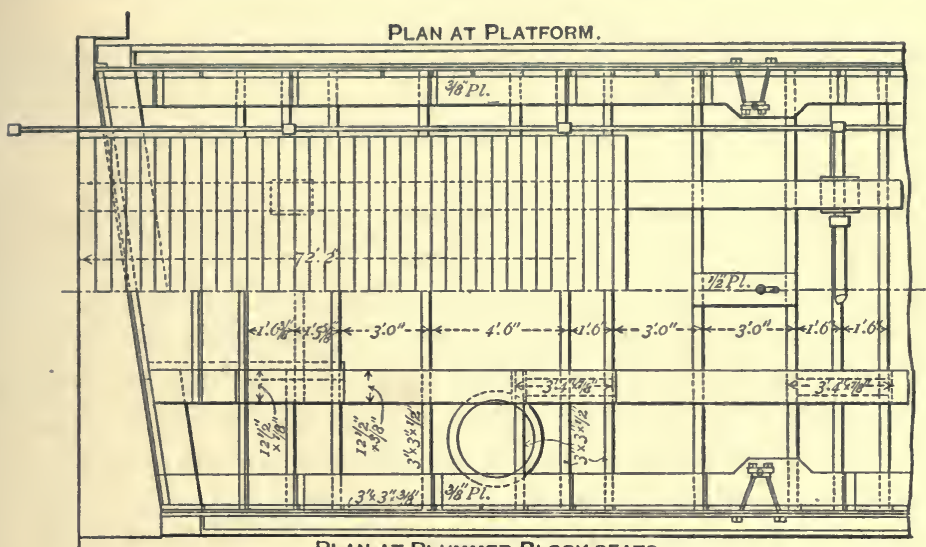

PLAN AT Plummer Block SEATS.

FIG. 266.

as the caisson is drawn back into the chamber, and so prevent abrasion of the timber meeting-faces.

The machinery for hauling the caisson into and out of the

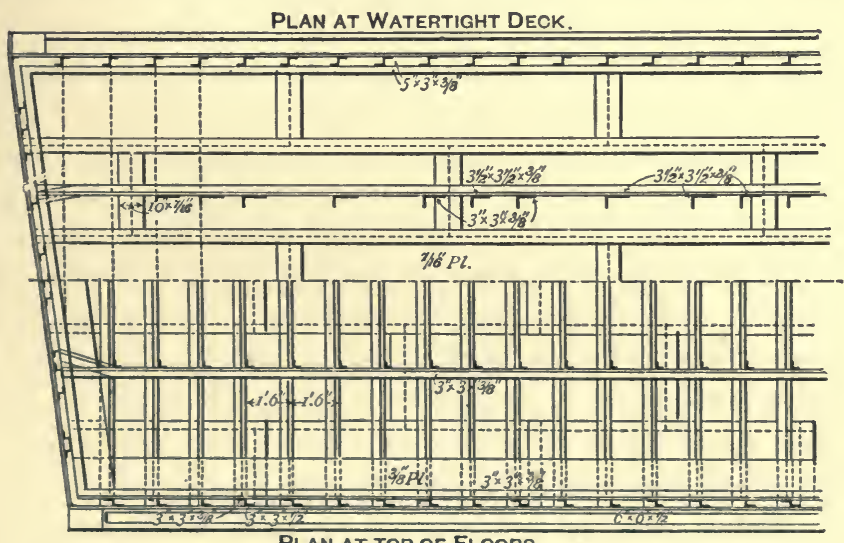

PLAN AT TOP OF FLOORS.

FIG. $26 \%$.

chamber consists of two endless-chain cables, one on each side attached to the ends of the yoke which is fastened to the caisson by the hauling bar; these cables pass round loose sheaves at the entrance to the chamber, and over two chain-wheels keyed 
on to the driving shaft at the head of the chamber, the slack of the chains being carried by the chain-rollers. The drivingshaft is worked by a worm-and-spur wheel wrought off a capstan on the quay.

Arrangements are made for keeping the caisson berth and chamber clear of mud by placing the outlets of the filling and emptying culverts of the dock in the end walls of the berth and chamber.

The chamber can be converted into a graving dock for repairing and painting the caisson by placing a temporary dam in a groove at the entrance to the chamber, and the water can be pumped out by a connection with the dock pumps. The caisson can also be floated out of its berth like an ordinary caisson, and placed against an outer meeting-face, and so enable repairs and renewals of any work about the dock entrance and chamber to be effected without the aid of a coffer-dam. When it is desired to do this, the caisson is disconnected from the hauling machinery; the adjusting valves are closed at lowwater, and as the tide rises the caisson floats and is hauled back about 15 inches, so that one end clears the side of the dock entrance; it is then pulled round, and sunk against the outer face in the position shown by dotted lines (Fig. 268).

Garvel Graving Dock Caisson. ${ }^{1}$ - In this design the rollers are attached to the caisson, and run upon plate-rails laid on the floor of the chamber and berth, instead of the rollers being laid on the floor and the keels secured to the bottom of the caisson.

The lowering bridge is mounted on the caisson, the roadway being at the same level as the quay when the caisson is in position closing the entrance. When the caisson is drawn into the chamber, the bridge and handrails are lowered sufficiently to allow them to pass under the covering of the chamber. The bridge roadway is carried by a series of levers or parallel bars, the upper ends of which are fixed to axles working in plummer-blocks secured to the bottom flanges of the girders of the bridge, and the lower ends to axles fixed in a similar manner to the cross-girders of the caisson (Figs. 272, 273). The outside bars are secured to the ends of the axles, and are continued to 4 feet above the roadway to serve as railing standards, the whole forming a parallel motion like an ordinary pair of parallel rulers.

1 M P.I.C.E., vol. $18 \mathrm{xv}$ p. 144. 


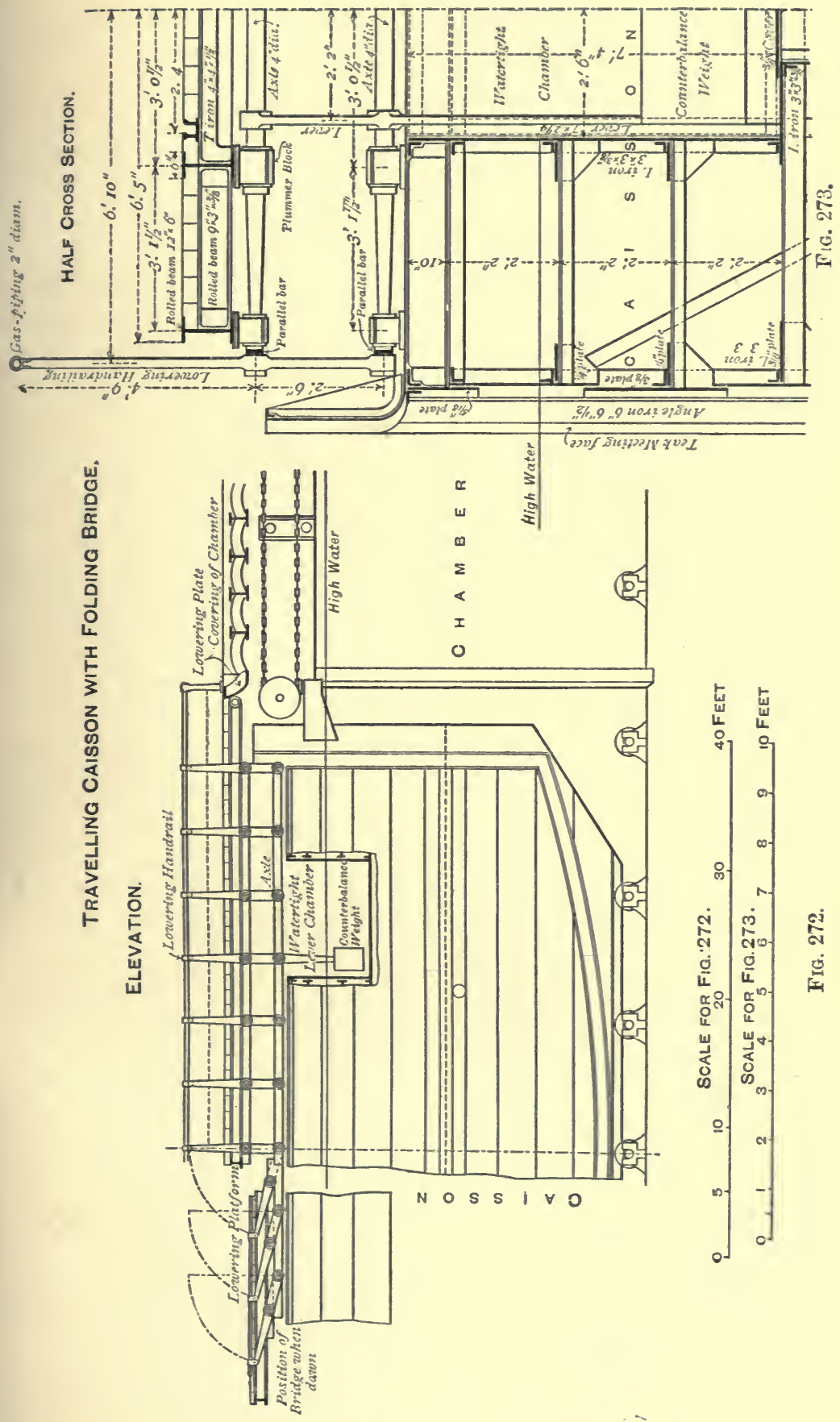


To counterbalance the weight of the bridge, the ends on two pairs of levers are extended downwards, and boxes containing ballast attached to them.

The raising and lowering of the bridge platform is effected by rollers fixed at each end which work against curved plates in the abutment, and the curved girder or lowering plate across the entrance to the recess. In hauling the caisson into the chamber, in order to open the dock, these rollers-one of which is shown in Fig. 272-abut against the convex lowering plate, causing the platform and the handrails to fall down automatically into the position shown by the full lines at the end of the elevation. To close the dock, the caisson is driven across the entrance, and the rollers on the other end of the platform come against a concave raising plate fixed in the opposite side wall of the entrance, causing the bridge platform to rise up to the level of the quay. When the bridge is "up," it is so locked between the abutments that it cannot fall down until the caisson is drawn back. The machinery for working the caisson consists of an oscillating three-cylinder hydraulic engine driving the shaft with chain-wheels and chains. The dock can be opened or closed at any state of the tide in three minutes.

To make the caisson scour out the berth and the chamber, the ends are close plated, so that there is no opening through the body. Thus, when the caisson is drawn back into the chamber, the whole of the water displaced by the advancing caisson rushes under it and past its sides, carrying along with it any mud which may have been deposited in the chamber or berth. 


\section{CHAPTER VIII.}

Deposits-Scouring power of water-Primary object in sluicing-Bottom velocity Duration of scouring-Fresh water for scouring purposes-Aronmouth entrance-Tilbury Dock entrance-Barry Dock entrance-Thames Embankment landing-places-Calais entrance channel-Dunkirk entrance channelSt. George's Stage, Liverpool-Removal of shoals by propeller sluicingHonfleur sluiciug basin-Canada Basin, Liverpool-Low-water Basiu, Birkenhead.

Deposits arise from two essentially opposite causes, viz. commotion and stagnation. They are also of different kinds of material. First, those lighter matters such as mud, silt, and fine sand which are held for a time in mechanical suspension, and which, as the water approaches stagnation, are gradually dropped in the order of their specific gravity and mass. Secondly, those grosser matters, such as the different kinds of sand and gravel which are rolled along the bottom or drawn forward with the water by the action of the waves and currents.

The first-named class are deposited within enclosed areas, and on the lee side of piers and groynes, which obstruct the progress of the waves and currents. The second class of deposits accumulate on the weather side of piers and groynes; the amount and position assumed will depend on the direction and force of the waves or currents in relation to the foreshore, and to the obstructions.

Scouring Power of Water.-There appears to be some difference of opinion as to the scouring action of water, as will be seen from the following data taken from different authorities, as to the bottom velocities required to move different materials.

\section{Stevenson. ${ }^{1}$}

15 feet per minute will just begin to work on fine clay.

$30 \quad, \quad$ " lift fine sand.

$40 \quad " \quad " \quad$ lift sand as coarse as linsced.

$60 \quad " \quad "$ sweep along fine gravel.

$120 \quad " \quad$ " roll along rounded pebbles 1 inch diameter.

1 SO $\quad " \quad$ sweep along slippery angular stones the size of an egg.

$39360 \quad$ " required at Havre and Fécamp to scour gravel.

1 Stevenson, "Construction of Harbours," 2nd ed. p. 238. 


\section{Hiscox. ${ }^{1}$}

\begin{tabular}{|c|c|c|c|}
\hline & & & \\
\hline 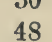 & " & $"$ & loam and fine sand. \\
\hline$t 0$ & $"$ & $"$ & fine gravel. \\
\hline & $"$ & , & gravel size of beans. \\
\hline & " & $"$ & shingle 1 inch diameter. \\
\hline & $"$ & , & stones $1 \frac{1}{2}$ inch diameter. \\
\hline & $"$ & " & 3 to 6 inch diameter. \\
\hline & " & , & boulders aud rocks. \\
\hline
\end{tabular}

\section{Beardmore. $^{2}$}

30 feet per minute will not disturb clay with sand and stones.

$\begin{array}{rccl}40 & " & \text { sweep along coarse sand. } \\ 60 & " & " & \text { fine gravel. } \\ 120 & " & " & \text { rounded pebbles. } \\ 180 & " & , & \text { angular stones. }\end{array}$

For the velocity required to move stones or shingle, Sir J. Leslie gives the following formula: $v=4 \sqrt{a}$. Where $a$ denotes in feet the side of a cubic block of stone, or the diameter of a boulder, and $v$ the velocity of the water in miles per hour which is capable of moving it along the bottom. ${ }^{3}$

Lentz gives $2 \frac{1}{2}$ feet per second as the lowest velocity that will scour silt, and 5 feet to $6 \frac{1}{2}$ feet as the lowest that will scour sand. ${ }^{4}$

These velocities greatly exceed those given by other authorities. The explanation of this is that Lentz's figures refer to the power of raising and scouring away, while others refer to transporting only; that is, that it takes ten times the velocity of water to scour up silt that has once become settled and firm than is required to prevent the silt from settling.

Rankine gives ${ }_{5}^{3}$ of the top velocity as the bottom velocity of ordinary currents, and $\frac{1}{2}$ in the case of very slow currents. ${ }^{5}$

The primary object in sluicing is to set in motion the whole body of water in the channel or basin at a velocity sufficient to remove the material to be dealt with. The sluicing should, as a rule, be frequent, so as to prevent any great deposit and aggregation taking place and establishing a condition which

1 Scientific American Supplement, vol, xxxi. p. 12,608.

2 "Manual of Hydrology," p. 39.

3tevenson's "Construction of Harbours," 2nd ed. p. 238.

4 M.I.I.C.E., vol. Ixvii. p. 461 ; vol. 1xx. p. 36.

- "Manual of Civil Engineering," p. 674. 
renders sluicing much more difficult, because once aggregation has taken place a much higher velocity is required to remove the deposit. ${ }^{1}$

The sluices should face as nearly as possible directly along the course to be scoured, and they should be distributed equally throughout the whole cross-section in order to produce a uniform current.

The water should issue from the sluicing apertures horizontally. A mass of water projected downwards will follow the same laws as a solid body falling from the same height, with the result of the bottom being torn up, whilst the water being deflected upwards on striking the bottom will produce upper or surface currents.

Under ordinary circumstances, it is possible to effect sluicing, provided the depth of water in the basin or channel is moderate, and that a sufficient quantity of water is obtainable to give the general velocity-not bottom velocity merely-necessary to move the material to be dealt with.

The bottom velocity will always be less than the top velocity, except in the immediate proximity of the sluicing apertures, when the water will issue and flow for some distance with a velocity due to the head of water with which it is propelled, but there are causes which prevent that action being continued for any considerable distance. In the first place, there is the enormous friction between the moving water and the immovable bottom over which it flows; and, secondly, a volume of water moving with a high velocity through a body of water in a nearly quiescent state encounters a very large resistance. In deep water, the effect of these causes will be augmented. Under such conditions, the water will rise, and a succession of waves and eddies be produced. 'The deposit will be moved away for a short distance, but as the water loses its velocity it will be collected again in banks and shoals.

When the volume of water discharged is great compared with the channel through which it has to pass, the stagnant water in the channel does not to the same extent destroy the momentum, as when the scouring has to be produced by a sudden finite impulse. In the one case, the scouring power dependscceteris paribus - simply on the relation subsisting between the quantity liberated in a given space of time and the sectional 1 MI.P.I.C.E., vol. $1 \times x$. p. 36. 
area of the channel through which it has to pass; while in the other case it depends on the propelling head and the direction in which the water leaves the sluice." 1

Duration of Scouring.-At Dunkirk, sections of the channel taken before and during the process of scouring, went to show that the whole effect is produced in the course of the first quarter of an hour, there being no alteration in the sectional area of the channel after that time. ${ }^{2}$

Mr. Keller, Government Engineer of Berlin, remarks with regard to artificial scouring that the flushing water should not be permitted to discharge suddenly, but be distributed over a period of some time. By such means, the dangerous rapidity of flushing would be prevented, and the scour, though less violent, would exercise a more lasting and beneficial influence ${ }^{3}$ as the issuing stream has to put in motion the whole of the water in the basin or channel, it is some time before it reaches its maximum velocity, therefore this period should be made to coincide with dead low water. ${ }^{4}$

When artificial scour is employed, it generally takes place only at spring tides. The sluices are opened a little before low water, and the scouring lasts from one and a half to two hours. This rarity of action has a bad effect, as compared with continuous natural scour, owing to the opportunity given to the silt to settle and harden. Artificial scour should, therefore, be more frequent, begin earlier and continue till the turn of the tide. $^{5}$

Fresh Water for Scouring Purposes.-It has been frequently observed that salt and fresh water flow in opposite directions, the salt water flowing in as an undercurrent, while the fresh water is running out over the tidal water. ${ }^{6}$ Observations made on the currents of the River Dee, at Aberdeen, showed that on certain occasions there was a perceptible outward current at the surface during the whole period of the flood tide, and that simultaneously there was a current of sea water running inwards. The salt water flowed in underneath, rising up the fresh water which in reality ran out over the top of the salt water. It was thought that these results were perhaps due to the steepness of the river bed and the velocity of the fresh water, but they tended to show

1 Stevenson, "Construction of IIarbours," 2nd ed. p. 235.

2 Itid., p. 237.

${ }^{3}$ M.I.I.C.E., vol. Ixx. p. 67.

4 Ibid., vol. Ixvii. p. 460 .

- Ibid., p. 462.

6 Ilid., vol. xxi. p. 336 ; vol. xx. p. 325. 
that the harbour or channel was not solely kept open by the influence of the fresh water, which was obviously inoperative on the bottom while it was running out over the salt water. ${ }^{1}$

At Woolwich, in 1824, ships used to be supplied with fresh water pumped up from alongside at the turn of the tide and up to the first quarter of the flood, but the end of the hose was not allowed to be more than two feet below the surface of the water. If this precaution was neglected, and the hose was allowed to reach three feet below the surface, salt water was immediately pumped up. This clearly showed that at Woolwich, at the date referred to, the salt water flowed up the river under the fresh water. ${ }^{2}$

Mr. W. Dyce Cay observes that among the causes of the phenomena of tidal estuaries the difference in the specific gravity of salt and fresh water is important. The fresh water floats like oil on the top of the salt water, and the currents of the two fluids proceed almost independently of one another, having different velocities, and sometimes flowing in different directions. Thus it is that during flood tide a river may continue running out, while the salt water beneath it may be running in to fill the estuary. ${ }^{3}$

Mr. H. Keller, in alluding to the use of fresh water for scouring purposes, says that the effect of such scour does not reach below a depth of 6 to 9 feet, so that its power upon a bar is limited.4 It would appear that this would depend greatly upon the volume of fresh water discharged, and the sectional area of the channel.

Avonmouth Dock Entrance.5-At the mouth of the Avon the water was made to debouch through one channel, simply by the tugs always taking that particular channel close upon low water, and so stirring up the mud, which was carried away by the last of the ebb.

Opinions appear to have differed as to the possibility of maintaining a fairway to the entrance and the entrance channel itself. On the one hand, it was anticipated that, considering the great amount of mud which the water held in suspension, difficulties would be experienced in keeping the entrance clear, and that it would eventually silt up; on the other hand, it was held that the flow from the Avon, scouring the entrance so near the

\footnotetext{
'M.P.I.C.E., vol. xxi. p. 337.

- Ibid., vol. lxvii. p. 461.

2 Ibid., p. 339.

${ }^{3}$ Ibid., vol. lxvi. p. 68.

${ }^{5}$ lbid., rol. lxx. p. 36.
} 
lock at a depth of about 8 feet 7 inches below the outer sills during the period of low water, would have a tendency to suck the mud out of the channel. ${ }^{1}$ This latter opinion appears to have been confirmed, at any rate so far as regards the entrance to the fairway channel. The channel itself up to the lock entrance is maintained and deepened by the scouring action of about three lockfuls of water per month ${ }^{2}$ discharged at low water. This would amount approximately to 3.50 million cubic feet per month. The deposit in the same time, if left undisturbed, would amount to about 15 inches. $^{3}$

Tilbury Dock Basin. ${ }^{4}$-In the Tilbury Dock Basin, which has an area of 17 acres, with a depth of 26 feet at low-water spring tides, the daily deposit is about $1 \frac{1}{2}$ to 2 inches. The system adopted for getting rid of this accumulation of mud is a combination of harrows and high-pressure water-jets, towed from the quarters of a small tug during ebb tide. The water-jets work at a pressure of about $80 \mathrm{lbs}$. on the square inch at the pumps, with an effective pressure at the bottom of the dock of about 60 lbs. per square inch.

Barry Dock Entrance. ${ }^{5}$ - For clearing the mud from gate platforms and entrance sills, the ordinary practice is to construct side culverts in the entrance walls, with openings into the back of the gate recesses. At the Barry Docks, the engineers have adopted a different course, considering the cutting away of the bottom of a wall just at the part where extreme pressure has to be encountered an objectionable course, and one that should be avoided, unless exceptional conditions necessitate such a method of construction. Accordingly all the sluices are placed in the gates, or in a large culvert on the west side of the entrance and passage, and at a higher level than the sills. The sluices in the gates are especially intended for removing any accumulation of mud that may take place on the sill and in the entrance channel leading to the dock, and for this purpose a sluice area of 200 square feet is provided.

Thames Embankment Landing-places. ${ }^{6}$-In order to prevent any accumulation of mud in the recesses containing the landingstages, arches were constructed under the embankment, into which the tide is admitted and retained at high tide, by means of penstocks. On these penstock valves being raised at low tide,

1 M.P.I.C.E., 1v. p. 91.

s Ibid., ci. p. 167.
2 Ibid. 3 Ibid., p. 7 . Ibid., vol.c. p. 65.

Ibid., vol. xxviii. p. 227; vol. liv. p. 11. 
the water is discharged through several openings in the length of the recess 4 feet 9 inches long by 9 inches high. The bed of the recess, which is paved, is thus flushed out, and any deposit of mud or other matter washed away.

Calais Entrance Channel. ${ }^{1}-\mathrm{A}$ discharge from the old sluicingbasins of 450 cubic yards per second, lasting with efficiency from one-half to three-quarters of an hour, produced first, in the channel between the jetties, a depth of 5 feet 9 inches to 8 feet 2 inches below the zero of the charts, or the level of the lowest tides known; and secondly, outside the jetties for a width of 130 feet a minimum depth, varying according to the frequency of storms from 10 inches to 4 feet below the lowest tide level.

Dunkirk Entrance Channel. ${ }^{2}$-With an average discharge of 510 cubic yards per second, and an efficient duration of about three-quarters of an hour; the effect of the scour on the sand in the inner channel was to maintain a depth of from 5 feet 9 inches to 8 feet 2 inches, and, outside, from zero to 2 feet 6 inches below zero, or the lowest tide level.

St. George's Stage, Liverpool. ${ }^{3}$-For the removal of a part of the Pluckington sand-bank, which by its extension northward projected under, and endangered the stage, Mr. G. F. Lyster adopted a method of sluicing along the foreshore in front of the river wall and at the rear of the landing-stage. The sluicing takes place at low water, when the working of the docks permits, when a vast quantity of water is ejected, which effectually keeps the sand clear.

The system as carried out consists of a series of twenty-two cast-iron pipes, spaced 20 feet apart; they are nearly semicircular in section, having a diameter of 4 feet and a sectional area of 12 feet 5 inches. The outfalls are 10 feet below the old dock sill, and 47 feet from the east side of the landing-stage (Figs. $274,275,276)$.

These pipes are connected to a main culvert of somewhat similar section, 8 feet in diameter, which is laid along the foot of the river wall, and is in direct communication with the southend docks, from which the water for sluicing is obtained.

By the time the sluices were ready for use, the sand-bank had increased to such an extent that from 5 to 7 feet needed removal before the pontoons of the landing-stage could be waterborne at low water of spring tides.

'M.P.I.C.E., 18x. $75 . \quad$ : Ilıd.

Ibil., vol. c. p. 78. 

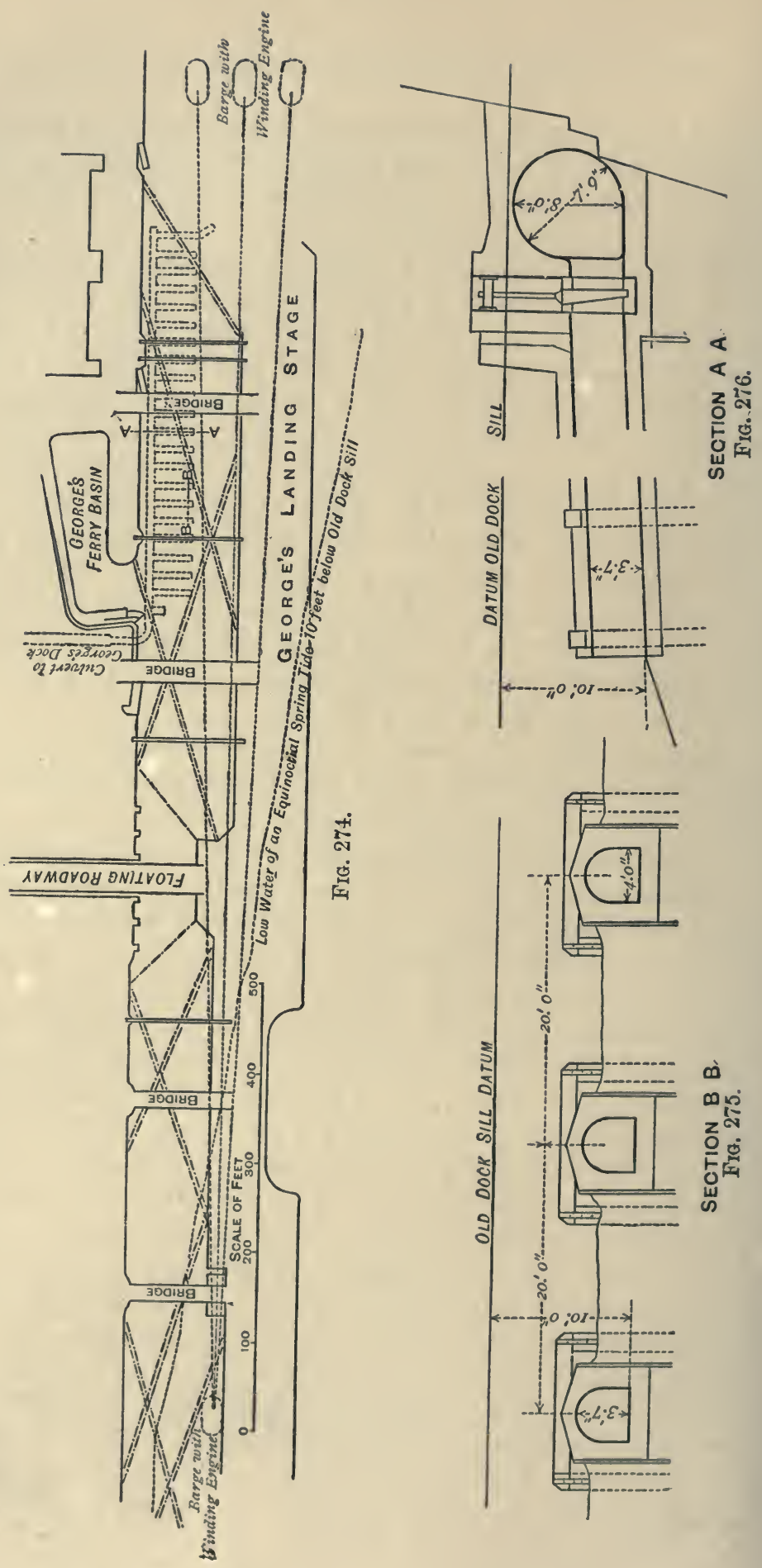

$+$

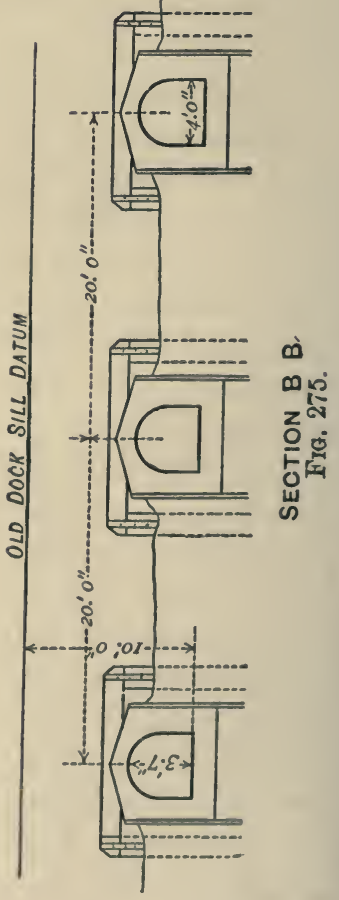


It was proved by experiment that with a head of 25 feet, the force of water was sufficient to scour the sand away to a depth of $\mathbf{1 6}$ feet below the old dock sill datum in an hour and a half. The whole of the sand-bank affecting the landing-stage could therefore have been readily removed by scouring, had not the stage intervened.

It was, however, found impossible to work the sluices to advantage with the pontoons high and dry aground, presenting an almost solid barren immediately in front of the outfalls at low water, and had it been possible to do so the effect would have been disastrous to the stage; for the river bed would have assumed the form of a huge step on the longitudinal section, the tread being 400 feet in length and the rise 7 feet in height; the consequence of which would have been an inevitable collapse of the pontoons where the step occurred. The only prudent course, therefore, to be followed was to work the sluices with great caution so as to avoid the formation of abrupt stepping, ridging, and furrowing; and, in order that such irregularities might be instantly detected, soundings were carefully taken every day until the stage became properly water-borne from end to end.

A partial trial of the sluices, continued for several days, removed a large quantity of sand from between the outlets of the culverts and the stage, as well as from under it at the extreme south end; but further north the bottom was not affected beyond the centre line, the reason being that the sluices could not be brought into use until the pontoons were off the ground, by which time the tide had risen sufficiently to obstruct the sluicing current, rendering it inoperative beyond a distance of 90 feet from the outlets.

Under these circumstances, it was found necessary to resort to mechanical appliances to assist in putting the sand in suspension, so that it might be in a better condition to be acted upon by the sluicing current.

These appliances took the form of scrapers, as commonly used for clearing the dock sills, but with a special form of tooth. Flat harrows, provided with tines or spikes (Figs. 277, 278), and drag-chains armed with plates (Figs. 279, 281), all of which were dragged over the bottom by steam-crabs placed on barges (Fig. 274).

For the purpose of reducing ridges in the sand, the formation 
of which could not be prevented, a drag consisting of twenty armed chains, each 4 feet long, placed side by side, and attached to timber bars 8 feet long connected to the hauling rope by halfbridle chains was used on special occasions; but for general work, the triangular arrangement (Fig. 279) proved the best.

The use of these appliances, combined with partial sluicing, was continued until the effects produced were such that it was considered safe to bring the sluices into full play by running two at a time full bore, near the time of low water for an hour and a half or two hours, according to circumstances, which course soon reduced the bank in front to the required depth. ${ }^{1}$

Removal of Shoals by Propeller-Sluicing. ${ }^{2}$-The practicability

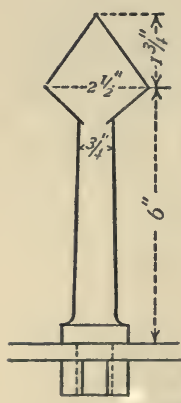

TINES

Frg. 277.

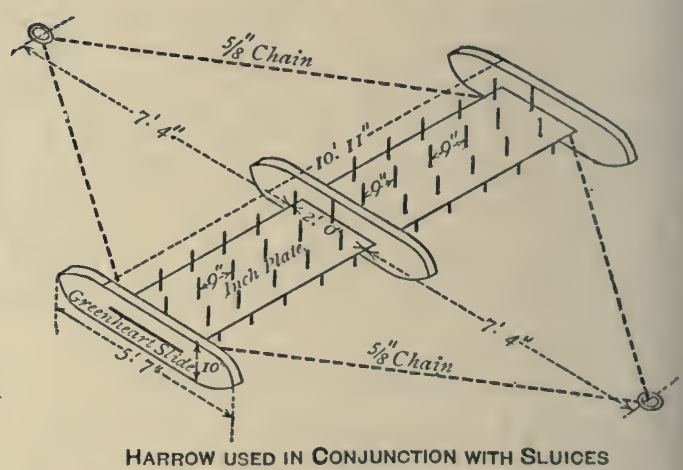

Fig. 27 .

of propeller-sluicing has been demonstrated by experiments made on the Colombia River, with the view of removing the St. Helen's bar, where the depth of water was $12 \frac{1}{2}$ feet.

The vessel used for this purpose was of 2124 tons register, 330 feet long, 40 feet beam, and 16 feet draught. The screw was 17 feet in diameter, with a pitch of 20 feet, and made a maximum of 54 revolutions per minute.

In the first instance, a channel 1200 feet long, 200 feet wide, with an average depth of cut of 6 feet, was sluiced out in three working days. A second trial resulted in a channel 1600 feet long, 150 feet wide, and an average of 6 feet depth of cut, completed in eight working days. At a third trial, a channel of the same length and width, but 10 feet depth of cut, was made without difficulty. The material removed consisted of sharp heavy sand. 
A further satisfactory effort was made by the same ship on a material consisting of sand and gravel, with a nucleus of solid cemented gravel. The cut was made apparently with no greater difficulty than in the looser material, stones the size of cocoanuts being washed out and driven down stream; in this instance,

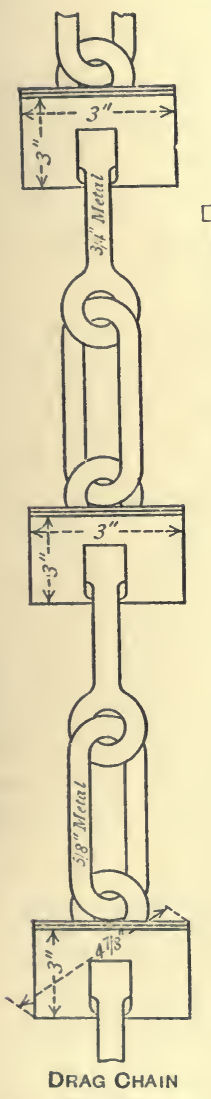

Fig. 279.

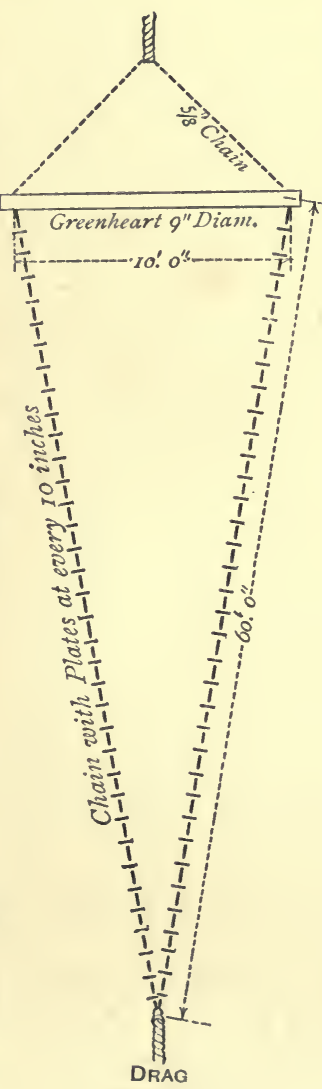

Fig, 280. about 10,000 cubic yards of material were removed in eight working days.

The method of mooring the ship is shown by Fig. 281. The vessel was backed to the shoal, or bar, and moored by the bow to an anchor placed up stream, and to anchors laid out on each

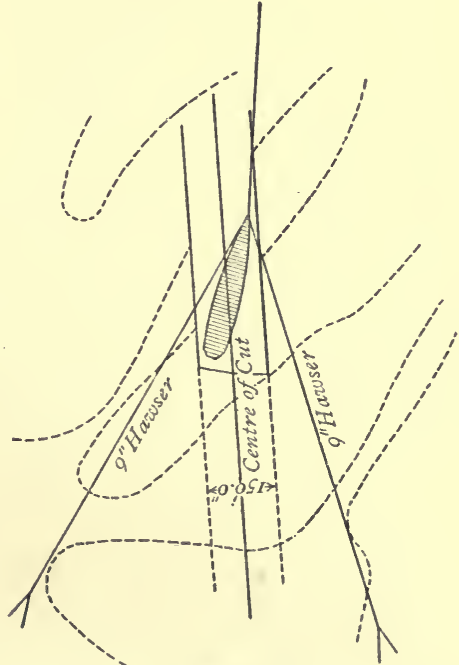

FIG. 281.

quarter. The vessel having been trimmed by the stern to just clear the bed of the river, the engines were started full speed ahead. The generated current being driven away from the ship, no injury could possibly occur from the stirred-up sand working into the stern-tube or pumps; and as the cut proceeded, the vessel pivoting on the bow was slewed from side to side of the intended channel by the rudder, and, as soon as a trench was 
cut across the full width of the channel, the ship was "fleeted" down about 25 feet into position for a fresh cut.

It was estimated that the stream immediately astern of the ship had a velocity of from 12 to 14 miles per hour, and at one quarter of a mile distance a speed of 3 to 5 miles, according to whether the vessel was working with or against the tide. The stream carried the bulk of the eroded material across the bar into deep water, while a portion was thrown up as a bank on the side of the channel towards which the propeller turned.

The longitudinal section of the cut showed a series of transverse waves; by using a drag or rake to break down these ridges, a further depth of about 2 feet could have been obtained at a very small additional cost.

Honfleur-Sluicing Basin. ${ }^{1}$ - The sluicing-basin constructed for the purpose of maintaining the entrance channel has an area of 143 acres, and was formed by enclosing a portion of the foreshore (Fig. 282). The embankment enclosing the basin is 40 feet wide at the top, and has a slope of 3 to 2 on the inside and 3 to 1 on the out or seaward side. The inner slope is covered with a layer of stones 20 inches thick, on which is laid a course of rubble stone of the same thickness, set in Portland cement. A trench of compact earthwork-puddle-3 feet 3 inches deep was formed at the bottom of the inner slope, to protect the bank against the infiltration through the silty foundation. The outer face is pitched with large blocks of rubble stone, and the foot protected by a deposit of rubble stone, extending to a depth of 42 feet below the surface.

The sluice has four openings, each 16 feet 6 inches wide, separated by piers 6 feet 6 inches in width. Each opening is closed by a sluice-gate, turning upon a nearly central vertical axis. The panel on one side of the axis is made $\mathbf{2}$ inches wider than the other panel, to facilitate the closing of the gate against the outgoing current. The working of the sluice is easily eflected by opening a little valve in the wider panel of the gate, which reduces the water pressure on that panel below the pressure on the other panel, so that the gate revolves and places itself in a line with the stream as soon as it is released by a turn of the post at the side, which retains it in place. The gate is shut by giving it a sideways push, after the latter has been closed, so as to make the current act on the larger panel. The sill of the ' M.P.I.C.E., vol. Ixvii. p. 464; and Le Genie Civil, vol. i. p. 554, 579. 


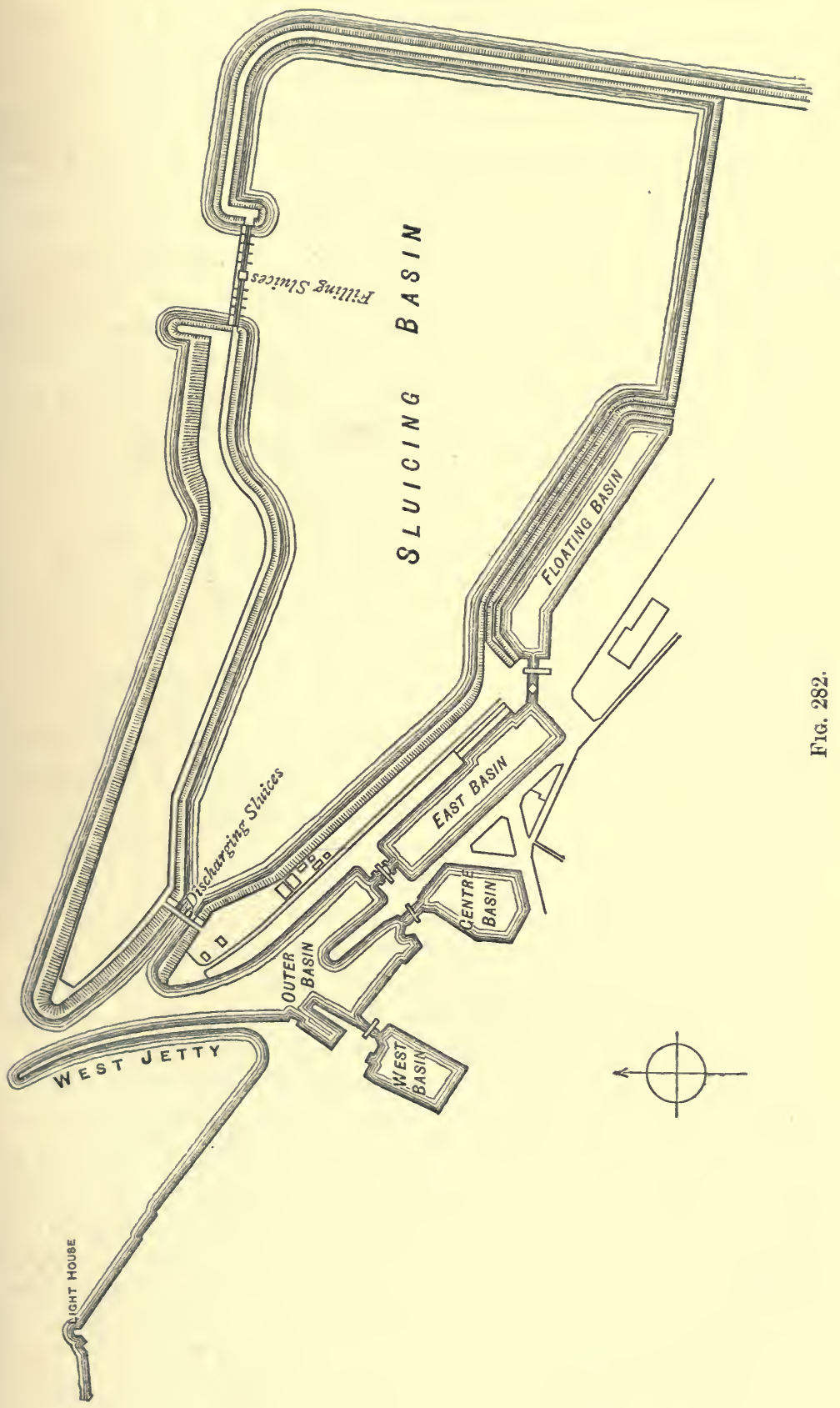


sluice is 11 feet 6 inches below the average bottom of the basin, which is sloped down to the sluice.

To protect the foundations of the sluice from all danger of being undermined by the scouring action of the current, a solid wall of masonry $\mathbf{1 6}$ feet $\mathbf{6}$ inches thick was carried right across the outer face of the foundations of the sluice, so as to overlap the abutments on each side for a length of 26 feet 3 inches, and carried from the sill down to the clay, a depth of 54 feet.

'The size of the inlet opening is sufficiently large to enable the basin to be completely filled during the two and a half hours of nearly slack water that occurs at Honfleur directly after high water. The water at this period is comparatively clear; by this precaution, the rapid silting-up of the sluicing-basin is avoided.

The inlet opening is composed of ten bays separated by masonry piers 6 feet 6 inches in width. Each bay is 32 feet 10 inches wide, and is closed by three gates opening inwards, and turning upon a horizontal axis on the apron of the weir. Each gate is 11 feet $1 \frac{3}{4}$ inch wide, and 7 feet $1 \frac{3}{4}$ inch high. These gates are placed at such a level that when raised their top reaches the level of the highest tides, and when lowered they are 2 feet below high-water level, so that they admit the clearest upper layer of water only into the basin. Each gate is worked by means of a chain, one end of which is fastened to the gate; it then passes in succession over two pulleys, the first having its axis parallel to the gate, and the other at right angles to it. By this means the direction of motion of the chain is converted, on passing through the second pulley, into a horizontal motion parallel to the line of the gates. Then, by using chains of equal length, having their other ends fastened symmetrically along a beam capable of moving backwards and forwards along a bridge placed across the piers of the weir, the gates can be moved in unison up or down by a movement imparted to the beam. Two of these beams are used for working the thirty gates. Each beam is connected with a pair of conjugate pistons, working in two cylinders containing water, and communicating with hydraulic machinery. The hydraulic power acts merely as a brake when the gates are being lowered, and only imparts motion when the gates are being raised.

A volume of 654,000 cubic yards of water is discharged 
through the sluice direct into the entrance channel in forty-five minutes, attaining a velocity of 26 feet per second.

Canada Basin, Liverpool.-The following particulars of the sluicing arrangements made for maintaining the depth in the Canada Basin are abridged from Mr. G. F. Lyster's paper on "Dock Extensions at Liverpool." 1

In designing the New North Docks, it was decided that the sills should be placed on the same level as those at Birkenhead, viz. 12 feet below datum, or 2 feet below low water of equinoctial spring tides.

This decision involved special arrangements to provide for the maintenance of the required depths at all times without dredging or such-like expedients.

The area of the basin is about $9 \frac{1}{2}$ acres, and the fairway within the splayed piers about 3 acres.

Mr. Lyster concluded that the only certain method of

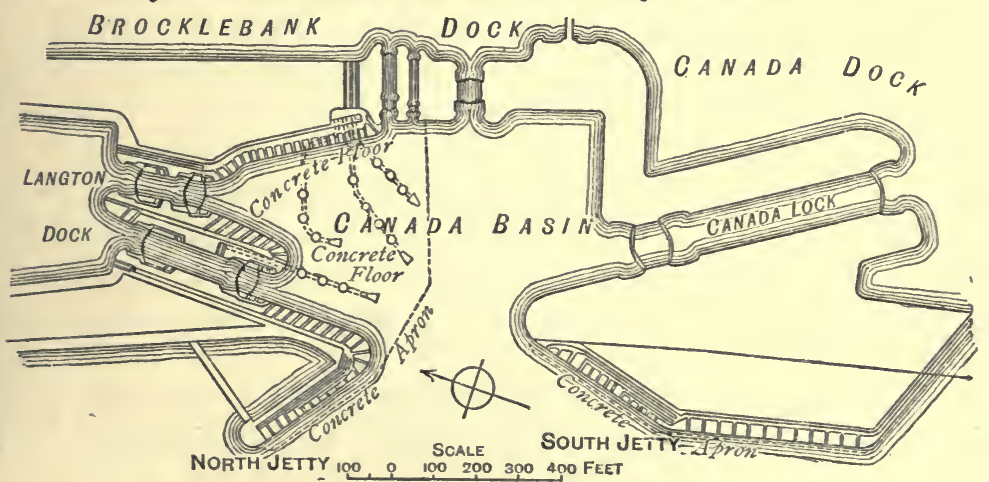

FIG. 283.

effecting the object in view was by the flow of water through culverts of such form, and placed in such positions, as would command the areas in question.

This has been attained by the construction of a system of large culverts (Fig. 283), connected with the Langton Dock, having short branches fitted with sluices, and carried into the basin through the wing walls, similar culverts and sluices being constructed through the masonry of the walls surrounding the island between the entrances. The culverts are for the most part of iron, with a special form of joint, and all are lined with a 3 -inch coating of Portland cement, kept in place by dovetail ribs cast on at near intervals. 
The whole system with the cement lining presents a perfectly smooth conduit to the passage of flowing water.

The main feeders or large pipes are built in behind the wing walls, bedded in masses of concrete.

The intakes from the Langton Dock are commanded by double clough-paddles of large dimensions, actuated by both hydraulic and hand-power machinery.

Water for sluicing purposes can as a rule be drawn off without interfering with the working of the docks; in fact, as regards the Langton Dock, the running off of water from it is a necessity of the mode of working, seeing that the water in it must each tide be lowered to suit the level of the next tide two hours before high water, when the gates have to be opened for the docking of ships.

Sweeping is carried on daily, and has proved amply sufficient to prevent the accumulation of silt in the immediate vicinity of the entrances, and for a limited distance outside the foot of the walls. Sluicing is, however, most effective during springs, owing to the lower level of the low-water in the basin and fairway.

For dealing with those portions of the basin and fairway beyond the reach of the wall sluices, pipes are laid under the bottom of the part of the basin to be kept clear, which, to render the retention of silt more difficult, is covered throughout with a concrete floor.

The pipes are laid in trenches excavated in the clay to a depth of 18 feet below the low-water level, bedded on, and surrounded with, concrete. The main pipes, 8 feet in diameter, are connected with the adjoining dock, and are controlled by paddles worked by hydraulic and hand power. The pipes are provided with short branches, having splayed openings or nozzles leading upwards, terminating about 9 inches below the finished concrete surface of the floor, and so spaced as to admit of the sluicing water commanding the entire area of this part of the basin.

Upon these openings are laid heavily framed discs of greenheart, connected to the pipe by four strong loose links of 2-inch iron. When in a quiescent state, these discs rest upon the openings of the upcast pipes, but when the paddles in the dock are lifted they are forced up by the flowing water to the extent of the range allowed by the links, thereby causing annular jets 
of water to fly out, sufficient to sweep a large circular area, and thus together clear the floor of the basin of sediment.

This system has been in operation for some years without the slightest mishap. Periodical examinations by divers have proved the surface of the concrete to be perfectly clean, and its face, as well as the lining of the pipes, in as good a condition as when first put in. A special condition in connection with the basin is that no anchors are to be let go within its area under a heavy penalty.

The intermediate fairway outside the basin, and within the pier-heads, is also kept deep and clear of sediment by artificial means. The timber jetties projecting into the river from the north and south pier-heads serve as guides or fenders, against which vessels entering or leaving the basin may bear; they also serve to limit the area within which deep water has to be maintained, whilst in their foundations a system of sluices has been constructed by which the removal of deposit is effected in the vicinity of the outlets.

In the base of the north jetty, three pipes, each 8 feet in diameter, are laid in connection with the main sluicing culvert of 12 feet diameter in the west wall of the basin. A series of sluicing outlets 4 feet in diameter, 24 feet apart, project nearly horizontally from the 8 -feet pipes. The discharge from these outlets is regulated by clough-paddles in the basin pier-head. A similar series of outlets is laid in the north-west face of the south jetty, the supply of sluicing water being in this case obtained from the Canada Dock. The combined action of the discharge from these sluices and of the flow through the Canada Basin, when its sluices are open, suffices to keep the fairway between the splayed piers at the required depth.

Low-water Basin, Birkenhead. ${ }^{1}$-In designing the scouring arrangements at the Low-water Basin, at Birkenhead, the intention of the engineer (the late Mr. Rendel) was that the current, when discharged from the sluices, should prevent an accumulation of deposit in the basin, rather than remove it after it had been allowed to form, and for that reason the water was to be run out as often as the tides would permit, at a velocity of three or four times greater than the flow of the tide into the basin, and therefore sufficiently powerful to remove any matter that might be brought in. The velocity referred to was intended to produce 
the effect of a river passing through the basin with a gentle current, not strong enough to hinder vessels of light draught remaining there during the operation; on the contrary, it was assumed that the scouring process would be more effectually carried on while the vessels were there than if the basin remained unoccupied.

The scouring water was to flow through the basin like a sub-aqueous river, sweeping over the bottom with scarcely any

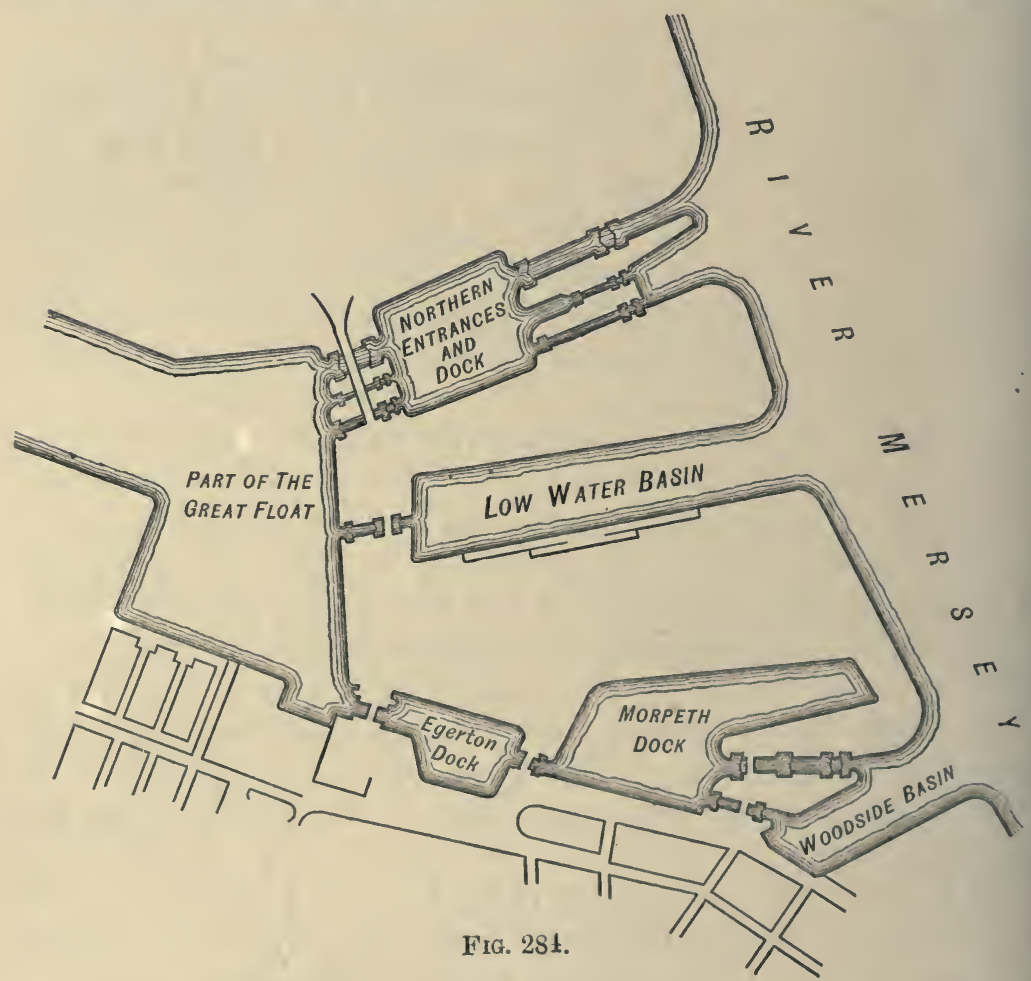

disturbance of the surface; there were to be no eddies or foul currents, as were known to exist under the ordinary modes of sluicing, the surface water would not be much agitated, there would be no bubbles rising up, neither would there be any tearing up of the bottom.

To effect this object, the head walls were to be constructed with sluices so designed as to pour forth for the whole width a stream of water as nearly as possible in a continuous sheet. The sills of these sluices were to be laid about 2 feet above the 
bottom of the basin, and the sluices were intended to operate in such a manner as to discharge a sheet of water that could be regulated to any degree of force by sluicing-valves.

The low-water basin was ultimately constructed to the following dimensions ${ }^{1}$ (Fig. 284).

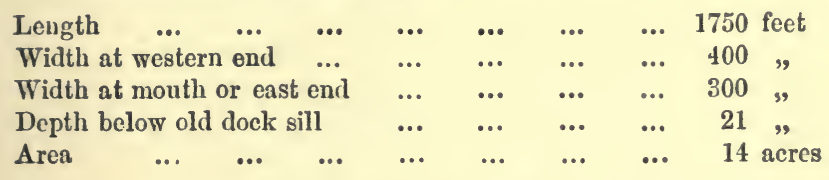

The arrangements ${ }^{2}$ for sluicing (Figs. 285, 286) consisted of two chambers or passages leading from the float, each 30 feet in width, and placed one on each side of the entrance-lock. These chambers were furnished with gates similar to a dockentrance, and provision also made for closing the end of each by means of a caisson. The inner sills were laid at a level of 8 feet below the old dock sill. The floors were inverted, and fell away from the float at an inclination of 1 in 33 for a length of about 200 feet, where a level of 15 feet below the old dock sill was attained; they then dropped rapidly, and in a length of 25 feet reached the 18-feet level, at which they continued for a distance of 45 feet to within 15 feet of the mouths of the sluices. In the latter length there was a slight fall of 6 inches. In the chambers, the width of 30 feet was continued for a distance of 30 feet from the commencement at the float; they then began to open out by a gradually enlarging width, until each finally closed at the back of the respective sluices, wide enough to embrace the whole group on one side.

The sluices were twenty in number, arranged in groups of ten on each side of the lock. The leading channel of each sluice measured 5 feet 2 inches by 8 feet, equal to a sectional area of 41 feet 4 inches for each sluice, or a total area of 826 feet 8 inches for the twenty sluices. At the chamber end each sluice widened out horizontally, and to a slight degree vertically ; but towards the basin the shape altered considerably, until the aperture became 4 feet 6 inches high, by 12 feet in horizontal width. The sills of the sluice openings were set at the level of 18 feet 6 inches below the old dock sill, and immediately outside, and in the basin a stone apron was laid with its surface forming a continuous slope with the sills for a distance of 30 feet,

I M.P.I.C.E., vol. xxviii. p. 521.

? Ibid., vol. xxviii. p. 522. 

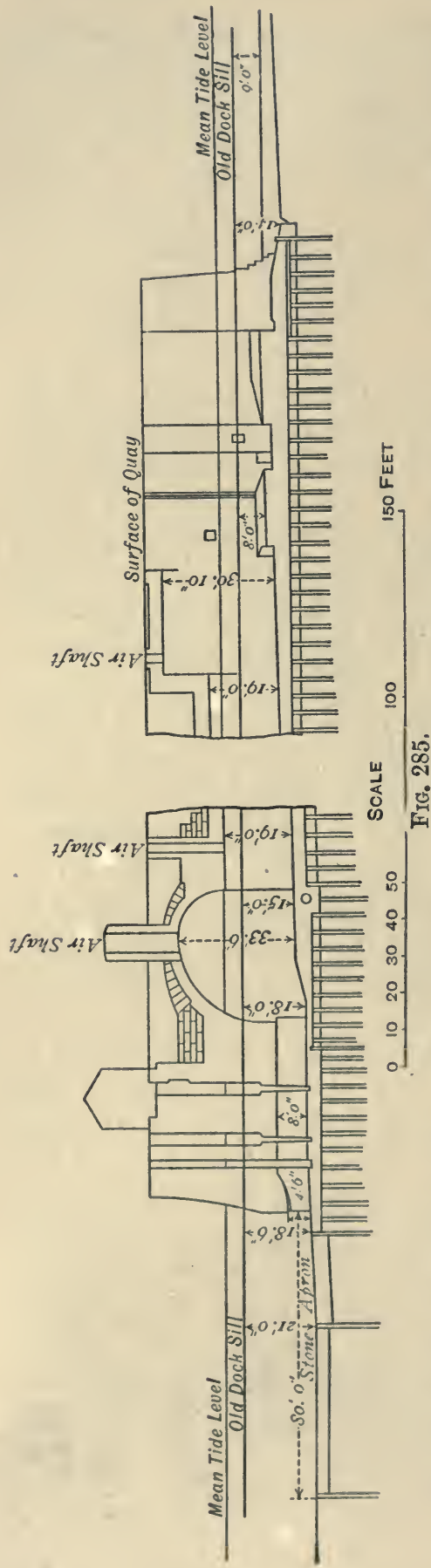

when a line of 12 -inch sheetpiling was driven, and when the level of the bottom of the basin was met, the whole width of the apron was 80 feet; it was laid with stone blocks 5 feet in thickness on the side next the sluices, and 3 feet thick for a width of 50 feet in the basin.

The sluicing paddles or valves were made of greenheart timber, wedge-shaped, 6 inches thick at the point, and 24 inches at the butt. Preparation was also made for a third valve, of iron, which sliding in a groove outside the other two, was for use only when examination or repair was necessary to the appliances within.

Hydraulic power was used for working the valves, and was so applied and connected with suitable. machinery that one or more of the paddles or valves, or the whole, could be raised or lowered simultaneously, swiftly or slowly, as might be required.

In addition, two large culverts, each 7 feet high by 6 feet in width, were built within the north and south side walls. These culverts terminated at the pier-heads in a group of small outlets, and were intended for clearing away any deposit which, having been driven down the basin by the action of the main sluices, might find a resting-place near the 
wings and within the line of current against the river wall.

The bursting of the temporary dam after the completion of the excavations within it down to the full depth of 21 feet below the old dock sill caused a deposit of 10 inches on the

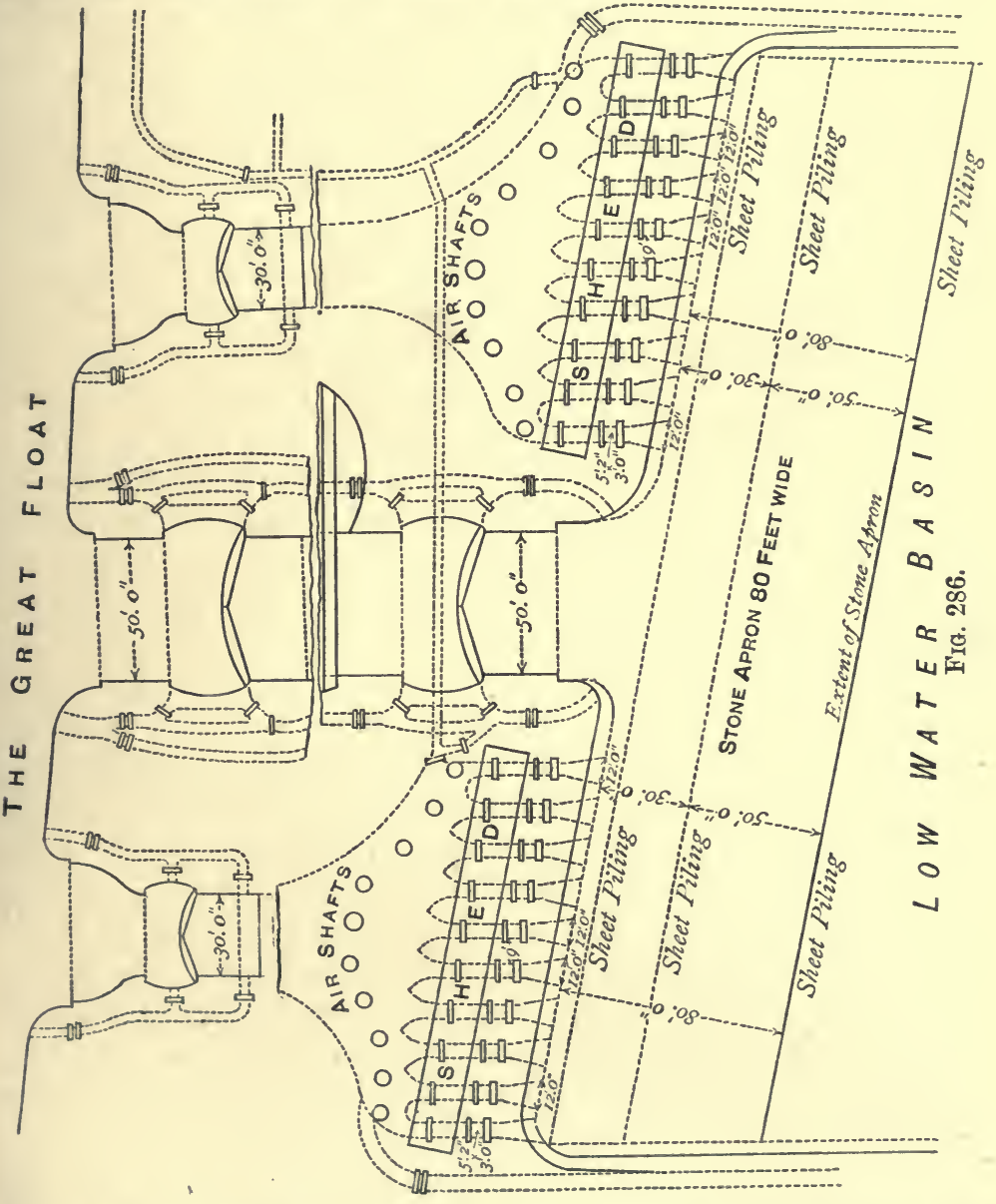

floor, which was increased to 32 inches by the daily tidal influences, within a period of seven months.'

The following extracts and particulars of the trials which took place to prove the efficiency of the arrangements, and the results which ultimately led to the abandonment of the work as a low-water basin, are taken verbatim from the Institution's papers. ${ }^{1}$

1 M.P.I.C.E., vol. sxviii. p. 526. 
"At the first opening of the sluices, the chief attention was directed to the working of the machinery; the paddles were slowly lifted and lowered sometimes singly, at other times in sets of a few only, and then altogether.

"The condition of the water on first leaving the sluices was that of a rushing torrent of white foam, through which and between the central sluice apertures occasional glimpses were caught of the stone apron below. Commencing on one side of the basin, the lines of direction of the current tended with a boiling tumbling motion towards the opposite side from whence they set out. In their course towards the river the tendency was to oscillate from side to side, forming for the most part a series of long curved lines, much broken into and disturbed by an irregular action constantly going on in the central space between them. While the main current, increasing in breadth as it approached the river, would be running in a series of bends at the rate of 8 miles and upwards an hour, the intervening portions would be moving slowly and irregularly in various directions. Sometimes at the close of the operations the current would gradually reverse itself, and finally set into the basin for a short distance, at an estimated rate of from half a knot to two knots an hour.

"Soon after the sluicing commenced, the colour of the water would be seen to change. A dark brown cloud would rise, and moving slowly with the rolling mass, would gradually extend itself to the mouth of the basin, and out into the river. It was also observed that, at a distance of about 150 feet from the head of the basin, a cross mound of water would rise from 12 inches to 18 inches higher than the natural level, and would fall off with a long slope on the opposite side, caused apparently by the impetus of the out-flowing water driving on, and heaping up the comparatively still water with which it had come in sudden contact.

"The disturbance of the water was very great, and nothing afloat could live in the basin while the sluices were in operation.

"During the fourth trial of the sluices, the gates of the north channel were torn from their fastenings and swept into the chamber. The paddles were immediately lowered, and all further sluicing operations suspended until an examination of the channel and chamber had been made. It was found on investigation that no damage had been sustained beyond the 
injury to the gates. The trials were resumed and continued at suitable intervals, when the gates of the south sluicingchamber were carried away in a similar manner to the former.

"From sections taken across the basin after every set of trials, it was soon discovered that a portion of the bottom, immediately beyond the stone apron, was being gradually washed out, and that a hole 6 feet deep had thus been formed. All attempts to fill up and reduce this hole by discharging large blocks of rubble stone into it, were ineffectual. It was found that the sheet-piling in front of the apron on the margin of the hole was bare on the face to a depth of 4 feet, sloping down suddenly to a depth of 9 feet below the finished bottom of the basin. The piling had also parted from the masonry of the apron, leaving a space between the stonework and the heads of the piles of from 3 to 9 inches.

"The water was pumped out of the north chamber, and an examination showed that the masonry therein had sustained considerable damage. The side walls and upper portions of the interior were uninjured, but a large quantity of the floor immediately at the back of the sluices had been torn up, and the concrete and the piles laid bare in several places. No remains of the broken-up masonry were found in the chamber, all had been carried out into the basin, except one sandstoneashlar block, which, being too large for the opening, had become jammed in one of the central sluices. A subsequent examination of the channel leading to the south sluices showed that similar damage, though not to the same extent, had taken place in the floor of that chamber.

"Prior to the commencement of the sluicing operations, a deposit had accumulated over the bottom of the basin to an average thickness of 32 inches. ${ }^{1}$ The result of the operations, which extended over a period of ten months, was that the deposit was reduced from 32 inches to 14 inches; equal to an average of 28 inches over the whole area of the basin, viz. 14 acres. The quantity of material removed was therefore 51,800 cubic yards, in addition to the quantity carried into the basin daily by the recurring tides, which was estimated to amount to 1264 cubic yards ${ }^{2}$ per week; equal to 54,352 cubic yards deposited within the period of 43 weeks over which the sluicing operations extended, and making a total of 106,100

1 M.P.I.C.E, vol, xxriii. p. 528.

2 Ilid., p. 529 . 
cubic yards. The total number of times the sluices were opened was $56,{ }^{1}$ and the aggregate time $22 \frac{1}{2}$ hours; therefore, the quantity removed at each operation was practically 2000 cubic yards within an average period of 24 minutes.

"The largest body of water run out of the great float at one time reduced it in depth 5 feet 3 inches. Some difficulty was experienced in arriving at the quantity run off, owing chiefly to the long oscillating wave that came into play immediately the sluices were closed. The extreme length of the float equalled about two miles; and when the flow from it commenced, a current was established throughout the whole length. The sudden check in the flow by the closing of the paddles caused a rise in the water against the wall of the float nearest the sluices of 12 to $\mathbf{1 5}$ inches above the previous level, producing the wave which afterwards began to roll back to the further end, to return and roll back again and again, with lessening volume, for upwards of an hour, until entirely spent.

"The mean head of water during the time of sluicing was from 21 to 24 feet. $^{2}$ The calculated velocities due to these heads would be 36.82 feet and 39.44 feet per second, or 25.67 and 26.86 miles per hour respectively.

"It soon became evident, during these operations, that the running of the water was attended, not only with much inconvenience and hindrance to business, but with a considerable amount of danger. The rapid lowering of the water in the great float was highly objectionable. The low-water basin had to be cleared of vessels before the sluices were raised, and delays arose at times on this account. The injury to the chambers showed the dangerous nature of the operations, for it indicated a tendency to destroy the foundations, and, by forming a sub-communication between the great float and the lowwater basin, to lead to the ultimate destruction of the works.

"The danger to be apprehended was shown early by the carrying away of the gates, and the uneasiness was not diminished when the sluicing had to be conducted in the dark mornings and evenings.

"The power let loose was of immense force, and a feeling arose that some great and sudden calamity, unforeseen and uncontrollable, might at any moment arise; sluicing in the dark was therefore discuntinued.

' M.P.I.C.E., vol. xxviii. p. 528.

\& Ibill., p. 530. 
"But notwithstanding the numerous drawbacks connected with the system, it will be apparent that the sluicing was capable of maintaining the low-water basin at its proper depth. In fact, it could do more than that, for at the time the operations were commenced a deposit of 32 inches in thickness had accumulated, and at the end of ten months, when the scour had operated with more or less regularity through fifteen sets of spring tides, the deposit had been reduced to 14 inches, leading to the conclusion that when the primary level had once been reached a less amount of scouring power would suffice to maintain the required depth.

"It was not, therefore, on the ground of inability to maintain it at its proper depth that the closing of the low-water basin and its conversion into a wet dock was determined on. The principal reasons for adopting this course were that the operation of the sluices had been found to be dangerous to the stability of the works and practically unsuited to the proper and efficient working of the great float and low-water basin for dock purposes."

Among the causes which led to the failure of these sluicing operations there appear to be the following : -1

The primary object was to set in motion the body of water in the low-water basin. This was 1750 feet in length, and varied from 300 to 400 feet in width, the depth being, when sluicing commenced, 19 feet 4 inches. The weight of water to be set in motion, or simply to be started, was therefore 338.275 tons ; and for this purpose twenty sluices were provided having a combined area of 826 square feet, with a head of water of 14 feet 3 inches, producing a total pressure of 336 tons; or less than one-thousandth part of the load.

This was a greater disproportion than was found to exist in other instances where a load had to be moved by a comparatively small power. The 336 tons of power appear to have been employed against the 335.275 tons of load at a velocity of about 17 knots per hour, which had the effect of disturbing portions of the water and throwing it into a state of great confusion.

The division of the sluices into two groups by an interval of 120 feet led to eddies and foul currents. 


\section{CHAPTER IX.}

Floating Docks - Classification - Durability-Strains-Applicability-Conditions affecting design-Stability-Cartagena Duck-Off-shore floating DockDepositing Dock-Hydraulic lifting Dock.

A FLOATING dock is any structure capable of lifting a vessel out of the water, and supporting it by virtue of its own buoyancy stability. As a rule, for a given displacement, the length being constant, the stability of a floating body varies in direct proportion to its breadth. ${ }^{1}$ Therefore, the form usually adopted for floating docks is the rectangular, with a breadth large in proportion to the depth of immersion, which varies from $\frac{1}{8}$ to $\frac{1}{10}$ of the breadth. But as the stability is materially influenced by the height of the centre of gravity above the line of flotation, other sections approaching a semicircular form may, by lowering the centre of gravity, have a stability equivalent to the rectangular form.

This form requires the ends to be closed, either by gates or caissons, after the vessel has entered, as the keel of the vessel would be considerably below the line of flotation of the dock.

In a rectangular dock, the same stability is obtained without closing the ends, and usually there is less water to discharge.

With a circular form of bottom, the volume of water between the outside of the ship and the inside of the dock has to be disposed of, while, with a rectangular form, only the quantity of water representing the weight of the ship and dock has to be cleared. In one case, the quantity of water to be pumped will vary as the weight of the ship; but, in the other case, the smaller the vessel the greater will be the quantity of water to be discharged. ${ }^{2}$

Classification.-Any structures with sides of an equal and uniform height throughout, and the ends closed by gates or

1 M.P.I.C.E., vol. xxxi. p. 299.

8 Ibid. 
caissons, may be classed as floating docks proper; structures having sides varying in height, with open ends, or with one side only, and of less displacement than the base, as pontoon docks; and closed or open rectangular structures, as pontoons simply.

Durability.-The life of a floating dock of any class will depend greatly on the facilities for, and the care and attention bestowed upon, periodical repairs, cleaning and painting of the submerged parts. These operations may be performed by careening or canting; beaching, when there is sufficient rise and fall of tide; raising the submerged parts out of the water; or by floating the dock into a shallow basin and closing the entrance. ${ }^{1}$

Strains.-The buoyancy of the empty chambers produces a strain over the basement while supporting a ship on its keel similar to that of a beam resting on a central fulcrum with a uniform pressure on the lower surface acting upwards, which is equal to the weight of the ship supported. ${ }^{2}$

Applicability.-In considering the applicability of a floating dock, a crucial point would be the attainment of a site sufficiently protected as to ensure a ship being placed and lifted under all conditions of weather. If such a site is not available, a floating dock of any class can hardly be considered suitable.

Conditions affecting Design.-The following remarks on the conditions to be observed in designing an open-ended floating or pontoon dock are from Mr. Taylor's paper on "Floating Docks," in the Transactions of the East Coast Institute of Engineers and Shipbuilders.

"The under-deck displacement should be greater than the combined weight of ship and dock.

"The dock should be sufficiently strong not only to support the intended maximum ship, but so strong that it will not be injured if the ship has been built or damaged in such a way that a great part of the ship's weight rests either amidships or at the ends.

"The sides should be made as low and as narrow as efficiency will permit, so that a wide working platform may be secured, and light and air have access to the ship, and that the top weight and displacement be a minimum.
II.P.I.C.E., vul. xxxi. p. 301.
Ibid., p. 300. 

tanks.

"The water should have only a limited cross range in the

"If the dock is emptied by pumps, they should be close to the bottom of the dock, so that the water may as far as possible run into the pumps without having to be drawn in."

The lifting power of various docks may be taken to vary roughly as the under-deck displacement. ${ }^{1}$

Sir F. Bramwell has pointed out ${ }^{2}$ that the stability varies

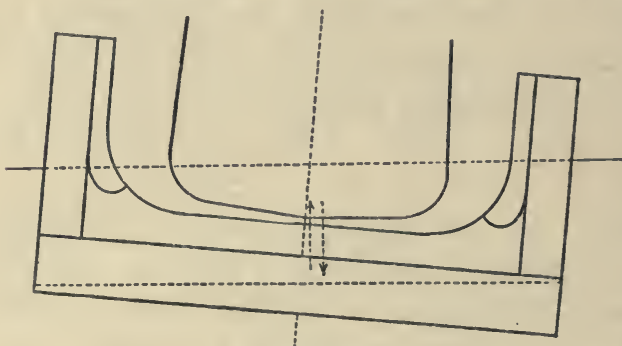

Fig. 287.

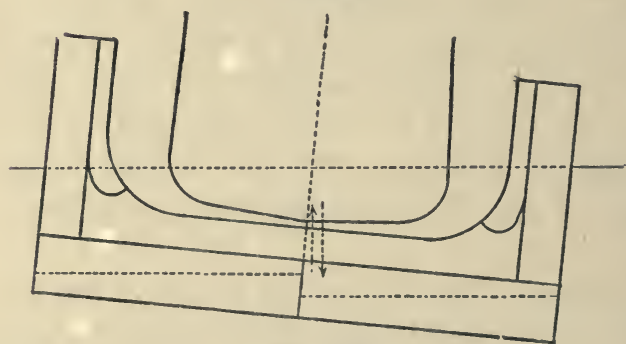

FiG. 288.

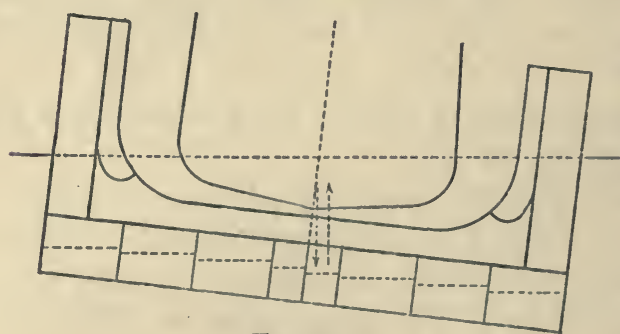

Fig. 289. as the square of the number of tanks in the cross-section of the dock; therefore, all floating docks should be built with numerous water-tight longitudinal bulkheads, so that the water may have comparatively little transverse motion.

The following diagrams illustrate this. ${ }^{3}$ Fig. 287 shows a dock and ship listed to 5 degrees. The water is allowed to travel freely from side to side. The position of the centre of gravity and the centre of buoyancy shows that it would go further over before coming to rest.

The same applies to Fig. 288, only in a less degree, as by the introduction of one

bulkhead, dividing the space into two compartments, the water can only travel between the centre and the sides.

1 Engineering, vol. xlvi. p. 136.

2 Transactions of the Institute of Mechanical Engineers, 1863.

- Engineering, vol.xlvi.p. 136; and Transactions of the North-Eust Coast Instituto of Engineers and Shipluilders. 
Fig. 289 shows the dock and the centre of buoyancy in the same position as in Figs. 287 and 288, but the centre of gravity is on the stable side, and if any internal or external force was able to list the dock so far over it would right itself.

The relative initial stability of the three Figs. 287, 288, 289, exclusive of the stability of the ship, and purely in consequence of their internal construction, is therefore 1,4 , and 49 .

Figs. 412, 413, 414, ${ }^{1}$ show a pontoon dock constructed in accordance with Mr. Alex. Taylor's letters patent for the Tyne Pontoon and Dry Docks Company, Wallsend.

Fig. 290 is a longitudinal view of the pontoon. Fig. 291 is a plan. Fig. 292 is a half cross-section and end view, FiG. 200.
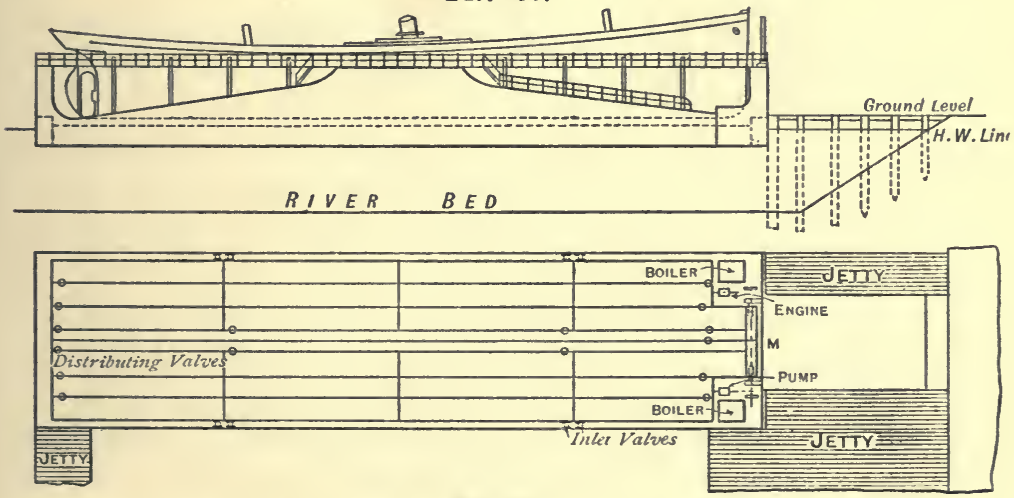

FiG. 291.

showing the keel-blocks supported on three longitudinal girders, $\mathrm{G}, \mathrm{F}$, and $\mathrm{G}^{1}$. These girders are stiffened by intercostal plates, A, on every third frame. Stanchions are fitted to the intermediate frames. The frames throughout are 31 inches from centre to centre. The transverse gusset-plates in the tank $\mathrm{C}$ are on every third frame, but in the tanks D and $\mathrm{E}$ are only on every sixth frame.

The frames between the gusset-plates are fitted with stanchions. The longitudinal water-tight girders are shown by $F, G, H, I, K$. Three transverse bulkheads divide the pontoon tanks into four longitudinal parts, as shown on the plan (Fig. 291), forming altogether twenty-eight separate tanks. The plan also shows that the main tanks terminate some distance

1 Engineering, vol. xlvi. p. 136 ; and Transactions of the North-East Coast Instilute of Engineers and shipbuilders. 
within the ends and sides of the pontoon. This arrangement permits of an all-round internal examination and free communication between the two engine-rooms, when the pontoon is sunk. The outside shell-plates, up to and a little above the tank top, are $\frac{7}{16}$ inch thick. They and the tank top-plates are double riveted in seams and butts throughout.

Two centrifugal pumps, engines, and boilers, are placed in the forward end. The pumps are placed, and draw from the main cross-drain M (Fig. 291), which forms part of the structure, and is in communication with the various tanks adjoining. There is a sluice-valve, $\mathrm{S}$, in the cross-drain in the longitudinal centre line, so that usually the port pump only pumps from

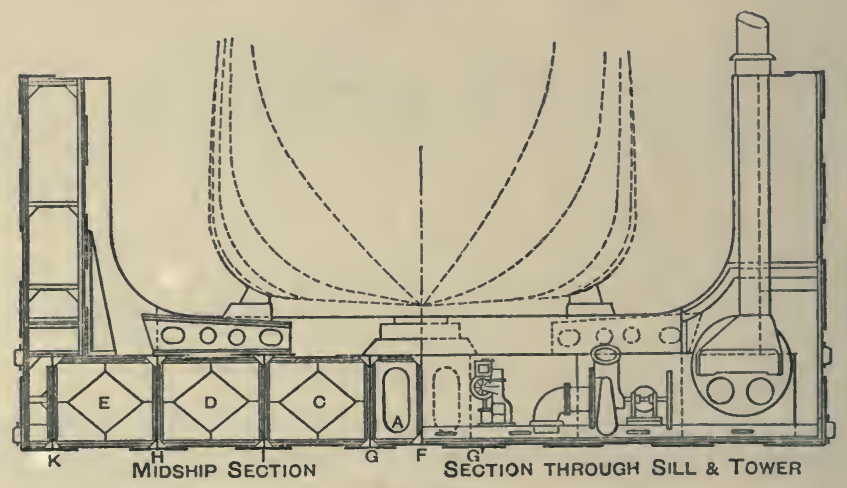

FIG. 202.

the port tanks, and the starboard pump from the starboard tanks.

Before sinking the dock, the distributing valves shown on Fig. 291 are opened, and remain open until the dock is completely raised again. In fact, it would be better not to have these distributing valves, but to draw direct from the end of each tank, and thus each longitudinal set of tanks would be entirely independent of its neighbours. The water coming in or going out is entirely controlled by the admission or exclusion of air from the various tanks; that is, if in lifting the dock it was considered necessary to keep the water in any particular tank, the air-pipe for that tank would be kept shut, and this gives the necessary control over the water. The pumps are run full speed during the lifting of a ship, and the man in charge is on the dock or ship and controls the air-pipes, as above described. There are two donkey pumps and a range 
of piping, by which the tanks can be drained or the dock washed, or ships supplied with water to test tanks, fill boilers, etc.

Some such reasoning as the following led to the sides being made in form as shown by Fig. 290. A ship to be moved into a dry dock or on to a slip must have sufficient stability in herself, or ballast must be added to give the necessary stability before she can be moved; therefore, in this condition she requires no external aid. A pontoon when sunk, ready to receive a ship, must in virtue of its construction have the combined centre of gravity of the structure and contained water some distance below its centre of buoyancy, and consequently it must remain upright, even if totally submerged. Now, as it has been shown that the ship must be stable, and the pontoon has enormous stability, it is evident the pontoon requires no sides above the water to give it stability at the time when it and the ship are combined; but while the water is being pumped out of the pontoon, the combined centre of gravity of the ship, pontoon, and its contained water, will rise, and the combined centre of buoyancy will fall, and therefore the dock must have sides to give stability as it rises, until ultimately the sides are made the full length, and the maximum stability is secured with a minimum of top weight and displacement. The sides being low, allow light and air free access to the ship, and the ship's bottom is thus easily seen and rapidly dried.

At Cartagena, ${ }^{1}$ the arrangement adopted by Mr. Rennie consists of an iron dock 324 feet long by 105 feet wide and a total height of 48 feet outside (Fig. 293). The basement, or lifting chamber, is 11 feet 6 inches deep, and is capable of lifting ships of five to six thousand tons.

The base, or pontoon, is divided longitudinally by a central water-tight bulkhead. Each side is further divided by transverse water-tight bulkheads into ten equal compartments, which are again divided by a bulkhead parallel to the centre one, which, however, is not water-tight, but is perforated so as to admit of a partial flow of water from one side to the other.

The side walls run the whole length of the dock, and are divided by transverse bulkheads similar to those in the basement, and also by horizontal bulkheads, thus separating the side walls

1 M.P.I.C.E., vol, s8xi. p. 302. 
into two parts, the upper serving as permanent air-chambers into which no water is allowed to enter.

The working of the dock is as follows:-Supposing it to be empty, and the floor well above the level of the water, the sluices are gradually opened and the water allowed to flow into the different compartments. The dock will then commence sinking, care being taken by watching the gauges that the supply of water is so regulated that it may sink uniformly and gradually. When the dock is sufficiently deep to take in the vessel, the sluices are closed, and the vessel hauled over the keel-blocks, and the breast and other shores applied. 'The water is then pumped out; thus, for every one ton of water pumped out one

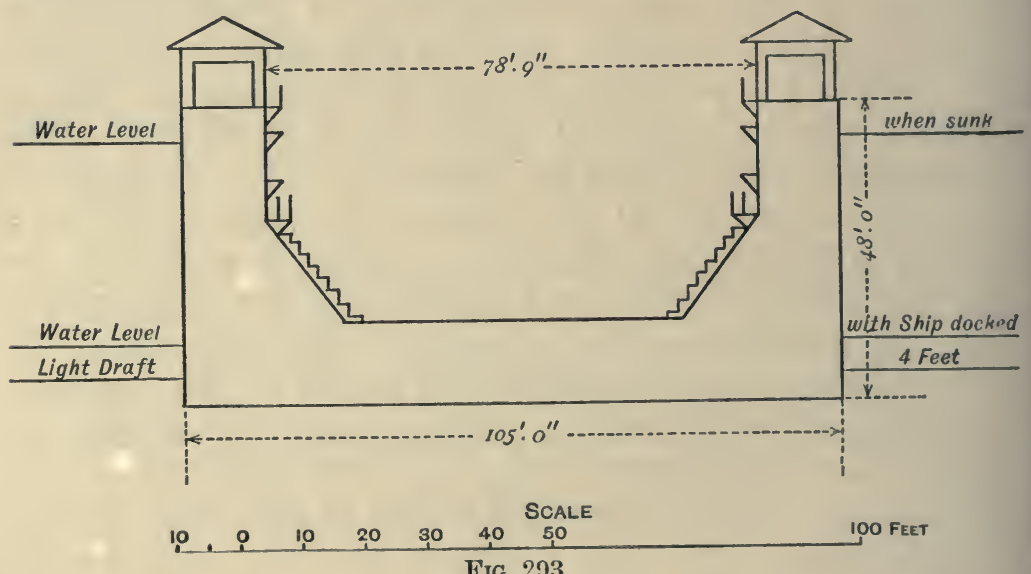

ton of ship and dock is lifted. This operation is continued until the floor of the dock is well out of the water.

This dock partakes of the character of a transporting dock, inasmuch as it is used for removing vessels from the harbour to the slips.

When it is desired to land a vessel, the dock is hauled into a small basin sufficiently large only to contain it, and of a uniform depth of 16 feet 6 inches from the top of the quay.

From the end of this basin there are three lines of horizontal ways (Fig. 294) radiating from the centre from which the end of the basin is described. Each slip is provided with four lines of timber-ways, spaced about 10 feet apart, with keel-blocks to correspond with those on the floating dock.

In transferring a vessel to the slip the dock is Hoated into 


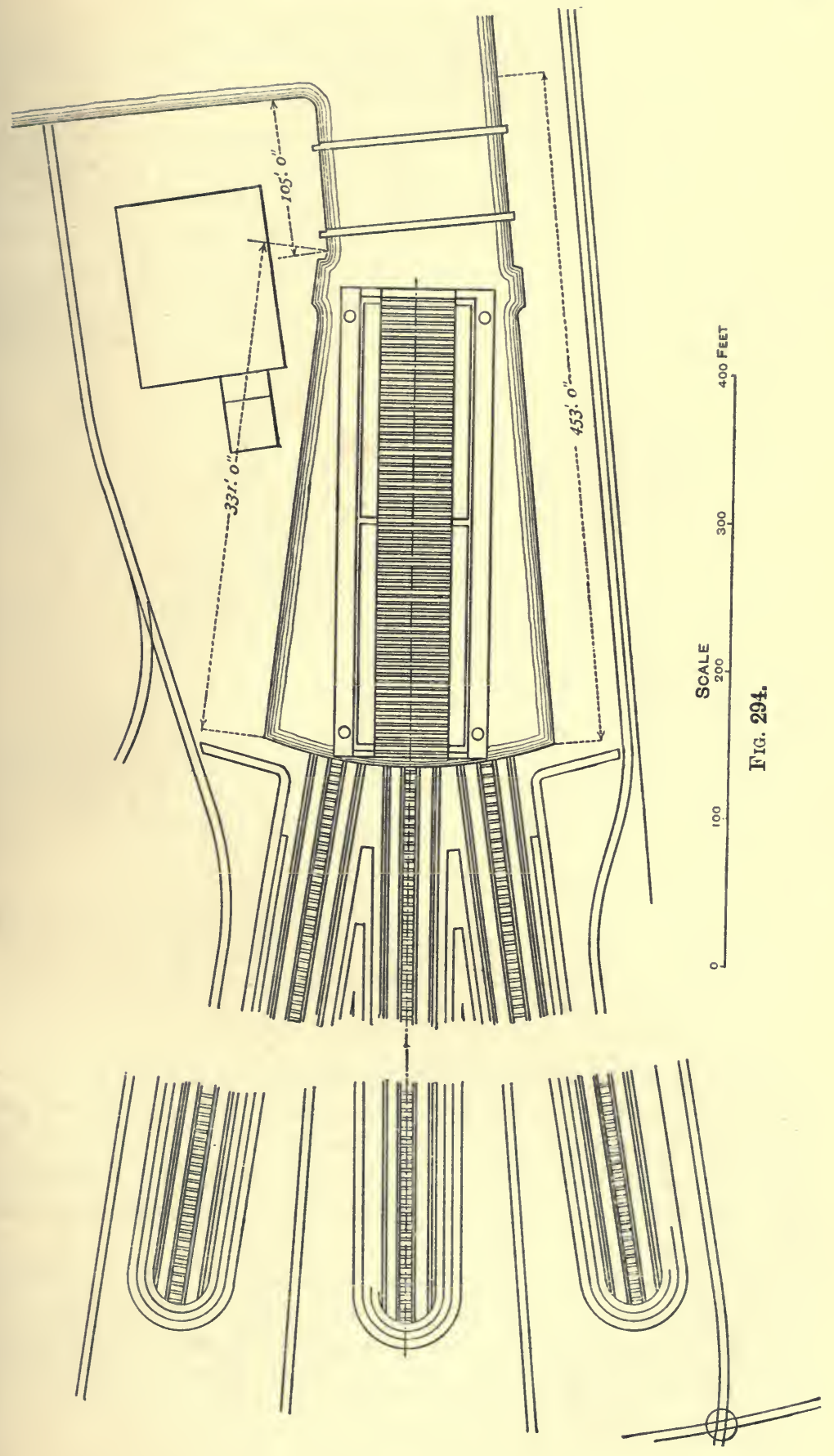


the basin and grounded. The timber-ways on the slip being then in exact line and level with those on the dock, the vessel can be hauled on shore by hydraulic power.

The entrance to the basin is closed when required by a floating caisson, so that when pumped out it can be utilized as a dry dock for effecting repairs to the floating dock.

Off-shore Floating Dock. -This type of dock (Fig. 295), used for lifting purposes only, is suitable for any sheltered position.

It is similar in all essential particulars, as regards construction, to the depositing dock, except that instead of being pro-

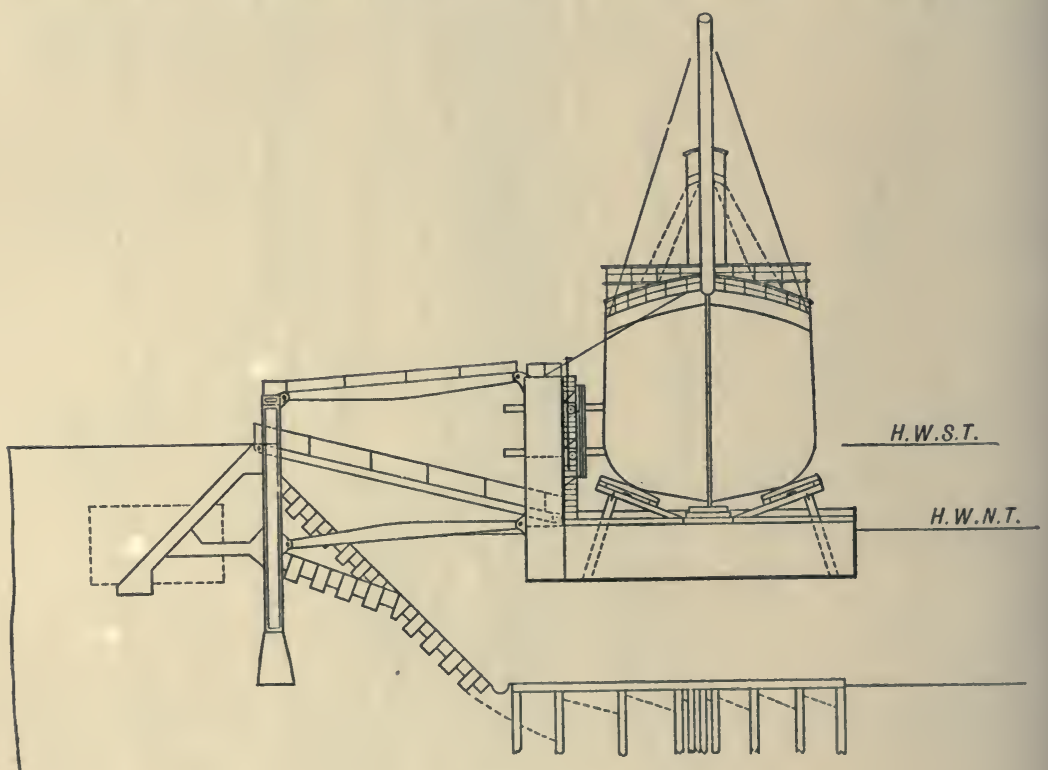

Fig. 295.

vided with a balancing or outrigger pontoon it is kept in a horizontal position during the rise and fall of the water, and its stability ensured during the operation of raising or lowering by parallel-motion booms connected to the vertical side of the dock and to vertical columns erected on shore. The arrangement of these booms is shown by Fig. 295.

Depositing Dock. - This class of dock consists of a rectangular box side, divided into separate water-tight compartments, to which are attached a series of pontoons forming the bottom. These pontoons are firmly connected at one end to the vertical 
side, but are perfectly free at the other. Each pontoon is divided into several compartments by means of internal bulkheads, some of which are permanently closed so that it is impossible to sink the dock. Each compartment is fitted with independent pipe connections with the pumps which are placed in wells close to the bottom of the vertical side, and worked by suitable engines placed on an engine-deck.

On the other side of the vertical member is attached a broad, shallow pontoon, the chief function of which is to keep the dock horizontal and to ensure its stability during the operations of raising or lowering a vessel. It forms also a very convenient working platform and store for spare blocks. This pontoon is also divided into several water-tight compartments, and is ballasted so as to always be immersed to half its depth. It is attached to the vertical side in such a way that it always floats on the surface, whatever may be the position of the dock.

Access to the pontoons forming the bottom is gained by means of gangways passing through the vertical side, and to the upper deck by self-adjustable ladders.

The special feature of this form of dock, and from which it takes its name, is that it is capable of depositing a vessel on staging provided for the purpose in any convenient position. One lifting dock may therefore be made to serve a large number of vessels, its usefulness, in a suitable position, being limited only by the length of staging provided.

The staging is formed of piers constructed of parallel rows of vertical piles of iron or wood, capped by horizontal timbers and platforms to carry the keel- and bilge-blocks. These piers, which are erected at right angles to the shore line, are generally from 4 to 5 feet wide, and spaced from 12 to 15 feet apart in the clear.

In docking a ship, the pontoons and vertical side are lowered to the necessary depth by admitting water. The vessel is then brought over the keel-blocks and centred by means of movable side shores, which are placed a little above the water-line and controlled from the upper deck. Sufficient water is then pumped out to cause the vessel to take a bearing on the keel-blocks. The bilge-blocks are then drawn in by means of chains worked from the upper deck. Pumping is then continued until the vessel is raised clear of the water.

To deposit a vessel, the dock is brought up to the timber 
staging and the pontoons passed between the piers with the keel of the vessel clear above the middle line of blocks on the staging, the outer or bilge-blocks being temporarily turned down. As soon as the vessel is over the keel-blocks, the dock is slightly

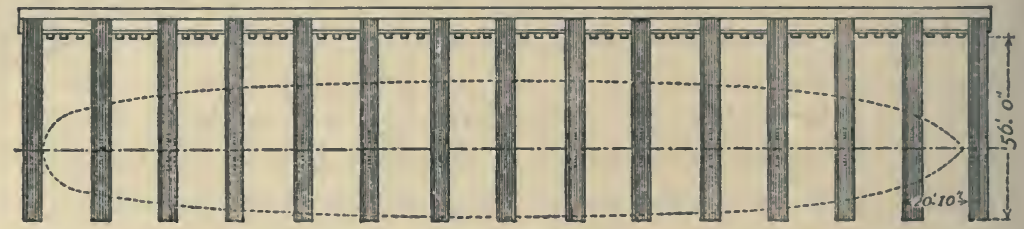

PLAN OF Gridiron Staging

FIG. 296.

lowered to allow the ship to take a bearing on them; the bilgeblocks are then adjusted, and the dock is lowered clear of the vessel and withdrawn. A slight variation in the level of the

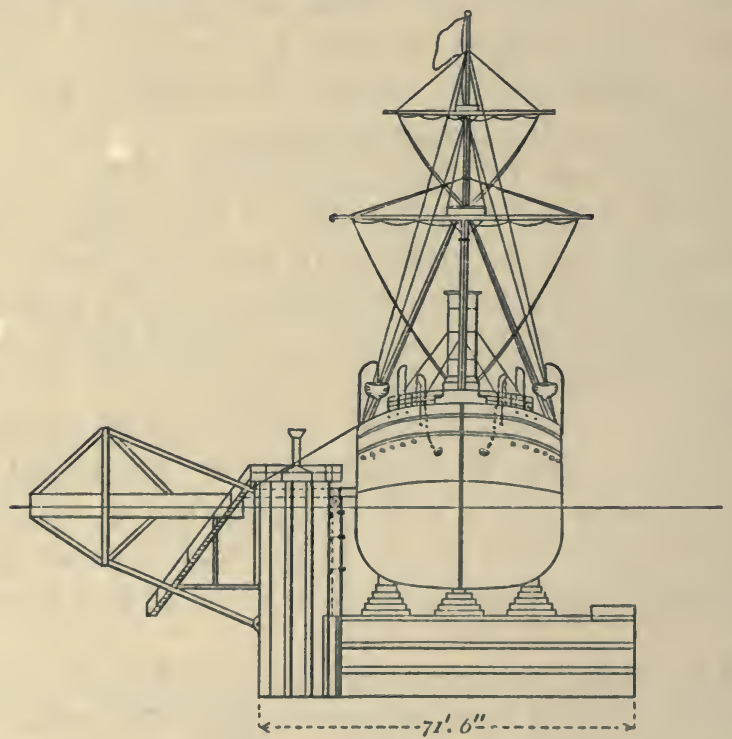

FIG. 297.

water can always be accommodated by the use of more or less blocking.

The operation of lowering the vessel from the staging into the water is the exact reverse of that of depositing.

Figs. 296 to 299 show the general arrangement of a depositing dock constructed at Barrow-in-Furness, by Messis. Clark and Standfield. 
Double-power Dock. ${ }^{1}$-For the double-power dock designed by Messrs. Standfield and Clark, two special features are claimed. The first is that of utilizing the buoyancy of its sides as well as

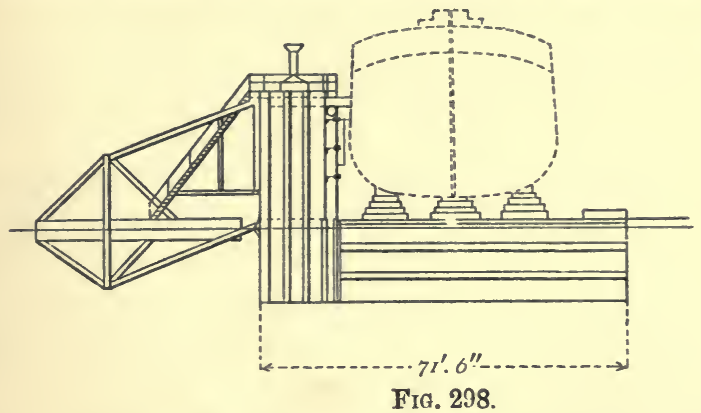

that of the bottom, by which a much less quantity of material is required for doing the same work as an ordinary floating dock.

The second feature is that it is able to dock itself, so that every part can be examined, cleaned, and painted, the life of the dock being thus considerably prolonged.

In an ordinary float- $\begin{gathered}\text { Floating } \\ \text { Spring Boom }\end{gathered}$ ing dock the sides add to the weight to be lifted, and, as far as the power of the dock is concerned, they represent useless cost. All the work has to

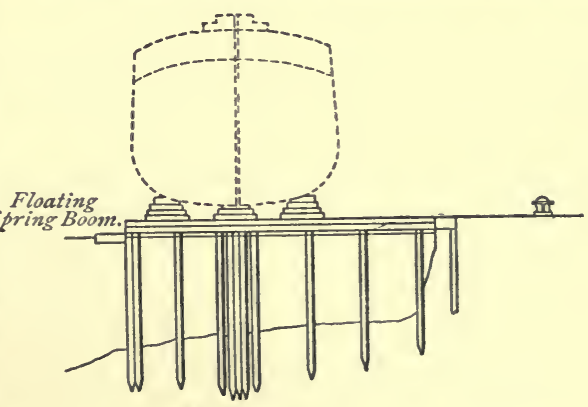

FIG. 299. be done by the bottom or pontoon, which must therefore possess sufficient buoyancy to lift the two sides of the dock as well as the vessel. If, therefore, arrangements be made to avoid the necessity of lifting the weight of the two sides, a great economy is effected either by using a smaller pontoon or lifting a heavier vessel for any given weight of material in the dock. Moreover, if means be taken for making the buoyancy of the two sides assist the pontoon, a still greater economy will be effected in either of these directions.

It is claimed that this economy has been effected in the 1 Trans. Society of Engineers, 1881, p. 90 ; Engineering, 1886, p. 396. 
design of the double-power dock of which Fig. 300 is a side elevation, showing a heavy vessel docked.

The sides marked $A$ are arranged to slide up and down between the fixed corners, B. The part marked $\mathrm{C}$ is the pontoon. When the sides are secured in the usual position, the appearance of the dock is similar to an ordinary floating dock, and it is lowered in the usual way to receive a vessel.

The vessel having been secured by shores or sliding bilgeblocks, it is raised as far as possible by pumping out the pontoon; the sides are then lowered one at a time by allowing water to enter them, and are secured in their new position, in which they have at least 5 feet freeboard. They are then pumped out, thus adding their lifting power to that of the pontoon; the vessel is thereby raised (as shown in Fig. 300), the buoyancy of every part of the dock except the four fixed corners having assisted in

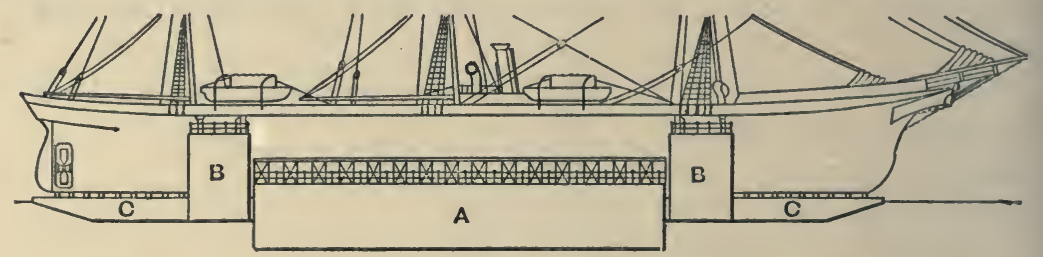

Fig. 300.

the operation of lifting. These corners, which have a freeboard of 5 feet, are divided into water-tight compartments.

The ends of the pontoon are pointed, so that the lifting power may be exerted under the heaviest part of a vessel.

On the pontoon are built strong upright frames, every 6 feet apart; these are used for supporting the shores to the vessel, and also as guides to the sliding sides.

At the first glance, it may perhaps appear that lowering one of the sides while a vessel is on the dock would dangerously affect the stability; but that this quality is always ample will be evident when it is remembered that the actual stability is due to the fact of the vessel and the other secured side of the dock being practically in rigid connection, and really forming one structure, with a breadth about twice that of the vessel.

Any movement towards either side is immediately resisted by immersing the vessel to a greater depth, and by raising the fixed side out of the water to a corresponding extent, or vice $v e r s \hat{a}$, the centre of gravity lying between the secured side and 
the vessel. At the time the side is lowered, the vessel, being only half out of the water, has nearly the same stability as when afloat, and any listing movement causes nearly the same displacement, bringing into play nearly as much righting power as if she were floating at her light water line. The sides of the dock are successively lowered and again secured long before the bilges of the vessel are raised out of the water, so that at the moment when the vessel ceases to add stability to the dock the stability is more than ample, being that due to the two sides in combination.

As already mentioned, this dock can readily dock itself on an even keel, without being taken apart or removed from its moor-

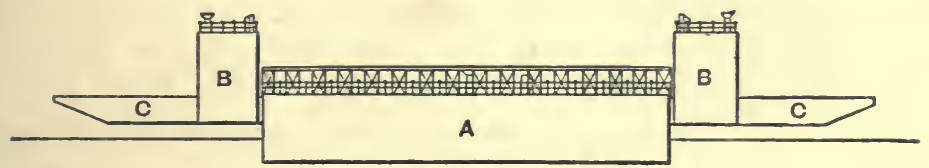

FIG. 301 .

ings; even the under side of the pontoon can be raised several feet clear of the water for examination and cleaning. To do this, the sides are lowered until the decks are level with the pontoon; they are then secured and pumped out, thus raising the pontoon and the fixed corners well out of the water, as shown in Fig. 301, leaving ample space for a boat or raft to pass under. Similarly, when the sides have been secured in

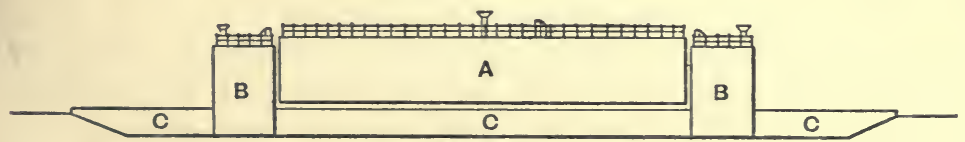

Fig. 302.

their highest position, and the pontoon has been pumped out, the bottom of the sides will be raised clear of the water, as shown by Fig. 302.

Bermuda Floating Dock.-This dock is an example of the round-bottom type, closed at either end by caissons, and has the following dimensions :-

$\begin{array}{lcccccccc}\text { Length over all } & \ldots & \ldots & \ldots & \ldots & \ldots & \ldots & \ldots & 381 \\ \text { Length between caissons } & \ldots & \ldots & \ldots & \ldots & \ldots & 330 \\ \text { Breadth over all } & \ldots & \ldots & \ldots & \ldots & \ldots & \ldots & \ldots & 124 \\ \text { Breadth insido } & \ldots & \ldots & \ldots & \ldots & \ldots & \ldots & \ldots & 84 \\ \text { Depth over all } & \ldots & \ldots & \ldots & \ldots & \ldots & \ldots & \ldots & 72 \\ & & & & & & & & \text { X }\end{array}$ 
The dock is divided longitudinally into eight water-tight compartments on each side of the keel, and each of these is again divided into three smaller compartments, not water-tight.

Transversely it is divided into three compartments on each side of the keel, termed respectively the load-chamber, the balance-chamber, and the air-chamber, each being water-tight and distinct from each other.

The dock, when not in use, has its chambers empty with the exception of the air-chamber, in which a quantity of water is always kept for supplying the pumps for filling the loadchambers when required.

The process of docking is as follows:-The load-chambers are first filled (Fig. 303) by the pumps driven by engines fitted on the top of the dock sides, the water being taken from the air-chambers. After this has been done, valves fitted in the lower part of the balance-chamber, and communicating with the sea, are opened and the chambers filled (Fig. 303); this operation sinking the dock to such a depth that, by opening valves fitted in the caisson, water can be run into the dock in order to bring the water inside up to the level of the outside water, when the caissons can be taken out, there being then a depth of 27 feet of water on the blocks.

The ship having been brought over the blocks, the water in the load-chambers is allowed to run out, and the balancechambers partly emptied, if required, as shown by Fig. 304 . The ship is then breast shored, and the caissons put in place, after which the water remaining in the dock is run into the air-chambers, as shown by Fig. 305, by means of valves fitted in the floor. In this state the dock remains until the vessel is ready for undocking.

Should the vessel not be exactly on the centre of the blocks, the dock is brought to a perpendicular position by letting a portion of the water out of the balance-chamber on one side or the other as the case may require.

To undock the vessel, water is run into the dock through the valves in the caisson, and the balance-chambers filled up; this brings the dock into the position shown by Fig. 306 with the ship afloat; the caissons are then removed, when the vessel may be undocked.

To render the dock again ready for use, the water in the air-chambers is pumped into the load-chambers and run into 
the sea, in order to allow the dock to be emptied into the airchambers.

Fig. 307 shows the position of the dock when heeled over in order that the bottom may be cleaned or repaired.

In docking small vessels, the dock has sufficient buoyancy to lift them quite out of the water, when the caissons are not roquired.

Hydraulic Lifting-Dock.-The following extract, taken from

Fra. 303.
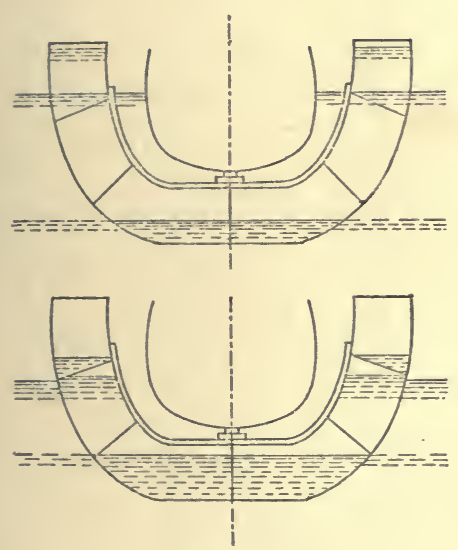

FIG. 305.
FIG. 304.
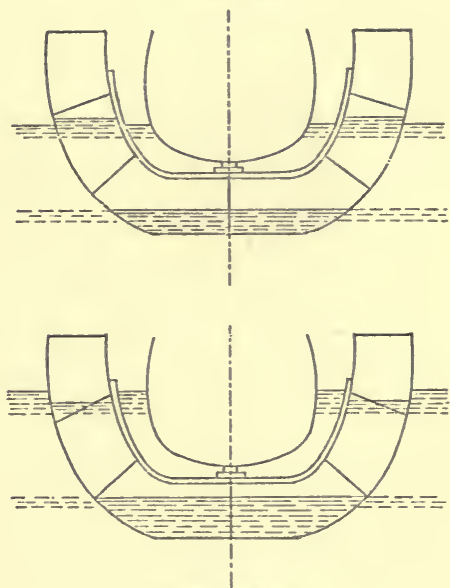

FIG. 306 .

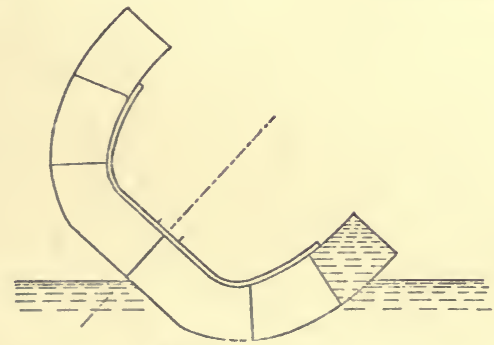

Fig. 307.

a paper by Mr. E. Clark,, on the hydraulic-lift graving dock erected at the Victoria Docks, London, gives a very clear description of this class of dock (Figs. 308 to 311).

"The lift is a direct mechanical appliance for raising the vessel by means of hydraulic presses. It consists of two rows of cast-iron columns, each 5 feet in diameter at the base, and

1 M.P.I.C.E., viol. xxv. p. 292. 
308 NOTES ON DOCKS AND DOCK CONSTRUCTION.

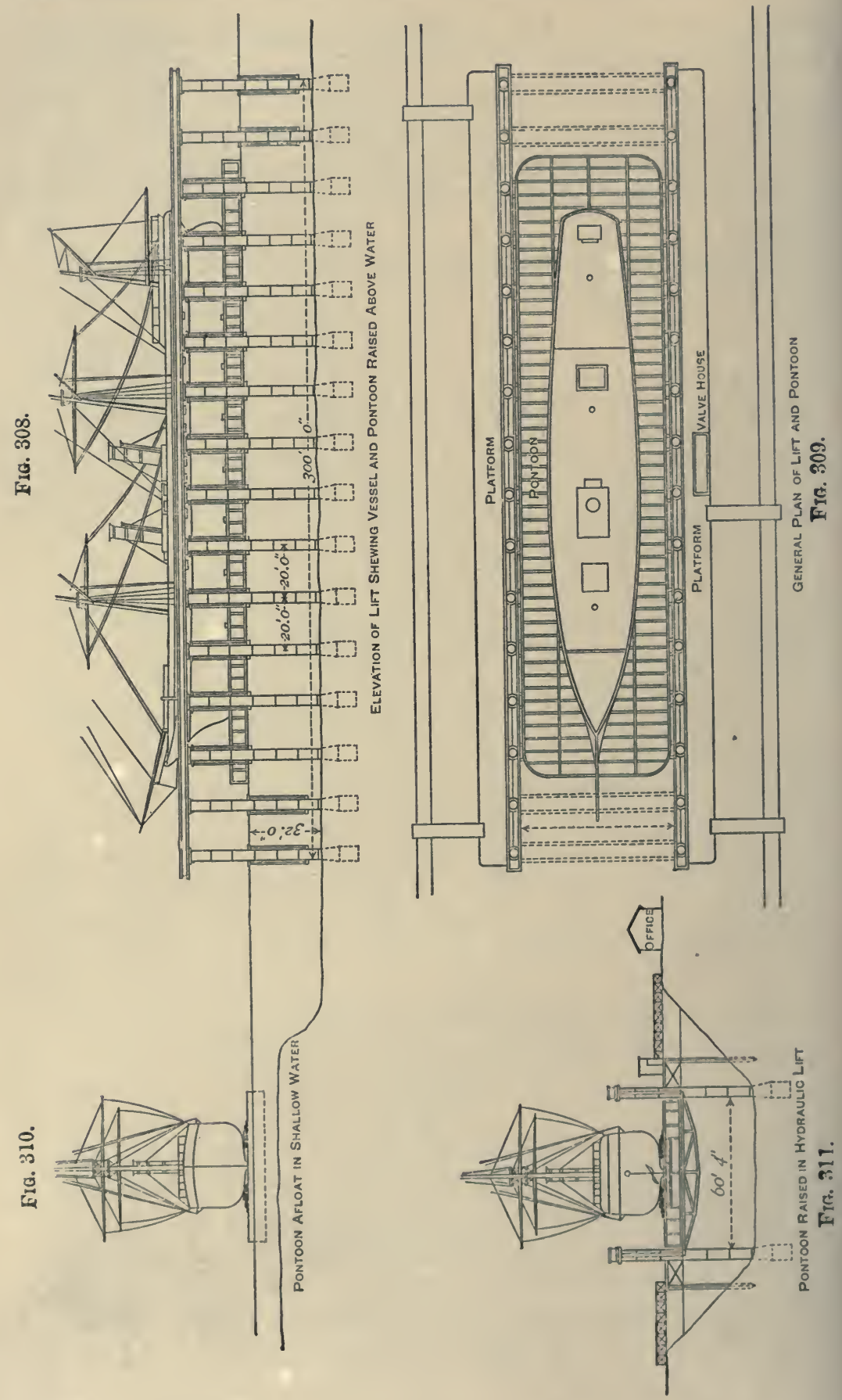


4 feet in diameter above the ground level, and sunk 12 feet in the ground. The clear space between the two rows is 60 feet, and the columns are 20 feet apart from centre to centre, and are placed on each side of the excavated lift-pit in about 27 feet of water. There are sixteen columns in each row, giving a length of 310 feet to the dock, but as vessels may overhang at each end, there is a practical working length of 350 feet. The columns were sunk in the usual manner. When the requisite depth was obtained, the base was filled with concrete, and covered with a layer of 2 -inch planks, to act as a cushion for the cast-iron seat on which the press rests. The columns support no weight, but act solely as guides for the cross-heads of the presses, which move in slots reaching from the top of the presses (just clear of high-water) to the top of the columns. The column is covered by a cap, and each row is firmly connected together at the top by a wrought-iron framed platform running from end to end of the dock on each side. This platform forms a convenient permanent scaffold for raising the rams. A scale is printed on each column to register the motion of the cross-heads while rising or falling.

"The presses or girders are arranged as follows:-Each column encloses a hydraulic ram of 10 inches diameter, with a length of stroke of 25 feet; the top of the press is just clear of the highest water, and it is kept in place by a collar or diaphragm in the column. The rams are solid, and each carries a boiler plate cross-head. From the ends of the cross head are suspended, by wrought-iron bars, two iron girders, each of which extend entirely across the dock to the corresponding column and press on the opposite side. There are thus sixteen pairs of suspended girders lying at the bottom in 27 feet of water when the presses are lowered, but rising above the surface when the presses are raised. They form a large wrought-iron platform which can be raised or lowered at pleasure with a vessel upon it. The sectional area of each ram being 100 circular inches, a pressure of 2 tons per circular inch gives 200 tons as the lifting power of each press, or 6400 tons for the whole lift; but to find the available lifting power, there must be deducted 620 tons, which is the weight of the rams, cross-head, chains, and girders, leaving 5780 tons for the pontoon and vessel. The presses were tested at $2 \frac{1}{2}$ tons per circular inch. The girders are designed for carrying the vessel as a load at 
the centre, although the load is distributed by the pontoon and the wide base uscd for the blocks. The water is forced into the presses immediately beneath the collars at the top, this being an accessible position.

The grouping of the presses was an important consideration. If each press were worked entirely independent of its neighbours, it is evident that precisely the same quantity of water must be thrown into each press to avoid unequal strain. Again, if the whole number were supplied from a common head, the slightest excess of weight at any part of the platform or gridiron would lower that part, the water passing back through the pipes to the presses, where less pressure existed. The same difficulty would be experienced with two groups, however arranged. Stability is, however, secured by arranging the presses in three groups, the whole number occupying both sides of one half the length of the lift from one group consisting of sixteen presses. The remaining eight presses on one side form a second group, and the opposite eight form the third group.

"The presses in each group are all connected, so that perfect uniformity of pressure is secured in each as regards the individual presses, while the three groups are so arranged that their centres of action form a tripod, and may be raised or lowered without regard to the other two, by the most simple manipulation. The pontoon can be either maintained perfectly level, or any inclination can be given to it that may be desired.

"Any pair of presses may be instantly cut off in the valveroom by means of a plug, during the operation of lifting, without interrupting the process. No delay, therefore, arises from the failure of a collar or pipe, and even should a press burst, which appears an impossible contingency, the water can only escape slowly through the half-inch pipe which feeds it, and by opening the escape-valves in the other groups, vessels partially raised descend slowly and steadily into the water.

"The force-pumps are $1 \frac{7}{8} \mathrm{inch}$ in diameter. There are twelve pumps worked by direct action by a 50 horse-power engine; six of these pumps are used for the large group, and three puinps for each of the smaller groups. The power, when required, is increased by cutting off one or more of the pumps.

"The raising of a vessel occupies about twenty-five minutes. During the operation, the engine continues to pump, and the 
valveman throws the water into either group or to waste at pleasure.

"The pontoons are not essential for raising or docking a single vessel, for it is evident that the lift as described is all that is required for that purpose. The girders might be connected together by other longitudinal girders, so as to form a sufficiently rigid platform, or the whole might be formed into a pontoon which would support a vessel after it was raised. Such an arrangement would be more economical and convenient than any ordinary dock, but it would accommodate only a single vessel, whereas, by the use of separate pontoons, an indefinite number of vessels may be placed afloat, whilst the most costly part of the system remains constantly available.

"The following is the arrangement adopted:-An open pontoon, proportioned to the size of the vessel to be docked is selected. Keel-blocks and sliding bilge-blocks adapted to her shape form part of the pontoon, which is placed on the girders, and sunk with them to the bottom of the dock. The vessel is brought between the columns, and moored securely over the centre of the pontoon. By lifting the girders, the keel-blocks are first brought to bear under the keel of the vessel, the side blocks are then hauled in by chains laid for the purpose on each side of the dock, and the gridiron and the pontoon, with the vessel upon it, are then all raised by the presses clear of the water.

The pontoon is provided with valves in the bottom, and thus empties itself of water. The valves are closed, and the girders again lowered to the bottom, but the pontoon with the vessel upon it remains afloat.

The number of vessels that can be thus docked is limited only by the number of pontoons, each pontoon constituting a separate and independent dock. The pontoons, which are all about 58 feet wide, vary in length and depth, according to the class of vessel intended to be docked, and are rectangular in form and open decked. The sides are vertical, and are strengthened longitudinally and transversely by wrought-iron girders, running from side to side and from end to end, and thus forming a series of rectangular divisions. The pontoons are divided into water-tight compartments, each provided with a circular valve in the bottom closed by a screw shaft. 


\section{CHAPTER X.}

Slipways-Advantages and Disadvantages-Inclination of Ways-Methods of constructing Fuundations-Slipways of ordinary construction-Modo of workingSlipways to accommodate more than cne Vessel-Hydraulic Hauling GearWire-rope Haulage-Stress in hauling-Resistance on sliding SlipwaysBroadside Slipways.

A SLIP is an arrangement by which ships can be hauled up on shore, clear of the water, by mechanical means.

Choice may be made between two systems. In one, a car or cradle, moving on a number of rollers or wheels, is employed, and in the other a sledge, running on well-greased ways, is used. In the first, the friction to be overcome is a rolling one, and in the second a sliding one.

The first of these systems is the one generally adopted, and has many advantages. The machinery, hauling appliances, and cradle may be lighter, and the wear of the working surfaces is less.

The selection of a slipway in preference to a dry dock will depend upon many considerations, amongst which may be mentioned the size of ships to be lifted, physical characteristics of the site, cost, nature of the strata, direction and strength of currents.

A slipway consists of a foundation, the nature of which will depend upon the special conditions appertaining to the locality. A platform or roadway, generally of timber, to carry the sliding ways or the rails. A carriage or cradle provided with sledgerunners, or with wheels or rollers, and with an arrangement of movable bilge-blocks for supporting the vessel; and, lastly, the hauling machinery whereby the ship is hauled above the water level.

Some of the advantages attaching to a slipway when required for ships of moderate tonnage are that the first cost is comparatively small. When hauled up, a ship can be readily 
exannined, and full advantage taken of daylight, which in winter-time is of some importance. There being perfect ventilation all round, a ship's sides are soon dry.

Amongst the disadvantages to be taken into consideration are, the wear and tear on the carriage, road, and hauling-gear is considerable; and when the road-timbers project far into the water, they are very liable to injury from passing vessels.

Slipways which project far into the channel beyond lowwater mark may deflect the current, and thereby lead to the formation of shoals to the detriment of navigation.

An objection to the adoption of a slipway for ships of great tonnage would be the great length required under water in any locality where the rise and fall of tide is not considerable. This objection would have still greater force where the range of tide is practically nil, or where it might be necessary to take up a ship at dead low water.

In some localities, such as on the shores of narrow rivers, slips arranged for hauling up ships of moderate dimensions, broadside on, may be adopted with advantage. ${ }^{1}$

For long ships, steamers especially, the objections to a slip appear to be serious, inasmuch as the head would be fixed, and begin to lift whilst the remainder of the vessel would be more or less afloat, and the hauling would continue for some time before the whole length would be taken up and be supported by the cradles. In the mean time, the vessel would be subjected to very serious strains.

For the purpose of storing small vessels, such as gunboats, torpedo-boats, steam-launches, or yachts, which could be more efficiently examined and kept in a better state of repair on shore than afloat, slipways are well adapted. The arrangements should be such that a large storage area may be served by one slipway, so that the cradle, after drawing up and depositing one vessel, may be speedily returned for another.

The inclination of the ways can generally be determined at once by a consideration of the amount and value of land available, by the depth of water it is necessary to provide over the carriage or cradle when at its lowest position, and by the natural slope of the ground.

As a rule, gradients of 1 in 13 to 1 in 22 have been adopted; 1 in 19 being a suitable slope for a large slipway; ${ }^{2}$ but these IM.P.I.C.E., vol. Isxii. p. 157.

I Ibid.s. p. 137. 
figures by no means form the limits, as it is obvious that no special engineering difficulties attend the introduction of greater or less inclination.

The character of the foundation to be adopted will depend upon the nature of the ground; a point of great importance to be observed being that it should be perfectly rigid, and of uniform stability throughout.

Messrs. Lightfoot and Thompson remark ${ }^{1}$ that piles should never be resorted to except in cases where they are absolutely necessary, and even then only with great caution, unless the whole length of way is to be piled.

When part of the way is supported on piles, and part on the natural ground, a difficulty is very likely to arise at the junction; for the ground being more or less yielding, the cradle, when passing into the more rigid piled portion, is subjected to excessive local stresses which may probably cause breakage of rollers, carriage, or rails. What is to be aimed at is, to have a uniform support for the ways throughout their entire length. Where the foundation of the ground varies, the desired uniformity may be obtained by excavating the defective portions, and filling in with suitable material.

In order to obtain a sufficient depth of water over the cradle when run down, it is necessary to carry the ways a considerable distance into the water. For this purpose, divers must be employed to a great extent, except in situations where the range of tide is such as to admit of the lower portion of the slipway being constructed during low water.

When it is necessary to resort to the aid of divers in constructing the lower submerged portions of a slipway, the work is generally carried out in the following manner: ${ }^{2}$ - The railbearers are first of all fastened together on land, on a continuous platform of transverse sleepers. The rails are then fixed, the land end of the bearers being properly scarfed to join the last length laid from the shore. The platform is floated out as nearly as possible over the position it is intended to occupy, the bed having been previously prepared. Guide-piles being driven, the platform is loaded with stones and sunk, after which the ends are keyed to the shore timbers, and the weights which are to be permanently left, are adjusted, sights being taken from time to time from the top of the way to check the 1 II.P.I.C.E., vul. Ixxii. p. 137.

s Ibid., p. 139. 
correctness of the work during sinking, and before it is permanently left.

The following is a method of constructing slip foundations under water, adopted and described by Mr. J. Thompson. ${ }^{1}$ "When the portion of the site below low water had been dredged out to the desired depth, the foundation was made by filling in broken stone of convenient size to near the level of the intended platform, upon which a layer of macadam was placed, bringing the foundation up to the required height.

"As a guide for the accurate execution of this work, a line of piles, A (Fig. 312), was driven on each side of the foundation

FiG. 312.

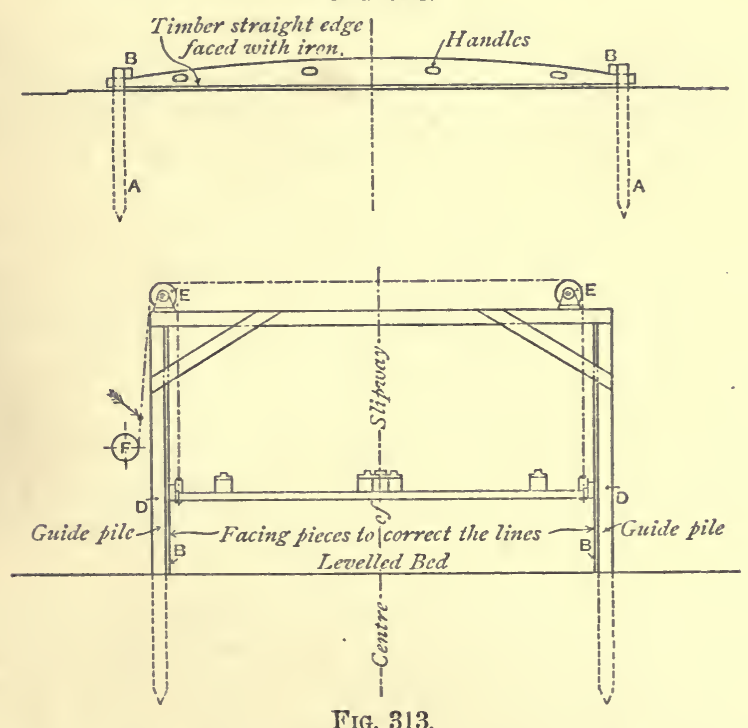

clear of the sides of the timber platform, and to these piles, guide-timbers, B (Fig. 310), were affixed at the required inclination of the slipway, and at the depth of the ends of the straightedge above it.

"The foundation is now ready to be dressed off true by the divers, who, as they frequently had to work in the dark, were provided with iron-faced straight-edges (Fig. 312), made about the same weight as a similar bulk of water, so as to be readily moved. These straight-edges were long enough to reach across the entire foundation, and to slide under the guide-timbers.

1 M.P.I.C.E., vol. Ixsii. p. 167. 
With these the divers were able to dress the macadam to a true face. The foundation having been thus completed, guide-piles, D (Fig. 313), were driven in pairs about 50 to 60 feet from each end of the intended platform near the position in which it had to rest. The platform, which was completely finished on shore, was then launched, and floated down between the guidepiles, DD (Fig. 313).

"Both the guide-piles, D, and the guide-timbers, B, were aligned from the shore without difficulty; but, in order to obtain complete accuracy, corrected facing-pieces were fixed to the guide-piles, and corresponding facings to the platform itself, so as to bring it in absolute contact with its guides. Chains were then attached to each side of the platform, carried over sheaves, E (Fig. 313), at the top of the piles, and being brought over to one side of the slipway, were connected together and attached to a winch, F (Fig. 313), placed on a barge floating alongside.

"The scarf joints at the water-line junction were then placed in position, and watched to see that they were not displaced during the operation of sinking. Large stones or ballast were then spread evenly over the surface of the platform until there was sufficient weight to sink it, when it was carefully lowered by the winch. In this way, any tendency of one side of the platform to sink before the other was prevented, and the platform placed in the position intended with certainty and readiness."

In preparing the foundation for a slipway at Earl's Shipbuilding-yard, at Hull, to accommodate vessels from 2500 to 3000 tons dead weight, Mr. Godfery used whole-timber piles, crosssleepers, and longitudinal bearers 13 inches square throughout. In the centre, two rows of piles were driven, 18 inches apart from centre to centre transversely, and 3 feet centre to centre longitudinally. For the side ways, single piles were driven 6 feet apart centre to centre ; these coming opposite every second row of piles in the centre way. A sleeper 30 feet long was placed transversely on the four piles, and one 6 feet long on the two intermediate piles. Upon these sleepers were fixed tho longitudinal timbers or rail-bearers, securely fixed with oak treenails. The centre timbers were 4 feet 6 inches wide, to take a plate of the same dimensions. The ground for 4 feet below the cross-sleepers was excavated and filled in with rough chalk 
for a width of 15 feet on both sides of the slipway. The whole was then planked over with 3 -inch redwood deals.

For carrying out this work, ${ }^{1}$ a 35 -feet traveller was constructed to span the slipway transversely. Longitudinal timbers were laid upon the prepared ground, having ordinary rails fixed upon them, the diameter of the traveller-wheels being made to suit the inclination of the slipway.

Upon this traveller was placed a steam pile-driver, with 40 -feet ladders, and a ram weighing $21 \mathrm{cwt}$.

The foundation was partly made ground on the foreshore,

Fig. 314.

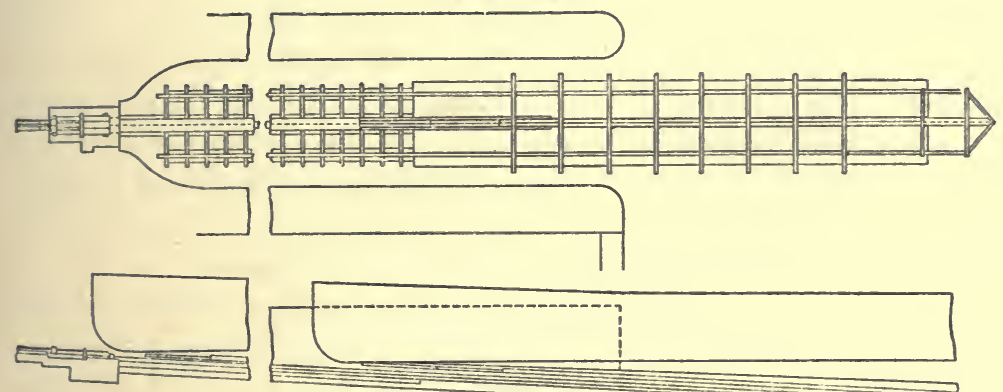

Fig. 315.

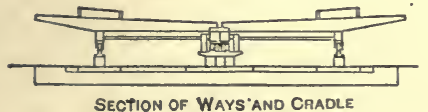

F1G. 316.

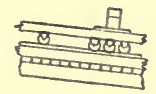

Fig. 317.

and, to obtain the requisite inclination, an average of 10 feet of excavation had to be taken out at low water, and carried to the upper portion of the slip, to form the necessary embankment for the slipway, and also for roadways leading from the ship-yard.

As the tide ebbed, the traveller carrying the pile-driver was allowed to go down by gravitation. The piles were then driven in each successive row, two and four alternately, the engine being worked across the traveller from side to side of the slipway. When the tide flowed, the traveller was hauled above high-water level, and the piling continued at the upper portions of the slipway, until the ebb allowed operations to be again resumed at the lower end. The piles varied from 25 to 50 feet in length, and were driven into the clay until the set at the last blow was 1 inch, with an 8-feet fall of the ram.

M.P.I.C.E., vol. Ixxii. p. 171. 
Sir J. Coode regarded the method of forming a platform, or way, by merely sinking it down into a dredged bed equalized by a layer of rubble stone, as an unsatisfactory engineering operation, and expressed an opinion that where the rise of tide is considerable, and the means exist of laying the full length in the dry, a slipway may be adopted with advantage for vessels of moderate size; but where the range of tide is small, the only thing that would enable an engineer to lay a slipway that would warrant a ship-owner in placing a ship upon it would be to construct a dam, and lay the foundation in the dry. ${ }^{1}$

A slipway $^{2}$ of ordinary construction, designed by Messrs. Lightfoot and Thompson, is shown by Figs. 314 to 317 . The longitudinal timbers, or rail-bearers, are supported by transverse sleepers placed close together. The cluster of timbers forming the centre ways consist of three baulks of whole timbers, all with scarfed and keyed joints. The outer bearers are spaced 25 feet apart centre to centre, and, having but little weight to support and distribute, are composed of single whole timbers.

The rails are of cast iron. The outer ones are single, about 5 inches deep and 5 inches wide. The centre rails are double, of nearly the same sectional area, and are connected to each other by a plate on which is cast a strong rack of about 6 inches pitch, for receiving the holding pawls of the cradle. These pawls are introduced to prevent the cradle running down the way, in the event of accident happening to the hauling-gear.

On each side of the centre rail there are wings cast on to support and guide the hauling-links, which extend nearly to the bottom of the ways.

The rails must be accurately cast and laid on the timbers, with an intervening layer of felt, to ensure a good bed. The joints must be carefully made, and throughout the work it is absolutely essential to avoid all inaccuracies, as they would be certain to lead to breakage of rollers, carriages, or rails, which, although not endangering the safety of the vessel, would, nevertheless, seriously interfere with efficient and economical working

The cradle ${ }^{8}$ is a structure of timber so constructed as to receive and maintain the vessel in very nearly the same trim as that in which she floats. It consists of a strong centre rib built up of several baulks of timber securely bolted together,

'M.P.I.C.E., vol. Ixxii. p. 163.

2 I lid., p. 138.

s Ilid., p. 139. 
forming the rest for the keel-blocks, and of two lighter side ribs corresponding in position with the side-ways.

From the centre rib to each of the sides stretch transverse pieces of wood or iron, carrying sliding bilge-blocks, worked by ropes and gear from the deck of the vessel, or from jetties. The sliding blocks are trimmed with supplementary loose blocks, shaped to suit the size and description of vessel to be hauled up.

The cradle ribs are carried on numerous cast-iron rollers fitted in cast-iron carriages (Figs. 316,317 ); those at the centre being placed as close together as possible, while those for the sides, where the pressure is small, may be placed some distance apart; about ten of the centre carriages are formed to receive the pawls for holding the cradle. It is also usual to provide two or three short, independent cradles, which may be attached to the top of the main cradle, according as the vessel to be repaired is long or short.

The other adjuncts of the cradle are wrought-iron ploughs at the after end of each rib, for removing silt or mud, or any other obstruction that may accumulate on the lower end of the ways; hinged iron rods for guiding the keel of the vessel properly into the centre of the cradle-one pair being placed at the top for the bow, and one pair at the bottom for the stern; also sundry gear for working the bilge-blocks and for lifting and lowering the pawls.

The arrangements for hauling up may consist of hydraulic or steam machinery, or other gear, actuating strong forged-iron rods and endless pitch chains, link chains, or steel-wire ropes.

Whatever form of hauling-gear is adopted, it will generally be of advantage to have a supplementary engine and crab with chain, for traversing the empty cradle quickly up and down, especially in positions where there is likely to be an accumulation of mud at the lower end of the ways, in which case the empty cradle, when run down, would not acquire enough velocity to overcome and remove the obstruction.

To avoid the expense of divers' work, various proposals have been made and carried out; the simplest and usual plan is to make the cradle telescopic-that is, in several divisions attached to each other by sliding lengthening bars-which permit the various sections to close up when the cradle is run down for taking up a vessel, and to open out when the hauling commences. ${ }^{1}$ 
Another plan for shortening the slipway, applicable in situations where there is sufficient range of tide, is to enclose the upper part of the slip within water-tight walls provided with gates, which, being shut at low water, exclude the tide. ${ }^{1}$

Mode of Working. - The method of working a slip will not greatly vary in the different cases; therefore, the following description of the operations of hauling up and launching, given by Messrs. Lightfoot and Thompson, may be taken as generally applicable. "The size ${ }^{2}$ and general description of the vessel to be taken on having been ascertained, the bilge-blocks on the cradle are trimmed to fit the ship as nearly as possible, and the guide-rods and other fittings looked to and put in proper position.

"The cradle is then run down into the water by its own weight, assisted if necessary by a down-hauling chain worked by an independent apparatus at the top, arranged also for quickly drawing up the empty cradle after launching a vessel. The extreme end of the cradle may project 30 to 50 feet over the end of the rails, the main ribs being made strong enough for this purpose. The vessel is then floated into position as accurately as possible, being guided by hawsers manipulated from a jetty or the shore, and also by the guides fixed at the front of the cradle, which are drawn up into a vertical position by ropes, afterwards secured to the vessel. The hauling up then commences, the ship all the time sitting on the keel-blocks placed on the centre rib, and being guided at the stern by the after-guides. At the proper time, the sliding bilge-blocks are drawn in by ropes previously taken up to the jetties, or on board the vessel; the operation thus proceeds until finally the ship is drawn out of the water, safely seated on the cradle, and supported uniformly over the whole length of keel, as well as by the bilge-blocks on each side.

"In launching, the reverse process takes place. The vessel is lowered by the machinery to within a convenient distance of the water; the cradle is then disconnected from the links, and, the holding pawls being raised, is left supported entirely on one special single pawl or dagger, at the top. The dagger is then knocked away by a blow from a hammer, and the cradle with its burden runs down the way until it reaches the water, and the vessel floats off. The empty cradle is drawn up by the 
supplementary hauling-chain, and after trimming, is ready to take on another ship."

Slipway to accommodate more than One Vessel. ${ }^{1}$ - A method by which a slipway can be made available for repairing two or more vessels at one time is called relieving, and is accomplished in the following manner:-The transverse arms of the cradle connecting together the centre and side ribs, and carrying the sliding bilge-blocks, instead of being permanently fixed, are hinged at their outer ends to the side ribs, and are thus capable of being swung round parallel with the side ribs, upon which they rest when in this position. After the vessel to be relieved has been hauled up, strong baulks of timber are placed between each pair of transverse arms to act as bilge-blocks, capable collectively of eventually carrying the whole weight of the vessel. Commencing at the top simultaneously on each side, these new blocks are tightly wedged against the bilge of the vessel, the weight being in this manner relieved from each old bilge-block, and taken by the new ones resting on the ground. All the old blocks are thus relieved and slid out on the arms, the vessel resting on the new blocks and on the keel-blocks, on the cradle. These latter are now relieved by placing under the keel at proper intervals hydraulic presses, connected with the pumps. Water, under pressure, being introduced into these presses, the vessel is raised just sufficient to permit the keelblocks to be knocked out, after which, on exhausting the water from the presses, the ship sinks back, and is entirely carried by the new blocks supported on the ground. The cradle is now clear and relieved from the vessel, and so soon as the hinged transverse arms are swung round into a longitudinal position, can be moved down the ways, and is ready to be used for another vessel.

Another method of relieving (Thomson and Cooper's patent) ${ }^{2}$ is shown by Figs. 318 to 321 . Instead of employing one cradle, two are used, constructed in such a manner that a vessel having been hauled up to a certain point on the main cradle, can be transferred to an auxiliary one, the main cradle being thereby set free to receive another vessel. With this object in view, the main rails of the slipway are constructed in the ordinary manner, and at the ordinary inclination, but of such additional length as may be required for the working of the auxiliary

${ }^{1}$ M.P.I.C.E., vol. Ixvii. p. 141.

2 Ibid., vol. lxii. p. 142. 
322 NOTES ON DOCKS AND DOCK CONSTRUCTION.

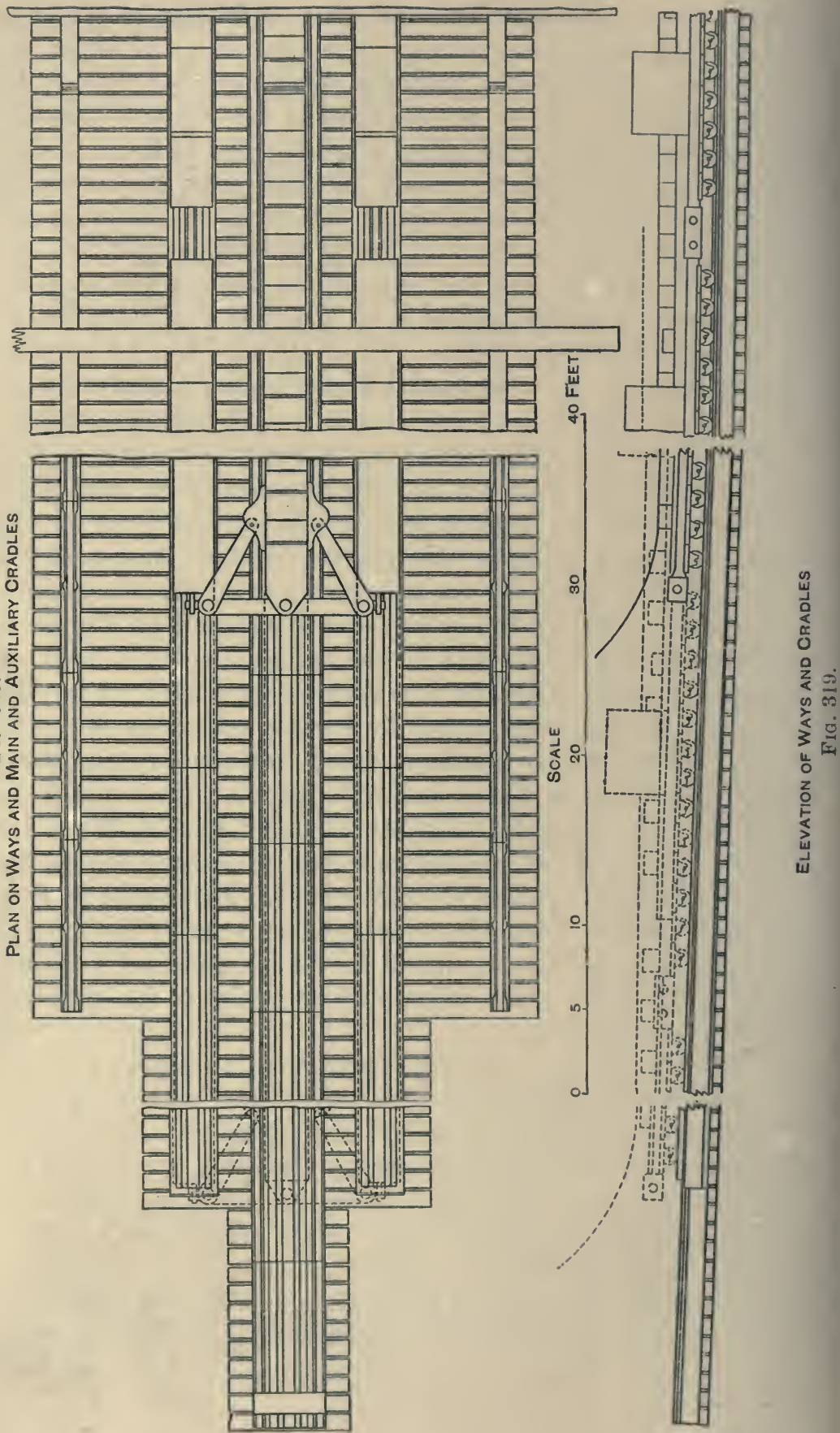


cradle. Alongside the upper portion of the main rails, and parallel with them, is placed a second set of ways, upon which the auxiliary cradle travels. The slope of these rails is greater than that of the main ways, in order that when a vessel has been hauled up until it is over the auxiliary cradle, and new bilgeblocks have been fitted, the hauling-up of the two cradles

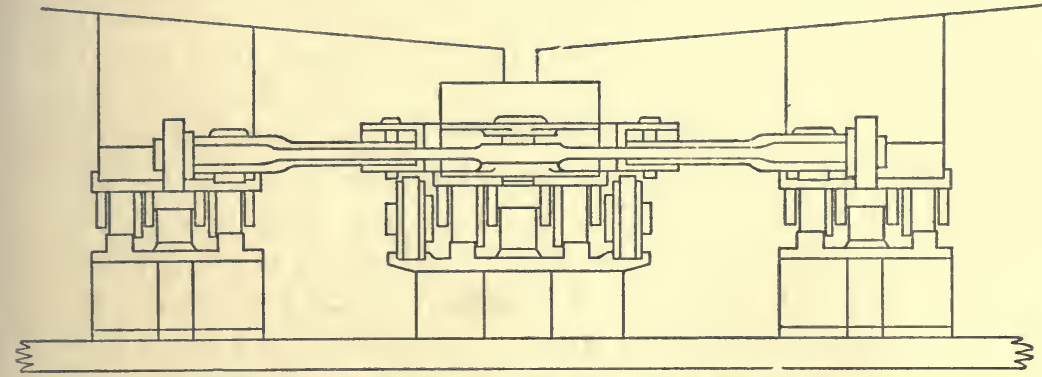

Frg. 320. End View of Cradles 50 feet from top of Slipway.

simultaneously may cause the vessel to be gradually lifted up by the auxiliary cradle from the increased inclination of its rails; so leaving the main cradle free to be lowered down the ways for receiving a second vessel after the transverse arms have been swung round into a longitudinal position.

When the ship is to be launched, the main cradle, with its

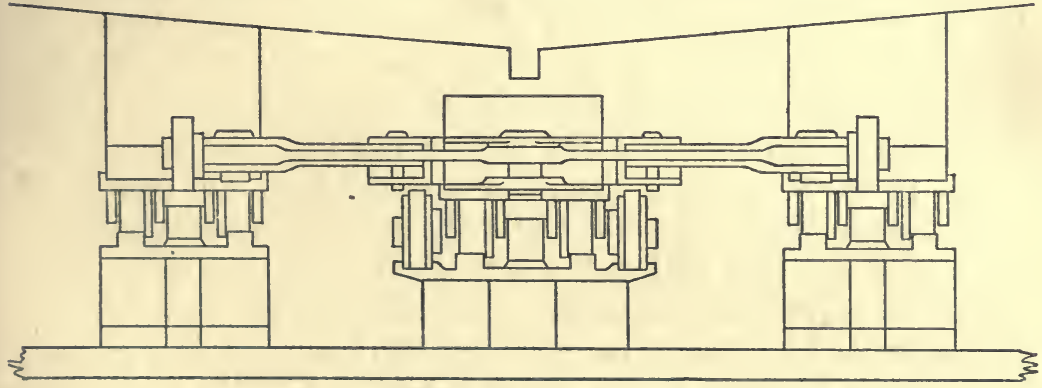

Fig. 321. End view.

arms, swings round, and resting on the side ribs, is hauled up under the vessel, the arms are then put into position and the bilge-blocks run in, and the main and auxiliary cradles simultaneously lowered down the ways. The greater slope of the rails of the auxiliary cradle causes the vessel gradually to approach and seat itself on the resting-blocks of the main cradle, and, the bilge-blocks on the auxiliary cradle being 
removed, the vessel, now supported entirely by the main cradle, is run down the ways and launched.

Hydraulic Hauling-gear. ${ }^{1}$ - The form of hydraulic haulinggear introduced by the late Mr. Morton consists of a directacting single cylinder, with one ram having about 10 feet length of stroke. On the outer end of the ram is a cross-head, and to this cross-head are attached two wrought-iron bars, one bar passing on each side of the cylinder. These two hars are connected at their lower extremities to a second cross-head, to which wrought-iron links for hauling up the cradle are secured. Figs. 322 and 323 show the general arrangement of this gear. In hauling up a vessel, after the ram has made one outward stroke, it is necessary to disconnect and remove one of the links, which are made in length to suit the stroke of the ram. This having been accomplished with the assistance of a small handcrane, the ram is run back by a constantly acting weight, and a new attachment made between the links. The ram then makes another forward stroke, drawing up the cradle another 10 feet, and the process of disconnection and connection is continued until the vessel is hauled up a sufficient distance. With the heaviest vessels, two lines of links are generally used, and two links have therefore to be disconnected and connected at each stroke. The great objection to this system is the delay and labour incurred by the removal of the links after each stroke.

An improved form of hydraulic gear designed by Messrs. Lightfoot and Thompson, with the view of obviating the delay incurred in removing the links, is shown in Figs. 324 and $325^{2}$

In place of working the press directly from the pumps, a small accumulator is introduced for the purpose of accumulating the water pumped, during the act of reversing the rams, and, as the water-pressure is constant, a set of treble-power cylinders, or a cylinder with two or more concentric rams, is used for giving the variable power. A cross-head is actuated by the rams, and is connected with a second tail-cross-head by two forged bars. From this tail-cross-head a double set of links extends nearly to the end of the ways, resting upon the wings cast on the centre rails, and being guarded thereby. To the top cross-head is attached a ram working in a cylinder always open to waterpressure. The action is as follows:-Water from the accumulator having been admitted to one or more of the main hauling-rams,

\footnotetext{
${ }^{\prime}$ M.P.I.C.E., vol. Ixxii. p. 142.
}

I Ilid., p. 143. 
according to the weight and position of the vessel on the ways, the cross-head is pushed up, forcing the ram into the retaining cylinder, and drawing up the links. On reversing the valvelever, the pressure is shut off, and the main cylinders opened to exhaust, so that the constant-pressure ram reverses the stroke, forcing in the main rams and-pushing down the links to the position from which they started. A definite upward and

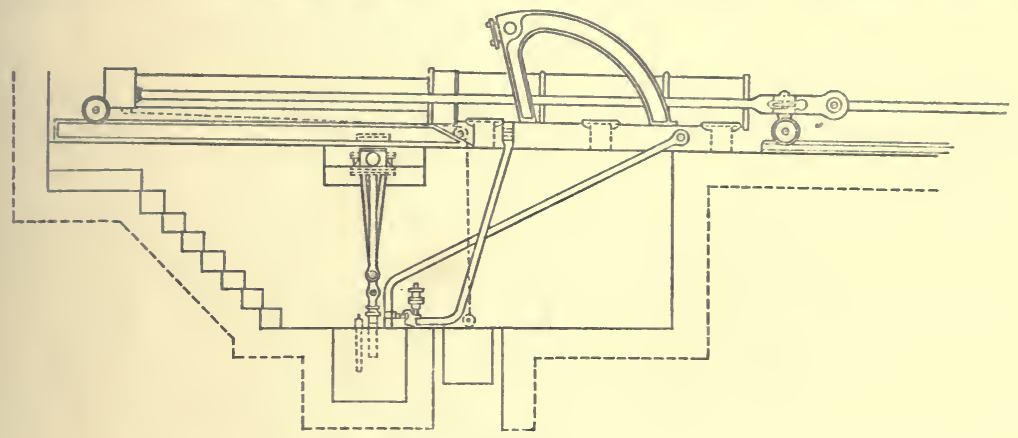

Fig, 322.

downward travel, equal in length to the stroke of the rams, can therefore be given to the links by the forward and backward movement of the hand-lever. The links are jointed together with rectangular flat plates, and as all links and plates are made of equal length, it follows that if suitable pawls are fixed to the cradle, and arranged to gear with the ends of the joint-plates, the cradle will be drawn up at each upward stroke of the rams, while during the downward motion of the links the pawls will slip,

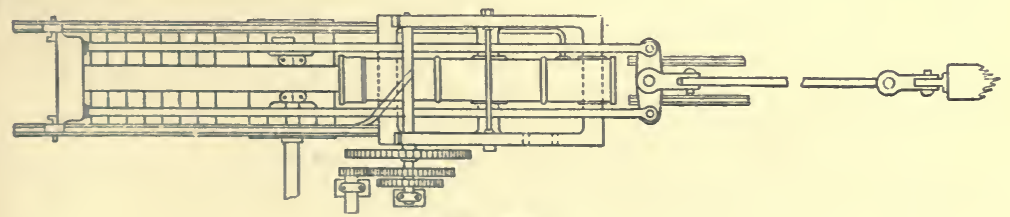

Fig. 323.

the cradle remaining in its highest position, being held by the pawls in gear with the rack cast on the centre line of rails. The hauling-pawls, of which several sets are used, are made of forged iron, secured to the main rib by cast-steel or malleable cast-iron brackets. With this system, no disconnections or removal of links or bars is required. The only loss is the time occupied in the return stroke, which, however, is not great, as, owing to the 
326 NOTES ON DOCKS AND DOCK CONSTRUCTION.
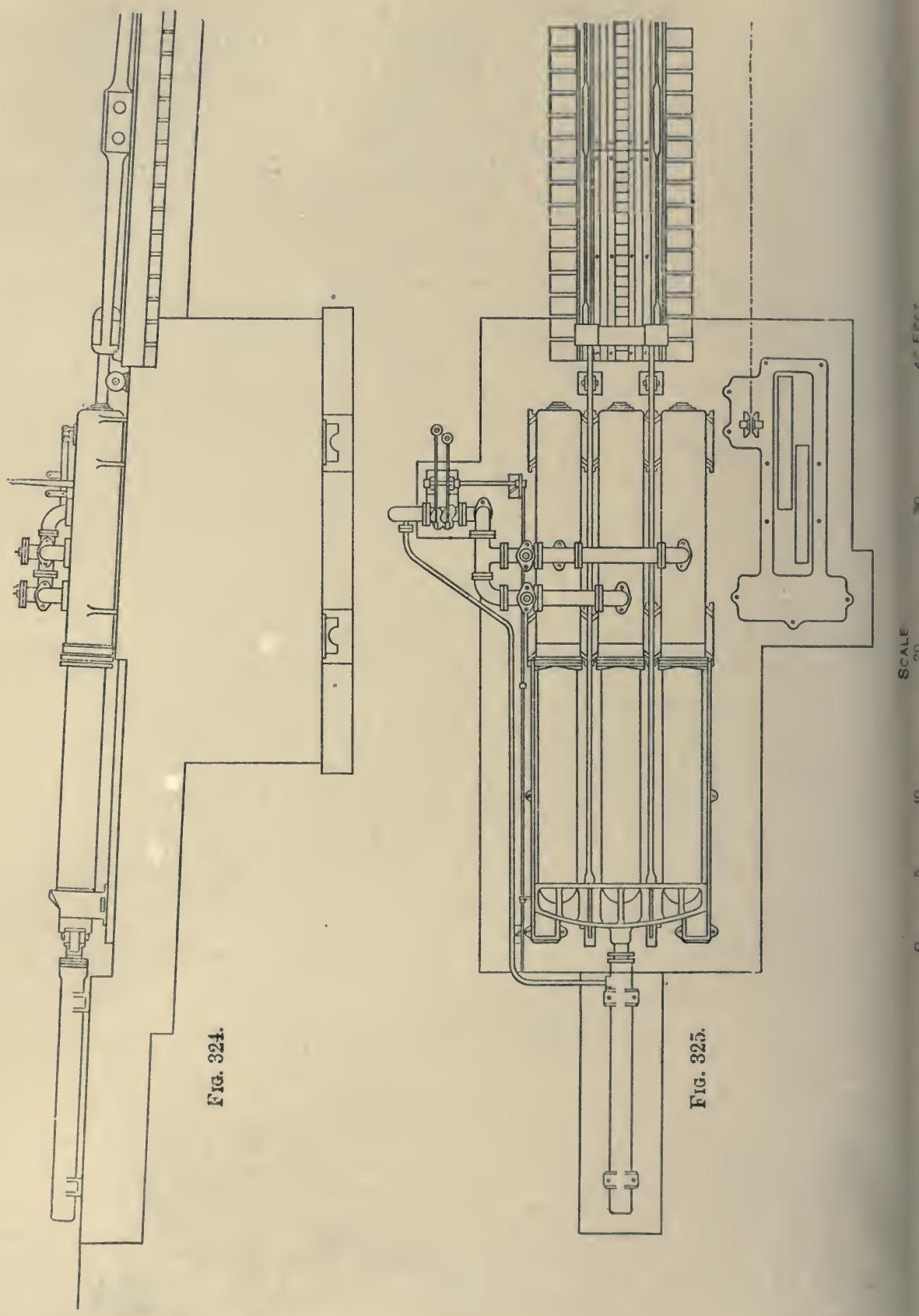
small size of the ram, it is forced out much more rapidly than are the hauling-up rams, the respective areas being approximately 1 to 19. During the short time the links are stationary, that is, at the reversal top and bottom, water under pressure is accumulated, to be given out so soon as the rams are permitted to travel in one direction or the other.

Several modifications of this hauling machinery can be made, all involving the upward and downward movement of the links as described, and in some cases the rams might be worked direct from a set of force-pumps. The accumulation is, however, convenient not only as a means of economizing time, but as a safety-valve to prevent shocks, and a regulator for adjusting the speed of the engine or the working of the pumps according to the demand for water.

Hydraulic hauling-gear, constructed by Messrs. Hayward, Tyler \& Co., consisted of a double set of cylinders and rams. These were so arranged that while one set of cylinders was in upward motion the other was returning. By attaching the hauling-links first to one set of rams and then to the other, the cradle was drawn up by an almost continuous motion. ${ }^{1}$

Wire-rope Haulage. ${ }^{2}$-Messrs. Summers and Day have successfully employed hauling machinery in which an engine working, through gearing, on to a large drum, rolls up a 9-inch wire rope attached to the cradle.

The advantages claimed for this system of haulage for slip. ways are, that it is more rapid in its action, inasmuch as the delay due to the reciprocatory action of the hydraulic ram, by which half the time is lost, and also the loss of time due to fluting the links, is altogether avoided. It is less costly to lay down, and less expensive to work, and can be employed for any size of vessel.

The following description of a set of gearing for working a slipway by wire-rope haulage is given by $\mathrm{Mr}$. T. Summers : ${ }^{3}-$ "The engines which worked the hauling-gear had two cylinders each 10 inches in diameter and 12 inches stroke, fitted with linkmotion for reversing. A worm on the engine crank-shaft geared into a worm-wheel having fifty-six teeth, and that drove a shaft carrying a pinion with fifteen teeth and 4-inch pitch, which geared into a spur-wheel with ninety-five teeth, to which was bolted a large band, which made one revolution whilst the engine made three hundred and fifty-five.
'M.P.I.C.E., vol. 1xsii. p. 1t4.
Illid.
Ibid., p. 161 
"A small band, keyed into the first-motion shaft, was found useful for hauling up the empty cradle, or for small vessels, and as it ran $6 \frac{1}{2}$ times as fast as the large barrel, it saved much time. The large barrel was 5 feet in diameter and 7 feet 3 inches long, and wound up a steel-wire rope 9 inches in circumference. Ordinarily a single rope was used, and a light vessel of say 1500 tons could be hauled up without stopping; but for heavier vessels the rope was passed round a large sheave fixed to the end of the cradle, giving two parts of the rope instead of one, with the standing part fixed to an anchor-bolt in the foundation under the steam-winch, by which the hauling power was doubled. If necessary, a second pulley could be introduced, and the hauling power thus multiplied threefold without putting more strain on the gearing of the steam-winch.

"The rate of haulage with the single rope was from 12 to 20 feet per minute, according to the weight of the ship."

Stress in Hauling.-The stress required for hauling up a vessel varies very much according to the efficiency of the ways. Everything being rigid, it may be found by the following formula:-

$$
\mathrm{S}=\tan \theta\left(w+w_{1}+w_{2}\right)+\frac{\left(w+w_{1}\right) r_{1}}{r} f+w_{2} f_{1} .
$$

where $\mathrm{S}$ is the total pull on the links, $w$ the weight of the vessel, $w_{1}$ the weight of the cradle, and $w_{2}$ the weight of the links, all in tons, $\theta$ the angle made by the rails with the horizontal, $r$ the radius of the rollers, $r_{1}$ the radius of the roller-axle, $f$ the coefficient of friction between the axle and the bearing, and $f_{1}$ the friction between the links and the rails.

The total amount of pull to be provided in the haulingcylinders of Messrs. Lightfoot and Thompson's gear would be this quantity $\mathrm{S}$, added to the total pressure on the returning ram, and what is required to overcome the friction of the hydraulic apparatus.

In practice, the values of $f$ and $f_{1}$ are difficult to determine, and vary according to the state of lubrication, and as there is besides another unknown element in the shape of extra pull to overcome the effects produced by deflection of the ways, it is usuai to estimate the hauling power in a much more empirical 
way. The following rule, constructed from actual observation, is fairly accurate for ways of an inclination of 1 in 20 :-

$$
\mathrm{S}=s+\frac{w+w_{1}+w_{2}}{8} . .
$$

$s$ being the total pressure on the returning ram. For other inclinations, some allowance must be made on one side or the other; but, as the friction due to the weight of vessel and cradle and of the hauling-gear does not vary with change in gradient, the total pull is not as a rule subject to great alterations for a given size of vessel. It also depends as much on the efficiency of the ways as on the inclination.

At Carthagena, ${ }^{1}$ the slips designed by Mr. G. B. Rennie for receiving the ships after being raised by the floating dock were made perfectly level, and the amount of power required to haul the vessels on shore was calculated on the assumption that the launchways for a heavy ship were made with an inclination of $\frac{1}{2}$ inch to the foot, or 1 in 24 , so that about $\frac{1}{24}$ of the weight of the vessel had to be overcome by the hydraulic machinery.

Resistance on Sliding Slipways. ${ }^{2}$ - It has been found from experience that a ship can be conveniently launched at an inclination of 1 in 13.3 , provided that no immediate contact takes place between the surfaces of the wood, but that they are separated by a thin layer of grease ; for, however carefully prepared the surfaces may be, the adhesion is always greater than the downward strain, unless diminished by the use of tallow.

As the friction during downward and upward movement is the same for like surfaces, it follows that the frictional resistance to be overcome equals $7 \cdot 5$ per cent. of the total weight on an inclination of 1 in 13.3 .

It has also been found by experiment that an additional allowance of 5 per cent. must be made for increase of friction due to rest.

Further, in hauling up on an incline of 1 in $13.3,7 \cdot 5$ per cent. of the dead weight has to be lifted, therefore the power to be provided must equal 20 per cent., or $\frac{1}{5}$ of the united weight of stage and ship.

Broadside Slipways. ${ }^{3}$ - The slipways at the shipbuilding yard of the Imperial and Royal Danube Steam Navigation Company

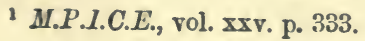

Ibid., rol. lxxix. p. 305.

2 lbid., vol, xlviii. p. 290.
} 
at Alt-Ofen, in Hungary, extend along the riverside for a distance of 650 feet, and have a depth inland of about 280 feet.

The slipways are arranged in groups to accommodate the barges and steamers of the company, the largest of which are 250 feet long and 460 tons light displacement.

Two small monitors belonging to the Government are also hauled up from time to time; these, on account of their weight being distributed over a short length, are more trying to the

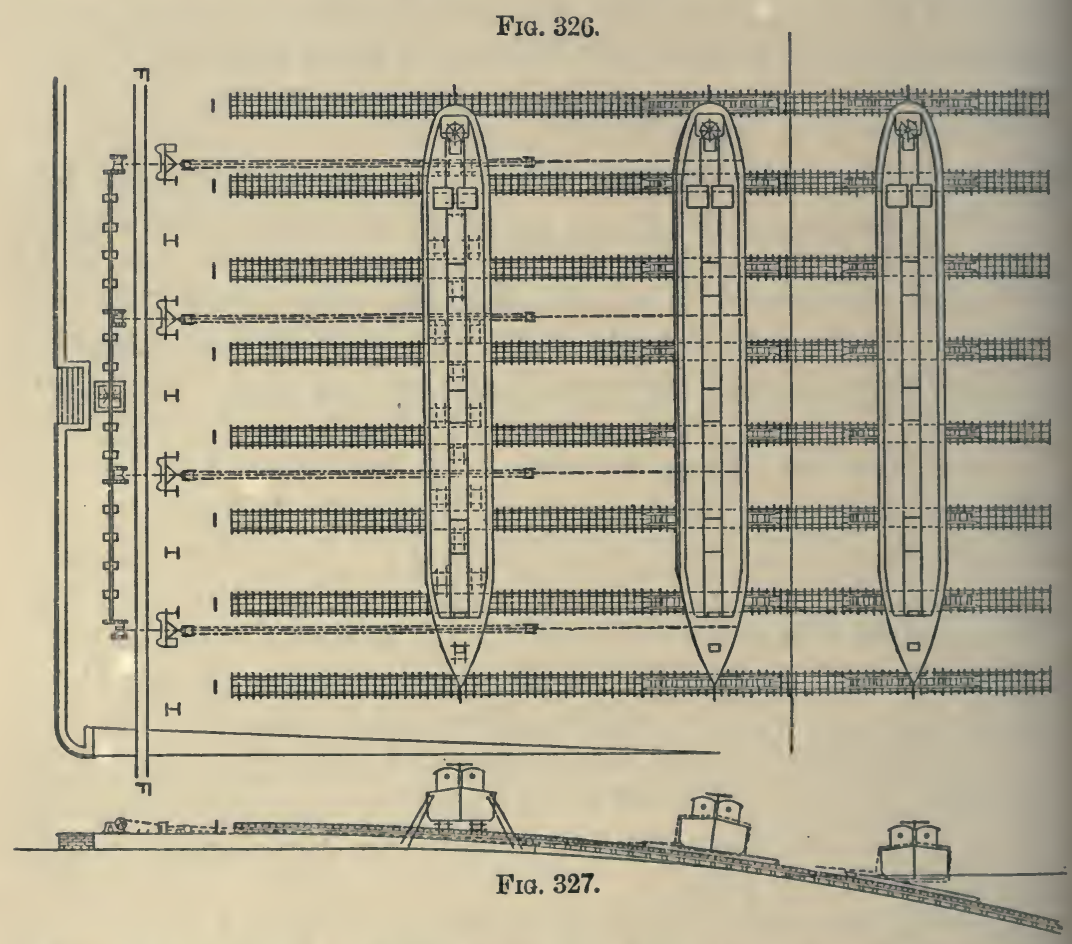

ways; but no difficulty has arisen either in hauling them up or in relaunching them.

Fig. 326 shows the general disposition of each group, which can be used for building purposes or for repairing. The vessels are drawn broadside out of the water by chains, the weight being taken up and distributed over the ways by cradles placed under water at the end of the slipway. On the section (Fig. 327 ), the lower vessel is represented in the act of coming in contact with the submerged cradle prior to the hauling-out commencing; the second is being hauled up the slipway; and 
the third is represented as having been made clear of the cradle and placed fair on cross-blocks of wood ready for examination and repair.

Only the lower portions of the slipways are permanent, the length of this part being about 150 feet. That part of the ways situated on the higher level can be removed after the vessels are hauled up, and relaid when required for launching.

The motive and hauling power is a 10 horse-power steamengine, geared by a line of shafting to four double-geared 9-to-1 winches, carrying $\frac{7}{8}$-inch best short-link chains, working through upper and lower three-pulley blocks.

The vessel is secured by $1 \frac{1}{8}$-inch iron slings, which are then attached to the lower blocks, which are carried on wheels running on ways laid down for the purpose.

The speed at which the vessels are hauled out varies from 1 to $1 \frac{1}{4}$ foot per minute, the motion being continuous and exceedingly smooth throughout. 


\section{CHAPTER XI.}

Pumping water from docks-Vertical centrifugal-puns $\mathrm{ps}-$ Horizontal pumps at Liverpool Docks-Reciprocating plunger-pumps at Portsmouth-Pumps at tho Barry Docks-Pumps at Bute Docks, Cardiff-Pumps at the Hamilton Docks, Malta-Temporary pumping.

For dock purposes, where large quantities of water have to be rapidly raised to moderate heights, centrifugal pumping. machinery is perhaps the best that can be adopted. Such machinery is simple in construction, economical, and durable, and has no complicated valves. In a dock, there is always a considerable quantity of refuse, such as scrapings from ships' bottoms, small chips, etc., much of which unavoidably passes into the well. There being no valves, a considerable portion of this refuse is drawn through the pumps without inconvenience, anything, in fact, being discharged that will clear the waterpassages, which, in the case of large pumps, are of considerable area.

Special care must be taken, by the use of suitable gratings, to stop all rope-ends, canvas waste, or anything that may be likely to coil round the spindle or hang in the fan, and so choke the pump.

A further advantage attaching to centrifugal-pumps is the absence of the incessant jar or pounding common to large reciprocating-pumps, and which is so detrimental to the surrounding masonry.

A drawback to the use of vertical centrifugal-pumps and directly connected driving machinery for dock purposes, is that it is necessary to place it below the water level, in a water-tight pit large enough to take both pumps and engine. With the horizontal or turbine type of centrifugal or lifting-pumps, this costly water-tight pit is not required, with the advantage that the whole of the driving machinery is kept above the water level. 
The pumping-gear at the Alexandra Dock, Hull, consists of two 39-inch vertical centrifugal-pumps, with 48-inch suctionpipes, driven by a single-cylinder engine to each pump.

Each pump, driven at 145 revolutions, is capable of throwing 31,250 gallons per minute, with a maximum difference of level of 21 feet.

For ordinary drainage purposes, a small centrifugal-pump, with a 6 -inch suction, and worked by an independent vertical engine, is used. ${ }^{1}$

For emptying the dry docks of the Liverpool Northern Extension, Mr. G. F. Lyster, M.I.C.E., adopted a horizontal or turbine type of pump, with a fan 5 feet diameter, driven by gearing from an independent horizontal engine to each pump. The ordinary drainage, which has to be lifted to a great height, is dealt with by chain-pumps of the ordinary pattern. ${ }^{2}$

An example of large reciprocating plunger-pumps is to be found in Portsmouth Dockyard. The plungers of these pumps are 6 feet in diameter, and have a stroke of 6 feet.

They are driven by a composite vertical inverted engine, with cylinders 64 and 40 inches in diameter. These pumps lift about 18,500 tons of water per hour, with an indicated horse-power of $862 .^{3}$

At the Barry Graving-dock, two 40-inch centrifugal-pumps are fixed in an engine-house, 11 feet below high water of spring tides. These pumps can raise 62,000 tons of water in about four hours. 4

Bute Docks, Cardiff. ${ }^{5}$-At these docks, both centrifugal and liftpumps are used for discharging the water from the graving-dock (Figs. 328 to 330 ).

The water from the dock flows through the culvert $V$, into the lifting-pump well, whence it passes by different culverts, $\mathrm{O} \mathrm{O}$, into the centrifugal-pump wells. The two latter wells are also connected by a culvert closed by a sluice, $T$. The water from the whole of the pumps flows through the culverts B B and $\mathrm{P}$ to the tank $\mathrm{C}$, under the floor of the engine-room, from which it is conveyed away to the outfall by the culvert U (Fig. 328).

The arrangement of the horizontal centrifugal-pumps, which

1 M.P.T.C.E., vol. xcii. pp. 155, 179.

2 Ibid. vol. c. p. 23.

3 Ibid., vol. lxiv. p. 145 ; and Gwynne, "Notes on Centrifugal PumpingMachinery."

'Ibid., vol. ci. p. 141.

s Institute of Mechanical Engineers, 18St, and Engineering, vol. xxxviii. p. 165. 
are placed in separate circular wells, is shown by Figs. 328 to 330. When these pumps are started, the sluice $T$, between the two circular wells, is closed, and each pump acts independently until the water-level in the dock is so reduced that the lift of the pumps is equal to about 15 feet. The sluice $T$ is then opened,

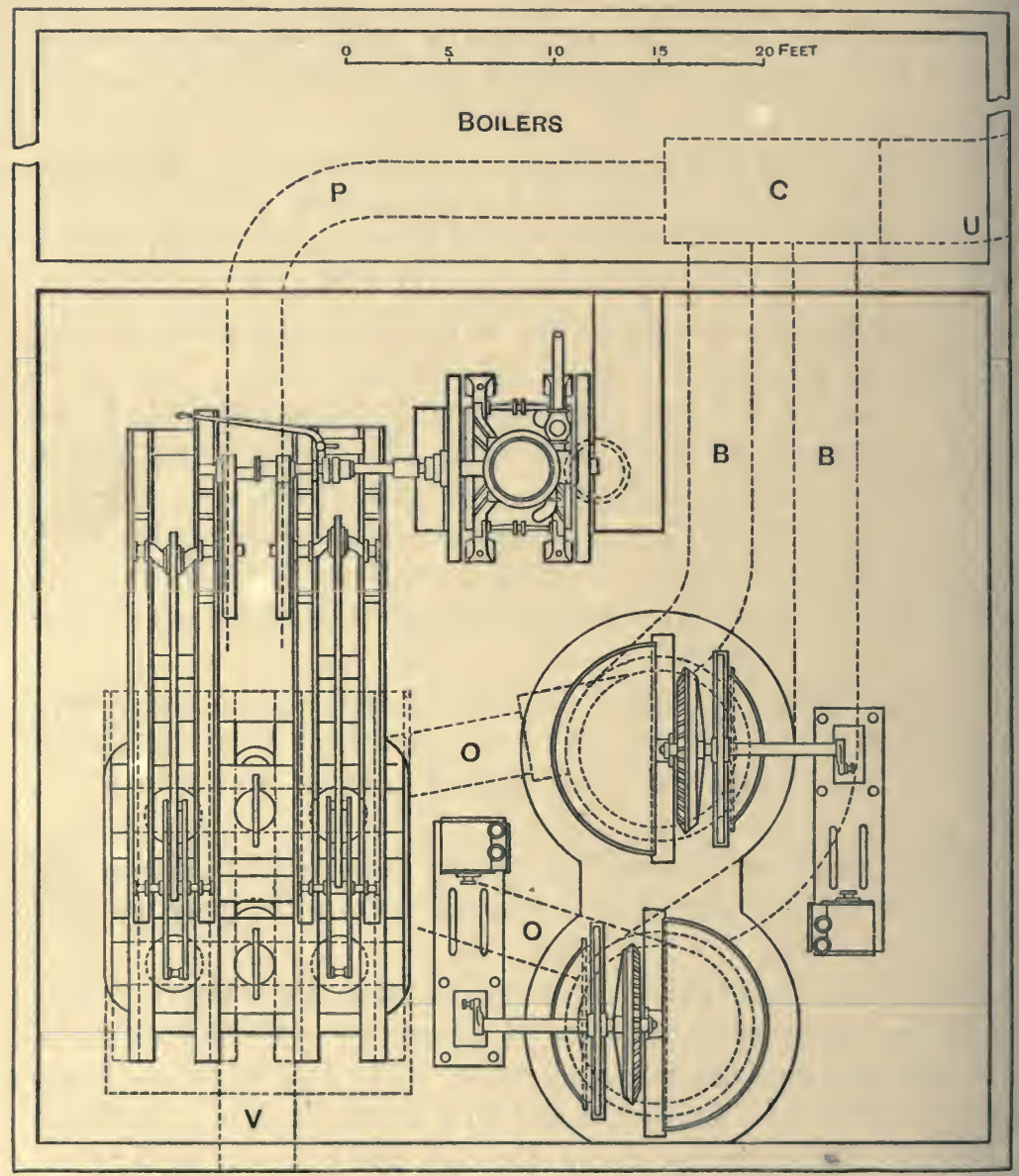

FIG. 328.

and the water discharged from the lower pump passes into the well below the level of the higher pump at D (Fig. 330). When this takes place, the self-acting flap-valve at $\mathrm{H}$ (Fig. 330) closes and prevents the return of the water to the dock. The water discharged by the lower pump is thus passed through both pumps, and the lift is divided between them. 
The fans are 4 feet 2 inches in diameter, and when driven at their usual speed of about 200 revolutions per minute, discharge about 3000 cubic feet in the same time. Each pump is driven by a separate high-pressure horizontal engine.

The four lift-pumps are fixed in one large square well (Figs. $328,329)$, and are driven by a vertical engine. These pumps are each $29 \frac{1}{2}$ inches diameter, and 48 inches stroke. The general speed at which they are worked is about 14 strokes per minute, at which rate each discharges about 250 cubic feet, equal
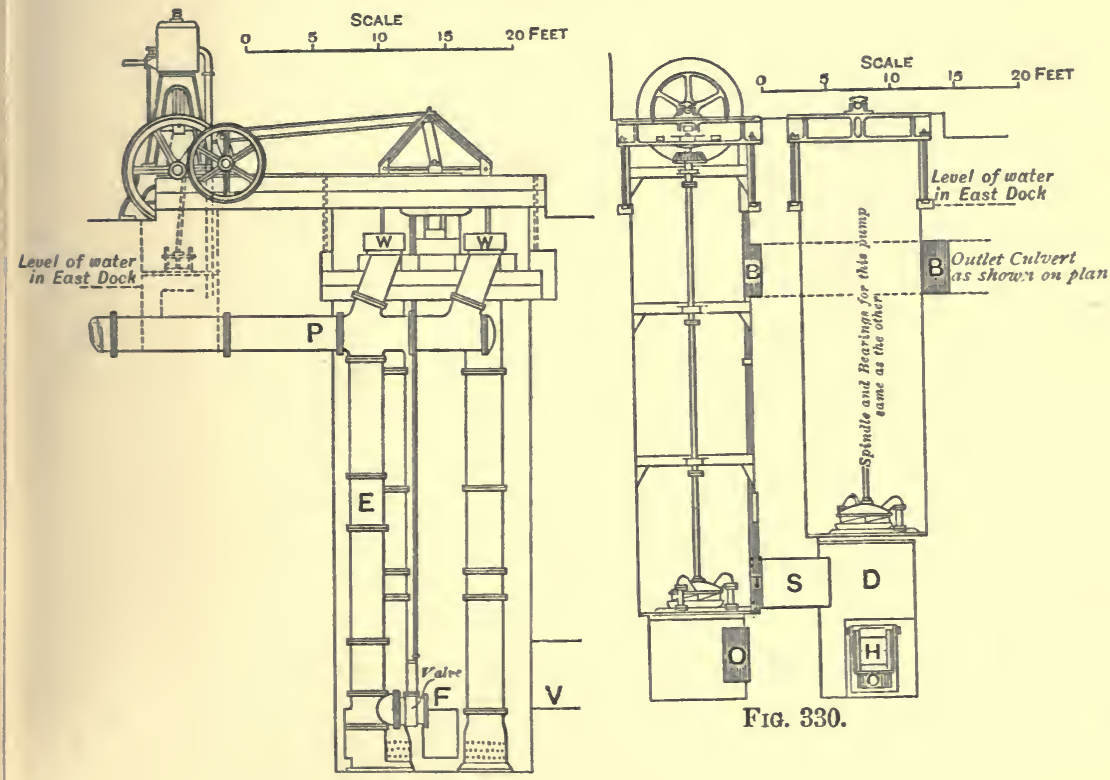

FIG. 330.

Fig. 329.

to $\mathbf{1 0 0 0}$ cubic feet discharged per minute by the four pumps together.

Figs. 331 and 332 show the arrangement of the engines and pumps adopted for pumping out the Hamilton Dock, at Malta.

The main pumping-engine is of the compound, invertedvertical type, having cylinders 26 and 44 inches in diameter, and 26 inches stroke.

The main centrifugal-pumps are driven direct from the shaft, and have gun-metal fans 7 feet in diameter. The cast-iron pump-casings are entirely distinct from the engine-bed, and are so arranged that the upper part can be readily removed so as to 
admit of the fans being changed or examined without difficulty. The discharge and suction-pipes are each 38 inches in diameter; the lower end of the suction-pipes being enlarged by a trumpet mouth to 60 inches.

These pumps are so arranged that, by means of suitable clutches, either fan can be disconnected from the engine-shaft, when they are not required to be working together.

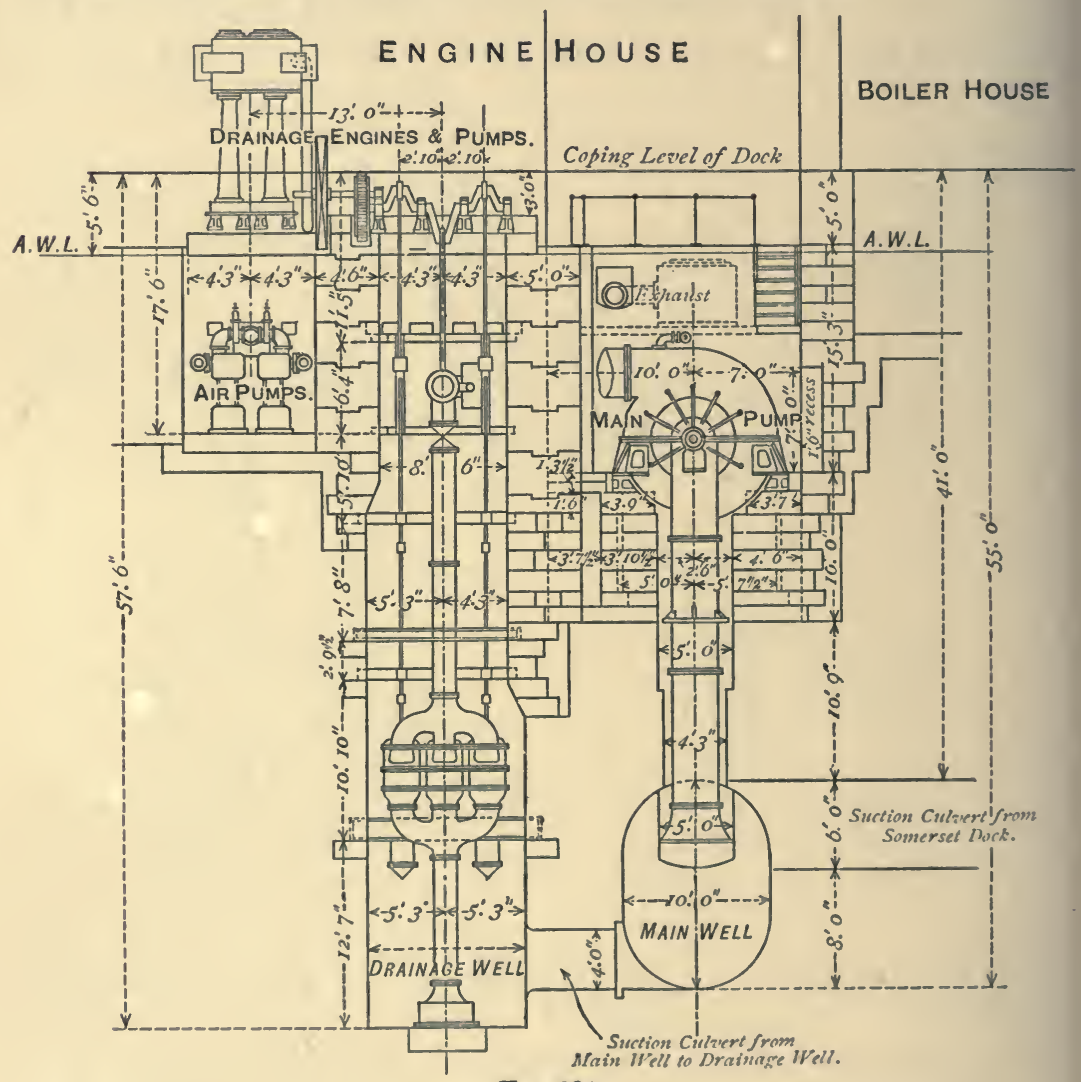

Fra. 331.

No foot-valves are employed on account of the trouble they give; but a sluice is fitted to the outlet branch of each pump. When this valve is closed, a steam-ejector, which is fixed to the top of each casing, charges the pump in a minute or two.

These pumps are capable of clearing about 50,000 tons of water in four hours; the total lift at the close being 36 feet.

The supplementary engine for driving the air- and drainage- 
pumps is also of the vertical-compound type, the cylinders being 16 and 27 inches diameter, with 28 -inch stroke.

The drainage-pumps consist of three single-acting barrels,

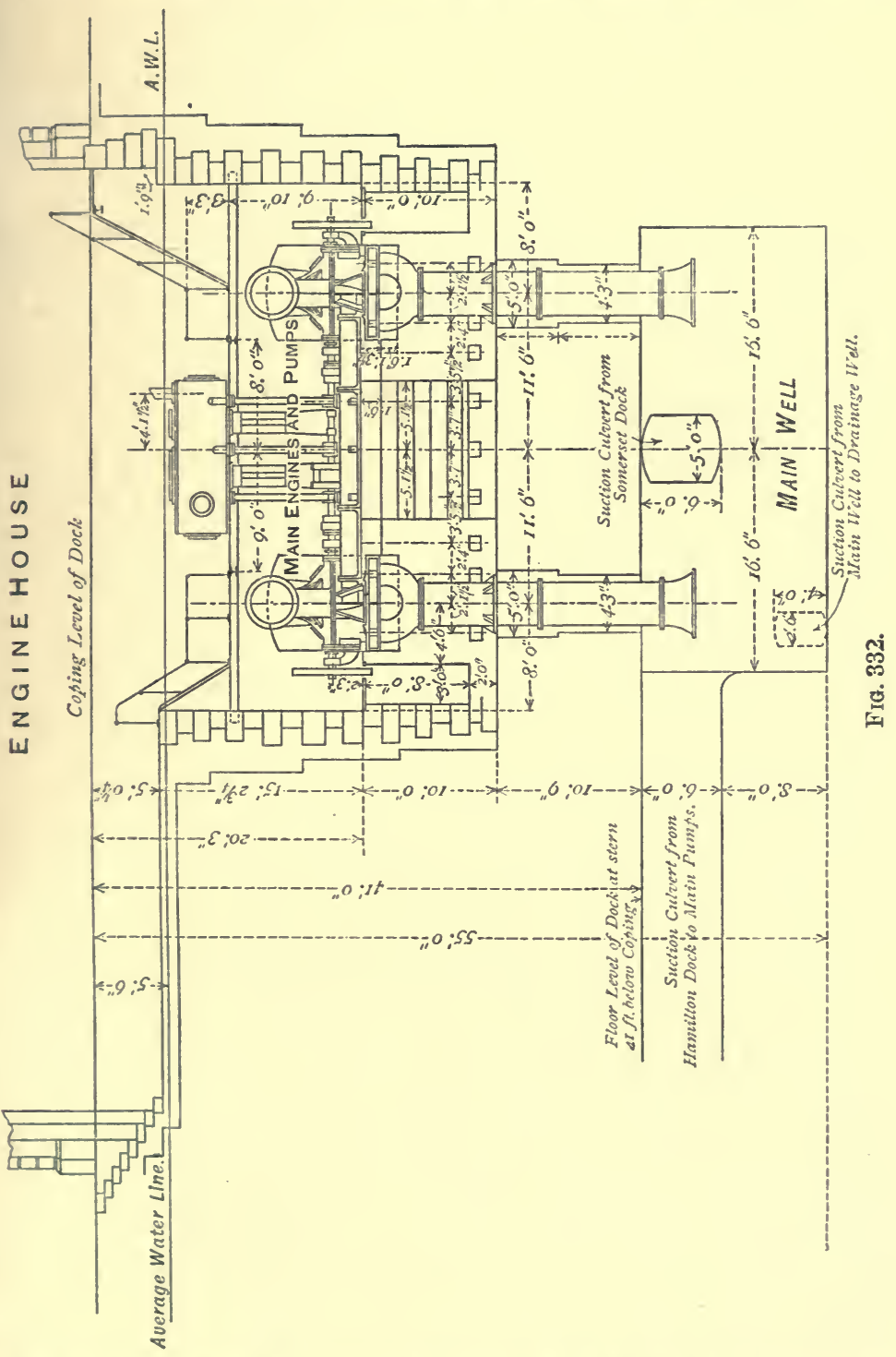

with solid plungers 18 inches diameter and 4 feet 6 inch stroke, and are capable of lifting 13 tons of water per minute to a 
height of 55 feet. The suction-pipe is 20 inches diameter, and terminates in a strainer 3 feet 6 inches diameter. The suctionpipe and strainer rest on the bottom of the well, and serve to support the weight of the valve-boxes.

Temporary Pumping.-The quantity of water likely to be met with in carrying out a large dock-work is always more or less problematical, and may be made up of natural drainage, rainfall, and leaks from the sea or other outside waters.

Local conditions and personal bias must always play an important part in the choice of appliances. It may, however, be taken as a maxim that for all temporary purposes the more simple the arrangement the better. Pumps, and engines for driving them, of a complicated construction, and requiring elaborate and costly foundations and high-classed skilled attention, are altogether out of place.

It is wise to concentrate the pumping as much as possible. If on a work of moderate size, to one or two points; or if on a large work, by districts. There will of course be exceptions to this rule; but isolated pumping-places should be reduced as much as possible.

The sumps should be well below the deepest permanent works. On the power to keep the water down a few inches extra for a short time may depend the success of some important part of a work.

The capacity of the pumps and driving power should be in excess of the actual requirements. To continuously work up to full power is false economy, and leaves no margin for contingencies.

The pumping appliances should be in duplicate, or divided in such a manner that any breakdown may not affect the whole. It must be borne in mind that pumping-gear and boilers cannot be expected to run satisfactorily without occasional stoppages for cleaning and adjustment. Accidents to pumps, engines, and boilers will happen at the most unexpected times, and when they certainly should not happen according to paper arrangements. If at such times duplicate pumping power is not available, stoppage of the works may result, possibly with very serious consequences. 


\section{CHAPTER XII.}

Dredging - Class of Appliances - Grabs - Pump-dredgers - Bucket-dredgers Stationary Dredgers versus Seagoing Hopper-dredgers-Variation of quantities of dredged material as compared with sections-Time actually employed in dredging.

SUBAQUEOUS excavation is frequently a matter of considerable importance in connection with dock construction, either in forming the leading channel from the open water to the entrance, the maintenance of a sufficient depth in the basins, locks, and approaches, alongside wharf walls, or in excavating large basin areas after the wharf walls have been constructed.

The appliances range from the primitive bag and spoon, worked by hand, to the elaborate and powerful machines costing twenty to thirty thousand pounds.

The class of machines to be used will very greatly depend upon the magnitude of the operations, the niture of the material to be operated upon, the distance to which the dredged material has to be removed, the facilities for disposal, and the conditions generally under which the work has to be carried on.

Generally dredging appliances may be classed under three types, i.e. grab-dredgers, pump-dredgers, and bucket-dredgers, each having their special uses.

Grabs are most efficient when soft materiai has to be removed in confined spaces, small docks, basins, and entrances, and for lifting blasted or broken-up rock.

Pump-dredgers render good service when large quantities of sand have to be removed. In open situations, they have been found to work efficiently in a slightly chopping sea. At Dunkirk, a two-foot swell did not impede their action.

The bucket-dredger is undoubtedly the most efficient appliance, when large quantities of material extending over considerable areas have to be removed, ensuring continuous work, and when a practically uniform bottom level is required. 
There is considerable difference of opinion as to the relative merits of stationary dredgers attended by hopper-barges, and combined hopper and dredgers, conveying the dredged material to the place of deposit. Mr. Messant has remarked that it has yet to be proved, "first, that a ladder-dredging apparatus would work with greater efficiency and economy if supported on a vessel that happened to have a hopper attached to it, than if supported by a vessel without a hopper; and, secondly, that a vessel with a dead weight of machinery, or amounting to considerably more than the cargo, and with a crew much larger than necessary for the purpose, could convey to sea a hopperload of dredged material at a cheaper rate than a vessel of only sufficient capacity for its cargo, and with only a sufficient crew, which would probably be about one-fourth of the crew required for the hopper-dredger." I It is objected that, with the hopperdredger, owing to the constant moving, it is difficult to pick up the same spot, face, or level on returning from a trip, consequently the bottom is more likely to be irregular than if a stationary dredger is used. ${ }^{2}$

Like other dredging appliances, the hopper-dredger meets special conditions where the stationary dredger, with its attendant hopper-barges, would be inapplicable, or more costly to work. Such as in cases when, owing to the range of tide, or other causes, dredging can only be proceeded with during a portion of a tide. The dredgers, crew, and vessel, would be more advantageously employed in taking the dredged material out to sea for deposit than in idly waiting for the time to resume work, while the dredged material is being conveyed away by other vessels and crews. In narrow, crowded channels or areas, where hopper-barges alongside an ordinary dredger would be inconvenient. In navigations of great length, where small quantities of dredging may be required at intervals in positions at long distances from each other. ${ }^{3}$ In exposed positions, where rough seas have to be encountered, and where danger would attend the loading of hopper-barges alongside a stationary dredger.

Of the different types of dredging appliances in use, Mr. Webster, M.I.C.E., has given a very valuable description in a paper laid before the Institution of Civil Engineers. ${ }^{4}$

M.P.T.C.E., lxxxix. p. 102.

${ }^{2}$ Ilinid., p. 111.

Illic..p. p. 102. 
Variation of Quantities.-The quantities, as taken from the cross-sections, will of course show the amount of work to be done in the solid; but, owing to the increase in bulk in breaking up, the silting that inevitably goes on during the operation of dredging, slips on the slopes, and the quantity of water mixed with and lifted with the dredged mud, silt, or clay, the quantity estimated from the cross-sections in the solid will be increased from 25 to 50 per cent., and in some cases to double the quantity as dredged material.

At Dunkirk, observations made with reference to the bucket-dredgers working in silty material with occasional boulders, showed that the difference between the quantities, as measured from the cross-sections, and in the hopper-barges, after the excess water had flowed off, varied from 25 to 45 per cent., according to the age of the deposit and the proportion of sand contained in the silt. ${ }^{1}$

As regards the actual quantity of material lifted by the suction-pump dredgers, tests made from time to time in a graduated measure showed that the mixture brought up by the pumps contained from 4 to 10 per cent. of sand, which settled in the hopper, the average being 6 per cent., sometimes the proportions extended to 15 or 20 per cent.; this, however, indicated that the slopes were slipping, and that a block of the suction-pipe was imminent. $^{2}$

In dredging in sand at the mouths of the ports of Amsterdam and Rotterdam, a proportion of 1 part sand to 7 parts water has been recorded equal. to about 14.28 per cent. of the total quantity lifted; of this about 6 per cent. remained in suspension, and was carried away with the surplus water. ${ }^{3}$

At the Oaklands Harbour Works in California, where the material was reduced to the consistency of mud by mechanical means before being dealt with by the pumps, as much as 40 per cent. of material was carried in suspension. Experience, however, showed that about 15 per cent. was the amount that could be most conveniently dealt with by the pumps. ${ }^{4}$

The following are the results of observations on the efficiency of a sand-pump dredger, fitted with underwater suction, made whilst working on the Liverpool Bar. ${ }^{5}$

1 M.P.I.C.E., vol. 1xxxix. pp. $74,75$.

Ibid., p. 83.

Ibid., p. 70.

- Engineering, vol. xxxviii. p. 30.

s Communicated by Mcssrs. Lobnitz, of Renfrew, Scotland. 


\begin{tabular}{|c|c|c|c|c|c|c|c|c|}
\hline \multirow[t]{2}{*}{ No. } & \multirow{2}{*}{$\begin{array}{l}\text { No. } \\
\text { of } \\
\text { Tests. }\end{array}$} & \multicolumn{3}{|c|}{$\begin{array}{c}\text { Proportion of sand in total } \\
\text { quantity of water } \\
\text { pumped into hopper. }\end{array}$} & \multirow{2}{*}{$\begin{array}{l}\text { Propor- } \\
\text { tion of } \\
\text { sand in } \\
\text { overflow } \\
\text { water. }\end{array}$} & \multirow{2}{*}{$\begin{array}{c}\text { Propor- } \\
\text { tion } \\
\text { deposited } \\
\text { in } \\
\text { hopper. }\end{array}$} & \multirow{2}{*}{$\begin{array}{l}\text { Depth } \\
\text { of } \\
\text { water. }\end{array}$} & \multirow{2}{*}{ Rcmarks. } \\
\hline & & Min. & Max. & Average. & & & & \\
\hline 1 & 7 & $\begin{array}{c}\text { Percent. } \\
11 \cdot 6\end{array}$ & $\begin{array}{c}\text { Per cent. } \\
44 \cdot 7\end{array}$ & $\begin{array}{c}\text { Per cent. } \\
\mathbf{3 0 . 9}\end{array}$ & $\begin{array}{c}\text { Per cent. } \\
8^{\circ} 0\end{array}$ & $\begin{array}{c}\text { Per cent. } \\
22 \cdot 9\end{array}$ & $\begin{array}{l}\text { Feet. } \\
27\end{array}$ & \multirow{2}{*}{$\begin{array}{l}\text { Fine sand. } \\
\left\{\begin{array}{l}\text { Sand of a more favour- } \\
\text { able and readily } \\
\text { depositing character. }\end{array}\right.\end{array}$} \\
\hline $\begin{array}{l}2 \\
3\end{array}$ & 5 & $\begin{array}{l}19 \cdot 0 \\
30 \cdot 0\end{array}$ & $\begin{array}{l}50 \cdot 0 \\
6 \pm \cdot 0\end{array}$ & $\begin{array}{l}38 \cdot 8 \\
47 \cdot 0\end{array}$ & $\begin{array}{l}2 \cdot 7 \\
8 \cdot 0\end{array}$ & $\begin{array}{l}36 \cdot 0 \\
39^{\circ} 0\end{array}$ & " & \\
\hline
\end{tabular}

Time actually employed in Dredging.-It is too often the practice to estimate the capabilities of dredging apparatus from the results of some trial made under the most favourable conditions and of a comparatively short duration, and upon this the power of the machine to lift so many cubic yards or tons during a working day is determined. Estimates as to the probable cost and duration of dredging operations based upon such information cannot fail to be fallacious. It will be found in practice that the time actually employed in effective dredging varies from one-half to not more than two-thirds the total working time.

The following details of the distribution of time from actual practice will show this :-

Swansea.-In forming the deep-sea entrance to the Prince of Wales's Dock : ${ }^{1}$

Repairs to maehinery and consequent stoppage Coaling

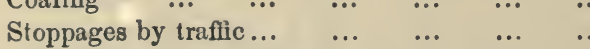

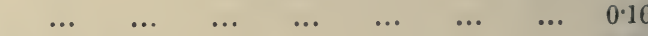

$\begin{array}{lllllllllll}\text { Shifting sinks and chains } \ldots & \ldots & \ldots & \ldots & \ldots & \ldots & \ldots & \ldots & 3.97\end{array}$

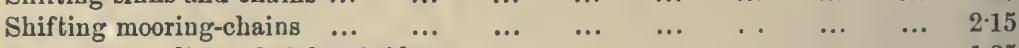

$\begin{array}{lllllllll}\text { From extraordinary height of tides } & \ldots & \ldots & \ldots & \ldots & \ldots & \ldots & 135\end{array}$

$\begin{array}{llllllllllll}\text { Bad weather ... } & \ldots & \ldots & \ldots & \ldots & \ldots & \ldots & \ldots & \ldots & \ldots & 16.50\end{array}$

$\begin{array}{lllllllllll}\text { Other delays... } & \ldots & \ldots & \ldots & \ldots & \ldots & \ldots & \ldots & \ldots & \ldots & 843\end{array}$

$\begin{array}{lllllllllll}\text { Timo aetually dredging } & \ldots & \ldots & \ldots & \ldots & \ldots & \ldots & \ldots & \ldots & 49 \cdot 78\end{array}$

$100 \cdot 00$

Ayr Harbour.-Particulars of time in dredging in hard clay, silt, and sand, and removing to sea by a hopper-dredger.

Time oecupied in dredging and conveying to sea, letting go moorings, ete. $\begin{array}{r}\text { Per cent. } \\ 7347\end{array}$

$\begin{array}{llllll}\text { Shifting bushes, repairing maehinery, cleaving boilers, etc. } & \ldots & \ldots & \ldots & 4.02\end{array}$

$\begin{array}{lllllllllllll}\text { Coaling } & \ldots & \ldots & \ldots & \ldots & \ldots & \ldots & \ldots & \ldots & \ldots & \ldots & 2.68\end{array}$

$\begin{array}{llllllll}\text { Detentions through bad weather and inspections } & \ldots & \ldots & \ldots & \ldots & 10 \cdot 39\end{array}$

$\begin{array}{llllllllllll}\text { Shifting mooring-chains } & \ldots & \ldots & \ldots & \ldots & \ldots & \ldots & \ldots & \ldots & \ldots & 4.08\end{array}$

$\begin{array}{lllllllllllll}\text { Grounding, etc. } & \ldots & \ldots & \ldots & \ldots & \ldots & \ldots & \ldots & \ldots & \ldots & 1.53\end{array}$

$\begin{array}{lllllllllllll}\text { On slip for repairs } & \ldots & \ldots & \ldots & \ldots & \ldots & \ldots & \ldots & \ldots & \ldots & 383\end{array}$

1 M.P.I.C.E., vol. eiii. p. 358. 
Aden Harbour. ${ }^{1}$-Dredging with a hopper-dredger of 1000 tons capacity in soft material, in varying depths up to 35 feet, and conveying to a distance of four miles.

Repairs to machinery

Coaling

Picking up moorings

Shifting moorings forward

Time actually dredging

Depositing

$$
\begin{array}{rrrrrr} 
& & & & \multicolumn{2}{r}{\text { Per cent. }} \\
\ldots & \ldots & \ldots & \ldots & \ldots & 24.77 \\
\ldots & \ldots & \ldots & \ldots & \ldots & 0.38 \\
\ldots & \ldots & \ldots & \ldots & \ldots & 6.93 \\
\ldots & \ldots & \ldots & \ldots & \ldots & 10.04 \\
\ldots & \ldots & \ldots & \ldots & \ldots & 37.06 \\
& & & & & 20.82 \\
\hline
\end{array}
$$

Plymouth-River Tamar.-No. 1. Dredging with double ladder stationary dredger in soft mud, to a minimum depth of 32 feet.

Filling hopper barges

l'er cent.

$\begin{array}{llllllllll} & \ldots & \ldots & \ldots & \ldots & \ldots & \ldots & \ldots & \ldots & 5350\end{array}$

$\begin{array}{lllllllll}\text { Waiting for hopper barges ... } & \ldots & \ldots & \ldots & \ldots & \ldots & \ldots & \ldots & 14 \cdot 25\end{array}$

$\begin{array}{lllllllllll}\text { Shifting moorings } & \ldots & \ldots & \ldots & \ldots & \ldots & \ldots & \ldots & \ldots & \ldots & 1550\end{array}$

$\begin{array}{llllllllll}\text { Repairs and cleaning } & \ldots & \ldots & \ldots & \ldots & \ldots & \ldots & \ldots & \ldots & 550\end{array}$

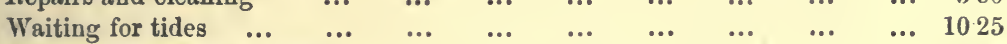

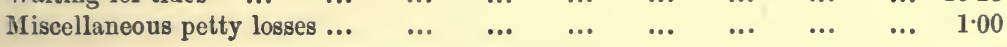

$100 \cdot 00$

No. 2. Stationary double ladder dredger working in soft mud in River Tamar.

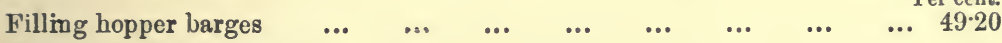

$\begin{array}{llllllllll}\text { Waiting for hopper barges } & \ldots & \ldots & \ldots & \ldots & \ldots & \ldots & \ldots & 370\end{array}$

$\begin{array}{llllllllllll}\text { Shifting moorings } & \ldots & \ldots & \ldots & \ldots & \ldots & \ldots & \ldots & \ldots & \ldots & 9 \cdot 10\end{array}$

$\begin{array}{lllllllllll}\text { Repairing and cleaning } & \ldots & \ldots & \ldots & \ldots & \ldots & \ldots & \ldots & \ldots & 4.40\end{array}$

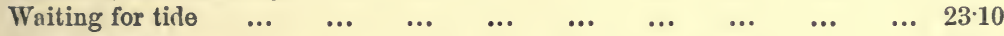

$\begin{array}{llllllllllll}\text { Rough weather } & \ldots & \ldots & \ldots & \ldots & \ldots & \ldots & \ldots & \ldots & \ldots & 10 \cdot 40\end{array}$

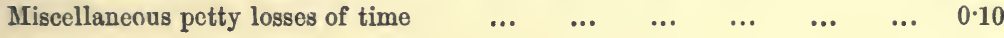

$100 \cdot 00$

No. 3. Stationary double ladder dredger working in soft mud in the Sound.

$\begin{array}{lllllllllll}\text { Shifting moorings } & \ldots & \ldots & \ldots & \ldots & \ldots & \ldots & \ldots & \ldots & \ldots & 250\end{array}$

$\begin{array}{llllllllll}\text { lepairing and cleaning } & \ldots & \ldots & \ldots & \ldots & \ldots & \ldots & \ldots & \ldots & 0.60\end{array}$

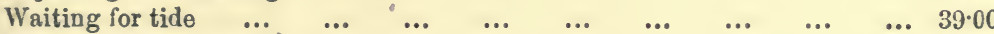

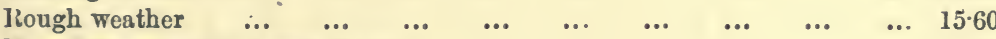

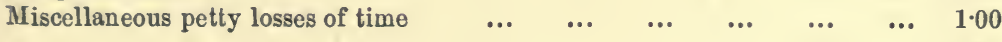

$100 \cdot 00$

In these three cases the effective dredging time would have been improved greatly had the barge service been better and the ladders longer. 


\section{CHAPTER XIII.}

Destruction of Timber-Marine Worms: Teredo navalis-Chelura terebrans-Limnoria terebrans-The Lepesma of the West Indies-'The Xycophago-Rate at which the Worm will destroy Timber-Effect of the Worm on hard Woods-Rot in Timber-Preserving Timber : Mechanical means-Chemical means-Corrosive Sublimate-Sulphate of Copper-Chloride of Zinc-Creosote-London Oils -Country Oils-Scotch Oils-Carbolic Acid-Apparatus used in creosotingProcess of crcosoting-Aitkins' process-Hayford's process-Charred 'TimberPractice of Eastern Railway of France-Practice on New Zealand Railways.

Marine Worms.-The most destructive of these pests are the Teredo navalis, or ship worm, the Chelura terebrans, and the Limnoria terebrans.

The Teredo Navalis is worm-shaped, growing generally to 4 or 6 inches long and $\frac{1}{8}$ inch in diameter, but instances are on record of its having been found far exceeding these dimensions. The head of the worm is provided with a hard calcareous substance or shell in two parts, working on a hinge, and performs the office of an auger. The head, like the gelatinous body, completely fills the cavity bored, and, as a rule, the outward indication will bear no comparison with the destruction going on within. The perforations of this worm are generally in the direction of the grain, but frequently across the grain, with many windings. The knots are always avoided, sometimes by the most intricate twists, especially when there are several worms close together. One worm will never enter the boring of another, but will work round it, leaving only a very thin partition between. The worm, having once entered the timber, never works out of it, although it will frequently approach to within one-hundredth of an inch of the surface.

It has been observed that the Teredo navalis, when possible, enters the timber at or near, but always above, the ground line, and it does not appear to enter above the ordinary low-water level; but inside the timber it has been traced up to about two 
feet above low water, and it has been found to work down to some 2 feet 6 inches below the ground. ${ }^{1}$

It has been stated that the Teredo navalis will not attack timber with the bark on; this does not appear to be universally correct, although it is a protection to a certain extent. At San Francisco, it was found that many worms did attack and penetrate the bark, but that the greater number died before doing so; the bark once penetrated presents no obstacle to the ravages of the worm.

At Port Elizabeth, in some jetties erected by Sir J. Coode, it was noticed that the Teredo navalis was more destructive in the horizontal timbers at low water than in the vertical timbers. ${ }^{2}$

The Limnoria Terebrans very much resembles a small woodlouse in general appearance; it is about $\frac{1}{6}$ inch long, of an ash colour, with black eyes. It appears to be furnished with a small mouth and strong teeth, with which it works its way into the softer parts of the timber, following, as a rule, the grain, avoiding the knots and harder parts. It appears to extend its ravages to a higher point above low water than the Teredo navalis.

The Chelura Terebrans differs from the Limnoria in appearance, being more like a minute sand-shrimp, rarely exceeding $\frac{1}{4}$ or $\frac{3}{8}$ inch in length, and is perhaps the most destructive of all the marine pests. In situations favourable for the exercise of its habits, it soon produces great effects on the wood to which it attaches itself. The borings are so close together that the wood is so disintegrated as to permit of a very moderate movement of the water washing away the surface. The riddled wood is also torn away by small crabs, which prey upon the worm. In the clear water in Malta Harbour, these small crabs could be seen constantly at work, comparatively large holes having been observed in some instances, dug out by these crustacea. The ends and joints, or where one piece comes in contact with another, appear to be the favourite points of attack; but under any conditions, an entrance onee effected, the destruction of the timber is rapid and complete.

In the West Indies, the Lepesma is very destructive, and

1 Transactions of the Society of Engineers, 1874, p. 112.

- Transactions of the South African Philosophical Society. 
begins to prey upon the wood as soon as it is put into the water. ${ }^{1}$

The Xycophago, a small bivalve mollusc, is also very destructive, entering the wood when young, and growing to maturity inside. $^{2}$

Two theories have been advanced to explain the cutting powers of these creatures, one chemical and the other mechanical; but traces of acid solvents are only found in some calcareous borers, and they also occur in animals which do not bore. On the other hand, silicious cutters have been found on some borers, such as the Teredo. ${ }^{3}$

The rate at which the worm will destroy timber will depend greatly upon the locality, and whether there are alternations or admixtures of fresh water. In cold water, the destruction will not be so rapid as in warm latitudes. At Greenock, a pile 13 inches square was eaten through in seven years. At Portsmouth, some of the stage-piles used during the extension of the dockyard were destroyed in about five years.

In Malta Harbour, isolated, unprotected stage-piles of white "Triest" timber 13 to 14 inches square were reduced, in between three and four years, to less than one-fourth the original dimensions-in fact, destroyed for all practical purposes by the Chelura terebrans, while the rate of destruction from the same pest, over the area of close-piled dams, was observed to be over one inch per annum.

Mr. Stevenson found that the Memel timber used at the Bell Rock Lighthouse was destroyed by the Limnoria terebrans at the rate of about one inch per annum. ${ }^{4}$

In the Gulf of Mexico, it is recorded that the marine worms cut off an unprepared pile in eight months. ${ }^{5}$

At Port Darwin, South Australia, Mr. James found that chafing-pieces of kerry wood, a West Australian timber, were soon attacked, and after about three years completely destroyed at the lower ends by the Teredo, the ravages of which extended to about halfway between high-and low-water mark. ${ }^{6}$

Of the timber usually employed in marine works, greenheart,

1 Hurst's "Carpentry," 2nd. ed., p. 377.

2 Professor McIntosh, in Engineering, vol. xxxviii. p. 436.

3 Ibid., p. 436.

"Stevensou's "Bell Rock Lighthouse."

- Engineering, vol. 1. p. 607.

- M.P.I.C.E., vol. ciii. p. 338. 
teak, ${ }^{1}$ Billian or North Borneo ironwood, ${ }^{2}$ and cypress pine, ${ }^{3}$ appear to hold the first place as regards the power of resisting in their natural state the attacks of marine worms. The two latter are referred to as unassailable, while the two first appear, up to a comparatively recent date, to have been considered almost, if not quite, indestructible, although not by any means impenetrable.

In cold northern waters, this is probably practically correct; but in tropical or semi-tropical latitudes, experience shows that they are not either unassailable or indestructible. Experiments carried out in Malta Harbour, extending over some time, show that greenheart and teak are not invulnerable, but the damage inflicted by the Chelura is of course small compared with that sustained by softer woods immersed in the same water.

The following, taken from a paper read before the South African Philosophical Society by Mr. R. H. Hammersly Heenan, M.I.C.E., refers to the activity of the marine worm, and the durability of greenheart in South African waters.

"In 1878, two jetties were erected for the Port Elizabeth Harbour Commissioners, from the designs of Sir I. Coode, V.-P.I.C.E. For the most part iron was used, but it was decided that the seaward ends should be of greenheart, and with this material the work was carried out.

"An inspection of the jetty made a few years after revealed what at first appeared to be signs of decay in one of the horizontal timbers. On cutting into it with an adze, it was found to be completely honeycombed for about one inch in depth with the tunnels of the Teredo. On further examination, it was found that all the horizontal timbers at low water had been attacked in the same way.

"In the vertical pieces and piles, it was noticed that though the worm had entered them, its progress was small as compared with the horizontal pieces.

"The timber frame placed as a fender outside the iron portion of the jetty, was also attacked by the Chelura in vast numbers, which had commenced work at the ends of the timbers, or where one piece came in contact with another."

Rot in Timber. - Under the influence of air and moisture,

' Stevenson's “ Bell Rock Lighthouse."

${ }^{2}$ M.P.I.C.E., vol. ciii. p. 338.

- Ibid., vol. xli. p. 263.

S Ibid., p. 341 . 
wood changes superficially, and takes a deeper colour; it oxidizes or undergoes combustion, but the action is exceedingly slow.

When the wood is placed in a warm moist situation, where there is little or no ventilation, fermentation of the sap takes place-dry rot is the result.

When wood is very wet, or is kept very wet, in a situation where there is little or no ventilation, wet rot is the result.

The characteristics of the two kinds of rot are found to differ materially.

Dry rot produces a brownish spot in the direction of the fibres of the wood, which penetrates gradually to the heart. The tissue appears swollen by moisture; it remains compact but is very easily cut, and then presents a smooth surface.

When wood is attacked by wet rot it develops a fungus of determinate character, and appears at parts the least exposed to the light.

Preserving Timber.-The mechanical means usually adopted for preserving timber used in marine works from the attacks of the worm consist in covering the whole surface, between high-water mark and the bottom, with flat-headed or scuppernails, which may be of iron, copper, or zinc, about 1 to $1 \frac{1}{2}$ inch in diameter, and driven so close together that the heads touch but do not overlap. This method is expensive both on account of materials employed and the time required in the operation.

A second plan is to cover the timber with zinc or copper sheets, the timber being first tarred and then covered with brown paper tacked on, and again tarred in the same way that ships' bottoms are treated before being covered with the copper or zinc sheathing. Either of these methods answer the purpose well when applied to straight piles or timbers where no underwater connections are required; but for framed structures neither can be considered altogether suitable, inasmuch as the slightest defect in the covering will leave room for the entry of the worm, and owing to the numerous cuttings and bolt-holes that must necessarily occur for framing and fastenings, such defects are practically unavoidable.

Metal sheathing or close scupper-nailing to piles should be carried down at least one foot below the ground line and up to extreme high-water mark.

$\Delta$ t Flushing, copper sheathing is used for the protection of 
the timber gates from the attacks of the worm, and for the same purpose large scupper-nails are used to protect the fenders and other timbers. ${ }^{1}$

For protecting the piles of a jetty at Port Darwin, Mr. J. W. James sheathed all, up to high-water line, with Muntz metal. ${ }^{2}$

The chemical processes for the preservation of wood are numerous; the principal and most valuable are the following :-

Corrosive Sublimate, or bi-chloride of mercury under the name of "kyanizing," has met with a considerable amount of success in dry or comparatively dry situations, but in water, and particularly sea water, as a remedy against the marine worm, it has invariably failed. ${ }^{3}$ It has been found that piles, after three years' immersion, did not contain a trace of the preservative compound.

Sulphate of Copper is useful as a preservation against dry rot, and has perhaps been the most successful of all the metallic salts as an antiseptic for timber; ${ }^{4}$ but for piers and other structures, exposed to the action of water, it has practically no value, as the water dissolves out the salt with great rapidity. Timber, prepared with this salt, used for marine purposes is as readily destroyed by marine worms as unprepared timber.

Chloride of Zinc is a powerful antiseptic, but its weak point for wood preserving consists in its extreme solubility in water. ${ }^{5}$ The timbers most resistant of decay, whether when immersed in water or buried in the ground, are those which are richest in tannic and gallic acid, such as the oak. Hatzfield's process of preservation, therefore, consists in the impregnation of timber of various kinds with tannic acid, followed by an injection of a solution of pyrolignite of iron which in the cells gradually becomes tannin of iron. ${ }^{6}$

Creosote, a distillate from coal-tar, is the only substance which, efficiently applied, accomplishes the object aimed at, namely, the preservation of timber against rot and against the ravages of marine worms.

True creosote is the product of the destructive distillation of wood, and has never been used for preserving timber; but a substance having been discovered in coal-tar, since called

I.P.I.C.E., vol. 1v. p. 373.

Ilid., vol. Ixxviii. p. 102.

${ }^{2}$ Ibid., vol. ciii. p. 337.

1 Ibid.

s Ibid., 103.

Ibid., vol. xliv. p. 322. 
carbolic acid, or phenol, which was thought by sorne to be identical with the creosote of wood, the process came to be called after a time the creosoting process. ${ }^{1}$

The antiseptic substances used in the process are all obtained by the distillation of coal-tar, which is subjected to heat placed beneath the still. The operation is sometimes aided by the injection of steam, and sometimes by the application of the exhausting air-pump. The products of distillation come over very nearly in the order of their respective volatilities, those of lightest specific gravity being followed in succession by heavier ones as the heat increases. The result is to break up the tar into three groups of products, viz. oils lighter than water; oils heavier than water; and pitch. ${ }^{2}$

The heavy oils of tar, or dead oils heavier than water, constitute the "creosote" of the timber-yards. They contain numerous substances, some of them liquid, some semi-fluid, varying considerably in their properties, but most of them now recognized as antiseptics. ${ }^{3}$

"London 0ils.-The dead oils made in London and in all places where the tar is produced by the carbonization of the coal of the Newcastle district, are, as compared with other dead oils, richest in semi-solid substances, such as napthalene, anthracene, pyrene, etc., and they require a higher temperature to volatilize. These are generally called London oils."

"Country 0ils. - The dead oils of the Midland districts are lighter, thinner, and more volatile, and contain usually a larger proportion of the ordinary tar acids. These are usually called country oils."

"Scotch Oils are, many of them, still lighter, thinner, and more volatile, sometimes lighter than water." 4

The process of creosoting consists in thoroughly impregnating the timber with the heavy tar-oils, the object being to coagulate the albuminous substances in the sap remaining in the wood, but chiefly to thoroughly fill the pores with an imperishable, antiseptic substance which renders the timber impervious to air and moisture, and acts, in the opinion of Dr. Letheby, as a positive poison to the lower forms of animal life. Timber treated by this process retains all its original elasticity.

Some difference of opinion appears to exist as to whether

1 M.P.I.C.E., vol. Ixxviii. p. $103 . \quad$ ' Ilid., 106. ' Ibid., 107.

- Ibid., p. 108. 
the light or the heavy dead oils are the most suitable for efficiently preserving timber; the earlier introducers of the process certainly advocated the use of the latter, containing napthalene, etc. $;^{1}$ while, later, the thinner oils, containing more of the tar acids, such as carbolic acid, were preferred.2 'This view is again controverted by others, who now hold that it is only the heavy oils which can be relied upon to excite a continuous preservative action, the creosote itself being liable to become dissipated in course of time. ${ }^{3}$ Mr. Boulton advocates an admixture of both, ${ }^{4}$ provided neither were so manipulated as to contain a larger proportion of volatile substances at the expense of the more durable, and therefore, for this purpose, more valuable antiseptics. ${ }^{5}$

In view of the more penetrating power of the thinner oils, Mr. F. M. Roberts suggests that the best system of creosoting timber would be to first inject the light, or country, oil, then, running this off, using the heavy, or London, oil, which being forced in by increased pressure would drive the thinner oil further in, while the thicker and heavier oil would hermetically seal the outer pores of the timber. ${ }^{6}$

Without pressure, light oils penetrate timber more easily than heavy oils. Of adulterative substances, bone oil penetrates more readily than creosote; solutions of metallic salts more readily still; and water more readily than all. Those substances which penetrate most readily are generally the least permanent. $^{7}$

The reasons why tar, in its entirety, is not adopted in the preservation of timber, are that the crude napthas or oils lighter than water are useless as antiseptics, and would immediately evaporate, whilst the pitch, from its too great solidity, would form an impediment to the injection. ${ }^{8}$

Carbolic Acid has been looked upon as one of the most important ingredients of creosote as a preservative of timber, and as an antiseptic it is one of the most powerful amongst the tar acids; but it appears to be now recognized that, owing to the fact, as determined by numerous and reliable authorities, of its being volatile at ordinary temperatures, it is soluble in water, that its combinations are not stable; that, although

1 M.P.I.C.E., vol. 1xxviii., p. 108.

3 Engineering, vol. 1. p. 607.

sllid., p. 197.
2 Ibid., 110.

IT.P.T.C.E., vol. Ixxviii. p. 119.

'Ibid., 194. $\quad$ Illid., p. 107. 
a powerful germicide, its efficacy ceases as soon as it evaporates, or is washed out of the substance intended to be preserved. It cannot be considered a durable agent, particularly for piles and other timbers used for harbour works. ${ }^{1}$

The apparatus required for the ordinary process of creosoting consists of a wrought-iron cylinder usually of about 6 feet diameter, and of a length sufficient to take in the longest timber required to be treated. Ordinarily one end of the cylinder is permanently closed, but a convenient arrangement is to have both ends open, so that the timber may be entered at one end and removed at the other. The ends are fitted with strong cast-iron doors, by which they are hermetically closed. A tank in close proximity to the cylinder to contain the creosote, fitted with an arrangement of steam-pipes for heating the contents. An exhaust air-pump connected with the cylinder, and a force-pump connected with both cylinder and tank, together with a suitable engine and boiler for efficiently working the apparatus. The cylinder is fitted with rails to a gauge corresponding with the roads extending through the timberyard. The timber to be treated is placed upon and firmly secured to strong trucks, which are then run into the cylinder.

In arranging the timbers on the trucks, care is taken to keep them separate from each other by means of small pieces of iron or wood, so as to admit of the free passage of the creosote between them.

The doors being hermetically closed, the air.pump is set to work, and a vacuum created in the cylinder as complete as possible, which is maintained for a considerable time, or until all the air is extracted from the pores of the wood.

The creosote heated to a temperature of about $120^{\circ} \mathrm{Fahr}$., to bring the whole of the suspended and solid constituents into a perfectly liquid condition, is then allowed to flow into the exhausted cylinder. When it ceases to flow freely of its own accord, the force-pump is started to force more creosote into the cylinder if required, and to raise the pressure to $150 \mathrm{lbs}$. or 200 lbs. per square inch. This pressure is maintained for a considerable time, depending upon the character of the wood under treatment, and the quantity of creosote per unit of measure to be injected.

The hygrometric condition of the timber at the time of

1 M.P.I.C.E., vol. lxxviii. pp. 113, 114 
treatment is an important element in the success of the creosoting process. Woody fibre itself is heavier than water; its specific gravity being generally considered as equal to $1 \%$. It is therefore owing to the looseness of the texture that so many kinds of timber are lighter than water. As fir timber can under certain conditions absorb so much moisture as to become waterlogged, or actually heavier than water, its powers of absorption may be estimated from its specific gravity. ${ }^{1}$

The weight of water in fresh-filled timber varies in different species from one-fifth to one-half the total weight. A large quantity of this is rapidly given off by evaporation, but as equality approaches between the hygroscopic state of the atmosphere and the moisture of the wood, drying takes place very slowly, and can never be complete. ${ }^{2}$ Timber thoronghly airdried hardly ever contains less than from 15 to 20 per cent. of water after from two to three years' stacking. ${ }^{3}$

Theoretically, timber should be thoroughly dry and free from all sap before being placed in the cylinder. Practically, except perhaps in very special instances, this condition is never attained. Various means have been tried to avoid the loss of time involved in stacking for the purpose of drying and seasoning, such as the application of superheated steam, currents of hot air, drying-stoves or ovens, but none have proved altogether satisfactory, and have been abandoned sooner or later so far as regards the preparation of timber on a large scale for marine purposes.

The action of the exhaust air-pump, as used in the ordinary process, withdraws the air from the pores of the wood; but however perfect the vacuum may be, it does not extract to any great extent the moisture and sap, upon the absence of which the efficiency of the creosoting process depends.

By the application of dry heat to the cylinder, the water and sap would be volatilized, and would be withdrawn as steam by the action of the air-pump, but the wood would crack and open to an extent that would be undesirable. ${ }^{4}$

Mr. Boulton meets the difficulty, and gets rid of the moisture in the wood, after it is placed in the cylinder, by taking advantage of the fact that while the boiling point of water is $212^{\circ}$ Fahr., the boiling point of the creosote oils ranges from $380^{\circ}$ to

I.P.I.C.E., vol. Ixxviii. p. 124.

3 Ibid., lxxviii. p. 125.
2 Ibid., vol. lii. p. 293.

- 1bid. 
$760^{\circ} \mathrm{Fahr}$. These boiling points are, however, lowered by the effects of a vacuum. He therefore raises the temperature of the creosote to something over the boiling point of water. The creosote is thus made the vehicle for conveying sufficient heat to the timber to evaporate the water and sap contained in it. The heat, being communicated through an oily medium, does not injure the timber from which the water has been volatilized. ${ }^{1}$

A cylinder, similar to that used for the ordinary process, but fitted with a dome on the top, to which is attached the exhaust-pipe of the air-pump, contains the timber introduced in the usual way.

The exhausting process, instead of ceasing on the creosote being passed into the cylinder, is continued, the creosote in the mean time being raised to a temperature of about $230^{\circ} \mathrm{Fahr}$. 'I'he creosote is not allowed to rise quite to the top of the cylinder, so that a clear space is reserved for the free passage of the vapour extracted from the timber, and as a precaution against the creosote being carried over into the exhaust-pipe.

The exhaust is continued until all the water and sap contained in the timber is extracted. By the aid of the high temperature of the creosote and the air-pump in the form of vapour, the pressure-pump is then applied in the usual way.

The vapour drawn through the exhaust-pipe of the air-pump is condensed by passing it through the coil of a condensing apparatus, the resulting water being collected and measured in a receiving tank. ${ }^{2}$

The quantity of creosote injected should exceed the quantity of moisture extracted. With charges of very wet sleepers, Mr. Boulton has withdrawn water equal in volume to fifty gallons per load, and replaced it with an equal volume of creosote by the action of the air-pump alone. ${ }^{3}$

An experiment made by Mr. Boulton on six fir sleepers 8 feet 11 inches by 10 feet 5 inches $=18.57$ cubic feet, showed that water to the extent of $120 \mathrm{lbs}$. $=$ to $6.45 \mathrm{lbs}$. per cubic foot, was extracted, yet the timber when removed from the cylinder after completion of the process, weighed $155 \mathrm{lbs}$. = to $8.35 \mathrm{lbs}$. per cubic foot more than when put in, thus proving that a total quantity of $275 \mathrm{lbs}$. of creosote, or $14.8 \mathrm{lbs}$. per cubic foot, had been injected. ${ }^{4}$

In England and Holland, for land purposes, the amount of
' M.P.I.C.E., vol. 1xxviii. p. 126.
${ }^{2}$ Ibid.
s Ibid.
- Mirl., p. 206. 
oil usually specified is about 8 to $10 \mathrm{lbs}$. per cubic foot, while for marine purposes 10 to $12 \mathrm{lbs}$. per cubic foot has hitherto been considered sufficient. ${ }^{1}$ For the higher temperatures of sea water on the French coast and in the southern harbours of the United States, a charge of about 19 lbs. per cubic foot is required to insure immunity from the attacks of the worm. ${ }^{2}$ In dealing with New Zealand woods, Mr. W. Sharp found that the quantity of sap produced by white pine was practically 1.08 gallons per cubic foot; by Rimu 0.97 gallon per cubic foot, and by Miro 0.705 gallon per cubic foot; and that the correct quantity of creosote for each of these timbers, allowing for a slight excess over sap extracted, was for white pine $13.8 \mathrm{lbs}$. per cubic foot, for Rimu 12.4 lbs. per cubic foot, and for Miro 9 lbs. per cubic foot. ${ }^{3}$

The charges placed in the cylinder should consist as nearly as possible of timber of the same class, length, scantling, density, and degree of dryness, otherwise the quantity of creosote absorbed by the several pieces making up each charge will be irregular, and the result unsatisfactory.

All timbers should be converted and all bolt-holes bored before treatment, otherwise any work upon them penetrating to parts not so thoroughly saturated with creosote as the outsides may form inlets for decay and points of attack by the worm.

A system introduced by Mr. H. Aitkin, of Falkirk, consists simply of soaking the timber in melted naphthaline, for a period of from two to twelve hours, depending on the bulk of the piece. A temperature of $180^{\circ}$ to $200^{\circ} \mathrm{Fahr}$. is all that is required for the process, and is most easily obtained by placing steam-pipes in the bottom of the tank containing the material. A valuable feature in this process appears to be that it can be applied to green timber. The naphthaline makes its way through the pores of the wood, decomposing the albumoid compounds and displacing both sap and water. The naphthaline then becomes fixed, and the whole substance is permeated with a solid antiseptic substance of a permanent character. A further advantage attributed to this process is, that it does not render the timber more difficult to cut; neither does it interfere with its being worked, painted, or varnished. ${ }^{4}$

Hayford's system of creosoting, introduced in America some
' M.P.I.C.E., vol. 1s $8 x$ iii. p. 448.
2 Ilid.
3 1bid., xciii. p. 414.

4 Engineering, vol. 1. p. 607. 
years ago, consisted in passing steam into the cylinder, after being charged with the timber in the usual way. Air was then forced in by an air-pump until a pressure of 30 to $40 \mathrm{lbs}$. to the square inch was reached. A temperature of $240^{\circ}$ to $250^{\circ} \mathrm{Fahr}$. was then maintained for some time by the assistance of a coil of steam-pipes in the bottom of the cylinder. When the timber had been subjected to this treatment for a sufficient length of time, determined by experience, the air and vapour within the cylinder were withdrawn. To completely exhaust the sap and moisture, several hours' work with the air-pump was required. When a vacuum of 24 inches was reached, the operation of pumping was suspended, and creosotes oil, heated to a ternperature of $200^{\circ}$ Fahr., was admitted into the cylinder through perforated pipes; when the cylinder was full, the pressure was raised to 100 lbs. on the square inch. ${ }^{1}$

In America, it has been concluded that whatever preservative is to be adopted, the timber for piles subjected to the action of sea-worms should first be charred so as to kill any germs near the surface, open the pores of the wood for the antiseptic, and destroy the nutritive matter on which the worm lives. ${ }^{2}$

The following is the practice of the Eastern Railway Company of France in creosoting timber and sleepers:--Sleepers as delivered are stacked and seasoned in the open air. They are then adzed and bored by a special machine, loaded on trucks, and run into a drying-oven, where they remain for twenty-four hours or more. After drying at a temperature of about $176^{\circ} \mathrm{Fahr}$., they are run into a metal cylinder 6 feet 3 inches diameter and 36 feet long, which is hermetically closed. The air is then exhausted, and a partial vacuum maintained for about half an hour. Communication is then opened with reservoirs of dead oil, which is allowed to flow in at a temperature of $176^{\circ} \mathrm{Fahr}$. under pressure. When the oil ceases to flow under moderate pressure, it is forced in by a pump up to a pressure of $83 \mathrm{lbs}$. per square inch, and this pressure is maintained for an hour or an hour and a quarter. Communication with the oil-reservoirs is then reopened, and the excess of oil not absorbed by the timber flows back. The cylinders hold 168 sleepers each. The quantity of oil absorbed is determined by measuring the volume of oil before and after

${ }^{1}$ M.P.I.C.E., vol. Ivi. p. 300; and Proceedings of the Engineers' Club, Philadelphic 1879 , p. 80.

2 Scientific American, vol. lxv. p. 87. 
the operation. The wood used is principally oak and beech. The oak sleepers absorb from 2.4 to 2.7 quarts per cubic foot, beech sleepers from $8 \cdot 7$ to 10 quarts per cubic foot. The whole operation takes about four hours. After fifteen years' service, the sleepers taken out have been 15 per cent. for creosoted oak and 50 per cent. for creosoted beech. ${ }^{1}$

The following are extracts from a specification for the preservation of timber sleepers used on New Zealand railways. ${ }^{2}$

"The creosote used under this contract shall be obtained from coal-tar. It is to be perfectly liquid at a temperature of $100^{\circ} \mathrm{Fahr}$. It shall contain not less than 20 or more than 30 per cent. of constituents that do not distil at a temperature of $600^{\circ} \mathrm{Fahr}$., and shall yield not less than 8 per cent of tar acids.

"The operation of extracting the moisture from the sleepers and impregnating them with creosote shall be as follows:-

"The sleepers shall be put into the creosoting-chamber in a green state. The chamber shall then be filled with creosote to the level of the top of the sleepers, space for gases being left in the dome. The temperature of the creosote is then to be raised to such a point as will exactly convert the moisture in the sleepers into steam without boiling the creosote, but never to exceed $250^{\circ} \mathrm{Fahr}$. The steam from the sleepers is to be exhausted by an air-pump connected with the dome, and condensed into a tank, where it can be measured.

"The air-pump is to be set to work as soon as the heat is applied, and kept going till all the moisture in the sleepers is extracted. During this time the heat of the creosote is to be carefully regulated to meet the variations in the boiling point through the action of the air-pumps.

"After the moisture has been completely extracted from the sleepers by the process just described, the chamber is to be filled quite full with creosote, and pressure shall be applied by hydraulic-pumps for such a length of time, and with such force as may be found necessary, to insure that each and every sleeper is impregnated with at least $18 \mathrm{lbs}$. weight of creosote.

"The temperature of the creosote shall be maintained at $120^{\circ}$ Fahr. during the impregnating process. The pressure-pumps

1 Extract from Revue Generale des Chemins de Fer.

$=$ M.P.I.C.E., vol. xciii. p. $\$ 16$. 
are not to be fed with creosote from the main tank, but from a small tank in which a gauge shall be placed, to measure the quantity taken up by the sleepers.

" A gauge shall also be fixed on the highest point of the creosoting-chamber, to ensure that the chamber is quite full before the pressure-pumps begin to work. The sleepers in the creosote-chamber shall be laid parallel, with one inch spaces all round, the spaces being kept by pieces of wood or iron.

"The creosoting-chamber and tanks shall be kept perfectly clean and free from muddy sediment at all times." 


\section{CHAPTER XIV.}

Cost of Works-Cost per Acre of Water Area-Cost of Locks and Docks-Cost of Quay Walls-Cost of Floating Docks-Dock Gates-Cost of Caissons-Cost of dredging.

IT is difficult to compare the cost of different dock works on account of dissimilarity in the physical characteristics of site and strata, local rates of labour, and materials available, the habits of the people, and their methods of working.

The probable approximate cost of a projected work may, however, be arrived at, based upon the cost per unit of works executed; but such data can only be of value when applied under conditions generally approximately similar.

Cost of Docks per Acre of Water Area-The Albert Dock, Hull.-22.8 acres

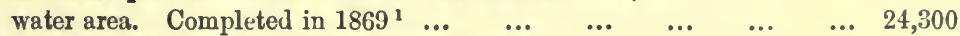
The Original London and St. Katherine's Docks。 ${ }^{2}$ from 30,000 to 50,000

West India Dooks (exclusive of the additions. Completed in 1870). ${ }^{3}-63$

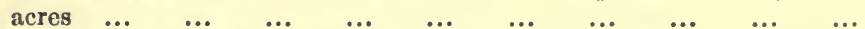
Sillouth Dock,-4 acres, with 25 feet 6 inclics depth of water. Completed in 1859

Ditto (including jetty, timber wharfing, sea channel, entrance gates, and

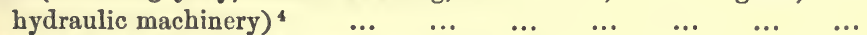

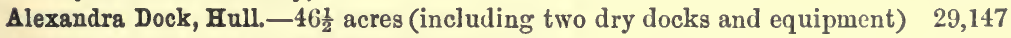

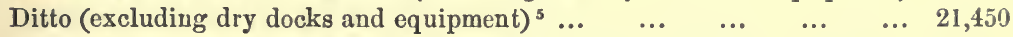
Ditto (excluding the cost of the two dry docks, but including equipment) ${ }^{6} \quad 28,867$ Portsmouth Dockyard Extension.-61 acres (exclusive of docks and locks) ${ }^{i} 24,000$

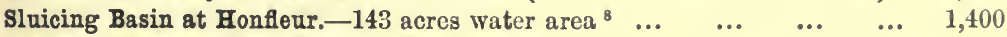

West India Dock and Basin.-32 acres water area (including entrance

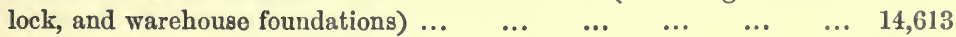
Ditto (including warehouses, railways, hydraulic machinery) ${ }^{9} \quad \ldots \quad \ldots \quad 17,845$ Queen's Dock, Glasgow.-33 acres (including land and equipment) $\quad \ldots \quad 44,444$

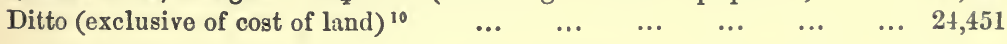

${ }^{1}$ M.P.I.C.E., vol. xli. p. $116 . \quad{ }^{2}$ Ibid., vol. xxxiv. p. 168.

Ibid., 169. 'Ibid., vol. xxi. pp. 328-343. 's Ibid., vol. xcii. pp. 175, 176.

- Ibid., deduced. ${ }^{7}$ Ibid., vol. lxiv. p. $227 . \quad{ }^{8}$ Ibid., vol. lxvii. pp. 464-466.

- Ibid., vol. xxxiv. p. 165.

10 "Description of the Queen's Duck, Glasgow, and the River Clyde," by Mr. J. Deas, C.E. 
Barry Docks. - Per acre of water area (including gates and caissous) (approx.)

Ditto, fully equipped (including all railway sillings round the doek, coaltipping machinery, hydraulic maehinery, buoys and moorings, water supply, eleetrie light, weighing-bridges, ete. ${ }^{1} \quad \ldots \quad \ldots \quad$ (approx.)

Prince of Wales's Dook, Swansea.-291 (including loek entranee and com$\begin{array}{lllllllll}\text { plete equipment) } & 2 & \ldots & \ldots & \ldots & \ldots & \ldots & \ldots & \text { (approx.) } 18,600\end{array}$

Cost of Docks and Locks.-Approximate cost per cubic yard internal capacity-

\begin{tabular}{|c|c|c|c|c|c|c|c|c|c|c|}
\hline \multicolumn{3}{|l|}{ Site." } & \multirow{2}{*}{$\begin{array}{c}\text { Depth on sill. } \\
\begin{array}{c}\text { Feet. } \\
16 \text { to } 20\end{array}\end{array}$} & \multicolumn{2}{|c|}{ Material. } & \multicolumn{5}{|c|}{ Cost per cubic yard. } \\
\hline es & & & & \multicolumn{2}{|c|}{ Timber and brick } & $\stackrel{8}{8}$ & $d$. & to & $\stackrel{8}{1}$. & \\
\hline arsenals & .. & $\ldots$ & Various & \multirow{2}{*}{\multicolumn{2}{|c|}{$\begin{array}{l}\text { Stone } \ldots \\
\text { Briek and stone }\end{array}$}} & 118 & 0 & 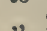 & 210 & \\
\hline Dock Com & pany & $\ldots$ & 27 & & & & & & 118 & \\
\hline and ... & $\ldots$ & $\ldots$ & - & \multicolumn{2}{|c|}{ Rock faced $\quad$... } & 117 & 8 & , & 10 & 0 \\
\hline & $\ldots$ & $\ldots$ & 25 & Brick & $\ldots$ & 20 & 0 & , & $\begin{array}{ll}3 & 0\end{array}$ & \\
\hline Wo & $\ldots$ & 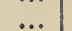 & 26 & Stone & $\ldots$ & 40 & 0 & $"$ & 416 & \\
\hline lackwall & $\ldots$ & $\ldots$ & - & Brick & & & & & 11 & \\
\hline s. & $\ldots$ & $\ldots$ & - & - & & & & & 411 & \\
\hline & $\ldots$ & $\ldots$ & - & - & & & & & 117 & \\
\hline dock & $\ldots$ & .. & 25 & Stone & & & & & 314 & \\
\hline t dock, Mal & & . & $33 \frac{1}{2}$ & Stone & & & & & 36 & \\
\hline \multirow{2}{*}{\multicolumn{4}{|c|}{ Avonmouth $\because$ dock (lock) about }} & Concrete... & ... & & & & 110 & \\
\hline & & & & & $\ldots$ & $\cdots$ & & & 1 & \\
\hline Hull ${ }^{5}$ doeks (loek) & about & & ... & ... & ... & $\ldots$ & & & 214 & 0 \\
\hline \multicolumn{11}{|c|}{ (This did not appear to include the whole of } \\
\hline
\end{tabular}

Portsmouth Docks.-Cost per foot lineal :-

No. 12 doek. ${ }^{6}$-Granite invert, Portland sub-invert. Portland lower altars; upper altars Portland, eapped with granite; granito broad altur; slides, slips aud coping; briek and concreto backing; beech and fir piles and fir timber in foundation and excavation. Mean depth of dock to floor 42 feet. Approximate cost ... ...

No. 13 dock.-Granite invert, Portland stono sub-invert. Granite lower altars; upper altars Portland stone, capped with granite; granite broad altar; slides, steps and coping; briek and conerete backing, beech piles in the foundation, fir timbers, and excavation. Mean depth of dock to floor, 42 feet 3 inehes. Approximate

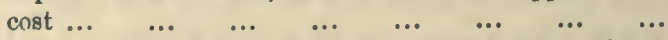

Deep doek.-Granito invert, also lower and upper altars, broad altar slides. Steps, sides and eoping; brickwork and eoncrete baeking. No timber or piles in the foundation. Mean depth of dock to the floor 46 feet 8 inehes. Approximate cost

1 M.P.I.C.E., vol. ei. p. 169.

3 lbid., vol. eiii. pp. 153-156.

3 "Lectures on Marine Engineering, Sehool of Military Lnginecring," 1875, 1876. J. B. Redman.

- Deduced from M.P.I.C.E., vol. Iv. p. 21.

- Ilid., vol. lxiv. p. 234.

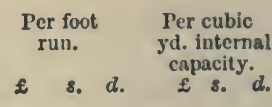

$\begin{array}{llllll}259 & 0 & 0 & 1 & 19 & 0\end{array}$ 
Locks.-Granite invert; lower altars Portland stone ; upper

altars Portland stone capped with grauite; grunite broad altars; slides, slips and coping; brick and concrete backing. No timber in the foundations. Mcan depth to the floor 47 feet 8 inches. Approximate cost

Alexandra Docks, Hull. ${ }^{1}$ - Including pumping machinery, stone and concrete, $\begin{array}{lllllllll}\text { cost per foot lineal } & \ldots & \ldots & \ldots & \ldots & \ldots & \ldots & \ldots & \ldots\end{array}$

Esquimalt Dock. ${ }^{2}$-Constructed of concrete, brickwork, and stouc, and including cost of coffer-dam, caisson and chamber, engines, pumps, boilers, and buildings, etc. 'Total length from coping line at entrance to back of work at head about 506 feet

Glasgow, No. 2 Dock $^{3}$ - Constructed entirely of concrete, on coucrete-cylinder foundations. Total length from coping line at entrance to back of work

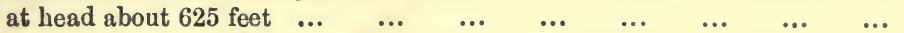

Walls and Piers-Liverpool Docks.-Cost of masonry in the ordin:ıry run of dock walls, consisting of rubble stone sct in lime mortar $\begin{array}{lllllll}\text { (per cubic yard) } \ldots & \ldots & \ldots & \ldots & \ldots & \ldots & \text { from } 188 \text {. to }\end{array}$

Ditto, about the entrances, including all especially dressed work in hollow quoins, and sills (per cubic yard) ${ }^{4}$... $\quad \ldots$ from $25 s$. to

Greenock.-Sea-picrs, with facing of cast-iron piles and stone blocks, backed with concrete deposited through the water at low tide. Upper portion of work composed of frecstone facing and rubble backing, walling of rubble stone, finished with granite coping and causeway. Total width of pier 60 feet; walls 33 feet in height, 11 fcet 6 inches at the base, and 5 feet at the top. $\begin{array}{lllllll}\text { Estimated cost (per lincal yard) } & 3 & \ldots & \ldots & \ldots & \ldots & \ldots\end{array}$

Quay Wall at the Mouth of the Rhons.-Concrete blocks fixcd in place

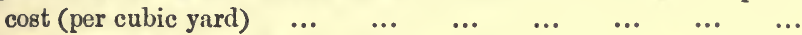

The total cost per lineal yard, including dredging, staging, and provisionally loading the concrete wall with concrete blocks before adding the superstructure-a precaution usually adopted in similar structures by French engineers, to guard against ultimate settlement ${ }^{6}$

Alexandra Dock, Hull.-Cost incluling foundations for coal-hoisting gear, and subsidiary works round walls. Height of walls ranging from 52 to 62 feet (per lineal yard) ${ }^{7} \ldots \quad \ldots \quad \ldots \quad \quad \ldots \quad \ldots$

Calais Harbour Wharves.-The tutal cost of sinking the foundation blocks, finished complete, including the purchase of pumps and all materials and labour, per cubic metre, about $3 s .3 d$; or, per $\begin{array}{lllllllll}\text { cubic }_{\operatorname{yard}}{ }^{8} & \ldots & \ldots & \ldots & \ldots & \ldots & \ldots & \ldots & \ldots\end{array}$

Queen's Dock, Glasgow. ${ }^{9}$-Cost of basin walls per yard lineal, on concrete cylinders, superstructure of freestone ashlar facing, in courses ranging from 15 to 18 inches in thickness, 2 feet on the bel,

1 M.P.I.C.E., vol. xeii. p. 176.

Ibid., vol. xlii. p. 566.

Ibi.l., vol. xxii. p. 427.

Ibid., vol. xcii. pp. 175-176.
2 Engineering, vol. xliv. p. 390.

M.P.I.C.E., vol. c. p. $7 t$.

- 1bid., vol. Iv. p. 106.

${ }^{8}$ Engineering, vol. xlvii. p. 578.

$48 \quad 0 \quad 0$ 
and stones not less than 4 feet long, backed with rubble stone, weighing from 2 to 3 tuns, set in 5-to-1 concrete, coped with granite stones 3 feet 6 inches wide by 17 inches thick, in lengths of not less than 4 feet, $£ 15128.4 d$.; $£ 13948 ; £ 129128.8 d$. ; $\begin{array}{llllllllll}\operatorname{mean} \quad \ldots & \ldots & \ldots & \ldots & \ldots & \ldots & \ldots & \ldots & \ldots\end{array}$

Ordinary quay wall founded on the boulder clay, consisting of concrete foundation, freestone ashlar face backed with rubble stone, set in 5-to-1 Portland-cement concrete, $£ 1165 \mathrm{~s}$. ; £101 78. 6d.; mean

Quay walls on piles and concrete foundations, substituted for concrete

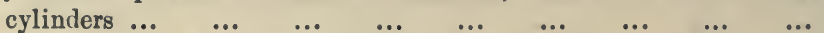

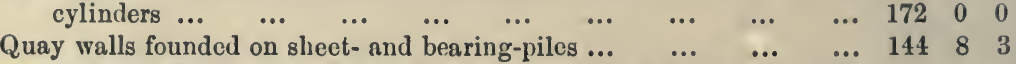

Albert Dock, Hull. ${ }^{1}$ - Cost of dock walls constructed of stone set in liaslime mortar, including excavation below the dock floor level, mooring-rings and ashlar blocks for the same, and all extras, per lineal foot

$\begin{array}{llllllll}\ldots & \ldots & \ldots & \ldots & \ldots & \ldots & \ldots & \ldots\end{array}$

$\begin{array}{lll}19 & 9 & 0\end{array}$

Quay Wall, Dublin.-The cost of construction complete is given by Mr. Stoney as follows: ${ }^{2}-$

Special Plant-

$\begin{array}{lllllllllll}\text { Diving-bell and barge } & \ldots & \ldots & \ldots & \ldots & \ldots & \ldots & \ldots & \ldots & 5,454\end{array}$

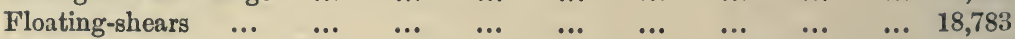

$\begin{array}{lllllllllll}\text { Block wharf } & \ldots & \ldots & \ldots & \ldots & \ldots & \ldots & \ldots & \ldots & \ldots & 18,783\end{array}$

Cranes, concrete mixer and engine chain, testing machine, rails, trueks,

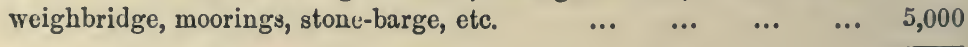

$33,8+7$

Quay wall per foot run complete $=$ to 16 cubic yards-

Excavating and levelling foundation, including maintenance of bell and $\begin{array}{llllllllll}\text { bell-barge } & \ldots & \ldots & \ldots & \ldots & \ldots & \ldots & \ldots & \ldots & \ldots\end{array}$

Block standing on wharf, including all materials, suspender-bars, $\begin{array}{lllllllllllll}\text { girders, etc. } & \ldots & \ldots & \ldots & \ldots & \ldots & \ldots & \ldots & \ldots & 16 & 0 & 0\end{array}$

Lifting, transporting, and setting blocks, including maintenance of $\begin{array}{lllllllllll}\text { floating-shears, etc. } \quad \ldots & \ldots & \ldots & \ldots & \ldots & \ldots & \ldots & 2 & 10 & 0\end{array}$

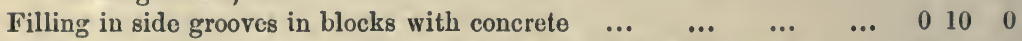

Superstructuro above concrete block, faced and coped with granite $\quad \ldots \quad \begin{array}{lllll}11 & 2 & 0\end{array}$

Shifting moorings, maintenance of wharf, and sundries $\ldots \begin{array}{llllllll}\ldots & \ldots & \ldots & 1 & 0 & 0\end{array}$

$31 \quad 2 \quad 0$

Interest on plant at 7 per cent., allowing 400 feet run completed per annum

Total cost per foot run

= per cubic yard of wall complete...

In some valuable articles in Engineering, on the subject of concrete blocks and their cost, it is suggested that the probable selling value of the special plant when done with should be credited to the work in estimating the cost.

It would appear reasonable, however, that works of this kind,

1 M.P.I.C.E., vol. 18i. p. 113, 116.

2 Ibid., vol. xxxvii. p. $34 t$. 
requiring a special class of plant, for which, on account of its special character, there may be little or no prospect of sale on completion, should bear the whole cost of the plant, in addition to interest on the total amount invested. The actual charge per unit of work depending upon the total quantity of work done, and the number of years over which it is spread. Dealt with in this way, the cost of the Dublin block-work set in place, including forming the foundation, would be as follows:-

Cost of special plant required for the manufacture and handling of the blocks :-

$\begin{array}{llllllllll}\text { Diving-bell and barge }{ }^{1} & \ldots & \ldots & \ldots & \ldots & \ldots & \ldots & \ldots & \ldots & 5,454\end{array}$

$\begin{array}{lllllllllll}\text { Lifting-shears } & \ldots & \ldots & \ldots & \ldots & \ldots & \ldots & \ldots & \ldots & \ldots & 18,783\end{array}$

$\begin{array}{lllllllllll}\text { Block-wharf } & \ldots & \ldots & \ldots & \ldots & \ldots & \ldots & \ldots & \ldots & \ldots & 4,610\end{array}$

Proportion of other plant, moorings, barges, chain-testing machine, etc. ${ }^{2}$... $\quad 3,400$

Representing a yearly capacity of 6400 cubic yards. $^{3}$

Cost of blocks on wharf, including all materials and labour, suspension-

bars, maintenance, etc., of block-wharf, etc. $£ 16 \div 16=$ per cubic yard $\quad 1 \quad 0 \quad 0$

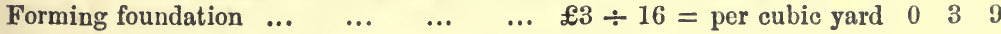

Lifting, transporting, and setting blocks, including maintenance of plant

$£ 3 \div 16=$ per cubic yard $0 \quad 3 \quad 9$

Shifting moorings, etc. $\quad \ldots \quad \ldots \quad \ldots \quad \ldots \quad £ 1 \div 16=$ per cubic yard $\quad 0 \quad 1 \quad 3$

Total per cubic yard 189

Assuming such work to have extended over periods of 5, 10, or 15 years, the proportionate charge for plant (with an addition of 5 per cent. per annum) per cubic yard, would be as follows:-

5 years. 10 years. 15 years.

Cost of blocks, including labour, materials, and

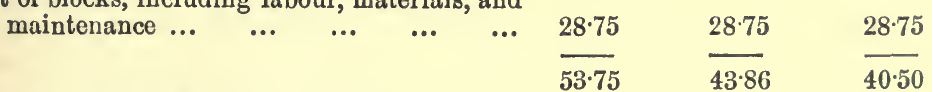

Quay Wall, Brest.-The total cost of the special plant required, including the barge, with all accessories for lifting, transporting, and setting the blocks, block-yard, slipway, and hauling-gear did not exceed the sum of $£ 4,000$.

The average daily work was 70 cubic yards of block-work laid, which, taking $300^{5}$ working days per annum, represents about 21,000 cubic yards per year.

1 M.P.I.C.E., vol. xxxvii. p. 344 .

2 It is assumed that this plant was also used for the superstructure.

${ }^{3} 400 \times 16$ (number of cubic yards per foot run of wall) $=6400$ cubic yards.

1 Enginecring.

s 300 working days per year appears much ton liberal an estimate, probably 200 days would be much nearer the fact. 
Allowing, therefore, interest on the above sum at the rate of 7 per cent. per annum, the cost for plant per cubic yard of blockwork set was 3.20 pence.

The cost of masonry blocks, including the platform or carriage on which

the blocks were built, labour, and material of all kinds was $\quad . . \quad 1580$

$\begin{array}{llllllllllll}\text { Launching } & \ldots & \ldots & \ldots & \ldots & \ldots & \ldots & \ldots & \ldots & \ldots & 1 \cdot 78\end{array}$

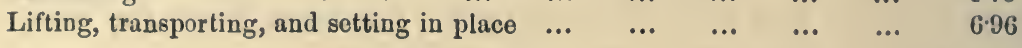

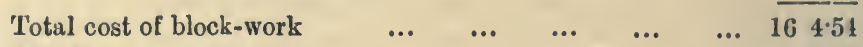

Add for interest on plant $\quad \ldots \quad \ldots \quad \ldots \quad \ldots r 20$

Or, $16 \cdot 8$ per cubic yard.

Total $\quad$... $\quad \ldots \quad \overline{167 \cdot 74}$

Assuming, however, that the block-work should bear the whole cost of the special plant required, with the addition of 5 per cent. interest on the first cost, then the charge for plant, spread over a series of years, and the total cost, would be as follows:-

5 years. 10 years. 15 years.

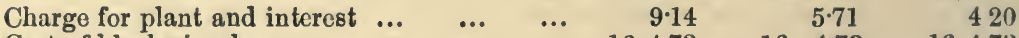

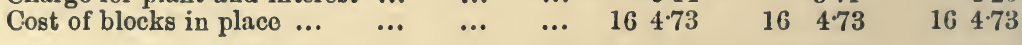

Portsmouth Dockyard. ${ }^{1}$

$\overline{171.87} \quad \overline{16 \quad 10.44} \quad \overline{168.93}$

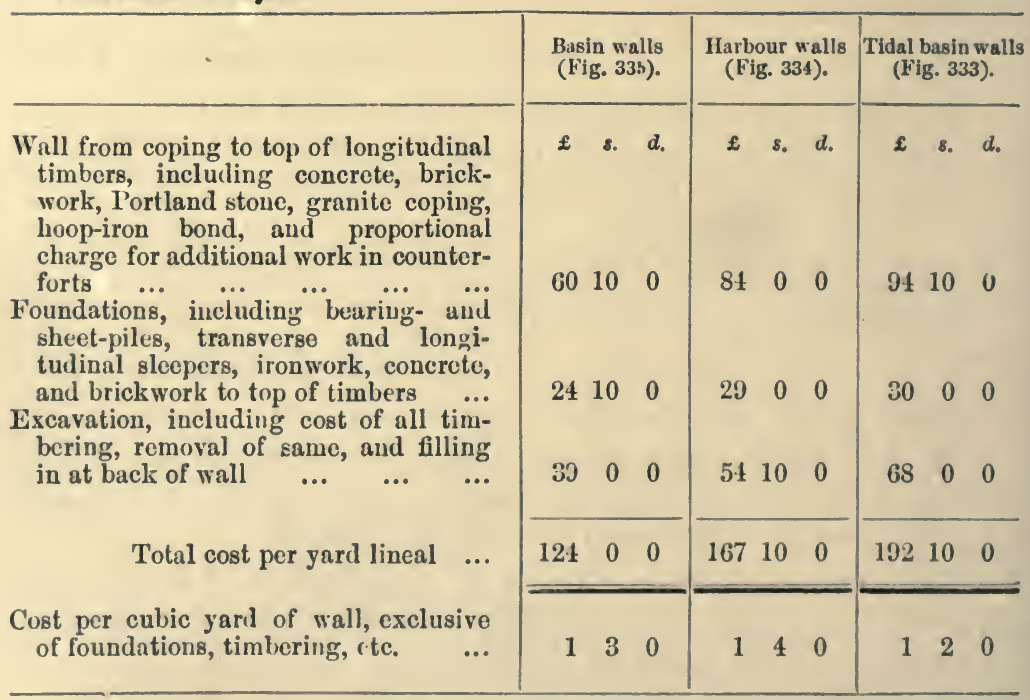

Carlingford Lock and Greenore. ${ }^{2}$ - The cost of the quay walls (Figs. 72, 73), averaging 45 feet in height, including foundations (except dredging the sites), staging, and fenders, per foot lineal, $£ 2788$.

' M.P.I.C.E, vol. Ixiv. pp. 233, 234, 235.

2 Ibid., vol. xliv. p. 141. 


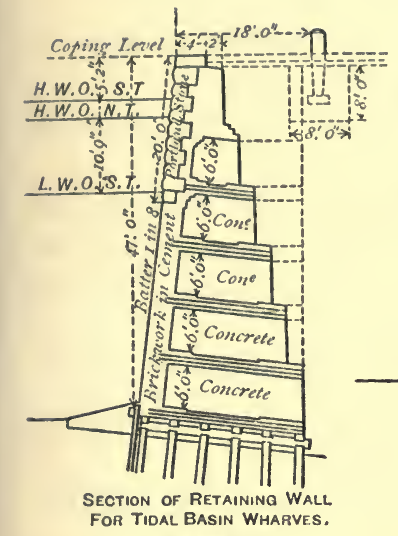

Fia. 333.

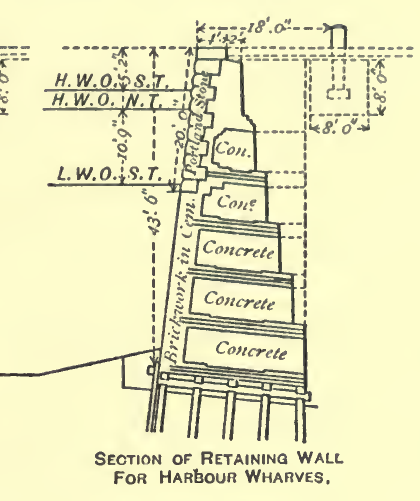

Fig. 334.

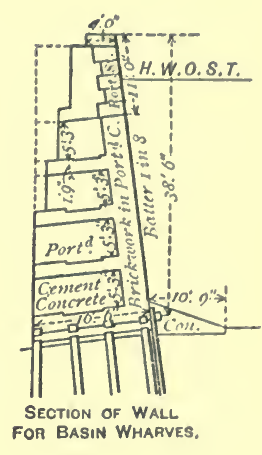

Fig. 335.
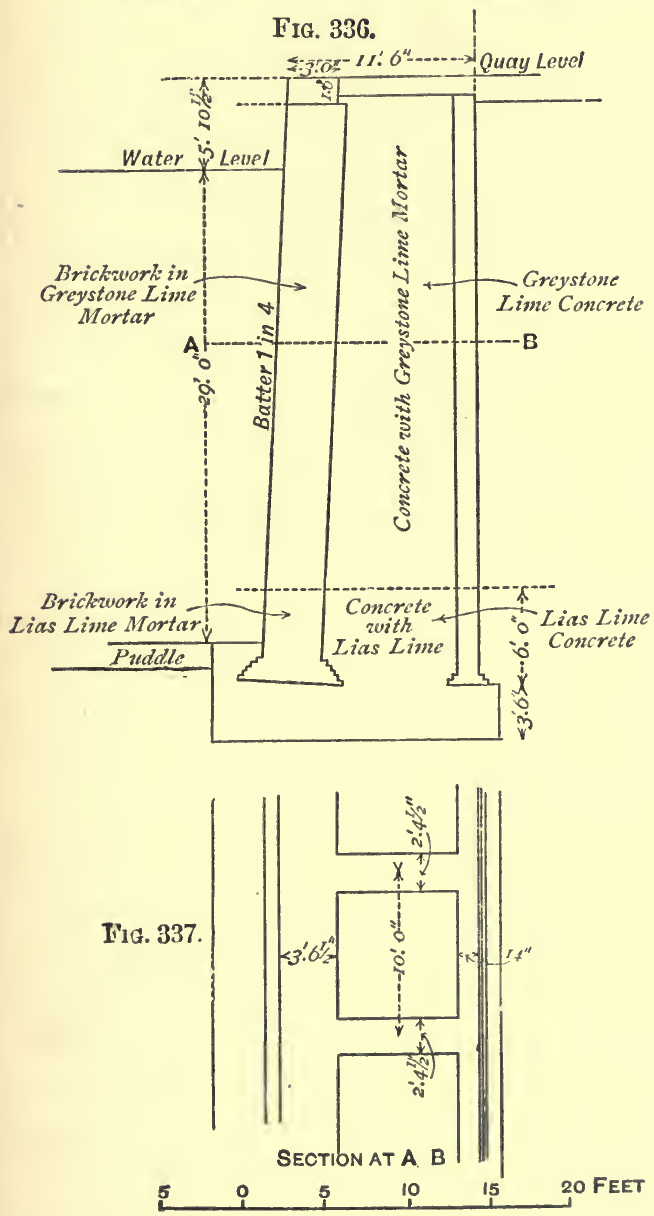

The Quay Walls at the London and St. Katherine Docks (Figs. 336, 337) cost about 12s. 6d. per cubic yard, or $£ 122 s$. per lineal foot. This low cost was due to the fact that the gravel and sand was obtained from the excavations. ${ }^{1}$

Floating Docks.Messrs. Standfield and Clarke give the following particulars as regards the cost and working of floating docks.

Taking a number of docks designed and constructed by the firm, they find that the cost of construction ranges from $£ 10$ to

1 M.P.L.C.E., vol. xxxiv. pp. 166, 176. 
$£ 15$ per ton of lifting power, the former rate obtaining as regards the more recently constructed docks.

Painting and repairs cost about $8 d$. per ton per year of lifting power.

Taking the Barrow Floating Dock, with a lifting power of 3200 tons as an example, the average annual expenditure for wages is given as $£ 450$, equal to a cost of $2 s$. $10 d$. per ton of lifting power, or about 1 per cent. on the first cost.

The cost of coal, oil, cotton waste, etc., varies with the work done; but it is charged at the rate of $4 d$. per ton of lifting power, or about one-ninth per cent. on the first cost.

The total yearly outlay on an average of years is equal to 4s. $1 d$. per ton of lifting power. ${ }^{1}$

Dams.-Cost of Iron Caisson Coffer-dam used in the construction of the Thames Embankment, including excavation, concrete inside, timber shoring, and cost of removal ${ }^{2} \quad \ldots \quad \ldots \quad \ldots$ per foot run

Cost of the timber dams employed in the construction of the Thames

Embankment, between Waterloo Bridge and the eastern end of the Temple Gardens, consisting of two rows of whole-timber piles with clay filling, supported by whole-timber shores and

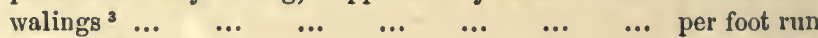
Cost of removal $\quad \ldots \quad \ldots \quad \ldots \quad \ldots \quad \ldots \quad \ldots$ per foot run $\begin{array}{lll}30 & 7 & 51\end{array}$

18114 $\begin{array}{lll}1 & 4 & 0\end{array}$

Cost of heavy timber and clay dam across the entrance of the Lowwater Basin, Birkenlead ${ }^{4} \quad \ldots \quad$... $\quad \ldots \quad$ per foot lineal Timber and clay dam constructed across the Victoria Dock, Hull ${ }^{\circ}$ per foot lineal

Cost of the Dublin Coffer-dam, including the front and back piling to the foundation pit, extending to a depth below coping of from 43 to 46 feet, cross-dam struts and every cliarge connected with the construction, maintenance, and removal ${ }^{6} \quad \ldots \quad$ per foot lineal $56 \quad 0 \quad 0$ 2100

The timber dam constructed in the entrance of the Avonmoutl Lock (Figs. 40, 41), consisting of borizontal whole-timber trusses and shoring, and sheeted on the outside with 4 -inch vertical planking, cost $£ 1500$, or about $98.9 d$. per foot super of dam on the face, or per foot run of length of coping level ${ }^{7} \quad \ldots \quad$... $\quad$... $\quad$... $\quad$... $2010 \quad 0$

\section{Portsmouth Dams ${ }^{8}$ -}

Inner dam-shallow part

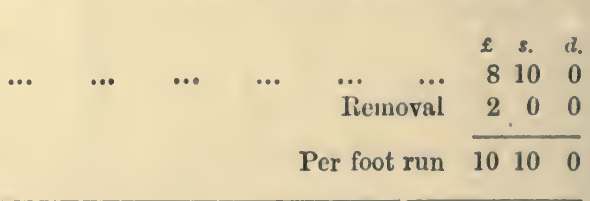

I Engineering, vol. lii. p. 460.

3 Thid., vol. xxxi. p. 25.

${ }^{2}$ M.P.I.C.E., vol. liv. p. 18.

- Ibid., p. 159.

4 Ibid., vol. li.p. 149

7 Ibid., vol. lv. p. 21. s Ibid., 150.

8 Ibid., vol. lxiv. 


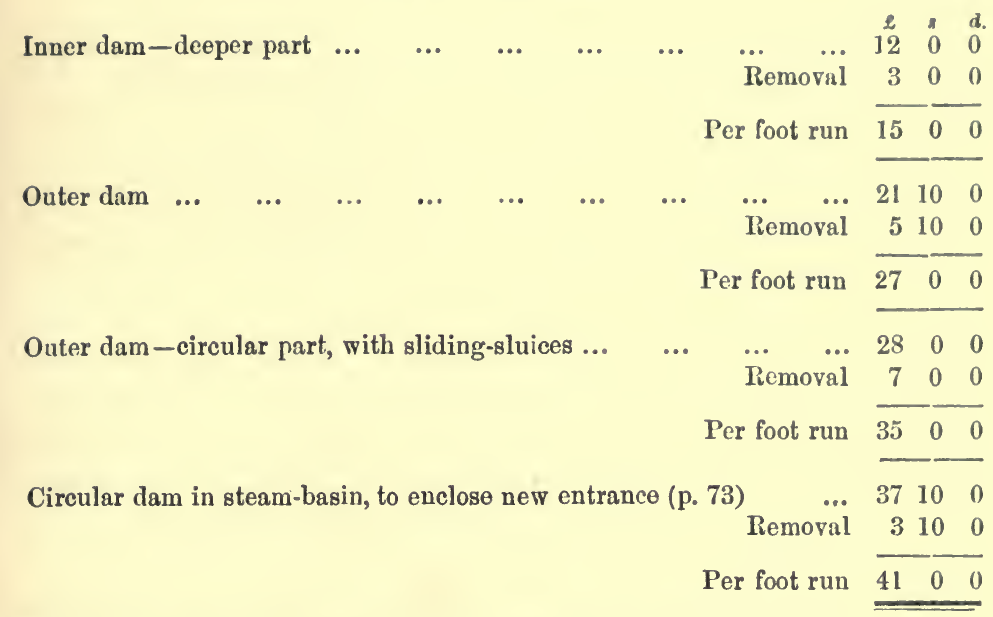

Approximate cost of constructing the earthwork embankment across the mouth of St. Mary's Creek, Chatham, consisting of materials

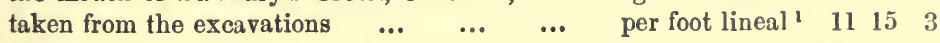

\section{Dock Gates.-Avonmouth Dock Gates 2 -}

$\begin{array}{cl}\begin{array}{c}\text { Average } \\ \text { per }\end{array} & \begin{array}{c}\text { Proportional } \\ \text { price per }\end{array} \\ \text { cubic } & \begin{array}{l}\text { cubic foot } \\ \text { of timber. }\end{array} \\ \text { s. } a . & \text { s. } d .\end{array}$

$\begin{array}{llllllllll}\text { Cost of timber } & \ldots & \ldots & \ldots & \ldots & \ldots & \ldots & \ldots & 2 & 5 \frac{1}{2}\end{array}$

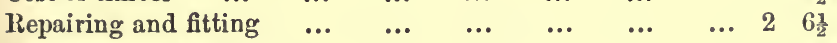

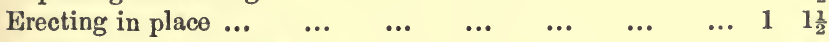

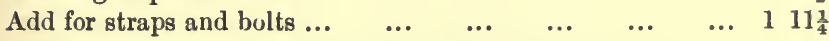

Add for castings, including anchors, gate-sluices, two sets of rollers to each leaf, pivots, and chain-roller boxes, but

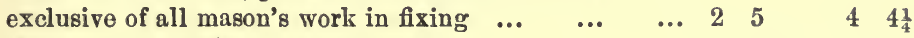

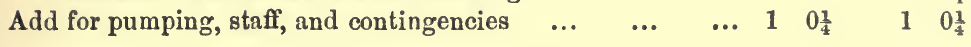
Total cost per cubic foot of timber $\quad \overline{11 \quad 6}$

Total cost of one pair of outer gates-

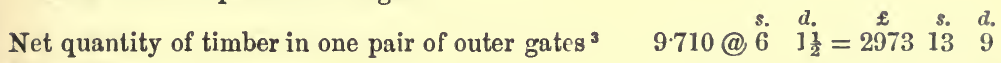

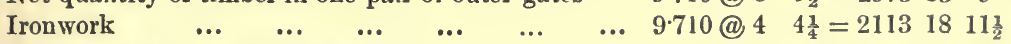

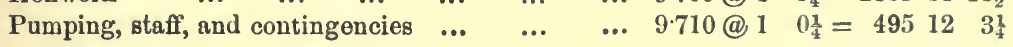

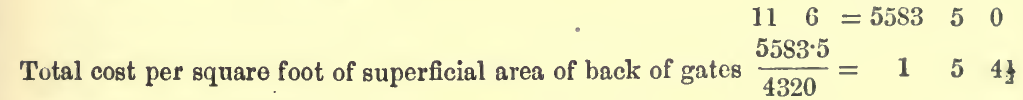
Or, taking the exact width between the copings, 70 feet by the

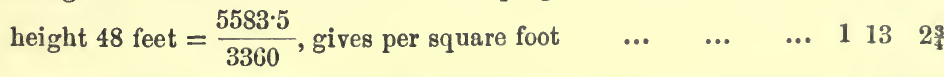
Dunkirk Dock Gates. ${ }^{4}-M r$. Guillain, the engineer of the 1 M.P.I.C.E., vol. xxxi. p. 26.

2 Ibid., vol. Iv. pp. 20, 118.

${ }^{3}$ Ibid., vol. Iv. p. 20, 118.

+ Ibid., vol. lix. pp. 26, 27. 
port of Dunkirk, made the following comparison of the cost of wood and iron gates, enclosing respectively two locks of the same width of 69 feet, and having the same rise of one-sixth the span. The outer faces of the gates were flat; the wooden ones were 23 feet 6 inches high, and 3 feet thick in the middle of each leaf; whereas the iron ones were 27 feet high, and 3 feet 7 inches thick in the middle. The lower part of the iron gates, down to the mean sea-level, formed a closed chamber, one part of which afforded flotation, and the other contained water-ballast. Both pairs of gates could safely bear a load of water corresponding to an equal difference of level of 22 feet between the dock and the sea. In both, the material had been distributed as economically as possible. These conditions afforded a favourable basis for comparison.

The price of equal surfaces was the same for both gates if the iron were galvanized, but the non-galvanized iron gate cost only four-fifths the price of the wooden one. The chances of durability were at least as great for the gate of galvanized iron as for that of wood, and they were almost as great for the non-galvanized iron where the paint could be often renewed.

\begin{tabular}{|c|c|c|}
\hline & Wood gates. & Iron gates. \\
\hline $\begin{array}{l}\text { Surface under pressure for } \\
\text { one leaf }\end{array}$ & 877 square feet & 984 square feet \\
\hline Total weight of one leaf in air & 50 tons & $\begin{array}{l}\text { Iron and wood, } 49 \text { tons; water- } \\
\text { ballast, } 8 \text { tons; total, } 57 \text { tons }\end{array}$ \\
\hline $\begin{array}{l}\text { Weight of wood and iron per } \\
\text { square foot of surface under } \\
\text { pressure }\end{array}$ & $126 \mathrm{lbs}$. & 112 lbs. \\
\hline $\begin{array}{l}\text { Effective weight of one leaf } \\
\text { immersed at mean sea-level }\end{array}$ & 32 tons & $\begin{array}{l}16 \text { tons, including wrter- } \\
\text { ballast }\end{array}$ \\
\hline $\begin{array}{l}\text { Effective weight of one leaf } \\
\text { completely immersed at high } \\
\text { water }\end{array}$ & 10 tons & $\begin{array}{l}10 \text { tons, including water- } \\
\text { ballast }\end{array}$ \\
\hline $\begin{array}{c}\text { Total } \\
\text { cost }\end{array}\left\{\begin{array}{c}\text { In } 1856, \text { date of con- } \\
\text { struction of wooden } \\
\text { of ono }\end{array}\right.$ & on na sont mare & $\begin{array}{l}\text { Iron, not galvanized, but } \\
\text { scraped, passod through } \\
\text { boiling oil, and painted with }\end{array}$ \\
\hline 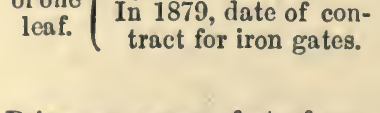 & $\begin{array}{l}20 \text { per cent. more } \\
\text { than in } 1856 \text {, or } \\
\text { £1 } 158 \text {. }\end{array}$ & $\begin{array}{l}\text { four coats of paint, } £ 1060 \\
\text { Iron, galvanized and painted } \\
\text { with four conts of paint, } \\
£ 1300\end{array}$ \\
\hline $\begin{array}{l}\text { Price per square foot of sur- } \\
\text { face under pressure in } 1879\end{array}$ & $£ 16$ s. & $\begin{array}{l}\text { Iron, not galvanized, but } \\
\text { passed through boiling oil, } \\
\text { and painted with four coats } \\
\text { of paint, } £ 1 \text { 18. } \\
\text { Iron, galvanized and painted } \\
\text { with four coats of paint, } \\
£ 16 \text {. }\end{array}$ \\
\hline
\end{tabular}


Alezandra Dock, Hull.'-Outer lock gates constructed entirely of greenheart timber, 40 feet high by 50 feet wide, built in three panels per foot super

Whitehaven Dock. ${ }^{2}$ - Gates constructed of pitch-pine, cxcept the heel-and mitre-posts, which are of greenheart $\quad . . \quad \ldots$ per foot super

Limorick Dock. ${ }^{3}$-Cellular gates constructed of Siemens-Martin mild steel, each leaf being 42 feet 7 inches long, by 25 feet 6 inches high, and 3 feet thick at the centre, cost, including all accessories

Or, per foot square of entrance per foot super $\quad 1 \quad 5 \quad 4$

West India Docks.4-Cellular iron gates 32 feet high, exclusive of gangway constructed of iron, except the heel- and mitre-posts, which are of greenheart $\quad \ldots \quad \ldots \quad \quad \ldots \quad \ldots \quad \quad \ldots \quad$ per foot super

Or, per square foot of entrance

Havre. ${ }^{3}$-Trans-Atlantic lock gates, 57 feet 5 inches long, by 34 feet 9 inches high, cellular, constructed of iron, with vertical main members, and all iron galvanized ... ... ... per foot super $\begin{array}{lll}1 & 10 & 9\end{array}$

Mr. Hayter, M.I.C.E., as the result of his experience, estimates the cost of iron gates at from $£ 110$ s. to $£ 2$ per foot super of gate, or an average of $£ 1$ 15s. per foot super. ${ }^{6}$

Mr. Hayter, M.I.C.E., expresses an opinion that by the omission of the roller, the spindle, and adjusting apparatus, the roller-path, etc., the saving in the cost of a pair of 60 feet gates may be taken to represent from $£ 400$ to $£ 500 .^{7}$

Caissons-Greenock. ${ }^{8}$-Rolling caisson closing entrance of the Garvel f $s, d$. Dock, 58 feet wide, and 28 feet 6 inches depth to invert, including the lowering bridge or roadway, 12 feet 10 inches wide, hauling-gear, and cover or deck of caisson-chamber

per square foot of entrance (about) $418 \quad 6$

Portsmouth. ${ }^{\circ}-F$ loating caisson closing east entrance of the north lock, 82 feet wide, and 39 feet depth to invert, width of roadway over caisson, 17 feet $\quad .$. approximate cost per square foot of entrance Portsmouth. ${ }^{10}$-Sliding caisson closing the west entrance to north lock, $\$ 2$ feet wide, and 47 feet 8 inches depth to invert, including lowering bridge, with 15 feet width of roadway, caisson-chamber, dcck, and hauling-gear $\quad \ldots \quad \ldots \quad \ldots \quad \ldots$ per square foot of entrance

Malta.-Sliding caisson closing entrance to Hamilton Dock, 94 feet wide by 41 feet from coping to invert, with fixed roadway deck with lifting ends, to form an approach to coping level, including the cover to caisson-chamber, hauling-gear, and hydraulic-engines

Cost of Dredging.-Statements as to the cost of dredging are, perhaps more than as regards any other engineering detail,
1 M.P.I.C.E., vol. xcii. p. 176.
- Ibid., vol. xcvii. pp. 335, 340.
Ibid., vol. xcii. pp. 451, 452 .
7 Ibid., vol. lix. p. 5 .
- Ibid., vol. lxiv. pp. 236, 237.

2 Toid., vol. lv. pp. 44, 97.

4 Ibid., vol. xxxiv. p. 176.

- Ibid., vol. lv. pp. 72, 118.

8 Ibid., vol. lxv. p. 346.

10 Ibid. 
open to criticism, owing to the diversity of practice in estimating and recording the quantities removed, and the details of expenditure included in the rate.

Carlingford Bar. ${ }^{1}$-The exceptionally heavy work of cutting through the Carlingford Bar in material consisting mainly of plastic blue clay, occasionally free from all stones, but generally with stones and boulders varying in size from shingle to stones of 4 tons weight, which were slung by divers and lifted by a crane carried by the dredger, cost on an average $1 s .5 d$. per ton $=2 s$. $1 \frac{1}{2} d$. per cubic yard, including all working charges. The total cost, including insurance, parliamentary expenses, and management, was $1 s .9 d$. per ton.

Bilbao. ${ }^{2}$-Dredging in sand and mud with a stationary centreladder dredger, working to 26 feet deep, and delivering into barges alongside, cost $2 \cdot 10$ pence per cubic yard, exclusive of all charges for plant.

Danube. ${ }^{3}$-Dredging in hard sticky clay by a single-bucket ladder dredger, and pumping ashore by a mud-pump attached to the same vessel, cost from 2.04 to 3.88 pence per cubic yard, measured by cross-sections; this cost included everything except interest and depreciation.

On the lower Danube, the average cost of dredging in fine sand and clay, and removing by hopper-barges a distance of about one mile, was 4.152 pence per cubic yard, including all charges except interest and depreciation. ${ }^{4}$

California..$^{5}$ - At Oaklands Harbour, near San Francisco, the average cost, taking over a period of eight years, of dredging in soft dock mud with grab or clam-shell machines, from a depth of 24 feet, removing by barges to a distance of one mile, and discharging, was 3.82 pence per cubic yard, exclusive of insurance, taxes, depreciation, and interest.

Dredging in Oaklands Harbour by means of a suction-pump, with horizontal cutting-gear, attached to the same vessel for reducing the material to be removed to the consistency of mud, raising to the surface and discharging through a line of pipes supported on floating pontoons, to the shore, a distance varying from 1100 to 2850 feet, cost, including all charges, $6 c l$. per cubic yard. ${ }^{6}$

1 M.P.I.C.E., vol. xliv. p. 135.

Ibid., vol. lxxxix. p. 90.

- Ibid., vol. Ixxxix. p. 94.
2 lbid, vol. li. pp. 245, 255.

I Ibid., vol. 1xv. p. 270.

- Engineering, vol. xxxviii. p. 30 . 
South Africa.-Taken over a period of twelve months, a Priestman's machine, with a 30-cwt. grab, lifted on an average 250 tons of sand daily. The cost for lifting, depositing in a barge alongside, and subsequently conveying ashore, was $11 \frac{1}{2} l$. per ton.

Calais and Boulogne. ${ }^{1}$-Dredging in sand and conveying about two miles out to sea, by a suction-pump hopper-dredger, has been estimated to cost, including all charges except interest, depreciation, and profit on plant, at Calais, 35 centimes per cubic metre $=2.50$ pence per cubic yard; at Boulogne, 46 centimes per cubic metre $=3.34$ pence per cubic yard.

This rate may be apportioned as follows :-

\begin{tabular}{|c|c|c|c|c|c|c|c|c|c|}
\hline Wages & $\ldots$ & .. & $\ldots$ & $\ldots$ & & ... & $\begin{array}{c}\text { ence per } \\
\text { abic yard. } \\
0.920\end{array}$ & $=$ & $\begin{array}{l}\text { Per cent. } \\
27.54\end{array}$ \\
\hline Coal & $\ldots$ & $\ldots$ & $\ldots$ & $\ldots$ & $\cdots$ & $\begin{array}{l}\cdots \\
\ldots\end{array}$ & 0.930 & $=$ & $27 \cdot 84$ \\
\hline Stores & $\ldots$ & $\ldots$ & ... & $\ldots$ & $\ldots$ & ... & 0.290 & $=$ & $8 \cdot 64$ \\
\hline \multirow{2}{*}{\multicolumn{4}{|c|}{ Repairs and maintenance }} & ... & ... & ... & $1 \cdot 200$ & $=$ & $35 \cdot 93$ \\
\hline & & & & \multicolumn{2}{|c|}{ Total } & & $3 \cdot 34$ & & $99 \cdot 99$ \\
\hline
\end{tabular}

Dredging by bucket-dredger in materials consisting of mud, and sand mixed with stones, hard soil, hard compact clay with boulders and beds of rock, measured in the solid, removed to sea a distance of two miles by hopper-barges and tugs, cost 3.38 francs per cubic metre $=2 s .0 \frac{1}{2} d$. per cubic yard. ${ }^{2}$

Ceylon. ${ }^{3}$ - At Colombo, dredging and conveying the material to sea has averaged $13 \mathrm{l}$. per ton, including interest and depreciation, the rate varying with the character of the material raised.

Holland. ${ }^{4}$-At the Maas, pump-dredging and depositing at sea has cost from $8 d$. to $10 d$. per cubic metre, equal to from 6.07 to $7 \cdot 64$ per cubic yard.

At the Amsterdam Ship Canal, dredging sand in the harbour, and transporting a distance of two miles to sea, cost, including 10 per cent. on first cost of plant, to cover interest and depreciation-

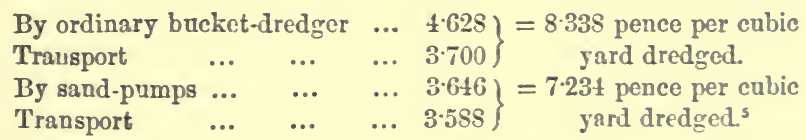

Ibid., vol. Ixxxix. p. 99.

Ilid.

5 Ibid., vol. lxii. p. 55. 
Dunkirk.-Dredging by bucket-dredger inside the harbour and in the basins carried out departmentally, and transported a distance of three miles, cost, including all expenses except interest and depreciation on plant-

$$
\left.\begin{array}{ccccc}
\text { Dredging } & \ldots & \ldots & \ldots & 1.93 \\
\text { Transport } & \ldots & \ldots & \ldots & 2 \cdot 00
\end{array}\right\}=\begin{gathered}
3 \cdot 93 \text { pence per cubic yard } \\
\text { of material dredged. }{ }^{1}
\end{gathered}
$$

Dredging in the sea channel departmentally with sandpump hopper-dredgers, and conveying a distance of about $2 \frac{1}{2}$ miles to sea, cost, including all charges except interest and depreciation, 1.46 pence per cubic yard of material dredged.

This rate, which is an exceptionally low one, is apportioned as follows :-

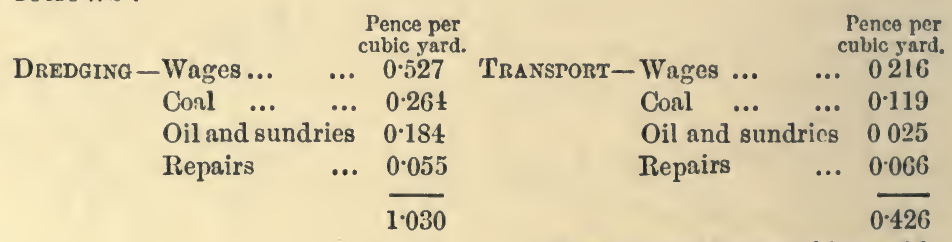

Total ... 1.456 per cubic yard. ${ }^{2}$

The percentage of cost being-

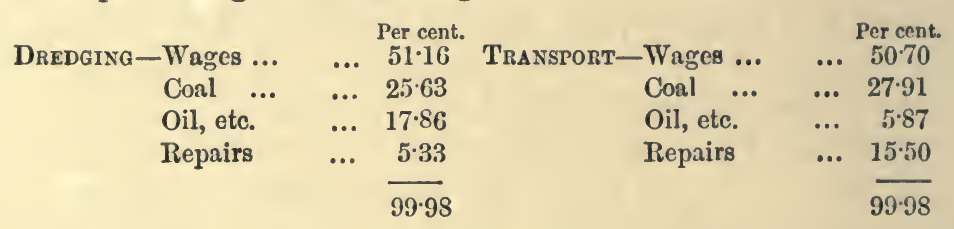

Or, for dredging and transport together-

$$
\begin{array}{lccccccccc}
\text { Wages } & \ldots & \ldots & \ldots & \ldots & \ldots & \ldots & \ldots & \ldots & 51 \cdot 03 \\
\text { Coal } & \ldots & \ldots & \ldots & \ldots & \ldots & \ldots & \ldots & \ldots & 26 \cdot 30 \\
\text { Oil and stores } & \ldots & \ldots & \ldots & \ldots & \ldots & \ldots & \ldots & 14 \cdot 35 \\
\text { Repairs } & \ldots & \ldots & \ldots & \ldots & \ldots & \ldots & \ldots & \ldots & 8 \cdot 31 \\
\hline
\end{array}
$$

Dredging in silt with a grab-dredger, and loading into a hopper-barge, cost from 5.82 pence to 11.65 pence, average $8 \frac{3}{4} d$. per cubic yard, including all charges except interest and depreciation. $^{3}$

Tees. ${ }^{4}$-Average cost of dredging with bucket-ladder dredger in sand, silt, and clay, with stones and boulders weighing from 5 cwt. to 1 ton, removing three miles to sea in hopper-barges

I M.P.T.C.E., vol. $1 \times x \times$ ix. p. 76.

2 1bid., pp. S0, 82.

3 llid., p. 74.

- Ibid., vol. 1xxv. p. 243. 
towed by tugs, including all charges except interest and depreciation, was $2 \cdot 77$ pence per ton of material dredged.

Ayr. $^{1}$-The average cost of working a hopper-dredger in four-fifths clay and boulders and one-fifth silt and sand, and conveying to sea a distance of three miles, is given as 0.94 pence per ton, exclusive of interest, depreciation, and insurance. This rate is divided in the following proportion :-

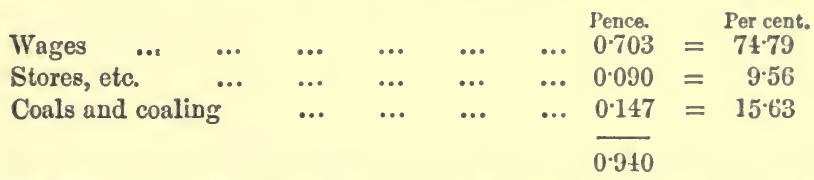

(In this rate, the cost of repairs and maintenance appears to have been omitted.)

Swansea.-Dredging in the entrance channel of the Prince of Wales's Dock, through mud, clay, and gravel, and removing a distance of seven miles to sea by hopper-barges, cost, including charges except interest and depreciation, 3.525 pence per ton of dredged material.

This rate is divisible in the following proportions :-

\begin{tabular}{|c|c|c|c|c|c|c|c|c|}
\hline \multirow{5}{*}{ DREDGING- } & $\ldots$ & ... & ... & ... & $\ldots$ & $\begin{array}{c}\text { Pence. } \\
0.969\end{array}$ & $=$ & $\begin{array}{c}\text { Per cent } \\
27 \cdot 49\end{array}$ \\
\hline & ... & ... & $\ldots$ & $\ldots$ & $\ldots$ & 0.979 & $=$ & $27 \cdot 77$ \\
\hline & $\ldots$ & $\ldots$ & ... & ... & ... & 0.293 & $=$ & $8 \cdot 31$ \\
\hline & $\ldots$ & $\ldots$ & ... & ... & ... & 0.293 & $=$ & $8 \cdot 31$ \\
\hline & nce & d sto & $\ldots$ & $\ldots$ & $\ldots$ & 0991 & $=$ & $28 \cdot 14$ \\
\hline & & & & & & 3.525 & & 00.02 \\
\hline
\end{tabular}

Dredging under the same conditions, but with hired bucketladder dredger and hopper-barges, including all charges for plant, cost 10.45 pence per ton of material lifted. ${ }^{3}$

Belfast Lough. ${ }^{4}$-Dredging carried on by hopper-dredgers of 800 tons capacity, in cutting the new deep-sea channel $3 \frac{1}{4}$ miles long in the exposed estuary, and conveying the dredged material an average distance of nine miles, cost 2.17 pence per ton, including all charges except interest and depreciation on the cost of the plant.

Tyne. ${ }^{5}$-The average cost of dredging on the Tyne, and conveying to sea to distances varying from four to seventeen miles, based on the result of one year's working (1886), was

\footnotetext{
1 M.P.I.C.E., vol. lxxxix. p. 85.

${ }^{3}$ Ibid., vol. ciii. p. 357 .

s Ibid., pp. 100, 101.
}

2 Ibid., p. 71 ; vol. ciii. p. 35 S.

- Ibid., vol. lxxxir. p. 104. 
for dredging 1.85 pence, and for conveyance 1.54 pence, or together 3.39 pence per ton, including every expense except plant charges.

As regards the cost of dredging, the rate is distributed as follows :-

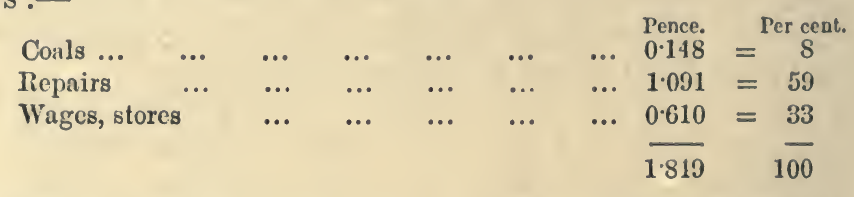

Aberdeen.-The average cost of dredging with bucket-ladder dredgers, taken over a period of eight years, viz. from 1879 to 1886 , amounted to 2.737 pence per ton, including all charges except interest and depreciation, the distribution being as follows :-

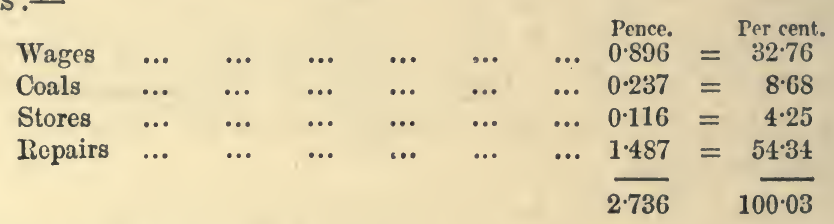

The average cost of dredging and removal by hopper-barges, taken over a period of twenty years, viz. from 1866 to 1886, amounted to $5 \cdot 589$ pence per ton, exclusive of charges on plant. With the addition of these charges, the cost was 8.35 pence per ton, or an increase of 50 per cent. on the working expenses. ${ }^{1}$

Mr. W. Dyce Cay, M.I.C.E., estimated the cost of dredging and removing stiff clay boulders, gravel, sand, and mud at $7 \frac{1}{2} d$. per ton, including interest and depreciation of plant; and assuming one ton of dredging equivalent to 18 cubic feet of solid ground or excavation, the cost per cubic yard was $11 \frac{1}{2} d$., or, with general superintendence, 1 s. per cubic yard. ${ }^{2}$

Clyde.-In the lower estuary of the Clyde below Port Glasgow, under the control of the Clyde Lighthouse Trust, dredging with a single-ladder dredger, and conveying the dredged material a distance of seven miles by hopper-barges, cost, including all working charges, repairs, interest and depreciation on plant, for lifting and loading into barges, 2.54 pence per cubic yard, transporting 2.47 pence per cubic yard; together 5.01 pence per cubic yard.

Dredging in hard material packed with boulders, presenting

$$
{ }^{3} \text { M.P.I.C.E., pp. 107, } 103 .
$$

2 Ilid., p. 72. 
the most severe ordeal to which a dredger can be put to, cost 18.03 pence per cubic yard. ${ }^{1}$

On the Clyde Navigation, the average cost of two years' work, 1870-72, of dredging in sand, silt, clay, and gravel, was 3.86 pence per cubic yard, including all working charges, and 10 per cent. interest and depreciation on the original cost of plant.

Transporting the dredged material by steam hopper-barges a distance of twenty-seven miles, and depositing, cost, taking the mean of two years' work (1870-72), 5.29 pence per cubic yard, including all working charges, and 10 per cent. interest and depreciation.

Total average cost of dredging and transporting a distance of twenty-seven miles (1870-71), $9 \cdot 15$ pence per cubic yard. ${ }^{2}$

Liverpool. ${ }^{3}$-Dredging with a steam hopper-vessel of 1000 tons capacity, fitted with Priestman's cranes and grabs, and conveying seven to eight miles to sea, cost 1.78 pence per ton, exclusive of interest and depreciation. This rate is divided as follows :-

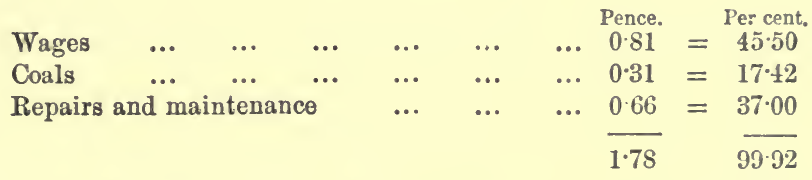

1 M.P.I.C.E., vol. lxxxix. p. 110 ; and Engineering, vol. xliv. p. 278.

2 M.P.I.C.E., vol. xxxvi. pp. 161, 163, 169. 3 Engineering, vol. xlvii. p. 406. 


\section{CHAPTER XV.}

Iron in Sea-water-Experiments made by Mr. Rennie-Experiments made by

Mr. Mallet-Experiments made by Mr. Thwaite-Composition of Sen-salts -Analysis of Sea-water-Fixing bolts in Masonry-Anchor-bolts-Experimonts made by Mr. Moore-Experiments made by Mr. E. F. Miner-Holding power of Drift-bolts in Timber-Experiments made by the United States Government-Experiments made in connection with the Brooklyn Jridge-Experiments made by Mr. Tscharner-Holding power of SpikesWire-rope fastenings - Clay suitable for puddle-Puddling bottoms of BasinsBoring-Surface friction on Cylinder Foundations-Experiments made by Messrs. Griber and Balzano-Surface friction on Piles-Resistance of different materials to horizontal stress-Sheet-piling-Increase in resistance of Piles due to quiescence-Displacement of Ground by piling-Composite pilingScrew-piles-Screw-piling in unstable Ground-Load on Piles-Defective Pile-heads-Water-jet in pile-driving - Water-jet in cylinder sinking-Testing stability of Ground-Pressure on Ground under Dock-floors-EquipmentBollards and Wharf-moorings.

Iron in Sea-water.-Recorded experiments as to the superior durability of cast iron as compared with wrought iron, when exposed constantly to the action of sea-water, appear to be somewhat conflicting.

Mr. G. Rennie made experiments in 1836 on 1-inch cubes of wrought iron, cast iron, and of bronze, with reference to their eligibility for lighthouse purposes. ${ }^{1}$

The cubes being previously weighed, were plunged into a saline solution considerably stronger than sea-water as follows:-

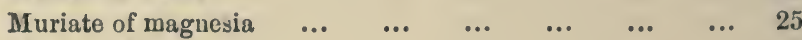

$$
\begin{aligned}
& \begin{array}{lllllllll}
\text { Muriate of lime } & \ldots & \ldots & \ldots & \ldots & \ldots & \ldots & \ldots & 6
\end{array}
\end{aligned}
$$

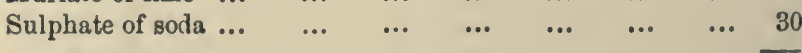

$$
\begin{aligned}
& 183
\end{aligned}
$$

Dissolved in $10 \frac{1}{2}$ ounces of Thames water.

The cubes were taken out of the water after being immersed seventy hours in separate vessels. The cast iron was found to ' "Steveuson's Design and Construction of Harbuurs," p. 186. 
have lost $\frac{1}{3307}$ part of its weight. The wrought iron had only lost $\frac{1}{6610}$ of its weight, being in the proportion of two lost by the cast iron to one only lost by the wrought iron, while the bronze cube had only lost ${ }_{10000}^{1}$ of its weight, which is decidedly in favour of the bronze in the ratio of three to one.

The cast- and wrought-iron cubes being accurately weighed, were again plunged into a strong solution of 1 measure of muriatic acid to 25 measures of Thames water, when, after remaining twenty-one hours, the cast-iron cube was found to have lost $\frac{1}{33}$ of its weight, and the wrought iron only $\frac{1}{25} 8$ of its weight, being in the proportion of 8 to 1 in favour of wrought iron.

The important experiments of the late Mr. R. Mallet, ${ }^{1}$ M.I.C.E., on specimens sunk in the sea, showed that the amount of corrosion decreased with the thickness of the metal, and that from $\frac{1}{10}$ to $\frac{4}{10}$ of an inch in castings 1 inch thick, and about $\frac{6}{10}$ of an inch of wrought iron will be destroyed in a century in clear salt water; this is equal to 1.5 to 1 in favour of cast iron.

Stevenson records instances of far more rapid deterioration. ${ }^{2}$

Experiments made at Dublin, by the late Mr. R. Mallet, M.I.C.E., show that cast iron, freely exposed to the weather and to all its atmospheric precipitations, was corroded nearly as fast as if in clear sea-water, the specimens being wholly unprotected in both cases. ${ }^{3}$

On the whole, it may be taken as a fact that cast iron is less liable to corrosion, when immersed in sea-water, than wrought iron; this may be due to the surface of the cast iron being covered with a skin of silicate of protoxide of iron produced by the molten metal fusing the sand upon the surface of the mould.

Iron exposed to tidal wash and alternately wet and dry is more liable to rapid waste, unless well cared for and protected, than when wholly immersed in water, or wholly exposed to the air. ${ }^{4}$

Cast iron, when exposed to the action of sea-water, sometimes slowly decomposes and becomes quite soft. The iron apparently dissolves, leaving behind a graphite or plumbago. This action is, however, very superficial and very slow, and is very far from being general. This softening process is not

1 "Stevenson on Harbours," 2nd ed. p. 187. 2 M.P.I.C.E., pp. 188, 189.

Ilid., vol. ii. p. 175.

4 Ibid., vol. iv. p. 329. 
clearly understood, but is probably due to some peculiar quality of the metal used.

Corrosion is accelerated by impurities in the water, and especially by the presence of decomposing organic matters or of free acids. It is also accelerated by the contact of the iron with any other metal which is electro-negative relatively to the iron, or, in other words, has less affinity for oxygen. If two portions of a mass of iron are in different conditions, so that one has less affinity for oxygen than the other, the contact of the former makes the latter oxidate more rapidly. In general, hard and crystalline iron is less oxidable than ductile and fibrous iron. ${ }^{1}$

Mr. Kinipple remarks that, after a life of from thirty to fifty years, structures depending upon cast iron exposed to the rapidly oxidizing action of sea-water can only be looked upon as of a comparatively temporary character, especially as regards very light cast-iron pile structures. ${ }^{2}$

Experiments tend to show that steel immersed in sea-water is more liable to corrosion than wrought iron. ${ }^{3}$

Experiments made by Mr. B. H. Thwaite, A.M.I.C.E., on the action of oxidation, in order to ascertain the metallic life of iron with a tolerable degree of exactitude, appear to show that a bar of wrought iron 4 inches by 1 inch, subjected to the corrosive atmospheric influences of a manufacturing city, would be entirely corroded away in a little over a single century.

Theobject of all methods of preservation is to protect the surface from the oxidizing influence of the air or water. For ironwork generally above water, good oxide of iron paints are perhaps the best preservatives that can be applied. Mr. Matheson thinks that for wrought iron oiling is a better protection than painting. ${ }^{5}$

At the Forth Bridge, two coats of oxide of iron paint were applied over two coats of red lead. ${ }^{6}$

For under-water work, all castings should be subjected to Dr. Angus Smith's process, which consists in heating the perfectly clean castings to a temperature of about $300^{\circ} \mathrm{Fahr}$., and at once immersing them in a bath of coal-tar and linseed oil also heated to, and maintained at, a temperature of about $300^{\circ} \mathrm{Fahr}$; in this bath the castings should remain for about one hour.

"In place of heating the clean castings before immersion

1 "Rankin's Civil Engineering," p. 514.

2 "Lectures to R. F. Inst., from Engineering," vol. 1. p. 515.

${ }^{3}$ M.P.I.C.E., vol. 1xxxii. p. 292, 293.

S Ibid., vol. Ixv. p. 113.

Ibid., vol. Ixxir. p. 215.

- Enginecring, vol. xlix. p. 273. 
the same effect will be produced by placing them in the bath heated and maintained at a temperature of about $300^{\circ} \mathrm{Fahr}$, and allowing them to remain therein for some time after they have become as hot as the tar." 1

In both these methods, as described in Dr. Angus Smith's specification, the essentials are absolutely clean surfaces, and a high temperature, but of the two that requiring the heating of the castings before immersion was evidently regarded by the inventor as the most efficient.

A thin coating or film of mud, and the adhesion of marine growths, such as weeds and shell-fish, by which the surface of the immersed iron is secured from contact with fresh supplies of water, have a considerable effect in preserving the surface from corrosion.

An examination as to the condition of the iron piles in the South Bassien Bridge, on the Bombay, Baroda, and Central India Railway, led to the conclusion that the greatest corrosion in cast-iron piles exists close to low water, and does not extend to any considerable depth below it, a conclusion which also applies to bolts and braces. After an exposure of twenty-five years in a salt-water tideway, the piles were found to be in a very good condition, and corrosion had only occurred in places which were easily accessible for repairs and renewals.

Average composition of sea-water salts : ${ }^{2}-$

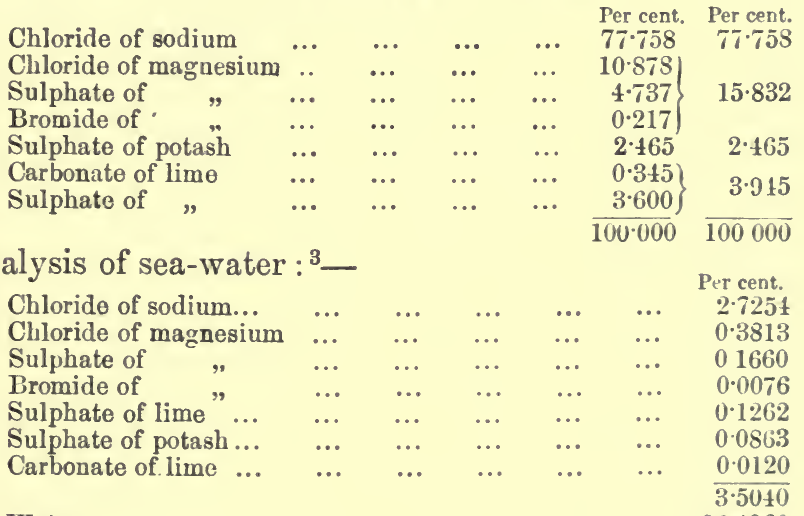

Water

Fixing Bolts in Masonry. ${ }^{4}$-In connection with the securing of

1 Dr. Angus Smith's Specification, No 12291, 1818. Printed 1857.

2 Pro. Royal Soc. Edinburgh, Scssions 1889-90, p. $102 . \quad$ Ibid., p. 103.

- Scientific American, vol. Ixiii. p. 181. 
columns on a rock or masonry foundation, experiments were made by American engineers to determine the value of Portland cement as a holding material.

For this purpose, fourteen holes were drilled in a ledge of solid limestone, seven of them being $1 \frac{3}{8}$ inch in diameter, and seven of them $1 \frac{5}{8}$ inch in diameter, all being $3 \frac{1}{2}$ feet deep. Seven $\frac{3}{4}$-inch and seven 1 -inch bolts were prepared with thread and nut on one end and plain at the other end, but ragged for a length of $3 \frac{1}{2}$ feet from the blank end.

Four were anchored with sulphur, four with lead, and six with cement mixed neat. Half of each were $\frac{3}{4}$-inch and half 1 -inch bolts, and all of them were allowed to stand till the cement was two weeks old. At the expiration of this time a lever of sufficient power was rigged, and all the bolts were pulled, with the following results :-

Sulphur.-Three bolts out of four developed their full strength, 16,000 and $31,000 \mathrm{lbs}$. One 1-inch bolt failed by drawing out under $12,000 \mathrm{lbs}$.

Lead.-Three bolts out of four developed their full strength, as above; one 1-inch bolt pulled out under 13,000 lbs.

Cement.-Five of the bolts out of six broke without pulling out; one 1-inch bolt began to yield in the cement at $26,000 \mathrm{lbs}$., but sustained the load a few seconds before it broke.

While this experiment demonstrated the superiority of cement, both as to strength and ease of application, yet it did not give the strength per square inch of area. To determine this, four specimens of limestone were prepared, each 10 inches wide, 18 inches long, and 12 inches thick, two of them having 13 inch holes, and two of them $2 \frac{3}{4}$ inch holes drilled in them. Into the small holes 1-inch bolts were cemented, one of them being perfectly plain round iron, and the other having a thread cut on the portion which was embedded in the cement. Into the $2_{4}^{3}$-inch holes were cemented 2 -inch bolts similarly treated, and the four specimens were allowed to stand thirteen days before completing the experiment. At the end of this time, they were put into the standard testing machine and pulled. The plain 1-inch bolt began to yield at 20,000 lbs., and the threaded one at 21,000 lbs. The 2 -inch plain bolt began to yield at 34,000 lbs., and the threaded one at 32,000 lbs., the strain in all cases being very slowly applied. The pump was then run at a greater speed, and the stones holding the 2-inch 
bolts split at $67,000 \mathrm{lbs}$. in the case of the smooth one, and at 50,000 lbs. in the case of the threaded one.

It is thus seen that cement is more reliable, stronger, and easier of application than either lead or sulphur, and that its resistance is from 400 to $500 \mathrm{lbs}$. per square inch of surface exposed. It is also a well-ascertained fact that it preserves jron rather than corrodes it. The cement used throughout the experiment was an English Portland cement.

In recent investigations of the strength and adhesion of iron anchor-bolts set in stone masonry, Mr. Robert Moore, Chief Engineer of the St. Louis Merchants' Bridge Terminal Railway, experimented with full-sized rods set with lead, sulphur, cement, etc. From a photograph taken after testing the results of two experiments, A and B are illustrated in Fig. 338. Stone blocks, of a size adapted to the testing machine, were drilled through, and 2-inch iron rods were set into them $11 \frac{1}{2}$ inches, and the space around them was filled with a thin mortar or grout of Harris's Portland cement, which was allowed to set ten days. The stone and rod were then placed in a testing machine and subjected to tension to pull out the rod. Briquettes of the cement, tested in the usual manner, deve-

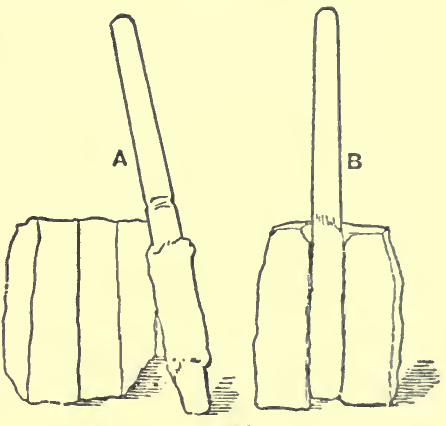

FiG. 338. loped a strength of about $475 \mathrm{lbs}$. per square inch in seven days, and $550 \mathrm{lbs}$. in ten days. In $\mathrm{A}$ the rod had a screw thread to improve the grip of the cement, and the stone began to yield at a load of $32,000 \mathrm{lbs}$, and broke at a load of about 50,000 lbs., without developing the strength of the cement joint. In $B$ the rod was plain and smooth, and the cement began to yield at a load of 34,000 lbs., but did not entirely part when the rock broke at a load of $67,000 \mathrm{lbs}$. Larger blocks of stone could not be accommodated in the machine, but it was inferred that in a suitable setting the cement joint on a smooth rod might be made to break the rod. ${ }^{1}$

Experiments on the holding power of anchor-bolts set in stone with different materials, made by Mr. E. F. Miner, gave the following results:- 
For the purpose of these experiments, tap bolts were prepared, $1_{4}^{3}$ inches in diameter, and 9 inches long, the bolt being set into the stone to a depth of 6 inches.

The holes in the stones were as nearly as possible 2 inches in diameter by $6 \frac{1}{2}$ inches deep, but in three of the experiments they were tapered to a diameter of $2 \frac{1}{2}$ inches at the bottom.

With an inferior quality of Babbitt metal, the bolt drew ${ }_{2}^{3} 8$ inch under a load of 10,000 lbs., due to the metal coming to a fair bearing. At 15,000 lbs. the bolt drew ${ }_{64}^{1}$ inch out of the setting, and at 16,000 lbs. the stone split.

With lead melted and poured round a bolt inserted in a tapered hole, an extension of $\frac{1}{32}$ inch was noted under a load of 2500 lbs., which did not increase until a load of 5000 lbs. was applied; above 6000 and up to 13,000 lbs. the extension was $\frac{1}{128}$ inch for each $1000 \mathrm{lbs}$; ; with a strain of $33,000 \mathrm{lbs}$. on the bolt the lead gave way.

With a setting of lead pipe in a straight hole, an extension of $\frac{1}{32}$ inch was noted at $4000 \mathrm{lbs}$., which did not increase until a load of 10,000 lbs. was reached; beyond this, each successive increment of load produced an extension; failure occurred with a load of 25,000 lbs.

With sulphur, no yielding whatever was noted with a load of $10,000 \mathrm{lbs}$; ; above this it was perceptible; at $29,000 \mathrm{lbs}$. it was 64. of an inch, and at $31,125 \mathrm{lbs}$. the stone split; the fragments of sulphur showed no signs of crushing.

With the same material, in a tapered hole, no movement was observed up to a load of 20,000 lbs., but on leaving this load on for five minutes an extension of $\Upsilon_{\frac{1}{2} \overline{8}}$ of an inch was noted, which, however, did not increase. ${ }^{1}$

Holding Power of Drift-bolts in Timber.-A number of experiments carried out by Messrs. Powell and Harvey, of the University of Illinois, United States, on the holding power of square steel drift-bolts gave the following results :-

The bolts were 30 inches long and 1 inch square. The timber used was pine. Holes $\frac{16}{16}$ inch, 15 inch, 14 inch, and $\frac{13}{16}$ inch were bored as nearly as possible perpendicular to the grain of the timber, and the bolts driven in for a depth of 6 inches. Five bolts were driven into each size of hole, and the following average results obtained:-

1 Extract from paper read before tho Washburn Enginecrs' Socicty, Mass., U.S. Taken from Engineering, vol. liv. p. 88. 


\begin{tabular}{c|c|c|c}
\hline \multirow{2}{*}{ Size of rod. } & Size of hole. & \multicolumn{2}{|c}{ Holding power in pounds. } \\
& & Total. & Per inch of depth. \\
\cline { 1 - 2 } sq. in. & in. & & \\
1 & 16 & 3972 & 662 \\
1 & 16 & 4260 & 710 \\
1 & 15 & 4660 & 777 \\
1 & 15 & 15 & 675 \\
\hline
\end{tabular}

After the bolts were withdrawn the timber was split, and the condition of the wood round the hole examined. From this it appeared that in holes larger than $\frac{14}{16} \mathrm{inch}$, only the corners of the bolts held effectively.

Extensive arrangements made by the United States Government, brought out the following important facts. ${ }^{1}$

The resistance of all drift-bolts increases with age, being 10 per cent. more at seven months after driving than if drawn at once.

The resistance to drawing a bolt through the hole is only 60 per cent. of that required to draw it out.

Smooth bolts were found to have much greater holding power than ragged bolts. In fact, the resistance is diminished by ragging from 25 to 50 per cent.

As regards the size of the hole, it appears that the holding power of an inch rod is greater when driven into a $\frac{11}{16}$-inch hole than when driven into any larger hole.

With a $\frac{3}{4}$-inch round bolt, the resistance is greater in a $\frac{10}{16}$-inch hole, than either a $\frac{9}{16}$ or an $\frac{11}{16}$-inch hole.

A round bolt is, weight for weight, 25 per cent. more efficient than a square bolt.

With a 1-inch round bolt driven into a $\frac{13}{16}$-inch hole in white pine, the holding power was found to be 10,000 lbs. per lineal foot of bolt. In Norway pine, the resistance of a similar bolt was $9000 \mathrm{lbs}$. per foot lineal.

Experiments made in connection with the Brooklyn Bridge, on the same subject, gave the following results :-

The holding power of a 1 -inch bolt driven into a 15 -inch hole in Georgia pine, was 12,000 lbs. per lineal foot, which was increased to $15,000 \mathrm{lbs}$. per lineal foot, when the hole was made 14 of an inch. With lighter timber containing less pitch, the holding power was 20 per cent. less, and in very dense timber containing more pitch, the resistance was about 10 per cent. more.

1 Extract from "Engineering News," in Engineering, vol. li. p. 314. 
According to another set of experiments made by $\mathrm{Mr}$. Tscharner, in the testing laboratory of the University of Illinois, U.S., the holding power of a 1-inch round bolt driven into a 15 -inch hole in pine, was $6000 \mathrm{lbs}$. per lineal foot.

In oak, under the same conditions, the holding power was found to be 15,600 lbs. per foot lineal. If the bolt is driven parallel to the grain, the holding power is reduced almost exactly one-half.

Holding Power of Spikes.-The following table gives the results of experiments on the holding power of railway spikes in ordinary wooden sleepers :-

\begin{tabular}{c|c|c|c}
\hline \multirow{2}{*}{ Spike. } & Depth driven. & \multicolumn{2}{|c}{ Holding power. } \\
\cline { 3 - 4 } & & Edge with grain. & Edge across grain. \\
\hline in. & in. & lb. & 16. \\
$7 \times \frac{3}{8} \times \frac{3}{8}$ & 3 & 1617 & 1317 \\
$7 \times \frac{3}{8} \times \frac{3}{8}$ & 4 & 1625 & 1342 \\
$8 \times \frac{3}{8} \times \frac{7}{16}$ & 5 & 2180 & 1720 \\
$10 \times \frac{1}{2} \times \frac{1}{2}$ & 7 & 3650 & 3000 \\
\hline
\end{tabular}

Wire-rope Fastenings. ${ }^{1}$ - Experiments made by Mr. W. Hewitt, on the strength of different forms of wire-rope fastenings, gave the following results :-

\begin{tabular}{|c|c|c|c|c|}
\hline Diam. & Kind of material. & Kind of fastening. & $\begin{array}{l}\text { Breaking } \\
\text { load. }\end{array}$ & Where fractured. \\
\hline in. & & & $27^{1 \mathrm{~b}}$ & \\
\hline 1 & $\begin{array}{l}\text { Cast steel } \\
\qquad,\end{array}$ & Thimble spliced in & 58,000 & $\begin{array}{l}\text { Broke in top splice and cut } \\
\text { one strand at hottom. }\end{array}$ \\
\hline$\frac{2}{8}$ & Swedish iron & "’ & 22,430 & At bottom thimble. \\
\hline$\frac{7}{8}$ & & " & 22,390 & At top thimble. \\
\hline$\frac{3}{4}$ & & ", & 21,670 & At bottom thimble. \\
\hline$\frac{3}{4}$ & & " & 19,450 & Cut at top thimble. \\
\hline$\frac{3}{4}$ & Cast steel & " & 28,870 & $\begin{array}{l}\text { One strand broke in severn } \\
\text { places. }\end{array}$ \\
\hline$\frac{3}{4}$ & " & Socket & 23,140 & Pulled out of socket. \\
\hline $\begin{array}{l}\frac{5}{8} \\
\frac{5}{8}\end{array}$ & " & Thimble"spliced in & $\begin{array}{l}14,290 \\
21,900\end{array}$ & Two strands broke in splice. \\
\hline$\frac{8}{8}$ & Swedish iron & $"$ & 12,730 & In the body of the rope. \\
\hline$\frac{5}{8}$ & Crst" steel & $"$ & $\begin{array}{l}14,060 \\
12,930\end{array}$ & Broke 1"in nin \\
\hline & & " & & $\begin{array}{l}\text { ture; gave way in two } \\
\text { strands. }\end{array}$ \\
\hline$\frac{1}{2}$ & " & Socket & 8,850 & Pulled out of socket. \\
\hline
\end{tabular}

1 Pro. American Society of Mechanical Engineers. Fxtract from Eingineering, vol. xlvi. p. 52. 
Figs. 339, 340 show the ordinary splice and thimble, and Fig. 341 a block with a conical hole, in which the rope is secured by fraying out the wires at the end to conform in shape with the conical form of the aperture, the interstices between the wires being filled up with spikes or nails driven in as tightly as possible, and the whole consolidated with Babbitt metal. This form of fastening, although neater, does not possess the strength of the splice and thimble, and in the experiments was pulled out under a load varying from $\frac{1}{2}$ to $\frac{3}{4}$ of the breaking load.

A $1 \frac{1}{2}$-inch clear rope, with a thimble and splice 18 inches long

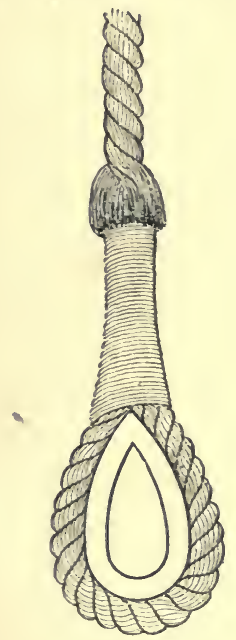

FIg. 339.

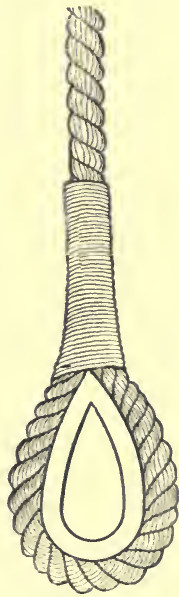

Fia. 340.

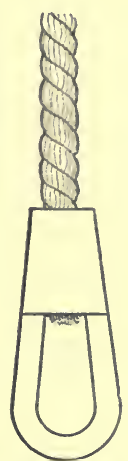

Fra. 311.

at one end, and a loop-socket at the other, pulled out of the latter at 129,320 lbs.

A sample of the same rope, with thimbles and splices at both ends, failed, when tested, by five strands breaking at one end, and the other being pulled out with a tension of $142,800 \mathrm{lbs}$.

A cast-steel rope, 2 inches in diameter, fitted with loopsockets, failed by being pulled out at one end by a strain of 228,400 lbs. ; about 20 of the wires parted in the socket.

Puddling. ${ }^{1}$-Clays well suited for puddle are opaque and not crystallized; they exhibit a dull earthy fracture, exhales, when breathed upon, a peculiar faint smell termed argillaceous, are unctuous to the touch, free from all gritty matter, and form a 
plastic paste with water. Important properties are its tenacity or cohesion, and its power of retaining water.

The tenacity of a clay may be tested by working up a small quantity with water into a thoroughly plastic condition, and forming it by hand into a roll about 1 to $1 \frac{1}{2}$ inch diameter by 10 to 12 inches in length. If such a roll is sufficiently cohesive as not to break on being suspended by one end when wet, the tenacity of the material is ample. To test its power of retaining water, 1 to 2 cubic yards of the clay should be worked with water by the usual methods to a compact homogeneous plastic condition, and then a hollow should be formed in the centre of the mass capable of holding 4 or 5 gallons of water. After filling the hollow, it should be covered over to prevent evaporation, and left for about 24 hours, when its capability of retaining water will indicate its suitability or unsuitability for making puddle.

Tempering the clay is effected by working it up with water so that its original formation is broken up and a new arrangement of particles formed, with additional water to fill up every pore. Tempering is greatly facilitated by exposing the material to the atmosphere, especially in winter, when the changes of weather and temperature materially assist in disintegrating the material.

In putting in the puddle, it is important that great care be taken to screen it from the too rapid action of the sun or quick-drying winds. Cracks or fissures due to this cause may, if the layer of clay, from motives of economy, is made too thin, extend quite through, and thus allow the water to escape.

Puddling Bottoms of Basins.-When the basins are excavated in gravel or other pervious material, and there is in consequence a risk of the water leaking through at low tides to a dangerous extent as regards the ships in the basin, or injurious to the adjoining lands and buildings, it may be necessary to cover the whole surface of the bottom with puddled clay. In carrying out this work, particular care is required to guard against cracks occurring, through which the water may subsequently leak away.

Boring. - A most important preliminary operation towards ascertaining the character of the ground is boring. Scattered at wide intervals over large areas, boring affords no reliable 
information for constructive purposes, the data so obtained applies only to a limited area immediately surrounding the hole, therefore the positions should be systematically arranged at moderate distances apart, and the holes carried down to such a depth as to enable as accurate an opinion as possible being formed as to the nature of the strata, the probability of water being met with, and as to the sufficiency of the bed on which it is proposed to place the foundations. As regards the latter condition particularly, it is important, in order to obtain reliable information on which to form an opinion as to the supporting power of the bed, that proper boring appliances be used, so as to recover specimens of the strata in as natural a state as possible.

As a rule, the penetration of an impervious foundation bed, and the possible tapping of a water-bearing strata beneath, should be avoided, provided, of course, that there proves to be a sufficient thickness of impervious strata to ensure a good foundation.

When it is necessary to ascertain the thickness of an underlying bed, the bore-holes should be put down clear of the foundations, and, if possible, in positions, where, in the event of a water-bearing strata being tapped, the flow of water can best be kept under control.

Friction.-The support afforded to cylinder foundations by surface friction will depend upon the nature of the strata and the depth to which the cylinder is sunk.

For cast-iron cylinders sunk through gravel, the skin or surface friction has been estimated at between 3 and 4 tons on the square yard for small depths, and at 4 to 5 tons per square yard when the depth is from 20 to 30 feet.

In sinking the brick-and-concrete cylinders in the silt of the Clyde, it was found to be about $3 \frac{1}{2}$ tons per square yard. ${ }^{1}$

In constructing the cylinder foundations for the PragueSmichow Bridge, it was observed that by increasing the air pressure the cylinders could be raised, and it was also noted that when the internal pressure in the chamber exceeded by $7 \frac{1}{2} \mathrm{lbs}$. per square inch the atmospheric pressure, the cylinder could be maintained in suspension. These observations gave a ready means of determining approximately the amount of surface friction developed, for the total weight of the caisson was 
balanced by the upward pressure of the air in the chamber added to the friction of the ground. The total weight in the cylinder, including all masonry and brickwork, was 916 tons, and the pressure exerted by the compressed air 638 tons; the difference, 278 tons, represents the part of the load taken up by friction. This friction was developed in a layer of 13 feet in thickness, composed of 9 feet 9 inches of sand and 3 feet 3 inches of coarse gravel irregularly stratified. The surface of the ground bearing against the cylinder was 183.2 square metres, therefore the friction per square metre was 1.5 tons, or about 2.8 cwt. per square foot. ${ }^{1}$

Experiments made by Messrs. Gerber and Balzano during the construction of the cylinder foundations of the Seinbach and Lech Bridges gave a surface friction of $3 \mathrm{cwt}$. and $3.35 \mathrm{cwt}$. per square foot. ${ }^{2}$

The pressure on the London clay at the base of the cylinders carrying the Charing Cross Railway-bridge is about 8 tons per square foot. This pressure is estimated on the assumption that no relief is afforded by the friction of the sides against the material through which the cylinders pass. ${ }^{3}$

Sir B. Leslie, K.C.I.E., has expressed an opinion that in estimating the weight on a cylinder foundation, it is not safe to rely on lateral friction of the earth through which the cylinder passes, as a permanent source of support, although it may exert a considerable temporary retarding influence. When the earth is compact and dense, it can only exert a small amount of lateral pressure, but when the earth is soft and loose, although it may jamb the cylinder for a time, the supporting power of its lateral pressure soon fails, as its cohesion is destroyed by vibration, and the cylinder derives but little support. ${ }^{4}$

It is recorded that in sinking an old-fashioned rectangularfoundation well 18 feet by 10 feet (so common in India), where the ground was sandy at 10 feet from the surface, a thin layer of clay 14 inches thick was encountered. This clay, and a depth of 3 feet of sand below it, was easily penetrated. It then rained, and the cylinder stuck fast, and only went down after a great deal of loading. Again it rained, and again the cylinder stuck. It was found that 3 feet of sand had been cleared away from under the curb and that the whole weight of the cylinder-250 tons-was

MI.P.I.C.E., vol. li. p. $230 . \quad 2$ Ibid. Ibid., vol. xxii. p. 516.

1bid., vol. xxxiv. pp. 41, 42 . 
holding on by the friction of the sides. It was then suggested by a native well-sinker that by cutting away the layer of clay the cylinder would go down at once, as the clay had swoollen during the rain, and gripped the cylinder. The clay was accordingly removed, and the cylinder dropped down, which showed that the whole weight was hanging on 14 inches of clay with a temporary friction, owing to the expansion of the clay equal to $3 \cdot 80$ tons per square foot. ${ }^{1}$

Mr. Hurtzeg, M.I.C.E., found, as the result of some three hundred direct observations made when drawing the piles of a dam, that the gross frictional resistance of ordinary rough Memel timber driven into clay amounted to 0.837 ton per square foot of surface, or deducting the weight of the pile and the power required to overcome the resistance of suction under the worst conditions, viz. a perfect vacuum, the coefficient of friction was 0.837 ton per square foot of surface in contact with the soil. ${ }^{2}$

The friction of a pile in sand is estimated by the Dutch engineers at from 3 to $4.5 \mathrm{lbs}$. per square inch, or, say, 614 lbs. per square foot. This co-efficient was adopted by Sir J. Alleyne, Bart., M.I.C.E., in designing the timber staging for fixing the Dordrecht Bridge in Holland. ${ }^{3}$

At the Portsmouth Docks a very marked alteration was observed in the condition of the hard clay, after the piles had been driven into it. The clay, when not affected by the piles, on being excavated freely fell to pieces, with a fracture closely resembling that of coal; but when altered by the driving of the piles, it was rendered extremely tough and difficult to excavate, having lost all its tendency to break, and only coming away as absolutely cut down by the pick. This toughening of the clay materially increased the friction on the pile surface. ${ }^{4}$

Piles driven in the soft clay at La Rochelle and Rochfort, support $164 \mathrm{lbs}$. per square foot of lateral contact, and in the silt of Loicent, $123 \mathrm{lbs}$. per foot super. ${ }^{5}$

In localities where the winter weather is severe, and thick ice is likely to form, a timber structure on piles is exposed to an element of destruction that has no parallel in temperate climates, that is, the upward pressure of the ice as the water rises tending to lift the piles, unless they have a sufficient

1 M.P.I.C.E., vol. xxxiv. p. 34.

Ibid., vol. xlii. p. 218.
2 Ibid., vol. lxiv. p. 313.

4 lbid., vol. lxiv. p. 199.

s Ilid., vol. l. p. 122. 
frictional hold on the ground to withstand the strain. Mr. J.W. James, M.I.C.E., found by experiment the adhesion of ice to timber to be $33.32 \mathrm{lbs}$. per square inch, therefore the force exerted on the piles will be in proportion to the superficial area of the portion of the timber gripped by the ice.

Mr. James gives the following practical formula for readily determining approximately the force capable of overcoming the frictional resistance and drawing the pile-

$\mathrm{R}=$ force in pounds required to draw the pile.

$\mathrm{W}=$ weight of the ram in pounds.

$\mathrm{F}=$ fall of ram in inches.

$\mathrm{S}=$ set of pile at last blow.

$\mathrm{P}=$ perimeter or girth of the pile in inches.

$\mathrm{C}=$ coefficient $=0.3285$ deduced from a number of experiments made with piles, 1 inch to $3 \frac{1}{4}$ inches square, driven into various descriptions of ground. ${ }^{1}$

Then

$$
\begin{aligned}
\frac{\mathrm{R} \times \mathrm{S}}{\mathrm{W} \times \mathrm{F}} \times \frac{\mathrm{P}}{4} & =\frac{\mathrm{R} \times \mathrm{S} \times 0.25 \times \mathrm{P}}{\mathrm{W} \times \mathrm{F}}=\mathrm{C} \\
\mathrm{R} & =\frac{\mathrm{W} \times \mathrm{F} \times \mathrm{C}}{0.25 \times p \times \mathrm{S}} \\
\frac{\mathrm{W} \times \mathrm{F} \times \mathrm{C}}{25 \times \mathrm{P} \times \mathrm{R}} & =\mathrm{S}
\end{aligned}
$$

As a pile 1 inch square has a perimeter of 4 inches $\frac{P}{4}$ appears in the formula.

Resistance to Horizontal Stress.-Experiments made by $\mathrm{Mr}$. J. W. Sandeman, M.I.C.E., with the view of ascertaining the amount of resistance offered by different material, such as clay, sand, ashes, to the horizontal movement of timber piling, tend to show that loose ashes afford the least resistance, clay more, and sand the greatest. It also appears, from the fact of all these piles breaking off at 5 feet below the surface of the ground, that a tie-pile driven 15 feet into the ground would meet with as much resistance to horizontal stress, applied at the level of the ground, as if the pile were driven to a greater depth. ${ }^{2}$

Sheet-piling.-At the dock works near Kiel, in driving the sheet-piling enclosing the works, which varied from 25 feet 6 inches to 37 feet long, it was found advantageous to drive two

$$
\text { I M.P.I.C.E., vol. xli. pp. 192, } 193 . \quad 2 \text { Tbid., vol. lix. p. } 282 .
$$


piles at once, fastened together by strong iron hoops, the gain being due, it is supposed, to increased rigidity; the vibration, which is a great source of loss of power, being thereby much diminished. ${ }^{1}$

In putting down sheet-piling where the lengths are not too great, and the conditions generally are favourable, a good plan is to drive the piles in one bay together; that is, to pitch all the piles in the bay, and drive them down a foot or two at a time, one after the other, until the whole are driven down to the proper depth; this method ensures the tongues being properly engaged in the grooves.

Increase of Resistance due to Quiescence. ${ }^{2}$-During the progress of the extensive pile foundations carried out at the Portsmouth Docks, it was observed that, on the resumption of driving, after an interval of some hours, the set of the pile was invariably less than that observed on ceasing driving.

In order to obtain information as to the value of such increased resistance accruing from quiescence, a number of special observations were made upon piles, the driving of which was completed or nearly completed immediately before leaving work for the night; as many as possible of piles which gave an excessive first set being included. On the following morning, one test blow of the ram with the same fall was given, and the resulting set compared with that recorded on the previous evening.

It was shown by these observations on thirty-nine beech piles, averaging 13.076 feet in length, 123.863 square inches in area, and an average of 0.0540 -foot set, that they gave, when tested, the following morning, an average set of 0.0234 foot, showing an increased resistance in the ratio of $2 \cdot 30$ to 1 .

Seventy-four fir piles, averaging 19.74 feet long, 162.70 square inches in sectional area, with an average set of 0.0366 foot, gave, when tested the following morning, an average set of 0.0130 foot, showing an increased resistance in the ratio of $2 \cdot 81$ to 1 .

This result is to be accounted for by the fact that during the driving the ground is to some extent disintegrated; the vibration of the pile also causes the hole from the surface downwards to be slightly enlarged, thus relieving the pile from the full frictional resistance. On the cessation of driving, the

'M.P.I.C.E., vol. sli. p. 260.

2 Ibid., vol. lxiv. 164 . 
ground settles or expands, and thus grips the pile to such an extent as to materially increase the frictional resistance.

The ground into which these piles were driven consisted of clay and the argillaceous sandy beds below the London clay.

The interval between the first and second observations was about fourteen hours.

Displacement of Ground by Piling. ${ }^{1}$-However compressible the ground may be, it will, on commencing driving particularly, naturally give in the direction of the least resistance, which will of course be towards the surface.

It has been noted that, in ground consisting of the compact sandy beds immediately below the London clay, the mean rise of the surface over an area of 1248 square feet, into which 66 round piles had been driven 12 feet deep, was 0.75 foot. The heads of these piles above the normal level averaged 1.33 square feet, therefore the total quantity to be removed to again reach the normal level was 870 cubic feet; from this a deduction of about one-fourth must be made to allow for increase of bulk due to disintegration, leaving 650 cubic feet as the nett quantity of solid material displaced.

The quantity of timber actually driven was 676.36 cubic feet, therefore the displacement of the ground due to the piles was 96 per cent. of the whole quantity of timber driven.

In ground of a more argillaceous character, but still within the sandy beds lying between the London clay and the lower beds of blue clay, the rise of the surface averaged 0.875 of a foot. This, over an area of 1520 square feet containing 80 $12 \frac{1}{2}$-inch square piles, driven 19 feet into the ground, is equal to 1330 cubic feet; deducting, in this case, one-fifth for increase of bulk due to the disintegration, the quantity actually displaced was 1064 cubic feet. The cubic quantity of timber driven as piles was 1649.30 cubic feet; therefore, the displacement of the ground was 64 per cent. of the total quantity of timber driven.

In stiff clay beds, the upper part of which had been oxidized, rendering the material more plastic and compressible, the average rise was 1.20 feet, over an area of 1596 superficial feet, into which 105 piles, $12 \frac{3}{4}$ inches square, had been driven 25 feet deep.

The quantity of ground displaced, after allowing for increase of bulk due to disintegration, was 1418.48 cubic feet. The 
quantity of timber driven as piles amounted to 2960.50 cubic feet; therefore, the actual displacement in this case was 47 per cent. of the quantity of timber driven as piles.

Composite Piling.-In positions where there is a considerable depth of soft material over the harder strata which has to be reached, but where, owing to the presence of the worm, or from other causes, it is objectionable to have timber above the ground, a composite method of construction consisting of an ordinary timber pile driven through the mud, with an upper length of

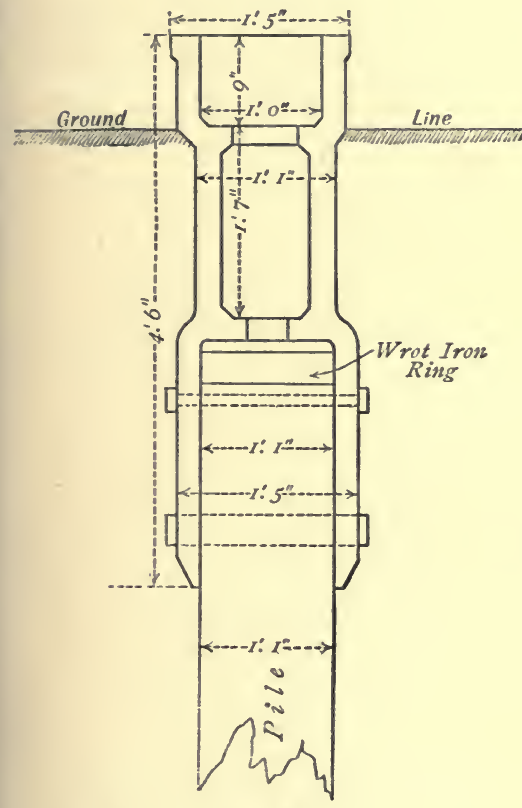

FIG. 312.

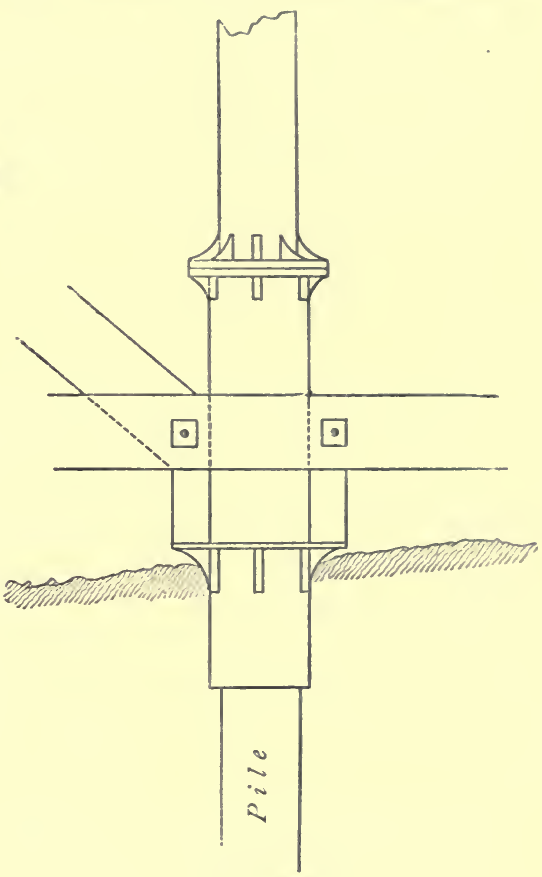

FIG. 343.

iron fitted over the top of the timber piles by a socket, as shown by Figs. 342, 343, may be adopted with advantage. If the top of the timber pile is kept well below the surface and efficiently protected by the cast-iron socket, it will last an indefinite time, while it is cheaper and more expeditious than putting down iron piling to a great depth.

Screw-piles.-In soft strata of indefinite depth, screw-piles are preferable, as the resistance to settlement is so much increased by the bearing surface of the screw; they are also particularly 
applicable to places where the concussion attending ordinary pile-driving is objectionable.

At the Clevedon Pier, the bases of the piles consisting of solid wrought-iron stems 5 inches in diameter, shod with castiron discs 2 feet in diameter, were screwed through mud and sand into hard red clay, till a $4 \frac{1}{2}$-inch rope, passed round capstan bars 6 feet long, failed with the strain. The screws penetrated the ground to depths varying from 7 to 17 feet, and although made with a 5-inch pitch, seldom descended more than $2 \frac{1}{4}$ to 3 inches at a turn. ${ }^{1}$

Screw-piling in Unstable Ground.-In putting in pile foundations on unstable ground, consisting of shifting sand overlying compact gravel 6 to 8 feet deep, with peat of an unknown depth beneath, Mr. Conybere, M.I.C.E., adopted a method of screw-

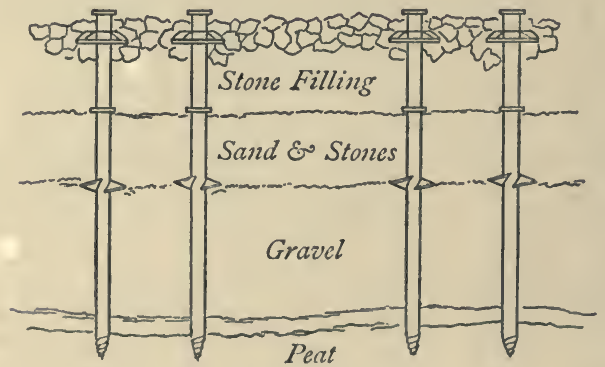

FIG. 344.

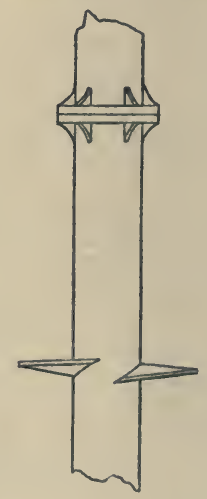

Fig. 345 .

piling shown by Figs. 344, 345. In this case, the crust of gravel was all that could be depended upon to carry the weight; the screw discs were therefore placed 8 feet up the pile, so as to take their bearing on the gravel which the lower portion of the pile penetrated. The bearing surface was augmented by discs bolted to the upper portion of the piles, and, bearing upon stone filling, formed the frustum of a cone of resistance whereby the weight was distributed over a larger area on the bed of gravel beneath. $^{2}$

In the construction of the pier at Huelva, ${ }^{3}$ where by repeated

1 M.P.I.C.E., vol. xxxii. p. 132.

2 Ibid., vol. liii. p. 140.

Ibid., p. 136. 
experiments the ground was proved to be incapable of supporting more than $700 \mathrm{lbs}$. per square foot, which was insutficient to support the working load, the following means were adopted as the most expeditious and effectual for obtaining the necessary supporting area.

Timber platforms composed of whole baulks of timber 12 inches square were placed round each group of piles transversely to the centre line of the pier, and arranged so as to break joint under the main bearing-sills, or at the centre between two of them. The main sills rested upon the platform and consisted of baulks laid longitudinally, one on each side of the screw-piles. The platforms were made on shore and floated off at high water; after being adjusted round the piles, the sills were placed in position and secured. The platforms were then weighted with
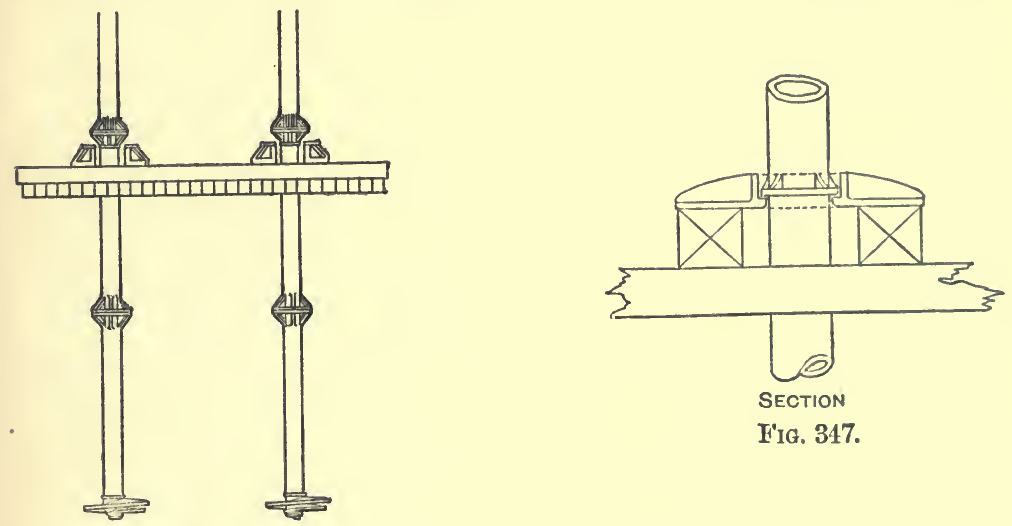

F'IG. 347.

Fig. 346.

a load greater than would be supported by the piles on completion of the pier. On the platforms coming to rest with the load upon them, a connection was made with the piles by castIron discs, arranged to clamp the piles below a collar cast specially on the pile shaft.

The load on the pier is thus transmitted through the columns, piles, and discs, to the bearing area of the platfor'm, thereby giving the necessary resistance to support the load (Figs. 346 to 349).

Load on Piles.-Mr. J. Gaudard, in his paper on foundations, states that the load a pile driven home and secure from lateral flexion can bear may be estimated at from one-tenth to oneeighth the crushing load. ${ }^{1}$ 
Crushing strain of timber usually used for piles-

\begin{tabular}{|c|c|c|}
\hline Beech & $6,400 \mathrm{lbs}$. & quare inch. \\
\hline Fir-red pino & 5,375 to $6,200 \mathrm{lbs}$. & " \\
\hline Larch & $5,570 \mathrm{lbs}$. & \\
\hline English oak & $10,000 \mathrm{lbs}$. & $"$ \\
\hline Elm & 10,300 lbs. & $"$ \\
\hline
\end{tabular}

Formula for determining the supporting power of piles.

Rankine $\mathrm{P}=\sqrt{\frac{4 \cdot e \cdot s \cdot u \cdot h}{l} \times \frac{4 \cdot e^{2} \cdot s^{2} \cdot x^{2}}{l}}-\frac{2 \cdot e \cdot s \cdot x}{l}$

The factor of safety against sinking is from 3 to 10 , whilst against crushing it should not be less than $10 .^{2}$

Stavelly ${ }^{3}$ and Weisbach appear to give the same formula-

$$
\mathrm{P}=w \times \frac{w}{w+m} \times \frac{h}{x}=\frac{w^{2} \times h}{w+m} \times x
$$

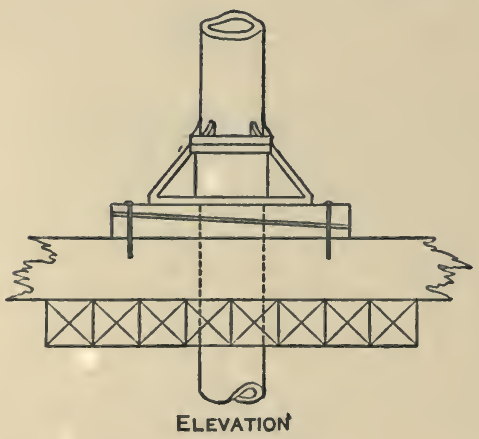

Fig. 348.

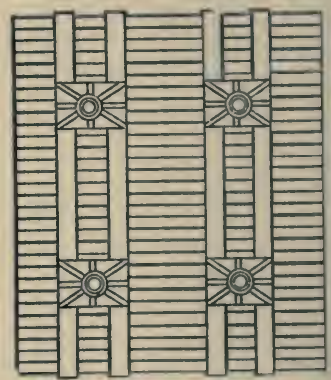

Fig. $3 \pm 3$.

In using this formula, the Dutch engineers adopt a coefficient of from 6 to 10.4

Major Saunders's formula is more simple and more readily applicable to practical work.

$$
\mathrm{P}=\frac{w \times h}{8 \times x}
$$

The result being the safe working load on the pile. ${ }^{5}$

1 Rankine's "Rules and Tables," p. 198.

2 Raukine's "Civil Engineering," 2nd ed., p. 604.

3 Stevenson's "Harbours," 2nd ed., p. 183.

4 M.P.I C.E., vol. xlii. p. 216.

s Journal Franklin Institute, 3rd series, vol. xxii. p. 304; and M.P.I.C.E., vol. xxvii. p. 307 ; vol. xxxii. p. 166. 
$\mathrm{P}=$ supporting power of piles in tons.

$w=$ weight of ram.

$h=$ fall of ram.

$l=$ length of pile.

$s=$ sectional area of pile.

$x=$ set of pile at last blow.

$e=$ modulus of elasticity.

$m=$ weight of pile.

Defective Pile-heads.-When the head of a pile becomes broken up, broomed, or cushioned by the repeated blows of the monkey, the value of the blow is partly lost through the extreme degree of elastic resistance at the pile-head, even though the brooming may not extend to a greater depth than one inch. The following results of experiments ${ }^{1}$ show the comparative influence of the solidity or looseness of the pile-head on the effect of the blow.

A green Norway pile was placed in position, and, when dropped through 10 feet of water, it penetrated the silt at the bottom of the river for a depth of 10 feet; the monkey was then set to work.

The 3rd foot of penetration required 5 blows.

\begin{tabular}{|c|c|c|}
\hline 4th & " & 15 \\
\hline 5 th & "s & 20 \\
\hline " 10th & " & 73 \\
\hline "12th & $"$ & 153 \\
\hline 14th & " & 684 \\
\hline
\end{tabular}

The head was then adzed off.

The 15th foot of penetration required 275 ",

"18th " 825 "

The head was then sawn off.

The 19th foot of penetration required 213 "

" 22nd " 378 "

Total number of blows 5228

A similar pile that had not been adzed or sawn during the driving required 9923 blows to descend to the same depth as the first pile. The weight of the ram was $2800 \mathrm{lbs}$, the fall 3 feet, and worked at the rate of 65 blows per minute. The friction caused by the working of the fibres upon each other under the blows of the ram was sufficient to ignite and burn the interior of the head of the pile from side to side.

Water-jet in Pile-driving.-At the Calais Harbour works,

1 Transactions of American Society of Civil Engineers, Nov. 1883, p. 441. 
the water-jet was largely used for putting down the sheet and other piles. Before this means was adopted, the operation of driving a panel of sheet-piling 9 feet high and 6 feet wide required 900 blows of a monkey weighing about $12 \mathrm{cwt}$., while the average time occupied in the driving was eight hours and a half. The resistance offered by the sand was so great that the thickness of the piling had to be increased from 3 inches to 5 inches. By the injection of water under pressure through two 1-inch pipes, with indiarubber prolongations to the pumps, the time occupied in getting down a panel was reduced to an average of one hour, while in many cases the operation was completed in fifteen minutes. The blows of the monkey were only required to overcome the friction between the adjoining panels. As a rule, the weight of the 12-cwt. monkey resting on the top of a pile 10 feet long was sufficient, with the water-jets in use, to force it down to its place. ${ }^{1}$

In sinking some piles for a bridge foundation at Berlin, in a position where ordinary driving was undesirable; after experiments with different-sized pipes and pressures, a $2 \cdot 5$-inch pipe was used connected with the town water service under a pressure of four atmospheres. With this arrangement, in five

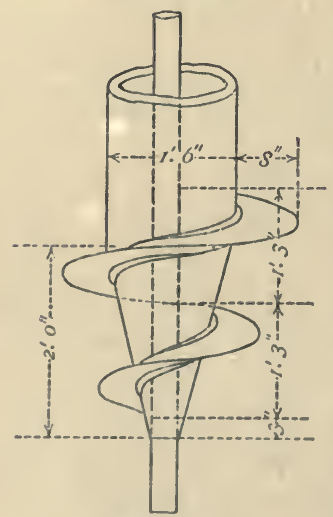

FIG. 350 . minutes, a pile sank about 11 feet 6 inches without loading, and in ten minutes more it sank an additional 4 feet 6 inches. In one hour, it reached a total depth of 22 feet 6 inches. Afterwards a 2 -inch untapered pipe was adopted, and the pileshoes were abandoned. The piles were easily rotated and lifted while the water was flowing. ${ }^{2}$

For fixing the screw-piles of the Birkenhead landing-stage, after failure to get them to the depth required by other means, the water-jet was applied with success. The first experiment was made by cutting off the point of the screw.(Fig. 350), thus forming a hole of about 3 inches diameter, through which a pipe of $1 \frac{5}{8}$-inch internal diameter was passed. This pipe reached to the top of the working-stage, and was connected by a rubber tube to an ordinary steam injector.

1 Engineering, vol. xlvii. p. 550; and M.P.I.C.E., vol. ci. p. 335.

'M.P.I.C.E., vol. lvi. p. 335. 
This injector, as anticipated, did not deliver a sufficient quantity of water when the pile was sinking. Nevertheless, the pile was got down to a depth of 12 feet below the surface of the bank.

A more powerful pump was then applied. A new bottom length of pile was also used, provided with a disc point (Fig. 351), on the under side of which, and at right angles to each other, were four ribs with serrated edges. With these appliances, a pile was got down 18 feet into the ground in two hours, including the time taken up in arranging the guides, pipes, and other incidental matters.

The water washed away the sand all round the pile, making a large hole, at the bottom of which all the stones collected. The point of the pile rested on these stones, and did not move, however long the pumping was continued. The pile was then twisted, so that the serrated edges of the ribs might work through the stones.

By combining this action of twisting with pumping, the pile was got down 2 feet further, or 20 feet into the ground.

Ordinarily the pressure in the delivery pipe was maintained at 20 lbs. per square inch, which was increased at the point of the pile to $35 \mathrm{lbs}$., owing to the difference of level between the top of the working-stage and the sand-bank.

With regard to the raking piles, it was considered that if the dises were placed at right

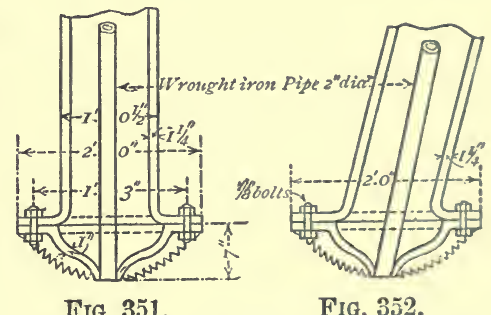
angles to the axis of the piles, the water would not drive the sand out equally all round the pile, and that in consequence they would have a tendency to move outwards and be difficult to guide. The dises were, therefore, placed horizontally (Fig. 352 ), by which arrangement the raking piles were got down as easily as the vertical piles. After the piles were down, they were filled with fine Portland-cement concrete.

Subsequent tests with hydraulic jacks fitted with gauges showed that the piles which went down easily required 8 or 10 tons to depress them, while those which had taken the stones down with them required a force of 14 to 15 tons. In nearly all cases, on the pressure being removed, the piles rose about one- 
fourth of the distance through which they had been depressed. The discs being 2 feet in diameter, the pressure per square foot was 2.50 to 3.18 tons in the first case, and 4.45 to 4.77 tons per foot superficial in the second case. ${ }^{1}$

In timbering the sides of the trenches in sand and peat, required in carrying out waterworks at the Hague, the method usually adopted was to attach to the poling-planks or piles a small iron pipe, which was connected by means of a flexible hose to a hand force-pump. As the water issued from the lower end, washing away the sand, the poling-plank sunk into its place. In this way, two men could place from twelve to fifteen planks, 8 feet long, per hour. With the view of saving time and cost, the engineer, Mr. Waldrop, devised an improvement which proved very satisfactory. An iron pipe, with holes drilled in two rows opposite to each other, was, instead of being

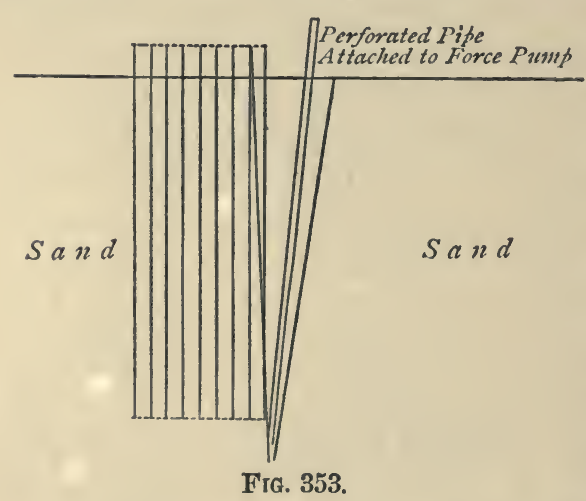
attached to the planks, forced vertically into the sand, and connected with a powerful force-pump. The pipe, once down, was dragged along, cutting a trench in the sand in its course. In this trench, as soon as made, the planks were placed (Fig. 353). By this arrangement, four men were able to place from 80 to 100 planks per hour. ${ }^{2}$

In placing piles in the open sea for defence purposes, the American engineers adopted the following course:-The site was the outlet to the Bay of Mobile, exposed to the heavy swell of the Gulf of Mexico, and through which there was a current of about three miles per hour. The depth of water was about 8 feet, and the mean rise and fall of tide 18 inches. A careful survey showed that the bottom generally consisted of sand to 20 feet deep.

Two rows of piles were driven 10 feet apart, the piles in one row being placed opposite the intervals in the other.

A steam fire-engine placed on the deck of a steamer, and connected with the vessel's boiler, supplied the necessary waterpressure.

'M.P.I.C.E., vol. l. p. 167.

Engineering, vol. xlvii. p. 250. 
Small sheerlegs, fitted with blocks and falls, were erected 'midships, with a sufficient overhang to clear the side of the ship.

About 50 feet of hose, fitted with a $1 \frac{1}{4}$-inch nozzle, was attached to the delivery of the pump, and the suction-hose passed into the sea.

At the lower end or foot of the pile were fixed two staples in which the nozzle was placed. At the end of the nozzle, below the staples, a small line was secured, passed up outside the staples, and held by the man directing the operations, so as to keep the nozzle in its place.

The pile suspended from the sheerlegs was then lowered to its proper position, and on its touching the sand the pump was started. As soon as the stream of water began to flow from the nozzle under pressure the pile began to descend, and sank into the sand at the rate of about 1 foot per second.

When the required depth was attained, the small line attached to the nozzle was let go, and the hose, with the water still flowing, pulled up clear of the bottom; the pump was then stopped, and within a short time the sand settled to its original surface, and the pile became immovable. ${ }^{1}$

Under the direction of the United States engineers, very successful application of the water-jet was made in sinking iron screw-piles at Lewes, Delaware. The piles consisted of solid wrought-iron shafts from $5 \frac{1}{4}$ to $8 \frac{1}{2}$ inches diameter. In attempting to screw the piles down they broke, owing to the extreme resistance of the material-into which they were forced, before they had reached the necessary depth.

Attempts were made to reduce the resistance by leading a jet of water to the material underneath the screw. The prevalence of gravel in the sand and the insufficient power of the pump led to unsatisfactory results.

An examination of a broken pile led to the conclusion that the greatest resistance encountered is on the upper surface of the screw, and is doubtless due to the friction caused by the superimposed cone of sand.

It was thought that if a jet of water were forced into the upper surface of the screw, it would accomplish the more complete liquidity of the sand above the screw, and change the volume of the pressure from that of an inverted cone to that

- Engineering, rol. slviii. p. 55. 
of a cylinder whose diameter would be equal to that of the smaller face of the frustum.

Streams of water through two $1 \frac{1}{4}$ inch iron pipes were led directly upon the screw, and the hitherto great resistance to screwing down the piles at once ceased.

A subsequent determination of the resistance to screwing down the piles developed the fact that nine-tenths of the resistance disappeared upon the proper application of the water-jet to the upper surface of the screws.

Through the aid of the water-jet, it became possible to settle the screw-piles as decply as was decmed necessary in a bottom where, without the jet, the strongest iron screws were broken as though they had been made of glass, when main force alone was used in the unsuccessful effort to sink them more than 4 feet.

When it became necessary to remove some of these piles, the application of the water-jet to the upper face of the screw rendered the operation quite easy, when previous efforts, by backing the screw, or to raise the pile bodily, had proved unsuccessful. ${ }^{1}$

At the Queen's Dock, Glasgow, in sinking some foundation cylinders constructed of concrete, 30 feet long and 12 feet diameter, by the aid of the water-jet, the presence of large boulders caused considerable difficulty, which was met by forcing the water-jet pipes some feet below the obstruction, and washing out the sand from beneath and round it. By this means the boulders were either lowered vertically or sideways so as to clear the cylinder edge. ${ }^{2}$

The general principle upon which the efficiency of the waterjet depends is the increased fluidity of the material; hence the efficiency is greatest in clean sand, mud, or very soft clay or marl.

In gravel, or in sand containing a large percentage of gravel, the jet is almost useless, except under a volume and pressure sufficient to force the stones from under the piles.

In applying the water-jet, it is better to deliver large quantities at a moderate pressure rather than a small quantity

1 Mr. L. T. Schermerthorn's paper on "The Water-jet as an Ail to Engineering Construction," from which the above is taken, gives an interesting and valuablo record of the application of the water-jet unler varying conditions. - " A merican Engincering and Building Record for 1889," pp. 117-131.

Engineering, vol. xlviii. p. 55. 
at a very high initial pressure. No hard-and-fast rule can however be laid down, therefore the quantity and pressure must depend in a great measure upon the character of the material to be dealt with.

Testing Stability of Ground.-The following course was pursued in testing the stability of the ground prior to determining the dimensions of the foundations for the Paris exhibition buildings.

A perfectly level surface, in the form of a square 118 feet wide, was first prepared. On this area four rectangular cast-iron blocks 1 foot 8 inches square were so disposed as to form the corners of a square, the distance apart from centre to centre being 11 feet 8 inches. The spaces between the blocks were then bridged over by girders constructed of T irons.

The girders were then uniformly loaded and the weights carefully noted. With a total weight of 7.31 tons per square foot, including the weight of the corner blocks and girders, indications of settlement became visible; during the night the settlement increased to between $10 \frac{1}{4}$ to 11 inches with the same load. The loading was then continued until some of the blocks had sunk completely into the ground, leaving the girders supported on the surface.

The conclusions arrived at were that the ground was capable of sustaining a load of 5.43 tons per square foot; that a certain amount of settlement might be expected when the load reached 7.31 tons per square foot, and that it was totally incapable of bearing a load amounting to 8.14 tons per square foot.

Details of Experiment made to determine the Stability of the Ground. ${ }^{1}$-In order to test the stability of the ground prior to abandoning the piles in the foundations of the locks and deep dock at Portsmouth, the following experiment was made on the site of No. 13 Dock, the nature of the ground in that position being the same as that in which the foundations of the locks and deep dock would be placed.

The geological formation was the lower tertiary, the strata consisting of the beds of very compact argillaceous and retentive sand subordinate to the London clay. A hole was sunk to about the excavation level, and on a stone base a brick pier, 
3 feet by 3 feet, was constructed, built in Portland cement, and terminated with a stone cap; stone corbels were also provided to support the straight-edges on which to place the level staff. On the stone cap a timber platform was constructed to carry the weights. During the adjustment of these weights, the platform was supported on folding wedges resting on a dwarf wall surrounding the pier, and which also served to protect it from injury. On the completion of the respective loads, the wedges were removed, leaving the mass supported solely by the pier.

In order that the experiment should be made under conditions approaching as nearly as possible those to which the permanent work was subjected, provision was made for saturating the ground by placing 3 -inch pipes at each side of the pier, by which to convey the water to the foundation.

The experiment may therefore be considered to consist of two parts, first, as regards resistance to compression with the foundation dry; and secondly, when saturated, the ultimate loads being the same in both cases.

The results showed that the actual subsidence of the pier with the foundation dry, and loaded with a weight of 8 tons per foot superficial, was 0.02 foot, and with the foundation saturated, slightly less, viz. 0.015 foot. On the removal of the load before saturating the ground, the pier returned to its normal condition.

It was therefore clearly demonstrated that with a load of 8 tons per superficial foot no subsidence of an appreciable character took place. Indeed, the slight difference observed may be due as much to the compression of the material in the pier as to the subsidence of the ground.

Pressure on Ground under Dock Floors. -The greatest intensity of pressure on the ground under a dock floor is at the centre when the ship is on the blocks. The weight is first distributed over a width of the floor equal to the length of the blocks, a greater distribution being effected to the ground by the line which would represent the direction of fracture through the material composing the floor of the dock, supposing subsidence from excessive weight to take place.

Equipment.-The equipment of a dock will vary with the class of trade to be accommodated, or the purpose for which the docks are established, whether for building and repairing 
vessels, general merchandise, or coal trade, or passenger traffic. Each will have its characteristic requirements. Generally the term comprises all those appliances necessary for the expeditious handling of ships, the materials and stores used in their construction, the rapid manipulation of merchandise of all descriptions, or for the comfort and convenience of a large number of travellers. These appliances comprise shops and manufactories of every description, storehouses, cranes, capstans, moorings, coal-hoists, railways, lighting, water service, drainage, etc.

Bollards and Wharf Moorings.-Timber is objectionable for this purpose on account of its liability to decay, and to be cut and worn by the friction of ropes and chains.

Granite, when well-proportioned and dressed, presents an excellent appearance, and is well calculated from its hardness to resist the wear of chains and hawsers. It is, however, comparatively deficient in transverse strength, and on this account is not well fitted to resist the sudden and severe strains to which bollards are occasionally subjected, therefore the dimensions required to provide sufficient strength are such as to render a mooring bollard of this kind inconveniently large and obstructive.

Wrought-iron rings to act as moorings are, under favourable conditions, fixed in the face of the wharf wall, secured by massive eye-bolts or staples passing through the wall, and secured with large washers and nuts at the rear. Such moorings are useful when they can be approached from the water, and when properly recessed into the wall face present little obstruction. The rings and staples are usually made from bar iron, 3 to 6 inches in diameter, the internal diameter of the rings varying from 15 inches to 24 inches in diameter. Mooring-rings should be hung so that the plane of the ring is vertical in all positions, that is, the axis of the hole in the eye-bolt should be vertical, not horizontal.

Hollow bollards of cast iron possess the greatest advantages. Such a bollard is cheap, durable, and comparatively light, and occupies but little space.

To arrive at a practical estimate of the strains to be provided 
for, the strength of chains or hawsers used to secure the vessels to the wharf should be considered. The anchor-chain being the

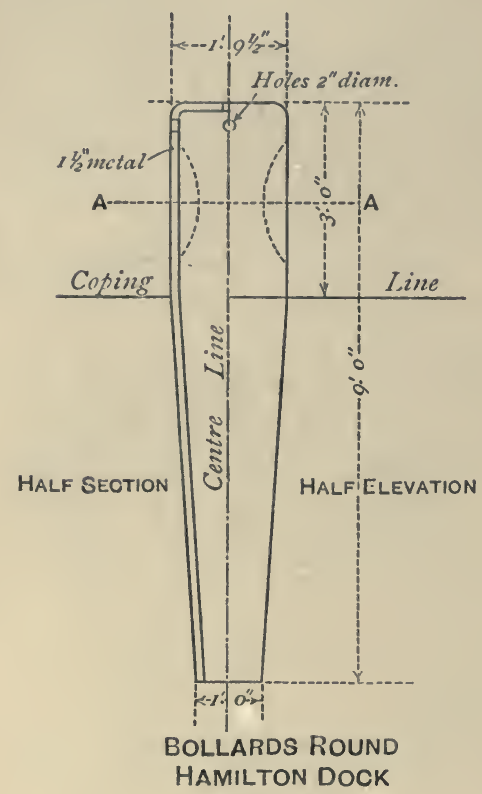

Fig. 355.

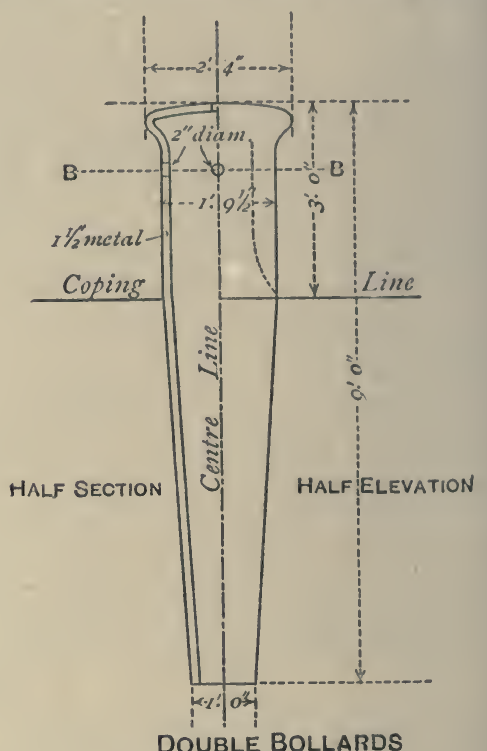

DOUBLE BOLLARDS

$8^{\prime}, 2^{1 / 2}$ 'Centres

ALONG WHARF WALL

FIG. 356.

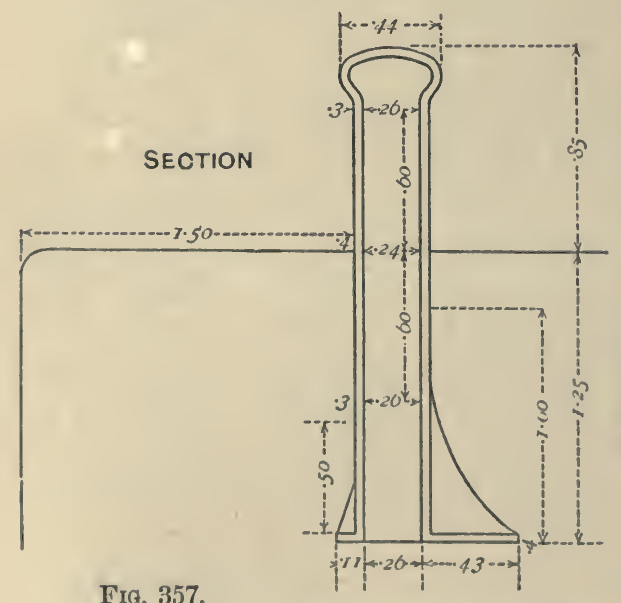

Fia. 357.

\footnotetext{
BOLLARDS AND SNATCHBLOCKS.
}

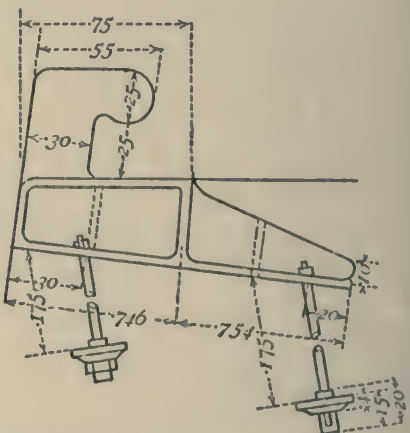

Fig. 358.

strongest carried by a ship is frequently used for mooring purposes. The maximum strain that can be applied through 
a $2 \frac{5}{16}$ inch studded chain is 135 tons; it will therefore be sufficient to provide a resistance of say 400 tons to cover contingencies.

A cast-iron bollard or mooring-post of 2-inch metal, as shown by Fig. 354, with a top diameter of 2 feet 3 inches, tapering to 1 foot 11 inches at the ground level, and about 21 inches at the bottom flange, with an overall length of 7 feet, fixed 5 feet into a concrete base, leaving 2 feet above the ground level, will occupy but a small space, and give the required strength.

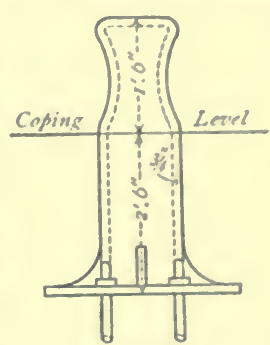

Fig. 359.

Different types of bollards are shown by Figs. 355 to 359 . 



\section{MISCELLANEOUS NOTES.}

Height of Waves.-The height of the waves to which an exposed entrance may be subjected will depend upon the greatest fetch or reach of open sea, and will closely approximate to the square root of the distance from the windward shore. The following formula by the late Mr. T. Stevenson, gives, with sufficient accuracy for all practical purposes, the height of waves due to long distances and heavy gales, and where the water is of sufficient depth to allow of waves being fully formed.

$$
h=1 \cdot 5 \sqrt{d}
$$

When $h=$ height of waves in feet, $d=$ length of exposure in miles.

It is, however, to be observed that, for short fetches, in narrow waters or arms of the sea, waves are raised higher during very violent gales than the above formula indicates, although it does not appear that the waves go on increasing in the same high ratio for any considerable distance. The following formula will therefore be more exact for short distances and heary squalls.

$$
h=1 \cdot 5 \sqrt{d}+(2 \cdot 5-\sqrt[4]{d})
$$

The table on page 408 shows comparatively the height of waves for different lengths of fetch, calculated from the above formula.

There are several other causes besides the direct effect of fetch, which may tend to influence the height of waves in front of an exposed entrance, and which it is necessary to take into consideration, such as alterations to existing works, or in the natural surroundings. The following may be considered as some of the principal of these causes.

(a) The removal of a spending beach by building a quay, or an embankment of any kind across it by which an area, over which waves may break and disperse, is lost.

(b) Deepening the entrance channel or the tidal basin itself, thus the difficulty of keeping vessels at their moorings alongside the quays of a harbour during flood-tide is increased. 


\begin{tabular}{|c|c|c|c|c|c|}
\hline Fetch. & $\begin{array}{l}\text { Height of waves } \\
\qquad h=1 \cdot 5 \sqrt{d_{0}}\end{array}$ & $\begin{array}{l}\text { Height of waves } \\
\begin{array}{l}h=1 \cdot 5 \sqrt{d}+ \\
(2 \cdot 5-\sqrt[4]{d}) .\end{array}\end{array}$ & Fetch. & $\begin{array}{l}\text { Ueight of waves } \\
\qquad h=1 \cdot 5 \sqrt{d} \text {. }\end{array}$ & $\begin{array}{l}\text { Height of waves } \\
h=1 \cdot 5 \sqrt{d}+ \\
(2 \cdot 5-\sqrt[4]{d})\end{array}$ \\
\hline 1 & $1 \cdot 50$ & $3 \cdot 00$ & 26 & $7 \cdot 64$ & $7 \cdot 88$ \\
\hline 2 & $2 \cdot 12$ & $3 \cdot 43$ & 27 & $7 \cdot 79$ & $8 \cdot 01$ \\
\hline 3 & $2 \cdot 59$ & $3 \cdot 77$ & 28 & $7 \cdot 93$ & $8 \cdot 13$ \\
\hline 4 & $3 \cdot 00$ & $4 \cdot 09$ & 29 & $8 \cdot 08$ & $8 \cdot 25$ \\
\hline 5 & $3 \cdot 35$ & $4 \cdot 35$ & 30 & $8 \cdot 21$ & $8 \cdot 37$ \\
\hline 6 & $3 \cdot 67$ & $4 \cdot 51$ & 31 & $8 \cdot 35$ & $8 \cdot 49$ \\
\hline 7 & $3 \cdot 96$ & $4 \cdot 83$ & 32 & $8 \cdot 58$ & $8 \cdot 70$ \\
\hline 8 & $4 \cdot 24$ & $5 \cdot 05$ & 33 & $8 \cdot 61$ & $8 \cdot 71$ \\
\hline 9 & $4 \cdot 50$ & $5 \cdot 26$ & 34 & $8 \cdot 74$ & $8 \cdot 82$ \\
\hline 10 & $4 \cdot 74$ & $5 \cdot 46$ & 35 & $8 \cdot 87$ & $8 \cdot 94$ \\
\hline 11 & $4 \cdot 97$ & $5 \cdot 64$ & 36 & $9 \cdot 00$ & $9 \cdot 05$ \\
\hline 12 & $5 \cdot 19$ & $5 \cdot 82$ & 37 & $9 \cdot 12$ & $9 \cdot 15$ \\
\hline 13 & $5 \cdot 40$ & $6 \cdot 00$ & 38 & $9 \cdot 24$ & $9 \cdot 25$ \\
\hline 14 & $5 \cdot 61$ & $6 \cdot 17$ & 39 & $9 \cdot 36$ & $9 \cdot 36$ \\
\hline 15 & $5 \cdot 80$ & $6 \cdot 33$ & 40 & $9 \cdot 48$ & \\
\hline 16 & $6 \cdot 00$ & $6 \cdot 50$ & 41 & $9 \cdot 60$ & \\
\hline 17 & $6 \cdot 12$ & $6 \cdot 59$ & 42 & $9 \cdot 72$ & • \\
\hline 18 & $6 \cdot 36$ & $6 \cdot 83$ & 43 & $9 \cdot 83$ & \\
\hline 19 & $6 \cdot 53$ & $6 \cdot 94$ & 44 & $9 \cdot 94$ & \\
\hline 20 & $6 \cdot 70$ & $7 \cdot 08$ & 45 & $10 \cdot 06$ & \\
\hline 21 & $6 \cdot 87$ & $7 \cdot 22$ & 46 & $10 \cdot 17$ & \\
\hline 22 & $7 \cdot 00$ & $7 \cdot 33$ & 47 & $10 \cdot 28$ & \\
\hline 23 & $7 \cdot 19$ & $7 \cdot 49$ & 48 & $10 \cdot 39$ & \\
\hline 24 & $7 \cdot 34$ & $7 \cdot 62$ & 49 & $10 \cdot 50$ & \\
\hline 25 & $7 \cdot 50$ & $7 \cdot 76$ & 50 & $10 \cdot 60$ & \\
\hline
\end{tabular}

(c) Removal of an artificial breakwater, or a protecting point of land, or spit of gravel, outside the harbour.

(d) Filling up side creeks or lateral basins in a harbour or its entrance channel.

(e) Shortening the distance between the sea and the entrance to an inner basin or dock by projecting the basin or dock further out from the shore, so as to bring the gates nearer to the sea entrance, or projecting the mouth of a harbour further seawards.

$(f)$ Removal of a jetty, or filling up an artificial side chamber, or converting "toters," or rough sloping embankments into plumb walls.

(g) Shortening an entrance channel or an outer side breakwater, or walls within a harbour.

(h) Widening the entrance or the entrance channel.

(i) Reduction of the area of the basin of a harbour.

(k) Making smoother the surface of a natural sloping beach, either within or outside the harbour, by pitching the surface.

(l) Lowering the top of a protecting outside breakwater, over which the sea breaks.

$(m)$ Converting an open timber quay into a close quay.

(n) Lengthening a breakwater or outer pier, so as to intercept a greater portion of the waves which come in certain directions. 
Wave Action. ${ }^{1}$ - Waves generally are classed under two heads, i.e. waves of oscillation and waves of translation, but it appears doubtful whether any wave generated by the force of the wind can be considered as purely oscillatory. When there is actual and continuous horizontal force applied, there must be actual transference of water, the amount of courso varying considerably with the strength of the wind, and the time it has been blowing.

That waves exert great disturbing powers at moderato depths is undoubted, and that their influence is felt in deep water is tolerably certain, but the nature and extent of this action in deep water is by no means so well understood.

The late Sir J. Coode stated from personal observation that the strength of the Chesel Bank is disturbed by storms at a depth of 8 fathoms.

Waves from 6 to 8 feet high have been seen to chango their colour from abrasion of the bottom after passing into water of 7 to 8 fathoms.

Sir J. Douglas has stated that coarse sand has been thrown from a depth of 25 fathoms on to the lantern gallery of the Bishop's Rock lighthouse. $\mathrm{He}$ also alludes to the fact, well known amongst fishermen on coasts with an Atlantic exposure, that lobster-traps are occasionally filled with coarse sand in depths up to 11 fathoms.

The late Mr. R. Stevenson held the opinion that the dispersion of fishes, evinced by their disappearance from fishing-grounds in stormy weather, tends to show the disturbance of the sea at a depth of 30 to 40 fathoms.

It is not unusual for vessels sunk in comparatively deep water to be broken up by subsequent storms. For instance, a ship which sunk off the Gold Stone, on the Northumberland Coast, in 11 fathoms, was broken up by a later gale, and part of the wreck washed on shore.

The late Sir J. Airy noted that heavy ground-swells break in a depth of 100 fathoms.

Proofs of the sea being disturbed to a considerable depth exist in the fact of some large drift-stones of more than 2 tons weight, having been thrown during storms from deep water on to the rock, on the Scotch coast, upon which the Bell Rock lighthouse is erected.

Formerly rubble foundations were considered safe from disturbance at very moderate depths below low water. Now, however, it is judged wiser to keep the surface of a rubble mound some 15 to 20 feet, and in some cases considerably more, below low-water level.

Valuable evidence as to the degree of exposure, and the

1 Stevenson's "Docks and Harbours;" Engineering, vol. xliv. p. 73; M.P.I.C.E., rarious. 
disturbance to be expected, may be found in the level of the mud below the water line, inasmuch as in very exposed situations mud cannot repose near the surface.

The absence of mud, however, in any locality, without taking into consideration other conditions, proves nothing; local currents may sweep it away, or the geological formation of the district may not produce it; on the other hand, its presence seems to afford both a delicate and certain test of the lowest limits to which the disturbance generated at the surface has reached. Therefore, if in front of a proposed work mud is found within a few fathoms of the surface of the water, there is in that fact good ground for considering that the work will never be assailed by a very heavy sea.

Facts appear to indicate fairly conclusively that the disturbing effect of waves is in many cases of more importance than that of any ordinary current. Even when the material composing the bed is particularly favourable to movement by current one or two heavy gales will cause a greater amount of disturbance than an ordinary tidal current in several months.

Chopping Seas.-Choppy water may be the result of two equal swells moving in opposite directions, or it may be due to the superposition of a number of swells of different amplitudes, heights, and directions, to currents and other causes. Chopping waves rise and fall vertically, and have twice the height of each of the two swells of which they are the components, and the same length. This double height explains why they break much more readily than travelling waves or swell.

Chopping is the natural motion of water in a limited basin or area, whilst swell is the natural motion of water of an indefinite extent.

Ground Swell.-When a strong gale has been blowing for some time a considerable forward motion is imparted to the water greater at the surface than at the bottom. Out of the influence of the wind the forward motion of both wave and water is maintained by momentum; but the propelling force being absent, the motion of the fluid becomes less at the surface than at the bottom, making what is known as ground swell.

Strains on Dock Gates.-The primary strains acting on dock gates are :-Water pressure, reaction at the mitre- and heel-posts, and reaction parallel to the gate.

The subject has been ably treated both mathematically and graphically by Mr. W. R. Brown ${ }^{1}$ and Mr. Blendy, ${ }^{2}$ in papers laid before the Institution of Civil Engineers, and previously in papers

I M.P.I.C.E., vol. xxxi. p. 317.

3 Ibid., vol. Iviii. p. 154 
by Mr. P. Barton ${ }^{1}$ and Mr. Kingsbury, ${ }^{2}$ all of which are worthy of careful study.

In practically designing dock gates a largo excess of strength beyond that theoretically indicated should be provided-particularly high up where the calculated strains are least-to guard against rough usage, and to cover possible dofects of workmanship or of material.

If the surface of the water in the dock is at a higher level than that of the outer waterway, the pressure on the gates due to this difference of level has to be withstood, and conveyed to the side walls by the structure of the gates.

If a dock gate be considered as divided by a series of cross-sections into a number of narrow vertical strips, say of 1 foot wide, the full

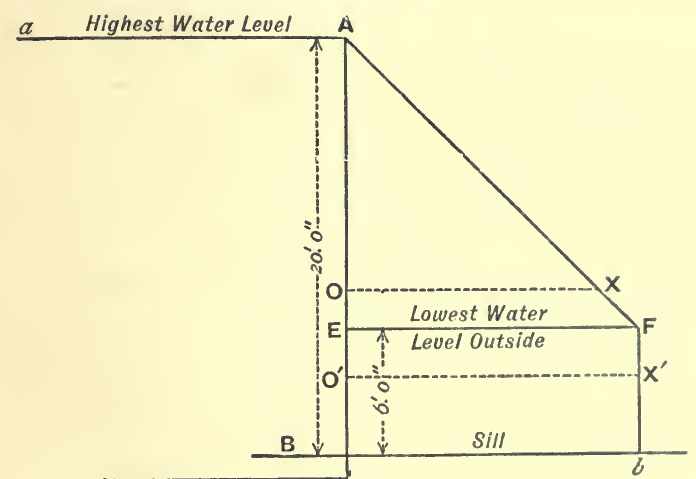

FIG. 360.

depth of the gate, then the total pressure on any such strip will be the pressure per unit of length of the gate. ${ }^{8}$

$\mathrm{P}=$ total pressure on any strip or the pressure per unit of length of gate.

$\mathrm{W}=$ weight of water per unit of measure.

$\mathrm{D}=$ depth of sill below highest water level.

$\boldsymbol{d}=$ depth of sill below lowest level of outer water.

$$
\text { Then } \mathrm{P}=\frac{\mathrm{W}}{2}\left(\mathrm{D}^{2}-d^{2}\right)
$$

If the outer water leaves the sill entirely dry $d=0$.

$$
\text { and } \mathrm{P}=\frac{\mathrm{W}}{2} \mathrm{D}^{3}
$$

This pressure ${ }^{4}$ is distributed thronghout the whole depth in proportion to the head of water at the various levels. In Fig. 360, $a$ is

M.P.I.C.E., vol. i. p. 67.

3 Ibid., vol. Iviii. p. 157.
2 Jbid., xviii. p. 445.

- Ilid., p. 158. 
the highest water level, $\mathrm{B} b$ the level of the sill, and $e$ the lowest level of the outer water. Then $\mathrm{AB}=\mathrm{D}$, and $\mathrm{E} \mathrm{B}=d$. Make $\mathrm{B} b$ $=\frac{2 \mathrm{P}}{\mathrm{D}-d}$, draw $b \mathrm{~F}$ parallel to A B, and complete the triangle A F E. The figure B A F $b$ will then graphically represent the rortical distribution of the pressures or forces acting on the gate. The area of the figure $\mathrm{B} \mathrm{A} \mathrm{F} b$ will represent the whole pressure, and if $\mathrm{O}^{\prime} \mathrm{O}^{\prime}$ be any part of the line $\mathrm{A} \mathrm{B}$, the portion of the pressure acting betwcen $\mathrm{O}^{\prime}$ is represented by that portion of the area $\mathrm{B} \mathrm{A} \mathrm{F} b$ which lies between the horizontal lines $\mathrm{OX}$ and $\mathrm{O}^{\prime} \mathrm{X}^{\prime}$. Also the intensity at any point $\mathrm{O}$ is represented by $\mathrm{O} X$, the portion of the horizontal line through $\mathrm{O}$, lying between $\mathrm{A} \mathrm{B}$ and $\mathrm{A} \mathrm{F} b$.

The diagram (Fig. 361) showing the value of the forces acting on a dock gate is taken from Mr. Brown's paper on "Dock Gates." 1 All questions of form and material are left out of consideration.

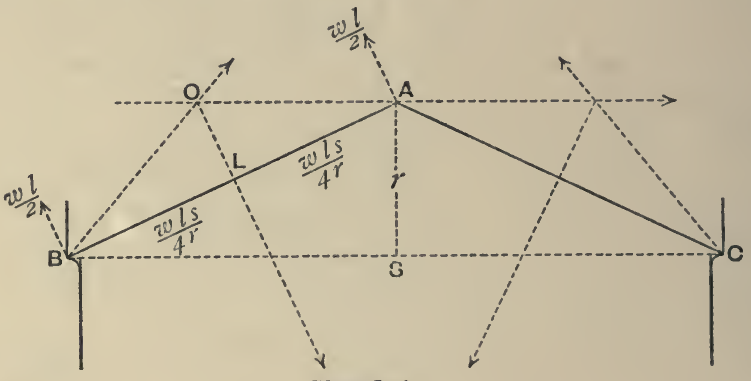

Fig. 361.

A pair of gates is taken as simply consisting of two rigid rods 1 inch thick, supporting the water pressure, and meeting at the mitre.

$s=$ span of lock.

$r=$ rise.

$l=$ length of either gate.

$w=$ water pressure in tons per inch run.

The dimensions are taken in inches, because the stress is always measured in tons to the square inch.

Then taking one gate as A B (Fig. 361), the forces acting upon it are-

The water pressure, equivalent to $v \times l$ acting at the centre or the middle point of the gate.

The reaction at the mitre-post. This by symmetry will act directly across the lock in the direction of $\mathrm{O} \mathrm{A}$.

The reaction at the heel-post, which by the triangle of forces 
must pass through the intersection of the lines of action of the two other forces.

Resolving the two latter forces in directions parallel and per. pendicular to the line A B, it follows by the ordinary conditions of equilibrium that the reaction at either end perpendicular to A $B$ $=\frac{2 v l}{2}$, and that the reaction parallel to the gate, or the compressive strain along the gate $=\frac{w l s}{4 r}$

The longitudinal strain will be the same whether the gates be straight or curved.

For all practical purposes the compression on any cross-section of the horizontal curved members may be found by the formula $t=p r ; t$ being the horizontal compression, $p$ the intensity of water pressure per unit of surface, and $r$ the radius of the gate. ${ }^{1}$

It has been pointed out " that this formula is only rigidly and accurately true in the case of an indefinitely thin cylinder of perfectly homogeneous material under an uniform external pressure normal to the surface." On the other hand, it is remarked " - "It was undoubtedly true that when the formula $t=p r$ was applied to dock gates, it was assumed that the centres of pressure coincided with the centre line of the cross-sections of the gate; but in a gate con. structed of such material as Memel or pitch-pine, the factor of safety was necessarily so large, owing to the variations in the strength of the timber, and to the fact that to some extent in practice the dimensions have to be regulated by the scantlings obtainable in the market, that the formula is ample to cover any deviation from the ideal condition," and therefore gives as good a practical result as more complicated methods.

Theoretically, the stresses on the front and back flanges of the horizontal beams in iron gates vary somewhat, but it has been shown ${ }^{4}$ that in ordinary cases the difference is so slight that practically it may be disregarded.

The following investigation of the stresses under normal conditions is taken from Mr. Blendy's paper on "Dock Gates." 5

Let Fig. 362 be a plan of a pair of dock gates, $\mathrm{A} \mathrm{A}^{\prime}$ being the centre of the heel-posts, B the centre of the meeting-faces of the mitre-posts. Considering the left-hand gate A B, the primary forces acting on this are $\mathrm{P}=$ water pressure, $\mathrm{M}=$ the reaction of the other gate on the mitre-post, and $\mathrm{H}=$ the reaction of the hollow quoin on the heel-post.

1 M.P.I.C.E., vol. 1v. p. 12 .

3 Tbid., p. 93.

- Ilvid, vol. Iviii. p. 159.
2 Ibil., p. 56.

' Ilidl., vol. xxxi. p. 34 . 
The water pressure $\mathrm{P}$ acts throughout the extent of, and in all cases normal to, the exposed surface of the back of the gate. If the pressure per unit of length $=p=\frac{W}{2}\left(D^{2}-d^{2}\right)$, the magnitude of the resultant force $\mathrm{P}$, equivalent to the whole of this pressure, is proportional to, and may be represented by, the length of the horizontal straight line $e f$ joining the extremities of the water-bearing surface, that is, $\mathrm{P}=p x e f$. The direction is that of a horizontal straight line $\mathrm{D} d$, perpendicular to and bisecting the first-mentioned line $e f$.

In the case of the reaction $M$ of the other gate on the mitre-post, assuming that the gates meet on the centre line of the passage, and that this is perpendicular to a straight line $\mathbf{A} \mathbf{A}^{\prime}$ drawn through the

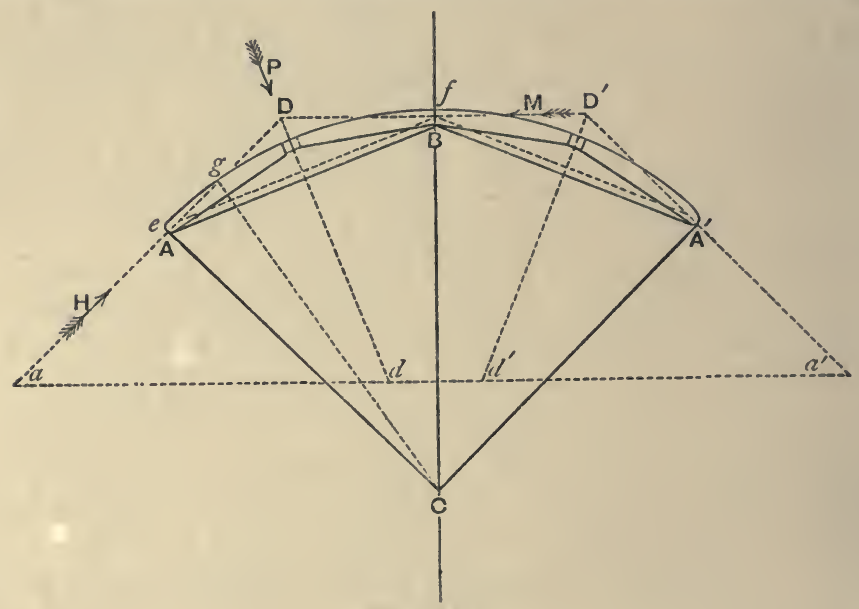

FIG. 362.

centres of the heel-posts, the natural reaction of the mitre-posts on each other will be perpendicular to the centre-line of the passage, and parallel to $\mathrm{A} \mathrm{A}^{\prime}$; no other direction will admit of equilibrium. It has already been assumed that the mitre-posts meet so that the mutual reactions are uniformly distributed throughout the width of the meeting-faces, consequently the direction of the resultant force M, representing the reaction of the other gate, will be that of the horizontal straight line $\mathrm{B} \mathrm{D}$ which bisects the meeting-face in $\mathrm{B}$, is parallel to $\mathrm{A}^{\prime}$, and cuts tho line $\mathrm{D} d$ at the point $\mathrm{D}$.

The reaction of the hollow quoins on the heel-post $H$ obriously acts through the centre of the heel-post, and from the conditions of equilibrium its line of direction must pass through the point of intersection of the other two forces. The line of direction of this force H will therefore be represented by the line A D. If from the point $e$, 
the extremity of the water-bearing surface at the heel-post, a line to $e c$ be drawn perpendicular to $\mathrm{A} \mathrm{D}$, and cutting the centre-line of the passage in $c$, then will the length of the line $c e$ be proportioned to the magnitude of the reaction $\mathbf{H}$, and the length of the line $c f$ will be proportional to the magnitude of the reaction $M$; that is to say, $\mathrm{H}=p \times c e$, and $\mathrm{M}=p \times c f$. Further, if $g$ be any point on the

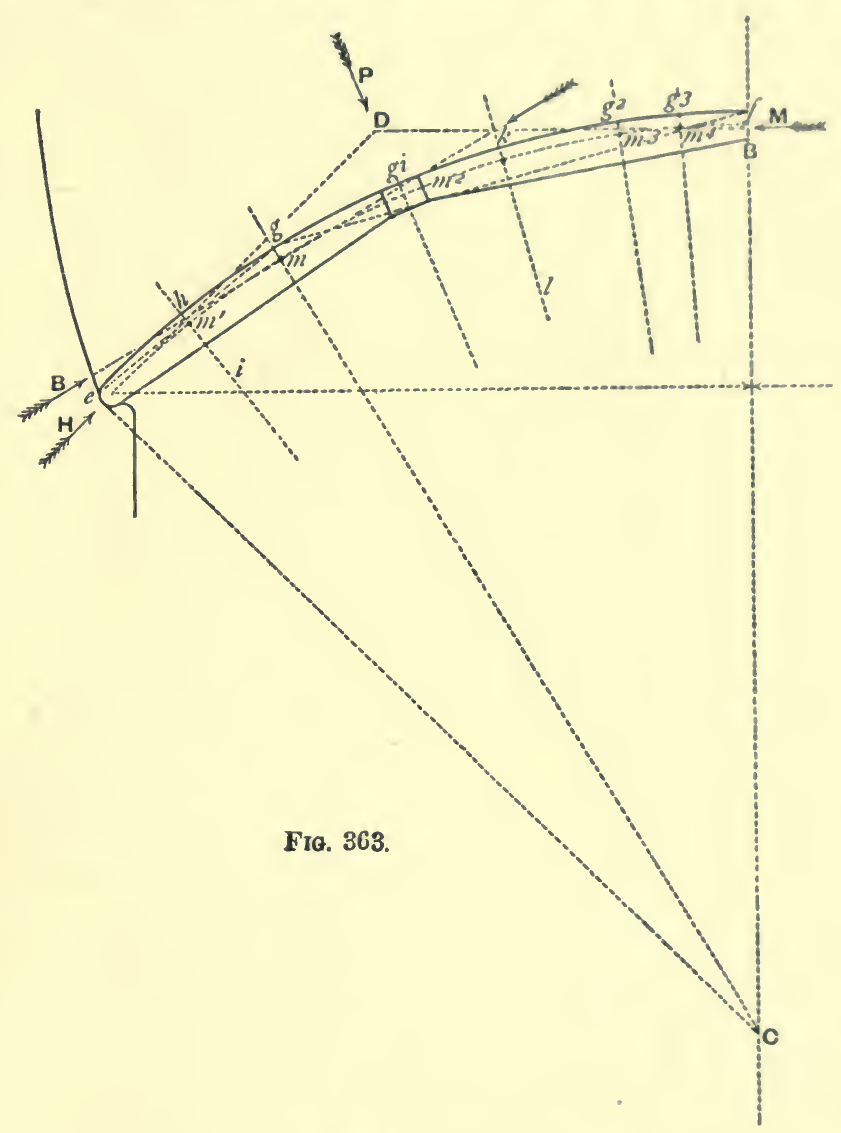

back of the gate, the length of the line $c g$ will be proportional to the magnitude of the resultant force $R$, acting on any rertical section passing through $g$; that is to say, $\mathrm{R}=p \times c g$, and the direction of such resultant will be perpendicular to $c g$.

To find the position of the resultant force $R$ acting on any vertical section passing through $g$, let Fig. 363 be an enlarged plan of the gate, A D and B D the lines of direction of $\mathrm{H}$ and $\mathrm{M}, \mathrm{C}$ the point on 
the centre line of the passage found as before, and $g$ any point on the back of the gate.

Join $\mathrm{C} g, g e$, and $g f$; draw $h i$ perpendicular to, and bisecting $g e$, and cutting $\mathrm{A} \mathrm{D}$ in $h$; also draw $h l$, cutting $\mathrm{C} g$ in M. Then will $h \%$ be perpendicular to the line $\mathrm{C} g$, and will be in the direction of $\mathrm{R}$, the resultant of all the forces acting on the heel-post side of any vertical section passing through $g$. It has already been said that the magnitude of $\mathrm{R}$ is proportional ${ }^{1}$ to the length of the line $\mathrm{C} g$. The resultant of the forces acting on the mitre-post side of the section is equal in magnitude but opposite in direction.

By taking a sufficient number of points, $g, g^{1}, g^{2}, g^{3}$, etc., and proceeding as above, a number of points $m, \mathrm{~m}^{1}, \mathrm{~m}^{2}, \mathrm{~m}^{3}$, etc., can be obtained, in which the respective resultants cut the lines $\mathrm{C} g, \mathrm{C} g^{1}$, $\mathbf{C} g^{2}, \mathbf{C} g^{3}$, etc. Then joining the points A $m, m^{1}, m^{2}, m^{3}, \mathrm{~B}$, a line will

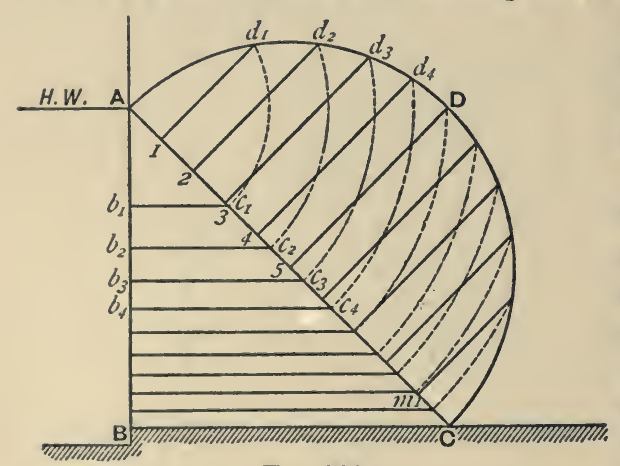

Frg. 364.

be obtained passing through the points $A B$, which may be termed the line of position of resultants.

Distribution of Material. ${ }^{2}$-In designing a dock gate, it is often convenient, as a guide to the distribution of material, to divide the rertical section into layers sustaining equal pressures. The following method of doing this may be useful.

If the sill is not submerged, draw A B (Fig. 364), representing a vertical section of the gate, and at right angles to A B draw A a representing the highest water level, $\mathrm{B} C$ representing the level of the sill ; make $\mathrm{B} \mathrm{C}=\mathrm{A} \mathrm{B}$ and join $\mathrm{A} \mathrm{C}$.

Mark off the points, $1,2,3,4, \ldots m-1$, dividing the line A C into the required number of equal parts. On $\mathbf{A ~ C}$ describe the semicircle A D C and from points $1,2,3,4, \ldots m-1$, draw lines perpendicular to A C, cutting the semicircle A D C in $d^{1}, d^{2}, d^{3}$, $d^{4}$, etc.; then with centre $\mathbf{A}$ describe the $\operatorname{arcs} d^{1}, c^{1}, d^{2}, c^{2}, d^{3}, c^{8}, d^{4}, c^{4}$, etc., cutting $\mathrm{AC}$ in $c^{1}, c^{2}, c^{3}, c^{4}$, etc. Parallel to $\mathrm{B} \mathrm{C}$ draw the horizontal lines $c^{1}, b^{1}$, $c^{2}, b^{2}, c^{8}, b^{8}, c^{4}, b^{4}$, etc. These lines will divide $\mathrm{AB}$ in the required manner; that is to say, if the total pressure on $\mathrm{A} B=\mathrm{P}$, the pressure on each of the parts $\mathrm{A} b^{1}, b^{1}, b^{2}, b^{2}, b^{8}, b^{3}, b^{4}$, etc. $=\frac{\mathrm{P}}{m} ; m$ being tho number of parts into which $\mathrm{A} \mathrm{C}$ is divided.

I $\mathrm{R}=p \times \mathrm{C} g ; p=\frac{\mathrm{W}}{2}\left(\mathrm{D}^{2}-d^{2}\right)$.

$=$ M.P.I.C.E., vol. Iviii. p. 205. 
If the sill is submerged, it is obvious that the above method will only apply to the part of the gate above the surface level of the outer water. The submcrged portion is subject to uniform pressure, and can readily be divided into any required number of equal parts.

The proof of the above depends on the fact that if $\mathrm{A} \mathrm{C}$ (Fig. 365) be any given finite line, and $\mathrm{A} \mathrm{D} \mathrm{C} \mathrm{a}$ semicircle described thereon, then if $\mathrm{A} \mathrm{C}$ is divided into any two parts at

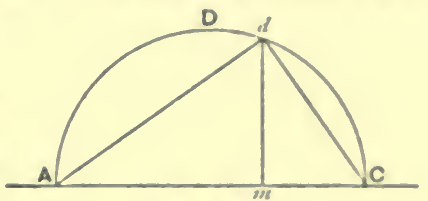

Fig. 36.5. $m$, and from $m$ a line be drawn perpendicular to $\mathrm{A} \mathrm{C}$, cutting the senicircle $\mathrm{ADC}$ in $d$, the point is such that joining $\mathrm{A}$ and $d$ by the straight line $A d$,

$$
\frac{\mathrm{A} d^{2}}{\mathrm{~A} c^{2}}=\frac{\mathrm{A} m}{\mathrm{~A} c}
$$





\section{N D E X.}

\section{A}

Additional bolts through puddle, 38

Advantages of docks, 3 of rollers for gates, 229

Aitkin's system of preserving timber, 355 Albert Docks, Hull, foundations, 79

Alexandra Dock, Hull, 14

$\longrightarrow$, , basin walls, 117

$\longrightarrow,-$ dam at, 61

,- - water in foundations, 94

— gates, Hull, 243

- Newport, 20

Amsterdam Canal dam, 66

Analysis of sea-water, $\mathbf{3 7 9}$

Anchor-bolts in masonry, 381

Applicability of floating doeks, 293

Avonmouth Dock, 13

- dam, 53

gates, 235

- Lock foundations, water in, 96

$\longrightarrow,-, 168$

\section{B}

Barry Dock gates, 238 caisson, 256

Basin walls, Alexandra Dock, Hull, 117

- Calais Harbour, 118

- Greenore, 112

_, Southampton Dock, 123

Basins, elosed, 10

- width of, 6

Backing to walls, 109

Batter to walls, 109

Bermuda Floating Dock, 305

Birkenhead dam, 56

Bollards, 405

Bolts, through, 38

Bordenux, quay walls, 135

Boring, 386
Bottom veloeity, 269

Brest, quay walle, 143

Broadside slipwaye, 329

Bronze in sea-water, 377

Bucket-dredgers, 339

Buckey Dock and Harbour, 116

Bute Docks, 17

- caisson, 259

C

Caisson dams, 42

Caissons, 245

-, advantages of, 247

-, Barry Dock, 256

-, Bute Dock, 259

- Esquimalt Dock, 260

—, Garvel Dock, 264

- - guards to prevent rising, 250

—_, Kowloon Dock, 257

- masonry stops for, 246

_, materials of construction, 246

—, sliding, 248

Calais, basin walls, 118

— Docks, 191 , embankment, 77

entrance channel, sluicing, 273

Harbour and Dock, 25

Canada Basin, Liverpool, sluicing arrangements, 281

Carbolic acid, 351

Cardiff Docks, 17

Cartagena floating dock, 297

Castings for covering leaks, 89

Cast-iron in sea-water, 377

Chatham embankment, 77

Chelura terebrans, 345

Chemical processes for preserving timber, 348

Chloride of zinc, 349

Chopping seas, 412 
Circular dam, Portsmouth, 73

Classification of floating docks, 292

Class of docks, 2, 4

Clay puddle, 385

- thickness of, 33

Closed basins, 10

Closing entrances, 217

Coffer-dam at Middle Level, 49

— at Dublin, 54

Composite piling, 393

Composition of sea-water salts, 379

Conditions affecting design of floating docks, 293

Corrosive sublimate, 349

Cost of caissons, 369

- dams, 366

— dock gates, 367

- docks and locks, 360, 361

_- dredging, 369

_loating docks, 365

—_ wharf walls, 361

— works per acre, 359

Counterforts, 108

Cracks in floor of docks, 167

Creosote, 349

—, country oils, 350

- London oils, 350

—, Scotch oils, 350

Creosoting, practice on Eastern Railway of France, 356

-, - New Zealand Railways, 357

Curved batter to walls, 109

Cylinder foundations, friction on, 387

Cylinders used at Glasgow, 129

\section{D}

Dam at Alexandra Dock, Hull, 61

- Amsterdam Canal, 66

- Avonmouth Dock, 53

- Birkenhead, 56

_ Esquimalt Dock, 61

- Limerick, 76

— Victoria Dock, Hull, 59

Dams, 36

- constructed of iron, 42

-

- double rows of piles connecting, 38

— of single rows of timbers, 40

- , risk of floating, $\mathbf{4 0}$

_- timber, on the Thames, 45

Danube improvement, 135

Defective pile heads, 397
Depositing dock, 300

Deposits, 267

Destruction of timber, 344

Disadvantages of rollers for gates, 228

Displacement of ground by piles, 392

Dock and quay walls, 104

- depth of water alongside, 111

Dock area, relation of, to sectional area of entrance, 12

Dock at Blackwall, 179

— Esquimalt, 213

- Genoa, 171

- Glasgow, 205

_- Leghorn, 199

—_Toulon, 183

- Wivenhoe, 177

Dock gates, cost of, 367

Docks, advantages of, 3

- at Calais, 191

$\longrightarrow$, classes of, 4

- constructed of timber, 186

- cost of, 361

_ floating, 3

location of, 4

Double-power dock, 303

Drags for removing shoals, 276, 277

Dredging appliances, 339

$\longrightarrow$, cost of, 369

_, effective time, 342

_ , variation of quantities, 341

Drift bolts in timber, 382

Dry docks, 3, 162

Dublin coffer-dam, 54

- quay walls, 146

Dunkirk dock gates, 231

- entrance channel, sluicing, 273

Durability of floating docks, 293

Duration of scouring, 270

$\mathbf{E}$

Early notes, 1

East and West Doeks, Cardiff, 19

Effect of hydrostatic pressure on walls, 110

Embankment at Chatham, 76 at Calais, 77

Embankments, 28, 36, 37

Entrance, principles governing design of, 5

$\longrightarrow$ position of, 11

- , sectional area of, 12

Equipment, $40 t$

Esquimalt caisson, 260 
Esquimalt Dock, 213

- dam, 64

Examples of dock plans, 13

Experiments by Mr. Boulton, 354

Extension of dock, Leghorn, 199

\section{F}

Fiume quay walls, 145

Fixing bolts in masonry, 379

Fleetwood Docks, leaks in foundations, 92

Floating box caisson, 250, 252

- caisson at Limekiln Dock, 255

- dock at Bermuda, 305

—— at Cartagena, 297

— at Wallsend, 295

$\longrightarrow$, cost of, 365

$\longrightarrow$, depositing, 300

$\longrightarrow$, double power, 303

- off shore, 300

docks, 3, 292

ship caissons, 249,251

- $\longrightarrow$ Bute Dock, 259

Form of gates, 221

Foundations for slipways, 314

Fresh water for docks, 15

- scouring, 270

Friction on cylinder foundation, 397

- on piles, 389

\section{G}

Garvel Dock caisson, 264

Gate platform, 217

Gates, Alexander Dock, Hull, 213

— at Dunkirk Dock, 231

-, Avonmouth Dock, 235

-, Barry Docks, 238

- form of, 221

- Havre Dock, 243

-, metal, 220

- on Amsterdam Ship Canal, 232

-

- rise of, 222

—_, rollers for, 227

- San Fernando Dock, 240

-

- West India Docks, 244

—, Whitehaven Docks, 237

Gauge-piles in dams, 37

General plan of basins, 7
Genoa Docks, 171

Glasgow dock walls, 129

-, No. 2 Dock, 20.5

-, Queen's Dock, 22

Gourock quay walls, 1 1

Grab-dredgers, 339

Graving docks, 3

Greonock quay wall, 152

Greenore quay wall, 112

Green's Dock, 179

Ground under dock floors, pressure on, 404

- swell, 412

II

Half-timler sheeting, 37

Havre Dock gates, 243

Hayford's system of creosoting, 355

Heel-post, 219

Height of waves, 409

Holding power of drift bolts in timber, 382

- of spikes, 384

Hollow quoins, 218

Honfleur sluicing basin, 278

Hopper-dredgers, 340

Horizontal centrifugal-pumps, 333 stress, resistance to, 390

Hydraulic rams for closing gates, 224

$\longrightarrow$, direct acting, 226

hauling-gear for slipways, 32 !

lifting-dock, 307

Hydrostatic pressure, effect of, on walls, 110

\section{I}

Imperial docks, sites for, 6

Increased resistance of piles due to quiescence, 391

Indian mud docks, 167

Iron dams, 42

— in sea water, 376

- , preservation of, 378

J

Jetties, 9

$\boldsymbol{K}$

Kowloon Dock caisson, 257 


\section{$\mathbf{L}$}

Leak in foundations at Albert Docks, Hull, 79

- Alexandra Docks, Hull, 94

Legal quays and wharves, 1

Lifling-dock, hydraulic, 307

Lifting-pumps, 333

Limerick Dock dam, 76

Limnoria Terebrans, 345

Load on piles, 395

Location of docks, 4

Locks, 162

- cost of, 360

Londun oils, 350

Low-water basin, Birkenhead, sluicing, 283

\section{II}

Malta Dock, 196

Marine worms, 344

Masonry veneering, 112

Metal gates, 220

- sheeting for preserving timber, 348

Middle Level coffer-dam, 49

Mitre-posts, 219

Mode of working slipways, 320

Moisture in wood, 353

Mount Stuart Dock, 190

Mud docks, 167

\section{$\mathrm{N}$}

Now York, quay wall at, $12 t$

Nipping of gates, 223

\section{0}

Offsets at back of walls, 110

Uff-shore floating dock, 300

Opening and closing gates, 224

- up works, Alexandra Docks, Hull, 28

—, Portsmouth Dockyard Fxtension, 31

- Southampton Tidal Basin, 35

Outer dam at Portsmuuth, 72

\section{$\mathrm{P}$}

Panama Canal locks, 174

Penarth Docks, 19

— Tidal Harbour, 20
Piles, half-timber, 37

—, friction on, 389

- , screw, 393

Plunger-pumps, 333

Pola Basin walls, 157

— Duck, sheet-piling, 62

Portsmouth Dockyard, dams at, 71

Position of entrances, 11

Preservation of iron, 378

Preserving timber, 343

Pressuro on ground under doek floors, 404

Prevailing winds, 6

Princes Dock, Bombay, quay wall, 138

Principles governing design of entrances, 5

Profile of walls, 109

Propeller sluicing, 276

Puddle, clay, thickness of, 38

- , clay for, 385

Pump, or suction dredgers, 339

Pumping, vibration caused by, 39

— water from docks, 332

\section{Q}

Quantity of creosote per foot cube of timber, 354

Quay at Bombay, 138

— at Brest, 143

— at Dublin, 146

— at Gourock, 141

- at Greenock, 152

- at Rouen, 139

at Spezzia, 155

—_, Now York, 124

- on the Rhone, 156

- wall at Greenore, 112

- walls at Bordeaux, 135

Queen's Dock, Glasgow, 22

Quoins, gate, 217, 218

\section{$\mathbf{R}$}

Resistance on sliding slipways, 328

— to horizontal stress, 390

Rise of gates, 222

Risk of timber dams foating, 40

Rollers, advantages of, 229

- objections to, 228

- to gates, 227

Rot in timber, 347

Rouen, quay wall at, 139 
Routh Dock, Cardiff, 17

- Basin, Cardiff, 17

Royal Albert Duck, Lnodon, 27

\section{s}

San Fernando Dock, Buenos Ayrea, 240 Seotch oils, 350

Scouring Barry Dock entrance, 272

_- by ship's propeller, 276

- Calais entrance channel, 273

- Canada basin, Liverpool, 281

- Dunkirk entrance channel, 273

- duration of, 270

- Honfleur basin, 278

- in A ronmouth Dock entrance, 271

- low-water basin, Birkenhead, 283

power of water, 267

- St. George's landing-stage, Liverpool, 273

- Thames Embankment landingplaces, 272 Tilbury Dock entrance, 272

Screw-piles, 393

Sea-water, analysis of, 379 salts, composition of, 379

Securing heel-post, 219

Segmental dams, 40

Shallow dam at Portsmouth, 71

Sheet-piling, 390

- at Pola, 62

Shield, timber, at Rio, 41

Single row of piles, 39

Sites near sea, 5 for Imperial docks, 6

Sliding caissons, Esquimalt Dock, 260

- caissons, 248

—, Cerro, Monte Video, 262

- Garvel Dock, 264

Slips, 3

Slipways, 312

—, broadside, 329

- foundations for, 315

_, hydraulic hauling-gear for, 324

__ mode of working, 320

- of ordinary construction, 319

_

_ stress in hauling on, 328

_. to take more than one vessel, 321

_. wire-rope haulage for, 327

Sluice-ralves in dáms, 37

Somerset Dock, Malta, 196
Fomerset Dock, Malta, stopping flsaurcs 93

Southampton Dock, basin walle, 123

— tidal dock, 24, 35

Spezzia q̨uay walls, 155

Spikes, holling power of, 381

Square quoins, 217

Stationary dredgers, 310

Staunchness of gates, 221

Stay gates, 231

Stock ramming, 101

Stopping joints, 102

- leaks, 97

- leaks through clay pu.lule, 33

Strains on floating docks, 2,33

- on gates, 412

Subsidence of walls, etc., 111

Suction-dredgers, 339

Sulphate of copper, 349

Support of dock gates, 230

$\mathbf{T}$

Temporary pumping, 338

Teredo navalis, 344

Testing stability of ground, 403

Thickness of clay puddle, 38

Through-bolts, 38

Tidal docks, 10 dock, Southampton, 21

Tilbury Docks, 16

Timber dams, 37

-

- dams on the Thames, 45

- docks, 186

- gates, 219

- shield at Rio, 41

— wharfing, 158

Time actually employed in dredging, 312

Tongued and groored piles, 37

'oulon Graving Dock, 183

Training-walls at Rouen, 140

\section{$\mathbf{V}$}

Valves, sluice, in dams, 37

Variatiou of quantities in dredging, $3 \pm 1$

Velocity, bottom, 263

Veneering, 112

Vertical centrifugal-pumps, 333

Vibration caused by pumps, 39 
W

Walls at Buckey Dock, 116

Wallsend floating dock, 295

Water area, cost per acre, 353

_. fresh, for scouring, 270

- in foundations, 79

— jet in pile-driving, 397

- scouring power of, 267

-, volume of, discharged, 269

Watertight joint in caisson dams, 43

Wave action, 411

Weight of Creosote injected, 35t, 355 of water in wood, 353
West India Docks, 214

Wet docks, 2

Wharfage, 7

Wharf moorings, 405

Wharf-wall at Glasgow, 129

$\longrightarrow$, New York, 124

walls, cost of, 361

Whitehaven dock-gates, 237

Width of basins, 6

Winds, prevailing, 6

Wire-rope fastenings, 384 haulage for slipways, 327

Wivenhoe Dock, 177

Wrought-iron in sea-wator, 377 


\title{
ENGINEERING, STRENG'TH OF MATERIALS, ETC.
}

RAIIWAY CONSTRUCTION. By W. H. MIIL., M.I.C.E., Enginoer-in-Chief of the Great Northern Railway of Ireland. With 516 Illustrations. 8vo, 18s. net.

MECHANICS FOR INGINERRS: a Text-book of Intermediate Standard. By ARTHUR MORLEY, M.Sc., University Scholar (Vict.), Professor of Mechanical Engineering in University College, Nottingham. With 200 Diagrams and numerous Examples. Crown 8vo, 45. net.

RAILWAY APPLIANCES: a Description of Details of Railway Construction subsequent to the completion of the Earthworks and Structures. By Sir Jokn Wolfe BARRY, K.C.B., F.R.S. With 218 Illustrations. Crown 8vo, 4s. 6d.

NOTES ON DOCKS AND DOCK CONSTRUCTION. By C. Colson, C.B., M.Inst.C.E. With 365 Illustrations. Medium 8 vo, 2 Is. net.

CALCULATIONS IN HYDRAULIC ENGINERriNG : a Practical Text-book for Students, Draughtsmen and Engineers. By T. CLAXTON FidLER, M.Inst.C.E.

Part I. Fluid Pressure and the Calculation of its Effects in Engineering Structures. With numerous Illustrations and Examples. 8vo, 6s. 6d. net.

Part II. Calculations in Hydro-Kinetics. With numerous Illustrations and Examples. 8vo, 75. 6d. net.

NOTES ON CONSTRUCTION IN MILD STEEI, arranged for the Use of Junior Draughtsmen in the Architectural and Engineering Professions. With Illustrations from Working Drawings, Diagrams and Tables. By HE.NRY FIDI.ER, M.1.C.E. With Diagrams. $8 \mathrm{vo}, 16 s$, net.

MECHANICS APPLIED TO अNGINEERING. By JOHN GOODNAN, Wh.Sch., M.I.C.E., M.I.M.E., Professor of Engineering in the University of Leeds, With 7 r4 Illustrations and numerous Examples. Crown 8vo, 9s. net.

RAILWAY WORIING AND APPLIANCES, to which are added a Chapter and Diagram on Railway Sketching. By EDWARD S. HADLEY. With 59 Illustrations and Diagrams. Crown 8 vo, is. 6 d. net.

FNGINEER'S VALUING ASSISTANT: being a Practical Treatise on the Valuation of Collieries and Other Mines, etc. By H. D. Hoskol.D. With an Introductory Note by Petik Gray. 8vo, 7s. 6d. net.

PRACTICAL HYDRAULIC (WATER SUPPLY AND DRAINAGE) TABLIS AND DIAGRAMS. By C. E. Housden. With 6 Plates and 7 Diagrams in the Text. Crown $8 v 0,3^{s}$. $6 d$.

PRACTICAL EARTework taBLES. By C. E. Holsden. With 9 Plates. Crown 8 vo, 2s. $6 d$.

A POCKET-BOOK FOR MECHANICAL ENGINEERS. By DAVID ALLAN IOW, (Whitworth Scholar). M.I.Mech.E., Protessor of Engineering, East London Technical College. With over 1,000 specially prepared Illustrations. Fcp. 8vo, gilt edges, rounded corners, 7s. $6 d$.

\author{
L O N G A NS, GRE EN, A N D CO. \\ LONDON, NEW YORK, BOMBAY, AND CALCUTTA
}


LIGHT RAILWAY CONSTRUCTION. By RICHARD MARION PARKINSON, Assoc.M.Inst.C.E. With 85 Diagrams. 8 vo, ros. $6 d$. net.

DOMESTIC SANITARY ENGINEERING AND PLUMBING, dealing with Domestic Water Supplies, Pump and Hydraulic Ram Work, Hydraulics, Sanitary Work, Heating by Low Pressure, Hot Water, and External Plumbing Work. By F. W. Raynes, R.P., Medallist, City and Guilds of London Institute. With 277 Illustrations. $8 \mathrm{vo}$, ros. $6 d$. net.

PRINCIPIES AND PRACTICE OF HARBOUR CONSTRUCTION. By WILliam SHeLd, F.R.S.E., M.Inst.C.E. With 97 Illustrations. Mediun 8vo, I5s. net.

GRAPHICS, or the Art of Calculation by Drawing Lines, applied especially to Mechanical Engineering. By ROBERT H. SMITH, Emeritus Professor of Engineering. Part I. With separate Atlas of 29 Plates containing 97 Diagrams. $8 \mathrm{vo}, \mathrm{r}_{5}$.

CIVIL ENGINEERING AS APPLIED IN CONSTRUCTION. By LeVfon FRANCIS VERNON-HARCOURT, M.A., M.Inst.C.E. Revised by HENRY FidLER, M.Inst.C.E., F.G.S. With 368 Illustrations. Medium 8 vo, r6s. net.

\section{SANITARY ENGINEERING WITH RESPECT TO WATER SUPPLY} AND SEWAGE DISPOSAL. By LEVESON FRANCIS VERNON HARCOURT, M.A., M.Inst.C.E. With 287 Illustrations. Medium 8vo, 14 s. net.

ENGINEERING CONSTRUCTION IN STEEL AND TIMBER. By WILLIAM HENRY WARREN, Whitworth Scholar, M.Inst.C.E. With 12 Folding Plates and 443 Diagrams. Medium 8vo, 18s. net.

TIE SEA COAST: Destruction, Littoral Drift, Protection. By W. H. Wheeler, M.Inst.C.E. With 38 Illustrations and Diagram. Medium 8vo, ros, $6 d$. net.

a PRaCtical MaNual of tides aNd Wavis. By W. H. Wheeler, M.Inst.C.E. With I9 Illustrations. $8 \mathrm{vo}, 7 s, 6 d$. net.

TIDAL RIVERS: their (1) Hydraulics, (2) Improvement, (3) Navigation. By W. H. WheEler, M. Inst.C.E. With 75 Illustrations. Mediun $8 \mathrm{vo}$, r6s, net.

STRENGTH OF MATERIALs. By ARTHUR MORLEy, M.Sc., University Scholar (Vict.), Professor of Mechanical Engineering in University College, Nottingham. With 245 Diagrams and numerous Examples. 8vo, 7s. 6d. net.

THE THEORY OF STRESSES IN GIRDERS AND SIMILAR STRUC. TURES : with Practical Observations on the Strength and other Properties of Materials. By Bindon B. Stoney, LL.D., F.R.S., M.I.C.E.. With 5 Plates and 143 lllustrations in the Text. Royal $8 \mathrm{vo}, 36 s$.

THE TESTING OF MATERIALS OF CONSTRUCTION. A Text-book for the Engineering Laboratory, and a Collection of the Results of Experiment. Byy W. CAWTHORNE UNWIN, F.R.S., LL.D. With 5 Plates and 206 Illustrations and Diagrams. $8 \mathrm{vo}, 18 \mathrm{~s}$. net.

THE STRENGTH OF MATERIALS AND STRUCTURES: the Strength of Materials as depending on their Quality and as ascertained by 'lesting Apparatus. By Sir J. ANDeksun, C.E., LL.D., F.R.S.E. With c6 Illustrations. Crown 8vo, 3s. $6 \mathrm{~d}$.

L O N G A NS, GREEN, A N C O. LONDON, NEW YORK, BOMBAY, AND CALCUTYA 
$s 1^{p}$ 


\section{PLEASE DO NOT REMOVE CARDS OR SLIPS FROM THIS POCKET}

UNIVERSITY OF TORONTO LIBRARY

S\&M

A

187 


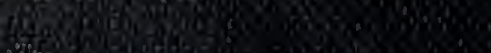

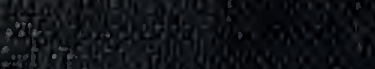

H.

20

3.

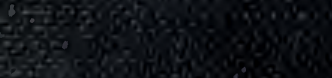

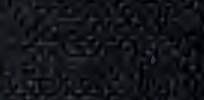

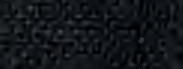

20

as

(ist)

6.5

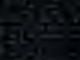

